\title{
Towards a Right to Cultural Identity? = Naar een recht op culturele identiteit?
}

Citation for published version (APA):

Donders, Y. (2002). Towards a Right to Cultural Identity? = Naar een recht op culturele identiteit?

[Doctoral Thesis, Maastricht University]. Intersentia. https://doi.org/10.26481/dis.20020920yd

Document status and date:

Published: 01/01/2002

DOI:

10.26481/dis.20020920yd

Document Version:

Publisher's PDF, also known as Version of record

\section{Please check the document version of this publication:}

- A submitted manuscript is the version of the article upon submission and before peer-review. There can be important differences between the submitted version and the official published version of record.

People interested in the research are advised to contact the author for the final version of the publication, or visit the DOI to the publisher's website.

- The final author version and the galley proof are versions of the publication after peer review.

- The final published version features the final layout of the paper including the volume, issue and page numbers.

Link to publication

\footnotetext{
General rights rights.

- You may freely distribute the URL identifying the publication in the public portal. please follow below link for the End User Agreement:

www.umlib.nl/taverne-license

Take down policy

If you believe that this document breaches copyright please contact us at:

repository@maastrichtuniversity.nl

providing details and we will investigate your claim.
}

Copyright and moral rights for the publications made accessible in the public portal are retained by the authors and/or other copyright owners and it is a condition of accessing publications that users recognise and abide by the legal requirements associated with these

- Users may download and print one copy of any publication from the public portal for the purpose of private study or research.

- You may not further distribute the material or use it for any profit-making activity or commercial gain

If the publication is distributed under the terms of Article $25 \mathrm{fa}$ of the Dutch Copyright Act, indicated by the "Taverne" license above, 
Towards a Right to Cultural Identity? 
To my parents: Frans and Marita

SChool of Human Rights Research Series, Volume 15

A commercial edition of this dissertation will be published by Intersentia under ISBN 90-5095-238-0

The titles published in this series are listed at the end of this volume. 


\section{Towards a Right to Cultural Identity?}

Naar een Recht op Culturele Identiteit?

(met een samenvatting in het Nederlands)

\section{PROEFSCHRIFT}

ter verkrijging van de graad van doctor aan de Universiteit Maastricht, op gezag van de Rector Magnificus, Prof. dr. A.C. Nieuwenhuijzen Kruseman volgens het besluit van het College van Decanen in het openbaar te verdedigen

op vrijdag 20 september 2002 om 12.00 uur

door

Yvonne Maria Donders

geboren op 17 januari 1972 te Haarlem 
Promotor:

Co-promotor:

Beoordelingscommissie:
Prof. dr. C. Flinterman

Dr. A.P.M. Coomans

Prof dr. M.T. Kamminga (voorzitter)

Dr. M. Galenkamp (Erasmus Universiteit

Rotterdam)

Dr. F. Grüneld

Prof. dr. M. Scheinin ( $\AA$ bo Akademi University, Turku, Finland)

Prof. dr. B. de Witte (European University

Institute, Firenze, Italië) 


\section{ACKNOWLEDGEMENTS}

At the start of this research I came across the following quote in a Dutch newspaper: "Culture is too important to be left in the hands of experts only". It concisely reflects why the topic of a right to cultural identity interests me. Cultural identity affects every individual and community. In fact, everyone and at the same time no one is an expert in this field. In any case, researchers or 'experts' should never lose sight of the people that are actually affected by the many complex issues surrounding a right to cultural identity.

This dissertation has provided me with many useful experiences, personally as well as professionally. At this point, I would like to express my gratitude and thanks to all who have helped and encouraged me over the last years.

First of all, I would like to thank my supervisors, Professor Cees Flinterman and Doctor Fons Coomans, for their input, comments, encouragement and support. It has been a very enjoyable experience to work with both of them, who were always able to remain calm when I had one of my "stressful" days. I would also like to express my appreciation to the members of the reading committee, Professor Menno Kamminga, Doctor Marlies Galenkamp, Doctor Fred Grünfeld, Professor Martin Scheinin and Professor Bruno de Witte, for reading and commenting on my manuscript.

Additionally, I have to thank my colleagues at the Department of International and European Law for their support and co-operation. A special word of thanks to Professor Ellen Vos for applying her critical mind on parts of my book, and then cheering me up over a good dinner. I am also thankful to Eva Rieter for reading parts of my book and providing me with helpfull comments. As far as the material realisation of the book is concerned, I am very grateful to Sophie Janssen and Chantal Kuypers for their help in editing the book, and to Chris Engert for correcting the English.

In May 2000, I was given the opportunity to visit the Institute for Human Rights of A bo Akademi University in Turku, Finland, which included a trip to Lapland. Thanks to the financial support of NWO and the warm welcome of Professor Martin Scheinin and his staff, it was both a wonderful experience and gave me extra insight into my research.

Two other 'AlO's' should be mentioned here, as without them my life as a researcher would have been much more difficult. To Nicola Jägers and Heleen Janssen, I express my thanks for sharing some of the tough moments with me and cheering me up with a good laugh and a drink. 
A special word of thanks to my 'paranimfen". To my sister, Ellen Janssen-Donders, who, after finding out what a "paranimf actually was, now knows more about procedures and defences than I do. And my thanks also to Marjorie Blagrove for making life in Maastricht so much more comfortable and fun. It was great figuring out life in "Mestreech" together with you.

This book is dedicated to my parents; Frans and Marita Donders, who have always loved and supported me, for which I can never thank them enough. Finally, Hans Lokker, thank you so much for supporting my going to Maastricht and for all the love and hugs when I most needed them. You truly are "the wind beneath my wings'.

Maastricht, 25 June 2002 


\section{TABLe OF Contents}

Acknowledgements

List of Abbreviations, Document Symbols and Websites

\section{Chapter I}

General Introduction

1. Background of a Right to Cultural Identity 2

1.1 Cultural Human Rights 2

1.2 Collective Rights 4

2. Supporters and Opponents of a Right to Cultural Identity 5

2.1 Formulation of a Right to Cultural Identity 5

$\begin{array}{lll}2.2 & \text { Supporters } & 6\end{array}$

2.3 Opponents 7

3. The Central Question of the Research 9

4. The Meaning of the Concept of Cultural Identity 12

5. Cultural Identity as a Human Right 14

$\begin{array}{lll}5.1 & \text { Universalism versus Cuitural Relativism } & 14\end{array}$

$\begin{array}{ll}5.2 \text { Equality and Non-Discrimination } & 15\end{array}$

$\begin{array}{ll}5.3 \text { The Proliferation of Human Rights } & 16\end{array}$

5.4 Level of Recognition and Justiciability of a Right to Cultural Identity 16

6. Plan of Research 19

\section{Chapter II}

\section{Culture and Cultural Identity in Social Sciences: A Survey}

1. Introduction

2. The Concept of Culture 24

2.1 The Meaning of 'Culture' Changing over Time '" 25

2.1.1 Culture in the Singular Form as a Normative Concept (1850-1950) 25

2.1.2 Culture in the Plural Form as Unique Entity $(1900-1950) \quad 26$

2.1.3 The Modern Notion of Culture as a Way of Life $(1950-\ldots) \quad 29$

3. The Concept of Cultural Identity 30

3.1 Cultural Identity as a Dynamic Concept 31

3.2 The Individual and the Collective Dimension of Cultural Identity 33

3.3 Cultural Identity in Relation to 'Otherness': the 'Us and Them' Principle

3.4 International Developments Encouraging Cultural Identity:

Decolonisation, Emancipation and Globalisation

3.5 Concluding Remarks on Culture and Cultural Identity 
4. The Accommodation of Cultural Differences 39

4.1 Tolerance and Multi-Culturalism 39

4.2 Forms of Recognition and Protection of Specific Cultural Identities 42

5. Concluding Remarks on the Social Science Framework of Cultural Identity 45

Chapter III

Cultural Rights and Collective Rights in Political Sciences

1. Introduction

2. A Liberal Theory for Collective Rights to Protect Cultural

Differences: Kymlicka and Others 49

2.1 Background of Kymlicka's Liberal Theory of Special Minority Rights 50

2.2 The Value of Culture and Cultural Membership 51

2.3 Individual Rights or Collective Rights?

2.4 Which Collective Rights and for Whom? : 57

2.5 What to do with Intolerable Cultural Practices? 61

3. Concluding Remarks on a Liberal Theory on Collective Rights to Protect Cultural Differences 63

Chapter IV

Cultural Rights and Collective Rights in a Human Rights Framework

1. Introduction 65

2. Cultural Rights as the "Cinderella of the Human Rights Family" 65

2.1 The Nature and Scope of Cultural Rights 69

2.2 Which Rights are Cultural Rights? 73

2.3 The Fribourg Group and the Draft Declaration of Cultural Rights 76

2.4 Levels of Recognition: Soft Law, Hard Law and Justiciability 79

2.5 State Obligations with regard to Cultural Rights 81

2.5.1 Positive and Negative Obligations $\quad 82$

2.5.2 State Obligations according to the Tripartite Typology: to Respect, $\begin{array}{ll}\text { Protect and Fulfil } & 87\end{array}$

2.5.3 The Core Content of Human Rights 90

2.5.4 The Possible State Obligations and Core Content of a Right to
Cultural Identity

3. Collective (Human) Rights 93

3.1 Background of Collective Rights 94

3.2 Supporters and Opponents of Collective Human Rights 97

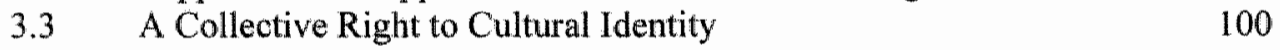

4. Concluding Remarks on Cultural Rights and Collective Rights 103 


\section{UNESCO and a Right to Cultural Identity}

1. Introduction

2. The UNESCO Organisation and Its Involvement in Human Rights 108

2.1 UNESCO and Human Rights

2.2 Standard Setting Process

3. UNESCO Instruments

3.1 Declaration of the Principles of International Cultural Co-operation

3.2 Recommendation on Participation by the People at Large in Cultural Life and their Contribution to It

3.2.1 References to Cultural Identity in the Recommendation 112

3.2.2 The Drafting Process of the Recommendation 113

3.2.3 Implementation of the Recommendation

3.3 Declaration on Race and Racial Prejudice

3.3.1 References to Cultural Identity in the Declaration

3.3.2 The Drafting Process of the Declaration

4. UNESCO Conferences on Cultural Policy

4.1 Inter-governmental Conference on Institutional, Administrative and Financial Aspects of Cultural Policies in Venice

4.2 Regional Conferences on Cultural Policies

4.2.1 Regional Conference on Europe

4.2.2 Regional Conference on Asia

4.2.3 Regional Conference on Africa

4.2.4. Regional Conference on Latin America and the Caribbean

4.2.5 Regionall Conference on Arab Countries

4.3 World Conference on Cultural Policies in Mexico

5. Culture and Development Report "Our Creative Diversity" : 130

5.1 Content of the Report

5.2 Comments on the Report by the Member States $\quad 132$

$5.3 \quad$ Follow-up of the Report 132

6. The Declaration on Cultural Diversity 134

7. Coneluding Remarks on UNESCO and a Right to Cultural Identity 137

\section{Chapter VI}

\section{The Right to Participate in Cultural Life}

1. Introduction

2. Article 27 of the Universal Declaration of Human Rights

2.1 Introduction

2.2 Travaux Préparatoires of Article 27 UDHR

2.3 Interpretation of Article 27 UDHR by Scholars

2.4 Article 27 UDHR in Relation to a Right to Cultural Identity

3. Article 15 of the International Covenant on Economic, Social and Cultural Rights 
3.1 Introduction

3.2 Travaux Préparatoires of Article 15 ICESCR 146

3.2.1 Commission on Human Rights 146

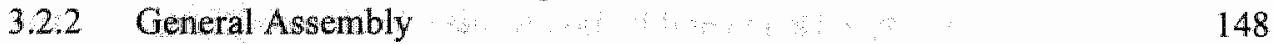

3.3 Guidelines for the Reporting Procedure under the ICESCR : 150

3.4 General Discussion on Article 15 by the Committee on Economic, Social and Cultural Rights

3.4.1 Working Paper on Cultural Rights

3.4.2 Day of General Discussion in the Committee 154

3.5 Interpretation of Article 15 ICESCR by Scholars 157

4. The Right to Take Part in Cultural Life in Relation to a Right to Culturall Identity

\section{Chapter VII}

\section{Cultural Identity and Minorities}

1. Introduction

2. Minorities and the Universal Declaration of Human Rights

2.1 The Sub-Commission on Prevention of Discrimination and Protection of Minorities

2.2 The Commission on Human Rights : 165

2.3 The General Assembly (Third Committee) 165

3. Article 27 of the International Covenant on Civil and Political Rights 166

3.1 The Drafting Process of Article 27 ICCPR

3.2 The Interpretation of Article 27 ICCPR by Scholars and the Human Rights Committee

3.2.1 The Subject of Article 27 ICCPR: Members of Minorities 169

3.2.2 The Object: the Content of Article 27 ICCPR . 172

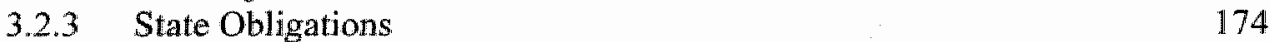

$\begin{array}{ll}\text { 4. Case Law on Article 27 ICCPR } & 176\end{array}$

4.1 A Broad Concept of Culture $\quad 176$

4.2 The Link between Culture and Traditional Economic Activities 177

4.2.1 Lubicon Lake Band versus Canada : $\quad 177$

4.2.2 Sami Cases versus Sweden and Finland 179

4.2.3 Apirana Mahuika versus New Zealand $\quad 181$

4.2.4 Diergaardt versus Namibia $\quad 183$

4.3 Language Rights: Culture and the Freedom of Expression 184

4.4 The French Declaration concerning Article 27 ICCPR and Minorities 186

4.4.1 Hopu and Bessert versus France 187

5. The Right to Enjoy Culture in Relation to a Right to Cultural Identity 188

6. The UN Declaration on the Rights of Persons Belonging to National or Ethnic, Religious and Linguistic Minorities

6.1 Background and Drafting Process of the Declaration on Minorities 191

6.2 Content of the Declaration on Minorities 
6.2.1 Subject of the Declaration on Minorities

6.2.2 Provisions in the Declaration on Minorities concerning Cultural Identity

6.3 Supervision of the Declaration on Minorities

7. Concluding Remarks on the UN Declaration on Minorities

\section{Cultural Identity and Indigenous Peoples}

1. Introduction $\quad 203$

2. General Observations on Indigenous Peoples 204

$2.1 \quad$ The Definition Issue $\quad 204$

2.2 The Right of Self-Determination 206

3. ILO Convention 169 on Indigenous and Tribal Peoples 208

3.1 ILO Convention $107 \quad 208$

$\begin{array}{lll}3.2 & \text { ILO Convention } 169 & 210\end{array}$

$\begin{array}{lll}3.3 & \text { ILO Supervision } & 212\end{array}$

3.4 Concluding Remarks on ILO Convention 169

4. UN Draft Declaration on the Rights of Indigenous Peoples … 215

4.1 The History: the Working Group on Indigenous Populations : 215

4.2 Content of the Draft Declaration in Relation to Cultural Identity 217

$\begin{array}{ll}4.2 .1 \text { Cultural Genocide } & 218\end{array}$

4.2.2 Other Provisions Regarding Cultural Identity $\quad \cdots \quad 220$

4.3 The Status and Future of the Draft Declaration $\quad 222$

5. Recent Developments and Concluding Remarks : : 224

\section{Chapter IX}

\section{Cultural Identity and the Organisation of American States}

$\begin{array}{ll}1 . & \text { Introduction }\end{array} 227$

2. Human rights Instruments and Procedures in the Americas : 227

3. Cultural Rights in the American Instruments: the Protocol of San

Salvador

4. Cases Before the Inter-American Commission and the Inter-American Court on Human Rights

4.1 The Guahibo Case v. Colombia

4.2 The Aché Case v. Paraguay

233

4.3 The Yanomami Case v. Brazil : 235

4.4 The Miskito Case v. Nicaragua : 236

$\begin{array}{ll}4.5 & \text { The Awas Tingi Case v. Nicaragua } 238\end{array}$

5. The Draft American Declaration on the Rights of Indigenous Peoples 241

6. Cultural Identity in the Inter-American Human Rights System 244 
Cultural Identity and the Council of Europe

1. Introduction

2. Cultural Rights in the European Convention on Human Rights and Fundamental Freedoms and the European Social Charter

3. The European Cultural Convention

4. The European Charter for Regional or Minority Languages

5. The Vienna Declaration

6. The Framework Convention for the Protection of National Minorities

6.1 The Development of the Framework Convention - Drafts and Proposals

6.2 The Subject of the Framework Convention and the Definition of 'National Minority'

6.3 Cultural Identity in the Provisions of the Framework Convention 255

6.3.1 Preamble

6.3.2 Article 5 on the Preservation of Identity

6.3.3 Article 6 on Non-Discrimination based on Cultural Identity 257

6.3.4 Articles 10 and 11 on Linguistic Rights

6.3.5 Articles 17 and 20 on Trans-Frontier Contacts 258

6.4 Implementation and Supervision of the Framework Convention 259

6.5. Concluding Remarks on the Framework Convention 261

7. Proposal for an Additional Protocol to the ECHR in the Cultural Field 262

7.1 The Mandate of CAHMIN

7.2 Provisions in the Draft Protocol concerning Cultural Identity 263

7.2.1 The Right to Cultural Identity

7.2.2 The Right to Choose to Belong to a Group 264

7.2.3 The Protection of Cultural and Scientific Heritage 264

7.2.4 The Right to Participate in Cultural Activities 265

7.2.5 The Right to Set Up Cultural and Educational Institutions 265

7.3 Other Provisions in the Draft Protocol relevant to the Protection of Cultural Identity

7.4 Outcome of the Drafting Process

8. Concluding Remarks on the Provisions in the Instruments of the Council of Europe

9. Selected Case Law of the European Commission and European Court of Human Rights

9.1 The Right to Education: the Belgian Linguistic Case

9.2 The Right to Freedom of Thought, Conscience and Religion

9.2.1 Jehovah's Witnesses in Greece

9.2.2 The Appointment of Muslim Leaders and Religious Pluralism

9.2.3 Ritual Slaughtering: the Case of Cha' are Shalom ve Tsedek v. 
9.4 The Right to Freedom of Peaceful Assembly and the Freedon of Association

9.4.1 Political Parties in Turkey 281

$\begin{array}{lll}\text { 9.4.2 Cultural Organisations } & 284\end{array}$

9.5 The Right to Respect for Private Life and Family Life, Home and Correspondence

9.5.1 Gypsy Cases: the Right to Respect for Home in Relation to Cultural Identity

9.5.1.1 Buckley v, the United Kingdom $\quad 289$

$\begin{array}{ll}\text { 9.5.1.2 Chapman } v \text { the United Kingdom } & 292\end{array}$

9.5.1.3 Beard $v$. the United Kingdom, Coster v. the United Kingdom, Lee v. the United Kingdom and Jane Smith v. the United Kingdom

9.5.2 Concluding Observations on the Gypsy cases on Cultural Identity

9.6 Concluding Remarks on the Protection of Cuitural Identity and the Selected Case-Law of the ECHR

Chapter XI

\section{A Right to Cultural Identity and the Sami in Norway, Sweden and Finland}

1. Introduction

2. The Sami as an Indigenous People

3. The Cultural Identity of the Sami

3.1. Reindeer Herding and Land Ownership 304

3.2 The Sami Language 305

4. Definition of Who is a Sami 306

5. The History of Sami Rights: the Lapp Codicil . 307

6. National Sami Policies and Legislation in Norway, Sweden and Finland

6.1 Norway

6.1.1 Sami Rights and the Alta Dam Case $\quad 310$

6.1.2 The Norwegian Sami Parliament $\quad 312$

$\begin{array}{ll}6.2 & \text { Sweden } \\ 6.212\end{array}$

6.2.1 Sami Rights and the Taxed Mountains Case $\quad 312$

$\begin{array}{lr}\text { 6.2.2 The Swedish Sami Parliament } & 314\end{array}$

$\begin{array}{lll}6.3 & \text { Finland } & 314\end{array}$

$\begin{array}{lll}\text { 6.3.1 Sami Rights } & 314\end{array}$

6.3.2 The Finnish Sami Parliament 315

$\begin{array}{ll}7 . & 316\end{array}$

7.1 International Covenant on Civil and Political Rights 316

7.2 The European Convention on Human Rights 317

7.3 The Framework Convention for the Protection of National Minorities 318

7.4 ILO Convention 169 on Indigenous and Tribal Peoples 322 
7.5 Protocol No. 3 to the Accession Treaty of Sweden and Finland to the EU

8. Concluding Remarks

\section{Chapter XII}

\section{Conclusion: Towards a Right to Cultural Identity?}

1. Introduction

2. What is the Value of Cultural Identity?

3. In What Form Could Cultural Identity be Recognised?

4. How Has Cultural Identity been Included in Existing Human Rights Instruments?

5. What Role Do Other Human Rights Provisions Play in the Protection of Cultural Identity?

6. What are the Subject, Object and State Obligations of a Right to Cultural Identity?

7. Should a Separate Human Right to Cultural Identity Be Developed?

8. The Emergence of Cultural Identity as a Principle of Human Rights Law

Nederlandse Samenvatting

Bibliography

Selected Documents of the United Nations, UNESCO, the Organisation of American States and the Council of Europe

Thahle of Caress

List of International Treaties and Declarations

Index

Curriculum Vitae

School of Human Rights Research Series 


\section{LIST OF ABBREVIATIONS, DOCUMENT SYMBOLS AND WEBSITES}

\begin{tabular}{|c|c|}
\hline $\mathrm{ACM}$ & $\begin{array}{l}\text { Adviescommissie Mensenrechten en Buitenlands Beleid / } \\
\text { Advisory Committee on Human Rights and Foreign Policy of the } \\
\text { Dutch Ministry of Foreign Affairs }\end{array}$ \\
\hline CAHMIN & $\begin{array}{l}\text { Ad Hoc Committee for the Protection of National Minorities } \\
\text { (Council of Europe) }\end{array}$ \\
\hline CCR & Committee on Conventions and Recommendations (UNESCO) \\
\hline CDCC & Council for Cultural Co-operation (Council of Europe) \\
\hline CDDH & Steering Committee for Human Rights (Council of Europe) \\
\hline CEACR & $\begin{array}{l}\text { Committee of Experts on the Application of Conventions and } \\
\text { Recommendations (ILO) }\end{array}$ \\
\hline CERD & Committee on the Elimination of Racial Discrimination \\
\hline $\mathrm{CoE}$ & Council of Europe \\
\hline ECHR & European Convention on Human Rights and Freedoms \\
\hline ECOSOC & UN Economic and Social Council \\
\hline $\mathrm{ESC}$ & European Social Charter \\
\hline FGM & Female Genital Mutilation \\
\hline HRC & Human Rights Committee \\
\hline IACHR & Inter-American Commission on Human Rights \\
\hline ICCPR & International Covenant on Civil and Political Rights \\
\hline ICESCR & International Covenant on Economic, Social and Cultural Rights \\
\hline $\mathrm{ICJ}$ & International Court of Justice \\
\hline ILO & International Labour Organisation \\
\hline IWGIA & International Working Group for Indigenous Affairs \\
\hline $\mathrm{NGO}$ & Non-Governmental Organisation \\
\hline OAS & Organisation of American States \\
\hline OAU & Organisation of African Unity \\
\hline $\mathrm{OSCE}$ & Organisation for Security and Co-operation in Europe \\
\hline UDHR & Universal Declaration on Human Rights \\
\hline $\mathrm{UN}$ & United Nations \\
\hline UNESCO & United Nations Educational, Scientific and Cultural Organisation \\
\hline UNGA & United Nations General Assembly \\
\hline WGIP & Working Group on Indigenous Populations \\
\hline WGM & Working Group on Minorities \\
\hline
\end{tabular}




\section{United Nations Documents (UN Doc.)}
A/...
General Assembly
A/C.3/...
General Assembly, Third Committee (Social Affairs)
A/RES/...
General Assembly Resolution
CCPR/C...
Human Rights Committee
CERD/C...
Committee on the Elimination of Racial Discrimination
E/...
Economic and Social Council
$\mathrm{E} / \mathrm{C} .12 / \ldots$
Committee on Economic, Social and Cultural Rights
$\mathrm{E} / \mathrm{CN} .4 / \ldots$
Commission on Human Rights
$\mathrm{E} / \mathrm{CN} .4 / \mathrm{Sub} .2 \%$...
Sub-Commission on the Promotion and Protection of Human Rights

\section{UNESCO Documents (UNESCO Doc.)}

... $\mathrm{C} / \ldots$

CLT $\%$...

.../CONF/...

.../DG/...

...EX/...

....PREP.COM/...

...S $/ \ldots$

$\mathrm{SS} / \ldots$

$\mathrm{SHC} / \ldots$

...WS/...
General Conference

Documents of the Department of Culture

Conferences

Reports of the Director General

Executive Board

Preparatory Commission of UNESCO

Secretariat

Social Sciences

Documents of the Department of Social and Human

Sciences

Working Series

\section{Documents of the Organisation of American States (OAS Doc.)}

$\mathrm{AG} / \ldots$

$\mathrm{OC} / \ldots$

OEA/Ser...
OAS General Assembly

Inter-American Court of Human Rights

Inter-American Commission on Human Rights

\section{Documents of the Council of Europe (CoE Doc.)}

CAHMIN...

CDCC...

CDDH...

CLD-MIN...
Ad Hoc Committee for the Protection of National Minorities

Council for Cultural Co-operation

Steering Committee for Human Rights

European Commission for Democracy through Law

\section{General abbreviations}

.../NGO/...

$\ldots / \mathrm{OR} / \ldots$

.../RES/...

$\ldots / \mathrm{SR} / \ldots$

...WG/...

...WP/...
Documents containing communications form NonGovernmental Organisations

Official Records

Resolution

Summary Records

Working Group Document

Working Paper 
Council of Europe

www.coe.int

Council of Europe - Minorities www.humanrights.coe.int/Minorities/Eng/Sitemap.htm European Court of Human Rights www.echr.coe.int Fribourg Group

LACHR

Indian Law Resource Centre

Inter-American Court of Human Rights

IWGIA

OAS

United Nations

UNESCO

UN High Commissioner for Human Rights www.unifr.ch/iiedl/recherche/recherche.him www. iachr.org www.indianlaw.org www.corteidh.or.cr/index-ingles.html www.iwgia org www.oas.org www.un.org www.unesco.org www. unhchr.ch 


\section{CHAPTER I GENERAL INTRODUCTION}

“L'identité culturelle, essence de la pérennité des peuples, confère au groupe son unité et sa spécificité, son caractère de formation sociale unique, inrépétible et irréductible. A la fois cadre de la mémoire collective et fondement de ses projets d'avenir, elle constitue le lien entre le passé, le présent et le futur d'une communauté. Priver les individus et les peuples de leur identité culturelle, $c$ 'est lles priver de leur histoire, $c^{\prime}$ est ôter le sens à leur vie, c'est - en dernier recours - nier leur droit à l'existence."

Yanomami Indians in Brazil fighting for protection of their traditional lifestyle, the Indians of the Awas Tingi community in Nicaragua claiming the demarcation of their land, Aborigines in Australia trying to overcome cruel and inhumane treatment in the past, Kurds in Turkey fighting for recognition and language rights, Sami in Scandinavia trying to protect their reindeer herding activities, Roma in many parts of Europe fighting against discrimination and racism; these are all examples of communities and individuals striving for the preservation and protection of their cultural identity. Both individuals and communities attach great importance to their cultural identity. Restricting or oppressing the expression and preservation of cultural identity may lead to a sense of confusion, alienation, and even violent conflict. It is because of the general value given to cultural identity, in relation to human dignity, that there is increasing demand for cultural identity to be protected as a separate human right. Indeed, some actually argue that such a right already exists in international human rights law. $^{2}$ However, no extensive survey has been done on the content and scope of a right to cultural identity. As a result, this book analyses questions surrounding the nature, scope and content of a right to culturat identity and its future development in international human rights law.

Wilhelm, 1993, p. 222.

2 In a resolution of April 2002, the UN Commission on Human Rights has recognised that States have the primary responsibility for the enhancenent of respect for different cultural identities; see Commission on Human Rights Resolution 2002/26, Promotion of the enjoyment of the cuitural rights of everyone and respect for different cultural identities, 22 April $2002, \$ 5$. Furthermore, Thornberry, for example, argues that the right to cultural identity has obtained a prominent place in human rights discourse. As an example, he refers to a statement made by the representative of the United Arab Emirates before the Human Rights Commission in 1992 in which he included the right to a cultural identity among hiss list of the most basic human rights. UN Doc. E/CN.4/1992/SR.7, Commission on Human Rights, 48th session, Summary Record of the 7 th meeting, 6 february 1992 , \$21. See, also, Thomberry, 1995, p. 41; Thornberry, 1993, p. 40. 


\section{BACKGROUND OF A RIGHT TO CULTURAL IDENTITY}

The idea of developing a separate right to cultural identity mainly originates from the debates within the human rights discourse on cultural rights and on collective rights. In these debates, the position of minorities and indigenous peoples plays an important role. In this study, a right to cultural identity is not, in principle, restricted to these communities.

\subsection{Cultural Human Rights}

The Universal Declaration of Human Rights (UDHR) of 1948 was confirmed by the General Assembly of the United Nations in 1966, when it adopted the International Covenant on Civil and Political Rights (ICCPR) and the International Covenant on Economic, Social and Cultural Rights (ICESCR). ${ }^{3}$ Together these three instruments form the International Bill of Human Rights. The two Covenants divided human rights into different categories, namely, civil, political, economic, social and cultural rights. However, this division does not imply that one category of human rights is more important than another. In the preamble of both 1966 Covenants, it is stated that all human rights, whether civil, political, economic, social or cultural in nature, are interrelated, indivisible and interdependent. The Member States of the United Nations have confirmed this principle on various occasions. ${ }^{4}$

However, practice shows that the different categories of human rights have not developed at an equal pace. Cultural rights have received less attention and are, therefore, less developed than both civil and political rights, and, to a certain extent, economic and social rights. ${ }^{5}$ One of the reasons given for this underdevelopment is the vagueness of the term 'culture'. Culture can refer to various things, for example, human culture in general, the culture of a specific society or period, or the culture of a person. Roughly speaking, it varies from cultural products, such as arts and literature, to the cuitural process or culture as a way of life, including knowledge and practices which are both intellectual and material. In between these concepts lie the cultural institutions established to transfer culture, such as museums, educational institutions and the media.

3 International Covenant on Civil and Political Rights and International Covenant on Economic, Social and Cultural Rights, New York, 16 December 1966.

4 For example, the Proclamation of Tehran (1968) and the Declaration of the World Conference on Human Rights in Vienna (1993). In April 2002, the UN Commission on Human Rights has in a resolution confirmed that "...cultural rights are an integral. part of human rights, which are universal, indivisible and interdependent". See Commission on Human Rights Resolution 2002/26, Promotion of the enjoyment of the cultural rights of everyone and respect for different cultural identities, 22 April 2002.

5 See, inter alia, "Cultural Rights: An Underdeveloped Category of Human Rights, Conclusions of the Eighth Interdisciplinary Colloquium on Human Rights, organised by the University of Fribourg, 28-30 November 1991", The Review of the International Commission of Jurists, No. 49/1992, pp. 51-53. See, also, Donnelly, 1989, pp. 154-155; Symonides, 2000-A, pp. 175-176. 
Cultural rights may, therefore, be a category of human rights which explicitly refer to culture as a residual category after civil, political, economic and social rights. This can be called the "narrow" group of cultural rights, which includes, for example, Article 15 ICESCR on the right to take part in cultural life and Article 27 ICCPR on the right of persons belonging to a minority to enjoy their own culture. It can also be an overlapping category of human rights that have a link with culture, which can be described as the 'broad' group of cultural rights. Although it is true that it can be argued that almost every human right has a link with culture, this broad group refers, in particular, to the right of self-determination, the right to freedom of religion, freedom of expression, freedom of association, and the right to education. ${ }^{.6}$ The listing of different cultural rights in human rights instruments, as described above, is something different than the grouping of cultural rights as an aggregate, replacing cultural rights by 'the right to culture'? In short, the category of culturall human rights, as such, should be clarified further.

The call for the clarification, promotion and protection of cultural rights has been especially encouraged over the last 25 years because of the numerous violations of cultural rights, for example, the oppression of indigenous peoples in several States in Latin America and the enforced assimilation of minorities by a number of States in Central and Eastern Europe. ${ }^{8}$ In many parts of the world, individuals and communities ${ }^{9}$ have been, and still are, unable to express and preserve their cultural identity because of intolerance and discrimination. The denial of the cultural rights of individuals and communities has led to forms of discrimination, nationalism, xenophobia and racism, and can be a source of violent conflicts. ${ }^{10}$ It has been argued that respect for cultural rights, in particular, the protection of cultural identity, is a constitutive element of respect for human dignity. In this respect, some have proposed a new codification of cultural rights,

6 See, inter alia, Donnelly, 1989, p. 155; Donnelly, 1990, pp. 54-55; Meyer-Bisch, 1993-A, pp. 18, 24. See, also, Prott, 1988. The category of cultural rights is further analysed in Chapter IV.

7 Symonides, 2000-A, pp. 176, 187. The meaning and content of cultural rights including the difference between cultural rights and a right to culture are further clarified in Chapter IV.

8 Staventhagen lists some examples of the denial of cultural rights of various communities in the world, for example, the denial of the cultural rights of the Kurds in Turkey, labelling them simply as 'mountain 'Turks'; the forced assimilation of indigenous peoples in Latin America, who had to conform to the national culture developed by the ruling groups that were the descendants of the colonial settlers; the denial of minority status to regional minorities in the unitary State of France, such as the Bretons or Corsicans etc, see Stavenhagen, 1998, p. 11 and Stavenhagen 2001, p. 97.

9 In this study, the term "communities" is used, instead of "groups' "societies" or "collectivities". "The term 'community' implies some form of a continuous structure and social or cultural bond, which form a common identity that is particularly important in this study on the development of a right to cultural identity. A community is supposed to be more than the sum of its members, and is based on common values and beliefs carried by its members, which refer to history, present and future. The terms "groups" or "collectivities" may refer to voluntary or temporary settlements, such as voluntary organisations, sports clubs, but also blond people, women, people weating glasses, etc. See, inter alia, Marie, 1993 , p. 201.

10 Highly publicised examples that come to mind are the violent conflicts in Kosovo and other parts of Former Yugoslavia, Chechnya and parts of Turkey and Irac. 
ineluding the development and adoption of a separate right to cultural identity." Advocates of this right argue that "...the preservation of cultural identity must be seen as a necessary precondition to the maintenance of human dignity." 12 Indeed, a right to cultural identity is considered by some as "...a general form of all cultural rights.." 13

\subsection{Collective Rights}

The second discussion behind a right to cultural identity concerned the development of collective rights: ${ }^{14}$ From the 1980s onwards, many scholars have argued that the individualistic approach to human rights based on the principles of equality and non-discrimination no longer meets the present global issues concerning development and the environment, and the needs of communities. The codification of human rights has focused too much on an individualistic outlook of the world and of human nature. It was asserted that communities are an important factor in creating valuable life for individuals, and that these communities should be protected by collective rights.

Karl Vasak, the 'inventor' of collective rights, called them the third generation of human rights, based on solidarity, complementing both the first generation of civil and political rights, and the second generation of economic, social and cultural rights. Vasak proposed the following as examples of the third generation of human tights: the right to development, the right to environment, the right to peace, the right to the co-ownership of the common heritage of mankind, and the right to communicate. ${ }^{15}$ Supporters of collective rights extended this list and added, inter alia, the right to be different, and the right to cultural identity. ${ }^{16}$ Cultural identity was considered of such a collective nature that individual human rights norms would not be sufficient to protect it properly. What was needed, here, was the recognition of a collective right to cultural identity. ${ }^{17}$

11 See Symonides, 1993, p. 71; Symonides, 2000-A, pp. 176-177. Within UNESCO and the Council of Europe, it has been tried to codify cultural rights, see Chapters V and X. A group of scholars, the Fribourg Group, has studied cultural rights and has drafted a Charter on Cultural Rights, see Chaptea IV.

12 Burgers; $1990, \mathrm{pp} .251-252$.

13 Meyer-Bisch, 1993, p. 302.

14 Some authors make a distinction between collective rights and group rights. Collective rights are rights for a community as such, while group rights are the rights of individuals who together compose a connunity. Both terms are also used inversely. In this study, collective rights are intended to mean the rights of a community as such.

15 Vasak, 1984, pp. 839-840. See, also, Marks, 1981, pp. 435-452.

16 See, inter alia, Alston, 1984 , p. 610, Marks, 19081 , p. 435, Berting, 1990, part $\mathrm{V}$, pp. 251-258 and Flinternan, 1990, p. 77.

17 Galenkanp, for example, argues that the right to the preservation of one*s cultural identity is a paradigm case of a collective right see Galenkamp, 1998, p. 15 and chapter 7, pp. 121-151. 
In short, it has been suggested that a separate right to cultural identity should be developed because the existing human rights system, with its individual character and underdevelopment of cultural rights, does not meet the claims of individuals and communities with regard to the recognition and protection of their cultural identity. A right to cultural identity could have an important symbolic value and could have practical implications in the sense of State policies to protect and promote the cultural identity of both communities and their members. The question arises, however, as to whether the protection of cultural identity does, in fact, require the development of a new separate (collective) human right to cultural identity and what this right should look like.

\section{SUPPORTERS AND OPPONENTS OF A Right TO CULTURAL IDENTITY}

\subsection{Formulation of a Right to Cultural Identity}

Even without rejecting the idea of developing a right to cultural identity, this right has been criticised as a rather strange formulation. How can one have an actual right to cultural identity? The right to cultural identity implies the right to have a cultural identity. This seems to be rather odd, since individuals and communities simply have a cultural identity, which cannot and should not be provided for by a State. As Donnelly argues, "[i]t is not a good, service or status that can be given to people." Consequently, authors have chosen other ways of formulating this right. MeyerBisch, for example, speaks of the right to cultural identification, "...car l'identité n'est pas un état mais une acte..." According to Meyer-Bisch, individuals acquire a cultural identity by living their life, and compose it along the lines of participation in multiple communities, such as nationality, race, family, religion, gender, etc. ${ }^{20}$ Symonides, basing himself on developments within LNESCO, uses the right to the protection and development of cultural identity. ${ }^{21}$ Galenkamp has chosen the term "the right to preserve one's cultural identity', because she considers a right to cultural identity "... a curious and dangerous way of formulating the matter." She argues that a right to cultural identity would be difficult to implement, since cultural identity cannot be created by design. If States are supposed to give individuals and communities a cultural identity, they might use it to discriminate against them, as shown by the policies in the South African homelands. ${ }^{23}$

A right to preserve and/or develop one's cultural identity might be a good option, since it emphasises that communities and individuals have the right to develop their cultural identity and to the protection and preservation of it. However, another formulation, which has not been mentioned so far, is also attractive: a right

18. Donnelly, 1989, p. 158; Donnelly, 1990, p. 58.

19 Meyer-Bisch, 1993-A, p. 35.

20 Meyer-Bisch, 1993-B, p. 281.

21 Symonides, 1993, p. 62.

22 Galenkamp, 1998, p. 116.

23. Galenkamp, 1989, p. 116. 
to freedom of cultural identity. It seems that one of the central claims of a right to cultural identity is not only the right to decide in freedom to have, develop and preserve a cultural identity, but also to change one's cultural identity. A right to freedom of cultural identity expresses the idea of development and change. In this respect, a right to cultural identity has much in common with the right to freedom of religion. Both rights have both an individual and a collective dimension; cultural identity as well as religion is experienced both individually and collectively. Another similarity between cultural identity and religion is that both concepts are hard to define; although one generally knows what they mean, there are no unambiguous legal definitions. Cultural identity and religion both concern the meaning and significance of human activities and relations. Furthermore, religion is an important aspect of cultural identity. It has played an important role in the creation and development of almost all cultures. Culture and religion influence each other at various levels. Religion shapes a culture's system of beliefs and practices, while culture influences how a religion is interpreted, how its rituals are carried out and what place religion has in society. ${ }^{24}$ However, because cultural identity as a right is used in different ways in both the literature and legal instruments, for the purpose of this book the general formulation of 'a right to cultural identity' is used temporarily.

\subsection{Supporters}

One of the active supporters of a right to cultural identity is UNESCO. In the $1970 \mathrm{~s}$ and 1980s, UNESCO organised various Conferences on Cultural Policies, during which much attention was paid to a right to cultural identity. During the World Conference on Cultural Policies in Mexico City in 1982, for example, the delegates recognised the growing awareness of people of their cultural identity and the importance of pluralism, the right to be different, and mutual respect for different cultures. One of the Recommendations of the Conference called upon Member States to respect and preserve the cultural identity of all countries, regions and peoples. The protection of cultural identity was further encouraged in the UNESCO Declaration on Cultural Diversity. ${ }^{25}$

Supporters of a right to cultural identity emphasise that the claim for a right to cultural identity originates from a situation of serious human rights violations. A (collective) human right to cultural identity is seen as necessary to protect cultural identity as an important element of human dignity. ${ }^{26}$ Stavenhagen, for example, argues that cultural identity as a collective value is an object for an ethical right at the very least. ${ }^{27}$ Although the subject and object of the right to cultural identity need further clarification, "...the collective rights of cultural groups are defensible... when

24 Parekh, 2000, pp. 146-147.

25 Symonides, 1993, p. 62, see, further, Chapter V on UNESCO.

26 Burgers, 1990, p. 252; Stavenhagen, 1990, pp. 256-258.

27 He wonders, however, to what extent this right can be transformed into a legal right. 
they are claimed in order to strengthen certain kinds of collective identities, which in turn strengthen the worth and dignity of the individual:, 28 .

Van Dyke agrees that peoples and communities should have the right to preserve their cultural identity "...unless good reasons exist for denying the right." ${ }^{29} \mathrm{He}$ argues, however, that this right cannot be absolute or unlimited, and that individual human rights and the rights of other communities should also be taken into account. ${ }^{30}$

\subsection{Opponents}

Several scholars explicitly reject the idea of developing a right to cultural identity. Donnelly, for example, asserts that "...recognizing such a right is a bad idea.", $\mathrm{He}$ argues that the promotion and protection of established civil, political and cultural rights could prevent attacks on cultural identity by the State or any other community. ${ }^{32}$ He argues that a right to cultural identity adds nothing to established human rights and can, in fact, have major defects, such as the abuse of this right by repressive regimes, as, for example, in South Africa during the period of Apartheid. Instead, attention should focus on the promotion and protection of existing individual human rights. He concludes that "...protecting cultural identity, so long as that identity is more or less freely chosen by the individual, is a waluable good... [but] we do not need a human right to cultural identity., ${ }^{933}$

Most critics of a right to cultural identity emphasise the obscurity of both the content and scope of this right. The concept of cultural identity is considered to be too vague to be transformed into a legal right. A right to cultural identity would be too complex to be justiciable. However, in my view, the development of a right to cultural identity should not be put aside simply because of the vagueness of the concept. Other human rights, too, were vague and not well defined at the time that they were incorporated in human rights instruments. The objects of, for example, the right to freedom of religion or the rights to family life or privacy have also developed over the years. Many human rights have been clarified by international and national supervisory bodies, scholars and States. In principle, the same could happen to a right to cultural identity.

Another major objection against a right to cultural identity concens the possible collective subject of this right. Collective rights have been criticised generally, but many authors specifically reject a collective right to cultural identity. Apart from the concerns with regard to the definition of the communities involved, special concern has been expressed on community representation and on the

28 Stavenhagen, 1990, p. 258. See, also, Stavenhagen, 2001, pp. $97-98$ and Stavenhagen, 1998, pp. 11 . 12.

29 Van Dyke, 1980, p. 2.

30 Van Dyke, 1980 , pp. 2,7 .

31 Donnelly, 1989, p. 158.

32 Donnelly, 1989 , p. 159; Donnelly, 1990, p. 58 .

33 Donnelly, 1989, p. 160; Donnelly, 1990, p. 59. 
position of the individual in relation to cultural communities. Although communities as a whole are meant to have the right to cultural identity, it is only a small representation of these communities that can actually invoke this collective right on behalf of the community. It is probably the elite or leading figures within the community who decide which cultural identity needs to be protected. In other words, who actually decides what the cultural identity of a community is?

It has further been argued that a collective right to cultural identity that protects the cultural identity of communities can also have a reverse effect of stigmatising communities, setting them apart within a society. This could encourage tensions such as xenophobia, nationalism and tribalism. It has also been pointed out that a right to cultural identity could lead to a certain form of forced assimilation of individuals within a community. This could imply the 'locking up' of individuals within a community identity that may no longer be theirs. To what extent can individuals oppose cultural practices imposed by the community, and to what extent can they leave the community?

Another objection to a right to cultural identity is the idea that not every aspect of cultural identity deserves to be protected. Such a right could be interpreted as supporting questionable cultural activities, for example, the subordinate position of women in certain cultural communities reflected in forced marriages and bride price, female circumcision, or less rights compared to men with regard to inheritance. Such cultural practices are in conflict with human dignity, the protection of which is an important argument for developing a right to cultural identity. With regard to the potential conflict with human rights, I suggest to make a distinction between a right to cultural identity as a cultural human right on the one hand and cultural practices on the other.

It has been argued that a right to cultural identity as a cultural human right could be in conflict with other existing human rights. However, at this point, no general conclusions could be drawn that would justify the rejection of a right to cultural identity solely on the grounds that it could conflict with other human rights. A general rule in this respect is that the enjoyment of human rights is always limited by the human rights of others: the enjoyment of human rights by one may not limit or violate the human rights of others. Many human rights can potentially be in conflict in certain situations. Each of these cases should be treated on a case-to-case basis to determine which right prevails over another in a given situation.

Another point, which must be taken into account; is the issue of cultural activities or practices - not to be confused with cultural rights - which are in conflict with human rights, for example, the discriminatory treatment of women or cruel ways of punishment. Such practices, it is argued, should not be protected by a right to cultural identity. Again, it is difficult to make any general statement on the acceptability of cultural practices and their relation to human rights, since these activities are very diverse and their possible conflict with human rights should be treated on a case-to-case basis. However, in general, cultural practices that are in conflict with the International Bill of Human Rights cannot be justified by stating that 
they fall under the category of 'cultural rights' or a right to cultural identity. An appropriate criterion could be that cultural practices should not be in conflict with the value of human dignity. In accordance, cultural rights in general and a right to cultural identity in particular should not be used to restrict the enjoyment of other human rights as laid down in the various international instruments. ${ }^{34}$ These matters are dealt with in more detail in Chapter III and IV.

To sum up, while some argue that cultural identity should be protected as a human right because it is an important element of human dignity, serious objections have been raised against this right. The controversiality of a right to cultural identity highlights the necessity of further research on both its content and its scope, in order to determine whether or not it should be further developed as a separate human right.

\section{The Central Question of The Research}

The overall purpose of this book is to provide clarification on the nature, scope and content of a right to cultural identity. Much of the discussion concerning this right has so far focused on the question of whether such a right should be developed and adopted by States. ${ }^{35}$ Formally, however, the concept of "cultural identity" has already been used in several international human rights instruments, although not explicitly in the form of a right to cultural identity. Several international legally binding instruments contain references to cultural identity in different forms, ${ }^{36}$ and there is also some "soft law", which includes references to cultural identity." Furthermore, aspeets of cultural identity, such as language and religion, can be found in existing international human rights instruments. This research analyses to what extent these provisions offer protection of cultural identity and whether the protection of cultural identity requires the development of a separate human right:

The central question of this study is therefore: should a right to cultural identity be further developed as a separate right within the framework of international human rights law, and, if yes, what could be the nature, scope and content of this right?

Both parts of the central question are closely inter-related. The first part concerns the question of to what extent it is desirable, necessary and possible to develop a right to cultural identity in international human rights law. To what extent can

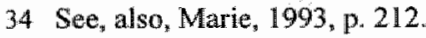

$35 \mathrm{See}_{*}$ for example, Berting, 1990, part V, pp. 251-258.

36 For example, Article 2 of ILO Convention 169 on Indigenous and Tribal Peoples, adopted in 1989, and Article 5 of the Framework Convention for the Protection of National Minorities, adopted by the Council of Europe in 1995:

37 For example, Article 1 of the UNESCO Declaration on Race and Racial Prejudice, adopted in 1978 , Article 1 of the UN Declaration on the Rights of Persons belonging to National or Ethnic, Religious and Linguistic Minorities of 1992 and Article 7 and 8 of the UN Draft Declaration on Indigenous Peoples of 1994. 
cultural identity, as an important value of both individuals and communities, be translated into a human right? What would such a right add to the existing human rights provisions? To determine whether or not a right to cultural identity should be further developed, it is necessary to clarify the content and scope of this right, whereby the three-term structure of its object, subject and addressee forms the starting point ${ }^{38}$ The object concerns the content of a right; the subject refers to the beneficiary, and the addressee relates to the obligations that correspond to such a right.

\section{The Object}

The object or content concerns the question of what one is entitled to when invoking a right to cultural identity. Some have argued that it is a general right which covers or contains several other rights, such as the right to be different, the right to individuality and the right to belong to local or wider communities. It would, furthermore, include the free determination and expression of people's specific characteristics in the economic, political, social and cultural sphere. ${ }^{39}$ Others have pointed out that the main entitlements under a right to cultural identity are the right to choose a cultural identity, the right to cultural heritage and the right to access to means of communication.

The object of a right to cultural identity is cultural identity. But what is meant by that term? Cultural identity is, in fact, more than a simple term; it is a dynamic and complex concept, ${ }^{41}$ which contains specific aspects such as language, religion and education. The question, therefore, arises as to whether a right to cultural identity would imply rights in all these specific fields. And if this were the case, would it not be better to name the rights in question separately, instead of 'shoving them' under 'a right to cultural identity'? Or can a 'core content' of this right - that States should respect and protect at all times - be distinguished?

\section{The Subject}

Cultural identity has both an individual and a collective dimension. Should the subject of a right to cultural identity be the individual or the community? In other words, should it be an individual or a collective right? The solution may perhaps lie in between, by formulating an individual right with a collective dimension, whereby it is explicitly recognised that the individual can enjoy the right as a member of a community or in co-operation with others. An individual right to cultural identity with a collective dimension would fit into the existing human rights discourse, where several human rights have a collective dimension, regardless of whether they are explicitly recognised or not. ${ }^{42}$

38 This approach has also been used by Galenkamp, 1998 and Meyer-Bisch, 1993.

39 See the Conclusions of the Fribourg Colloquium on Cultural Rights in: Meyer-Bisch, 1993, p. 302.

40 Meyer-Bisch, 1993 , p. 13.

41 From here on, cultural identity is referred to as a concept.

42 For example, Articles 18,21 and 22 ICCPR on the right to freedom of religion, peaceful assembly and association and Article 13 ICESCR on the right to education, which are provisions with an 
Some, however, argue that the collective dimension of cultural identity is of such importance that cultural identity should be protected by a collective right. A collective right to cultural identity poses the question as to which communities could be the bearers of this right. Three specific communities have been mentioned in relation to a collective right to cultural identity: peoples in general, minorities and indigenous peoples. However, no political consensus has been reached on a definition of these communities and they are far from homogeneous. In other words, if the subject of the right to cultural identity is a community, more clarity is needed on which communities can enjoy this right.

Authors often use the collective and the individual dimension of cultural identity interchangeably. While both dimensions are interconnected, they do not mean the same. The cultural identity of a community as such is not necessarily the sum of the cultural identities of the individual members of this community. Individuals do not have a cultural identity based on one single community, but obtain their cultural identity by participating in various communities, such as a State, a family, a linguistic community, a religious community, etc. Some communities incorporate one main aspect of cultural identity, such as religious communities or linguistic communities, while others involve a variety of these aspects, such as minorities or indigenous peoples. In other words, there are different levels of community, whereby the corresponding cultural identity can be more of less comprehensive. Especially for a State it is important to know what community is meant to be the bearer of a collective right to cultural identity and what the content of this collective cultural identity is.

\section{The Addressee}

One person's right implies a duty for somebody else. The addressee of a right to cultural identity is most likely to be the State. ${ }^{43}$ However, it is unclear which responsibilities and obligations a State has in relation to a right to cultural identity. Should a right to cultural identity be a right to freedom based mainly on State abstention, or should it also imply positive State obligations? With regard to the implementation of the ICESCR and the ICCPR, scholars have developed the socalled 'tripartite typology" of State obligations, which include the obligation to respect, the obligation to protect, and the obligation to fulfil. ${ }^{44}$ To what extent are all three types of obligation applicable to a right to cultural identity?

obvious collective dimension that is not specifically mentioned, while Article 27 ICCPR explicitly refers to the right of members of a minority to enjoy, in community with the other members of their group, their own culture, language and religion.

43 Although the State might be the main addressee, several authors recognise that other social actors. such as other individuals and communities, might also have some responsibility. In this study, however, only the obligations of States will be focused on. See, inter alia, Symonides, 1993, p. 63.

44 See, on the obligation theary, Ph. Alston and K. Tomaševski (eds:), The Right to Food, Martinus Nijhoff Publishers/SIM, Utrecht, 1984, especially the contributions of Ph. Alston, H. Shue, G.J.H. van Hoof and K. Tomasewski, pp. 9-68, 83-95, 97-110 and 135-167 respectively. See, also, A. Eide, Food as a Human Right, UN University, Tokyo, 1984, pp. 249-260; A. Eide, Final Report of the Special Rapporteur on the Right to Food, UN Doc. E/CN.4/Sub.2/1987/23; The Limburg Principlest 
In short, the object, subject and addressee of a right to cultural identity raise several issues that need to be addressed. They are approached from mainly two angles. First, the theoretical questions on the object, subject and addressee of a right to cultural identity are addressed (Chapters II to IV). Secondly, several established human rights provisions are analysed to determine both their content and scope, and what they have to offer in relation to the protection of cultural identity (Chapters $\mathrm{V}$ to XI).

\section{THE MEANING OF THE CONCEPT OF CULTURAL IDENTITY}

One of the crucial issues with regard to a right to cultural identity is the meaning of the concept of cultural identity. The clarification of this concept from a social science perspective as well as a political science and legal point of view forms an important part of this book. Although the concept of cultural identity has been used in various international human rights instruments there is no generally accepted legal definition of cultural identity. Social scientists have done much work in clarifying this concept, but they, too, have not come up with the, perhaps impossible, solution of one generally acceptable definition of "cultural identity". Although the concept of cultural identity is analysed in detail in Chapter II, several preliminary remarks should be made here.

The concept of cultural identity is closely related to the concept of culture. In fact, both concepts are frequently interchanged. The difference between the culture of an individual or a community and their cultural identity is not quite clear and forms a complex issue. For the purpose of this study, it is sufficient to note that 'culture' seems to be more of an overall concept, and that it is broader in scope than "cultural identity". The term 'culture' may refer to the human culture, the culture of a society or the culture of a person. Furthermore, culture is often used. with an adjective, for example, in business culture, street culture, youth culture, mass culture, etc., whereby "culture" refers to the aspect of human life reflected by the adjective. ${ }^{45}$

Cultural identity reflects the personification or specific interpretation of a certain culture. Culture generally refers to the aspects of culture, while cultural identity refers more directly to the feeling of individuals and communities in the sense of how they experience these aspects. Cultural identity is not only the presence of certain characteristics, but also the perception of these characteristics. Cultural identity reflects the specific way of life of individuals and communities including customs, language, clothing, etc. Both 'culture' and 'cultural identity' are clarified in Chapter II, after which the concept of cultural identity is mainly used.

on the Implementation of the Intemational Covenant on Economic, Social and Cultural Rights, UN Doc. E/CN,4/1987/17; Th. van Boven, C. Flinterman and 1. Westendorp (eds.), The Maastricht Guidelines on Vholations of Economic Social and Cultural Rights, STM Special No. 20, SIM, Utrecht, 1998.

45 Parekh, 2000, p. 143. 
Another point to be made is that identity is not only preeded by the term 'cultural", but also by other terms such as 'ethnic', 'national', 'religious' or 'linguistic'. These identities cannot always be easily separated and their difference is often unclear. Several authors use the concepts of various identities interchangeably. Some identities can, to some extent, be chosen, such as cultural identity, while others are based on descent, such as ethnic identity. Some argue, for example, that ethnic identity is "the first stage" of cultural identity. ${ }^{46}$ Without going into detail on this matter, it can reasonably be argued that individuals derive their cultural identity from participation in different communities and that therefore ethnic, national, religious and linguistic identity are all part of cultural identity, which is the broad and overall concept that is addressed in this book.

It should be noted that, in this study, the concept of cultural identity is based on the premise that cultural identity is not an inactive notion, but something that can develop and change in the course of time. Cultural identity is not something static; it is not just a product or a fixed item, but a dynamic process. ${ }^{47}$ This process is characterised by the fact that cultural identity becomes relevant and important when it is in jeopardy. People become more aware of their cultural identity in situations of confrontation, domination and subordination, for example, when the culture of a minority is dominated by a majority community, or within the framework of the European integration process. Accordingly, international developments such as colonisation and globalisation are important factors in the encouragement of cultural identity. People may start to worry about the preservation of their cultural identity, and claim legal protection through a right to cultural identity. This is a familiar process within the human rights sphere. ${ }^{48}$

Cultural identity is also distinguished by characteristics such as language, religion, education, customs, land rights, arts, literature, work, sports, etc. It seems to be a so-called 'umbrella concept' covering these aspects. For the purpose of this study, cultural identity is primarily approached from the framework of international human rights where it is supposed to be protected as an important element of human dignity. Emphasis is, therefore, laid on those aspects of cultural identity that directly relate to human rights, as laid down in the international human rights instruments, such as language, religion, education, cultural heritage and land. Accordingly, in this book, cultural identity is not approached from the perspective of the protection or development of eultural products such as arts and literature, or cultural activities that do not relate to human rights, such as sports. Most cultural products are usually not dealt with in human rights terms, although some of them can be brought under the term 'cultural heritage'. Consequently, subjects such as the movement and trade of cultural goods fall outside the scope of this study. The focus lies on the development of a right to cultural identity to protect and promote the cultural identity of individuals and communities as an element of human dignity.

46 Council of Europe Doc. CDCC Misc. (94) 3, Draft List of Cultural Rights, October 1994.

47 Meyer-Bisch, 1993, p. 302.

48 See, inter alia, Von Benda-Beckman and Verkuyten, 1995-A, pp. 4-5, 8. 


\section{CUltural IDENTITY as a Human Right}

Several more general human rights issues arise in relation to a right to cultural identity. It has been argued that a right to cultural identity does not fit into the existing human rights system, since human rights aim at universality and equality, while a right to cultural identity would stress the diversity of cultural values and seems to particularise and exclude. ${ }^{499}$ Meyer-Bisch calls it the two faces of cultural identity:

"Ce sont les deux faces de l'identite culturelle: Identité de distinction et d'appartenance, droit au particulier et droit à l'universel ${ }_{n}{ }^{250}$

\subsection{Universalism versus Cultural Relativism}

One of the main debates within the human rights discourse concerns universalism and cultural relativism. A detailed analysis of this debate falls outside the scope of this study, but it can be summarised as follows. In general, universalism asserts that every human being has certain human rights by virtue of being human. These human rights are meant to protect their human dignity, and all persons should be able to enjoy these rights equally. At the opposite side are the cultural relativists, who, in general, claim that there are no universal human values, and that the variety of cultures in the world implies that human rights can, and may, be interpreted differently. In between, moderate forms of both views exist. ${ }^{51}$

In this discussion, a right to cultural identity is interesting, since this right pre-eminently values and promotes different cultures. The question arises as to whether a right to cultural identity, which leads to increasing emphasis on and value for cultural identities, implies some form of cultural relativism. Although a right to cultural identity would give special attention to the cultural identity of individuals and communities, the right itself can have universal value. It is generally accepted that the universal value of a human right does not mean universal implementation of this right. In this sense, a right to cultural identity would be no different from any other human right, especially those with a link to cultural identity, such as the right to freedom of religion and the right to education. A distinction should be made in this respect between the norm itself and the implementation of the norm. While human rights norms have a universal character and apply to everyone on the basis of their human dignity, the implementation of these rights does not necessarily have to be uniform. States may take specific situations and context into account when implementing human rights, although the basic norm is universally applicable.

49 See, inter alid, Galenkamp, 1998, pp. 140-144; Stavenhagen, 1998, p. 8; Stavenhagen, 2001 , p. 93. One can, however, just as well argue that equality is also supposed to recognise differences and diversity.

50 Meyer-Bisch, 1993-A, pp. 26-27.

51 See, on the debate on universalism versus cultural retativism, Baehr, 1996-B, pp. 25-41; Brems, 2001; Donnelly, 1989, pp. 107-160; Donnelly, 2001; Steiner and Alston, 2000, Part B, pp. 323-556. 
Taylor also recognises the tension between universally applieable human rights and a right to cultural identity. He points out two contrasting developments in this respect: the politics of universalism, which includes the principle of the equality of all persons, and the politics of difference, which focuses on the recognition of cultural identity. Taylor recognises the overlap between both developments in the sense that everyone is entitled to the recognition of his or her unique cultural identity. This can be done by giving "...due acknowledgement only to what is universally present - everyone has an identity - through recognising what is peculiar to each." 52

In short, a right to cultural identity should be universally applicable to all communities and individuals, regardless of their language, traditions, geographical place, etc, because cultural identity is an important element of human dignity. The specific implementation of this right may, in principle, vary, depending upon the situation and the cultural identity involved. However, as argued above, the implementation of a right to cultural identity cannot take place unconditionally. "To prevent that the implementation of a right to cultural identity devoids existing human rights of their meaning, it must not restrict existing human rights.

\subsection{Equality and Non-Discrimination}

Another issue in relation to human rights is that a right to cultural identity has been argued to be in contradiction with one of the fundamental principles of human rights, namely, equality and non-discrimination. Instead of focusing on equality, the right to cultural identity seems to be based on the fact that communities and individuals want to be different and to be treated differently. It has been asserted that the right to cultural identity seems to specify and differentiate, instead of striving for equality as human rights are supposed to do. However, it is reasonable to argue that equality and non-discrimination as key principles of human rights also concern the recognition of diversity and a right to be different. Having equal rights is not the same as being treated equally. Indeed, equality and non-discrimination not only imply that equal situations should be treated equally, but also that unequal situations should be dealt with unequally. Again, the difference lies in the distinction between the norm and the implementation. Although a right to cultural identity seems to differentiate, the basis of this right can be equality as long as each community or individual can, in principle, invoke a right to cultural identity. With regard to the implementation of this right, there may be differences in treatment and necessary means. It is generally accepted that the equality principle requires more than a mere formal equality and includes substantive equality, which may require different treatment. Consequently, a right to cultural identity may reflect the right to be different, and may imply different treatment without being in contradiction with the principle of equality.

52 Taylor, 1994, pp. 38-39.

53 See, inter alio, Stavenhagen, 1998, p. 7, Stavenhagen, 2001, pp. 91-92. 


\subsection{The Proliferation of Human Rights}

Another issue to be briefly dealt with in this general introduction is the debate among human rights scholars on the proliferation of human rights and the question as to what extent 'new' human rights should be added to the list of existing human rights provisions. Especially in relation to the discussion on collective rights, the issue of prolliferation has played an important role. ${ }^{54}$ Opponents of the expansion of the list of human rights argue that it would lead to a loss of respect for established human rights and could create more tension between the various human rights. I agree that, in general, one should be very careful in adopting new human rights, because the concept of human rights is valuable and should be reserved for a group of special rights protecting human dignity. This does not, however, mean that the list of human rights is exhaustive per se and that no developments can take place. On the contrary, one of the strengths of human rights is that they can develop. Certain human rights which now seem important were not part of the discussion 55 years ago, for example, specific rights for vulnerable groups such as women, children, minorities and indigenous peoples. One of the issues that has gained interest is cultural identity. In my view, a right to cultural identity should not be rejected solely because no new rights should be added to the existing human rights. Such a right should be developed if it reflects an important value, can truly add something to the existing spectrum of human rights, achieves sufficient consensus among States on the necessity of such a right, and is sufficiently precise to bring about obligations. ${ }^{55}$ Thus, the choice of whether a right to cultural identity should be further developed depends on the norm, the content and the implications of this right. Advantages and disadvantages should be weighed in order to determine whether proliferation is desirable or necessary. This complex issue is examined in this book.

\subsection{Level of Recognition and Justiciability of a Right to Cultural Identity}

One of the arguments against the proliferation of human rights is that not all values should immediately be called human rights. Several authors emphasise that a distinetion should be made between ethical values, political goals and legal standards. While some issues may be important to individuals and communities, and can even represent values part of their human dignity, this does not imply that they should automatically lead to the acceptance of international human rights.

Brownlie, for example, makes it clear that, in his view, collective rights may be acceptable as standards of morality or policy goals, but that it does not mean that they can automatically be called legal rights, unless they are formally

54 See, inter alia, Alston, 1982, pp. 307-322; Alston, 1984, pp. 607-621; 1. Brownlie, 1988, pp. 12-15; Groeneveld, 1996; Cliteur, 1997, pp. 79-90.

55 These criteria are taken from Alston, who has formulated criteria for the proliferation of human rights. See Alston, 1984, pp. 614-615. 
recognised in an international legally binding instrument. He takes the exanple of the right to development, which is announced as a new human right by many, but which has not been legally recognised, except in the form of a declaration. ${ }^{56}$ Prott adds, in this respect, the example of linguistic rights. She argues that there may be an ethical obligation to respect language rights, and that these claims may be transferred into political strategies and policy programmes, for example, with regard to government services and education. However, this does not mean that linguistic rights are automatically legal rights, since they cannot always be enforced. ${ }^{57}$

This division into ethical standards or moral values, policy goals and international legal rights is relevant in relation to the development of a right to cultural identity. The idea expressed above is that cultural identity is an important value that deserves to be protected as an important element of human dignity. In this book, human dignity is considered a basic value, or as Schachter calls it, an 'intrinsic worth'. Respect for human dignity implies that individuals are not treated as instruments or objects of the will of others. Instead, individual choices in matters of beliefs, way of life, ideas and feelings should be respected. Human dignity is clearly violated if certain treatment humiliates beliefs and choices of individuals. Respect for human dignity implies also respect for the communities that individuals are part of. Human dignity is the source of human rights: Human rights are derived from the basic value of human dignity, not from the State or any other authority. This implies that human rights are for everyone and that these rights cannot be taken away. ${ }^{58}$ Respect for human dignity and the intrinsic worth of individuals, may imply a necessity to formulate new human rights to apply to new situations. A separate right to cultural identity could be such a new human right. However, respect for human dignity does not have to imply the assertion of rights. Respect for human dignity can also be obtained by adopting certain policies, whereby certain social processes are stimulated. Such policies could, for example, aim at making people aware of humiliating treatment or disrespect. ${ }^{59}$

In other words, respect for or protection of cultural identity, as an important element of human dignity, can be internationally recognised at various levels. First, it can be recognised as a moral and social value. Secondly, in legal terms, it can take the form of soft law, reflecting its value as a mainly political goal requiring policy-making. The next step might be the international legal recognition of a right to cultural identity as hard law in an internationall legally binding instrument. Soft law can, in fact, become hard law by inclusion in a treaty, or if the rule develops

56 Brownlie, 1988 , p. 14.

57 Prott, 1998, p. 162.

58 Schachter, 1983, pp. 848-853.

59 Schachter, 1983, pp. 853-854. 
into international customary law. Such progressive development from soft law to hard law is not uncommon in international law. ${ }^{60}$

Another issue in this respect is the justiciability of rights. There has, for example, been a debate on whether economic, social and cultural rights can be called human rights, or whether they should be addressed mainly as policy goals. Several authors have expressed doubts about the legal character of economic, social and cultural rights, principally because they consider them to be non-justiciable. ${ }^{6}$ A right is justiciable if it can be subjected to the scrutiny of a court of law or another judicial or quasi-judicial body. A judge should be able to apply the right in a specific case, whereby this application can result in the further clarification of the content of this right. Consequently, a justiciable right should be sufficiently clear and should imply concrete State obligations. It has been alleged that economic, social and cultural rights in the ICESCR are not justiciable because they are vaguely formulated in the treaty, which has, as a consequence, left their content and corresponding State obligations unclear. Consequently, a judge would be unable to expose the meaning of such rights in a concrete case. ${ }^{62}$ The question of the status of economic, social and cultural rights is dealt with in more detail in Chapter III. Here, it is sufficient to say that recent developments have shown that there is increasing consensus that economic, social and cultural rights are "real rights', because they have been included in legally binding human rights instruments. ${ }^{6.3}$ Furthermore, much work has been done on the clarification of economic, social and cultural rights. However, the question of justiciability still remains relevant to the development of a right to cultural identity. To what extent could or should such a right be justiciable?

The matter of justiciability should, however, not be exaggerated. Conclusions in this study should not solely be taken on the basis of whether or not a right to cultural identity could be justiciable; attention should also given to the value behind this right and the need for the protection of cultural identity. Even if a right to cultural identity would be a principle or policy end, or a "soft right', it may be valuable, because States have to develop policies with regard to the protection and promotion of cultural identity.

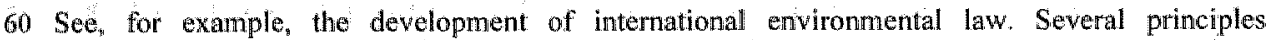
concerning the protection of the environment were laid down in the Rio Declaration of 1992. While originally meant to serve as principles or policy ends without legally binding force, several of them have developed into international customary law, for example Principles 2,18 and 19 . See Malanczuk, 1997, p. 251.

61 See, for an overview of several authors, such as Cranston, Orwin and Pangle, Vierdag and Bossuyt, Arambulo, 1999, Chapter III, pp. 53-97. This matter is dealt with in more detail in Chapter IV of this study.

62 Arambulo, 1999, pp. 55-56.

63 See, among others, The Limburg Principles on the Implementation of the International Covenant on Economic, Social and Cultural Rights, UN Doc. E/CN.4/1987/17; Th. van Boven, C. Flinterman and I. Westendorp (eds.), "The Maastricht Guidelines on Violations of Economic, Social and Cultural Rights", SMM Special No. 20, SIM, Utrecht, 1998. 


\section{Plan of Research}

As set forth above, the central question of this study is to what extent a right to cultural identity should be further developed within the framework of international human rights law, and what the nature, scope and content of this right should be. The focus in the following chapters is on the protection of cultural identity as a dynamic process, which includes aspects such as language, religion, education and land. The analysis of a right to cultural identity includes research into the various levels of recognition and addresses both its individual and its collective dimension.

With regard to the methodology of this study, it should be noted that, in this book, a right to cultural identity is approached from various perspectives; because this right involves social, political and legal aspects. This book is not a pure multidisciplinary study, because the main perspective is the legal one, but inspiration has been drawn from non-legal disciplines by examining a limited number of sources from social and political sciences. These social and political sources are mainly used to analyse the background and content of the concept of cultural identity emanating. The legal perspeetive concerns an analysis of the category of cultural rights as well as of collective rights, which is based on theory and international human rights instruments. This legal part of the study not only concerns the explanation of the existing legal rules and case law, but also deals with the question of whether a right to cuitural identity should be further developed. As such, this study not only deals with the law as it is (de lege lata), but also contains a normative opinion on the desirable development of the law, of how the law should be (de lege ferenda). As such, this study purports to contribute to several debates within the human rights discourse, such as on cultural rights, collective rights, the rights of minorities and indigenous peoples, and, of course, on a right to cultural identity. It fits into the research done within the Maastricht Centre for Human Rights and the Netherlands Research School for Human Rights on economic, social and cultural rights and rights of minorities and indigenous peoples. ${ }^{64}$

The second, third and fourth chapter of this study are devoted to the clarification of the concept of cultural identity, the category of cultural rights and collective rights

64 In Maastricht, two important documents on the clarification and implementation of economic, social and cultural rights have been adopted: The Limburg Principles on the Implementation of the International Cowenant on Economic, Social and Cultural Rights (UN Doc. E/CN.4/1987/17), and the Maastricht Guidelines on Violations of Economic, Social and Cultural Rights (SMM Special No. 20, SIM, Utrecht, 1998). Within the School of Human Rights Series (Intersentiar-Hart, Antwerp), several volumes concern economic, sociall and cultural rights or minority rights: B. Toebes, The Right to Health as a Human Right in International Law, No. 1, 1999; $\mathrm{K}$. Arambulo, Sirengthening the Supervision of the International Covenant on Econowic, Social and Cultural Rightis, No. 3, 1999; C.D. de Jong, The freedom of thought, conscience and religion or belief in the United Nations (1946-1992), No. 5, 2000; A Meijknecht, Towards International Personality: the Position of Minorities and Indigenous Peoples in International Low, No. 10,2000; C. Packer, Using Human Rights to Change Tradition, No. 13, 2002. 
from a social sciences, political sciences and legal perspective, providing a theoretical framework for a right to cultural identity. Chapter II starts with an analysis of the sociological and anthropological literature on the development and content of the concepts of culture and cultural identity, including the importance of cultural identity for both communities and individuals. Chapter III and IV turn to the translation of the social scientific concept of cultural identity into a right. In Chapter III, attention is paid to Kymlicka's liberal theory on collective rights to protect cultural differences, including the question of how to respond to intolerable cultural practices. In Chapter IV, the legal perspective of cultural rights and collective rights is analysed. The chapter aims at answering the question of which human rights can be considered to be cultural rights and what the object, subject and State obligations of these rights are. The background of collective rights is also discussed, as well as the relationship between individual rights and collective rights.

Chapters $\mathrm{V}$ to XI concern an analysis of several cultural rights provisions in international human rights instruments relating to the protection of cultural identity. This book focuses on the protection of cultural identity and a possible right to cultural identity at the international level. No separate attention is paid to a right to cultural identity at the national level or, for example, in bilateral agreements between States concerning minorities. ${ }^{65}$ The main focus lies on provisions that explicitly refer to 'culture' or 'cultural identity', because they are closest to a right to cultural identity and offer most understanding of the object, subject and addressee of this right: Furthermore, they show what kind of protection these provisions already offer in relation to cultural identity. Limited attention is paid to other provisions concerning aspects of cultural identity, such as language, religion and education. Several of these human rights provisions have been studied by others, although not (always) in direct relation to cultural identity. ${ }^{66}$ Not only the wording of the provisions is examined, but also the drafting process, the implementation and the monitoring.

65 Apart from a limited analysis of legislation in the Nordic countries on the Sami in Chapter XI, no attention is paid to a right to cultural identity in national legislation in States such as Canada or Australia. With regard to the protection of cultural identity in bilateral agreements concerning minorities, see, for example, B. Nagy, "Hungary - Romania: treaty on Understandling, Co-operation and Good Neigborlliness", Imternational Legal Materials, Vol. 36, 1997, pp. 340-352; K. Gál, "The role of bilateral treaties in the protection of national minorities in Central and Eastern Europe", Helswiki Monitor, No. 3, 1999, pp. 73m90.

66 See, for example, the following volumes: on the right to freedom of religion, C.D. de Jong, The freedom of thought conscience and religion or belief in the United Nations (1946-1992), School of Human Rights Series No. 5, Intersentia-Hart Antwerp, 2000; B. Tahzib, Freedom of religion or bellef: ensuring effective international legal protection, Utrecht, 1995. See, on the right to selfdetermination, $\mathrm{K}$. Henrard, Devising an adequate system of mimority protection: individual human rights, minority rights amd the right to self-determination, Nijhoff, The Hague, 2000. See, on linguistic rights, F. de Varennes, Language, minorities and human rights, Nijhoff, The Hague, 1996. See on the right to education, D. Hodgson, The Human Right to Education, Aldershot Dartmouth, 1998; A.P.M. Coomans, De Internationale Bescherming var het Recht op Onderwijs [The International protection of the Riglt to Education]; Stichting NJCM Boekerij Leiden, 1992. 
The analysis of the incorporation of culture and cultural identity in international human rights instruments is first undertaken at global level in Chapters V to IX. Chapter V starts with a study of the developments within UNESCO. Both discussions on cultural rights and collective rights were initiated and actively supported by UNESCO and UNESCO has also supported the development of a right to cultural identity. ${ }^{67}$ Although not all instruments of UNESCO are legallybinding, the organisation has a specific place in the discussion on a right to cultural identity, for example, through its Conferences and studies on cultural ritghts. As such, UNESCO forms a bridge between the clarification of the concept of cultural identity in Chapters II, III and IV and the international human rights instruments dealt with in Chapters VI to IX.

The next chapters focus on cultural rights provisions in several UN instruments. ${ }^{68}$ In Chapter VI, two provisions that explicitly refer to culture in the International Bill of Human Rights are analysed in detail, namely, Article 27 of the Universal Declaration and Article 15 ICESCR on the right to participate in cultural life. Chapter VII concerns the protection of minorities in international law, including an analysis of Article 27 ICCPR on the right of members of minorities to enjoy culture and various provisions in the UN Declaration on Minorities. In Chapter VIII, attention is paid to the protection of indigenous peoples in international law, including Convention 169 of the International Labour Organisation (ILO) and the Draft UN Declaration on Indigenous Peoples.

After the global level, several human rights instruments at regional level are examined in Chapters IX and $\mathrm{X}$. The focus chosen is on the human rights instruments adopted within the Council of Europe and the Organisation of American States, because both have well-developed systems of human rights protection including supervisory mechanisms that have dealt with cases concerning the protection of cultural identity. ${ }^{69}$ Chapter IX concerns the Council of Europe. In

67 See, for example, the outcome of a Conference organised by the Netherlands Commission for UNESCO in 1988: J. Berting et al (eds.), Human Rights in a Pluralist World, London 1990 and the outcome of another Conference supported by UNESCO in 1991: P. Meyer-Bisch (ed.), Les Droits Culturels, une categorie sous-developpée de droits de lhomme Acres du Whle Collogue interdisciplinaire, Editions Universitaires Fribourg Swisse, 1993. See also H. Niec (cd.), Cultwal Rights and Wrongs, A Collection of Essays in Commenoration of the 50 th Anniversary of the Universal Declariation of Human Rights, UNESCO Publishing, 1998. UNESCO has furthermore played an inportant role in the drafting process of Article 1.5 ICESCR and has organised many other conferences on cultural rights, which are dealt with in Chapters V and VI of this study,

68 The World Trade Organisation (WTO) is also concerned with the protection of cultural identity, especially national cultural identity, in relation to the principle of free trade. This tnainly concerns the trade in cultural goods and services, which fall outside the scope of this study. See inter alia de Witte, 2001 , pp. 237-238, 242-249.

69 Other regional organisations, such as the Organisation of African Unity (OAU) and the Organisation for Security and Comoperation in Europe (OSCE), have also done work in the fielid of the protection of cultural identity, but they are not dealt with in this book. See, on Africa, inter alia, R.A. Baal, Human rights in Africa: the conflict of implementation, Lanhan, Ma. [ete.], University Press of America, 2000; E. Ankumah. The African Commission on Human and Peoples "Rights Practice and Procedures, Kluwer Law International, The Hague, 1996; W'. Schmale (ed.), Humam 
this chapter, attention is, inter alia, paid to the European Convention on Human Rights (ECHR) and the European Social Charter, as well as the Framework Convention on National Minorities. The drafting of an additional Protocol to the ECHR on Rights in the Cultural Field, although interesting from a scholarly point of view, has been a disappointing exercise and the process has been suspended. Furthermore, several cases of the European Court of Human Rights are analysed that have a link with cultural identity.

In Chapter $X$, the main human rights instruments of the Organisation of American States (OAS) are examined, such as the American Declaration and Convention on Human Rights. The OAS is of special interest, because the American continent has many indigenous peoples whose cultural identity has been jeopardised for many years. The American Draft Declaration on Indigenous Peoples contains several references to cultural identity. Attention is also paid to several cases before the Inter-American Commission on Human Rights (IACHR) and the Inter-American Court concerning the protection of the cultural identity of indigenous peoples. The case law of both the European and the Inter-American monitoring bodies shed light on the question of what existing human rights provisions have to offer for the protection of cultural identity.

Chapter XI contains an illustration of a specific case of an indigenous people and its cultural identity, namely, the Sami in the Nordic countries. This illustration provides clarification of the concept of cultural identity from a more practical perspective and provides insight into what role international human rights provisions could play in protecting the cultural identity of a specific community. The Sami form an interesting illustration, since they have brought several cases to the Human Rights Committee and to the European Court of Human Rights concerning the protection of their cultural identity through land related claims.

Finally, Chapter XII forms the synthesis of the previous chapters and includes the concluding observations, which answer the questions posed in this general introduction. Based on this study, suggestions are advanced as to whether or not the protection and promotion of cultural identity requires the development of a separate right to cultural identity.

rights and cultural diversity: Europe - Arabic-Islamic world - Africa-China, Goldbach, Keip, 1993. See on the OSCE, inter alia, W. Zellner, On the effectiveness of the OSCE minority regime: comparative case studies on implementation of the recommendations of the High commissioner on national minorities of the OSCE, Hamburg: Institut fur Friedensforschung und Sicherheitspolitik an der Universitaet Hamburg, 1999; K. Birmingham, The OSCE and minority issues, The Hague, Foundation on Inter-Ethnic Relations, 1995.

Furthermore, no attention is paid to the European integration process, where the protection of (nationaly cultural identities as well as the protection of a 'European cultural identity' plays an increasing role, however, mainly from the perspective of (limiting) free trade. See, inter alia, de Witte, 2001, pp. 249-255. 


\section{CHAPTER II \\ CULTURE AND CULTURAL IDENTITY IN SOCIAL SCIENCES: A SURVEY}

\section{INTRODUCTION}

Before analysing the political and legal aspects of a right to cultural identity, the concepts of culture and cultural identity should be clarified. Both concepts emanate from social sciences and thus a short excursion into this discipline would seem to be in place. As shown above, within the legal context, the attention to cultural rights is increasing after a long period of neglect. However, culture and cultural identity are concepts that cannot easily be described in legal terms. Thus, their social science background can be helpful in this respect. How have social scientists and other nonlegal scholars dealt with the concepts of culture and cultural identity? Although many of them have described the context of both concepts, no single, balanced definition of culture and cultural identity can be found in the literature. Consequently, the main purpose of this chapter is to place the concepts of culture and cultural identity in a social science framework.

In the first part of this chapter, an overview is given of the development of the notion of 'culture', because the concept of cultural identity is closely related to it. Culture is a rather 'new' notion that has only been used in its current independent form since the end of the 19th century, instead of as adjective. Part of the development of the concept of "culture" was caused by a debate on the meaning and background of culture between universalist scholars and relativist scholars. As mentioned in the general introduction, a similar discussion took place, at a later stage, within the human rights discourse.

The second part of this chapter contains a clarification of the concept of cultural identity. Cultural identity is a dynamic concept, bound to time, place, community and individual. It contains several aspects, such as language and religion and has an individual and a collective dimension. The individual members of communities can identify with various different communities. Consequently, cultural communities and cultural identities are not homogenous. It should be pointed out here that the distinction between the individual dimension and the collective dimension of cultural identity is not always clear, and authors sometimes use both dimensions interchangeably. Both dimensions of cultural identity are important with regard to the development of a right to cultural identity, especially

1 The various authors examined have different backgrounds, such as sociology, anthropology, philosophy or political science. They are addressed as 'non-legal' scholars of whom a limiterl mumber of sources has been analysed. 
with regard to the issue of whether it should be an individual or a collective right. Subsequently, the question of why cultural identity has become such a crucial notion to individuals and communities is dealt with. Several international developments, such as colonisation, decolonisation and globalisation, have played a principal role in the rise of the awareness and the encouragement of cultural identity.

In the final section, attention is paid to the different forms of recognition of cultural identity. In the second part of the 20th century, concepts of tolerance and multi-culturalism were used in relation to cultural differences. The general question is whether the specific cultural identity of persons and communities should be positively recognised and emphasised by giving them special rights, for example, a right to cultural identity, or whether the focus should, instead, be on equality and non-discrimination. Two scholars defending these extremes, Taylor and Margalit, are dealt with below.

\section{THE CONCEPT OF CULTURE}

The term 'culture' can be used in various ways. It can relate to human culture in general, the culture of a specific community or period, or the culture of a person in the meaning of his civilisation. Hundreds of definitions and descriptions have been given to the term 'culture'. ${ }^{2}$ Until the 19th century, culture was only used in combination with other words meaning the development or civilisation of something. In the 19 th century, the notion of culture became an independent notion indicating the moral and intellectual qualities through which people could distinguish themselves. Culture implied striving for perfection, the fulfilment of the best human qualities. In the 20th century, culture was used in the plural form to stress differences in cultures, which should be valued.

The changes in the concept of culture are partly caused by two streams within cultural anthropology that have developed since the end of the 19th century: universalism and relativism. Generally stated, universalism emphasises the system of unity. The central point of universalism is that, behind all diversity, there must be some sort of unity. Relativism, on the other hand, emphasises the system of diversity. It focuses on the specific character of an individual or a community. The central point of relativism is that reality is full of unique phenomena and differences, which are all valuable. These differences cannot be reduced to a common unity. Every community or culture has its own values and meanings of good and bad, which should be valued and tolerated. Another important aspect of relativism is its emphasis on the fact that all observations are influenced by the culture of the observer. The main critique of relativism on universalism is that its so-called universal standards are mainly products of just one specific culture, the

\footnotetext{
2 Many definitions have been analysed by A.L. Kroeber and C. Kluckhohn in their book. Culture, $a$ Crifical Overview of Concepts and Definitions, Vintage, Random House, New York, 1952.

3 Goudsblom, 1987, pp. 57-59.
} 
western culture, which makes universalism a form of cultural imperialism. Consequently, cultures should only be judged from within. Both universalism and relativism are presented here as extremities. In between these two poles, many intermediate lines of thinking can be found. The discussion on universalism and relativism will not be dealt with as such, but is used to clarify the development of the concept of culture.

\subsection{The Meaning of 'Culture' Changing over Time}

The origin of the concept of culture can be found in antique Greek history, where the philosopher Plato launched the idea of the 'paideia', the ideal of a philosophically-shaped human being. Men could only reach true knowledge through philosophy. "The 'paideia' was the true realisation of human nature, the true cultivation of the human being, the only true civilisation or 'culture'. The concept of culture expressed a fundamental aspect of society, namely, the way in which the human being should cultivate himself to be a true civilised human being. The Romans translated this 'paideia' into the term 'cultura animi'. The term 'culture' thus emanated from Latin, meaning 'civilisation' or 'process". Essential to this classic concept of culture was the fact that it implied a norm, a spiritual ideal of a small élite. The virtuous human being had to live his life according to this norm. It was, therefore, a normative and appreciative notion. It was not used to describe a life form neutrally, but rather to give norms for the correct way of life. In short, the term 'culture' expressed the "culture ideal". This notion of culture prevailed until the end of the 19th century.

\subsubsection{Culture in the Singular Form as a Normative Concept (1850-1950)}

At the end of the 19th century, culture became a central notion in modern western civilisation. Cultural scientists started to examine so-called "primitive cultures" by not only describing them but also by valuing them. In their view, the western culture was superior to these primitive cultures, since it was the most developed. Primitive cultures, on the other hand, were created by non-developed people. Early anthropology was, therefore, far from being a science devoid of value judgements, and culture was used as a normative concept. At that time, anthropologists treated human differences as evolutionary stages. Mankind was one and the differences between peoples represented different phases in the same process from savagery, via barbarism, to civilisation. It was normal to assume a hierarchy of races in which the white race was superior. Culture was considered to be a process of natural progress, stimulated by human activity and intelligence, which was called "evolutionism".

4 Lemaire, 1976, pp. 26, 32, 37, Van Berkel, 1986, p. 35, Goudsblom, 1987, pp. 57.58.

5 Lemaire, 1976, pp. 20, 39-41, Goudsblom, 1987, p. 191; Stocking, 1982, pp. 70-71. 
One of the defenders of evolutionism who is considered to be one of the 'founders' of cultural anthropology at the end of the 19 th century is E.B. Tylor, ${ }^{6}$ who was convinced that cultures differed because they were in different phases of cultural development towards civilisation. The western European culture was superior because it had reached the final phase. Tylor also defended the idea of the psychological and cultural unity of mankind. According to Tylor, the continuity between lower and higher cultures could be proven by the so-called 'survivals'. These were elements of an earlier phase in a culture, which, out of habit, survived in modern civilisation, for example, folklore, superstition, astrology, magic, etc. Tylor developed a definition of 'culture' which is still valuable today:

"Culture or civilisation...is that complex whole which includes knowledge, belief, art, morals, law, customs, and any other capabilities and habits acquired by man as a member of society.",

This definition reflects a broad concept of culture including various aspects. Tylor still remained in the tradition of the 18 th century by using the term 'culture' in the singular form. He also relied on the normative, evaluating aspect of culture and did not consider cultures to be equal. When Tylor spoke of the culture of a community, he merely meant the cultural stage or degree of a community. For Tylor, culture was not the passing on of social traditions from generation to generation through mechanisms of unconscious imitation. Although he did speak of a remarkable agreement that united people, for example by using the same language, following the same religion and customary law, he did not call this consensus 'culture'?

\subsubsection{Culture in the Plural Form as a Unique Entity (1900-1950)}

Fieldwork had always been an important aspect of cultural anthropology. Because of technological developments, it became more and more decisive from the beginning of the 20th century onwards. Fieldwork showed that the so-called 'primitive cultures' could not be explained as simply as it had seemed at first. Anthropologists started to study cultures in a value free, unprejudiced and openminded way. The Eurocentric or ethnocentric view common to the previous century was now challenged. It was argued that all cultures should be equally valued. The European culture was no longer considered superior. ${ }^{10}$

6 See, infer alia, E.B. Tylor, Primitive Culume (2 parts), Harper Torch, New York, 1958 (or. 1871); E.B. Tylor, Researches into the Early History of Mankind and the Development of Civilisation, University of Chicago Press, Chicago, 1964 (or. 1865); E.B. Tylor, Anthropology, Ann Arbor, 1965 (or. 1881).

7 Lemaire, 1976, pp. 69-70; Van Berkel, 1986, pp. 35-36, Goudsblom, 1987, pp. 60-61, 64-66.

8 Tylor, 1920, p. 1, see, also, Stocking, 1982, p. 73.

9 Lemaire, 1976, p. 74, Stocking, 1982, pp. 72-75, 81-83; Van Berkel, 1986, pp. 35-36, Goudsblom, 1987, pp. 60-61, 64-66.

10 Procee, 1991, p. 29, Lemaire, 1976, pp. 20 and 78. 
This change in the direction of cultural relativism was further stimulated by the cultural identity crisis in the West at the turn of the century. Forms of pessimism grew and were strengthened by the events of the First World War. People became sceptical about the predicted progress. This climate led to a revival of the Romantic period and a negative attitude towards positivism and evolutionism. Intellectuals were becoming more and more negative about their own western culture and more positive about other, non-western cultures. This climate proved to be fertile for cultural relativism. ${ }^{11}$

The first half of the 20th century saw a firm empirical reaction against the classical evolutionist theories. The evolutionists were criticised for putting the European culture in the centre as the standard for all cultures. It was stated that different communities had their own lifestyles. Elements of cultures could not simply be interchanged; every culture formed an individual, independent unity. Influenced inter alia by the increase of empirical data, three major changes took place in using the notion of culture: firstly, the notion of culture was now used in the plural form and included the bond of tradition and culture over people. Before, scholars had referred to 'cultural stages' or 'cultural forms', but had never spoken of 'cultures' as such. Secondly, cultures were considered to be equal, which meant they should be studied free of values and prejudices. Thirdly, the European culture was no longer the central example for all cultures. The concept of culture lost its Eurocentric or ethnocentric meaning. ${ }^{12}$

These changes were developed by the relativist scholars in the first half of the 20 th century. F. Boas, who is often referred to as the "father of relativism", started the process which led to the development of relativist theories. ${ }^{13}$ Boas did extensive fieldwork which made him reject scientific generalisations on cultures, because he realised that he had no right to look down on these cultures. Consequently, he rejected the Eurocentric studies of cultures. Boas was convinced that researchers should not project their own western values upon the cultures they described. A culture should only be described in its own language and terms. ${ }^{1 / 4}$ Furthermore, Boas criticised the universal reconstruction of the evolutionists including Tylor. They had gathered cultural elements from different parts of the world and took them out of their cultural context to develop a universal reconstruction of the various stages of development in which cultures could be placed. Boas emphasised the mutual dependence and integration of elements of cultures. ${ }^{15}$

11 Procee, 1991, p. 30.

12 Lemaire, 1976, pp. 17, 83, 88-89, Goudsblom, 1987, pp. 64-65; Procee, 1991, p. 31; see, also, Stocking, 1982, pp. 203, 233 .

13 See, inter alia, F. Boas, Race, Language, Culture, The Free Press, New York, 1966 (or. 1940); If. Boas, Anthropology and Modern Life, New York, 1962 (or. 1.928), F. Boas, The Mind of Primitive Man, New York/London, 1965 (or. 1911).

14 Boas, 1940, p. 311; Stocking, 1982, pp. 140-142, 148, 168, 179; Lemaire, 1976, pp. 83, 87.

15 Lemaire, 1976, p. 86; Procee, 1991, p. 31; Stocking, 1982, p. 232. 
Another two relativist scholars, Benedict and Herskovits, further developed the theory of relativism. ${ }^{16}$ They stated that there could be no absolute or universal norms, since all observations are influenced by the habits, ideas and institutions of the culture of the observer. Consequently, no one is allowed to judge (aspects of) other cultures, since all judgements are influenced by the culture in which the researcher has grown up. Instead, cultures should only be judged by and from themselves. ${ }^{17}$

This call for tolerance and the equality of all cultures was reflected in the advice of the American Anthropological Association to the UN Commission on Human Rights during the drafting of the Universal Declaration of Human Rights in 1947. This advice, which was basically written by Benedict and Herskovits, reflected cultural relativism. It stated that the Universal Declaration should reflect mankind in all its diversity by recognising the equality of moral systems. It was stated that:

"1. The individual realises his personality through his culture, hence respect for individual differences entails respect for cultural differences.

2. Respect for differences between cultures is validated by the scientific fact that no technique of qualitatively evaluating cultures has been discovered.

3. Standards and values are relative to the culture from which they derive so that any attempt to formulate postulates that grow out of the beliefs or moral codes of one culture must to that extent detract from the applicability of any Declaration of Human Rights to mankind as a whole."

The UN Commission did, however, put aside this advice in drafting the final version of Universal Declaration which lays down universal values for all individual human beings, based on their human dignity. ${ }^{19}$

Cultural relativism in turn was criticised. It was inter alia argued that relativism would tolerate 'deficient' cultural activities such as aggressive and intolerant behaviour: Such behaviour could never be judged if it was argued that it was part of the traditional, cultural practice of a people. Consequently, relativism was said to be forced to tolerate intolerance. Opponents of relativism further argued that the decolonisation process had shown the one-sidedness of relativism. Decolonised people did not fully return to their ancient culture; instead they copied various western cultural aspects and modernised themselves, although not under western supervision. ${ }^{20}$

16 See, inter alia, M. Herskovits, Franz Boas, the science of man in the making, New York/London, 1953; M. Herkovits, Cultural Relativism, perspectives in cultural pluralism, Vintage, Random House, New York, 1973; R. Benedict, Patterns of Culture, Mentor, New York, 1960.

17 Procee, 1991, pp. 31-32, Lemaire, 1976, pp. 86-87, 91-93.

18 Lemaire, 1976, p. 97.

19 Lemaire, 1976, pp. 96-97.

20 Lemaire, 1976, pp. 162- 163. 


\subsubsection{The Modern Notion of Culture as a Way of Life $(1950-\ldots)$}

In the second half of the 20 th century, the meaning of the concept of culture again widened to indicate the lifestyle of a society. Included were not only the higher culture, the spiritual side or culture with a capital ' $\mathrm{C}$ ', but also mass culture, 'kitsch', sports and all expressions of a society, or culture with a small ' $c$ '. More emphasis was laid on the psychological aspects of culture as a factor in the development of personalities and identities. ${ }^{21}$

In short, culture became the whole of human life, in other words "...a complex web of relationships and beliefs, values and motivations." ${ }^{, 22}$. Parekh, for example, describes culture as "[a] historically created system of meaning and significance... a system of beliefs and practices in terms of which a group of human beings understand, regulate and structure their individual and collective lives."23 Culture is developed and transmitted by cultural institutions, which include educational institutions, such as schools; media institutions, such as newspapers and television; and other cultural institutions, such as historical archives, museums and theatres. ${ }^{24}$

Culture is also described in terms of its sources or aspects: ".... culture is distinguished by such characteristics as language, religion, and race, and more broadly by shared attitudes, customs and traditions." ${ }^{25}$ In a broader perspective, elements such as values, beliefs, sciences, arts and cultural institutions could be added. ${ }^{26}$ These definitions show that culture is mostly considered as something important for human beings: "...culture shapes all our thinking, imagining and behaviour... a dynamic source for change, creativity, freedom, and the awakening of innovative opportunities. For groups and societies, culture is energy, inspiration and empowerment.",27

Culture is a dynamic process, without fixed centres or precise boundaries. It is a complex system of beliefs and practices, which can change and develop, although there is a certain core. Culture has an objective dimension, reflected in visible characteristics such as language, religion, or customs, and a subjective dimension, reflected in ways of thinking, feeling and acting. These often unarticulated aspects of culture become evident mainly when they are being questioned or challenged. ${ }^{28}$

21 Van Berkel, 1986, pp. 37-38, Goudsblom, 1987, pp. 64-65.

22 World Commission on Culture and Development, 1995, p. 7.

23 Parekh, 2000, p. 143.

24 Margalit, 1996, p. 165.

25 Van Dyke, 1980, p. 2; see, also, Parekh, 2000, pp. 143-144.

26 See, for example, the discussion within the Council of Europe concerning the drafting of an Additional Protocol to the ECHR in the Cultural Field; CoE Doc. CAHMN(95)16 Appendix IV, May 1995, p. 27.

27 World Commission on Culture and Development, 1995, p. 11.

28 Benda-Beckmann, won and Verkuyten, 1995-A, p. 12; Kymlicka, 1995, p. 83; Parekh, 2000, pp. $143-144,153$. 
Some authors, Waldron, for example, thus argue that there are no such things as cultures, since it is impossible to tell where one culture ends and another culture starts. There are many cultural sources and cultural fragments, but they do not possess any structure connecting or underlying them. ${ }^{29} \mathrm{I}$ agree with Kymlicka, who admits that no walls should be built around cultures, but argues that cultural aspects only make sense because one can weigh them against one's own culture. The fact that people borrow cultural aspects of other cultures through cultural interchange does not mean that these people do not belong to a certain culture or speak a certain language. ${ }^{30}$ In my view, a dynamic view of culture is needed, as also proposed by Von Benda-Beckmann and Verkuyten, who argue that culture should not be addressed as a static entity with certain features, unsusceptible for changing circumstances. ${ }^{31}$

\section{THE CONCEPT OF CULTURAL IDENTITY}

"Just now everybody wants to talk about "identity.",

Although perhaps 'everybody' talks about (cultural) identity, the question is whether they mean the same thing. The concept of cultural identity has various implications and meanings and social science literature contains a variety of descriptions and definitions of cultural identity. No clear single definition can be detracted, so instead a social science framework of the concept of cultural identity is given. It should be noted that, in this section, identity is used both with and without the adjective 'cultural'. While the general focus in this study is cultural identity, some analysed sources referring to the term 'identity' provide useful material in relation to the concept of cultural identity. Furthermore, the individual dimension and the collective dimension of cultural identity are not always clearly distinguished. Most authors refer to the cultural identity of the individual, with or without a direct relationship to the community involved, while others refer to the cultural identity of a community as such.

Cultural identity can be seen as the personification of culture. Comparable to culture, eultural identity is not static and homogeneous, but dynamic and heterogeneous. Aspects of cultural identity are numerous, for example, arts, literature, language, religion, cultural heritage, education, but also habits, traditions, customs and institutions. ${ }^{33}$ Cultural identity mainly concerns the way these aspects are perceived by individuals and communities. Cultural identity is important to individuals and communities, because it gives them a sense of belonging and, as

29 Waldron, 1995, pp. 106-108.

30 Kymlicka, 1995, pp. 102-105.

31 Benda-Beckmann, von and Verkuyten, 1995-A, p. 8.

32 Mercer, 1990, p. 43.

33. As explained in the general introduction, this study only focuses on aspects of cultural identity that have a link with human rights, which are language, religion, education, cultural heritage and land. 
such, concerns their human dignity. This concept of belonging is very important, since it gives individuals a sense of personal integrity and a feeling that they can represent themselves and be recognised. ${ }^{34}$ Weeks has described this element of (cultural) identity as follows:

\begin{abstract}
"Identity is about belonging, about what you have in common with some people and what differentiates you from others. At its most basic, it gives you a sense of personal location, the stable core to your individuality. But it is also about your social relationships, your complex involvement with others, and in the modern world these have become even more complex and confusing., ${ }^{, 35}$
\end{abstract}

Weeks emphasises the importance of identity for individuals and the fact that identity is build by relationships with other individuals and with a community, Taylor also argues that identity is closely relation to the person. It is "... who we are, where we are coming from. As such, it is the background against which our tastes and desires and opinions and aspirations make sense." within the Council of Europe on the drafting of a cultural protocol the concept of cultural identity was also described in similar terms. ${ }^{37}$. This definition refers to both the cultural identity of the individual and of the community. The experts emphasise the process-like character of cultural identity and its different aspects. The drafting committee, consisting of experts in the field of social science and law, argued that

"[c]ultural identity applies to all those elements of culture through which individuals and groups define and express themselves and by which they wish to be recognised; as a phase in a process which is never completed, it embraces the liberties of which personal dignity is compounded, and covers cultural diversity, the particular and the universal, memory and aspiration. ${ }^{38}$

\title{
3.1 Cultural Identity as a Dynamic Concept
}

One of the central characteristics of cultural identity is that it is neither static nor homogenous:

"...instead of thinking of identity as an already accomplished fact...we should think...of identity as a 'production', which is never complete, always in process..., ${ }^{39}$

34 Rutherford, 1990-A, pp. 24-25.

35 Weeks, 1990 , p. 88.

36 Taylor, 1994, pp. 33-34.

37 The Member States of the Council of Europe have attempted to draft an Additional Protocol to the ECHR on Rights in the Cultural Field. This drafting process and its final suspension are dealt with in Chapter X.

38 Council of Europe Doc. CAHMIN(95)16 Appendix IV, May 1995, p. 27.

39 Hall, 1990, p. 222. See also Meyer-Bisch, 1993, p. 302; Stavenhagen, 1990, p. 258 and Von BendaBeckmann and Verkuytem, 1995-A, pp. 4-5, 8 . 
Hall distinguishes two ways of thinking about cultural identity. The first position defines cultural identity in terms of one shared culture. Cultural identity makes individuals into a people and reflects their common historical experiences and shared cultura rules. Cultural identity provides them " ${ }_{\text {... }}$ stable, unchanging and continuous frames of reference and meaning, beneath the shifting divisions... of our actual history. ${ }^{340}$ This rather static concept of cultural identity was the central element in post-colonial struggles and remains the central argument in current demands for representation by subordinate communities, whereby these communities focus on their common culture which is distinguished from the majority. ${ }^{41}$

The second view of cultural identity mentioned by Hall emphasises that, apart from similarities, there are significant differences which constitute "what we are' and "what we have become". Cultural identity is not only a matter of "being", but also of 'becoming'. Cultural identity concerns the future as much as the past, and reflects a process. Cultural identity is not fixed in a certain past or confined to certain practices and customs; instead, it is continuously influenced by history, culture and power.

“...[C]ultural identity is not a fixed essence...lying unchanged outside history and culture. It is always constructed through memory, fantasy, narrative and myth. Cultural identities are points of identification within the discourses of history and culture."

Most authors support such a dynamic approach of cultural identity. Cultural identity should be considered a process, instead of a creation according to a fixed scheme. ${ }^{4}$ Cultural identity is not a simple, uniformly consisted entity given from birth. Individuals identify themselves through many different aspects. All sorts of fields of social development can play a role, such as gender, nationalism, religion, regionalism and race. ${ }^{44}$

Cultural identities are furthermore not homogeneous, because they are not created within bounded areas, but within spaces of interaction. Individuals participate in various cultural communities and create heterogeneous communities, ${ }^{45}$. Cultural identities are furthermore not neutral. Rutherford explained this in relation to the collective dimension of cultural identity. He argued that different and often conflicting values lie behind the claim for cuitural identity. The beliefs, needs and desires expressed by this claim are often potentially in conflict, not only between different communities, but also within communities themselves.

40 Hall, 1990, p. 223.

41 Hall, 1990, p. 223 .

42 Hall, 1990, pp 225-226. See, also, Keller, 1998, p. 36, and Rutherford, 1990-A, pp. 19-20.

43 Morley and Robinson argue, for example, that cultural identity is a "...continuous and continuously problematic process", see Morley and Robins, 1990, pp. 44-45.

44 Watney, 1990, pp. 182-183.

45 Morley and Robins, 1990, 128-129. See, also, Keller, 1998, p. 36. 
This brings up sensitive issues such as how to compromise between collective needs and specific individual needs, and how to balance the universal and the particular. ${ }^{46}$

\subsection{The Individual and the Collective Dimension of Cultural Identity}

As mentioned before, cultural identity has an individual and a collective dimension, although this distinction is not always clearly made. The individual dimension reflects that individuals derive their cultural identity from participation in different communities. Some argue that individuals can, therefore, have "multiple cultural identities'. Individual identity may be based on nationality, ethnicity, religion or culture, and each of these identities has its complex meaning. These identities may not come to surface, until they are being forced by, for example, social circumstances. ${ }^{47}$ One can also say that individuals have one 'overall' cultural identity, including various separate identities, such as a linguistic identity, religious identity, national identity, etc. It is these elements together that form the unique individual cultural identity of a person.

In other words, individual identity is formed through an interchange with family, religion, society and all the other communities a person is part of. These communities offer concepts and practices by which individuals can form their identity. As Appiah explains: "We make up selves from a tool kit of options made available by our culture and society:" 48

Appiah subsequently points at the two dimensions of individual identity: a collective dimension, including the characteristics derived from the relation with communities, for example, linguistic and religious, and a personal dimension including other socially important features, such as intelligence, charm, wit, etc. These personal characteristics cannot be the basis for a collective identity, since persons who share such qualities do not form a social community. ${ }^{49}$ Furthermore, these aspects do not play a direct role in relation to cultural identity.

The collective dimension of cultural identity is a complex matter. The question is whether a community can have a "cultural identity", which has been described as a personal matter of feeling and belonging. Besides; as cultural communities are not homogeneous, how can one speak of the cultural identity of a community? Parekh argues that cultural communities do have a cultural identity even though they are not homogeneous. Some members of the community might adhere to all beliefs, while others share only a few. Interpretation of these beliefs might also differ within

46 Rutherford, 1990, p. 89.

47 Von Benda-Beckmann and Verkuyten, 1995-A, pp. 15, 17; see, also, Donnelly, 2001, p. 37; Keller, 1998 , p. 37

48 Appiah, 1994, pp. 154-155.

49 Appiah, 1994, pp. 151-152. 
the community. If this system of beliefs and practices is constantly contested and changed, then identity, too, is also never settled or static. According to Parekh, this does not, however, mean that cultural communities do not have a cultural identity. "Like the identity of an individual, that of a culture changes slowly and in parts, allowing its members time to absorb and adjust to changes and reconstitute its identity on a new basis." $\$ 50$

In any case, the cultural identity of the community finds its basis in the individual members of the community and the fact that they share certain cultural characteristics. However, the cultural identity of a community is not necessarily the same as the sum of the cultural identities of the individual members, since they all have unique identities. As stated above, these individual identities contain various aspects that might relate to different cultural communities. It is, therefore, hard to determine which aspect of the cultural identity should be protected. Furthermore, it is important to determine which collective cultural community is meant. Cultural communities can be found at different levels. Some communities are based on one cultural aspect, such as language or religion. Others involve more cultural aspects, for example, a national or regional cultural community. The cultural identity of a community is hard to define, although one can describe the elements of this cultural identity. The broadness of a collective cultural identity depends on the level of the community.

A remark should be made here that may be important in relation to a legal protection of cultural identity. From the individual perspective, it is clear that every individual cultural identity has a collective element and refers to one or more communities, which should also be reflected in any form of legal protection. With regard to the collective dimension of cultural identity, it is more difficult to describe the cultural identity of a community, since it concerns different levels of community and a heterogeneous concept.

\subsection{Cultural Identity in Relation to 'Otherness': the 'Us and Them' Principle}

Cultural identity is furthermore related to 'otherness' whereby recognition by others and the definition of boundaries play an important role. It means that the identity of an individual or a community is based on opposing other communities that are considered different or subordinate in the sense of class, race, culture, etc. This creates the image of 'the rest' or 'us and them'. As Von Benda-Beckmann and Verkuyten argue:

"Identities refer to what people conceive themselves to be, to which collectivities they belong. This intrinsically implies a conception of those to whom one does not belong: to be 'us', one needs those who are 'not us'., "s!

50 Parekh, 2000, pp. 148-149.

51 Von Benda-Beckmann and Verkuyten, 1995-A, pp. 15, 17. 
The individual as well as the collective cultural identity is constructed within a system of sociall relations, whereby the recognition of others is required. Taylor, for example, rightly emphasises the importance of recognition or non-recognition by others. ${ }^{52}$ Accordingly, cultural identity concerns a process of defining boundaries, which may change in the course of time, because cultural identity is a continuous process of restructuring. ${ }^{53}$

This process is characterised by the fact that cultural identities come to surface when they are directly confronted with other cultural identities. The idea behind it is that one's pure and authentic culture might be polluted or overthrown by other cultural influences. These 'bad influences' are responded to by the call for the return to the pure certainties and old traditions on which the cultural identities were based. ${ }^{54}$ This form of identity has been described as 'negative identity' based on negative unity. It means that identity is formulated in terms of hostility towards, and reaction against, something else. The identity is constructed in terms of who is in and who is out, of 'us and them'. Cultural identity is strongly related to its boundaries. It is a symbolic geography that separates the insiders from the outsiders. This does however not imply that cultural identities are not influenced by others. Cultural identities exist in the midst of others and are therefore inescapably influenced by them. Cultural identities may copy certain aspects of others, while at the same time oppose other aspects of them. This is all part of the basic characteristic of cultural identity, namely its dynamic character as a process. ${ }^{55}$

The relational aspect of cultural identity is explained by various authors. Taylor, for example, points at the dialogical relations with others that form an individual identity. The human languages of expression, including not only spoken words but also other forms of expression through gestures or non-verbal. communication, are essential in defining an identity. ${ }^{56}$ Morley and Robinson argue that cultural identities are only created in and through their relations to other cultural identities. The characteristic of cultural identity is being what the others are not. For example, the Islamic culture is shaped by its distinctions from, and opposition to, the American culture, the European culture, the Asian culture, etc. Considered from this perspective, "... difference is constitutive of identity.

In short, cultural identity is as much about inclusion and similarities (positive identity) as it is about exclusion and differences (negative identity). It is a social process concerning others, other communities, cultures, histories and traditions, and the definition of social boundaries to distinguish one cultural community from

52 Taylor, 1994, p. 25. See, also, Rockefeller, who also argues that a strong sense of identity colneres with the demand for recognition and acceptance by others, Rockefeller, 1994, p. 97.

53 Morley and Robins, pp. 45-46, Rutherford, 1990-A, p. 14.

54 Morley and Robins, pp. 6-8, Mercer, 1990, pp. 56-57.

55 Morley and Robins, pp. 21-22. See also Stavenhagen, 2001, pp. 89-91; Stavenhagen, 1998, pp. 4-6.

56 Taylor, 1994, pp. 26-32. See, further, Appiah, who also emphasises the importance of dialogue in shaping individual identities, Appiah, 1994, pp. 154-155.

57 Morley and Robins, p. 45. 
another. In a legal sense, this means that a right to cultural identity should be based on equality and mon-discrimination on the one hand, and the right to be different on the other.

\subsection{International Developments Encouraging Cultural Identity: Decolonisation, Emancipation and Globalisation}

One specific element of cultural identity keeps coming forward:

"....identity onlly becomes an issue when it is in crisis, when something assumed to be fixed, coherent and stable is displaced by the experience of doubt and uncertainty., ${ }^{58}$

People become more aware of their cultural identity when they fear that other cultures may erode their own culture, values and traditions. In response to this fear, communities and individuals start to emphasise their own cultural identity and their specific characteristics, including a claim to the protection of their cultural identity. Several major international developments such as colonisation and globalisation have played an important role in creating and stimulating such a feeling of crisis and have increased the interest in the protection of cultural identity.

In the 1960 s, anti-colonialism was one of the main freedom movements that led to claims for the recognition of the cultural identities of communities. During colonisation, the cultural identity of colonialised communities had often been oppressed. The communities fought for independence, self-determination and liberation, combining western forms of statehood with their own traditions and indigenous life forms. These struggles led to forms of revolutionary nationalism that sometimes overwhelmed regional, ethnic and indigenous identities. Many of these communities were not based on already: formed identities, but the transformation and democratisation process made the emergence of these new communities and identities possible. ${ }^{59}$

From the $1970 \mathrm{~s}$, a general emancipation movement arose, emphasising difference, instead of unity and coherence. It was argued that there could be no fixed beliefs in unchanging identities based on race, gender, ethnicity and sexuality. A fixed and static notion of cultural identity was now uprooted by the politics of difference, which emphasised the interdependent and relational nature of identities. Cultural difference was no longer considered to be a threat to power, it was considered a value in a democratic society which should be based on pluralism and multi-culturalism. ${ }^{60}$

In the $1980 \mathrm{~s}$, this development continued with political and social movements such as feminism, gay liberation and black power. Values such as

58 Mercer, $1990, \mathrm{p} .43$.

59 Mercer, 1990, pp. 59-60.

60 Rutherford, 1990-A, pp. 10-11. 
freedom, equality and solidarity became central notions of social and political life. Subordinate communities, such as women, but also minorities or indigenous peoples who were denied these values, started to stand up for themselves, by arguing that they were confronted with a dominant culture and could not, therefore fully develop and articulate themselves: Accordingly, these communities sought to be represented and to participate in political decision-making, including the claim. for the protection of their cultural identity. ${ }^{61}$

At the same time, there was a movement that emphasised the common destiny of mankind, human solidarity and the interdependence of human beings. It was stressed that what people have in common is more important than what divides them as members of different communities. Human solidarity was heavily threatened by the encouragement of economic, national, linguistic, ethnic and religious differences. A balance was needed between diversity and community. This was supposed to be multi-culturalism, in which different cultural communities would evolve gradually into a neighbourly society. ${ }^{62}$

Since the $1990 \mathrm{~s}$, new technologies have enormously increased flows of information, communication and transportation. This process, called globalisation, in which people, culture, goods and information go all over the world, has changed people's sense of space and location. The natural limits of a community or nation are no longer determined by physical boundaries, such as geographical distances, seas or mountains. Apart from the symbolic boundaries of language and culture, the boundaries are now determined by transport and communication networks.

Globalisation has led to new forms of bonding and belonging, new senses of communities, new attachments, and, consequently, to new identities of communities and individuals. Developments such as the global circulation of products, new and increasing contacts and exchanges between cultures, and migration and refugee streams have built and changed cultural communities and cultural identities. People used to define themselves mainly in terms of nationality, through citizenship of a nation state. Nowadays, the notion of citizenship has changed and instead of being aligned to nationality, citizenship relates to new alliances in an enlarged form, such as the European Union, or, in a restricted form, through local communities. ${ }^{63}$

In this respect, Morley and Robinson point to an interesting paradox in the process of globalisation. On the one hand, it creates world markets, global industries and globall cultures, while, on the other, local production, local distribution networks and local cultures have all developed. They call this the tension between globalism and localism. In reaction to globalisation, an increasing emphasis on national and local identities can be identified. ${ }^{6.4}$ This tension is, for

61 Rutherford, 1990, pp. 11-13, 18-19, 23.

62 Weeks, 1990, pp. 91-92.

63 Morley and Robins, 1990, pp. 59, 74, 114, 182-183, 186.

64 Morley and Robins, 1990, pp. 1-2, 19-20, 12.2 
example, visible in the development of the European Union. On the one hand, the Member States are trying to create a European cultural identity and, at the same time, various communities and individuals within Europe tend to emphasise local forms of place and identity, including the flourishing of cultural regionalism and nationalism in the cases of, for example, the Basques, Scots, or Bretons. Apart from this local development, there are minorities and refugee groups living in Europe that also not feel attached to the European cultural identity. Furthermore, there are challenges to the European cultural identity from outside Europe, for example, the developments in Central and Eastern Europe, the Balkans, North Africa and the Arab, Islamic and Mediterranean countries, all of which have implications for the $\mathrm{EU}$ and its common identity. ${ }^{65}$

Another important example of the tension between globalism and localism mentioned by Morley and Robins is the so-called 'Americanisation' of cultures. American movies and satellite channels such as MTV and CNN have brought the American culture all over the world. The "coca-colonisation" and spread of American mass culture in the form of Levis and McDonalds are considered a threat to national and local cultures, traditions and identities. Consequently, a counter development takes place in the form of new regionalism. In order to compensate for this standardisation, cultural homogenisation and loss of identity associated with Americanisation and global networks, there is a rising interest in regionalism. This regionalism emphasises diversity and difference and the conservation of national and regional cultural identities and heritage. ${ }^{66}$

The international processes described above have caused many communities and individuals to fear that their cultural identity may be lost. People worry that their cultural communities have to make way for global networks and regional entities. Another important factor in the encouragement of cultural identity is migration and the rise of minority groups. ${ }^{67}$ On the one hand, globalisation offers a positive view of human development and a multiplicity of potential identities, while on the other, it may represent a threat of fragmentation and lack of personal, collective and moral boundaries. This partly explains the struggle of many communities and individuals for the preservation of their cultural identity. Cultural identity concerns cohesion, community, unity, integration and security, which must be preserved against forces of disintegration. The search for identity is therefore mostly described as a struggle. As Rutherford rightly argues, there are no fixed, ready-made identities "...that we can unproblematically slip into." the struggle to preserve cultural identity may lead to what Morley and Robinson call the "...enclosure and fortification of identity." ${ }^{, 69}$ This process also leads to the claim for the protection of culltural identity in the form of a separate human right.

65 Morley and Robins, 1990 , pp. 2-3.

66 Morley and Robins, $1990, \mathrm{pp} .17,44$.

67 Von Benda-Beckmann and Verkuyten, 1995-A, pp. 4-5.

68 Rutherford, 1990-A, p. 25.

69 Morley and Robins, 1990, p. 23. 


\subsection{Concluding Remarks on Culture and Cultural Identity}

The previous sections show that cultural identity is a complex concept. It consists of two components, namely, culture and identity. Culture should be understood as a broad concept, or way of life, including various aspects, such as language, religion and cultural heritage, which are important values for the individual's well-being. Furthermore, culture is dynamic, not homogeneous, and it has an individual as well as a collective dimension. Identity concerns belonging and rootedness, which makes it an important concept for individuals and communities. Cultural identity concerns a way of thinking, feeling and acting. Because it is so important for the well-being and dignity of individuals and communities, to oppress or limit the development and expression of cultural identity would make people feel alienated and inconvenienced. Cultural identity develops as a dynamic process full of possible changes and influences from outside, and is determined by defining insiders and outsiders. The development and protection of cultural identity are, in fact, strengthened when it is in jeopardy and people fear that their cultural identity may be lost. This explains why processes such as globalisation have made individuals and communities claim respect for, and the protection of, cultural identity. The question is how this dynamic and comprehensive concept can be translated into a right.

\section{THE ACCOMMODATION OF CULTURAL DIFFERENCES}

In the second half of the twentieth century, several concepts were developed concerning the accommodation of cultural differences, such as tolerance and multiculturalism. Both concepts are relevant in relation to the development of a right to cultural identity in the sense of how to deal with cultural differences.

\subsection{Tolerance and Multi-Culturalism}

Developments such as migration, the rise of capitalism, the influence of the mass media and improvements in mass communication and transportation, have led to forms of what Raz called "communal disintegration and individual alienation". Two liberal policies counterbalanced this process, namely tolerance and multiculturalism. Tolerance means bearing and enduring something which, at the same time, one might disapprove of. Tolerance implies accepting different cultures without considering these differences as having special value. ${ }^{70}$ This can concern values and norms, but also people, communities, acts and ideas. Tolerance is only necessary when the interaction between people leads to power differences. One can only truly speak of tolerance when it is the community or individual in power that tolerates, since they may be able to change the situation that they disapprove of. ${ }^{71}$

70 Margalit, 1996, $\mathrm{p}_{1} 177$.

71 Procee, 1991, p. 133. 
Tolerance can furthermore be seen as a response to pluralism and diversity, which characterises many liberal societies today. The liberal policy of tolerance implies that minority communities can freely develop themselves and act as they wish without being punished, as long as they do not interfere with the majority culture. According to Raz, in practice, this often means limited possibilities for these minority communities to use public spaces and media. Consequently, most cultural activities of these minority groups are financed out of the resources of these minority communities themselves.

Tollerance is based on the relativist idea that all cultures have equall value. However, as Procee rightly points out, tolerance based on the equality of cultures cannot solve all the problems that may arise in practice. Tolerance might imply that one has to give up certain values in favour of others. He mentions the example of the discussion on blood transfusions or vaccinations for Jehovah Witnesses. The fact that the value systems of the doctor and of the Jehovah Witness are equal worth does not solve the problem of a sick child that needs a blood transfusion. To what extent should a doctor respect the Witness' views in relation to his work of saving lives? Or should the Jehovah Witness give up his religious ideas? Procee shows that tolerance does not always help in such practical situations. ${ }^{73}$

Tolerance can have different forms, varying from indifference, to respect, and to active support. At the first stage, tolerance does not yet mean respect. It can be a paternalistic form of tolerance, whereby tolerance is based on indifference. Such a form of tolerance implies that the community involved is not recognised as an equal participant in the State structure. Such ignorance results in a لack of influence and may imply that the minority culture cannot take part in the general society. The second stage of respect implies more than just acceptanee as alien and strange. It, instead, involves respect for the traditions and cultures of communities, which will also encourage dialogue between the different communities. Tolerance should in fact imply at least respect, because it is hard to develop empathy for communities that one simply tolerates as alien. Tolerance needs to be more than an affirmation of pluralism; it should include a sense of solidarity. This implies that the majority is limited in interfering in the views, beliefs and commitments of the minority. The third stage of tolerance reflects its positive dimension and implies that the majority actively supports the way of living of the minority, mainly through three institutions: the education system, the media and the law. ${ }^{74}$ Such active interference is often based on human rights in general and non-discrimination in particular. The majority actively involves minority communities in public life. Minorities are no longer passively tolerated and thereby excluded from schools,

$72 \mathrm{Raz}_{\mathrm{*}} 1993, \mathrm{pp}$. $129-130$

73 Procee, 1991, pp. 131-132.

74 Addis, 1997, pp. 120-122. See, also, Margalit, 1996, p. 179. On toleration see also D. Heyd (ed.), Toleration: an elusive virtue, Princeton University Press, Princeton, 1996; I. Shapiro and W. Kymlicka (eds.) Ethnicity and Group Rights, New York University Press, New York, 1997, part II "The idea of Toleration". 
labour or neighbourhoods. Public services and institutions are made available to all members of society. ${ }^{75}$

Another liberal response to the problem of minorities is multi-culturalism. Multiculturalism can be described as a society in which sizeable cultural communities exist next to each other and, where these communities wish to, are able to remain separate communities and to keep a distinct cultural identity against policies of assimilation. In principle, these cultural communities have equal standing and deserve an equal share of opportunities and resources to maintain their distinct cultures. Multi-culturalism goes beyond non-discrimination rights, since it also focuses on communities instead of merely individuals. While multi-culturalism endorses individual non-discrimination rights, it emphasises that individual freedom depends on membership in a cultural community. Individual freedom is no goal in itself, but is connected to full membership in a respected and flourishing cultural community. Furthermore, multi-culturalism implies a belief in value pluralism, meaning that different norms and practices of different societies are equally valuable. ${ }^{76}$ Scholars supporting multi-culturalism, such as Taylor, argue that the politics of equality are insufficient to meet the claims for recognition by different communities. In his famous 'Politics of Recognition', Taylor goes beyond equal rights and aims at the specific recognition of cultural identities. Multi-culturalists fear that, behind the principle of universal equality, the specific cultural values of the majority society dominate. As a result, multi-cultural scholars plead for the affirmation and positive recognition of cultural identities and for respect for other cultures. 77

According to Raz, the main argument for multi-culturalism is the importance of cultural communities for individual freedom. Multi-culturalism. confirms that cultural communities are important as such, and not just as the sum of individual actions. The moral claim to respect cultural communities rests, however, on their importance to the freedom and development of the individual members. ${ }^{78}$ This theory of multi-culturalism reflects a similar debate within the human rights discourse. It is argued that communities are of such importance for individuals that they should be protected. Such protection would be insufficiently guaranteed by the

$75 \mathrm{Raz}_{1}, 1993$, p. 130.

76 Raz, 1993, pp. 131, 136-138. See on multi-culturalism inter alia W. Kymlicka, Multicultural Citizenship - A Liberal Theory of Minority Rights, Clarendon Press Oxford, Oxford, 1995; W. Kymlicka (ed.). The Rights of Minority Cultures, Oxford University Press, Oxford, 1995; A. Gutman (ed.), Multiculturalism - Examining the Politics of Recognition, Princeton University Press, Princeton, 1994; I. Shapiro and W. Kymlicka (eds.) Ethricity and Group Rights, New York. University Press, New York, 1997.

77 See inter alia W. Kymlicki, Multicultural Citizenship - A Liberal Theory of Minority Rights, Clarendon Press Oxford, Oxford, 1995; W. Kymlicka (ed.), The Rights of Minority Cultures, Oxford University Press, Oxford, 1995; Ch. Taylor, "The Politics of Recogrition", in: A. Gutman (ed.), Multiculturaliss - Examining the Politics of Recognition, Princeton Uniwersity Press, Princeton, 1994, pp. 25-74.

$78 \mathrm{Raz}, 1993$, p. 136. 
principles of equality and non-discrimination and the protection of individual human rights. Special protection of communities through special rights for them has been pleaded for, either or not in a collective form. The debate concerns inter alia whether such rights should be collective rights or individual rights. ${ }^{79}$

The fact that multi-eulturalism values different cultures does not, however, mean that multi-culturalism is opposed to change. According to Raz "...liberal multi-culturalism does not arise out of conservative nostalgia for some pure exotic cultures. ${ }^{, 80}$ Multi-culturalism is based on the idea that members of different cultural communities are aware of the different cultures in their society and learn to appreciate and respect them. Such knowledge will in itself lead to developments and changes in the existing cultures. Change may even lead to the disappearance of cultures through, for example, assimilation. Liberal multi-culturalism is not opposed to assimilation, as long as the basic principles of tolerance and respect are observed. "The dying out of cultures is as much part of normal life as the birth of new ones." $" 81$

It is interesting to note that multi-culturalism has received similar critique as a right to cultural identity. Multi-culturalism was for example accused of lacking attention for individual freedom and, as a result, it could be supportive of communities 'locking up' members against their will. Others further argued that cultures that violate liberal principles should not be supported by multiculturalism and oppressive cultural communities should not be given equal rights. Raz admits that "...some cultures or aspects of some cultures are unacceptable, and should not benefit from the positive attitude to plurality of cultures which multi-culturalism stands for." Finally, some liberals argue that multi-culturalism would undermine social solidarity based on one common culture. Without such a common culture giving people a sense of belonging, society would fall apart. ${ }^{82}$

\subsection{Forms of Recognition and Protection of Specific Cultural Identities}

The notions of tolerance and multi-culturalism generally responded to the question of how to deal with the factual diversity within States and societies. Multiculturalism is based on the recognition of different cultural communities. The question is, however, how such recognition should be modelled. Should cultural identities be positively recognised as suggested by, among others, Taylor? Or should such an affirmation of cultural identity not be supported and should one, instead, concentrate on a form of indirect protection, as proposed by Margalit, who

79 See Chapter III and IV on cultural rights and collective rights.

80 Raz, 1993, p. 139.

81 Rar, 1993, p. 139.

82 Raz, 1993, pp. 132, 141-142 (quote), 144-146. These issues, for example how to deal with intolerable cultural practices, are more extensively dealt with in Chapter III. 
emphasises the elimination of the forms of humiliating rejection of the communities to which people belong? ${ }^{83}$

Positive recognition, as advocated by Taylor, can have three forms. The first is the recognition of the equal value of cultures. However, recognition of cultures as such may be problematic, because 'cultures' as such are not fixed items and are not homogeneous. Cultures as such do not exist; they only exist in relation to the people and territory involved.

The second form is the recognition of cultural communities, which concerns a historical call for recognition often based on former injustice. Cultural elements, such as language and religion, play a role in this respect, although this does not always mean that these communities are solely based on culture. However, as Appiah has highlighted, communities often use cultural elements to stress a history of economic and social exploitation. ${ }^{84}$ Instead of being a prerequisite for community identity to be established, culture is often a factor that afterwards provides content to the identity of a community. Communities may use certain characteristics, for example, language, to obtain certain rights, such as linguistic rights or land rights. They translate political demands into cultural terms in order to obtain recognition of their collective identities. ${ }^{85}$

The third form of respect is the recognition of individuals and their cultural identity. This raises the question of whether such recognition requires new politics of recognition, because existing politics of equal citizenship and human rights already protect individuals from being discriminated against and excluded because of their cultural identity. As mentioned earlier, the protection and recognition of the cultural identity of a community and that of an individual are often not clearly divided. Both dimensions are interdependent and intermixed.

In his 'Politics of Recognition', Taylor emphasises that identities of persons should be positively recognised through the politics of multi-culturalism. He argues that the recognition of cultural identity is important, because without such recognition people are unable to develop a positive self-image. According to Taylor

"...our identity is partly shaped by recognition or its absence, often by the misrecognition of others... Non-recognition or misrecognition can inflict harm, can be a form of oppression, imprisoning someone in a false, distorted, and reduced mode of being."

83. This question has been dealt with by $\mathrm{S}$. Koenis in an essay "De secularisatie en politisering van cultuur" [secularisation and politicisation of culture], to be published in a volume of the Dutcti Institute for Scientific Research (NWO) in 2002. The following section is inspired by his arguments.

84. Appiah, 1994, pp. 151, 160-162; Appiah, 1997, pp. 30-31, 35.

85. Habermas, 1994, p. 117; Kukathas, 1995, p. 233.

86 Taylor, 1994, p. 25. 
Taylor argues that a politics of equality provides insufficient recognition and protection of different communities. Taylor's politics of recognition go beyond equal rights and aim at the specific recognition of cultural identities. People should be recognised not only as equal citizens, but also as carriers of a community identity: Taylor seems to refer mainly to the cultural identity of individuals, although he makes a clear link to the community involved.

At the other end of the spectrum are those who do not support the specific affirmation of identity, but instead focus on the equality of all and the elimination of discrimination and disrespect. One of the advocates of this theory is Margalit. In his book 'The Decent Society', Margalit pleads for the negative recognition of cultural identity through the elimination of forms of humiliation. According to Margalit, the advantage of eliminating disrespect over the positive confirmation of respect contains three elements. Firstly, there is a moral aspect implying that it is much more urgent to eliminate evil than to promote respect. Secondly, there is a logical difference between goals that can be reached immediately and goals that are byproducts of certain actions and cannot be realised immediately. To gain respect is a goal that cannot be reached directly, but should be seen as a by-product of general behaviour towards people. Only through indirect policies can certain values such as tolerance, equality and respect be reached; while non-humiliation can be reached immediately. The third cognitive aspect concerns the fact that it is easier to identify humiliating treatment than respectful treatment. Margalit compares this with the fact that a doctor can identify illness better than health. ${ }^{88}$

In his book, Margalit paints a picture of a decent society, which is not a society with only decent or civilised people, who do not humiliate each other, but a society whose institutions do not humiliate people. ${ }^{89}$ Humiliation is "...any sort of behaviour or condition that constitutes a sound reason for a person to consider his or her self-respect injured." A paradigmatic case of humiliation is the violation of human rights. But, according to Margalit, there is more to humiliation than the violation of rights. Humiliation may also be the result of actions and signs that do not relate to human rights. Humiliation can, for example, exist when these institutions make people feel ashamed to belong to a certain community. ${ }^{91}$

Not all communities fall under the theory of humiliation. It merely concerns communities that Margalit calls 'encompassing groups'. Such communities are characterised by a shared culture that shapes the members' way of life and their actions, aspirations and relations, through, for example, a common

87 Taylor, $1994, \mathrm{pp} .38-43,51-52,68-69$; Kynllicka has developed a liberal theory of recognition of cultural differences, which is discussed in the Chapter III.

88 Margalit, 1996, pp. 4-5.

89 Margalit, 1996, p. 1.

90 Margalit, 1996 , p. 9.

91 Margalit, 1996, pp. 9-27, 41-53, especially p. 52 and p. 137. 
language, clothing, traditions and customs. Another characteristic of encompassing groups is that people growing up in these communities acquire the community culture. Membership of such a community is not based on certain achievements but on belonging and on informal recognition by other members, which is important for the self-identification of the members. These communities are not formal settings with clear rules for membership, but are anonymous in the sense that not all members know each other personally. Thus, these communities need rituals and customs to distinguish the members from the non-members. All persons belong to such communities, mostly to more than one, for example, nationality, religious or ethnic community, gender, sexual identity, etc. A decent society is a society that does not reject morally legitimate encompassing groups. ${ }^{92}$

Margalit further addresses the question of what rules could be imposed on individuals and cultural institutions in order to reach a decent society. There is a difference in the cultural expressions of individuals and those of cultural institutions. While the expressions of individuals are less harmful and should not, therefore, be constrained too much, institutional humiliation is very harmful and, accordingly, the expressions of cultural institutions could be restraint if necessary. ${ }^{93}$

Both forms of recognition are relevant in relation to a right to cultural identity. The development of such a right implies a positive recognition of cultural identities. However, a right to cultural identity poses various difficulties, as explained in the general introduction. Therefore, the suggestion of protecting and promoting cultural identities indirectly, inter alia by the promotion and protection of existing human rights, is an interesting idea, and will be elaborated upon in the next chapters.

\section{Concluding Remarks on the Social Science Framework of CULTURAL IDENTITY}

The purpose of this chapter was to clarify the concept of cultural identity within its social science framework. For this purpose, first, the development of the concept of culture over the last century was analysed. It appeared that the notion of culture has developed from a singular, normative notion relating to an élitist idea of civilisation and necessary progress to a plural notion that is used 'value free' to describe differences among individualls and communities, under the influence of the debate between universalism and relativism in cultural anthropology. Universalism studies cultures from the perspective of the unity of mankind, arguing that differences between cultures are reflections of different stages of development of these cultures. Relativism argues that all cultures should be equally valued and that no judgement would be objective, since they all reflect the cultural background of the observer. Relativism pleads against the ethnocentric vision of universalism and for tolerance towards other cultures. In the second half of the twentieth century, the term culture 
received its broad meaning as 'way of life'. It should be considered a dynamic process, or a system of beliefs and practices, including aspects such as arts, sports, language, expression, religion and education.

Cultural identity can be considered the 'personification' of culture. It is an important value for communities and individuals, since it concerns their belonging and, as such, is an important element of their human dignity. It involves cultural aspects such as religion, nationality, language and traditions, all of which are central to people's everyday lives. Moreover, it is a dynamic concept that can change and develop over time, and has an individual and a collective dimension. An individual shapes his or her cultural identity by participating in various communities. All these communities provide elements, such as religion or language, which together form the unique cultural identity of an individual. The collective dimension of cultural identity relates to the cultural identity of a community, although it remains hard to determine what the cultural identity of a community actually is. Individual members with their unique cultural identities form a community's collective cultural identity. These communities can be based on language, or on religion, or on more of these aspects together. Such a collective cultural identity is even more heterogeneous and changeable than an individual cultural identity. Consequently, it would be a complex matter to establish the cultural identity of a community in sufficiently clear terms to translate it into a right. A right to cultural identity may, however, be desirable or even necessary considering another characteristic of cultural identity, which is that it comes forward when it is threatened or 'in crisis', in other words when its cultural aspects cannot be developed or expressed. Many developments may cause such a 'crisis', including the international developments connected to colonisation, decolonisation and globalisation. These developments have led to an increasing attention for, and an awakening of, the consciousness of cultural identity, including the demand for the protection of cultural identity as a right.

Linked to the development of a cultural identity is the issue of accommodating cultural differences in societies. Policies of tolerance and multi-culturalism were developed in this respect to guarantee a society in which different cultural communities exist alongside each other, and in which they are able to keep a distinct cultural identity against policies of assimilation. Multi-culturalism defends the idea that cultural communities have, in principle, equal standing and deserve equal opportunities and resources to maintain their distinct cultural identity.

Cultural identity can be positive recognised in the forms of a right to cultural identity, or negatively through an emphasis on equality and the elimination of humiliating treatment. However, the question remains of whether it is possible to describe the concept of cultural identity and its dynamic character in legal terms. Furthermore, the relationship between the individual and the community is not clear in this respect. The other possible road to be followed would imply negative recognition through the elimination of humiliation, which means to focus on respect for the self-esteem and dignity of individuals and communities. To avoid the issues 
relating to the recognition of a separate right to cultural identity, the idea to protect and promote cultural identity in an indirect way, without developing a separate right to cultural identity, is, in my opinion, interesting and valuable. States could generally recognise different cultural communities and identities as a confirmation of the value of difference. The recognition of the value of cultural identity for communities and their members could be translated into policies, perhaps not by developing a separate right to cultural identity, but through the promotion and protection of human rights in the line of multi-culturalism and tolerance. It seems that existing human rights in the field of non-discrimination and freedom of religion, expression and association are likely to have to offer something in this respect. The theory of the recognition of cultural differences, especially the 'negative' variant of Margalit, offers interesting starting points that will be used in the next chapters in relation to the possible development of a right to cultural identity. 


\section{Chapter III \\ Cultural Rights and COLlective Rights IN Political SCIENCES}

\section{INTRODUCTION}

In the previous chapter, the social science framework of the concepts of culture and cultural identity has been established. The purpose of the next two chapters is to establish the political and legal framework of a right to cultural identity. In this chapter, these concepts are linked to the recognition of rights. As explained in the general introduction of this study, there can be different levels of recognition, from a moral value via political recognition to legal recognition.

In this chapter, the theories of several political scientists concerning cultural rights and collective rights are dealt with. The focus lies on the work of Kymlicka, who has developed a political liberal theory for collective rights to protect cultural differences. 'The central question is how liberalism can adapt to the claims of mimorities and other communities for the protection of their collective interests, such as their cultural identity. To what extent can the liberal theory of rights formulated in an individual way adapt to collective actors? Kymlicka argues that liberal thinkers have unjustly neglected the community aspect of individuals, which is important to their free development. He tries to fit collective rights, or what he calls 'group-differentiated rights', into a liberal framework. Furthermore, in this chapter, attention is paid to another important aspect in relation to the development of a right to cultural identity, namely, the problem of how to deal with illiberal or intolerable cultural practices within communities.

\section{A Liberal Theory for Collective Rights to Protect Cultural DIFFERENCES: KYMLICKA AND OTHERS}

Several political scientists have connected the concepts of culture, communities and cultural identity to human value and human rights, and, of these, Kymlicka has become one of the most well-known in recent years. Kymlicka has developed an extensive liberal theory on collective rights for minorities, in which he has shown that many of the demands made by communities can be consistent with the liberal principles of individual freedom and justice. However, while several forms of

1 It should be noted that the terms 'collective rights' and "group rights" are often used interchangeably. In this study, collective rights are rights assigned to the community as such, while group rights are rights assigned to individuals as members of a community. 
collective rights can be defended from a liberal perspective, he distinguishes two main limitations:

"...minority rights should not allow one group to dominate other groups and they should not enable a group to oppress its own members.",2

\subsection{Background of Kymlicka's Liberal Theory of Special Minority Rights}

According to Kymlicka, traditional liberal thinkers had no answer to minority problems or to their claim for the protection of their cultural identity. Traditional liberal thinkers relied on the indirect protection of minorities through individual human rights based on equality. They did not support direct protection through special collective minority rights:

"The members of ethnic and national groups are protected against discrimination and prejudice, and they are free to try to maintain whatever part of their ethnic heritage or identity that they wish, consistent with the rights of others. But their efforts are purely private, and it is not the place of public agencies to attach legal identities or disabilities to cultural membership or ethnic identity." ${ }^{3}$

Although several liberal scholars made an exception for affirmative action for disadvantaged communities as a temporary measure, they generally rejected the idea of permanent differentiation between communities. Community specific rights could only serve to remedy historical discrimination and could not serve to accommodate enduring cultural differences. ${ }^{4}$

Kymlicka's main aim is to defend special collective minority rights from a liberal perspective. He disagrees with the large group of liberals that insist that minority rights are inherently in conflict with liberal principles of individual liberty and universal rights. Kymlicka, instead, presents two claims underlying a liberal defence of collective minority rights. The first is that individual freedom is tied to membership in a community and that therefore collective rights could actually enlarge the freedom of individuals. Secondly, group-specific rights could promote equality between the minority and the majority. ${ }^{5}$

Kymlicka bases his arguments on two preconditions for leading a good life. Firstly, individuals should have the resources and liberties to lead a life according to their beliefs about value. Secondly, they should be able to question those beliefs and to reformulate them in the light of new information. Hereby, aspects such as education, information, and freedom of expression and association are important. According to Kymlicka, a liberal State should allow people to lead a certain way of

\footnotetext{
Kymlicka, $1995-$ B, p. $\| 94$.

Kymlicka, 1995-B, pp. 3-4.

Kymlicka, 1995-B, pp. 3-4.

5 Kymlicka $1995-$ B, pp. 52, 75.
} 
life, but should also provide information concerning other ways of life to make a revision of their ideas possible. ${ }^{6}$

\subsection{The Value of Culture and Cultural Membership}

Kymlicka goes on to describe the importance of cultures and cultural membership for individuals. He uses the term "societal culture', which is

"... a culture which provides its members with meaningful ways of life across the ful" range of human activities, including social, edueational, religious, recreational and economic life, encompassing both public and private spheres. These cultures tend to be territorially concentrated and based on a shared language. ... [T] hey involve not just shared memories and values, but also common institutions and practices."

Kymlicka argues that such societal cultures should be protected from disappearing, because they create choices for individuals.

"Cultures are valuable, not in and of themselves, but because it is only through having access to a societal culture that people have access to a range of meaningful options." $" 8$

Here lies his main argument for collective rights. In order to make meaningful choices, individuals need access to information and the capacity to evaluate this information, including freedom of expression and association. They need access to a societal culture, which should be protected and promoted through collective rights. Kymlicka further argues that cultural membership plays an important role in creating people's self-identity, because it gives people a strong sense of belonging."

Several other authors have emphasised the importance of cultural communities for individuals. Raz, for example, asserts that cultures and cultural communities should be valued because they give life options to individuals. Individuals, therefore, strongly wish to integrate into a cultural community. The cultural and material prosperity of these communities gives the members cultural and material wealth and opportunities. Furthermore, the unity within a cultural community facilitates social relationships, which may, in turn, lead to rich and extensive personal relationships. Finally, membership of a cultural community provides individuals with both a sense of belonging and a strong focus of identification. As such it contributes to the constitution of one's identity. ${ }^{10}$

Parekh also emphasises the importance of communities for individuals. In this respect, he makes a distinction between cultural communities and voluntary

6 Kymlicka, 1.995-B, pp. 81-82.

7 Kymlicka, 1995-B, p. 76.

8 Kymlicka, 1995-B, p. 83.

9 Kymlicka, 1995-B, pp. 84, 87-89.

$10 \operatorname{Raz}_{3}, 1993$, p. 135. 
organisations, such as sports clubs, political parties or pressure groups. Cultural communities are not, as voluntary organisations are, instrumental in the sense of promoting certain specific interests. A cultural community plays an important role in human life by giving members a sense of belonging and stability, and by shaping their lives through values and ideals. Membership of a cultural community creates and shapes the individual's personality, and gives it an identity. "

The consequence of this importance is that members of cultural communities are strongly affected if their culture is persecuted, ridiculed or not valued. Such attitudes, especially if they come from the majority or the authorities of a State, offend the dignity of the persons involved. If individuals have to abandon the strong ties to their culture, it constitutes a major sacrifice. Cultures are valuable for their role in shaping the personality and identity of individuals, because they affect their choices, their opportunities and their ability to engage in relationships. Individual identity and freedom are strongly connected to a sense of belonging to a cultural community. ${ }^{12}$

However, the importance of cultural membership is not agreed on by all. Waldron, for example, argues that the importance of cultural membership is often exaggerated. He does not agree with the idea that individual identity is created by a community, nor that each individual owes its identity to the community in which he or she has grown up. ${ }^{13}$ Waldron does not totally deny the role of culture and community in the constitution of human life. However, he questions the assumption that the world is divided into clear distinct cultures, one for every community, and he doubts that every person needs one single, coherent culture to give meaning to his life. ${ }^{14}$ According to Waldron, Kymlicka tries to show that liberal theorists have underestimated the importance of culture for individual lives by giving individuals options to choose from. Waldron argues that, while these options may come from a cultural meaning, it does not automatically imply that they must originate from one cultural framework. While individuals may need cultural materials, these do not have to come from one cultural source or be part of one cultural structure. According to Waldron, Kymlicka uses a concept of culture which is too static, as if it were something clear-cut and homogeneous. ${ }^{13}$

Accordingly, Waldron is not convinced that cultures should be preserved per se. He argues that cultures should be free to change and adapt, which might be reduced by preserving or protecting it. He explains it as follows:

11 Parekh, 2000, p. 162.

12 Margalit and Halbertal, 1994, pp. 503-505. See, also, Margalit and Raz, 1995, p. 87; Raz, 1993, pp.

13 Waldron, 1995, p. 95.

14 Waldron, 1995 , p. 105.

15 Waldron, 1995, pp. 106-108. 
"In general, there is something artificial about a commitment to preserve minority cultures. Cultures live and grow, clrange and sometimes wither away; they amalgamate with other cultures, or they adapt themselves to geographical or demographic necessity. To preserve a culture is often to take a favoured "snapshot" version of it, and insist that this version must persist at all costs, in its defined purity, irrespective of the surrounding social, economic, and political circumstances."

While Waldron in my yiew correctly emphasises the dynamic character of cultures, it should be possible to protect certain features of cultures without limiting their changeable character. Waldron is correct to suggest that individuals need more than one cultural framework, but this should not prevent authorities from adopting measures to protect certain cultural aspects or values. The importance of a cultural community or framework or, as Waldron suggests, more than one, for the wellbeing of individuals should be the central point. This framework should be protected, however, without limiting its dynamic character. Protection should not imply that cultures are 'fenced'. The question remains whether collective rights are needed for such protection.

\subsection{Individual Rights or Collective Rights?}

If one agrees that cultural communities and cultural membership are important, to what extent should special collective rights be developed and adopted? Several liberal theorists have argued that cultural membership is adequately protected by universal individual human rights. It has also been argued that, in principle, cultures do not need State support to survive. If a culture is worth saving, its members will do so. According to Kymlicka, these arguments are false. He defends groupdifferentiated rights with, inter alia, the equality argument and the argument of the value of cultural diversity. ${ }^{17}$

The equality argument means that special rights for national minorities are needed to provide them with genuine equality, because they have been unfairly disadvantaged. If such a disadvantage exists in relation to cultural membership, special rights and differential treatment are needed to obtain true equality. ${ }^{18}$ The cultural diversity argument means that cultural diversity should be considered valuable, because it creates a more interesting world in general and because it specifically creates more valuable options to individuals. The cultural diversity argument focuses not only on the advantages of special rights for minorities, but also on the benefits of special rights for the larger society. Instead of pointing to the

16 Waldron, 1995, pp. 109-110.

17 Kymlicka, 1995-B, pp. 108-109,

18 Kymlicka, 1995-B, pp. 108-109. This is a familiar distinction made between de jure and de facto equality, or formal and substantial equality. De jure equality is formal equality under the law. Such equality, however, gives persons a freedom of choice and action that can lead to inequality. Therefore, special policies may be necessary to reach de facto or substantial equality. See, inver alia, Habermas, 1994, p. 114. 
obligations of the majority, the argument of the value of cultural diversity appeals to the interests of the majority. According to Kymlicka, however, the diversity argument cannot, in itself, provide sufficient reason for collective rights, since there could be other ways of promoting diversity. The diversity argument should mainly be considered as being supplementary to the equality argument. ${ }^{19}$

Apart from Kymlicka, several other authors have shown their principle support for collective rights. Glazer, for example, asserts that it is odd that individual claims on the basis of community characteristics, such as race, religion and national origin, are treated in law as a problem of protecting the rights of individuals. In some cases, certain communities are given special rights through affirmative action. The question is whether, apart from affirmative action, communities should be given special rights. Glazer argues that the decision concerning collective rights or individual rights should be made by the State. If a State considers different communities as distinct entities that will permanently remain as such, then communities should have collective rights. ${ }^{20}$ This suggestion is very much State oriented. The development of collective rights is purely based on the decision by States whether or not communities are supposed to integrate or to remain as distinct entities, whereby all kinds of political or social considerations can be decisive.

Johnston presents a more general argument for collective rights. He argues that if it is recognised that the individual's well-being is closely tied to membership in a community, then collective rights, as not reducible to individual rights, should be recognised as well. One of the collective rights mentioned by Johnston is the right of self-preservation, whereby every community has the right to preserve itself and to maintain its distinct characteristics. Such a general right to preservation may imply specific rights, for example, in the case of indigenous peoples, the right to land. ${ }^{21}$ Green mentions several examples of rights that communities can have towards the majority, for example, limited autonomy in areas such as education, exemption from general obligations such as military service, recognition of specific practices with regard to marriage, and support of specific institutions. ${ }^{22}$ The question is whether these rights are true collective rights or individual rights based on membership of a community.

However, the idea of collective rights also meets criticism whereby it is suggested to remain an individual approach. The main arguments are that communities and their culture are sufficiently protected by individual rights and that, although communities are important to individuals, these communities do not need specia] rights. States can respect cultural differences and allow minorities equal freedom to

19 Kymlicka, 1995-B, pp. 121-123.

20 Glazer, 1995, pp. 125-126, 133-134.

21 Johnston, 1995, pp. 181, 187-188, 194.

22 Green, 1995, pp. 258, 261. 
organise themselves and express their cultural values based on existing human rights. ${ }^{23}$

Kukathas, for example, is critical on collective rights because, according to him, individual rights, especially the right to freedom of association, offer sufficient protection for minorities. He argues that liberal thinkers never presumed that the world was made up of isolated individuals and have not totally neglected collective interests. The recognition that membership of a community is important for the shaping of individual identities, does not mean that special rights should be attached to such communities. ${ }^{24}$ Instead, the protection of cultural differences should be based on the individual right to freedom of association. The claim of minorities to live according to their own cultural characteristics does not have to be respected because cultures as such are entitled to protection, but because individuals have the freedom to associate. They are free to form communities and live according to the culture of such communities. ${ }^{25}$

Galenkamp is another critic of collective rights, because, in her opinion, classical human rights, such as freedom of religion, freedom of association and the right to education, offer sufficient protection of community identity. She does not agree with Kymlicka's argument that universal human rights erode the differences between communities and lead to the assimilation and homogenisation of minority groups, while special rights will preserve differences. She argues that, in fact, the accentuation of differences through special rights can lead to a process of 'absolutising' collective identities. Placing these communities in a special position can make them more vulnerable to stigmatisation and discrimination. Furthermore, to absolutise cultures may lead to the "locking up" of individuals into their cormmunity culture and could suppress internal differences and opposition, which would lead to the homogenisation of cultures. Galenkamp argues that collective rights for minorities are not necessary to do justice to differences between people. ${ }^{26}$

The vulnerable position of the individual in relation to the community, including the possible conflict between individual and collective rights, is one of the other arguments against collective rights. Habermas, for example, agrees that protecting the identity of the community would lead to a policy of conservation of this identity and, consequently, the "locking up" of individuals in that community identity. It is up to the individual members of communities to determine whether their culture is worth preserving and the individual members decide whether or not to maintain certain cultural characteristics. Cultures as such should not be protected

23 Walzer, 1994, pp. 100-101.

24 Kukathas, 1995, pp. 231-232, 234, 236, 238-239; Kukathas, 1997, pp. 77-78, 88. See, also, Margalit and Halbertal, 1994, pp. 503-505; Margalit and Raz, 1995, p. 87.

25 Kukathas, 1995, pp. 241-242, 245. In this respect, Donnelly asserts that the emphasis on freedom of association as the central element of community membership is problematic. He argues that freedom of association "... models group membership as a "woluntary" exercise of the protected autonomy of its members.", while most identities of communities are imposed externally or based on biological factors, such as skin colour or sex. See Donnelly, 2001, p. 24

26. Galenkamp, 1996, pp. 214-216. 
as if they are an endangered species. ${ }^{27}$ Parekh agrees that cultures can only survive if members of that culture feel sufficiently attached to it.

"A culture has no authority other than that derived from the willing allegiance of its members, and it dies if they no longer subscribe to its system of beliefs and practices. . No culture can, therefore, be preserved by force or artificial means." 28

In other words, although community membership is important to individuals, this claim does not in itself imply that communities should have rights. The community mainly has value because of its contribution to the welfare of its members. These individuals should therefore be the main beneficiaries of rights. Collective rights may in fact be risky because they can diminish the attention for individual rights. ${ }^{29}$

Many opponents of collective rights also argue that communities as such cannot be the proper rights holders. Johnston identifies two important criteria for communities to be rights holders. Firstly, the community must be an entity by itself, which means that it has a distinct existence and identity separate from its members. In other words, the community should be more than the sum of its members. The second criterion concerns the interdependence of the members and the community, whereby the identity of the members of the community should be directly linked to the identity of the community. These criteria are not easily met by communities. ${ }^{30}$ Walzer agrees that, if communities as such are asserted rights, it should be clear who the members of the community are and where the boundaries of the community lie. However, communities do not have such fixed boundaries and there are no rigid distinctions between communities, unless every individual was obliged to choose a certain identity. ${ }^{31}$. Nickel also asserts that communities should not be assigned rights, because they are often unable to play an active role in exercising, interpreting and defending their rights. This is what Nickel calls the "deficiency thesis': communities are deficient as rights holders, because they do not have an effective agency and a clear identity. A clear identity means that a community has reasonable clear boundaries that make it possible to determine which persons belong to it. Most communities do not have such clear boundaries. Such a lack of a clear identity makes it hard for communities to have an authorised leadership that is truly representative for the whole community. Consequently, a lack of clear identity leads to a lack of agency. ${ }^{32}$ Nickel points out that there are several groups or associations that have clear identity and agency, for example, NGOs, universities and corporations, which have clear rules on membership and leadership. However, minorities often lack both, especially non-territorial minorities. ${ }^{33}$

27 Habermas, 1994. pp. 130-131.

28 Parekh, 2000, p. 169.

29 See, for example, Hartney, 1995, pp. 203, 208, 214-215, 218-219; Walzer, 1995, p. 154.

30 Johnston, 1995, pp. 182-183.

31. Walzer, 1995, pp, 149-150.

32 Nickel, 1997, pp. 235, 237.

33 Nickel, 1997, pp. 238, 241, 253. 
In conclusion, the above has shown the importance of cultural membership for individuals. Since cultural communities give individuals a sense of belonging, they play an important role in the well being of the individual. This is confirmed by the fact that oppression or limitation of cultural communities affects the human dignity of individuals. As such, cultural communities deserve protection, but the question remains how. Kymlicka proposes collective rights based on the equality principle and the value of cultural diversity. While he does acknowledge that cultural diversity can also be accomplished in other ways, the question remains of whether genuine equality can only be achieved by collective rights. With several authors, I am not convinced that the protection of cultural communities and cultural identities should take place through collective rights. While the recognition of the cultural community and its role in the life of the individual is important, collective rights pose various problems. The definition of the community and its cultural identity poses difficulties, but more important are the arguments of locking up individuals in a collective cultural identity, the relation between the individual and the community and the possible conflict between individual and collective rights. An individual approach appears more appropriate, because cultural communities only exist through the consent of the members of the community. In my view, communities should not be allowed to oppress individuals by invoking collective rights. Kymlicka has, however, developed an interesting liberal, and therefore not antiindividual, theory of collective rights, which he calls 'group-differentiated rights'.

\subsection{Which Collective Rights and for Whom?}

Kymlicka starts from the empirical fact that many modern societies are confronted with minority communities that demand recognition of their identity and accommodation of their cultural differences. These communities should be divided into what Kymlicka calls 'national minorities' and 'ethnic groups'. National minorities are territorially concentrated communities that were previously selfgoverning, which wish to stay or become distinct and potentially self-governing societies incorporated within a larger State. Ethnic groups have arisen from voluntary familial immigration and are looser associations that wish to integrate into the larger society. ${ }^{34}$ Although these ethnic groups may seek recognition of their ethnic identity, they do not aim at developing a separate, self-governing nation. This distinction between national minorities and ethnic groups originates from the two main sources of cultural diversity within States, which are, according to Kymlicka, the co-existence of more than one community within a given State and the process of immigration. ${ }^{35}$

34 Kymlicka realises that there are several immigrant groups, which have not really had a choice to move, for example refugees or children of immigrants.

35 Kymlicka, 1995-B, pp. 10-14, 17. It is worth noting that what Kymlicka calls "national minorities" are national minorities in the classical sense, and do not include "new minorities", such as immigrants or refugees, which fall under "ethnic groups. Indigenous peoples, however, would, 
Kymlicka makes a distinction between two general claims of communities labelled as collective rights. Firstly, collective claims may concern internal restrictions: claims of communities against their own members, to protect the community from destabilisation by internal dissent. Secondly, collective claims may concern external protection: claims against the larger society, to protect the community from the impact of external decisions. ${ }^{36}$ This distinction between external protection and internal restriction is important to distinguish between acceptable and nonacceptable collective rights. According to Kymlicka,

6..liberals can and should endorse certain external protections, where they promote fairness between communities, but should reject internal restrictions which limit the right of community members to question and revise traditional authorities and practices. ${ }^{37}$

He further emphasises that external protection is limited to the extent that one community may not oppress or exploit other communities. External protection is only legitimate to promote equality and to correct former disadvantages.

"In short, a liberal view requires freedlom within the minority group, and equality between the minority and majority groups." 38

Kymlicka distinguishes three forms of collective rights or 'group-differentiated rights': self-government rights, polyethnic rights and special representation rights. Self-government rights concern the demand of communities for some form of political autonomy or territorial jurisdiction. Polyethnic rights are specific measures for communities to express and develop their cultural particularities. Special representation rights are temporary measures to repair political underrepresentation and to increase the reflection of the diversity of the population, for example, public funds for advocacy groups, guaranteed representation in political bodies or veto rights over specific policies that affect the community identity. Contrary to special representation rights, self-government rights and polyethnic rights are not considered temporary measures, because they aim at protecting cultural differences without eliminating them. ${ }^{39}$

Applying these three forms of group-differentiated rights to national minorities and ethnic groups, Kymlicka finds that not all group-differentiated rights can be enjoyed by both communities. While immigrants who have voluntarily

according to Kymlicka"s description, fall under "national minorities". Another point to be made is that the distinction between both communities is not always easy to make. One can think of voluntary immigration in relation to refugees and asylum seekers, and the second and third generation immigrants. This issue is dealt with below.

36 Kymlicka, 1995-B, p. 35.

37 Kynulicka, 1995-B, p. 37.

38 Kymlicka, 1995-B, p. 152.

39 Kymlicka, $\ 995-B$, pp. 27, 31, 32, 141. 
moved to another country can legitimately assert certain polyethnic rights to protect and express their identity, they cannot claim rights to national seif-government. The measures based on polyethnic rights should take the form of adapting to the existing system, and not of setting up separate cultures or societies. National minorities can, in principle, enjoy all group-differentiated rights, as long as they do not form internal restrictions. ${ }^{40}$

With regard to external protection and internal restrictions, Kymlicka argues that all three forms of group-differentiated rights, self-government, polyethnic and special representation rights, could be used for external protection. With regard to internal restrictions, both self-government and polyethnic rights can potentially be used to limit the rights of members of communities. According to Kymlicka, such rights cannot be defended from a liberal point of view. However, "[m]ost demands for polyethnic rights are defended in terms of, and take the form of, external protection against the larger community.":4!

According to Kymlicka, collective rights do not have to be dangerous for stability and integration. He argues that the demand for such rights is often a demand for recognition and accommodation, in short, inclusion into the larger society instead of segregation. A demand for polyethnic and representation rights should, therefore, not automatically be seen as a threat to unity, but can also be considered as evidence of a desire to integrate. Self-government rights may, indeed, be more dangerous for political stability. While representation rights indirectly take the existing political system for granted, self-government rights demand adaptation in that political system. ${ }^{42}$ As Kymlicka argues

"...the basic claim underlying self-government rights is not simply that some groups are disadvantaged within the political community (representation rights), or that the political community is culturally diverse (polyethnic rights). Instead, the claim is that there is more than one political community, and that the authority of the larger State cannot be assumed to take precedence over the authority of the constituent national communities." ${ }^{43}$

Although self-government rights might potentially have a destabilising effect, ignoring them could also have detrimental effects. It may, for example, stimulate a demand for increasing autonomy and perhaps independence. ${ }^{44}$

Various authors have responded to the theories of Kymlicka. Galenkamp, for example, makes several points concerning Kymlicka"s approach. According to her, the replacement of 'collective rights' by 'special rights' including the three forms set out above does not diminish the vagueness and ambiguity of the matter. Her

40 Kymlicka, 1995-B, pp. 63,95-97.

41 Kymlicka, 1995-B, pp. 37-41.

42 Kymlicka, 1995-B, pp. 174-176, 181.

43 Kymlicka, 1995-B, p. 182.

44 Kymlicka, 1995-B, pp. 185-186. 
main points concern the definition of the subject of collective rights and the distinction between national minorities and ethnic groups. Galenkamp does not agree with the fact that Kymlicka indirectly places indigenous peoples under the category of national minorities. Such an approach denies the difference between both communities, which is inter alia confirmed in the distinction made between both in international law. ${ }^{45}$ Furthermore, Galenkamp argues that some doubts could be expressed on the volition of ethnic groups to move to another country and their readiness to integrate into the new society. It is often the bad economic situation in their homeland that "forces" persons to leave and they are often less willing to integrate than Kymlicka suggests. ${ }^{46}$

This distinction made by Kymlicka between communities based on inheritance (national minorities) and on choice (ethnic groups) is also criticised by Pogge, who argues that the distinction between chosen and inherited identities is not clear. Communities have a single legal status, but community members may differ in the degree to which their identifications with the community are inherited or chosen. Within what Kymlicka calls "ethnic groups" based on choice, there could also be elements of identity that have not been openly chosen. Consequently, Pogge does not agree that national minorities have a more valuable claim to special protection than ethnic groups, and proposes not to make a political distinction between inherited and chosen cultural identities. ${ }^{47}$

In short, the theory of Kymlicka offers an interesting defence of collective rights to protect communities from outside threats, while rejecting collective rights against their members. I consider the subdivision in self-government rights, polyethnic rights and special representation rights, interesting to distinguish the different collective claims. However, in my view Galenkamp rightly argues that several problems in relation to collective rights are not solved by his theory, such as the subject of these rights. Apart from the definition issue, the distinction between national minorities and ethnic groups should be criticised. The placing of indigenous peoples under national minorities is confusing because in international law a distinction is rightly made between both communities. While the volition of the migration of various ethnic groups may be questioned, it is wise and common to distinguish them from historically settled communities that used to be selfgoverning. A distinction can be made between indigenous peoples, minorities in the classical sense and immigrant communities. In principle, all these communities have a legitimate claim to protection of their cultural identity, just as the majority of a society does. The responsibility of the State may however vary. For example, in the case of indigenous peoples, former injustice often still has to be resolved, which may demand a more active State policy. In the case of immigrant communities,

\footnotetext{
45 There are two different UN instruments on these groups: the Declaration on the Rights of Persons belonging to National or Ethnic, Religious and Linguistic Minorities (1992), see Chapter VII, and the Draft Declaration on the Rights of Indigenous Peoples (1994), see Chapter VIIL

46 Galenkamp, 1996, p. 209.

47 Pogge, 1997, p. 212.
} 
there is no former injustice and the State should focus more on possibilities of protecting their cultural identity while integrating them into society.

\subsection{What to Do with Intolerable Cultural Practices?}

An important part of the discussion on a liberal theory on collective rights concerns the question of how to deal with cultural practices that are considered illiberal or intolerable. Examples are the subordinate position of women, the refusal of medical treatment even when the lives of children are at stake, mandate operations such as female circumcision and ritual scarring, and the practice of cruel, inhumane and disproportionate punishment. ${ }^{48}$ Various authors, including Kymlicka and Kukathas, have dealt with this matter.

As mentioned earlier, Kymlicka argues that, while certain communities should be granted collective rights to protect their cultural identity against the majority society, these communities cannot impose internal restrictions upon their members. According to Kymlicka, liberals cannot uncritically accept all cultural activities. However, they should not aim at eliminating illiberal cultures or impose liberal traditions upon minority communities, but should instead try to liberalise

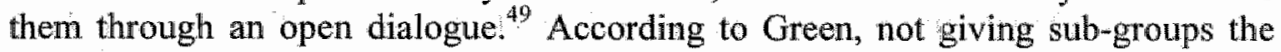
same rights against the minority as the minorities have against the majority would imply that minorities could act against their sub-groups in a way that would be condemned if it was done by the majority against the minority. Just as minorities should be protected against assimilation into the majority culture, so internal subgroups should be protected against assimilation into the minority community. ${ }^{50}$

Kukathas has another point of view and maintains that Kymlicka's approach offers insufficient tolerance to minorities. The threat of internal oppression should not be solved by external oppression. Kukathas argues that, in principle, minorities can impose internal restrictions on the freedom of their members, as long as one essential freedom is guaranteed the right to exit. The basis for a policy of non-interference in illiberal cultures finds Kukathas in the fact that cultural communities are based on the individual right to freedom of association and dissociation. As explained above, Kukathas argues individuals are free to form communities, and to develop and be part of the culture of such communities. Freedom of association implies, however, that individuals should also have the opposite right, namely, the right to dissociate and leave the community. Consequently, communities have a considerable degree of power over their members as long as they respect the right to leave. According to Kukathas, cultural communities that persist in illiberal practices are likely to disappear if their members apply their right to leave the community. ${ }^{51}$

48 Kukathas, 1997 , p. 70.

49 Kymlicka, 1995-B, pp. 94, 154-155, 167-168, 171.

so Green, 1.995 , pp. $261-263$.

51 Kulkathas, 1995, pp. 231-232,234, 236, 248-249, 251-252; Kukathas, 1997, pp. 77-78. 
Several authors emphasise the importance of the right to exit. Raz, for example, proposes that cultural communities should be denied the right to suppress their members and should be strongly encouraged to guarantee the right to exit. $\mathrm{He}$ argues that the opportunity to leave the community forms an important safeguard for members who feel repressed by their community. ${ }^{52}$ Margalit and Halbertal assert that communities have a prima facie right to control entry into the community, but they do not have the right to control the exit of members out of the community. People cannot be forced to stay within a certain culture to prevent it from disappearing. ${ }^{53}$

Kukathas' idea that internal restrictions could be defended on the basis of tolerance and the right to exit, has been criticised by others. One of the counter arguments is that leaving a community is not as easy as Kukathas presents it. Especially vulnerable members of the minority, who might need it most, will find it most difficult to leave the community. ${ }^{54}$

Parekh mentions interesting criteria to respect cultures. He argues that outsiders should generally respect each community's right to culture, but they do not have to respect the content of each culture. A community's right to have a culture should be respected because human beings are free to decide how they wish to live and because culture is important for their identity and well-being. A culture itself deserves respect on the basis of its content and of what it makes possible for its members. Cultures may, for example, give stability to people's lives, hold them together as a community, and may encourage creativity. However, "[a]lthough all cultures have worth and deserve basic respect, they are not equally worthy and do not merit equal respect.". ${ }^{55}$ Critical conditions in this regard are that the cultural community respects human dignity, and both values and safeguards human interests. In addition, it should pose no threat to outsiders and should enjoy the loyalty of most of its members. ${ }^{36}$

It is very difficult to make general statements on cultural communities and the toleration of their cultural practices, because it is an extremely complex matter. The main approach should be to deal with these issues on a case-to case basis, taking the specific situation as well as the context into account. The theory of Kymlicka is convincing, although the absolute prohibition of all internal restrictions on the members of cultural communities is hardly tenable. Cultural communities need a

$52 \mathrm{Raz}, 1993, \mathrm{pp} .143-144,148$.

53 Margalit and Halbertal, 1994, pp. 507-508. Margalit argues in his book "The Decent Society" that not all conmunities possess human value. It this volume he describes a society based on the elimination of forms of humiliation as a form of negative recognition of cultural identities. Communities in which humiliation is a constitutive element, even if they bring satisfaction to the members, lack human value. If they are allowed to exist, they should not be given a public platform or public presence. See Margalit, 1996, pp. 174-175.

$54 \mathrm{Green}_{4}$ 1995, pp. 266, 268.

55 Parekh, 2000, pp. 176-177.

56 Parekh, 2000, p. 177. See, also, Margalit and Halbertal, 1994, p. 491, and Gutman, 1994, pp. 10-11. 
certain freedom to arrange their internal structure, whereby limitations are conceivable, for example, in the sphere of non-discrimination. For example, the Catholic Church is not forbidden to make a distinction between men and women, and Muslims : are not prohibited from instructing boys and girls separately. However, cultural practices should not be tolerated uncritically. The single right to exit does not provide sufficient guarantee for the well-being of individual members, because it is not always a true option in practice. It can, in my opinion, be argued that, while cultural communities have a certain margin of freedom to organise themselves, they may not suppress their members or limit their possibilities to take part in the decision-making process of the community and in the general life of the society. The cultural community may not, for example, seriously harm the physical or mental well-being of its members, which makes practices of Female Genital Mutilation (FGM) and the sacrificing of persons intolerable. Furthermore, all individuals should be able to take part in the decision-making process within a community in order to be able to change certain rules. Finally, cultural communities may not, for example, limit the rights to freedom of education, health care, voting rights and other participation rights in the general society.

\section{Concluding Remarks on a liberal Theory on Collective Rights to Protect Cultural Differences}

The above shows that a liberal theory of collective rights to protect cultural differences is not easy to draw. While the value of cultural membership for individuals is generally agreed on, the question remains of how the cultural identity of communities and individuals can be best protected. Many scholars reject collective rights because they do not fit into the individual human rights discourse. Some authors are not convinced that collective rights are needed to protect minority cultures, since individual rights provide sufficient protection. Finally, collective rights are rejected because the communities which should benefit from them are not proper rights holders. Kymlicka, however, argues that collective rights do fit into a liberal theory of rights, because cultural communities give individuals meaningful choices which enlarge their freedom. He makes an interesting division of collective rights into self-government rights, polyethnic rights and special representation rights. He argues that some minority communities can, within reason, claim these collective rights in order to obtain factual equality with the majority.

Thus, a collective right to cultural identity falls within the category of polyethnic rights, by which minorities can develop and preserve their cultural characteristics. Kymlicka's theory merely concerns the question of whether or not collective rights provide the correct answer to minority claims for the protection of their culture and does not address the content of such rights. More attention was paid to the subject of collective rights to protect cultural differences. Kymlicka considers national minorities to be most suitable subjects for all three forms of rights, while ethnic groups may invoke polyethnic rights. As argued above, the 
distinetion made by Kymlicka between national minorities and ethnic groups based on the measure of the volition of their migration is not convincing, partly because indigenous peoples are indirectly placed under the category of national minorities. Furthermore, the issue of the definition of communities to be proper bearers of rights was not sufficiently resolved. Communities as well as cultures are not homogeneous and their boundaries are unclear. Accordingly, while Kymlicka may have shown that collective rights fit into the liberal theories of rights, from a practical point of view these rights remain problematic.

Another point of debate was the question of what to do with illiberal practices within cultural communities, which is also directly relevant for a right to cultural identity. Opponents of the right to cultural identity have, inter alia, argued that such a right could be abused to excuse intolerable cultural practices. Again, it should be argued that no general statements can be made on these matters. While most agree on the "black and white" matters, there is whole grey area of cultural practices that may or may not be tolerable. Kymlicka argues that cultural communities should respect the rights of their members and may not impose internal restrictions. I agree that the rights of communities should not prevail over the rights of individual members. Kukathas, however, argues that communities may limit the rights of their members as long as the right to exit is guaranteed, basing his arguments on the individual right to freedom of association. Kukathas has in fact realistically shown the importance of freedom of association in relation to cultural differences. Consequently, the right to freedom of association also plays a role in relation to a right to cultural identity. ${ }^{57}$ However, the right to exit does not provide sufficient protection of individual interests against potential suppression by a cultural community, because it is not always a valuable option in practice. I would conclude that more guarantees are needed, especially in relation to the physical and mental well-being of the members of the community, and in relation to their participation rights, in the community itself and in the general process of society. These guarantees play an important role in relation to the possible development of a right to cultural identity. They are needed to prevent a right to cultural identity from having negative consequences for the promotion and protection of human rights.

This chapter has shown that translating the protection of cultural identity into cultural rights is not easy. While the value of cultural membership and cultural communities for individuals should be emphasised, the translation of this value into rights or claims is much more difficult. Kymlicka has developed an interesting theory on collective rights, but he did not solve all problems in relation to the object and subject of such rights, which are important to translate it into legal terms. The following chapter further elaborates upon these issues by approaching a right to cultural identity from a legal perspective in which it is explored both as an individual right which is part of cultural human rights, and as a collective right which belongs to communities as such.

57 In Chapter X, several cases of the European Commission and Court of Hunan Rights are analysed, inter alia, in relation to the right to freedom of association. 


\section{CHAPTER IV \\ Cultural Rights And Collective Rights IN \\ A Human Rights Framework}

\section{INTRODUCTION}

In this chapter, the legal framework of a right to cultural identity is analysed. A right to cultural identity would, within the international human rights framework, fall under the category of culltural rights, which is dealt with in the first part of this chapter. Questions are, inter alia, which rights can be considered cultural rights and which State obligations follow from them. Special attention is paid to the so-called tripartite typology of State obligations, whereby State obligations are divided into the obligation to respect, protect and fulfil. Furthermore, the different levels of recognition are discussed, including the distinction between soft law and hard law. In the second part of this chapter, another important legal aspect is addressed, namely, the question of whether a right to cultural identity should be an individual right or a collective right. Since Vasak started the discussion on collective rights, there has been much debate on these rights. Various authors assert, for example, that, even if there is good reason for collective rights, they cannot fall within the category of human rights, because human rights are reserved for individuals. Another issue is the subject of collective rights and the description of the communities that could benefit from these rights. Another discussion point directly related to a right to cultural identity is the possible tension between individual human rights and a collective right to cultural identity. All these matters are examined below.

\section{CULTURAL RIGHTS AS "THE CINDERELLA OF THE HUMAN RIGHTS FAMILY"I}

"... A]ny attempt to talk about cultural issues in terms of rights may be slippery and difficult." 2

The reason that cultural rights are 'slippery and difficult" is that their content and scope are unclear. One of the developments behind the debate on a right to cultural identity was the discussion on the improvement of cultural rights. Cultural rights form one of the so-called "categories", of human rights as included in the

\footnotetext{
1 Cultural rights have been described as such to show that, from a legal standpoint, they are the least developed rights within the human rights spectrum; see Niec, 1997; p. 3 and Niec, 1998-A, p. 176.

2 Prott, 1988, p. 94.
} 
International Bill of Human Rights. These categories are civil, political, economic, social and cultural rights. They were laid down in two different instruments, the ICESCR and the ICCPR, to point out the different character of these rights, particularly with regard to their means of implementation. The ICCPR enumerates a number of civil and political rights or 'classic freedom rights', which are supposed to be immediately guaranteed by States. ${ }^{3}$ It was argued that the enforcement of civil and political rights mainly demanded States not to interfere; in other words, they should refrain from action in these fields. The ICCPR further provides for rather extensive means of review and supervision: a reporting procedure (Article 40), a State complaint procedure (Article 41, optional) and an individual complaint procedure (Optional Protocol).

The ICESCR contains economic, social and cultural rights to be 'recognised' by States ${ }^{4}$ These rights were considered to require a proactive role of the State involving financial and material resources. Since these resources might not necessarily be directly available, the implementation of economic, social and cultural rights could only be undertaken progressively. ${ }^{5}$ The provisions of the ICESCR were formulated in a programme-type manner. States should promote these rights, but national circumstances may be taken into account. The supervisory mechanism is more modest and consists only of a reporting procedure.

Some authors have expressed doubts as to whether economic, social and cultural rights can be called human rights, or whether they should merely be considered as policy goals or even as "letters to Santa Claus". Several authors question the legal character of economic, social and cultural rights mainly because they consider them to be non-justiciable, since they are vaguely formulated in the ICESCR, which makes their content and corresponding State obligations unclear. Consequently, a judge would be unable to expose the meaning of such rights in a concrete case. ${ }^{7}$ Several authors do, in fact, consider justiciability to be a key requirement for legal rights. Cranston, for example, argues that all human rights lack justiciability and that they should not, therefore, be considered legal rights but moral rights. ${ }^{8}$ Vierdag also considers justiciability to be the main criterion for rights to be 'real' in international law. Two aspects are important in this respect: are the rights capable of being enforced by their bearers in courts of law or comparable bodies, and do these rights imply government action that can be described in terms

3 In Article 2 ICCPR, it is stated that States Parties undertake to respect the rights in the ICCPR and to undertake to take the necessary steps in the field of legislation and policy measures.

4 In Article 2 of the ICESCR, it is stated that States Parties will undertake to take steps, "...to the maximum of its available resources, with a view to achieving progressively the full realisation of the rights recognised in the present Covenant..." The ICESCR Committee in 1990 adopted a General Comment on this provision. See $\$ 2.5$ on State obligations.

5 See Article 2 of the ICESCR, which is discussed in mone detail in section 3.4 .2 of this chapter.

6 Orwin and Pangle, 1984, p. 15.

7 See, for am overview of several authors, Cranston, Orwin and Panglle, Vierdag and Bossuryt, Arambulo, 1999, Chapter III, pp. 53-97, in particular, pp. 55-56.

8 Cranston, 1973, p. 21. 
of law? Vierdag concludes that economic, social and cultural rights are not justiciable and that government action in relation to these rights cannot be described in terms of law. Consequently, economic, social and cultural rights cannot be considered as "real' rights."

There is much more to be said about the nature and scope of economic, social and cultural rights. However, I agree with Steiner and Alston, who argue that the "...debate over whether economic (and social and cultural, YD) rights are 'really' rights was settled long ago." ${ }^{\text {"10 }}$ Recent developments have confirmed that there is general consensus that economic, social and cultural rights are real rights', among others because they have been included in legally-binding human rights instruments. Although individuals do not (yet) have a possibility of complaining directly to the supervisory body of the ICESCR, economic, social and cultural rights may be invoked in national procedures and national judges have used them. The UN Commission has in April 2002 confirmed that cultural rights are an integral part of human rights in a resolution concerning the promotion of the enjoyment of the cultural rights for everyone and respect for different cultural identities."

This approach was confirmed by Türk, Special Rapporteur on the Realisation of Economic, Social and Cultural Rights, who submitted four reports on the implementation of economic, social and cultural rights. ${ }^{12}$ In his final report of 1992, Türk argues that, economic, social and cultural rights are generally recognised as being legal rights, although authors and States may have different opinions on the content of the rights and the corresponding State obligations. Türk argues that the critique of the alleged vagueness of economic, social and cultural rights has only recently been accompanied by an effort to clarify them. He asserted that the International Labour Organisation (ILO) had started earlier with the clarification of labour rights, but the areas of economic, social and cultural rights not covered by the ILO conventions were neglected by commentators until the $1990 \mathrm{~s}^{13}$ Since then, scholars and experts within UN bodies have worked on the clarification of norms ${ }^{14}$ and on the accountability of States for violations of economic, social and cultural rights. ${ }^{15}$

9 Vierdag, 1978, pp. 71-73, 82; see, also, Van Hoof, 1984, p. 99.

10 Steiner and Alston, 1996, p. 268.

1) Commission on Human Rights Resolution $2002 / 26$ "Proniotion of the enjoyment of the cultural rights of everyone and respect for different cultural identities", 22 April 2002, $\$ 5$.

12 The reports of Special Rapporteur Türk are: UN Doc. E/CN.4/Sub.2/1989/19, 28 June 1989; UN Doc. E/CN.4/Sub.2/1990/19, 6 July 1990 ; UN Doc. E/CN.4/Sub.2/1991/17, 18 July 1991; UN Doc. E/CN.4/Sub.2/1992/16, 3 July 1992.

13. UN Doc. E/CN.4/Sub.2/1992/16, 3 July $1992,25-32$, pp. 7-9,

14 See, for example, the following volumes: C.D. de Jong. The freedom of thought, conscience and religion or belief in the United Nations (1946-1992), Sichool of Human Rights Research Series No. 5, Intersentia-Haurt, Antwerp, 2000; B. Tahzib, Freedom of religion or belief: ensuring effective intermational legal protection, Utrecht, 1995; $\mathrm{K}$. Henrard, Devising an adequate system of minority protection: individual human rights, minority rights and the right to self-determination, Nijhoff, The Hague, 2000; F. de Varennes, Langucage, minorities and human rights, Nijhoff, The Hague, 1996; D. Hodgson, The Human Right to Education, Aldershot, Dartmouth, 1998; A.P.M. Coomanis, 
As stated before, the category of cultural rights is, compared to the other categories of civil, political, economic and social rights, underdeveloped or neglected. ${ }^{16}$ Special Rapporteur Turk also pays extra attention to cultural rights, since these rights have received "by far the least amount of serious attention", which he blames on the lack of clarification of cultural rights. ${ }^{17}$ The term 'culture' is vague, which makes the content of cultural rights unclear. A political reason for the underdevelopment of cultural rights is that relatively few regimes have been eager to control the cultural life of the community. Most States did not consider cultural rights as implying positive State obligations. The few regimes that did interfere in culture did it as part of a more or less totalitarian control over social life as a whole, which included the denial of other human rights. ${ }^{18}$ Another argument is that States fear that strengthening cultural rights may lead to tension in society, which may endanger national unity. ${ }^{19}$ The underdevelopment of cultural rights could also be specifically caused by the formulation of one of the leading examples of cultural rights: Article 15 ICESCR on the right to take part in cultural life. By listing several "sub-categories" of rights in the second and third paragraph of Article 15, such as the right to intellectual and creative property and the right to benefit from scientific progress, the provision loses the idea of the totality of culture and uses culture as an operational concept, while culture is more than just these sub-categories. ${ }^{20}$

The following sections elaborate upon the background, scope and content of cultural rights. Only general statements can be made on the content and corresponding State obligations of cultural rights, since they depend on the specific provision involved. The question is where a right to cultural identity fits in, and what the relation is between a right to cultural identity and other cultural rights.

De Internationale Beschepming van het Recht op Onderwijs [The International protection of the Right to Education], Stichting NICM Boekerij, Leiden, 1992.

I5 See, inter alia, The Limburg Principles on the Implementation of the International Conemant on Economic, Social and Cultural Rights, UN Doc. E/CN.4/1987/17,; Th. van Boven, C. Flinterman and 1. Westendorp (eds.). "The Maastricht Guidelines on Violations of Economic, Sacial and Cultural Rights", SrM Special No. 20, SIM, Utrecht, 1998.

16 The term "neglect" is used by J. Symonides, former Director of the Human Rights Biwision of UNESCO and active scholar in the field of cultural rights. He prefers the term neglect, because the term "underdeveloped" would demand further development, perhaps in the form of new rights. However, as he argues, the list of eultural rights is long enough; attention should be placed on the improvement of their implementation. See Symonides, 2000-A, p. 175. Special Rapporteur Türk agrees that no new rights should be developed to avercome the non-implementation of existing rights. The improvement of economic, social and cultural rights does not necessarily imply the creation of new standards, but development and clarification of existing standards is necessary. See UN Doc. E/CN.4/Sub.2/1992/16, 3 July 1992, \$187, p. 49.

17 UN Doc. E/CN.4/Sub.2/1992/16, 3 July 1992, \$198-199, pp. 51-52.

18 Donnelly, 1989, p. 154; Donnelly, 1990, p. 55.

19 See, inter alia, Symonides, 2000-A, p. 176.

20 Konate, 1993 , p. 105. 


\subsection{The Nature and Scope of Cultural Rights}

The nature and scope of cultural rights are closely tied to the term "culture". As shown in the previous chapters, the concept of culture has broadened over the years. It has moved from the narrow élitist concept which mainly included arts and literature to a broader perspective as a process in which aspects such as language, religion and education play an important role. A similar development is visible in the debate on cultural rights.

The first international conference on cultural rights was organised by UNESCO in July 1968. It should be kept in mind that two years earlier, in 1966, the ICESCR had been adopted, including, in Article 15, the right to take part in cultural life. ${ }^{21}$ The experts at the conference discussed the evolution of the concept of cultural rights since the Universal Declaration, the recognition of cultural rights and the measures to be taken to improve their implementation. There was also discussion on one special cultural right that was not provided for in the International Bill of Human Rights: the right to culture. ${ }^{22}$

One of the main issues during the conference was the clarification of cultural rights through a definition of the term 'culture'. In the end, the experts agreed on a broad definition. Culture was considered to be:

"...the totality of ways by which men create designs for living...Culture is everything which enables man to be operative and active in his world, and to use all forms of expression more and more freely to establish communication among men., ${ }^{, 23}$

In the final Statement of the Conference, it was stated that cultural rights were important because culture enabled persons "...to maintain and perpetuate life." According to the experts, cultural rights were therefore related to the right to life and the right to peace. ${ }^{24}$ Other aspects of importance were communication and education, or 'the freedom to know", by which individuals could develop themselves. The Statement did not contain a reference to aspects of culture such as religion, language, cultural heritage or land. ${ }^{25}$ Although the broad definition of culture might suggest otherwise, the approach towards the right to culture showed a rather narrow interpretation of this concept. According to participant Boutros-Ghali, for example, the right of an individual to culture meant that "... every man has the

21 See, for a detailed analysis on Article 15 ICESCR, Chapter VI of this study.

22 UNESCO, 1970, p. 3.

23 UNESCO, 1970, pp. 10-12, 1.05-106; see, also, Symonides, 2000-A, pp. 179-180.

24 Other authors have argued that the Genocide Convention contains one of the most fundamental cultural rights, namely, the right of groups to exist. According to Article 2 of the Genocide Convention, the act of genocide includes, among others, acts causing serious bodily or mental harm to members of the group and forcibly transferring children of a group to another group. See Stavenhagen, 2001, pp. 87, 103. The Genocide Convention is dealt with in Chapter VIII. UNESCO, 1970, pp. 106-107. 
right of access to knowledge, to the arts and literature of all peoples, to take part in scientific advancement and to enjoy its benefits, to make his contribution towards the enrichment of cultural life."26 This description is similar to Article 15 ICESCR. However, the scope of the right to culture was given a broader interpretation. According to Boutros-Ghali, the right to culture implied that a person should have a decent standard of living with regard to food, shelter, healthcare, and education, or else a person would not have the desire or the possibility of participating in culture. "A minimum of material well-being is necessary if the very notion of culture is to have the least significance," 27

The question is to what extent cultural rights and the right to culture need certain social and economic standards. Although it cannot be denied that social and economic factors, especially through education, play an important role in the enjoyment of cultural rights, they do not have to be decisive. In my opinion, several aspects of culture, such as religion, language and customs, are less dependent on economic factors. Individuals speak a language ${ }^{28}$, practice or do not practice a religion, and have their own customs; they automatically participate in these aspects of culture irrespective of economic factors. However, if one considers participation in culture as having access to culture in the form of books, arts and museums, then economic and social factors become more decisive.

More recent sources show that the scope and content of culture have broadened to culture as a process. Symonides, for example, argues after analysing UNESCO and UN instruments relating to cultural rights that there was a tendency among States and scholars to accept a broad understanding of culture, which was no longer restricted to arts, literature and philosophy, but instead included distinctive features, ways of thinking and the organisation of people's lives. ${ }^{29}$ Meyer-Bisch, an important scholar in the field of cultural rights, considers cultural rights as a category that includes, for example, linguistic rights. He argues that culture should not only be seen as a consumer product, but as an expression of the identity of an individual or a community. Cultural rights have too often been considered as rights to enjoy a (cultural) product instead of real human rights as part of human existence. Another difficulty is that the adjective 'cultural' can often be found at the end of a list of other adjectives, such as ethnic, linguistic, scientific, etc., as if it concerns a remnant group of everything that has not been mentioned yet. ${ }^{30}$

Apart from the meaning of 'culture', the question has been posed of whether cultural rights belong next to economic and social rights or next to civil and political rights. According to Meyer-Bisch, the core problem of cultural rights is

26 Boutros-Ghali, 1970, p. 73.

27 Boutros-Ghali, 1970, p. 73.

28 While the grammar and writing have to be learned through education, even without education there is a form of communication and language.

29 Symonides, 2000-A, p. 180.

30 Meyer-Bisch, 1993-A, pp. 18-20, 23-24. See, also, UNESCO, 1970, p. 44. 
that they are a category connecting other categories of rights and linking individual rights and the rights of peoples and communities. Cultural rights are important not only as a separate category of rights, but also as a reference to the cultural elements in other human rights. ${ }^{31}$ Meyer-Bisch argues that:

"Les droits eulturels sont une catégorie occultée parce qu"en tant que droits très généraux, ils remettent en question toutes les catégorisations des droits de l'homme, ainsi que les rapports entre droits de l'homme, droits des peuples et droits des minorités; ces droits ne peuvent donc être acceptés par compromis, ils supposent une réinterprétation de l'indivisibilité dans son ensemble." ${ }^{32}$

He calls this the 'transversal character' of cultural rights, as overlapping the categories of economic, social, civil and political rights. Cultural freedoms, such as freedom of religion, expression and communication, refer to civil rights, while the right to participate in culture refers to social and economic rights. The right to education is an example of a mixed right. The second part of this transversal character lies in the fact that cultural rights can be considered as being in between individual rights and collective rights. Cultural rights have a special character within human rights, because individuals and communities can benefit from them. ${ }^{33}$

The transversal character of cultural rights forms the central point of the Conclusions of a Colloquium in Fribourg in 1990 on the nature and logic of cultural rights. ${ }^{34}$ In these Conclusions, the experts agree that cultural rights jeopardise the division of human rights into freedom rights based on State abstention, and rights of credit demanding State action. Cultural rights imply negative as well as positive obligations for States, and can be enjoyed by each individual alone and jointly with others. Although cultural rights have been included in a treaty with economic and social rights, their connection with civil and political rights, for example, the rights to freedom of religion and expression, is clear. In the Conclusions, the experts further agree that cultural rights are both individual rights and community rights, since the subjects of these human rights are individuals who are also members of communities. ${ }^{35}$

31 Meyer-Bisch, 1993-A, p. 18. See also the reports of Special Rapporteur Turk who agrees that many human rights have an important cultural dimension. The protection for example offered to indigenous peoples, minorities or other communities by human rights would be meaningless if their cultural rights, such as the right not to be assimilated and the right to cultural antonomy, are not respected. See Türk, UN Doc. E/CN.4/Sub.2/1992/16, 3 Jully 1992, \$ 198-199, pp. 51-52.

32 Translation: cultural rights are an occult category because, as wery general rights, they question all categories of human rights, as well as the link between human rights, rights of peoples and rights of minorities; these rights can therefore only be accepted by compromise, they suppose a reinterpretation of the indivisibility in its totality. Meyer-Bisch, 1993-A, p. 17.

33 Meyer-Bisch, 1993-A, pp. 18-19.

34 In between 1968 and 1990, UNESCO organised various Conferences on Cultural Policies" see Chapter $\mathrm{V}$ of this study. The focus during these conferences was on cultural policies, not on cultural rights.

35 Meyer-Bisch, 1993, pp. 302-303. 
Many authors emphasise that cultural rights have both an individual and a collective component. As mentioned above, Meyer-Bisch emphasises the intermediate role of cultural rights between the rights of individuals and the rights of peoples, and the importance of cultural rights for communities. ${ }^{36}$ Marie calls the position of cultural rights a bridge between individual rights and collective rights, since many cultural rights have an individual as well as a collective dimension. He mentions the individual right to participate in cultural life, which makes no sense without, and, indeed, can only be enjoyed within, a community. ${ }^{37}$ Eide adds that individual cultural rights can, to some extent, coincide with collective cultural rights, but that they may also represent a challenge to each other. Individual concerns and community concerns with regard to culture may be different, and cultural rights can be lie in between both interests. ${ }^{38}$

Prott mainly emphasises the collective dimension of cultural rights. She argues that, apart from individual cultural rights, such as freedom of religion, expression and association, which are essential to the development of cultures, new claims of communities have been added, such as the collective right to the protection of cultural identity. She distinguishes two groups of collective cultural rights. On the one hand, there are rights relating to the cultural identity and uniqueness of a people, such as the right to develop and preserve a culture, the right to respect for cultural identity, and the right not to have an alien culture imposed. On the other, there are rights to cultural heritage, such as the right of a people to its own cultural heritage and to participation in the cultural heritage of the world. ${ }^{39}$

Wilhelm points to the fact that the State approach towards cultural rights has been mainly individual, because States consider a collective approach towards cultural rights to be too dangerous for the stability of the society. In this way, cultural identity is disposed of its collective dimension and its total character. Cultural rights are reduced to the rights to forms of expression, such as language, religion, education, and artistic creation. Wilhelm asserts that reduced to these forms of expression, cultural identity remains a fossilised, picturesque notion to be used for tourism. Instead, she pleads for respect for the collective dimension of cultural identity, comparable to the recent developments in the field of rights of minorities and indigenous peoples, where a broader and more collective perspective of culture has been adopted.

In short, the clarification of cultural rights starts with the meaning of the term 'culture'. This concept should be interpreted broadly, not only to include cultural products, but also the process of culture, including, for example, language, religion

36 Meyer-Bisch, 1993-A, pp. 38-39.

37 Marie, 1993, pp. 203-207, 213.

38 Eide, 2001-B, pp. 300-301.

39 Prott, 1988, pp. 95-97.

40 Wilhellm, 1993, pp. 226-231, 236-237. These recent developments are the adoption of the UN Declaration on the Protection of National or Etlmic, Religious and Linguistic Minorities (1992) and the work on the UN Draft Declaration on the Protection of Rights of Indigenous Peoples (1994). 
and education, which are directly related to human dignity. The broad interpretation of culture implies that the category of cultural rights overlaps civil, political, economic and social rights. Cultural rights are not so much the rights to create and enjoy cultural products, but as human rights, they concern the protection and promotion of human dignity. Many human rights have a cultural dimension, for example, freedom of expression, freedom of religion, freedom of association and the right to education. It should further be noted that cultural rights have a universal and a particularistic side. The dilemma concerns the use of cultural rights to affirm differences between, for example, the majority and the minority in a State, and the use of cultural rights to unify these communities. A right to cultural identity also concerns such a dilemma. Furthermore, it is clear that cultural rights have an individual and collective dimension. Not only does the enjoyment of cultural rights often take place in relation to communities, cultural rights are also especially important to communities such as minorities and indigenous peoples. These aspects of cultural rights, the broad interpretation of culture, a category overlapping other categories of human rights, and the individual and collective dimension are equally important for a right to cultural identity. The protection of cultural identity should not be limited to a narrow concept of culture or to an individual approach.

\subsection{Which Rights are Cultural Rights?}

Which rights can be considered to be cultural rights? Again; the list of cultural rights depends on the definition of culture. As explained in the second chapter, culture may vary from the intellectual and artistic achievements of individuals and communities, to culture in the anthropological sense as the way of life of both individuals and communities, including shared beliefs, traditions and customs. In any case, culture is a dynamic concept, which implies that "[c]ultural rights have an exceptional internal dynamic due to the fact that culture is a living and growing organism, constantly manifesting itself in new ways." 4 !

The difficulty of drawing up a list of cultural rights lies in the fact that 'cultural rights' can refer to different things. Cultural rights can refer to culture or cultural dimensions, for example, rights concerning creativity, such as copyright, artistic and intellectual freedom, and rights to education, religion and expression. Cultural rights can also concern the right to culture, in the sense of the right to preserve, develop and have access to a culture. ${ }^{42}$ Some authors, however, use cultural rights and the right to culture interchangeably. ${ }^{43}$ In my opinion, a clear distinction should be made between cultural rights as a category of human rights that relate to culture, and separate cultural rights, such as the right to culture or the right to cultural identity, that fall under this category.

41 Niec, 1998-A, p. 181.

42 Prott, 1998, p. 165.

43 See, for example, Stavenhagen, 2001, pp. 89-93; Stavenhagen, 1998, pp. 4-8. 
Authors have made different lists of legal provisions that can be called cultural rights. The main general distinction is made between cultural rights in the narrow sense and cultural rights in the broad sense. The narrow group of cultural rights contains those rights that explicitly refer to 'culture', such as the right to participate in cultural hife, as laid down in Article 27 of the Universal Declaration and Article 15 of the ICESCR. The broad group of cultural rights includes the above-mentioned rights, but further includes other civil, political, social and economic rights that have a link with culture. It might be defensible that almost every human right has a link with culture, but the rights specifically meant here are the rights to freedom of religion, freedom of expression, freedom of association and the right to education. ${ }^{44}$ Some authors, however, place the right to education in the narrow group of cultural rights. They base themselves on the ICESCR and argue that Articles 13, 14 (on the right to education) and 15 (on the right to participate in culture) ICESCR fall under the category of cultural rights as referred to in the title of this treaty. ${ }^{45}$

Stavenhagen argues that the content of cultural rights, or what he calls the right to culture, depends on the definition of culture. If culture were considered to be the accumulated material heritage of humankind, then the right to culture would mean the right of equal access to this cultural capital and the right to cultural development. If culture is mainly considered from the creative perspective, meaning the process of artistic and scientific creation, the right to culture would mean the right of individuals to create freely and the right of individuals to have free access to these creations in museums, theatres and libraries. Culture can finally be considered a way of life; the sum of material and spiritual activities and products of a social group, including a system of values, symbols and practices, that distinguishes it from another group. The right to culture then implies the right of a community to maintain and develop its own culture or the right to cultural identity. Stavenhagen prefers such a collective approach towards cultural rights, since many of these rights can only be enjoyed by individuals together, and several are meant to give communities the possibility of developing, protecting and preserving their cultural identity. ${ }^{46}$

Prott makes a comparable distinction between culture in the sense of intellectual achievements, such as music, art, and literature, and culture in the anthropological sense meaning the totality of knowledge and practices, both intellectual and material, of a community. ${ }^{47}$ She concludes that, in speaking of culltural rights, it has not always been clear which form of culture is being referred to. According to her, a distinction should be made between general cultural rights,

44 Donnelly, 1989, pp. 155-156; Meyier-Bisch, 1993-A, p. 25; Leuprecht, 1993, p. 76; Eide, 2001-B, p. 292; Kartashkin, 1982, p. 127. It will appear that several monitoring bodies, such as the European Court of Human Rights and the Inter-American Commission on Human Rights, have also used other provisions to protect culture, such as the right to life, the right to health and the right to fanily life and home. See Chapter IX and X of this study.

45 See Meyer-Bisch, 1993, p. 12; see, also, Symonides, 1993, pp. 52-53.

46 Stavenhagen, 2001, pp. 89-92; Stavenhagen, 1998, pp. 4-6.

47 Prott, 1988 , p. 94. 
such as the right to education and the right to participate in cultural life, rights related to (the protection of) a specific culture, and rights related to cultural resources of universal importance as part of the cultural heritage of humankind. ${ }^{48}$

Wilhelm defines cultural rights from the perspective of inequality. She argues that two inequalities have led to the adoption of cultural rights: the inequality between individuals in, for example, access to cultural institutions, the educational system, or cultural goods, and the inequality between different ethnic, linguistic and religious communities with regard to the possibility of their expressing their cultural identity. Most cultural rights follow from the first inequality, such as the right to education and cultural participation. The second inequality has led to the recent development of rights, for example, for minorities and indigenous peoples. ${ }^{49}$

The participants in the Fribourg Colloquium listed the following cultural rights:

1. The right to cultural identity, including the right to free cultural choices of one's language(s) or convictions and the right to cultural heritages.

2. The right to free participation in cultural life, including the right to freedom of conscience and expression, the right to freedom to research and creativity, the right to communicate and the right to intellectual property.

3. The right to education, including the right to basic and general education, to practical education and vocational guidance and training. ${ }^{50}$

Meyer-Bisch divides cultural rights into three groups, of which the first two are already recognised in international human rights instruments, while the third has been developing more recently and is less defined. These three groups reflect the development of cultural rights from the passive enjoyment of culture, via the active participation in and creation of culture, to the protection of the cultural identity of communities. ${ }^{5 \mathrm{~F}}$ His scheme of cultural rights is as follows:

1. The right to cultural participation, including the right to participate freely in cultural life (especially freedom of conscience and religion), the right to benefit from scientific and technical progress and the enjoyment of the arts, and the right to intellectual property.

2. The right to education, including the right to elementary and functional education and the right to orientation and professional formation.

3. The right to cultural identification, including the right to choose a culture and especially a language, the right to cultural heritage, and the right to access to communication and expression facilities (the right to communicate). ${ }^{52}$

48 Prott. 1988, p. 101.

49 Wilhelm, 1993, pp. 224-225.

50 "Cultural Rights, an underdeweloped category of human rights, Conclusions of the Eighth Interdisciplinary Colloquium on Human Rights", Fribourg 28-30 November 1991, in: Meyer-Bisch, 1993, p. 303 and in: the Review of the International Commission of Jurists, No. 49/1992, pp. 51.53.

51 Meyer-Bisch, 1993-A, p. 35.

52 Meyer-Bisch, 1993-A, p. 36. 
In my view, cultural rights form a general category of human rights that relate to the protection of a distinctive culture. As such, cultural rights are more than merely the rights that explicitly refer to culture, but include other human rights that protect aspects of culture. Meyer-Bisch has made an interesting point in arguing that the right to cultural identity is the third stage of a development of cultural rights from the passive enjoyment of culture, via the active participation in and creation of culture, to the protection of the cultural identity of communities. Because of the comprehensive scope of cultural identity, a right to eultural identity could be considered an 'umbrella right', which includes different other rights. These rights resemble traditional individual human rights, such as the right to freedom of expression or freedom of religion. Such an umbrella right may also reflect the dynamic character of cultural identity, because various and changing issues can be brought under this right. As a separate right by itself, the precise content and State obligations remain unclear.

\subsection{The Fribourg Group and the Draft Declaration of Cultural Rights}

Meyer-Bisch was the initiator of a group of experts who prepared a Draft Declaration on Cultural Rights, the so-called Fribourg Group. ${ }^{53}$ The Fribourg Group explained that it did not wish to develop new rights but to clarify existing cultural rights and thus reach a better understanding of the fundamental cultural dimension of all human rights. The final draft presented in 1998 enumerated six cultural rights: the right to cultural identity and heritage, the right to identify with a cultural community, the right to participate in cultural life, the right to education and training, the right to information, and the right to participate in cultural policies and co-operation. There is also an informal explanatory comment available on several provisions. ${ }^{55}$ Cultural identity formed a central principle in the draft. It was argued that rights that contributed to the recognition and the expression of cultural identity were fundamental rights for every human being. Non-respect for cultural identity would be a violation of the integrity of the human being and would make the enjoyment of other human rights impossible. ${ }^{56}$

The draft declaration defines the terms 'culture', 'cultural identity' and 'cultural community' as follows:

53 The Fribourg Group submitted a report on cultural rights to CAHMIN, the Committee which prepared a draft Additional Protocol to the ECHR on Rights in de Cultural Field, see Chapter $X$ of this study. After the suspension of the work on the additional protocol, the Fribourg Group continued working on cultural rights, which led to a draft declaration of cultural rights to be adopted within the framework of UNESCO. For more information on the Fribourg Group, see http://ww unifr.ch/iiedh/recherche/recherche.html (last visited June 2002).

54 Draft Declaration of Cultural Rights, in: Niec, 1998, Appendix C.

55 Commentaire article par article, see http://www.unifr.ch/iledh/recherche/recherche.html.

56 See the Commentaire article par article, $\$ 4-5$ and $7-11$. 
"a) the term "culture" applies to the values, beliefs, languages, arts and sciences, traditions, institutions and ways of life by means of which individuals or groups express the meanings which they give to their life and development.

b) the term "cultural identity" applies to all cultural references through which individuals or groups define and express themselves and by which they wish to be recognised; cultural identity embraces the liberties imherent to human dignity and brings together, in a permanent process, cultural diversity, the particular and the universal, memory and aspiration.

c) a "cultural community" is a group of persons who share those cultural references which comprise a common cultural identity, and which they wish to preserve and develop, as essential to their human dignity, in the respect of human rights. ${ }^{* 57}$

According to the explanatory comment, cultural communities are the central actors of a democratic culture, whereby they are more than associations with a cultural character. Instead, they are political communities, without being a nation. The Fribourg Group firmly established that cultural identity should be considered the fundament of a cultural community containing a certain multiplicity, because individuals can identify with various communities at the same time. Apart from the voluntary decision of the members of the community to be part of it, there must be an objective heritage and tradition that influences the joining of the members. The Fribourg Group developed various criteria for cultural communities to be recognised, namely, respect for human rights; the declaration of the common heritage as a necessary source of identification, which they wish to preserve and develop; and a public space for procedures of debate and decision making that are open to external control: $^{58}$ These criteria are useful in relation to the issues discussed in the previous chapter conceming cultural communities and their practices. While cultural communities may have a certain freedom to organise their internal structure, they should respect human rights and their actions should be open to external control

The right to cultural identity is incorporated in Article 3 of the Declaration, according to which:

"... everyone, alone or in community with others, has the right to free choice of, and respect for, his or her cultural identity and its various means of expression..."

Furthermore, Article 3 contains the right to knowledge of, and respect for, one's own culture and the cultures of others including, in particular, the right to knowledge of human rights, and the right to access to cultural heritages that are significant manifestations of the various cultures.

57 Draft Declaration of Cultural Rights, in: Niec 1998, Appendix C, Article 1.

58 See the Commentaire article par article, $\$ 7-11$. 
According to the explanatory comment, the right to cultural identity goes beyond the freedom of opinion, conscience and expression as individual subjective freedoms and also includes rights to respect for objective references, such as cultural heritage. The explanatory comment further describes the positive and negative obligations of Article 3. The negative obligations are, inter alia, non-interference with the free choice of cultural identity, whereby restrictions are only possible with regard to the expression of this identity. In addition, States should not interfere with the dignity of cultures and should abstain from intentional deformation of their characteristics, especially historical ones. States should also protect cultural heritage from irreparable demolition. Positive obligations are, for example, administrative procedures for the recognition of cultural heritage, and for the free access and use of this heritage for a larger part of the public. Cultural communities should be actively involved in the whole process. ${ }^{59}$

According to Symonides, who also participated in the Fribourg Group, the right to cultural identity means that "...everyone, alone or in community with others, may freely choose his or her cultural identity in its various aspects such as language, religion, heritage and traditions; that everyone may have one or several cultural identities and may freely decide whether or not to identify with one or more cultural communities. ${ }^{, 60}$

This corresponds to the description of Meyer-Bisch, who argues that the right to cultural identification means the right to respect for, and the expression of, one's cultural values. According to Meyer-Bisch, it implies the following rights:

- the right to exercise freely, in public and in private, cultural activities and especially to express oneself in the language of one's choice;

- the right to exercise the freedom indispensable for research and creation;

- the right to cultural heritage, not to be hindered to access to one's own culture and the knowledge of cultures together;

- the right to correct information;

- the right to identify or not with cultural communities of one's choice and to maintain relations with them without consideration of boundaries. ${ }^{61}$

Although the Fribourg Group had started negotiations with the Director-General of UNESCO in 1998 on the adoption of this Draft Declaration, it was never formally adlopted by States. One of the reasons was that Member States had serious problems with the collective approach of the Draft Declaration. Although the rights are defined in terms of "everyone, alone or in community with others', the definitions of culture and cultural identity also refer to communities as such. The work of the Fribourg Group has, however, contributed to the adoption of the UNESCO Declaration on Cultural Diversity in 2001. The Draft Declaration has generally

59 See the Commentaire article par article, $27-33$

60 Symonides, 2000-A, p. 189.

61 Meyer-Bisch, 1993-A, p. 37. 
served as an important doeument for discussion on cultural rights and the Fribourg Group is still active in the field of clarifying cultural rights.

The Draft Declaration on Cultural Rights and the explanatory comment contain interesting issues. It is a valuable suggestion to regard cultural identity as a central element or principle underlying all cultural rights. These cultural rights include rights of access to, and participation in, culture, but they are also linked to freedom of expression, freedom of information and the right to education. Cultural identity is used in the Declaration as a broad umbrella concept which includes all these aspects. As a right, cultural identity mainly gives rise to negative obligations, such as non-interference in the choice of cultural identity. The positive obligations with regard to a right to cultural identity mainly concern aspects of cultural identity such as the preservation of cultural heritage.

\subsection{Levels of Recognition: Soft Law, Hard Law and Justiciability}

As stated earlier, the recognition of cultural identity as a value can take place at different levels. One of the earlier conclusions was that cultural identity is a value that is worth preserving, as an important element of human dignity. As such, it has a direct relationship with the promotion and protection of human rights. A distinction was made between moral standards or values, policy goals and legal (human) rights. Recognition may lead to political recognition in terms of an international political declaration for example. Such an international political statement would give a right the status of "soft law". Soft law is distinguished from hard law in the sense that soft law contains 'guidelines of conduct', which are not legally-binding norms of law, but which have moral, political, but limited legal value. Soft law is mainly laid down in declarations, while hard law is expressed in legally-binding instruments such as treaties, or through customary law or ius cogens. Soft law can become hard law by inclusion in a treaty or through developing into a norm of international customary law.

A declaration is considered as a formal instrument, "...suitable for rare occasions when principles of great and lasting importance are being enunciated." ${ }^{22}$ Although not legally binding upon Member States, declarations may influence the future development of the law, especially when they are adopted unanimously or with a large majority. Recommendations are another form of non-binding recognition, containing norms that are not subject to ratification. They are suggestions of international organs, which invite Member States to take whatever legislative or other steps may be required and are intended to influence the development of national laws and practices. As such, although not legally-binding, they do have a certain legal effect. As members of the international organisation, States are bound, by virtue of the principle of good faith, to co-operate in realising

62 Report of the Commission on Human Rights, UN doc. E/3616/Rev. 1, 105. 18th Session ECOSOC, New York, 19 March-14 April 1962. See, also, Marks, 1995, pp. 580-581. 
the purposes of the organisation, including a recommendation adopted in the framework of such an organisation.

In a binding form, a right may be recognised as hard law, by inclusion in an international legally-binding instrument, such as a treaty, or through the development of international customary law. Such progressive development is one of the characteristics of international law, although States can also lay down rules directly in hard law. New areas of international law, such as environmental law or law related to minorities and indigenous peoples, often follow the pattern of recognition as a moral value, to soft law and eventually hard law. ${ }^{6.3}$

It was stated in the introduction that cultural identity as a concept has been included in some international legal instruments, most of which are soft law. The question is to what extent it is desirable to develop a separate right to cultural identity in the form of hard law. Furthermore, to what extent should individuals be able to invoke a right to cultural identity; in other words, should such a right be justiciable? The above has shown that it is difficult to define the broad concept of cultural identity in terms of law, which implies that it can hardly be justiciable.

The position of a right to cultural identity has also been described as "underlying principle', for example within the Fribourg Group. The term 'underlying principle' needs further clarification. Cultural identity is often referred to as a principle, also in legal instruments. Sometimes the term 'principle' means a policy end ${ }^{64}$ and sometimes it has a somewhat broader meaning. The term 'underlying principle' brings to mind the issue of general principles of law as in article 38(1)(c) of the Statute of the International Court of Justice (ICJ), as a source of international law to be applied by the ICJ. The issue of what general principles of law are is disputed, but according to Kooijmans general principles of law are those principles that can be found in almost all legal systems in the world and which are necessary for a proper application of the law. These principles were incorporated in the Stature of the ICJ to allow the Court to supplement lacunas in the law. ${ }^{65}$ Brownlie describes the general principles of international law as "...logical propositions resulting from judicial reasoning on the basis of existing pieces of international law and municipal analogies." As examples the authors mention the principles of consent, reciprocity, equality of States, the legal validity of agreements and good faith. ${ }^{6 ?}$ According to the Charter of the United Nations, the principles of human rights such as human dignity, equality and non-discrimination are also part of the general principles of international law. ${ }^{68}$ These principles can also be found in the

63 Malanczuk, 1997, p. 54

64. The Framewark Convention on the Protection of National Minorities of the Council of Europe (1995), for example, contains principles, such as cultural identity, as policy ends. See Chapter X.

65 Kooijmans, 2000 , p. 14.

66 Brownlie, 1990, p. 19.

67 Kooijmans, 2000, p. 14, Brownlie, 1990, p. 19.

68 United Nations Charter Preamble and article 1. De Waart has argued that the right to development is also a principle of modern international law. See De Waart, 1991, pp. 228-236. 
Declaration on Principle of International Law concerning Friendly Relations and Co-operation among States in accordance with the Charter of the United Nations. In this Declaration, seven principles of international law have been laid down: prohibition of the threat or use of force, peaceful dispute settlement, noninterference in internal affairs, duty to co-operate, equal rights and selfdetermination of peoples, sovereign equality of States and good faith. ${ }^{69}$

As cultural identity has been described as an important element of human dignity, the question arises as to whether it could serve as some sort of principle of human rights law. While human dignity is the core value of human rights and as such the source of human rights, several general issues, such as non-discrimination and self-determination, serve as principles for the promotion and protection of human rights. Could cultural identity also become such a principle? This matter is part of the analysis in the next chapters. For now, the term 'underlying principle' is used either as a policy end or in the sense of an essential idea in relation to the interpretation and implementation of human rights. This matter is finally dealt with in Chapter XII.

\subsection{State Obligations with regard to Cultural Rights}

Rights imply a claim by the beneficiary or holder of a right towards the addressee to do something or to refrain from doing something. In the case of human rights, in particular cultural rights, the main addressee is the State. The UN Commission has confirmed in a resolution of 2002 that "... States have the primary responsibility for the protection of the full enjoyment of cultural rights by everyone..." What is the nature of States' obligations with regard to cultural rights and a right to cultural identity? Cultural rights laid down in a treaty, for example the ICESCR, follow the regime of State obligations of that treaty. Apart from this, an elaboration of State obligations has been developed in relation to human rights, namely, the tripartite typology of State obligations.

A general distinction concerning State obligations is made between the obligation of conduct and the obligation of result. An obligation of conduct, active or passive, positive or negative, refers to the behaviour of the addressee. The provision involved requires a specific course of action, leaving the State no freedom

69 UN Doc. A/Res. 2625 (XXV) or A/8028, Declaration on Principles of International Law concerning Friendly Relations and Co-operation among States in accordance with the Charter of the United Nations, adopted by the General Assembly on 24 October 1970.

70 Commission on Human Rights Resolution 2002/26, Promotion of the enjoyment of the cultural rights of everyone and respect for different cultural identities, 22 April 2002. Other addressees may be identified, such as other individuals and communities. See, for example, Article 29 of the Universal Declaration on Human Rights, which says that all members of society shate a responsibility in the realisation of hunian rights, and the preanble of the ICCPR and the ICESCR, which also refer to the obligations of individuals towards other individuals and the community. See, also, P. Alston. "International Law and the Human Right to Food" in: Ph. Alston and K Tomaševski (eds.), The Right vo Food, Martinus Nijhoff Publishers/SIM, Utrecht, 1984, pp. 9-68. The focus in this study will, howewer, be on the obligations of States. 
of policy. An obligation of result does not refer to the path of action by the State, but instead points to the concrete result that the State should achieve or avoid. States have free choice in the measures and methods to achieve the required result. According to Eide "[t]he relationship between these two classifications of obligations is complex." It cannot be stated in abstract which obligations follow from which rights, it depends on the context and circumstances. ${ }^{71}$

\subsection{Positive and Negative Obligations}

Generally, State obligations can be divided into negative and positive obligations. Negative obligations imply that the State should refrain from action whereas positive obligations require State action.

At first, a distinction was made between civil and political rights that demanded State abstention or negative obligations, and economic, social and cultural rights that required an active State policy or positive obligations. However, this firm distinction has been disputed. Not only has it been confirmed that all human rights are indivisible and interdependent, but also that all categories may imply positive as well as negative State obligations. Civil and political rights are not only freedom rights demanding State respect and abstention, and economic, social and cultural rights may also require non-interference by the State. Van Hoof, for example, argues that freedom of expression, may require, apart from the negative obligation to respect the prohibition of censorship, also a positive obligation to create the conditions necessary for the freedom to demonstrate, for example, police escort and protection, and pluralism in the media. Another example is the right to vote, which implies that the State should organise elections. Examples of economic, social and cultural rights that lead to negative State obligations are trade union freedoms and the right to housing, which also implies that the shelter of poor people may not be destroyed by the State in order to be replaced by luxury houses without providing alternative housing for the poor. ${ }^{72}$ Accordingly, in principle, cultural rights may require positive as well as negative obligations.

Meyer-Bisch asserts that States mainly have negative obligations in relation to cultural rights. He argues, for instance, that linguistic rights cannot be claimed under all circumstances, for example, in the relations with public authorities. But there would be no justified reason to prohibit the use of language of choice in many other cases, for example, in the home. Another example concerns the right to

71. Eide; UN Doc. E/CN.4/Sub.2/1987/23, 1987, \$ 71-72; UN Committee on Economic, Sociall and Cultural Rights, General Comment 3 on the nature of States parties" obligations (art. $2, \$ 1$ of the Covenant), fifth session, December 1990, \$1; Maastricht Guidelines, 1998, guideline 7, pp. 4; Vlemminx, $1998, \mathrm{pp} .67-72$. See also the definition of a violation of an obligation to conduct by the International Law Commission: "There is a breach by a State of an international obligation requiring it to adopt a particular course of conduct when the conduct of that State is not in conformity with that required of it by that obligation", Draft Articles on State Responsibility, article 20.

72 See, inter alia, Van Hoof, 1984, p. 107. 
education. The State may limit the development of educational facilities for minority communities according to the resources available to those comnunities that, for example, have a certain number. But there would be no justification for prohibiting a cultural community, small or large, to organise the teaching of its own values itself. Meyer-Bisch argues that there are several cultural rights that require more positive State obligations. The example he mentions is literacy, which he considers to be a fundamental cultural right, demanding urgent action by the State. ${ }^{73}$

Kymlicka also makes the distinction between non-interference and active State policy with regard to cultural rights. He asserts that there are principally two ways of accommodating cultural differences and cultural identities: nondiscrimination and active promotion. According to the non-discrimination model, cultural identity is neither supported nor punished by public policy. The expression of cultural identity is considered not to be the concern of the State, but is left to the private sphere. The active promotion model demands public measures to promote and protect cultural identity, for example, through rights in the field of language, land and representation. Kymlicka also supports a more active State policy in the field of cultural rights. ${ }^{74} \mathrm{I}$ agree that, in principle States have positive as well as negative obligations in relation to cultural rights.

If cultural rights are laid down in specific treaty provisions the State obligations can be deducted from the specific treaty regime under which the provisions fall. Cultural rights that are part of the ICESCR fall under the regime of that treaty. The key provision in the ICESCR with regard to State obligations is Article 2(1), which lays down the principle of progressive achievement conditioned by the availability of resources. It says that States should undertake to take steps to the maximum of their available resources, "... with a view to achieving progressively the full realisation of the rights recognised in the present Covenant by all appropriate means, including, in particular, the adoption of legislative measures."

What does such a 'progressive realisation' mean? To what are States obliged when implementing the rights in the ICESCR? To what extent can States postpone their obligations by claiming, for example, lack of resources? An important interpretation of the provisions and obligations of the ICESCR is laid down in the 'Limburg Principles on the Implementation of the International Covenant on Economic, Social and Cultural Rights'. These Limburg Principles were the outcome of a conference of experts organised in Maastricht in 1986. ${ }^{76}$

73 Meyer-Bisch, 1993-A, pp. 29-30.

74 Kymlicka, 1995, pp. 9-10. Margalit and Halbertal agree that the State should abandon its neutrality "... to make it possible for members of minority groups to retain their identity". Margalit and Halbertal, 1994, p. 492.

75 ICESCR, article 2(1).

76 "The Limburg Principles on the Implementation of the International Covenant on Economic, Social and Cultural Rights", Human Rights Quarterly, Vol. 9 (1987), pp. 122-135, also published as UN Doc. $E / C N .4 / 1987 / 17$, See, further, one of the working papers of the Conference by Alston and 
The Limburg Principles were unanimously adopted and listed as an official UN document, but as the outcome of a Conference of experts they have no legallybinding character. Another important document concerning the interpretation of Article 2(1) ICESCR is the General Comment on Article 2 concerning the nature of State obligations adopted by the Committee on Economic, Social and Cultural Rights in $19900^{77}$ Many of the Limburg Principles are reflected in this General Comment. General Comments are also not legally-binding, but form an important source of interpretation.

In its General Comment on Article 2, the Committee stated inter alia that the obligation to take steps or measures as laid down in Article 2(1) has an immediate character. States should take steps "...within a reasonable, short period of time..." after the Covenant has entered into force. ${ }^{78}$ Furthermore, taking the appropriate measures implies not only legislative measures, but also administrative, financial, educational, social and other measures, including judicial remedies "... with respect to rights which may, in accordance with the national legal system, be considered justiciable." consider best to implement the material provisions of the ICESCR, whereby the Committee, as supervisory body, finally determines whether the State has, in fact, taken the appropriate measures. ${ }^{80}$

The Committee further states in its General Comment that the core of Article $2(1)$ is the duty to achieve progressively the full realisation of the rights. This duty to 'progressively realise' is closely related to the availability of financial and economic resources. According to the Committee, this phrase means that the States should start the implementation immediately and should move as fast as possible towards the end of total realisation. ${ }^{81}$ Consequently, Article 2 implies not only obligations of result, but also obligations of conduct. States should, regardless of their level of economic development, do the maximum possible to ensure the enjoyment of economic, social and cultural rights and should guarantee "...at the very least, minimum essential levels of each of the rights. ${ }^{982}$ This phrase points to the so-called 'core content' of rights, the essential minimum that States should always guarantee, regardless of the availability of resources or any other

Quinn, "The Nature and Scope of States Parties' Obligations under the International Covenant on Economic, Social and Cultural Rights", Human Rights Quarterly, Vol. 9 (1987), pp. 156-229.

77 UN Committee on Economic, Social and Cultura』 Rights, General Comment 3 on the nature of States parties' obligations (Art. 2, \$1 of the Covenant), fifth session, December 1990.

78 See General Comment No. 3, 1990, pp. $83-87, \$ 2$. The Limburg Principles use a stricter regime and lay down that States should take steps immediately; see the Limburg Principles, 1987, No. 16.

79 General Comment No, 3, 1990, \$ 5.

80 See General Comment No. 3, 1990, \& 4 and 7; Limburg Principles, 1987, no, 17, 18 and 20; Symonides, 2000-A, p. 206.

81 See General Comment No. 3, 1990, \& 9; Limburg Principles, 1987, no. 21; The Maastricht Guidelines, 1998 , guideline 8, p. 5 .

82 See General Comment No. 3, 1990, $\$ 10$ and 11; Limburg Principles, 1987, no. 25. 
difficulties. $^{83}$ The issue of core content is dealt with below. With regard to retrogressive measures, the burden of proof lies with the State. The Committee determined in its General Comment that:

"...any deliberately retrogressive measures... would require the most careful consideration and would need to be fully justified by reference to the totality of the rights provided for in the Covenant and in the context of the full use of the maximum of available resources."

Article 2(2) of the ICESCR contains a provision that obliges States to take measures to immediately ban de jure discrimination in the enjoyment of the rights in the Covenant. The idea of progressive realisation is not applicable here, since the term 'to ensure' is used. Forms of passive discrimination, for example, caused by a lack of resources, should be banned as soon as possible. According to the Limburg Principles, de facto discrimination cannot be removed by legislative measures alone. Consequently, positive measures are required that may make large demands on scarce resources. This guarantee of non-discrimination based on Article 2(2) implies a firm legal obligation that is immediately applicable and justiciable for a national court ${ }^{85}$ This non-discrimination principle may also have implications for the implementation of cultural rights. If, for example, the State finances a cultural institution for one community, it should also take financial measures for the benefit of other communities.

Article 4 ICESCR contains a possibility for States to limit the enjoyment of rights. This provision is, however, not absolute but conditional. The State may only subject the rights to limitations if these limitations are "...determined by law only in so far as this may be compatible with the nature of these rights and solely for the purpose of promoting the general welfare in a democratic society. clause is not meant to provide States with a simple excuse not to implement the provisions of the ICESCR. According to Alston and Quinn, Article 4 has a permissive as well as a protective purpose. The permissive purpose implies that States are allowed to impose limits on the enjoyment of rights, The protective purpose is intended to protect the rights in the Covenant by limiting the possibilities for limitation and by establishing criteria as to the way they may be imposed. ${ }^{87}$ This provision also suggests that it is not applicable to rights that have not yet been implemented. Furthermore, the limitations may not be in contradiction with the

83 Maastricht Guidelines, guideline 9, p. 5. See, on the notion of 'core content', inter alia, Arambulo, 1999, pp. 130-145; Alston, 1987, p. 353; Coomans, 1992, pp. 235-239; Toebes, 1999, pp. 276-281, 342 .

84 General Comment No. 3, 1990, \$ 9 .

85 Limburg Principles, no. 35-39; see, also, Coomans, 1992, p. 36 and General Comment No. 9 on the domestic application of the Covenant, Decenber 1998, $\$ 9$.

86. See Article 4 ICESCR.

87 Alston and Quinn, 1987, p. 193. 
nature of the rights in the Covenant, otherwise the provisions would no longer have value and content. ${ }^{88}$

According to the Limburg Principles, the "nature" of a right means the core or essential part of that right. Consequently, a State that wishes to limit the enjoyment of a certain right must prove that the limitation is in accordance with the nature of that right. With regard to the phrase 'promoting the general welfare', the Limburg Principles say that the general welfare means the well-being of the population as a whole. Finally, lack of financial or other resources does not fall under the limitation clause of Article 4 and is therefore not a sufficient ground for limitation. ${ }^{89}$

The scope of the limitation clause of Article 4 ICESCR remains unclear. According to Toebes, not much has been written about it and Article 4 has hardly been used in legal procedures. She argues that limitations seem to be allowed when the exercise of rights in the ICESCR would endanger or harm individuals or society. ${ }^{90}$ This idea is confirmed by Vlemminx, who has 'tested' several limitations and came to the conclusion that economic, social and cultural rights may be limited if their enjoyment harms others. As an example, he mentions inter alia Article 15 ICESCR on the right to take part in cultural life. This right may be limited if cultural activities include discriminatory expressions."

The issue of limiting cultural rights is difficult and too general to be answered in a simple way. The phrase 'for the general welfare' may be too broad, and therefore dangerous, if States abuse it to justify certain cutbacks. However, the unlimited exercise of cultural rights may seriously endanger the rights of others or of society. The question is how the State should be able to limit cultural rights without making it an excuse for not implementing cultural rights at all. Such an issue cannot be solved with one general answer, but depends on the circumstances and on the particular cultural right involved. ${ }^{92}$

Violations of economic, social and cultural rights have been examined by a group of experts, who have unanimously adopted the 'Maastricht Guidelines on Violations of Economic, Social and Cultural Rights." ${ }^{33}$ The Maastricht Guidelines were the result of a Conference held in Maastricht in 1997 on the occasion of the tenth amiversary of the Limburg Principles. The purpose of the Conference was to examine possibilities of identifying violations of economic, social and cultural

88 Alston and Quinn, 1987, pp. 193-194; Coomans, 1992, pp. 38-39.

89 Limburg Princlples no. 52,56. It clearly remains difficult to determine the true intentions of States. They may, for example, claim to have insufficient resources, while in fact they wish to limit the working of the ICESCR, which they will not likely admit.

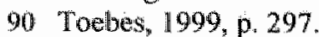

91 Vlemminx, 1994, p. 117. Article 15 ICESCR is dealt with in detail in Chapter 5. See, on the limitations of cultural rights, also section 2.5 of this chapter on what to do with illiberal cultural communities.

92 See Toebes, 1999, p. 298; Vlemminx, 1992, pp. 325-326; Vlemminx, 1994, pp. 117-119 and the travaux préparatoires, UN Doc. E/CN.4/SR.235, p. 6.

93 "Th. van Boven, C. Flinterman and I. Westendorp (eds.), "The Maastricht Guidelines on Violations of Economic, Social and Cultural Rights", SIM Special No. 20, SIM, Utrecht, 1998. 
rights. The so-called violations approach had been proposed earlier by Chapman as an alternative approach to monitor compliance with economic, social and cultural rights, since the notion of 'progressive realisation' turned out to be a hindering factor in the realisation of these rights. ${ }^{94}$ It was agreed that the violations approach in relation to economic, social and cultural rights is essentially the same as that in relation to civil and political rights. The term 'violation' can just as well be used in relation to economic, social and cultural rights, because of the undisputed interdependence and indivisibility of all human rights. ${ }^{9.5}$ The Guidelines formulate inter alia several factors that influence the determination of the meaning of violations of economic, social and cultural rights, such as the typology of obligations, the margin of discretion and the minimum core obligations."

The progressive realisation principle of Article 2 ICESCR applies only to cultural rights in the ICESCR. Cultural rights in the ICCPR and other relevant human rights instruments demand immediate steps to be taken by States, irrespective of the availability of resources. With regard to rights under the ICCPR that concern aspects of cultural identity, such as freedom of religion, expression, association and the right to education; less discussion takes place on the content and scope of these provisions. These provisions are generally not considered vague and programmatic, but should be guaranteed immediately. ${ }^{97}$ The corresponding State obligations can be positive as well as negative obligations. According to Article 2(1) ICCPR, each State Party should respect and ensure the rights of the ICCPR to all individuals, "...without distinction of any kind, such as race, colour, sex, language, religion, political or other opinion, national or social origin, property, birth or other status."

\subsubsection{State Obligations According to the Tripartite Typology: to Respect, Protect and Fulfil}

An important theory with regard to State obligations is the tripartite typology of State obligations, developed inter alia by Shue and Eide. This theory is not based on specific treaty provisions, but instead claims that three types of State obligations, namely, to respect, protect and fulfil, can in principle result from all human rights, whether civil, political, economic, social or cultural in nature. Eide emphasises that it is important to identify State obligations with regard to human rights in general and economic, social and cultural rights in particular. He argues that legal rights, in contradiction to, for example, moral rights, require a recourse procedure. In other words, legal rights should be justiciable. Human rights, however, form a special category of legal rights, since the individual as the subject of these rights does not always have the possibility of complaining in cases of violations of these rights.

94 Chapman, 1996, p. 24.

95 Mastricht Guidellines, 1998 , guidelines 4 and $5, p p, 2-3$.

96 Maastricht Guidelines, 1998, guidelines 14 and $15, \mathrm{pp} .7-8$.

97 Aricle 2 ICCPR and Symonides, $2000-A$, p. 207. 
Part of the problem, according to Eide, is the lack of precision concerning the State obligations "... without which it is difficult or near impossible to determine whether the right has been violated." Eide was one of the supporters of the so-called "tripartite typology" of State obligations. Many scholars have used this theory to clarify the content and scope of economic, social and cultural rights in particular.

The tripartite typology of State obligations means that there are three types of obligations: the obligation to respect; the obligation to protect and the obligation to fullfil. ${ }^{99}$ The basis for the tripartite typology was developed by Shue in his book "Basic Rights", in which he analyses the right to subsistence. ${ }^{100}$ Shue identified three types of basic rights: the right to liberty, for example, in the form of participation rights and freedom of physical movement, the right to security, meaning mainly physical security through the right not to be subjected to torture, murder, rape, assault, etc., and the right to subsistence, which are rights to a minimum of economic security. ${ }^{101}$ According to Shue, each of these rights implies various duties, negative as well as positive. These obligations are:

1. duties to avoid depriving, which means a negative obligation "...not to eliminate a person"s only available means of subsistence";

2. duties to protect from depriving, which means a positive obligation ".... to protect people against deprivation of the only available means of subsistence";

3. duties to aid the deprived, which also means a positive obligation "...to provide for the subsistence of those unable to provide for their own". ${ }^{10}$

Eide has developed this division of duties by applying Shue's theory on the right to food. ${ }^{10.3} \mathrm{He}$ rewrote the different obligations into the obligation to 'respect', to 'protect' and to 'fulfil'. The obligation to respect means that States should refrain

98. Eide, UN Doc. E/CN.4/Sub.2/1987/23, 1987, pp. 13-14, \$56-58, 63-64.

99 See, on the obligation theory, Ph. Alston and K. Tornaševski (eds.), The Right ro Food, Martinus Nijhoff Publishers/SIM, Utrecht, 1984, especially the contributions of Ph. Alston, H. Shue, G.J.H. van Hoof and $K$. Tomasevski, pp. 9-68, 83-95, 97-110 and 135-167 respectively, See, also, $A$. Eide, Food as a Human Right, UN University, Tokyo, 1984, pp. 249-260; A. Eide, Final Report of the Special Rapporteur on the Right to Food, UN Doc. E/CN.4/Sub.2/1987/23, 1987; The Limburg Principles on the Implementation of the International Covenant on Econoinic, Social and Cultural Rights, UN Doc. B/CN.4/1987/17, Th. van Boven, C. Flinternian and 1. Westendorp (eds.), The Maastridht Guidelines on Vialations of Economic, Social and Cultural Rights, SIM Special No. 20, SIM. Utrecht, 1998.

100 Shue, 1980

lai Shue, 1980, pp. 21-23, 71-87. See, also, Toebes, 1999, p. 307.

102 Shue, 1980, pp. 53,55 . See, also, Toebes, 1999, p. 308.

103 In 1983, the ECOSOC mandated the Sub-Commission on Prevention of Discrimination and Protection of Minorities to carry out a study on the right to food (ECOSOC Res. 1983/140,20 May 1983). The Sub-Commission appointed one of its members, Eide, as Special Rapporteur on this subject. In various reports on the right to food, Eide refined the tripartite typology. Eide published two interin reports: UN Doc. E/Sub.2/1983/25 and E/CN.4/Sub.2/1984/22. The final report was published as UN Doc. E/CN.4/Sub.2/1987/23, 1987 
from *... anything that violates the integrity of the individual or infringes on his or her freedom, including the freedom to use the material resources available to that individual in the way he or she finds best to satisfy the basic needs." 104 "The obligation to protect means that the State should take the necessary measures "...to prevent other individuals or groups from violating the integrity, freedom of action, or other human rights of the individual - including the prevention of infringement of the enjoyment of his material resources." 105 The obligation to fulfil means that the State should take measures "...to ensure for each person within its jurisdiction has opportunities to obtain satisfaction of those needs, recognised in the human rights instruments, which cannot be secured by personal efforts." 106 .

One can say that Eide has generalised the theory of Shue. While Shue focused on the rights to subsistence Eide made the tripartite typology applicable to all human rights, whether civil, political, economic, social or cultural. Consequently, this typology contributes to the unity of all categories of human rights. It shows that each separate right involves one or more of these types of obligations, no matter which category it belongs to. The tripartite typology shows that a certain right can require State abstention as well as State action, regardless of whether it is a social right or a classic freedom right. ${ }^{107}$

Other scholars have tried to extend and refine the tripartite typology of State obligations. Eide himself has, in later publications, added the obligation 'to assist" to the obligation to fulfil. In so doing, he responded to Shue's criticism that the obligation to fulfil, which replaced his 'duty to aid', went too far beyond the duties to respect and protect. The duty to aid was meant to redress former failures in the obligation to respect and protect, but the obligation to fulfil went further. Eide argued that the obligation to assist could, in the case of the right to food, entail, for example, the duty to take measures for the improvement of the production, conservation and distribution of food. 108

Van Hoof also refined the tripartite typology by dividing the obligation to fulfil into the obligation 'to ensure' and the obligation 'to promote'. The obligation to ensure concerns a result obligation and means that States should actively create conditions for the realisation of the recognised rights and freedoms. The obligation to promote has the same purpose, but refers instead to more vaguely described future goals and requires States progressively to achieve these long-term ends. ${ }^{109}$ Vlemminx has examined and developed this distinction in various Dutch publications. He argues that, unlike the obligation to promote, the obligation to ensure concerns measures that can easily be taken and at short notice.

104 Eide, UN Doc. E/CN 4/Sub.2/1987/23, $1987,867$.

105 Eide, UN Doc. E/CN.4/Sub.2/1987/23, 1987, \$68; see, also, The Maastricht Guidelines, 1998 , guideline 6, p. 4 .

॥06 Eide, UN Doc. E/CN $4 / 5$ ub.2/1987/23, $1987, \$ 69$.

107 Van Hoof, 1984, p. 107; Coomans, 1992, p. 32.

108 See Shue, 1984, p. 86; Eide 2001-A, p. 22.

109 See Van Hoof, 1984, p. 106. 
Consequently, these obligations have immediate effect and lend themselves to justiciability. ${ }^{110}$

The tripartite typology to respect, protect and fulfil is most commonly used at international level ${ }^{111}$ and it is also used in this study. The extra duties suggested by others do not add much to the three obligations described by Eide. The obligation to promote, for example, seems to be focused on the future, including the reference to progressively achieving, which recalls the confusing obligations described in Artiele 2(1) ICESCR. The obligation to fulfil does not mean that all measures should be taken immediately; moreover, it does not deny that the implementation of certain rights takes time and can be done gradually. ${ }^{112}$ The tripartite typology is a functional way of clarifying State obligations in relation to human rights. Especially in relation to economic, social and cultural rights, it demonstrates that States do not just have positive obligations which include financial implications. States may also have the negative duty to respect and to refrain from action, which does not have financial consequences. Furthermore, the typology has gained international recognition and can be found in many scholarly publications. Given this character and authority, the tripartite typology is used to clarify the content and scope of cultural rights in general, and a right to cultural identity in particular.

\subsubsection{The Core Content of Human Rights}

As stated above economic, social and cultural rights are often described in a programmatic way, requiring States to take measures. However, the obligations are usually vague and open-ended, which leaves it unclear how and to what extent these rights should be realised. The principle of "progressive realisation" to the maximum of available State resources adds to the obscurity. The definition of a 'core content' of a right can make clear what States should immediately realise, irrespective of their available resources. The ICESCR Committee refers to core content in its General Comment on Article 2(1) ICESCR, in which it states that States have, regardless of their level of economic development, a "...minimum core obligation..." to guarantee at least the "...minimum essential levels..." of economic, social and cultural rights. ${ }^{113}$ Furthermore, the issue of core content is closely related to the limitation clauses included in, for example, Article 4 ICESCR and other human rights instruments. In this provision, it was indicated that limitations may not be in violation of the nature or essential part of the right involved.

110 Vlemminx, 1994, p. 126; Vlemminx, 1998, pp. $72-76$.

111 See, inter alia, Coomans, 1992, pp. 233-235; Craven, 1995, pp. 109-114; Hunt, 1996, pp. 130-133;

Toebes, 1999, pp. 311-338.

112 See Coomans, 1992 , p. 32.

113 See General Comment No, 3, 1990, $\$ 10$ and 11; Limburg Principles, 1987, no. 25. 
The issue of core content was addressed by the Committee on Economic, Social and Cultural Rights in 1987, when the Rapporteur of the Committee, Alston, stated that "...each right must give rise to a minimum entitlement, in the absence of which a state party is in violation of its obligations." inserted the concept of core content in its General Comment on Article 2, scholars and the ICESCR Committee have tried to define the core content of specific human rights provisions. ${ }^{115}$ To what extent can a core content of a right to cultural identity be identified?

It should be noted that the concept of core content should be dealt with carefully. Whereas the concept of core content may be interesting from an academic point of view, politically it can be dangerous. Identifying the core content of a right brings the risk that the remainder of the right is considered unimportant and therefore to be denied. It should be made clear that States should also take measures concerning the aspects that are not part of the core content. The core content is a minimum that States should guarantee, but they are obliged to do as much as possible to do more than just the minimum. In this respect I agree with Toebes, who argues that ".... [r]ealising the core content of rights is not sufficient, and States should strive to realise the full spectrum of rights. $" 16$

\subsubsection{The Possible State Obligations and Core Content of a Right to Cultural Identity}

It is impossible to apply the tripartite typology as such to the general category of cultural rights as a whole, as it is impossible to formulate obligations in relation to the other general categories of human rights. It is only applicable to specific human rights provisions. Several cultural human rights, such as Article 15 ICESCR and Article 27 ICCPR are dealt with in detail in the following chapters, where attention is allso paid to the corresponding State obligations. It is further impossible to define a core content of cultural rights as a category of human rights, because it includes different rights with a different core content. Meyer-Bisch has tried to clarify the intangible core of these rights, in other words, the minimum guarantees that should be provided by States. They include respect for the cultural dimension of other human rights, such as the right to food or the right to information, respect for the identity of the subject, including respect for the freedom to participate in cultural activities, respect for cultural expressions and linguistic rights, and the recognition

114 Alston, 1987, p. 353; see also Resolution 1993/14 of the Commission on Human Rights on economic, social and cultural rights, $\$ 7$.

115 See, inter alia, Coomans, 1992 on the core content of the right to education; Toebes 1999 , pp. 281 . 283 on the core content of the right to health. The ICESCR. Committee has used the concept of core content and core obligations in several General Comments: see General Comment no. 3 (1990) on the Nature of State Parties Obligations, $\$ 10$; General Comment No. 12 (1999) on The Right to Adequate Food, \& 8; General Comment No. 13 (1999) on the Right to Education, 57; General Comment no. 14 (2000) on the Right to the Highest Attainable Standard of Health, $43-45$.

116 Toebes, 1999, p. 276. 
of cultural communities: ${ }^{117}$ These guarantees, which mainly involve State abstention and respect, are not very concrete and do not truly concern the core of these rights that States should always respect.

What would be the State obligations of a right to cultural identity? Margalit and Halbertal identify three levels of, what they call, the right to culture, which are comparable to the tripartite typology of the obligation to respect, protect and fulfil.

\begin{abstract}
"The first one is the right to maintain a comprehensive way of life within the larger society without interference, and with only the limitation of the harm principle. The second level includes the first and adds the right to recognition of the community's way of life by the general society. The third level includes both the previous levels and adds the right to support for the way of life from the State's institutions so that the culture can flourish.,
\end{abstract}

In a comparable way, one could approach the possible development of a right to cultural identity. The obligation to respect would entail that the State should not interfere with the free development and enjoyment of cultural identities by individuals or communities. The obligation to protect would imply that States have to protect individuals and communities from interference by third parties in the free enjoyment of the right to cultural identity. For example, the State must ensure that certain cultural expressions of one community do not harm the cultural identity of other communities. One can further think of protecting the land of cultural communities from being exploited by large companies. The obligation to fulfil could mean that States have a duty to provide the means and take the measures necessary for individuals and communities to develop and enjoy their cultural identity, for example, through the adoption of legislation. The question is whether these means would also include financial resources to be provided by States, something that would probably be hard to accept for many of them. Another matter is that these obligations with regard to a right to cultural identity are rather general, because the term cultural identity is an umbrella concept. It raises the question whether a right to cultural identity also implies obligations in relation to the various aspects of cultural identity, such as language, religion, land etc. This would make the matter more complicated and gives a right to cultural identity a rather extended content and scope. The issue of core content can accordingly hardly be solved. It cannot be generally argued which specific aspects of cultural identity belong to the core content of a right to cultural identity. The core content cant relate to language, religion, or other cultural aspects, or to more than one, which will also depend on the context and community involved. In short, the concrete elaboration of core content and State obligations with regard to a right to cultural identity is hard to make and will mainly come down to the protection of aspects of cultural identity whereby cultural identity is used as a general value. 
Perhaps the existing cultural rights provisions and the provisions on cultural identity discussed in the next chapters provide more clarity on these matters.

In conclusion, cultural rights are a complex category of human rights, overlapping other categories. The above has shown that a distinction should be made between cultural rights as a general category of human rights, the list of cultural rights in a broad or narrow sense, and the right to culture or cultural identity as examples of cultural rights. A right to cultural identity is especially complicated, because it can as such be considered a principle or a cultural right containing or underlying subrights in the field of culture, such as linguistic rights, religious rights and land rights. The general nature of a right to cultural identity makes it hard to determine specific State obligations and a core content. Another important aspect of cultural rights in general, and of a right to cultural identity in particular, is their individual and collective dimension. It has justly been argued that cultural rights are in between individual human rights and collective (human) rights, but to what extent is the collective dimension of cultural identity one that can only be protected by a collective right?

\section{Collectrve (HumaN) Rights}

An important issue with regard to the development of a right to cultural identity is whether this right should be an individual right or a collective right for a community as such. In the previous chapter, attention was paid to the ideas of several non-legal scholars concerning collective rights. This section addresses collective rights from a legal perspective and, inter alia, analyses the background of collective rights. Furthermore, the subject of collective rights is dealt with as well as the issue of possible conflict between collective rights and individual rights.

Before examining specific matters concerning collective rights, it is worth mentioning that several collective rights have already been recognised in international law. These are: the right to physical existence; corresponding to the prohibition of genocide, the right of self-determination, as laid down in Article I(1) of the ICCPR and the ICESCR, and the right to use natural resources, as laid down in Article 1(2) of the ICCPR and the ICESCR, in Article 47 of the ICCPR and Article 25 of the ICESCR. While these rights are legally assigned to 'peoples', there is no legal definition of what constitutes a people, and the content and scope of these rights are unclear. ${ }^{19}$ The question, therefore, is not whether collective rights for communities as such exist, because they do, but whether they should exist, whether new collective rights should be developed and whether a right to cultural identity should be one of these new collective rights.

119 Dinstein, 1976, pp. 105-110. See, on the right of self-determination, Henrard, 2000. 


\subsection{Background of Collective Rights}

Karl Vasak, former Director of the Division of Human Rights and Peace of UNESCO, started the debate on collective rights by arguing that human rights could be divided into three generations. The first generation contained civil and political rights, the classic freedom rights, which were based on State-abstention and laid down, inter alia, in the ICCPR. The second generation consisted of economic, social and cultural rights, also called 'rights of credit', requiring an active role of the State and laid down, inter alia, in the ICESCR. According to Vasak, a third generation of human rights should be added in the form of collective rights that were based on fratemity and solidarity. These rights were required to overcome inequalities in the world that made the enjoyment of the first two categories more difficult. Vasak mentioned the following rights as examples of the third generation of human rights: the right to development, the right to environment, the right to peace, the right to co-ownership to the common heritage of mankind, and the right to communicate. ${ }^{120}$

Supporters of collective human rights generally argue that the individualistic approach of human rights based on the principles of equality and non-discrimination no longer meets the present global issues concerning development and environment, and the needs of communities. They emphasise that the codification of human rights has focused too much on an individualistic outlook of the world and of human nature. They assert that communities are an important factor in realising a valuable life for individuals. Consequently, these communities should be protected by collective rights.

Vasak's division of human rights into 'generations' has been criticised. ${ }^{121}$ The term 'generation' is considered to be confusing, since it suggests that one generation precedes and replaces the other, while, in fact, all three generations are meant to mutually strengthen each other. Furthermore, the strict division itself between the different generations of freedom rights, such as civil and political rights, and rights demanding an active State policy, such as economic, social and cultural rights, is considered to be unconvincing. As stated above, civil and political rights may also demand State action, while economic, social and cultural rights can require non-interference by the State. ${ }^{122}$ The strict division between individual rights and collective rights has also been disputed, since many individual rights have a collective dimension, for example, the right to freedom of association and the right to education. Furthermore, there are rights that are conferred upon individuals, but which can procedurally be asserted by a collective agent.

120 Vasak, 1984, pp. 839-840. See, also, Marks, 1981, pp. 435-452.

121 See, for example, Donnelly, 1989, pp. 144-145; Baehr, 1996-A, pp. 8-9; Flinterman, 1990, pp. 7576; Kooijmans, 1990, pp. 316-317; Advisory Committee on Human Rights and Foreign Policy, 1995, pp. 3-4.

122 See, inter alia, Van Hoof, 1984, p. 107. 
Communities or organisations can bring a claim to defend the rights of individuals. This is called a 'class action' or 'collective action". 123

Galenkamp has made a useful distinction between individual rights, "imperfect" collective rights and 'perfect' collective rights. Individual rights are rights assigned to individuals that have an individual character, for example, the right to equal treatment. Imperfect collective rights are rights assigned to individuals, but which have a clear collective dimension, for example, the right to freedom of association. Perfect collective rights are rights assigned to the community as such to protect a collective interest, for example, the right of selfdetermination and the right to preserve one's eultural identity. ${ }^{124}$ In this study, collective rights are those rights that belong to the category of "perfect" collective rights: the community as such is the subject of collective rights and the object is a collective interest.

The debate on collective rights has, in fact, turned from the solidarity rights of Vasak to the rights of communities, such as minorities and indigenous peoples. While Vasak aimed at world-wide problems, such as the development and protection of the environment, which could only be solved by collective solidarity, the term 'collective' is now used to refer to the rights of certain communities. Galenkamp again makes a valuable distinction between three approaches to collective rights. The 'globalist' approach refers to collective rights as a response to global problems to be solved by international co-operation, for example, the right to a clean environment. The subject of these rights is the world community at large. The 'Third Worldist' approach relates to root causes of human rights violations, expressed in, for example, the right to development. The subjects of these rights are Third World countries. The 'rights of communities' approach concerns rights for special communities, such as minorities and indigenous peoples, for example, the right to preserve one's cultural identity. Galenkamp considers only the last approach to reflect real' collective rights. ${ }^{125}$

The main source of debate concerning collective rights is the subject of these rights. The central questions are which communities could be eligible to be the subject of collective rights and how these communities should be identified and defined. The Advisory Committee on Human Rights and Foreign Policy of the Dutch Ministry of Foreign Affairs (AIV) agrees with Galenkamp in its report on collective rights that the world community and States cannot be possible subjects of collective rights. It argues that the world community at large, or "mankind", would be too broad and undetermined to be the subject of collective rights. States, in general, would also not be proper rights subjects, since they could not principally be the bearers of rights. States are the addressees of rights; human rights are meant to protect human

123 See, for a short overview of collective actions or class actions in international law, Galenkamp, 1995, pp. 80-92.

24 Galenkamp, 1996, p. 206, see, also, Chapter 5 of Galenkamp, 1998.

125 Galenkamp, 1998, pp. 21-25; Galenkamp, 1991, p. 291; Galenkamp, 1995, p. 70. 
beings against the State. The Committee, furthermore, asserts that peoples, minorities and indigenous peoples could, in principle, be subjects of collective rights, although none of these communities have been legally defined. Criteria, in this sense, could be a non-forced membership of communities, participation rights for the members of communities and a justifiable representation of the members. ${ }^{26}$

Other authors agree that the only possible subjects of collective rights are minorities and indigenous peoples. These communities might need collective rights, especially related to the protection of their cultural identity. ${ }^{127}$ Several authors and institutions have tried to develop criteria to develop collective rights. According to the Dutch Advisory Committee on Human Rights and Foreign Policy, the recognition of collective rights depends on the question of whether collective rights could add something to the protection of human dignity that is already offered by existing human rights. It formulated six criteria for collective rights:

- there should be an object, material or immaterial, which cannot be considered other than as concerning a whole community or people;

- there should be a subject in the sense of a collectivity that is more than the sum of the members;

- there should be an addressee against which or whom the right can be invoked;

- the claim should be of fundamental value for human dignity;

- the claim should not be possible at an individual level;

- the claim should strengthen the promotion and protection of individual human rights and, in any case, not diminish recognised human rights; in cases of conflict between the human rights of the individual and the claims of a collectivity to which the individual belongs, in principle, the rights of the individual prevail. ${ }^{128}$

Galenkamp formulated three conditions for collective rights: collective rights need a non-reducible collective agent, of a constitutive kind, which has a distinctive group identity. A non-reducible agent means that the rights are ascribed to a collectivity as such which cannot be reduced to the sum of its members, such as in the case of the freedom of association, and which does not apply to individuals as members of a community, such as in the case of the freedom of religion. Such a colleetivity should have a collective interest or a collective identity which needs to be protected by collective rights. And it should have a certain internal structure which leads to a representative body that could legitimately speak on behalf of the

126 Advisory Committee on Human Rights and Foreign Policy , 1995, pp. 6-8. See, also, Kooijmans, 1990, pp. 325-326.

127 See, for example, the contributions of Donnelly, Galenkamp, Kymlicka, Habermas; see, also, Berting, 1990. Severall international instruments on the rights of minorities and indigenous peoples, including collective rights, have been adopted. They are dealt with in more detail in Chapters VII and Vill of this book.

128 Advisory Committee on Human Rights and Foreign Policy "1995, p. 5. 
whole community. Subjects of this kind are, for example, indigenous peoples and minorities. ${ }^{129}$

It seems that these criteria are hard to be met. Kooijmans, rightly, does not have "a very hopeful attitude" with regard to collective rights. He formulated three criteria for "new' human rights in general, and collective rights in particular: there should be a rights holder, an objective claim, and a duty bearer who must honour the claim. ${ }^{130}$ These criteria are, according to Kooijmans, not easily met in relation to collective rights. The rights holder should be a community that can clearly be identified and distinguished, which is not easy to achieve. The object or claim is also unclear. To what is one entitled in applying, for example, the right to peace or the right to development? Kooijmans concludes that "[t]he aspirations underlying the concept of the third generation human rights are absolutely legitimate, but they cannot be fulfilled by the creation of a new category of human rights." 31

\subsection{Supporters and Opponents of Collective Human Rights}

The idea of collective human rights has further raised questions concerning the position of the individual in relation to the community, and the relation between individual rights and collective rights. Various arguments can be distinguished concerning the question whether or not collective rights can in fact be called human rights, used both ways by supporters and opponents of collective human rights. These arguments of a historical, theoretical, practical, political and subjective nature are briefly as follows. ${ }^{132}$

The historical argument against collective human rights has been that human rights stem from natural rights that were meant to defend the individual against the State. Protecting collectivities does not fall within the individual nature of human rights. Others argue, however, that the natural rights theory was not entirely alien to collective rights and that these rights could fit in into the category of human rights.

The theoretical argument against collective human rights has been that human rights are those rights that human beings possess simply because they are human beings, based on the protection of human dignity and individual freedom. This is in contradiction to the idea of collective rights, which are rights of communities. On the other hand, the supporters of collective human rights state that not only individual freedom, but also solidarity could be a basis for human rights. Individuals do not live in isolation, but need communities to give their life value. Human rights are supposed to protect goods that are essential to human dignity, and these goods may as well have a collective nature, for example, cultural identity.

129 Galenkamp, 1991, pp. 296-299, Gallenkamp, 1995, p. 72 .

130 Kooijmans, 1990 , p. 323.

131 Kooijmans, 1990 , p. 327.

132 See, for a more extensive summary of these arguments, Bachr and Vander Wal, 1990, pp. 35-37 and furthermore Part II of Berting, 1990, pp. 33-107; see, also, Galenkamp, 1995, pp. 65-68. 
There is, furthermore, a practical argument against collective human rights. It has been stated that collective rights may lead to the neglect or even violation of individual rights. Opponents of collective rights have argued that the development and promotion of collective rights could diminish the attention for the existing categories of individual human rights. On the other hand, it was argued that there may also be mutual tension between individual rights. The fact that there may be tension between individual and collective rights should not be the primary reason to ban collective rights from the human rights discourse. Moreover, supporters argue that individual and collective rights do actually depend on each other.

Finally, the political argument against collective rights is that collective rights may be politically abused by oppressive regimes that wish to justify disrespect of individual human rights while suppressing individual criticism. Advocates of collective rights maintain that, in principle, all human rights can be abused and that, in fact, the inclusion of collective rights might attract non-western regimes to the human rights notion. They argue that the concept of human rights is not static and that it can be open to the inclusion of a new category of collective human rights. If new developments demand protection of human dignity through the development of collective rights, these rights can be part of human rights. ${ }^{133}$

One of the main critics of collective human rights is Donnelly, who relies on several of the arguments set out above. Firstly, he uses the theoretical argument by arguing that human rights are rights that one simply has because of being human as they are derivations of the inherent dignity of the human person. ${ }^{134} \mathrm{He}$ further argues that the notion of solidarity cannot be the source of human rights, because solidarity is based on a relationship among persons and communities, and confers benefits on the basis of membership of these communities. Donnelly finally claims that collective rights are not necessary, since they mainly reflect the lack of respect for individual human rights. "Collective human rights provide little new leverage in the struggle for human dignity." 135

Several authors also express concerns on the practical argument concerning the possible tension between colleetive rights and individual rights. Such tension concerns the alleged primacy of collective identity over individual identity and the corresponding choice between collective and individual rights. Human rights, by definition, give priority to individuals and their claims over communities. What should be done if the exercise of individual rights threatens the community? As Niec formulated:

133 Baehr and Vander Wal, 1990, pp. 34-37. See, also, Berting, 1990, pp. 33-107; Galenkamp, 1995, pp. 65-68; Doninelly, 1989, pp. 144-145; Flinterman, 1990, pp. 77-79; Kooijmans, 1990, pp. 316317; Advisory Conmittee on Human Rights and Foreign Policy, 1995, pp. 3-4.

134 Donnelly quotes this from the preamble of the International Covenant on Civil and Political Rights and the International Covenant on Economic, Social and Cultural Rights, 1966.

135 Donnelly, 1989, pp. 144-145; Donnelly, 1990, pp. 42-43, 48-49 (quote). 
"... is it the individual who has the right to declare that aspects of the group's cultural identity are a violation of their human rights, or is it the group that has the right to maintain its practices and rituals in the name of cultural identity? ? $^{2136}$.

Donnelly firmly argues that individual human rights should be given priority. "So long as the group is eroded or transformed by the free exercise of the human rights of its members, such an outcome is likely to be morally and politically acceptable, and often even desirable." ${ }^{3}$ ? I agree with this idea, based on the fact that communities are composed of their members, being individuals. The community should only be able to survive if its members value it sufficiently to be able to survive. Since the community derives its existence from the members it is composed of, possible collective rights cannot prevail over the individual rights of the members. ${ }^{38}$ The alternative would be to impose a cultural identity on individuals, even if they reject, deny or try to change it. In my view, identities may not be imposed on other persons or communities, not even on successive generations. While some form of organisation is necessary to make the community a totality, the community needs the support of (the majority of) its members, or else one can speak of forced membership or dictatorship including the denial of human rights. As Donnelly argues "[t]here is a real loss when a community dies out, but if its members freely choose another way of life, that is a loss that we must be prepared to accept." ${ }^{, 139}$

The above does not mean that communities may never have rights. In fact, there are many communities, such as families, corporations, ethnic and religious communities that may have rights. Furthermore, the rejection of collective human rights does not mean that individuals do not have an important link with communities. As argued earlier, community membership is an important source for individual identity. Communities based on, for example, family, religion, race and gender are important to the forming of the identity of individuals. Consequently, individuals do not enjoy their individual rights in total isolation, but also as community members. I agree with Donnelly as he points out that many individual human rights specifically protect the individual as a member of a community, for example, through non-discrimination on the basis of membership. They also protect the community as such in an indirect manner, for example, through freedom of speech, religion and association. But this does not mean that these are rights for the community as such. ${ }^{140}$

$136 \mathrm{Niec}, 1997$, p. 4 and Miec, 1998-A, p. 178.

137 Donnelly, 1989 , p. 151 ; Donnelly, 1990, p. 51.

$138 \mathrm{Kymlicka}$ also argues that communities may have collective rights as external protection against the majority, but may never impose internal restrictions upon its members. See Chapter III, Section 2.4.

139 Donnelly, 1989, p. 151; Donnelly, 1990, p. 51; Donnelly, 2001, p. 38. See, also, Leuprecht, who argues that "... 1" homme prime le groupe". Leuprecht, 1993, p. 78.

140 Donnelly, 1989, pp. 150-151; Donnelly, 1990, pp. 43-44, 49-50; Donnelly, 2001, pp. 3.8-39. 
In short, communities undoubtedly play an important role in the well-being of the individual. As such, the community or the protection of collective interests can be part of the sphere of human dignity. However, collective rights for communities as such raise serious issues especially in relation to individual human rights. It should therefore be argued that collective rights may not diminish individual rights and that, in principle, individual rights prevail.

\subsection{A Collective Right to Cultural Identity}

Cultural rights in general, and the right to cultural identity in particular, have a special position in the discussion on collective rights. While most individual human rights in principle refer to individuals separate from their communities, cultural rights refer directly to individuals as members of communities. Cultural rights protect the individual within the cultural community against the State or other communities and can also protect a cultural community as such. As Donnelly states:

"Cultural rights protect those essential aspects of personal dignity that are based on membership in a cultural community, much as political and economic rights protect those aspects that rest on membership in political and economic communities. ${ }^{, 141}$

The issues set out above concerning collective rights are directly relevant in relation to a potential collective right to cultural identity. For example, the relationship between the individual and the community has specific significance for a right to cultural identity. The cultural identity of a community is made, developed and changed by the members of the community. But, whose cultural identity is supposed to be protected by the right to cultural identity, that of the individual or that of the community? If a right to cultural identity is supposed to protect the cultural identity of the individual as part of human dignity, an individual right would be a logic choice. The cultural identity of the community as such could be protected by a collective right. In between an individual right and a collective right lies the option of an individual right with a collective dimension.

It is clear that a right to cultural identity has an individual and a collective dimension. Margalit and Halbertal, for example, conclude that the right to culture seems, in principle, only available to a community and not to individuals. They argue that individual human beings have a right to their own culture. However, the concept of culture involved in this right concerns the broad concept of a full way of life, which only exists in a community. Consequently, Margalit and Halbertal see a paradox. While individuals have a right to culture, the content of culture as the way of life can only be attributed to a community, which accordingly are more appropriate subjects of a right to culture. ${ }^{142}$ These communities should, however, meet certain criteria, especially in the numerical sense. Margalit and Halbertal

141 Donnelly, 1989, p. 156; Donnelly, 1990, p. 56.

142 Margalit and Halbertal, 1994, pp. 491, 497-499. 
conclude that " $[1] \mathrm{n}$ order to demand its right to a culture that constitutes a sufficient reason for obligating others, a group must pass some numerical threshold of rightbearers.":143

Donnelly is one of the main opponents of a collective right to cultural identity. He argues that:

\begin{abstract}
"Group identities...are not now, and I think ought not become, subjects of international human rights protection. Only individual autonomy gives rise, and value, to the sorts of identities that must be respected by others. Any particular identity is entitled to protection only because it is an expression of the right and values of those who carry it."14:
\end{abstract}

Galenkamp has extensively dealt with the collective right to preserve one's cultural identity in her book "Individualism versus Collectivism". In this volume, she regards the right to preserve one's cultural identity as the most perfect and paradigmatic collective right in the theoretical sense. It can meet the three conditions formulated above: collective rights need a non-reducible collective agent, of a constitutive kind, which have a distinctive group identity. ${ }^{145}$

However, Galenkamp recognises no less than six 'dilemma's" with regard to the collective right to preserve one's cultural identity that cannot be solved at theoretical level and remain problematic in practice. ${ }^{146}$ These dilemmas, to some extent, reflect the earlier mentioned difficulties with regard to collective rights. They are briefly the following:

The first is the dilemma of difference, which concerns the question of whether or not to emphasise differences and distinctions without qualification. Such an emphasis on difference may lead to stigmatisation and exclusion. The second dilemma concerns the choice between considering the individual as an individual human being or as a member of a community. A collective right to cultural identity could have the effect of 'locking up' individuals within their community and culture. The third dilemma relates to communal integrity versus individual autonomy. Focusing on community rights may imply moral conservatism; a preservation of things without a critical reflection. Besides which, who decides what the cultural identity of a community consists of? What should be done with the imposing of traditional values upon individual members who no longer share these values? The fourth dilemma is that of the possible conflict between the values of a traditional culture and universal human rights. What if the recognition of a collective right to cultural identity is at odds with the individual human rights protection of members of these communities? Dilemma five relates to the 'us and them' principle. By clustering communities, emphasis is laid on the difference between the persons who are members of the community and those who are not.

143 Margalit and Halbertal, 1994, pp. 500-501.

144 Donnelly, 2001, p. 36.

145 Galenkamp, 1998 , p. 119 ; see, also, Chapter 7 of ther volume.

146 Galenkamp, 1998, Chapter 7 and 8. 
Internal solidarity may thereby increase, but the external solidarity and tolerance among communities may diminish. The sixth dilemma is the dilemma of modernity. To what extent can the positive aspects of modernity, such as integration of mankind, and the liberation and emaneipation of individuals from oppressive ties to family, tribe and State, balance the costs of modernity in the sense of the loss of integrative communities and feelings of alienation. Is the collective right to cultural identity possibly based on a too narrow and static view of cultures? ${ }^{147}$

To partly overcome these dilemmas, Galenkamp sums up two minimum guarantees that have to be met for the collective right to preserve one"s cultural identity. She argues, first of all, that the rights of sub-groups within a community should be guaranteed and respected. Furthermore, cultural traditions or activities should have the full consent of the individual members of the community. Galenkamp realises that the question remains how to establish 'the full consent' of the members, which can only be expressed by a representative group. In addition, how can it be determined whether such a group is truly representative? ${ }^{148}$

Galenkamp has become more critical of collective rights and the collective right to cultural identity in the postscript in the second edition of her book. She expresses increasing doubts about the desirability and possibility of special collective rights. Firstly, she argues that the content and subject of the collective right to cultural identity are generally unclear. Secondly, she doubts that collective rights would be the best way of solving minority problems. In fact, she does not see what collective rights would add to the existing human rights.

"To me, it is unclear why respect for the cultural identity of ethmic minority groups requires anything other than the ascription of quite familiar civil and political rights such as freedom of religion." 49

I agree with Galenkamp that a collective right to cultural identity raises many issues that can hardly be solved. While the collective aspect of cultural identity is clear, the debate on a collective right to cultural identity is complex and shows many problems, which were also identified in the previous chapter. While the demand for a collective right to cultural identity might be justifiable from a social perspective, it remains problematic from a legal point of view. Its symbolic function is clear in the sense of recognition of the community as such and the protection of the interests of the community, which can also be relevant to individual dignity and development. However, the issues regarding the definition of the subject, the position of the individual within the community and the possible abuse are not easy to solve. Furthermore, the question of what such a collective right could add to existing individual human rights remains.

147 Galenkamp, 1998, pp. 136-146; Galenkamp, 1995, pp. 75-76.

148 Galenkamp, 1995, pp. 77-78. Kymlicka and others have also dealt with the issue of illiberal cultural practices and internal restrictions. See section 2.4 and 2.5 of Chapter III.

149 Galenkamp, 1998, pp. 192-193. 


\section{Concluding Remarks on Cultural Rigitts and Collective Rights}

The development of a right to cultural identity has been part of two debates within the human rights discourse on cultural rights and collective rights. Cultural rights form one of the categories of human rights. The fact that they have been neglected by States and scholars is the result of the vagueness of the concept of culture, the fear of States that cultural rights may encourage tension within society, and because the corresponding (financial) obligations of States are unclear.

The category of cultural rights was developed under the ICESCR, but as has been shown above, many other rights including some in the ICCPR can also be considered to be cultural rights. It depends on which definition of 'culture' is used, a narrow definition of culture in the sense of arts, literature and the accessibility of culture, or a broad definition of culture as a process whereby, for example, language, religion and education play a role. The narrow group of cultural rights consists of rights explicitly referring to the term culture, while the broad group of cultural rights contains not only the aforementioned rights but also all other human rights that concern aspects of culture. A right to cultural identity would fit into both groups, since it directly relates to culture and includes different aspects according to its broad description and process character. Because of its broad scope, a right to cultural identity can actually be considered to be one of the central cultural rights. I agree with the Fribourg Group that cultural identity can be considered the common object or substance of all cultural rights and that non-respect for cultural identity is a violation of the integrity of the human being. As such, a right to cultural identity refers to, or includes, many other cultural rights, such as linguistic rights, religious rights and land rights. Furthermore, a right to cultural identity has an individual and a collective dimension.

Attention was also paid to the different levels of recognition of rights. The above has shown that cultural identity is a value that deserves protection as an important element of human dignity. As a principle, it has been recognised in soft law or non-binding declarations, which are examined in the next chapters. As such, it has political value and States have to adopt policies in the field of the protection and promotion of cultural identity, although these are not legally binding. The question remains as to what extent it is desirable and necessary to develop a right to cultural identity in the form of hard law or a legally enforceable right. The concept of cultural identity is broad and complex, which makes State obligations unclear and can lead to a misuse of such a right. State obligations lie more in the sphere of aspects of cultural identity, such as language and religion, which leads to the question of what a right to cultural identity could add to existing human rights provisions.

In general, it has been argued that cultural rights demand negative as well as positive obligations. Specific State obligations depend on the particular provision involved. Cultural rights provisions that have been included in treaties or other human rights instruments follow the obligations theory of that instrument. Treaties 
are, for example, legally-binding upon States, while declarations are not. The tripartite typology of State obligations is a useful tool to determine concrete State obligations with regard to specific human rights provisions. The State obligations relating to a right to cultural identity are of a broad nature and include positive as well as negative obligations. It seems that the protection of a general right to cultural identity also implies rights in the field of the various aspects of cultural identity, such as language, religion and land. This again leads to the question of what existing human rights provisions already offer in this respect, and whether specific rights in these fields would provide more clarity than a general right to cultural identity. Several authors did, in fact, propose to focus on the development of the cultural dimension of all human rights, by which cultural rights would automatically receive more attention. I consider this an interesting way of promoting cultural rights. Instead of developing new rights, such as a right to cultural identity, a concept such as cultural identity could be "read into" the existing human rights, whereby cultural identity could serve as an underlying principle. This idea is further elaborated in the next chapters.

One of the reasons for developing a right to cultural identity was that the existing human rights provisions had an individualistic background that was in contradiction with the collective nature of cultural identity. A collective right to cultural identity would have to be developed. Generally, however, collective rights have been disputed by many authors. The main problems relate to the subject of collective rights and to the position of the individual in relation to the community. The subject should be a community as such, but it is almost impossible to define these communities. Furthermore, collective rights may imply that the members of the communities are limited in their enjoyment of individual rights. A collective right to cultural identity, which is meant to preserve the cultural identity of a community as such, may imply that individuals belonging to that community have less opportunity to develop their own cultural identity. I therefore support the idea of the Dutch Advisory Committee on Human Rights that collective rights should only be developed if they add something to existing human rights and that, in principle, individual rights precede over collective rights. Otherwise, collective rights risk a diminution of the protection of individuals provided by human rights.

The collective right to cultural identity offers similar problems to collective rights in general. These difficulties might detract attention from the fact that a serious claim underlies the right itself, namely, the lack of protection and possibilities of developing the cultural identity of communities and individuals. The central question is what the right to cultural identity is supposed to protect: the cultural identity of individuals as part of their human dignity, or the cultural identity of the community? Both approaches can be found in international human rights instruments, as will be shown in the following chapters. Most provisions in relation to cultural identity are individual rights, although they have a collective dimension and sometimes include direct references to the community. Such a solution is not 
uncommon within the human rights discourse, since many human rights have a collective aspect, whether it is specifically emphasised or not. ${ }^{150}$ This collective dimension is, in fact, indispensable to emphasise the collective nature of cultural identity, and an individual right to cultural identity should always refer to the collective dimension. Some soft law or draft provisions include "perfect' collective rights and a collective right to cultural identity, but, as will become clear, the communities they concern are not defined. In fact, the collective nature of several provisions is the reason that States have not (yet) adopted these provisions. ${ }^{151}$

From the above, I conclude that a collective right to cultural identity should not be developed. An individual right to cultural identity already poses difficulties concerning its content and State obligations, and a collective right would pose even more. Apart from the definition of the subject, the general content of a collective cultural identity is hard to define, also because it depends on the level of the community, for example national, regional, religious, linguistic etc. Furthermore, the arguments of 'locking up' individuals in a collective cultural identity, the suppression of individual freedoms by the collective protection of cultural identity, and the representation of individuals in the decision-making on what the cultural identity of the community is, are decisive. Finally, it is doubtful that a collective right to cultural identity would add extra protection compared to a possible individual right to cultural identity, apart from a symbolic recognition of the importance of communities for individuals. Thus, a right to cultural identity should, in principle, be developed as an individual right with a collective dimension.

150 Compare, for example, Articles 18,21 and 22 ICCPR on the right to freedom of religion; peaceful assembly and association and Article 13 ICESCR on the right to education, which are provisions with an obvious collective dimension that is not specifically mentioned, with Article 27 ICCPR on the right of members of a minority to enjoy, in community with the other members of their group, their own culture, etc.

151. See, for example, the negotiations on the Draft Declaration on Rights of Indigenous Peoples, Chapter VIII. See, also, the failed attempt to draft an Additional Protocol to the ECHR on Rights in the Cultural Field, discussed in Chapter X. 


\section{Chapter V UNESCO AND A RIGHT TO CULTURAL IDENTITY}

\section{INTRODUCTION}

In the previous chapters, the concept of cultural identity was clarified from a social and political science perspective and was placed in a human rights framework. As shown in these chapters, a right to cultural identity evokes several issues with regard to the object or content, the subject, the addressee and corresponding obligations of this right. The next chapters focus on different cultural rights provisions in international and regional human rights instruments. Some of these provisions explicitly refer to cultural identity, while others relate to it indirectly. The question is how the problems raised above have been dealt with in these specific provisions.

One of the main international organisations active in the field of cultural human rights is the United Nations Educational, Scientific and Cultural Organisation (UNESCO). UNESCO has developed a considerable system of human rights instruments, and instruments in the field of the protection of culture in general, cultural products such as arts and cultural heritage, and cultural producers such as artists and writers. It should be noted that, in this chapter, the focus lies on the broad meaning of cultural identity as a process; the work of UNESCO in the field of the protection of cultural products or the rights of cultural creators and artists is not addressed.'

Most of UNESCO's instruments have the form of recommendations or declarations and, as such, are not legally-binding upon the Member States. Generally speaking; most of the work of UNESCO does not lie in the field of preparing legally-binding instruments, but in the field of the development of concepts and the attunement of policies. In the previous chapters, a distinction was made in this respect between cultural identity as a moral value, as a political value

1 Instruments in these fields are, for example: the Agreement on the Importance of Educational, Scientific and Cultural Materials (Florence Agreement, 1950); the Convention for the Protection of Cultural Property in the Event of Armed Conflict (The Hague Convention) and its Protocol (1954); the Convention on the Means of Prohibiting and Preventing the Illicit Import, Export and Transfer of Ownership of Cultural Property (1970); the Convention Concerning the Protection of the World Cultural and Natural Heritage (1972); UNIDROIT Convention on Stolen or Illegally Exported Cultural Objects (1995); the Convention on the Exchange of Official Publications (1958); the Universal Copyright Convention (1952 and revised in 1971); the Recommendation on the Status of Scientific Researchers (1974); the Recommendation on the Status of the Artist (1980); the Recommendation on the Safeguarding of Traditional Culture and Folklore (1989). These instruments are not discussed in detail, since they do not include a right to cultural identity and other cultural rights in the sense of human rights. 
implying State policies, and as a legal value implying State obligations. The work of UNESCO takes place mainlly at the first two levels.

The general question in this chapter is how the concept of cultural identity has been used within the context of UNESCO with regard to its human rights instruments, its studies and conferences. First the role of UNESCO in the field of the promotion of human rights is dealt with. Subsequently, several UNESCO instruments that refer directly or indirectly to the protection of cultural identity are analysed, including the social and legal background of these instruments, and the content of their provisions on cultural identity. In addition, several large conferences organised by UNESCO on cultural rights and cultural policies, during which the concepts of culture and cultural identity were discussed, are dealt with. Another relevant development is the presentation of the study 'Our Creative Diversity' by the Commission on Culture and Development in 1996, which also concerned concepts such as culture, cultural identity, human rights and cultural rights. A final relevant development within UNESCO is the adoption of the Declaration on Cultural Diversity in 2001, in which the Member States confirm the value of cultural diversity and the promotion and protection of cultural rights.

\section{ThE UNESCO ORGaNISATION AND ITS INVOLVEMENT IN HUMAN RIGHTS}

UNESCO has three main organs: the General Conference, the Executive Board and the Secretariat. The General Conference consists of the representatives of the Member States and determines the general policy line of UNESCO. Every Member State has one vote. In principle, it meets every two years, but, if the agenda so demands, it can assemble every year. ${ }^{2}$ The Executive Board is elected by the General Conference and consists of $58 \mathrm{Member}$ States. ${ }^{3}$ The Executive Board meets twice a year and prepares the agenda of the General Conference. It is further responsible for the execution of the work programme and the budget adopted by the General Conference, and it can make recommendations to the General Conference. ${ }^{4}$ The Secretariat is headed by the Director-General, who participates in the General Conference without a vote. He prepares annual reports on the activities of the organisation and makes proposals for activities to the General Conference and the Executive Board. ${ }^{5}$

2 See UNESCO Constitution Article IV.

3 The Executive Board used to consist of independent experts. In 1954, the Gieneral Conference decided, at the proposal of the United Kingdom and the United States, to abolish the independence of the menibers of the Executive Board. They still had to be experts in the field of UNESCO's mandate, but they would no longer speak on personal title, but on behalf of their State. In 1995, at the proposal of Japan, the General Conference decided at its 25 th session (28 C/Resolutions) that the Executive Board would consist of 58 government representatives, although these still have to be experts in (one of) the fields of competence of UNESCO.

4 See UNESCO Constitution Article V.

5 See UNESCO Constitution Article VII. 


\subsection{UNESCO and Human Rights}

UNESCO was set up in November 1945 as an autonomous UN organisation or specialised agency under Article 57 of the UN Charter. It is not funded out of the regular UN budget, but, instead, the Member States pay separate contributions to UNESCO. Its main purpose is described in Article 1 of its Constitution:

"...to contribute to peace and security by promoting collaboration among nations through education, science and culture in order to further universal respect for justice, for the rule of law and for the human rights and fundamental freedoms... without distinction of race, sex, language or religion..."

One of the tasks of UNESCO is the promotion and protection of human rights within its sphere of competence. These rights include the right to education (Article 26 UDHR and Article 13, 14 ICESCR), the right to participate freely in cultural life and share in scientific advancement (Article 27 UDHR and Article 15 ICESCR), and the right to information, including freediom of opinion and expression (Article 19 UDHR, Article 19 ICCPR). ${ }^{7}$ To fulfil this task, UNESCO carries out studies, issues publications and organises seminars and conferences where scholars, politicians and other interested persons discuss the subjects within the mandate of UNESCO. The Member States of UNESCO can, according to Article IV(4) of its Constitution, adopt conventions, which are binding upon the Member States, and recommendations, which are not legally binding, but do have a legal effect in that they should be implemented by States. The possibility of adopting declarations and other, non-binding, instruments was added later by an amendment of the General Conference at its seventh session in $1952 .^{8}$ Apart from these instruments adopted by the General Conference, international conferences under the auspices of UNESCO can adopt conventions, treaties, agreements, recommendations, or declarations.

Symonides, former Director of the Human Rights Division of UNESCO, has argued that, although cultural rights are not specifically mentioned in the Constitution, the preparation of normative instruments in the field of culture is one of the main tasks of UNESCO. ${ }^{9}$ UNESCO has contributed to the definition of cultural rights in terms of the rights of creators and transmitters of culture, the rights of the people at large to contribute to and participate in cultural life, and the right of peoples to cultural identity. This development started with the adoption of the Declaration of Principles of International Cultural Co-operation in 1966 and has led to the adoption of many other instruments. The protection or development of cultural identity can also be found in some of these instruments. ${ }^{10}$

6 UNESCO Constitution, Article 1.

7 Marks, 1977, p. 42; Coomans, 1999, p. 221.

8 See UNESCO Constitution Article IV(2), (3) and (5).

9 Symonides, 1993, p. 48 .

10 Marks, 1977 , p. 50. 


\subsection{Standard Setting Process}

In general, the standard setting procedure within UNESCO is as follows: first, the Director-General, or any other person invited to do so, prepares a preliminary study of the technical and legal aspects of the question involved. This study is submitted to the Executive Board for prior consideration. The Executive Board can put the proposal for an international regulation on the agenda of the General Conference. The General Conference decides on the desirability of the regulation and on the form that it should take, e.g., a convention, a recommendation, or a declaration. The Director-General is then instructed to prepare a preliminary report including an outline of the problem and the possible action of regulation. The Member States are invited to present their comments and observations, on the basis of which the Director-General prepares a final report. This final report is submitted to the General Conference, or if the Conference so decides, to a committee of experts. The General Conference finally considers the draft texts submitted and adopts the instrument. Recommendations are adopted by a simple majority, while a two-thirds majority is required for the adoption of conventions. ${ }^{\text {I }}$

The implementation and monitoring mechanism of UNESCO consists of a reporting procedure, described in Article VIII of the Constitution, and a communication procedure adopted by decision 3.3 of the Executive Board in 1978 . The reporting procedure implies that Member States must periodically submit a report on the action taken in the field of the instruments adopted by UNESCO. ${ }^{12}$ The Committee on Conventions and Recommendations (CCR), a permanent subsidiary body of the Executive Board, examines these reports. The CCR is composed of 30 representatives of the members of the Executive Board. The CCR considers the reports without a dialogue with the Member States. The CCR drafts a report on its findings to the Executive Board, which sends it with its comments to the General Conference.

According to the communication procedure every individual, group or nongovernmental organisation having reliable knowledge of a violation of human rights within UNESCO's sphere of competence can submit a so-called 'communication' to UNESCO. It is, however, determined that UNESCO should not play the role of an international judicial body. The main characteristic of the procedure is that the CCR enters into a dialogue with the parties involved and tries to reach a friendly settlement. The whole procedure is confidential. ${ }^{13}$ In general it can be argued that UNESCO's monitoring procedure is rather weak. It lays another burden on the Member States, which often copy reports sent in for the UN human rights treaties.

11 See Article IV(4) of UNESCO's Constitution and the Rules of Procedure concerning Recommendations to Member States and International Conventions covered by the terms of Article IV(4) of the Constitution, $\$ 12$. Both can be found on hitp:/www unesco.org/general/eng/legal/index.shtml.

12 See Part VI of the Rules of Procedure of the General Conference.

13 UNESCO Doc. 104/EX/3.3, 1978. See, on both procedures, Marks, 1995, pp. 620-625; Coomans, 1999, pp. 224-229; Symonides, 1993, pp. 66-67. 
The reports are considered by the CCR without a dialogue with the Member States. The complaint procedure is not well-used because of lack of knowledge of the procedure and lack of confidence in it. Moreover, all results of the procedure are confidential, and there is no accountability to the world community with regard to the work of the CCR, since its members are no independent experts but State representatives. ${ }^{14}$ in this study, the State report procedure alone will be touched upon only as far as it offers further clarification of the concepts and provisions in UNESCO instruments. ${ }^{15}$

\section{UNESCO INSTRUMENTS}

The four most important UNESCO instruments that have a link with a right to cultural identity are the Declaration of the Principles of International Cultural Cooperation (1966), the Recommendation on Participation by the People at Large in Cultural Life and their Contribution to It (1976), the Declaration on Race and Racial Prejudice (1978) and the Declaration on Cultural Diversity (2001).

\subsection{Declaration of the Principles of International Cultural Co-operation}

In November 1966, at the twentieth anniversary of the foundation of UNESCO, the General Conference adopted the Declaration of the Principles of International Cultural Co-operation. According to the Preamble, the idea behind the Declaration is the fact that ignorance of the life, customs and culture of communities is considered to be an obstacle to friendship among nations and to peaceful cooperation. International cultural co-operation could contribute to a better understanding and, consequently, to peace. The Declaration mainly deals with international co-operation in the field of culture, which only has an indirect link with a right to cultural identity of communities and individuals, and does not include an explicit reference to cultural identity. However, the equality of cultures and the value of cultural differences, important elements in relation to a right to cultural identity, were confirmed inter alia in the first article of the Declaration. This provision has become a well-known line within UNESCO and elsewhere in relation to the protection of culture and cultural rights. In Article 1, it is stated that:

"1. Each culture has a dignity and value which must be respected and preserved.

2. Every people has the right and the duty to develop its culture.

3. In their rich variety and diversity, and in the reciprocal influences they exert on one another, all cultures form part of the common heritage belonging to all mankind."

14 Marks, 1995, pp. 624-625. See, also, Coomans, 1999, pp. 228-229.

15 The Communication procedure is confidential and thus is not used here. 
The first paragraph shows the importance that the Mernber States attach to culture as a value that must be preserved and respected. The second paragraph contains a collective right and duty to develop culture. The implications of this right and duty were not further clarified and no definition or clarification was given to concepts such as people and culture. As such, the Declaration is not legally-binding, but does have a moral and political force.

\title{
3.2 Recommendation on Participation by the People at Large in Cultural Life and their Contribution to It
}

At its nineteenth session in November 1976, the General Conference adopted the Recommendation on Participation by the People at Large in Cultural Life and their Contribution to It. The Recommendation emphasises the broad meaning of culture, including not only cultural products and arts, but also the whole way of life of communities and individuals, including issues such as education and communication. The Recommendation was developed to give communities and individuals the opportunity not only to have access to culture, but also to participate actively in cultural life. This implied specific cultural policies that are integrated in other policies in the field of economics, social policy and education. The Recommendation further emphasises the special position of minorities in relation to the development and preservation of their own cultural identity.

\subsection{References to Cultural Identity in the Recommendation}

The recommendation includes various references to (cultural) identity, for example in the Preamble:

\begin{abstract}
"Considering that participation in cultural life takes the form of an assertion of identity, authenticity and dignity; that the integrity of identity is threatened by numerous causes of erosion stemming, in particular, from the prevalence of inappropriate models or of techniques which have not been fully mastered, considering that the assertion of cultural identity should not result in the formation of isolated groups, but should, on the contrary, go hand in hand with a mutual desire for wide and frequent contacts..."
\end{abstract}

The concept of cultural identity is now explicitly used in a UNESCO instrument. Although the wording of these phrases is somewhat vague, it shows the awareness of the importance of cultural identity as a value and policy principle. Furthermore, it emphasises the fact that the possibilities of participating in cultural life relate to the development and maintenance of cultural identity.

Another interesting provision is Article 4(f), in which Member States are recommended to: 
"...guarantee the recognition of the equality of cultures, including the cultures of national minorities and of foreign minorities if they exist, as forming part of the common heritage of all mankind, and ensure that they are promoted at all levels without discrimination; ensure that national minorities and foreign minorities have full opportanities for gaining access to and participating in the cultural life of the countries in which they find themselves in order to enrich it with their specific contributions, while safeguarding their right to preserve their cultural identity." (Italics added by author)

In this provision, the equality of cultures is the starting point. The provision further provides for State obligations to protect the right of national and foreign minorities to preserve their cultural identity. This is an interesting step. While the equality of cultures is emphasised, it is acknowledged that national and foreign minorities might be in a special position in wishing to preserve their own cultural identity. However, which communities are meant by "national and foreign minorities" is not explained in any of the drafting reports. In a comment by the UNESCO Secretariat, it is stated that foreign minorities include, firstly, workers employed abroad, but there is no final clarification. 16 also remains unclear what this general obligation entails in concrete terms, for example, in the field of legislation or policies.

The Recommendation also contains provisions on artists and creative work, on the mass media, and on the protection of cultural heritage and the environment. In one of the final articles on international co-operation, another reference is made to cultural identity. In Article 18(d), it is stated that Member States should develop cultural exchanges to promote "...an ever deeper appreciation of the values of each culture and, in particular, draw attention to the cultures of the developing countries as a mark of esteem for their cultural identity." With this provision, special attention is paid to former colonies and developing countries to emphasise that these countries have valuable cultural identities that are important for their self-esteem. ${ }^{17}$

\subsubsection{The Drafting Process of the Recommendation}

The adoption of the Recommendation was the result of a long process, which started in 1952 with the adoption by the General Conference of Resolution 4.52 . In this resolution, the General Conference authorised the Director-General to organise a meeting of experts on the "...practical application of man"s right "freely to participate in the cultural life of the community, to enjoy the arts...", in accordance with Article $27(1)$ of the Universal Declaration of Human Rights and in the light of

16 UNESCO Doc. SHCMD/31, Final Report, 11 March 1976, Annex II, p. 7.

17 See, for example, UNESCO Doc. SHC/MD/28, 22 August 1975, p. 6 \& 19 in which the DirectorGeneral in his preliminary teport argues that "[d]eveloping countries evince a resolve to be the masters of their own destiny and to strengthen the authenticity of their own culture, the basis upon which a nation asserts its identity, while also participating in the movement of world-wide progress."' See, also, p. $8, \& 28$ of this report. The Special Committee of Covernmental Experts has included this paragraph in order to stress the importance of cultural identity for colcnial peoples to gain freedom. See UNESCO Doc. 19 C/27, 6 August 1976, Annex 11, p. 7. 
any further development in the United Nations concerning this right." 18 This reference to developments within the UN concerned the preparation of the ICESCR adopted in 1966.

The Recommendation was prepared in two stages. The first stage followed after the resolution mentioned above and included a study of the right to participate in cultural life, which was the background document for a meeting of experts held in October 1952. ${ }^{19}$ The study contains various interesting issues, including, for example, the question of whether rights related to culture were suitable areas of international regulations, since these rights seemed very indefinite and variable. Another interesting question concerned the obligations in relation to the right to participate in cultural life. Furthermore, it was asked whether, apart from the creative minority, such as scholars and artists, the cultural activities of the masses should also play a role, such as folk arts, religion, music, etc. The study approached culture mainly in the sense of the arts and sciences. Culture was not yet considered a process in itself, including language, religion, education, etc. According to the study, "the right freely to participate" meant a freedom that went beyond the absence of prohibitions, but instead demanded practical State measures. Special attention should be given to minorities and non-self governing peoples, whose cultural needs might differ considerably from those of the national community. ${ }^{20}$

The Committee of Experts, meeting in October 1952, discussed the following issues: the concept of culture, the dissemination of culture, the role of the State, obstacles to participation by all in cultural life and the special problems of underdeveloped countries. Much attention was paid to the situation of minorities. It was argued that the State should respect the rights of minorities to enjoy their own culture and to the use of their traditional languages. Furthermore, all racial and linguistic minorities should be recognised as being equal. ${ }^{21}$ The experts preferred a broader interpretation of culture as "la vie de l'esprit", or a "...continuing creation at all stages and levels of human activity, varying in its expression according to its environment - ethnic, economic, geographical, social and historical..." 22 The Committee of Experts finally suggested the suspension of the work within UNESCO on an international regulation on the right to participate freely in cultural life until the work on the ICESCR was finished, and this was endorsed by the Executive Board. ${ }^{23}$

The second stage of the Recommendation started in 1972, with the first Intergovernmental Conference on Cultural Policies in Venice. ${ }^{24}$ In his opening

18 General Conference, 6th session, 1952, Resolution 4.52.

19 UNESCO/CUA/42, Programme of UNESCO for 1952 - Resolution 4.52 - Study of the "Right to Participate in Cultural Life" - Basic Document, Paris 2 May 1952.

20 UNESCO/CUA/42, 2 May 1952 , pp. 8-13, 15-23.

21 UNESCO Doc. 7C/PRG/10, 3 November 1952, pp. 10 and 14.

22 UNESCO Doc. $7 \mathrm{C} / \mathrm{PRG} / 10,3$ November 1952, pp. $3-8$ (quotations pp. 7 and 8 ).

23 UNESCO Doc. 7C/PRG/10, 3 November 1952, pp. 3-8.

24 The Conferences on Cultural Policies are separately dealt with in Section 4 of this chapter. 
statement to the Conference, the Director-General of UNESCO stated that, if everyone had the right to share in the cultural heritage and the cultural activities of the community, the State had a duty to provide the means for such participation. The concept of culture was widened to include not only arts and the system of knowledge, but also to embrace 'the individual's whole way of life'. The DirectorGeneral stated:

"The recognition of the right to culture as a human right marks the end of culture as an object and of culture for the elite, quite as much as of the laissez-faire abstentionist attitude of the State in cultural matters.".25

In June 1974, the Director-General started the process to adopt a UNESCO instrument by submitting a preliminary study on the technical and legal aspects of an international regulation concerning individual access to, and participation in, culture. In his prelliminary study, the Director-General confirmed the broadening of the concept of culture. He further argued that participation did not just mean access to culture, but active participation, including partnership and co-operation, at every level of cultural policy. Such participation was important to give people a sense of belonging to a certain culture, especially countries that had been under foreign cultural and political domination and wished to assert their cultural identity as the expression of their dignity. All this should go hand in hand "... with a recognition of cultural pluralism and the right of cultural minorities to express themselves. $\$ 26$ According to the Director-General, the main obstacles to participation in culture were the persistence of material inequality and the cultural domination of certain peoples over others. He proposed to adopt an international regulation on access to, and participation in, culture in the form of a recommendation, which would reflect the fact that the Member States have different cultural policies and different constitutional situations. ${ }^{27}$

Based on the preliminary study of the Director-General, the Executive Board, in its 94th session, decided to include this question on the provisional agenda of the 18 th session of the General Conference in $1974 .^{28}$ The General Conference decided that it was desirable to prepare an international recommendation on this issue. It set up a special committee of governmental experts to prepare a final draft. The recommendation was to be adopted at the 19 th session of the General Conference in October/November $1976^{29}$

The Director-General prepared a preliminary report on the issue, including a preliminary draft recommendation, largely based on his preliminary study as described above. The preliminary draft Recommendation of early 1976 was sent to

25 UNESCO Doc. SHCIEUROCULT/4, 30 March 1972, pp. 1-2.

26 UNESCO Doc. 94 EX/18, 1974, pp. 6-7.

27 UNESCO Doc. 94 EX/18, 1974, pp. 11 and 14.

28 UNESCO Doc. 94 EX/Decisions, 4.4.3.3, 1974.

29. UNESCO Doc. $18 \mathrm{C} /$ Resolutions 3.462, 1974. 
the Member States for comments and observations. Only 22 Member States out of a total of 135 responded to the request and shared their comments. These comments were analysed and a revised draft was included in the final document to be studied by the Conmittee of Governmental Experts: ${ }^{30}$

In their comments, several Member States expressed their general concern that this Recommendation would oblige them to adopt one uniform cultural policy, which, in their opinion, would be impossible considering the different social, economic and constitutional situations of States. A few Member States, including the United States and Italy, expressed doubts that access to, and participation in, culture could be regulated by an international instrument. Various Member States articulated their concern that a concept of culture that was too broad would be too vague to be included in an international instrument and could have unwanted implications for Member States. The Committee of Experts finally agreed that the Recommendation should be no more than a statement of basic principles or standards acceptable to all without entering into too much detail. ${ }^{32}$

Only a few Member States commented on the specific draft provisions on minorities and cultural identity and none of them involved the clarification of the concept of cultural identity. The comments of the Member States did not lead to major changes in the draft compared to the preliminary draft. It seemed that most Member States did not seriously participate in the work on the Recommendation until the negotiations started in the Committee of Governmental Experts. This Committee, composed of 117 experts representing the governments of $60 \mathrm{Member}$ States, extensively discussed the draft and made many changes. The final version of the committee was sent to the General Conference. ${ }^{34}$

In this final draft, the descriptions of access to culture, participation in cultural life and communication were finalised. Changes included, for example, the addition of a reference to respect for the sovereignty of Member States in the preamble. The definition of culture was changed from 'the whole way of life' to 'all forms of creativity and expression..." Access to culture was no longer provided for 'all groups and individuals', but instead for 'everyone', taking away the collective dimension. Later in the text, however, a reference is made to individuals and groups. ${ }^{35}$ Specific references to cultural rights and the right to culture were replaced by general references to human rights. The general term 'minority cultures' was replaced by "cultures of national and foreign minorities'. Finally, the cultures of developing countries were added to Article 18(d) "...as a mark of esteem for their cultural identity..." to emphasise the value of cultural identity for these developing

30 UNESCO Doo. SHC/MD/28, 1975, pp. 7-8, UNESCO Doc. SHC/MD/28, Paris, 1975, Annex III.

31 UNESCO Doc. SHC/MD/31, 1976; UNESCO Doc. 19 C/27, 1976, Annex II, p. 2.

32 UNESCO Doc. 19 C/27, 1976, Annex II, p. 3.

33 See the comments of Argentina, Italy, Japan and the United Kingdom at LNESCO Doc. SHC/MD/31, 1976, Annex I, pp. 2, 5 and 9.

34 Compare UNESCO Doc. SHC/MD/31, 1976, Annex III with UNESCO Doc. 19 C/27, 1976, annex II.

35 For example article 2(b) and (c), 3(a) and (d), and 6 (b). 
countries in gaining freedom from colonisation. ${ }^{36}$ The Recommendation was not unanimously adopted. Before the vote on the Recommendation, several dellegations expressed their objection to the terminology and meanings of the Recommendation as well as to its possible implication of State control over creativity. ${ }^{3 ?}$

Considering the content of the various drafts in relation to a right to culture or cultural identity, it is noteworthy that the text of the preamble on cultural identity had already been formulated in the preliminary draft and was not changed. The content of the final Article 4(f) on the equality of cultures and the protection of the cultural identity of minorities can also be found in the preliminary draft, although not in one specific article and not in exactly the same wording. ${ }^{38}$ The process of the drafting of the Recommendation also shows interesting points with regard to a possible right to cultural identity. Cultural identity was used mainly in the context of communities, especially those living under foreign domination for whom it was important to confirm their cultural identity in order to gain freedom. In the Recommendation, culture was approached from a broad perspective. The important message of the Recommendation was that culture was not merely a combination of cultural products, but also a process involving various aspects, which demanded coherent policies in the field of education, language, work, etc. The protection and promotion of culture also demanded not only that States provide the means for access to culture, but also that they grant the possibility of active participation in culture for as many people as possible. The Recommendation was supposed to provide principles, which were to be implemented by the Member States in their national policies and legislation.

\subsubsection{Implementation of the Recommendation}

As explained above, Member States are supposed to submit reports on the action taken upon the recommendations and conventions adopted by them. Accordingly, the Member States were asked to include the action taken in relation to the Recommendation on Participation by the People at Large in Cultural Life and their Contribution to it in their reports. In 1978, only fourteen States responded to this request: They all stated that they had submitted the Recommendation to their competent authorities, and some mentioned the fact that the Recommendation had been translated into their national language. Some States added information on actions taken in the general field of participation in cultural life. They asserted that

36 UNESCO Doc. $19 \mathrm{C} / 27$, Draft Recommendation on action to ensure that the people at large have free, democratic access to culture and participate actively in the cultural life of society, 6 August 1976.

37 These delegations were Belgium, Canada, the Federal Republic of Germany, France, Guatemala, Italy, Portugal, the United Kingdom and the United States. See Symonides, 1993, p. 71 .

38 See UNESCO Doc. SHC/MD/28, 1975, Annex, Preliminary Draft Recommendation on Action to Ensure that the People at Large have Free, Democratic Access to Culture and Participate Actively in the Cultural Life of the Society. 
most of these actions, mainly in the field of arts, museums and cultural festivals, had already been part of their legislation before the adoption of the Recommendation. No State specifically dealt with the process of culture, or with the protection of the cultural identity of specific communities. ${ }^{39}$

Almost ten years after the adoption of the Recommendation, UNESCO decided to evaluate its functioning. In 1985, UNESCO sent a questionnaire to the Member States concerning the circulation of the Recommendation to the competent national authorities, the legislative and other measures taken and their effect, and the problems in applying the Recommendation. Finally, Member States were asked whether they considered the Recommendation still up to date or whether they wished to propose certain changes. ${ }^{40}$ Only 23 Member States replied to the questionnaire. ${ }^{4}$ These States responded that they had circulated the Recommendation to official government organisations, and pointed to the various activities and policies that they had developed in relation to the Recommendation, and several States again argued they already had these policies before the Recommendation was adopted. The main problem deseribed was the financial burden upon States in relation to the Recommendation. Other problems mentioned were the lack of human resources and skilled personnel as well as the lack of technical means. Developing countries expressed their concern with regard to the link between the level of education and cultural participation, including the fact that people without a certain level of knowledge were often excluded from cultural activities. Finally, most States found the Recommendation still up to date after ten years, although they emphasised its ambitiousness and the fact that it was difficult to apply mainly because of its financial consequences. ${ }^{42}$

Only two States, the Federal Republic of Germany and Australia, paid attention to the protection of minority cultures as laid down in Article 4 of the Recommendation. These States referred respectively to specific programmes for foreign residents and to a multi-cultural arts programme and assistance to nonEnglish speaking cultures such as the aborigines. UNESCO argued that the lack of specific responses concerning minorities pointed to two problems: the lack of recognition of minority languages and cultures, and the lack of acceptance of the culture, expression and participation of immigrant communities. The report encouraged States to recognise the identity of these communities and to promote their integration, while preserving traditional forms of expression and languages. ${ }^{43}$

The fact that so few States responded to the questionnaire appears as a lack of interest in the Recommendation, although the report expressed the 'hope' that

39 UNESCO Doc, $20 \mathrm{C} / 26,1978$ and Add, 1,2 and 3, 1978.

40 UNESCO DOC. CC/CSP/CP/4, 1986, p. 2 .

41 These States were: Australia, Buhgria, Burundi, Chile, Congo, Cote d"Ivoire, Czechoslovakia, Cuba, Federal Republic of Germany, Finland, German Democratic Republic, Indonesia, Japan, Nepal, Peru, Rwanda, Spain, Sri Lanka, Sweden, Syrian Arab Republic, Thailand, Ukrainian Soviet Socialist Republic, and the Union of Soviet Socialist Republics.

42 UNESCO Doc. CC/CSP/CP/4, 1986, pp. 3-4 and 9.

43 UNESCO Doc. CC/CSP/CP/4, 1986, pp. 36-37. 
this was not the case. ${ }^{44}$ It could also have been caused by the above-mentioned increasing burden on States to report to the supervisory bodies of UN treaties and other organisations. Many States stated at the time of drafting that they already had cultural policies aimed at large scale participation in culture. However, the lack of responses does not help to clarify the concepts in the Recommendation.

\subsection{Declaration on Race and Racial Prejudice}

In 1978, the General Conference of UNESCO adopted the Declaration on Race and Racial Prejudice. This Declaration was meant to deseribe the background of differences between people, emphasising the value of these differences. It did not intend to give certain communities or individuals specific rights. The Declaration starts in Article 1(1) with the fact that all human beings come from a common stock. It continues in the second paragraph with the right of individuals and groups to be different. For the first time, this right was officially recognised in an international instrument. According to the Preamble, the right to be different concerns, inter alia, the right not to be excluded, humiliated, exploited or forcibly assimilated. $^{45}$

\subsubsection{References to Cultural Identity in the Declaration}

The Declaration contains several references to cultural identity. Article 1(3), for example, reads as follows:

"Identity of origin in no way affects the fact that human beings can and may live differently, nor does it preclude the existence of differences based on cultural, environmental and historical diversity, nor the right to maintain cultural identity."

This provision implies that identity of origin, the fact that human beings come from a common stock, does not affect the right to be different or the right to maintain cultural identity. The concepts used in this provision, such as identity of origin and cultural identity, are not further clarified. An earlier draft of the Declaration included an explanatory report, which clarified the content of several provisions. However, while adopting the final version of the Declaration, the explanatory report was removed, because it was considered to be unnecessary for a declaration which would not provide legal obligations. ${ }^{46}$ Although an explanatory report has no legally-binding force, it forms an important guide of interpretation. According to the draft explanatory report, Article 1(3) "...constitutes the assertion of cultural autonomy, an essential pre-requisite for the independence of peoples." The different

44 UNESCO DOC. CC/CSP/CP/4, 1986 , p. 39.

45 This phrase is in line with the theory on cultural differences developed by Margalit, as analysed in Chapter II of this book, who focuses on the negative recognition of cultural identity by preventing humiliating treatment, instead of developing a positive right to cultural identity. 
communities were supposed to decide on the development and expression of their cultures, thereby denouncing policies of forced assimilation of national, religious, linguistic, cultural and ethnic communities. ${ }^{47}$ It is worth noting that Article \|(3) of the Declaration does not have the 'classical' three-term structure of an object, a subject and an addressee. In particular, the subject and the addressee of this provision are not clear from the text.

Article $5(1)$ of the Declaration also explicitly refers to cultural identity:

\begin{abstract}
"Culture, as a product of all human beings and a common heritage of mankind, and education in its broadest sense, offer men and women increasingly effective means of adaptation, enabling them not only to affurm that they are born equal in dignity and rights, but also to recognise that they should respect the right of all groups to their own cultural idenity and the development of their distinctive cultural life within the national and international contexts, it being understood that it rests with each group to decide in complete freedom on the maintenance, and, if appropriate, the adaptation or enrichment of the values which it regards as essential to its identity."

(Italics added by author)
\end{abstract}

The central element in this provision is culture, as providing proof that human beings are equal and have the same rights. Besides, culture makes human beings realise that they should respect the right of groups to their own cultural identity. It is interesting to note that the right to cultural identity is given to "groups", which are not further specified. These groups should also have the freedom to determine which values of their identity they want to preserve, and to what extent they wish to join the common culture, as described in the second paragraph of the provision. The emphasis lies on the collective protection of cultural identity. ${ }^{48}$

According to the draft explanatory report, Article 5 would have farreaching consequences. It was, first of all, emphasised that the preservation of cultural values by different communities does not ipso facto constitute a threat to the State. Furthermore, the diversity of cultures should be officially recognised and all cuitures should receive financial support. The preservation of cultures should not, however, be imposed on any community. Since the explanatory report was not adopted in the end, it is hard to determine whether the Member States would accept such extensive consequences particularly in the financial field. Furthermore, the draft explanatory report asserts that "...the minorities have...the right to maintain those cultural values they consider important. ${ }^{, 49}$ The report suddenly switches to 'minorities', which are not further defined. Consequently, the question is whether minorities, instead of groups or communities in general, are the subjects of this provision. Since no other reference is made to minorities, this matter remains unclear.

47 UNESCO Doc. $20 \mathrm{C} / 18,1978$, Annex Explanatory report, \$ 5; see, also, Lerner, 1991, p. 157.

48 See, also, Lerner, 1991 , p. 158.

49 UNESCO Doc. SS-77/CONF.201/1, 1977, pp. 18-19; UNESCO Doc. 20 C/18 Annex, 1978, p. 4. 
Article 5 is also not formulated in the form of an object, subject and addressee. It is not directed towards the State; but towards people in general. Although in Article 6 of the Declaration it is laid down that the State has the prime responsibility for the promotion and protection of human rights, Article 5 aims for 'men and women' to respect each others' cultures. In this provision, there is a clear collective dimension. in stating that groups have the right to cultural identity and may decide on the devellopment and preservation of cultural values. However, because the object, subject and addressee were not clearly formulated, the content of the 'rights' in this provision remains vague. But, as stated above, the purpose of the Declaration was not to develop specific rights and obligations, but to serve as a background instrument.

In conclusion, the Declaration shows that, even in 1978 , a right to cultural identity had been formulated into an international instrument, although not so much as a right but as a principle or policy goal. The Declaration confirms that differences between people are worth preserving, for example, by the right to be different, which is closely related to a right to cultural identity. It further emphasises the need to protect the cultural identity and cultural development of communities against forced assimilation.

\subsection{The Drafting Process of the Declaration}

The process of adopting the Declaration on Race and Racial Prejudice started in the early fifties when UNESCO initiated research on issues related to race and culture. Scientists were invited to exchange views and draft statements on the explanation of differences between human beings in the light of race and racial prejudice. In the fifties and sixties, UNESCO issued four so-called 'statements on race' drafted by scholars to encourage the discussion within UNESCO on these matters. ${ }^{50}$ Their most important message was that there is no scientific evidence that differences in what people can achieve are based on differences in race. Differences between people are, instead, based on culture and on economic and social circumstances. Instead of eliminating differences between people, for example, by assimilating minorities, cultures should be able to exist next to each other. ${ }^{51}$

In 1973, on the occasion of the celebration of the 25th anniversary of the Universal Declaration of Human Rights (UDHR), the UN proclaimed the Decade for Action to Combat Racism and Racial Discrimination. UNESCO wanted to contribute to this Decade and considered it the right moment to complete the scientific work done in the field of race by a political statement or a declaration on race and racial prejudice. Although it was stated that such a declaration would not

50 Statement on Race (Paris, July 1950); Statement on the Nature of Race and Race Differences (Paris, June 1951); Proposals on the Biological Aspects of Race (Moscow, 18 August 1964); Statement on Race and Racial Prejudice (Paris, September 1967).

51 See, also, Marks, 1995, Lerner, 1991, p. 155. 
have legally-binding force, it could be an important signal if many Member States supported the declaration. The UNESCO declaration could be an addition to the UN Convention on the Elimination of Racial Discrimination in that this declaration would focus on the social, cultural and economic background of racial prejudice, and on the fact that differences between people should not lead to different treatment: $^{52}$

The importance of cultural identity was mentioned early in the process of drafting the Declaration. During a meeting of experts in 1972, it was emphasised that various communities struggled for identity, autonomy and liberation in the field of culture against the values, goals and ideologies imposed on them by others. It was acknowledged that it was important to ensure that different religious and ethnic communities within a State have the opportunity and the freedom to preserve their cultural identity, which could prevent these communities from striving for secession. The assertion of cultural identity, often stimulated by large independence movements, as was the case during decolonisation, created a sense of dignity. It brought people back to the roots of their culture, which is vested in a common history, religion and language. ${ }^{53}$

In 1974, the Director-General submitted a preliminary study on the legal and technical aspects of a draft Declaration on Race and Racial Prejudice, in which he advised the General Conference to prepare such a declaration. The General Conference approved this at its eighteenth session, and authorised the DirectorGeneral to establish a Committee of Governmental Experts to prepare a draft declaration. A preliminary draft was produced and, at its nineteenth session in 1976, the General Assembly invited the Director-General to prepare a new text based on the preliminary one. This draft, including an explanatory report, was submitted to the General Conference to be negotiated at its twentieth session in 1978. However, as mentioned above, the explanatory report was not adopted with the final version, since it was considered unnecessary in a declaration which would not provide legal obligations. ${ }^{54}$ The Declaration was finally adopted in November 1978 by consensus, without opposition. ${ }^{55}$

The Declaration is not legally-binding and does not clearly define rights and duties. It was meant to be a general statement of goals and a background document on race and racial prejudice. This was confirmed by the various follow-up reports of the Director-General of UNESCO, in which he evaluated the implementation of the Declaration. With regard to his first report on the world situation in the field covered by the Declaration in 1980 , only 26 Member States responded to the

52 See, inter alia, UNESCO Doc. 18 C/36, 1974, pp. 2-3; UNESCO Doc. SS-77/CONE.201/1, 1977, pp. $5-8$.

53 UNESCO Doc. SHC/MD/21, 1972, pp. 4-6.

54 UNESCO Doc. SS-77/CONF.201/1, 1977; UNESCO Doc. 20 C/18 Add., 1978, \&59, p. 10.

55 UNESCO Doc. 18 C/36, 1974; UNESCO Doc. SS-77/CONF.201/1, 1977; UNESCO Doc. SHC/MD/33, 1976; UNESCO Doc. 20 C/18, 1978 ; see, also, Lerner, 1991, pp. 155-156. 
Director-General's request for information. In 1987, the same number of Member States replied, in 1991 this number increased to 44 , but in 1995 the lowest number of 20 Member States replied to the request for information. ${ }^{56}$ The State responses were mainly of a general nature in which States reported that they were implementing the principles of the Declaration without providing information on legislative or other measures taken. Most States sent in a copy of their report to the CERD and did not pay any attention to the specific provisions in the Declaration. ${ }^{57}$ The right to cultural identity was not further clarified.

\section{UNESCO CONFERENCES ON CULTURAL POLICY}

Another relevant development within UNESCO with regard to cultural rights was the organisation of various Intergovernmental Conferences on Cultural Policies. After the first international conference in Venice in 1970, regional conferences took. place between 1972 and 1981. The results of the regional conferences were discussed at the World Conference on Cultural Policy in Mexico in 1982. During these conferences, much attention was paid to cultural rights and the right to cultural identity.

\subsection{Inter-governmental Conference on Institutional, Administrative and Financial Aspects of Cultural Policies in Venice}

As explained earlier, the World Conference on Cultural Policies in Venice, held from 24 August to 2 September in 1970 , was part of the developments concerning the adoption of the Recommendation on Participation by the People at large in Cultural Life and their Contribution to it. The main topics of discussion were the role of public authorities in defining and achieving cultural development; research on cultural policies; international cultural co-operation and the role of UNESCO in this field. It was agreed that cultural needs and activities required more than just a 'laissez-faire' policy. Although cultural problems did not always seem to be as pressing as, for example, health, education and welfare, States confirmed their responsibility to develop long-term policies in this field. ${ }^{58}$

The delegates discussed the definition of 'culture', without formulating conclusions on this issue. It was confirmed that the concept was understood differently in different parts of the world. All participants agreed that creative and performing arts fell within the definition, but some added that physical culture and the particular ways and customs in which a society and its members express themselves should also be taken into account. ${ }^{59}$

56 See UNESCO Doc. 21 C/78, 1980, UNESCO Doc. 24 C/14, 1987, UNESCO Doc. 26 C/104, 1991 and UNESCO Doc. $28 \mathrm{C} / 231995$.

57 See UNESCO Doc. $21 \mathrm{C} / 78,1980$, p. 7 and UNESCO Doc. $26 \mathrm{C} / 104,1991$, pp. 17-18.

58 UNESCO Doc. SHC/MD/13, 1970, pp. 9-10.

59. UNESCO Doc. SHC/MD/13, 1970, p. 10; see, also, UNESCO Doc. 16 C/84, 1970, p. 2. See, also, 
During the Conference, emphasis was laid on the equality and dignity of all cultures and the prohibition of cultural imperialism. No common standard could be developed that would be applicable to all States, since the machinery for cultural policies differed greatly. ${ }^{60}$ No explicit attention was paid to cultural identity or the protection of cultural rights. However, it was stated in the final report that "... in countries with several cultural, ethnic or linguistic communities...cultural autonomy is overwhelmingly accepted as a guiding principle." Such cultural autonomy is an important aspect of the protection of cultural identity. The Venice Conference adopted several recommendations which emphasised an integral approach to culture and cultural policies, including education, the rights of artists, museums and the media. Equality of cultures, mutual respect and co-operation between Member States were the guiding principles. No specific cultural rights for communities or individuals were adopted, although it was confirmed that "culture is an inalienable and indivisible human right..." that "...pervades all aspects of life.",652

\subsection{Regional Conferences on Cultural Policies}

The Regional Conferences on Cultural Policies were organised in Europe (Helsinki, 1972), Asia (Yogyakarta, 1973), Africa (Accra, 1975), Latin America and the Caribbean (Bogota, 1978), and Arabia (Baghdad, 1981). For this section, the General Reports and the Declarations and Recommendations of each Conference were examined, as well as the report of the Director-General to the General Conference which summarised the results of each Conference.

All Conferences focused on streamlining priorities and cultural policies, and on the exchange of information and co-operation among the participants. Cultural rights or a right to cultural identity were not specifically dealt with although the concepts were mentioned several times, especially during the regional conferences on Africa and Latin America. In the documents on the Conferences, no clear distinction is made between cultural policies and cultural rights. The concepts of culture and cultural identity were, for the most part, used as values implying the development of integrated policies in various cultural fields and not as legally enforceable rights. The outcome of the UNESCO Conferences focused on cultural identity as a moral and political value implying State policies, not translated into legal terms.

UNESCO Doc. SHC/EUROCULT/4, 1972, pp. 1-2.

60 UNESCO Doc. SHC/MD/13, 1970, pp. 11-12.

61 UNESCO Doc. SHC/MD/13, 1970, p. 12.

62 UNESCO Doc. SHC/MD/13, 1970, p. 15 (resolution 1) and p. 21 (resolution 11). 


\subsection{Regional Conference on Europe}

The first regional conference organised in Helsinki in $\$ 972$ dealt with cultural policies in Europe. The Conference confirmed the ideas formulated at the World Conference in Venice:

- Cultural development is an integral part of overall development and cultural policy cannot be considered apart from economic and social policy.

- The right to culture and consequently the responsibility of the State to develop cultural policies should be recognised.

- Culture should not be an élitist concept merely relating to arts and literature, but involves the participation of the whole population.

- Culture should be linked to education, communication, environment, cultural heritage, arts, and specific groups such as youth and women.

- Culture should be encouraged by international and regional co-operation. ${ }^{63}$

The Conference adopted various recommendations to encourage States to adopt cultural policies, including the promotion of cultural rights. Furthermore, the European States were encouraged to implement effectively the right to culture and the right to free access to the 'treasures' of national and universal culture for all members of society based on the principle of non-discrimination. The States should inter alia "...give legal backing to the right to culture in their constitutions..." The right to culture was explicitly recognised, albeit without clarifying its content and the corresponding State obligations.

Recommendation 27 of the Helsinki Conference specifically refers to national minorities. It is stated that national minorities play a role in the development of cultural co-operation. Nothing is said on the protection of the cultural identity of these national minorities. On the other hand, in Recommendation 28 , cultural identity is mentioned in relation to foreign minorities, which are communities which result from migratory movements. It is laid down in this recommendation that their "...right to preserve their original cultural identity must not deprive them of the right to take part in the cultural life of the community in which they live". 65

In short, concepts such as cultural and cultural identity were present and recognised as broad values or principles, without being specifically defined. Accordingly, cultural policies should incorporate the various aspects of cultural identity. It is worth noting that the steps taken in the direction of minorities concerned immigrants, not national or ethnic minorities. The focus lay on their integration, although they were to have a right to preserve their original cultural identity, albeit not as a separate legal right, but in terms of a policy goal to be implemented by States.

63 UNESCO Doc. SHC/MD/20, 1972, p. 8; UNESCO Doc. 17 C/70, 1972, pp. $1-2$.

64 UNESCO DOC. SHC/MD/20, 1972, pp. 22, $23,25$.

65 UNESCO Doc. SHCMD/20, 1972, p. 44. 


\subsection{Regional Conference on Asia}

During the Conference in Yogyakarta on cultural policies in Asia held in 1973, the eoncept of cultural identity obtained a prominent place. Firstly, the participants emphasised the role of the State in the promotion and development of culture in general. The participants specifically stressed the history of colonialism, which had encouraged the search for new cultural identities, and self-determination as important factors for cultural policies. It was argued, however, that the search for an individual cultural identity should always be combined with a receptive attitude towards other cultures. ${ }^{66}$

The Yogyakarta Conference Declaration emphasised that the objectives of cultural development included the reassertion of the dignity and identity of the individual. The right to preserve and develop culture was also confirmed in the first recommendation without formulating a subject. In the second recommendation, much attention was paid to colonialism as a threat to national cultures, although it was stated that, despite ideological domination, Asian States and peoples had succeeded in preserving their own culture. ${ }^{67}$ During the Conference in Asia, the emphasis was laid on the protection and development of national cultures, not the cultures of specific communities.

\subsubsection{Regional Conference on Africa}

During the Conference in Accra on cultural policies in Africa held in 1975, the assertion of cultural identity was one of the main topics addressed, mainly in relation to the past colonial oppression of African cultures. The assertion of cultural identity was considered to be an important means of liberation and independence, based on the recognition of the equality and dignity of all cultures. ${ }^{68}$

The assertion of cultural identity is also central in the Conference Declaration, as "a reality common to all the peoples of Africa". This was again confirmed in Recommendation 25 . The awareness of cultural identity was considered a basis for independence and the building of modern African nations. Culture was considered a broad concept, defined in the first recommendation as "... all the material, moral and spiritual assets, works of art, knowledge and knowhow, language, ways of thought, forms of behaviour and store of experience...." In Recommendation 26, it was stated that, in order to assert cultural identity, African States should focus on a selective acceptance of foreign influences, on educational, political and economic institutions and on international co-operation. ${ }^{69}$

The Conference on Africa emphasised the importance of the concept of cultural identity, especially in relation to liberation, as a weapon of independence

66 UNESCO Doc. SHC/MD/23, 1973, pp. 7-8; UNESCO Doc. 18 C/88, 1974, pp. 1-2.

67 UNESCO Doc. SHC/MD/23, 1973, pp. 18-20.

68 UNESCO Doc. SHCMD/25, 1975, pp. 7-8; UNESCO Doc. 19 C/107, 1976, pp. $2-4$.

69 UNESCO Doc. SHCMD/25, 1975, pp. 23, 25, 40, 42. 
after the period of colonisation. Cultural identity was not directly referred to as a right, but the assertion of the collective cultural identity, affirmed by language, education and co-operation was to be a central aspect of cultural policies.

\subsubsection{Regional Conference on Latin America and the Caribbean}

The fourth regional Conference took place in Bogota in 1978 and dealt with the cultural policies of Latin America and the Caribbean, in relation to the formation of a cultural identity in this region. Significant factors in this respect were the history of migration, the demographic movements from Europe, Africa and Asia, and the history of the indigenous peoples on the territory. The cultural identity of the region was the product of the mixture of indigenous, European, African and Asian cultures. The State was considered to be primarily responsible for the participation of the whole population in culture, although it was admitted that the relationship between the State and the development and protection of culture was complex. ${ }^{70}$

Cultural identity is referred to in the Declaration of Bogota as an important element of cultural development and the basis of the life of peoples. Cultural identity was considered to be dynamic and constantly renewing itself. The Bogota Declaration also contained a specific right to cultural identity: "....every people or group of peoples has both the right and the duty to determine independently its own cultural identity, based on its historical antecedents, its individual values and aspirations, and its sovereign will." ${ }^{71}$ In this case, cultural identity is approached from a collective perspective as a right as well as a duty. Cultural identity is also mentioned in several recommendations, especially in relation to the integration of indigenous peoples and immigrants in the region. For example, the first recommendation concerned the recognition, by States, that indigenous peoples should be integrated with absolute respect for their cultural identity. ${ }^{72}$

During the Bogota Conference, much attention was paid to cultural identity, which was not considered in terms of rights, except for the right to determine one's cultural identity, but as an important principle of cultural development. Cultural identity was in fact considered "... a source of inspiration for independence, sovereignty and nation building, as an instrument of harmonious economic and social development and as a pre-requisite for the strengthening of regional and international co-operation based on the right of peoples to selfdetermination and on the recognition of the equal dignity of all cultures." ${ }^{.73}$

70 UNESCO Doc. SHCMD/39, 1978, pp. 7, 8, 10, UNESCO Doc. 20 C/87, 1978, pp. 1-3.

71 UNESCO Doc. SHCMD/39, 1978, pp. 22-24.

72 UNESCO Doc. SHC/MD/39, 1978, pp. 26, $27,64$.

73 UNESCO Doc. $20 \mathrm{C} / 87,1978$, p. 1. 


\subsubsection{Regional Conference on Arab countries}

The regional conference on cultural policies in the Arab countries in Baghdad in 1981 was not organised or supported by UNESCO. ${ }^{74}$ Instead, it was organised by the Arab Educational, Cultural and Scientific Organisation (ALECSO). After the failure to organise a Conference on Cultural Policies similar to those in the other regions, ALECSO decided to put the issues on the agenda of the Conference of Arab Ministers of Cultural Affairs held in Baghdad in 1981.

During the Conference, the Arab countries emphasised their common background and the fact that they all belonged to one unique Arab cultural identity, with a unity of language, civilisation and a common heritage. The Arab language was considered to be the essence of the Arab identity and a condition for its preservation and survival. International co-operation should always be related to the preservation of this Arab culture. With regard to the right to culture, the Arab States asserted that culture belonged to all citizens as a right, which was just as important as political and social rights. However, cultural development was also an individual, collective and national duty. Much attention was also paid to liberation from colonial rule and to anti-Zionist sentiments in the Arab countries. The recommendations, too, reflect a strong anti-Zionist and anti-colonialist attitude. ${ }^{75}$ It was this last emphasis, in particular, which caused the report not to be adopted or supported by UNESCO.

From the above, it should be concluded that all the regional conferences show increasing interest in the concept of cultural identity. The assertion of cultural identity is mainly brought up in relation to colonial rule or other foreign domination. This confirms that cultural identity, as described earlier, is encouraged in situations of oppression or subordination. Other elements described earlier, such as the dynamic character of cultural identity and its individual and collective dimension were also present. In several conferences, attention was paid to the preservation and development of cultural identity of not only the nation, but also of specific peoples and communities. The focus of the conferences was to develop cultural policies whereby such preservation and development of cultural identity could be guaranteed. Cultural identity was mainly referred to in terms of policies, not in terms of legal rights of individuals or communities.

74 UNESCO was planning a conference on cultural policies for the Atrab countries, but due to political problems this conference never took place. The Arab countries came together in Baghdad under the auspices of the Arab Educational, Cultural and Scientific Organisation (ALECSO). The final report was never officially recognised by UNESCO, because of the anti-Israel and anti-Zionist sentimerts expressed in the report.

75 ALECSO, 1981 , pp. 2, 5, 8-13, 18, 24-26, 31. 


\subsection{World Conference on Cultural Policies in Mexico}

After the regional conferences, the second World Conference on Cultural Policies took place in Mexico from 26 July to 6 August 1982. At the conference, concepts and issues that had come up during the regional conferences were further discussed. Most delegates emphasised the growing awareness of people's cultural identity and of their right to be different. Both the preservation and development of cultural identity had become permanent requirements for individuals, communities and nations striving for recognition. Mutual respect for other cultures was required including those of minorities, which would lead to cultural pluralism. Such pluralism could contribute to enrichment and should not be considered a divisive factor. It was finally asserted that although cultural identity was closely linked to traditions, history and ethical values, this should not lead to an excessive attachment to tradition or to an introspective attitude. ${ }^{76}$

In general, the participants agreed that cultural policies implied the participation of all parts of society, which required respect for rights such as freedom of expression and communication as well as equal access to culture. Furthermore, special attention should be given to the cultural rights of minorities, and States should provide assistance, where needed, for their free development. ${ }^{77}$ The Conference also addressed issues such as culture and development, culture and science, culture and communication, culture and peace and cultural heritage. It was stressed that, since the first World Conference in Venice, concepts such as culture and cultural heritage had been broadened to include, besides arts and crafts, all other expressions, yalues and ways of life of a community. ${ }^{78}$

The Conference unanimously adopted the Mexico Declaration on Cultural Policies, in which the concept of cultural identity was significantly present. It was determined that the assertion of cultural identity could contribute to the liberation of peoples. Forms of domination could constitute a denial or an impairment of that identity. Cultural identity was inseparably linked to cultural diversity and cultural pluralism. ${ }^{79}$ The Declaration states that " $[t]$ he international community considers it its duty to ensure that the cultural identity of each people is preserved and protected. ${ }^{80}$ Accordingly, the States agreed that there was a need for cultural policies that would protect, stimulate and enrich the cultural identity of each people. It was stated that

"[i]he equality and dignity of all cultures must be recognised, as must the right of each people and cultural community to affirm and preserve its cultural identity and have it respected by others." ${ }^{\text {, } 11}$

76 UNESCO Doc. CLT/MD/1, 1982, pp. 8-9.

77 UNESCO DOC. CLT/MD/1, 1982, pp. 9-10.

78 UNESCO Doc. CLT/MD/1, 1982, pp. 12-14.

79 UNESCO Doc. CLT/MD/1- Mexico City Declaration on Cultural Policies 1982, pp. 41-42.

80 UNESCO Doc. CLT/MD/1- Mexico City Deciaration on Cultural Policies 1982, 37.

81 UNESCO Doc. CLT/MD/1- Mexico City Deciaration on Cultural Policies 1982, 89. 
The Declaration also encloses statements on culture and democracy, cultural heritage, arts, the relation between culture and education, science and communication, the financing of cultural activities, international co-operation and the role of UNESCO. It is interesting that cultural identity is included in this Declaration not only as a value, but also as a right. States formulated a collective right of peoples and communities to affirm and preserve their cultural identity. Apart from this collective dimension, the individual approach is also used elsewhere in the text. Generally, the rights in the Declaration seem to reflect principles that should guide the cultural policies of States. For example, individuals and communities cannot invoke a right to cultural identity based on this Declaration and no clarification is given to the content or State obligations of this right.

The issue of cultural identity received much attention at the Mexico Conference. The description of cultural identity in the Mexico Declaration reflects several aspects described earlier. It was, for example, asserted that, through cultural identity, each people could express the continuity between past, present and future. Cultural identity was considered to be a dynamic process of originality, creativity and free determination, constantly undergoing changes. Cultural identity was based on the cultural heritage of a society, which, at the same time, contributed to the common heritage of mankind as a whole. ${ }^{82}$ Since the Mexico Conference, the concept of cultural identity is internationally established in a broad sense as a value that deserves protection through State policies. The Mexico Declaration also contains rights in this field, but it is as such not legally-binding. These rights should be mainly considered as recommendations for State policies. After the Mexico Conference, within UNESCO, the protection of cultural identity was taken up on several occasions, for example, in the World Report on Culture and Development and the adoption of the Declaration on Cultural Diversity.

\section{Culture and Development Report “Our Creative Diversity"}

In December 1992, within the framework of the World Decade for Cultural Development (1988-1997), UNESCO and the UN jointly set up the independent World Commission on Culture and Development. The World Commission was mandated to prepare a policy-oriented report on the interactions between culture and development on which new cultural policies could be based. Between March 1993 and September 1995, the Commission held nine meetings in different regions, during which scholars, NGOs, policy-makers and artists expressed their ideas. In November 1995, the Commission presented its report, entitled 'Our Creative Diversity', to the General Conference of UNESCO and to the General Assembly of the UN. ${ }^{83}$

82 UNESCO Doc. CLT/MD/1, 1982, Recommendation no. 6, p. 62. See also Maskaminan Makagiansar, 1983, pp. 17-18.

83 World Commission on Culture and Development, 1995. See, also, UNESCO World Commission on Culture and Development, Fact Sheet la, 6 November 1996. 


\subsection{Content of the Report}

In general, the report asserts the view that development is not only about access to goods and services, but also about the opportunity of people to choose a satisfying and valuable life. The report addresses various interactions between culture and development, such as global ethics, pluralism, the media, gender, young people, cultural heritage and the environment. It ends with an International Agenda, a set of actions to be transformed into development strategies, among which are the publication of an annual report on culture and development (action 1), the protection of cultural rights as human rights (action 7), and the organisation of a global summit on culture and development (action 10) ${ }^{84}$

Action 7 is most relevant for this study. It was based on the fact that, according to the report, human rights violations were often motivated by cultural considerations; for example, illegal detention or persecution of artists, journalists, teachers, scholars and members of minority communities, the destruction of cultural heritage and the restriction of the freedom of speech or cultural expression. ${ }^{85}$ According to Action 7, specific actions were needed to confirm that cultural rights deserve protection as human rights. The report proposed the following:

- The International Law Commission (ILC) should be requested, by a resolution of the UN General Assembly, to draft a list of cultural rights which were not (yet) protected by existing international instruments.

- Based on this list, an International Code of Conduct on Culture could be developed, by the ILC, to mobilise international solidarity and to condemn violations of cultural rights.

- The ILC could also examine the possibilities for the establishment of an International Office of the Ombudsperson (sic) for Cultural Rights, which could deal with the complaints of individuals and communities and could negotiate with governments to search for a peaceful solution.

- Part of the re-examination of the international enforcement procedures to improve the prosecution of violations of cultural rights could be the examination of the possibility of establishing an International Court, which could deal with the accusations against violators of cultural rights. This Court might become a part of the International Criminal Court. ${ }^{86}$

84 The complete list of actions is: 1. The publication of an annual report on culture and developrinent. 2. The preparation of new cultural-sensitive development strategies. 3. International mobilisation of cultural heritage volunteers. 4. An international plan for gender equality. 5 . The implementation of new media policies. 6. Media rights and self-regulation. 7. The protection of cultural rights as human rights. 8. Global ethics and global governance. 9. A people centred United Nations. 10. A Global Summit on Culture and Development. See World Commission on Culture and Development, 1995, pp. 271-288.

85 World Commission on Culture and Development, 1995, p. 281.

86 World Commission on Culture and Development, 1995, pp. 281-284. 


\subsection{Comments on the Report by the Member States}

Since the report was addressed to UNESCO and not created or adopted by it, the Member States were asked to respond to it officially. ${ }^{87}$ In general, Member States confirmed the importance of the subject of culture and development. However, most Member States found the way in which the report dealt with the problems rather naive and too far-reaching. It was, in fact, Action 7 of the International Agenda concerning cultural rights that received most criticism. While the suggestion to draft an inventory on cultural rights received general support, Member States considered the other measures proposed, especially the establishment of an International Court for cultural rights, as going too far. Furthermore, it was argued that various other international organisations, for example; the Council of Europe, were already working in the field of cultural rights and that UNESCO should not interfere. In fact, several Member States asserted that the measures on cultural rights were not part of the mandate of UNESCO, but were a task of the UN. Others added that the Commission on Human Rights would be the appropriate body to examine this material, instead of the Intemational Law Commission.

Member States also argued that the efforts of other organisations to promote cultural rights showed how difficult it is to define cultural rights in a world with so many different cultures, religions and languages. They generally expressed the concern that the development of new cultural rights would only increase the list of existing international provisions that were not well-implemented, and emphasised that the fact that existing rights were not well-respected should not lead to the development of new rights. Setting up new committees and commissions would only cost money, and their powers would be limited.

\subsection{Follow-up of the Report}

"Our Creative Diversity" was intended to intensify the discussion on links between culture and development and it did so. The report succeeded in putting culture on the international policy agenda. In 1996, the Director-General of UNESCO set up a Steering Committee, chaired by Mr. Pérez de Cuéllar, to supervise the follow-up activities. Three of these follow-up activities relating to Action 1,7 and 10 are discussed below.

Action 1 implied a yearly report on culture and development. The first and second World Culture Reports were published in 1998 and 2000, and it is UNESCO's

87 Most Member States officially responded to the report. These comments are not published, but have been examined at the Department of Culture at UNESCO Headquarters in Paris. Additional information was obtained from interviews with Mrs. L. Arizpe, Assistant Director General, Sector for Culture and Mr. Y. Isar, Head of the Sector of Culture, in May 1998. 
intention to publish such a report every two years. The World Culture Reports contain a survey of trends in culture and development. The reports consist of articles on global and regional cultural policy issues, such as economic development, globalisation, ethics, arts and the media. Furthermore, the reports contain much statistical data and tables on populations, languages, education, etc The reports do not have a legal background, but mainly focus on social and economic issues. Cultural rights or the right to cultural identity are not specific topics in the reports, probably because of the cautious reaction to this subject by the Member States, as described above. Two contributions in the first report, out of 20 , dealt with cultural rights in relation to indigenous peoples. ${ }^{89}$ The second report does not include a specific contribution on cultural rights. Since these reports do not have political or legal implications and do not provide new insights on cultural identity, they are not further discussed here.

Follow-up was also given to Action 7 on cultural rights. Because of the critical notes of the Member States on this Action and the far-reaching nature of the proposals, it was decided to work carefully and start with a less ambitious proposal in Action 7, namely, to prepare an inventory of cultural rights that were not protected by existing international instruments. First, a consultant would prepare an inventory on cultural rights which were already included in international instruments. Subsequently, a Working Group on Cultural Rights, consisting of specialists in cultural rights; would examine the list and decide which cultural rights needed to be further or newly developed. The conclusions of the Working Group would be presented to the Executive Board and the General Conference of UNESCO. ${ }^{90}$

In 1996, a UNESCO consultant, Birgitta Leander, prepared an analysis of cultural rights. ${ }^{91}$ Leander listed, in an extensive way, all the rights related to culture in the various international and instruments, such as the UDHR, the ICCPR, ICESCR, ILO Conventions and the regional instruments of Europe, Africa and America. She did not clarify the content of the rights provisions, but merely listed them according to subject. She divided them into several categories, one of which was 'rights to and respect for cultural identity", in which various rights specifically referring to cultural identity were mentioned. ${ }^{92}$ However, the Working Group that

88 UNESCO, World Culture Report, "Culture, Creativity and Markets", UNESCO Publishing Paris, 1998; UNESCO, World Culture Report, "Cultural Diversity, Conflict and Pluralism", UNESCO Publishing Paris, 2000.

89 UNESCO, World Culture Report, 1998, Chapter 4: O.H. Magga, "Cultural rights and indigenous peoples" the Sami experience", pp. 76-84, and Chapter 5: H. Rasmussen and I. Sjoerslew, "Culture and indigenous rights", pp. 85-92.

90 UNESCO, Culture and Development Co-ordination Office, Working Group on Cultural Rights, 30 September 1996, pp. 1-3.

91 Birgitta Leander, Preliminary List of Cultural Rights, UNESCO, Culture and Development Coordination Office, 1996.

92 These rights were, inter alia, included in ILO Convention 169, to be dealt with in the next chapters. 
was supposed to consider additional cultural rights was never set up, because it did not receive sufficient support from the Member States. ${ }^{93}$

The global summit as proposed in Action 10 was organised in Stockholm from 30 March to 2 April 1998, under the title "The Power of Culture'. This world conference was preceded by a smaller conference with the same title in Amsterdam. ${ }^{94}$ During both conferences, the participants discussed the importance of culture, cultural policy, cultural rights and subjects such as global ethics and pluralism. The Stockholm Conference did not intend to adopt declarations and recommendations or to focus on theoretical concepts. Instead, it aimed at the adoption of practical outcomes. The purpose was to give States some guidelines to adopt cultural policies which could meet the challenges of globalisation, pluralism and diversity. ${ }^{95}$

One of the themes discussed during the Stockholm Conference was the issue of cultural rights. Although both the individual and the collective dimension of cultural rights were recognised, the emphasis lay in an individual approach. It was argued that collective claims should not take place at the expense of individual rights, for example, the rights of women. Human rights were considered inherent to each individual human being and "...the right to retain and nurture his or her cultural identity must also be given to each unique human being." 96

During the Stockholm Conference, serious attention was given to the value of cultural identity, and States were recommended to promote it as a value. This, however, did not imply an enforceable right to cultural identity for communities or individuals including State obligations. Cultural identity was recognised at the level of a moral value and a policy goal, but not as a legal right. ${ }^{97}$

\section{THE DECLARATION ON CULTURAL Diversity}

At the UNESCO General Conference in November 2001, the Member States adopted the Declaration on Cultural Diversity. The Declaration followed from the 'Our Creative Diversity' report of 1995, the Conferences on Cultural Policies in Mexico in 1982 and Stockholm in 1998, and the two World Culture Reports of 1998 and 2000. At its $160^{\text {th }}$ session in 2000, the Executive Board had adopted a decision in which it invited the Director-General to identify the preliminary considerations for a UNESCO draft declaration on cultural diversity. ${ }^{98}$

93 Information from interviews with Mrs. L. Arizpe, Assistant Director General, Sector for Culture and Mr. Y. Isar, Head of the Sector of Culture, in May 1998.

94 The Power of Culture, Conference Report (Amsterdam, 8-9 Nowember 1996), Den Haag 1997.

95 UNESCO Doc. CLT-98/Conf. 210/3, 1998, \& 8-10.

96 UNESCO Doc. CLT-98/Conf. 210/3, 1998, \& 18-19.

97 See the final document of the Stockholm Conference: UNESCO Doc. CLT-98/Conf. 210/4 Rev2, 1998.

98 UNESCO Doc. 160 EX/Decision 3.1.1, Part II, 2001. The first Round Table of Ministers of Culture had taken place in Paris on 2 Nowember 1999. 
The Director-General prepared a report on a draft declaration on cultural diversity for the $161^{\text {st }}$ session of the Executive Board in April 2001. In this report, he explained that UNESCO's efforts in relation to a declaration on cultural diversity showed two concerns:

\begin{abstract}
"...the need to ensure respect for all cultural identities and the participation of all in democratic States (inclusiveness), and the need to promote the emergence of a climate conducive to the full realisation of the creative capacities inherent in each individual (empowerment), so that culture becomes a real motor of development.:"99?
\end{abstract}

The Director-General submitted a preliminary draft declaration with the intention of developing a draft declaration for the $162^{\text {nd }}$ session of the Executive Board, which could be adopted in its final version at the $31^{\text {st }}$ session of the General Conference in 2001 . $^{100}$

In the Preamble of the preliminary Draft Declaration, definitions were given of culture and cultural identity, inspired by the work of the Fribourg Group ${ }^{101}$ and the Mexico Declaration on Cultural Policies. Culture is described as "...the whole complex of distinctive spiritual, material, intellectual, and emotional features that characterise a society or social group..." including "...not only the arts and letters, but also modes of life, ways of living together, the fundamental rights of the human being, value systems, traditions and beliefs..." ${ }^{102}$ Cultural identity "....represents all the ethnic, linguistic, religious and other references that underpin the conscious or unconscious identification with a group." It is also stated that "... identity is by no means essentially changeless but can evolve, draw on allegiances of various kinds, and be enriched through contact with other cultures." 03

The preliminary draft, which was generally described in terms of principles and not in terms of rights, contained, in Article 1, a reference to the rights of groups and the rights of persons belonging to national or ethnic, religious and linguistic minorities to have free access to the expression of their own culture and that of others. The concept of cultural identity was present in severa] provisions. According to Article 2, a democratic framework promoting cultural diversity should ensure "respect for cultural identities... fostering the ability of persons or groups with different cultural identities to live together (inclusiveness) and thus contributing to the development of an environment conducive to the expression of creative capacities (empowerment)." 104 The fields of priority set out in the draft declaration were the preservation and transmission of heritage, linguistic diversity, creativity

99 UNESCO Doc. $161 \mathrm{EX} / 12,2001$, p. 2.

100 UNESCO Doc. $161 \mathrm{EX} / 12,2001$, p. 2.

101 The Fribourg Group is a group of experts in the field of cultural rights. Their work is described in Chapter IV of this study.

102 UNESCO Doc. 161 EX/12, 2001, Annex, p. 3.

103 UNESCO Doc. $161 \mathrm{EX} / 12,2001$, Annex, p. 3.

104 UNESCO Doc. 161 EX/12, 2001, Annex, p. 4. 
and cultural industries and education. In relation to linguistic diversity, the preliminary draft contained another reference to cultural identity. In Article 7(b), it was stated that "[g]iven that language is one of the foundations of cultural identity, all individuals should have the right to express themselves, create, disseminate their own works and have access to information and knowledge in the language of their choice, including, among others, their mother tongue". Finally, cultural identity was coupled to education. In Article 9(b), it was laid down that "[e]ach individual has a right to good-quality education and training which fully respects his or her cultural identity." Mesmber States were asked to comment on this preliminary draft, which was done by a few States individually and several States collectively. ${ }^{106}$ They generally agreed upon the necessity of a declaration on cultural diversity and the role of UNESCO in promoting it. ${ }^{10}$

The final Declaration adopted by the General Conference reflects cultural diversity in the context of respect for human rights. The final text is, however, very different from the preliminary draft. Cultural identity is no longer defined, although a reference is made in the preamble that "....culture is at the heart of contemporary debates about identity..." the Declaration, except as a general value, and certainly not in terms of rights. In Article 2, it is, for example, laid down that, in contemporary diverse societies, it is essential to ensure "...harmonious interaction among people and groups with plural, varied and dynamic cultural identities..." General references are also made to the importance of cultural rights as an integral part of human rights, whereby Article 27 UDHR and Articles 13 and 15 ICESCR are explicitly referred to. There is no specific reference to the protection and promotion of $\$ anguages and the provisions on cultural heritage were shortened. With regard to education, the link with cultural identity remained in Article $5 .{ }^{109}$

The Declaration mainly includes principles to be generally implemented by States. The 'main lines of an action plan' for its implementation confirm that States have the obligation to adopt policies to protect and promote cultural diversity. It is inter alia determined that the Member States should make further headway in clarifying the content of cultural rights. Furthermore, States should take measures to encourage linguistic diversity at all levels of education, to preserve and enhance cultural heritage, and respect and protect traditional knowledge, especially of indigenous peoples. It is striking that religion is not part of the Declaration. It should be noted that several States, including the Netherlands and the UK, issued

105 UNESCO Doc. 161 EX/12, 2001, Annex, p. 6.

$\| 06$ These were Belgium, Canada, France, the Netherlands, Turkey and the United Kingdom and two groups of UNESCO Member States, namely the Group of Fifteen (the EU Member States) and the French-speaking Group (Organisation Internationale de la Francophonie), in which more than fifty States participate.

107 UNESCO Doc. 161 EX/INF.19, 2001, pp. 2-3.

108 UNESCO Doc. $31 \mathrm{C} / 44,2001$, Annex, p. 1.

109 Compare UNESCO, Declaration on Cultural Diversity, 2 November 2001 with UNESCO Doc. 31 C/44, 2001, Draft Declaration on Cultural Diversity, Annex, pp. 2-3. 
declarations that they could agree with the Declaration, but that they disagreed with the Action Plan that was added, especially where it called for the development of norms and standards in the field of cultural diversity. It, therefore, remains to be seen what role this Declaration can play in the policies of the Member States, apart from a set of pleasing phrases reflecting the general value of cultural diversity. It seems that, when it comes to concrete obligations, States are not willing to take these steps.

\section{CONCLUDING REMARKS ON UNESCO AND A RigHT TO CULTURAI IDENTITY}

Since its foundation in 1948, UNESCO has been active in the field of the protection and development of culture, although not always in legal terms. UNESCO has organised many conferences on the concept of culture and has adopted various instruments in this field. Although most of these instruments are not legally-binding and mainly focus on the development of State policies, they provide important information on the perception and development of the concepts of culture and cultural identity, and provide valuable information on the development of a right to cultural identity.

The first instrument in this respect is the Declaration on Cultural Cooperation, adopted in 1966, which mainly deals with international co-operation in the field of culture. The importance of the Declaration lies in the fact that it lays down that each culture has dignity and value, and is worth respecting and preserving. The second relevant instrument is the Recommendation on the Participation by the People at large in Cultural Life and their Contribution to it, adopted in 1976. This Recommendation shows the development of the concept of culture and participation. Culture is no longer an élite concept, including merely arts and literature, but has been given a broad scope which includes customs, traditions, language and religion. Besides passive respect for cultures, it is now recognised that persons have the right to participate actively in culture and develop it. The Recommendation contains various references to cultural identity, for example, towards foreign minorities, which are granted a right to preserve their cultural identity while participating in the cultural life of the community. Another UNESCO instrument that includes a right to cultural identity is the Declaration on Race and Racial Prejudice, adopted in 1978. This Declaration was meant to be a background document on race and differences between people. Various references are made to cultural identity, for example, in Article 1(3) on the right to maintain cultural identity, and Article 5(1) on societies that should respect each other's right to cultural identity. The provisions are not defined in terms of legally enforceable rights, but as general statements on the background of differences between people.

Other developments with regard to a right to cultural identity took place at the inter-governmental conferences on cultural policies, during which cultural identity was discussed in the context of cultural rights. It is interesting to see that cultural rights played a modest role during the first World Conference in Vienna 
(1970) and during the European Conference (1972), perhaps because cultural rights issues, for example in relation to minorities, were not part of the agenda yet. However, the other conferences, especially those in Asia (1973), Africa (1975), and Latin America (1978), paid much more attention to cultural identity, especially in relation to the struggle for freediom from colonisation. The Mexico Declaration of the second World Conference (1982) contains a right to cultural identity for communities.

The report entitled "Our Creative Diversity", prepared by the Commission on Culture and Development, contains it its action plan inter alia the promotion of cultural rights. However, this aspect of the report was heavily criticised by the Member States, and UNESCO had to follow a less ambitious road. The working group on cultural rights was never established, but UNESCO did adopt the Declaration on Cultural Diversity in 2001. This Declaration again mainly confirms the value of cultural diversity, without defining explicit rights.

The developments within UNESCO show the increasing importance which States attach to the concepts of culture and cultural identity. These concepts received a broad scope, including an individual as well as a collective dimension. The developments within UNESCO also confirm that the awareness of cultural identity is strengthened when it is jeopardised, because it was considered especially important in relation to former colonies and communities formerly under foreign domination. The developments within UNESCO show much similarity with the analysis of the notions of culture and cultural identity in the earlier chapters of this book.

UNESCO also paid attention to cultural rights and a right to cultural identity. A right to cultural identity was, in fact, included in several UNESCO instruments, although not always formulated in legal terms. Cultural identity was mainly recognised as a moral value worth preserving and as a political value, whereby States were held responsible for adopting cultural policies to respect and protect cultural identity. However, which concrete obligations resulted from these responsibilities was not made clear. States did not speak in terms of rights of individuals or communities, but focused on general guidelines for cultural policies without strict legal obligations.

As such, this chapter forms the transition to the next chapters, which focus on severall international human rights provisions that have an important link with cultural identity. 


\section{CHAPTER VI The Right to Participate in Cultural Life}

\section{INTRODUCTION}

A right to cultural identity as such cannot be found in the International Bill of Human Rights, composed of the Universal Declaration on Human Rights (UDHR) and the two Covenants on Civil and Political Rights and Economic, Social and Cultural Rights (ICCPR and ICESCR). These instruments do, however, contain cultural rights that may provide starting points for the protection of the cultural identity of individuals and communities. Several of these provisions are examined in the next two chapters. The drafting and interpretation of these provisions are analysed for two purposes. Firstly, to shed light on issues raised with regard to a right to cultural identity, for example, concerning the object, subject and addressee of this right. Secondly, in order to determine whether a right to cultural identity should be developed, it is interesting to see what role the existing cultural rights provisions can play in the protection and promotion of cultural identity. Without directly referring to cultural identity, do these provisions offer any help in the development and protection of the cultural identity of individuals and/or communities?

This chapter is devoted to two provisions on the right to take part in cultural life, namely, Article 27 UDHR and Article 15 ICESCR. These provisions are examined according to the interpretation methods described in Articles 31 and 32 of the Vienna Convention on the Law of Treaties, such as the wording of the text adopted, the travaux preparatoires concerning the drafting process and the intentions of the drafters, case law or statements of a supervisory body, and finally reports or statements of learned writers.'

\section{ARTiCle 27 OF THE UNIVERSAL DEClaRation of Human Rights}

\subsection{Introduction}

Acting under the supervision of the Economic and Social Council (ECOSOC), the Commission on Human Rights (Commission), composed of representatives of Member States, started drafting the Universal Declaration in 1947. The drafting process of the Universal Declaration took place in the Sub-Commission on

1 Vienna Convention on the Law of Treaties, adopted 23 May 1969, entry into force: 27 January 1980. 
Prevention of Discrimination and Protection of Minorities (Sub-Commission), set up by the Commission in 1946 and initially composed of experts who served in their personal capacity, and the General Assembly, more specifically the Third Committee. ${ }^{2}$

The governments of Chile, Cuba, the United Kingdom and Panama submitted the first formal drafts of a Bill of Human Rights to the General Assembly and the Commission. The Secretariat (Division on Human Rights) prepared an "outline", as the preliminary draft was called. The task of making a first draft of concepts to be turned into provisions to be included in the Bill of Human Rights was assigned to the French representative, Professor René Cassin. ${ }^{3}$ His draft was revised by a drafting committee set up by the Commission, which prepared a final draft to be discussed in the Commission itself. The Draft Declaration, adopted by the Commission at its third session, was sent by ECOSOC to the General Assembly, which discussed it during its third session in September 1948. After exhaustive discussions on every provision in the Commission, the Assembly's Social, Humanitarian and Cultural Committee (the Third Committee), composed of representatives of all Member States, reviewed the draft word by word. ${ }^{4}$ The Universal Declaration on Human Rights was finally adopted by the General Assembly on 10 December 1948.

Articles 22 to 27 of the Universal Declaration deal with economic, social and cultural rights. Article 27 is of special interest for this study. It reads as follows:

"1. Everyone has the right freely to participate in the cultural life of the community, to enjoy the arts and to share in scientific advancement and its benefits.

2. Everyone has the right to the protection of the moral and material interests resulting from any scientific, literary or artistic production of which he is the author."

The first paragraph of Article 27 is the only provision of the UDHR that specifically refers to 'culture' and, as such, has a link with the protection of cultural identity. However, what is meant by 'to lture' or "cuparticipate in the cultural life of the community"? Which definitions have been given to "cultural life", and what is meant by "participation'? Which community is meant here? To answer these questions, mainly two means of interpretation are used, namely the drafting process as laid down in the travaux préparatoires and the interpretation by several scholars.

2 For more details on the background and drafting process of the Universal Declaration on Human Rights, see Verdoodt, 1963; Humphrey, 1984; Robinson, 1958; Kanger, 1984; United Nations, 1950; Cassin, 1951; Johnson and Symonides, 1998.

3 United Nations, 1950, pp. 6-9; Kanger, 1984, pp. 17-18; Humphrey, 1984, pp. 23-28, 42-43.

4 United Nations, 1950, pp. 12-13; Robinson, 1958, pp. 25-27; Kanger, 1984, p. 20. 


\subsection{Travaux Préparatoires of Article 27 UDHR}

In one of the first proposals of the Universal Declaration by the Chilean delegation, this provision merely focused on science and did not contain a reference to culture. It was the United States delegation that proposed to examine the possibility of including the cultural field in this provision. Based on concrete proposals to this end by Saudi-Arabia, Bolivia, Brazil, Uruguay and Yugoslavia, the Secretariat drafted a provision to be discussed by the Commission. The idea was that eulture was an important aspect of human life. In its classic form including arts and literature, culture had to be made more accessible to the masses. The travaux show that the first part of paragraph 1 of Article 27 as prepared by the Secretariat has hardly been negotiated and has not been altered. The first draft of the Secretariat turned out to be mainly the same as the final text, except for the term freely', which was included by the Third Committee of the General Assembly? The Third Committee of General Assembly discussed this provision during its third session in 1948, and added the term 'freely' before 'to participate' on the suggestion of the Peruvian delegation. The Peruvian delegation pointed out that the individual should not only have the right to take part in the cultural, artistic and seientific life of the community, but should also have the right to do so in complete freedom. This view was widely supported and it was adopted with 38 votes to none, with two abstentions. ${ }^{6}$

The discussion on Article 27 in the Commission and the General Assembly mainly focused on the inclusion of a second paragraph on author's rights. ${ }^{7}$ The Mexican delegation submitted a proposal on this issue, which was adopted as the second paragraph of the final provision. Another amendment by the USSR to include that scientific advancement should be in the interest of democracy and the cause of international peace and co-operation was rejected on the basis that science should be free from any interference, especially from the State. The final Article 27 was adopted in the Commission by 36 votes to none, with four abstentions. The General Assembly adopted it unanimously."

The travaux show that no discussion took place on the exact content of participation in the cultural life of the community. The main idea was to include a reference to culture in the Universal Declaration, without clearly defining the concepts of culture, participation and community. Several authors have, however, tried to give an interpretation of Article 27.

\footnotetext{
5. Verdoodt, 1963, p. 253; Morsink, 1999, p. 218; United Nations, 1950, pp. 70-72.

6 United Nations, 1950, pp. 70-72; UN Doc. A/C.3/SR.150, pp. 619 and 634; Verdoodt, 1963, pp. 253-254, Morsink; 1999, p. 218.

7 UN Doc. A/C.3/SR. 150, 1948, p. 617; United Nations, 1950, p. 71, Morsink, 1999, pp. 220-221.

8 UN Doc. A/C.3/SR. 150, 1948, pp. 633-634; United Nations, 1950, p. 71.

9 United Nations, 1950, p. 71; Verdoodt, 1963, pp. 255-256.
} 


\subsection{Interpretation of Article 27 UDHR by Scholars}

According to Verdoodt and Robinson, who based themselves on the travaux preparatoires and on the discussions in the Third Committee of the General Assembly, Article $27(1)$ implies that every person has the right to participate in every aspect of cultural life. Furthermore, every person has the right to participate actively in scientific progress and passively to enjoy the results of science. According to Verdoodt and Robinson, the term 'freely to participate" means without interference or limitations other than those mentioned in the general limitation clause of Article 29(2) UDHR: $:^{10}$ Verdoodt and Robinson further argue that the reference to arts and scientific advancement in the first paragraph does not necessarily imply a restriction of the expression of culture to these two branches. According to Robinson, these aspects of culture were specifically mentioned because they were cultural products that had almost been inaccessible to the average person."

The travaux préparatoires show that; with regard to the object of Article $27(1)$, the drafters had a narrow concept of culture in mind with an emphasis on arts, literature and education. The background of Article 27 was the fact that culture used to be something of a small élite, in which large parts of the population did not take part. Article 27 was considered to be an encouragement to the State to have the masses to participate in culture and to make culture available to them. At that time, culture did not refer to a specific lifestyle or to the tradition of a community, or to aspects such as language or religion. As explained above, Verdoodt and Robinson suggest that article 27 (1) may imply a somewhat broader concept of culture, which means that other expressions of culture could also fall under Article 27(1). In my view, however, the drafters had a narrow concept in mind, which focused on the material aspects of culture. The question is of whether the current scope of Article 27 might be broader than just the advancement of the arts and science.

Which 'community' does Article 27 refer to? Verdoodt and Robinson argue that the term refers to more than the State. Because of the universality of the rights included in the Universal Declaration, it has to comprise "...the whole organised human race as well as parts thereof:" Morsink agrees that "the community" refers to the national community and maybe to the world community. In any case, the term 'community' did not refer to the situation of minorities, indigenous peoples or other local or regional communities. Morsink argues that the drafters did not use the formulation of 'the culture of his or her community', because that would have

10 In Article 29(2) UDHR, it is laid down that limitations should be based on law in order to protect the rights of others or to protect morality, public order or the general interest of a democratic society.

11 Robinson, 1958, p. 139; Verdoodt, 1963, p. 256.

12 Robinson, 1958, p. 139; Verdoodt, 1963, p. 256. 
referred to the possibility of the culture of one's community being not the same as the culture of the State in which one lives. According to Morsink,

"[a]rticle 27 seems to assume that "the community" one participates in and with which one identifies culturally is the dominant one of the nation-state. There is no hint here of multi-culturalism or pluralism." ${ }^{13}$

The subject of Article 27 is the individual, since it refers to 'everyone'. The addressee is the State, but what obligations does the State have? According to Kanger, Article 27(1) concerns a right to freedom as well as a right to service. In general, rights of freedom imply a freedom of action combined with noninterference by others, especially the State. Rights to service imply that the subject of the rights is supposed to be given something. According to Kanger, Article 27(1) is a right of freedom to participate in the cultural life of the community and a right of service in the sense that the State should provide the conditions under which both the arts and the scientific benefits can be enjoyed. ${ }^{14}$ With regard to the tripartite typology of State obligations, these obligations concern the obligation to respect as well as to fulfil. Perhaps, it also concerns the obligation to protect, in the sense that the State should prevent interference by others, as Kanger indicated.

The precise content of participation in cultural life and the corresponding State obligations remain unclear. The travaux préparatoires and the work of scholars do not provide definitive answers in this respect. As indicated in the Vienna Convention on the Law of Treaties, case law or statements of a supervisory body can be helpful in the interpretation of rights' provisions with regard to content and State obligations. However, the nature of the Universal Declaration is a declaration of principles that were later to be included in a legally-binding instrument. Accordingly, States have no clearly defined obligations and do not have reporting obligations on the provisions of the UDHR. Consequently, no clear State practice has developed and the content of Article 27 UDHR remains uncertain.

\subsection{Article 27 UDHR in Relation to a Right to Cultural Identity}

Article 27(1) falls within the narrow category of cultural rights as described earlier, since it directly refers to culture. At the time of drafting this provision, culture was considered from a narrow perspective, including mainly cultural materials such as arts and literature. As such, Article 27 (1) could be seen as part of a right to cultural identity. However, it has another nature other than that of a right to cultural identity. While a right to cultural identity is meant to protect and develop cultural identity as a process in a broad sense, Article $27(1)$ was meant to make the material results of culture available to the masses. However, the question arises as to whether this is still the correct interpretation of this provision.

13 Morsink, 1998, p. 269.

14 Kanger, 1984, pp. 150-151, 159-160, 163. 
As argued above, there is not much information on this matter, probably because the UDHR was a declaration meant to reflect the intentions of States. More could be expected from the ICESCR, adopted two decades later, in which a similar provision on participation in cultural life was included in Article 15. The ICESCR has legallybinding force and contains a monitoring system which includes a State report procedure. Accordingly, State Parties and the Committee on Economic, Social and Cultural Rights have given an interpretation of Article 15 and have thus developed the provision: Article 27 UDHR, however, remains applicable for those States that have not ratified the $\mathrm{ICESCR}^{15}$

\section{ARTICLE 15 OF THE INTERNATIONAL COVENANT ON ECONOMIC, SOCIAL AND CULTURAL RIGHTS}

\subsection{Introduction}

When the General Assembly adopted the Universal Declaration in December 1948, it also adopted resolution $217 \mathrm{E}$ and $\mathrm{B}$ (III), in which it requested ECOSOC to ask the Commission to prepare a draft covenant on human rights. The Commission started the drafting process of the covenant at its fifth session in May and June 1949. It also asked the Secretary-General to prepare a report on the activities of the UN organs and specialised agencies in the field of economic, social and cultural rights, as described in Articles 22 to 27 of the Universal Declaration. This report ${ }^{16}$ was discussed during the sixth session of the Commission in May 1950. The importance of economic, social and cultural rights was also acknowledged by the Assembly in Resolution 421 (V), Section E, adopted at its fifth session in September-December 1950, in which it requested the Commission, through the ECOSOC, to include these rights in the draft covenant. ${ }^{17}$

During its seventh session in April and May 1951, the Commission considered proposals concerning economic, social and cultural rights, drafted by Governments and specialised agencies, such as the ILO, UNESCO and WHO. The Commission decided to set up a Working Group of several members of the Commission to study the various proposals."

After ample discussions in the Commission, ECOSOC and the General Assembly, the Assembly adopted Resolution 543 (VI), during its sixth session from November 1951 to February 1952, whereby it requested ECOSOC to ask the Commission to draw two separate covenants on human rights. ${ }^{19}$ During its eighth

15 Currently, 145 States have ratified the ICESCR. For the other States, Article 27 is the valid provision with regard to cultural participation (June 2002).

16 UN Doc. E/CN.4/364, May 1950.

17 UN Doc. A/2929, July 1955, \$1-20, pp. $2-4$.

18 See on the seventh session of the Commission UN Doc. E/1992 (E/CN.4/640), 24 May 1951, pp. 23-24.

19 The discussion on whether or not to draw up two separate Covenants falls outside the scope of this study. See, on this issue, UN Doc. A/2929, July 1955; Tolley Ir., 1987; Humphrey, 1984. 
session in April to June 1952, the Commission started working on these two separate covenants, following the work already done on a single instrument. The Commission finished its drafting work during its tenth session from February to April 1954. ECOSOC submitted the drafts to the General Assembly, which considered them at its minth session in 1954. It requested the governments to comment and suggest amendments. ${ }^{20}$ The General Assembly worked on the Covenant between 1950 and 1957, and, after several years, resumed its work in 1966. The International Covenant on Economic, Social and Cultural Rights (ICESCR) was finally adopted in $1966^{21}$ and entered into force in 1976.

The ICESCR is the first legally-binding document that explicitly includes a reference to "cultural rights" in the title. However, the only provision directly referring to culture is Article 15. This provision is similar, but not identical, to Article 27 UDHR and reads as follows:

"1. The States Parties to the present Covenant recognise the right of everyone:

(a) to take part in culturall life;

(b) to enjoy the benefits of scientific progress and its applications;

(c) to benefit from the protection of the moral and material interests resulting from any scientific literary or artistic production of which he is the author.

2. The steps to be taken by the States Parties to the present Covenant to achieve the full realisation of this right shall include those necessary for the conservation, the development and the diffusion of science and culture.

3. The States Parties to the present Covenant undertake to respect the freedom indispensable for scientific research and creative activity.

4. The States Parties to the present Covenant recognise the benefits to be derived from the encouragement and development of international contacts and cooperation in the scientific and cultural fields."

The first two paragraphs of Article 15 ICESCR are particularly relevant for a right to cultural identity. Concerning the relationship between Article 15 ICESCR and a right to cultural identity, several questions can be posed: why was this provision included in the ICESCR? How should Article 15 be interpreted? Did the drafters or the Member States at any stage give a description of 'cultural life' or "culture", perhaps referring to cultural identity? What is meant by 'to take part"? Is there a specific reason why, in comparison with Article 27 UDHR, the terms 'community' and 'freely' are absent in Article 15(1) ICESCR? Article 15 adds a provision on the conservation, development and diffusion of culture. Is culture considered in a broader sense compared to the Universal Declaration? To answer these questions concerning the interpretation, first the travaux préparatoires are examined. The main discussion on and drafting of Article 15 of the ICESCR took place during the seventh session of the Commission (1951) and during the meetings of the Third

20 UN Doc. A/2929, July 1955, \$21-50, pp. 4-6.

21 General Assembly resolution 2200A (XXI), 16 December 1966. 
Committee of the General Assembly during its twelfth session (1957). Subsequently, other sources are discussed, such as the guidelines for the reporting procedure by the Committee on Economic, Social and Cultural Rights and a debate on Article 15 in the Committee. Finally, attention is paid to the interpretation of Article 15 by various scholars. Another important source of interpretation of provisions is case law. However, no individual complaint procedure has been established under the ICESCR.

\subsection{Travaux Prếparatoires Article 15 ICESCR}

\subsubsection{Commission on Human Rights}

The drafting of Article 15 ICESCR by the Commission on Human Rights started during its seventh session in $1951 .^{22}$ During the fifth session of the General Assembly in October 1950, several governments had brought up issues related to culture to be included in the Covenant. The USSR proposed the right to leisure and culture, ${ }^{23}$ Czechoslovakia suggested the right to education and creative expression, ${ }^{24}$ and Syria wished to include the right to speak one's own language and to study and develop one's own culture. ${ }^{25}$

UNESCO played an important role in the drafting of Article 15 ICESCR. During the seventh session of the Commission, the Director-General of UNESCO stated that cultural rights and rights to participate in culture could not be omitted from the draft covenant. ${ }^{26} \mathrm{He}$ presented the following preliminary draft proposal:

"The signatory States undertake to encourage the preservation, development and propagation of science and culture by every appropriate means:

(a) by facilitating for all access to manifestations of national and international cultural life, such as books, publications and works of art.....;

(b) by preserving and protecting the inheritance of books, works of art and other monuments and objects of historic, scientific and cultural interest;

(c) by assuring liberty and security to scholars and artists...;

(d) by guaranteeing the free cultural development of racial and linguistic minorities." ${ }^{27}$

22 See UN Doc. E/1992 (E/CN 4/640), 24 May 1951 .

23 UN Doc. A/C.3/SR. 289, September-December 1950, \$32, p. 114.

24 UN Doc. A/C.3/SR. 299, September-December 1950, \$33, p. 188.

25 UN Doc. A/C 3/SR. 299, September-December 1950, 55, p. 189. See UN Doc. E/CN.4/513, 2 March 1951, \$20, p. 14; UN Doc. E/CN.4/529, 29 March 1951 , \& xiv, p. 9.

26 UN Doc. E/CN.4/AC.14/SR.1, 17 May 1951, pp. 13, 16, 21. The General Conference of UNESCO adopted Resolution 9.1 in February 1952, in which it was laid down that UNESCO was prepared to take the responsibilities inwolved in the implementation of the right to education and the right to culture; see UN Doc. E/CN.4/655/Add.4, 17 April 1952, p. 2.

27 UN Doc. E/CN.4/541, 18 April 1951. 
At the same time, the Director-General submitted an alternative text "....in case the Commission would prefer a briefer enunciation of cultural rights." The text was as follows:
"The signatory States undertake to encourage by all appropriate means, the conservation, the development and the diffusion of science and culture. They recognise that it is one of their principal aims to ensure conditions which will permit everyone:
1. to take part in cultural life;
2. to enjoy the benefits of scientific progress and its applications;
3. to obtain protection for his moral and material interests resulting from any scientific or artistic production of which he is the author. ${ }^{28}$

Chile formally submitted this preliminary UNESCO draft provision to the Commission. ${ }^{29}$ Draft Article $30,{ }^{30}$ adopted by the Commission at its seventh session, was similar to the brief version proposed by the Director-General of UNESCO. However, the third sub-paragraph on author's rights was rejected. ${ }^{31}$

During the eighth session of the Commission in 1952, several amendments to Article 30 were submitted. In Paragraph 1, after 'science and culture', the USSR wished to insert the words: "... and to ensure the development of science and education in the interests of progress and democracy and of the maintenance of peace and co-operation between peoples", similar to the proposals made during the drafting of the Universal Declaration. ${ }^{32}$ The French delegation proposed to reinsert a third sub-paragraph on authors' rights. ${ }^{33}$ The United States submitted a proposal to reformulate the provision in a more direct way:

"State Parties to the present Covenant recognise the right of everyone:
(a) to take part in cultural life;
(b) to enjoy freedom necessary for scientific research and ereation..,34

Paragraph (b) was later revised by the United States on the initiative of Lebanon into 'to enjoy the benefits of scientific progress and its applications. ${ }^{35}$

28 UN Doc. E/CN.4/541 Rev.1, p. 3.

29 UN Doc. E/CN.4/613 and E/CN.4/613 Rev.1, May 1951.

30 The first drafts were part of a single human rights Covenant. When separating the various provisions into two separate Covenants, Article 30 first became Article 16 and later Article 15 ICESCR.

31 See UN Doc. E/1992 (E/CN.4/640), 24 May 1951, p. 34 and Annex 1, p. 72.

32 UN Doc. E/CN.4/L.52, 25 April 1952.

33 UN Doc. E/CN.4/L.75, France: Draft amendment to Article 30, 29 April 1952.

34 UN Doc. E/CN.4/L.81, United States of America: Draft amendment to Article 30, 2 May 1952.

35 UN Doc. E/CN.4/L.105 and E/CN.4/L.105 Rev.1, Lebanon: amendment to the amendment submitted by the United States of America (E/CN.4L.81), 13 May 1952; UN Doc. E/CN.4/L.81/Rev. 1, United States of America: Draft amendment to Article 30, 14 May 1952. 
No thorough discussion took place on the first part of the provision concerning the right to participate in cultural life. The proposal of the United States to include a specific recognition of what was called 'the right to culture', instead of ensuring conditions for the development of cultural life, was widely supported. It was adopted by 14 votes to none with three abstentions. ${ }^{36}$ Apart from some general statements on the importance of the inclusion of such a provision on culture, the meaning of the term 'cultural life' and the scope of the provision were not discussed. The negotiations in the Commission on Article 30 mainly focused on the proposals of the USSR to include a reference to democracy and peace, and on the French proposal on authors' rights. Most delegations were opposed to including a reference that the development of science and culture should be in the interest of peace, democracy and co-operation. They stated that scientific research and creative activity should be independent of any external criteria. Such a statement could be a pretext for State control. The French proposal on authors' rights was also rejected in the Commission, because most delegations found the issue too complex to be dealt with in a human rights covenant. Moreover, they argued that this matter was properly being dealt with within UNESCO ${ }^{37}$ At its eighth session in 1952, the Commission adopted the final draft Article 16. This provision was similar to the final Article 15 ICESCR, except for : paragraph 1(c) on authors' rights and Paragraph 4 on international co-operation, which were added by the General Assembly.

\subsubsection{General Assembly}

The General Assembly had been working on the ICESCR since 1950, when several States submitted the first proposals to the Commission. Over the years, the General Assembly closely followed the work of the Commission and several delegations expressed their opinions on drafts circulating in the Commission. States generally supported the draft provision on participation in cultural life. In general, the same issues as discussed in the Commission were brought up during the negotiations in the General Assembly. The USSR still wished to include a reference to the fact that science and culture should serve the interest of peace and democracy, ${ }^{39}$ while France expressed the need for the inclusion of authors' rights. ${ }^{40}$

In October and November 1957, five years after the adoption of the draft in the Commission, the main negotiations on the drafting of Article $15^{41}$ took place in

36 UN Doc. E/2256, April-June 1952, p. 19; E/CN.4/SR.294, 27 May 1952, p. 5.

37 UN Doc. E/2256, April-June 1952, p. 19; E/CN.4/SR.292, 27 May 1952, pp. 5-15; E/CN.4/SR.293, 27 May 1952; E/CN.4/SR.294, 27 May 1952, pp. $3-5$.

38 UN Doc. E/CN.4/666/Add.5, 14 May 1952; see, also, UN Doc. E/2573; Annex 1, Draft International Covenants on Human Rights, Article 16.

39 UN Doc. A/C.3/SR.565, October 1954, 32.

40 UN Doc. A/C.3/SR.566, October 1954, \$16 and 22.

41. At that time, it was Article 16, but, for the sake of clarity, from here it will be referred to as Article 15. 
the General Assembly. Czechoslovakia submitted an amendment to add the issue of peace and co-operation to the second paragraph and to add a fourth paragraph on international co-operation in the field of science and culture. ${ }^{42}$ Saudi-Arabia issued a proposal, similar to the first Czech proposal, to include the interests of progress and democracy. ${ }^{43}$ Uruguay proposed to include a paragraph on authors' rights, similar to that of Article 27 UDHR. ${ }^{44}$

In general, the negotiations in the General Assembly on the various amendments were similar to those in the Commission several years before. Many States found a reference to peace and co-operation unnecessary and undesirable, because such a reference would give States an opportunity to exert their influence on science and culture. ${ }^{45}$ Limited debate took place on the precise content of the right to participate in cultural life. The first broader draft of UNESCO to the Commission referred to access to manifestations of national and international cultural life. The briefer text, which was adopted, merely spoke of cultural life. Which cultural life was meant? According to the representative of UNESCO, Article 15 should make some reference to communities involved in the participation in cultural life. It was argued that the individual normally participates in the cultural life of various communities. According to UNESCO, States should not only recognise the right of everyone to participate in his or her national cultural life, but States should also respect the right of a person to have access to foreign cultures or the cultural life of smaller communities within the State. UNESCO accordingly proposed to change the first paragraph into 'to take part in the cultural life of the communities to which he belongs'. 46

The outcome of the negotiations was the adoption of the Czech amendment on an extra paragraph on international co-operation and the adoption of a paragraph on authors' rights. The other amendments and the proposals of UNESCO were rejected or withdrawn. The General Assembly adopted the final draft during its twelfth session in $1957^{47}$ The ICESCR, however, was not adopted until 1966. Between 1957 and 1966, the text of Article 15 was not changed.

Article 15 ICESCR is similar to Article 27 of the Universal Declaration. However, the negotiations, especially in the General Assembly, show that some States, under the influence of UNESCO, were willing to consider the provision in a somewhat

42 UN Doc. A/C.3/L.633, Czechoslovakia: amendment to Article 16 of the draft Covenant on Economic, Social and Cultural Rights (E/2573, Annex IA).

43 UN Dec. A/C.3/L.634, Saudi-Arabia: amendment to document $A / C .3 / L .633$, October-November 1957.

44 UN Doc. A/C.3/L.636 and Add.1, Costa Rica and Uruguay: amendment to Article 16 of the draft Covenant on Economic, Social and Cultural Rights (E/2573, Annex IA), October-November 1957.

45 UN Doc. A/C.3/SR. 796, October 1957, pp. 173-174; see, also, A/OR/12 Annexes, agenda item 33, 1957.

46 UN Doc. A/C.3/SR. 797, October 1957, p. 178; see, also, A/OR/12 Annexes, agenda item 33, 1957

47 UN Doc. A/C.3/SR. 799, October 1957, pp. 190-191; see, also, A/OR/12 Annexes, agenda item 33, 1957. 
broader context. UNESCO, in particular, brought up new issues, such as the role of cultural conmunities, and pointed out that apart from the national culture, other cultural communities could also be important to individuals. However, States did not extensively discuss the content of the provision and gave no interpretation of the concept of 'culture' or 'cultural life'. At the time of its adoption, Article 15 was still mainly meant to make the 'high' material aspects of culture more broadly available. No reference was made to any community. The concrete proposal on communities by UNESCO was rejected, which shows that the emphasis still lay in participation in the national cultural life.

It is understandable that UNESCO played such a significant role in the drafting of Article 15 ICESCR. As described in the previous chapter, UNESCO had been working on cultural rights and the concepts of culture and cultural identity since its foundation, and had adopted several instruments in this field. ${ }^{48}$ In this process, UNESCO already adopted a broader concept of culture including nonmaterial aspects and paid attention to the collective dimension of culture.

The question is to what extent the intention of the drafters is still the valid interpretation of Article 15 ICESCR. Other relevant texts of interpretation are the authoritative texts of the monitoring Committee of the ICESCR. How has the Committee on Economic, Social and Cultural Rights dealt with the implementation of Article 15 ICESCR?

\subsection{Guidelines for the Reporting Procedure under the ICESCR}

In 1990, the Committee on Economic, Social and Cultural Rights adopted revised guidelines for the reporting procedure. ${ }^{49}$ These guidelines provide States Parties with directions on how to report on the implementation of the ICESCR. With regard to Article 15, States Parties should describe the legislative and other measures adopted to fulfil the right of everyone to take part in cultural life and to manifest. their culture. According to the guidelines, the Committee inter alia wants to know which funds are available for the promotion of cultural development, what institutional infrastructure has been established, what role the mass media play in this process, and how mankind's cultural heritage is preserved and presented. The Committee also asks States to provide information on the steps taken for the conservation, development and diffusion of science and culture, through the educational system, the media and communication. It also requests information on the "...promotion of awareness and enjoyment of the cultural heritage of national ethnic groups and minorities and of indigenous peoples." Finally, the Committee explicitly refers to cultural identity in asking information on the "...promotion of cultural identity as a factor of mutual appreciation among individuals, groups, nations and regions.", $\$ 0$

48 O'Keefe, 1998. p. 913. See, for more details, Chapter V of this study.

49 The reporting procedure under the ICESCR is laid down in Article 16 of the Covenant.

50 UN Doc. E/1991/23, Annex 4, revised guidelines, 1990, pp. 108-110. 
In the guidelines, no description of culture is given. It is interesting that the concept of cultural identity is used in the guidelines and thereby brought into a direct relationship with Article 15 ICESCR. The use of the term 'cultural identity' can be a sign of the (silent) acceptance of a broader concept of culture than the drafters of Article 15 had in mind. Cultural identity "as a factor of mutual appreciation", as described in the guidelines, is more than merely the material aspects of culture. Special attention is further given to minorities and other communities, and to the protection of their cultural heritage. With the revised guidelines, the Committee seems to broaden the scope of Article 15 to include more than access to culture and cultural products, and to include a reference to the collective dimension of culture. According to the guidelines, the role of the State is not only a passive one, but allso active. Article 15 may require positive obligations, such as funds to be made available, the establishment of institutions and the involvement of the media and communication. While the drafters considered the State to be the proper body to determine which cultural activities should be supported, in the guidelines the Committee argues that Article 15 contains the right to take part in the cultural life "... which he or she considers pertinent." ${ }^{\text {". }}$ It appears that the ideas of UNESCO concerning the role of cultural communities other than and beyond the national community, which had been rejected during the drafting of Article 15 , were now endorsed by the Committee.

\subsection{General Discussion on Article 15 by the Committee on Economic, Social and Cultural Rights}

The Committee on Economic, Social and Cultural Rights further clarifies provisions in the Covenant by adopting General Comments on specific provisions. ${ }^{52}$ These General Comments are usually preceded by so-called 'days of general discussion" on a specific provision. The Committee held such a day of general discussion on Article 15 during its session in December 1992. It concerned not only Article 15 ICESCR, but also cultural rights in general. Aecordingly, attention was not only paid to the right to participate in culture, but also to the 'right to culture' and other cultural rights. In aid of this debate, one of the Committee members, Mr. Konate (Senegal), prepared a working paper on these matters. A General Comment on Article 15 was, however, not adopted.

51 See also O"Keefe, 1998, p. 913.

52 Another important task of the Committee on Economic, Social and Cultural Rights, which could also contribute to the interpretation and cllarification of provisions is the examination of State reports. Although a detailed study of State reports falls outside the scope of this study, several scholars who have studied these reports are dealt with in the next section. As mentioned above, no indiwidual complaint procedure has been established under the ICESCR, which could have been a useful tool in the clarification of Article 15. 


\subsubsection{Working Paper on Cultural Rights}

In his working paper ${ }^{53}$ Konaté starts by noting that cultural rights are generally underdeveloped, because of a lack of clarity about the content and legal implications for States. Konaté makes a distinction between the right to take part in cultural life and the right to culture. He argues that these rights are often confused, but do not have the same meaning and implications. The right to culture, although acknowledged as relevant, for example by UNESCO, is, according to Konaté, not included in international law. The Committee, however, made no distinction in its guidelines and took the two expressions together. According to Konaté, the right to culture is more than the right to take part in cultural life. It implies that the individual plays an active role in the development of this culture and can identify himself as part of it. The right to take part in cultural life presupposes the recognition of the right to culture of the community to which the individual belongs. Consequently, the right to participate in cultural life is considered to be an individual right, while the right to culture may be regarded as a collective right. ${ }^{54}$

With regard to Article 15 ICESCR, Konaté argued that, unlike other provisions of the Covenant, Article 15 does not refer to precise terms, but to a general concept of 'cultural life'. Konate confirmed that the drafters of the ICESCR had a limited conception of culture in mind, focusing on the external manifestations of culture, such as libraries, museums and works of art. He noted that UNESCO had: started to widen the concept of culture to include human dignity and aspects of human life in addition to its practical manifestations. In general, Konaté advised the Committee to widen the scope of the concept of cultural life, including its individual and collective dimension. "Culture is no longer an expression of knowledge or demand for recreational activities as consumer goods, but reflects a way of being and feeling, in short, the community's way of life and thought.." ${ }^{55}$

Konate further asserts that the right to participate in cultural life includes the right to have access to culture, to enjoy the benefits and demand their protection and to contribute freely to its development. He also argues that the right to have access to culture includes the right to choose a culture and implies equal opportunities and non-discrimination in this respect. The right of access to culture entails the freedom to engage in creative activity, access to the means of dissemination, and protection of the cultural and artistic heritage as an important aspect of cultural identity. ${ }^{56}$

Konate also pays attention to the ways that the Committee could monitor State obligations with regard to Article 15. In his view, States could, for example, be asked whether they had acceded to other international instruments including

53 UN Doc. EA/C. 12/1992/WP.4, Konaté, 25 November 1992.

54 UN Doc. E/C. 12/1992/WP.4, Konaté, 25 November 1992, p. 4.

55 UN Doc. E/C.12/1992/WP.4, Konaté, 25 November 1992, pp. 2-3, 15-16.

56 UN Doc. E/C.12/1992/WP.4, Konaté, 25 November 1992, pp. 5-8. 
cultural rights. Furthermore, the Committee could request States to provide information on their cultural policies, to indicate the administrative and finanoial means used for the promotion of cultural rights, and to explore to what extent they use cultural indicators in development planning. Since education and culture are closelly connected, State Parties could, for example; be requested to report to what extent they had integrated culture into the school curriculas?

In his working paper, Konaté pays special attention to the situation of minorities in relation to culture. He refers to Article 27 ICCPR, which lays down the right to enjoy culture for members of a minority. According to him, both the right to participate in culture and the right to enjoy culture embody the idea of the autonomy and identity of the individual. The individual must have the possibility of identifying with the cultural community of his choice and of establishing relations with it. In his view, minorities are justified in demanding not only recognition of but also respect for their cultural values. The Committee should, thus, give priority to the protection of the cultural rights of minorities. ${ }^{58}$ He also used the concept of cultural identity in relation to minorities. He concluded that "[t]he concept of cultural identity and the requirement to protect it must be defended because they are fundamental aspect of the protection of the rights of linguistic, ethnic and religious minorities...,, $599^{2}$

Finally, Konate describes several difficulties in the implementation of cultural rights. He argues that the progress achieved by State Parties in implementing cultural rights largely depends on the level of implementation of other rights, such as the right to education and the right to an adequate standard of living. Konate argues that access to culture is largely dependent on the economic and social development of a particular society. A minimum of physical well-being is necessary to give the idea of culture any significance. ${ }^{60}$

The Konate working paper offers an interesting interpretation of cultural rights in general and Article 15 ICESCR in particular. For example, the link between cultural rights and other rights, such as the right to education, the right to freedom of expression and rights related to cultural heritage is noteworthy. In my view, it is important to connect other rights to the concept of culture. The link between culture and economic and socilal development is also important. In Konaté's view, a minimum of development is necessary to give culture any meaning. This matter has also come up in Chapter IV. ${ }^{61}$ There, it was argued, however, that if culture is considered in a broad sense, as a 'way of life', it is, to some extent, independent of the level of development. Aspects of culture such as language, religion and traditions also exist in the economically most underdeveloped parts of the world.

57 UN Doc. E/C.12/1992/WP.4, Konate, 25 November 1992, pp. 8-9, 12.

58 UN Doc. E/C.12/1992/WP.4, Konate, 25 November 1992, pp. 8-9.

59 UN Doc. E/C. $12 / 1992 /$ WP:4, Konate, 25 November 1992, p. 16.

60 UN Doc. E/C. $12 / 1992 /$ WP.4, Konaté, 25 November 1992, pp. 12-14.

61 See section 2.1 of Chapter IV of this study. 
Some other aspects of culture, such as museums, the protection of cultural heritage and education, might demand more economic and social development. The definition of minimum core content of Article 15 ICESCR could be helpful in this respect, which should be guaranteed and respected by States, irrespective of their economic and social development.

With regard to the object, subject and addressee of Article 15, Konaté made several interesting remarks. The object of culture and cultural life should be considered in a broader perspective than was envisaged by the drafters, including material as well as immaterial aspects. The subject of Article 15 is the individual. However, Konate clearly recognised the collective dimension of culture and, accordingly, of Article 15. He did, however, distinguish this collective dimension from a collective right, such as, for example, the right to culture. The collective dimension also comes forward in the recognition that speciall attention should be paid to the cultural rights of minorities. Finally, the addressee is the State, which has negative as well as positive obligations. Konate did not pay much attention to the content of these obligations.

\subsubsection{Day of General Discussion in the Committee}

In December 1992, the Committee on Economic, Social and Cultural Rights held a day of general discussion on Article 15. The report of Konaté was the main point of reference during this debate on Article 15. Apart from the Committee members, several external experts were invited to take part in the debate, including UNESCO and the International Movement for Rights and Humanity. UNESCO did not, however, play a prominent role in the discussion, because, as explained by the representative, the organisation was being restructured and had to limit its activities. In general, Committee members stated that the lack of reporting by governments on cultural rights in general, and Article 15 in particular, showed the need to clarify this provision. They generally expressed their agreement on the ideas in the working paper and endorsed the broad vision on Article 15 as formulated by Konate. ${ }^{63}$

While the discussion was too short to draw firm conclusions, the contributions of individual members of the Committee show a possible development of Article 15. Several members explicitly expressed their willingness to adopt a broad concept of culture as being more than cultural manifestations, as to include language, literature, clothing, shelter, arts, customs and traditions. The scope of Article 15 should accordingly be broadened to include not only access to cultural materials but also active engagement in culture and participation in the decision-making process. Several sub-elements of Article 15 were formulated, such

62 The Committee on Economic, Social and Cultural Rights has developed several General Comments in which it describes the minimum core content of ICESCR provisions; see, also, Chapter IV, Section 2.5 .3 of this study. 
as participation, access, policy-making and artistic freedom. Especially for minorities, participation in policy making was considered to be of importance to prevent a certain culture from being turned into a mere tourist attraction, or being 'museumised'. States should not consider cultural rights a luxury, but instead should do as much as possible to allow the greatest number of people to participate. ${ }^{64}$

Another important point was that several members indicated the individual as well as the collective dimension of Article 15. While it was emphasised that Article 15 is an individual right, the community aspect of it was firmly acknowledged. In that respect, several members agreed that the right to participate in cultural life as an individual right was something different from the right to culture, which applied to collectivities. The collective dimension of Article 15 lies in the fact that communities often provide cultural values. ${ }^{65}$ Here again one finds an interesting link with a right to cultural identity, which was also approached as an individual right with a collective dimension.

A limited number of Committee members paid attention to the State obligations with regard to Article 15. The emphasis was laid on negative obligations such as the obligation to respect. Positive obligations following from the obligation to protect and to fulfil were not explicitly discussed. States should mainly respect the development and preservation of cultures and should, as far as possible, refrain from interference. ${ }^{66}$ The formulation of a core content of Article 15 as a minimum to be guaranteed by States was not discussed. In my view, the clarification of State obligations including the formulation of a core content is essential to determine the content and scope of Article 15.

One of the problems distinguished by several members was that cultures of States and the cultures within States differ, which would make a general approach towards the monitoring of Article 15 almost impossible. It was proposed to ask State Parties themselves to describe their cultural indicators, which could be compared with the Committee's indicators. ${ }^{67}$ Besides the fact that it remains unclear what these 'indicators' are, it might be dangerous to invite States Parties to decide on the description of the culture and the communities involved, since that would give them an opportunity to restrict the application of Article 15. On the other, the involvement of States Parties provides information on the specific situations and, if it was tested against the Committee's own indicators, it would be interesting to

64 See, for example, the contribution of Mrs. Bonoan-Dandlan (Philippines), Ms. Hausermanin of the International for Rights and Humanity, and Mr. Texier (France) at UN Doc. E/C.12/1992/SR.17, 11 Decemiber 1992, pp. 4-5, 6-7, and 12.

65. See, for example, the contribution of Mrs. Bonoan-Dandan (Phillippines) and Mr. Mratchkov (Bulgaria) at UN Doc. E/C.12/1992/SR.17, 11 December 1992, pp. 4-5 and 8.

66 See, for example, the contribution of Mr. Wimer-Zambrano (Mexico) at UN Doc. E/C.12/1992/SR.17, 11 December 1992, p. 5.

67 See, for example, the contribution of Mrs. Bonoan-Dandan (Philippines) at UN Doc. E/C.12/1992/SR.17, 11 December 1992, pp. 4-5. 
involve States in the whole process of developing cultural rights in general and Article 15 in particular.

The representative of the International Movement for Rights and Humanity touched upon the sensitive issue of cultural expressions that violate human rights. She argued that cultural practices which are damaging to health or to the enjoyment of other human rights should not be regarded as part of the right to participate in cultural life ${ }^{68}$ Unfortunately, none of the Committee members expressed an opinion on this matter. This issue has also been addressed in previous chapters. Although these matters should be dealt with on a case-to-case basis, the starting point was that cultural activities or expressions that clearly violate human rights should not be excused by an appeal to Article 15 or other cultural rights.

At the end, the Committee invited Konaté to implement the ideas that had come up during the discussion in his working paper. It expressed the wish to continue the discussion in order to come to a clarification of the obligations of States with regard to cultural rights in general, and Article $15 \mathbb{I C E S C R}$ in particular. It was decided to translate the working paper into the Committee's working languages in order to be able to draw general conclusions. ${ }^{69}$ However, it was not until recently that the Committee followed up the work on Article $15{ }^{70}$ It is unclear why the Committee did not continue its debate on Article 15 in 1992. Perhaps the issues diseussed were considered too difficult to solve at the time.

The value of this discussion in the Committee is that it shows the potential of Article 15 ICESCR. As stated above, Article 15 is one of the most important cultural rights, since it is the only article in the ICESCR that directly refers to culture. The debate in the Committee showed that the members of the Committee participating in this debate struggled with several problems familiar to the discussion on a right to cultural identity, such as the definition of culture, the individual and the collective dimension, and the State obligations. It appears that Article 15 could be helpful to protect cultural identity if its scope was broadened to include the broad concept of culture and a collective dimension. Consequently, it is interesting to follow the developments with regard to Article 15.

68 See the contribution of Ms. Hausemann of the International for Rights and Humanity at UN Doc. E/C.12/1992/SR.17, II December1992, pp. 6-7.

69 UN Doc. E/C.12/1992/SR.18,11 December 1992, p. 2.

70 The current chair of the Committee, Mrs. Bonoan-Dandan, has indicated that the debate on article $15(1)$ is reopened to draft a General Comment on cultural rights in general and article $15(1)$ in particular. This process has started with a Round Table discussion in February 2002 in Manilla (Philippines), where Committee members have exchanged view with experts in the field of cultural tights. When finishing this study, no report was yet available. Hopefully, this Round Table will followed by a day of general discussion in the Committee and the adoption of a General Comment. 


\subsection{Interpretation of Article 15 ICESCR by Scholars}

As mentioned before, cultural rights have generally been neglected, not only by States, but also by scholars. Only a few authors have concerned themselves with Article 15 ICESCR. These authors have focused on the content of Article 15, in particular the concepts of culture and participation, and on the corresponding State obligations.

O'Keefe, for example, studied the comments of the Committee on State reports and made an interesting comment on the development of Article 15. With regard to the background of Article 15 ICESCR, O'Keefe argues that the reason that a provision on cultural life was included was again to make culture accessible and available for the masses. He asserts, however, that the drafters did not have in mind what he calls the "popularisation' of culture. The right to take part in cultural life did not imply the right of all a people to enjoy these cultural activities that they themselves found worthwhile. Cultural access did not mean that the masses could rule on which cultural activities should be available and accessible. The drafters wished to recognise merely the aspects of 'high' culture. ${ }^{71}$

$O$ 'Keefe distinguishes three concepts of culture, which were also discussed in Chapter IV, in relation to cultural rights. The first is the classic concept of culture as including arts, literature, theatre and museums. The second concept is culture in a plural form including all manifestations and expressions, for example, folk music, handicrafts, popular press, television and radio. The third concept of culture emanates from anthropology as the way of life of a society, in other words, the society's underlying and characteristic pattern of thought. ${ }^{72} \mathrm{I}$ agree with $\mathrm{O}^{3} \mathrm{Keefe}$, who argues that the content of Article 15 seems to have followed these three stages. While the drafters still focused on the first concept of 'high' culture, the guidelines of the Committee suggest a move to the second concept, which includes popular forms of culture. Finally, during the day of general discussion in 1992, the members of the Committee expressed their willingness to consider culture, in its anthropological form as a way of life. This broad interpretation of culture has also led to increasing attention for minorities and other communities and the protection of their eultural identity. In the Committee's debates on State reports, O'Keefe found that the Committee considered Article 15 as guaranteeing, for both minorities and indigenous peoples, the freedom to practice their culture as well as the opportunity to promote awareness of it, including a degree of autonomy. He asserts that "States are expected to do more than simply allow these communities to practice their lifestyles without hindrance. Governments must take active measures to preserve and foster minority, and especially indigenous, cultures." Accordingly, O'Keefe suggests approaching Article 15 ICESCR as an individual as well as a collective right, depending on the context in which it is sought to be exercised. ${ }^{73} \mathrm{In}$

71 O$^{\prime K e e f e, ~ 1998, ~ p p . ~ 912-9 » 3 . ~}$

72 O'Keefe, 1998, p. 905. See, also Stavenhagen 1998, pp. 2-7 and Stavenhagen, 2001, pp. 87-91.

73 O'Keefe, 1998, pp. 916-918 (quotation p. 918). 
principle, Article 15 is formulated as an individual right and, as such, is applied by the Committee. However, as argued above, O'Keefe found that the Committee also encourages States to protect distinct cultures and communities, which suggests a collective dimension.

With regard to State obligations, O'Keefe argues that a State Party does not fulfil its obligations under Article 15 by merely removing formal obstacles to the equal participation in culture. Article 15 is more than a non-discrimination provision; the State Party should provide substantive ability to participate in culture, which implies negative as well as positive obligations. States Parties should not only promote popular participation in culture in general, but should also actively support the accessibility of cultural activities to the widest possible audience, and the means of their support should also include financial means. ${ }^{74}$

Vlemminx agrees that Article 15 concerns what he calls "passive" and 'active' measures or, in other words, the obligation to respect and to fulfil. With regard to participation in cultural life, the State has the passive duty to respect participation and cultural autonomy, but it also has to take active measures to develop and enlarge participation and autonomy. ${ }^{75}$ Vlemminx argues that Paragraphs 1 and 3 of Article 15 ICESCR concern the passive measures of respect and State abstention. In his opinion, the right to participate in cultural life implies the freedom to provide, collect and pass on cultural information and cultural ideas, which should be respected by the State. Such respect should always be guaranteed, even if practical circumstances, such as a shortage of resources, occur. The active measures to be taken by the State are described in the second paragraph of Article 15. This paragraph lays down various goals of cultural participation, such as the conservation and diffusion of culture. ${ }^{76}$ Vlemminx distinguishes four general purposes of the right to participate in cultural life that a State should pursue. Firstly, individuals should be able to move freely and autonomously in a cultural climate. In other words, the State should protect cultural autonomy and cultural pluriformity. Secondly, the State sliould make sure that, despite pluriformity, a culture does not lose its identity. Individuals should be able to identify with a culture and thus the spread of culture amongst the population should be encouraged. Thirdly, the State should promote the development of culture for the future. Finally, the State should protect cultural heritage for generations to come. ${ }^{77}$

O'Keefe and Vlemminx both argue that Article 15 also concerns the obligation to protect. O'Keefe asserts that States should under Article 15, protect rights from interference by public or private bodies, but also by foreign cultural influences. He argues that, in this sense, the Committee closely watches interference in cultural life by religious institutions and that it has also expressed its

74 O'Keefe, 1998, pp. 905-906, 908, 911 .

75 Vlemminx, 1992, pp. 197, 207, 239.

76 Vlemminx, 1992, pp. 231-233; Vlemminx, 1994, pp. 115, 138.

77 Vlemminx, 1992, pp. 199-200. 
concern about the possible standardisation of cultures. ${ }^{78}$ Vlemminx also stresses the abligation to protect under Article 15(1) sub c, according to which the State should protect the moral and material interests which result from creative activity. $\mathrm{He}$ argues that this implies protection of these rights against disrespect by other individuals. $^{79}$

Eide and Symonides have also applied the tripartite typology to Article 15 ICESCR. They argue that, first and foremost, the State is obliged to respect the freedom of the individual to develop and assert a preferred cultural orientation. States should refrain from action that would obstruct the individual from taking part in cultural life. With regard to the obligation to protect, the State should protect the individual's right to participate in culture against third parties who, by the assertion of their cultural identity or engagement in cultural activities, disrupt the enjoyment of this right. For example, the cultural expressions of one community might be offensive to other communities and should not be allowed, because they might become the origin of community conflicts. Finally, at the level of the obligation to fulfil, the State should take measures to improve the conditions under which the right to participate in culture can be enjoyed. These measures may, for example, concern improving access to culture through funds or the establishment of an institutional infrastructure to promote popular participation in culture. As others also indicated, Eide and Symonides argue that the State has a special responsibility with regard to vulnerable or disadvantaged groups in society. ${ }^{80}$

Several authors point at the limits of Article 15 ICESCR. O'Keefe asserts, for example, that the Committee does not accept the unlimited freedom of creative activity. Creative expressions should not harm the cultural life of society as a whole or of specific vulnerable groups, such as children. Such censorship would, according to O'Keefe, be in accordance with Article 4 ICESCR as a means of promoting general welfare. ${ }^{81}$ Vlemminx argues that limitations seem to be allowed when the exercise of rights in the Covenant would endanger or harm individuals or society. He specifically asserts that Article 15 ICESCR may be limited if cultural activities include discriminatory expressions. ${ }^{82}$

\section{The Right to Take Part in Cultural life in Relation to a Right to CULTURAL IDENTTTY}

In this chapter the nature, scope and content of Article 27 UDHR and Article 15 ICESCR were analysed to examine their role in the protection of cultural identity. Essential in this respect are the descriptions of the concepts of culture and cultural life, the individual and collective dimension and the State obligations.

78 O'Keefe, 1998 , pp. $911,919$.

79 Vlemminx, 1994, p. 139.

80 Eide, 2001-B, pp. 293-295; Symonides, 2000-A, p. 206.

81 O'Keefe, 1998, pp. 911-912.

82 Vlemminx, 1994, p. 117. See, also, Toebes, 1999, p. 297. 
Article 27 UDHR contains the right to participate freely in the cultural life of the community. Culture was considered in its narrow scope as involving material aspects, such as arts and literature. This 'material culture' that used to be mainly reserved for a small elite should be made available and accessible to all people. The term 'community" refers to the national community. No reference is made to the concept of cultural identity or to the protection of the cultural identity of individuals or communities. The importance of Article 27 is that it includes culture as a value to be protected by human rights. Furthermore, Article 27 served as a model for Article 15 of the ICESCR.

Article 15 ICESCR includes the right to take part in cultural life, without the term 'freely' and without a reference to 'the community'. Article 15 ICESCR has the same background as Article 27 UDHR. Culture used to be something for a small group in society and Article 15 was meant to make cultural life accessible and culture available to the whole population. At the time of drafting Article 15 ICESCR, culture mainly implied national culture and was approached in a narrow sense as equivalent to cultural material. Other aspects of a broader concept of culture, such as language, religion and education, were dealt with in separate provisions in the ICESCR and the ICCPR. Moreover, Article 15 was drafted as an individual right; no attention was paid to its possible collective dimension. The suggestion by UNESCO to include a reference to the community to which someone belonged was rejected.

During the first 25 years of the Covenant, Article 15 was hardly given any attention by either the Committee or by States Parties in their periodical reports. ${ }^{83}$ The Committee first broadened the scope of Article 15 in its revised guidelines for the reporting procedure adopted in 1990. In these guidelines, the Committee used new concepts such as cultural identity, cultural development and the right to manifest one's culture. It asked States Parties, for example, what they did to promote cultural identity, which was considered to be a factor of mutual appreciation among individuals, communities, nations and regions. The Committee also wished to know how States dealt with the promotion of the cultural heritage of national ethnic groups, minorities and indigenous peoples. Article 15 no longer merely referred to national culture, but States were also considered to have a responsibility for the preservation of cultures of other communities:

The Committee made a further attempt to clarify the content and scope of Article 15 ICESCR during its general discussion on this provision in 1992. While the Committee, as such, did not draw general conclusions; the interventions by the different Committee members showed the possible development of Article 15. Most members endorsed the broad concept of culture that went beyond its practical results, and included non-material aspects, such as traditions, language, religion, efc. Furthermore, participation in culture was more than simply having access to it, but should include active participation in the decision-making process and being able to contribute to culture actively. With regard to State obligations, the

83 O'Keefe, 1998, pp. 904-905. 
Committee members tended to stress the negative obligations, such as the obligation to respect. States should not interfere with the free development and expression of culture. The obligations to protect and to fulfil were, however, hardly discussed by the Committee. Notwithstanding this, in my opinion, various authors have correctly emphasised that Article 15 implies negative as well as positive obligations, and includes the obligation to respect, protect and fulfil. These measures include, inter alia, respect for the freedom to provide and collect cultural information, protection of culture from disrespect by others, and active support, also financially, for the accessibility of culture, including its required cultural infrastructure.

The study of Article 27 UDHR and Article 15 ICESCR confirms the increasing general attention for cultural rights, a fact which is similar to the developments within UNESCO. In fact, UNESCO played an important role in the development of cultural rights within the UN by drafting Articles 27 UDHR and 15 ICESCR, and by taking part in debates on these rights. Under the influence of UNESCO, both provisions have been developed over the years. While, at the time of adopting Article 27 UDHR and Article 15 ICESCR, the right to participate in cultural life was supposed to make the material aspects of culture available and accessible to the masses, it now has a broader content and scope. If Article 27 UDHR and Article 15 ICESCR were interpreted according to the intention of their drafters, they would have a limited link with the protection of the cultural identity of individuals and, more particularly, of communities. In a broader sense, however, both provisions have a growing link with the protection of cultural identity. In other words, Articles 27 UDHR and 15 ICESCR can be part of the protection of the cultural identity of individuals and communities if they are interpreted in the broad sense, including the broad concept of culture, the individual and the collective dimension and the three levels of State obligations to respect, protect and fulfil.

With regard to the development and interpretation of Article 15 ICESCR, the Committee has an important role to play. If the Committee is willing to adopt a broad interpretation of Article 15 definitively, which will also have its influence on Article 27 UDHR, it will thereby give Article 15 an important meaning in relation to the protection of cultural identity. Such an attempt to clarify and broaden cultural rights in general, and Article 15 ICESCR in particular, may diminish the need to develop a right to cultural identity. If existing rights could protect the cultural identity of individuals and communities, it would save negotiations on a right that would be difficult to define. The approach would be to focus on the existing international instruments and clarify them, instead of developing a new one. The need for clarification of the object and State obligations under Article 15 has been made clear, which could be provided for by the Committee in a General Comment. In this General Comment, the Committee will likely try to formulate a minimum core content of Article 15, which is not an easy task. Furthermore, it should deal with sensitive issues, such as how to deal with cultural activities that violate human rights. Apart from interpretation through a General Comment, the supervisory rolle 
of the Committee in its dealing with State reports is important to clarify the scope of Article 15. Unfortunately, no individual complaint procedure has been established under the ICESCR, which could be helpful in the clarification of Article $15 .^{84}$ The next chapter, on Article 27 ICCPR, shows how important such procedures can be for the development of provisions in the Covenants.

84 See, for an extensive analysis of an individual complaint procedure under the ICESCR, Arambulo, 1999. 


\section{CHAPTER VII CULTURAL IDENTITY AND MINORITIES}

\section{INTRODUCTION}

In the previous chapter, the potential significance of the right to participate in cultural life for a right to cultural identity has been examined. Another place to search for cultural rights and the concept of cultural identity is the human rights protection of minorities and indigenous peoples. The increasing attention for these two groups has led to the development of human rights instruments especially designed for them. Since the cultural identity of these communities is often in jeopardy, the protection of their cultural identity has a prominent place in these instruments.

This chapter examines the debate on the minority rights provisions in the Universal Declaration of Human Rights (UDHR), and Article 27 of the International Covenant on Civil and Political Rights (ICCPR), which guarantees members of minorities the right to enjoy their culture in community with others. Furthermore, specific provisions of the UN Declaration on Minorities, including one on cultural identity, are analysed. The main questions are how the concept of cultural identity is dealt with in relation to the protection of minorities, the content and scope of cultural rights provisions relating to those minorities, and the role of these provisions in the protection of the cultural identity of minorities and other communities. The analysis focuses on the development of the concept of cultural identity and its protection rather than on the issue of minority protection per se. Thus, limited attention is paid to specific matters relating to minorities, such as the definition of minorities, the background and development of minority protection, and their relation to other communities, such as indigenous peoples.'

\section{Minorities AND the UnIVERSAL DEClaRATION OF HUMAN RIGHTS}

Due to a failure to reach an agreement, the UDHR does not contain any provision on minorities or the protection of their cultural identity, despite the fact that these issues had always been an integral part of the drafting negotiations. The concept of culture also played a role in the discussions among the UN Member States. The following section examines the negotiations in the Sub-Commission on Prewention of Discrimination and Protection of Minorities (Sub-Commission), the Commission

1 Indigenous peoples and the protection of their cultural identity under intemational law are dealt with in Chapter WIII. 
on Human Rights (Commission), and the General Assembly, more specifically, the Third Committee.

\subsection{The Sub-Commission on Prevention of Discrimination and Protection of Minorities}

The Sub-Commission discussed a preliminary draft provision of the Secretariat on minorities in its first session in December 1947. This preliminary draft stipulated that countries with a 'reasonable number' of individuals of another race, language or religion than the majority, such individuals of ethnic, linguistic or religious minorities were entitled to set up their own schools, religious or cultural institutions, and that these would be partly State-funded. They were also to enjoy the right to use their own language before courts and State organs, in the press and at public meetings. The reference to public funds was rapidly removed, but the remainder of the text stayed intact. ${ }^{3}$ The Sub-Commission studied the draft from the following perspective:

“...protection of minorities is the protection of non-dominant groups which, while wishing in general for equality of treatment with the majority, wish for a measure of differential treatment in order to preserve basic characteristics which they possess and which distinguish them from the majority of the population... The characteristics meriting such protection are race, religion and language."

It recognised that, apart from equality, particular communities could strive for specific protection of their distinct characteristics. Culture was not explicitly cited as one of these characteristics, although the Sub-Commission did identify two important aspects of culture: language and religion.

The Sub-Commission maintained the individual-based approach, but replaced the term 'minorities' by 'groups', adding that such groups should be welldefined and should want to be treated differently. Another issue was whether these rights should apply to all individuals, or only to nationals of the state concerned. The Sub-Commission was of the idea that minority rights were more a question of the generosity of individual States rather than an inherent right on the part of the communities involved. Consequently, a minority was to be collectively loyal to the State and its members were to be nationals of that State. ${ }^{5}$ It is interesting to note that, on the one hand, the Sub-Commission recognised that some communities might be in need of extra protection apart from non-discrimination, but that such

2 For a detailed overview of this process, see, Morsink, 1999-B, pp. 1013-1028. The author tries to establish a link between the refusal to include a provision on cultural genocide in the Genocide Convention, adopted on 9 December 1948, and the rejection of a provision on minorities in the Universal Declaration, adopted on 10 December 1948.

3 Verdoodt, 1963, pp. 288-289; Thomberry, 1991, pp. 133-134; Morsink, 1999-A, p. 271.

4 United Nations, 1950, pp. 106-108.

5 Maskowitz, 1968, p. 156. 
protection was not considered an inherent right. The "generosity" of the State was to be rewarded by the undivided loyalty of the communities involved who had to be nationals of that State. There was a general lack of agreement on the inclusion of a provision on minorities which many members of the Sub-Committee simply found too vague. The text was finally adopted by six votes to four with two abstentions. In the report to the Commission, the Sub-Commission addled a comment that this provision had been an issue of much discussion. ${ }^{6}$

\subsection{The Commission on Human Rights}

The scope and content of the draft provision were negotiated in the Commission during its third session in June 1948. Supporters of the draft text emphasised that many minorities had been assimilated against their will and were in need of special protection. Opponents wanted to delete the entire draft article as superfluous, because the draft UDHR already included provisions on equality and nondiscrimination. Other delegates added that the rights of minorities were already sufficiently protected by the rights to freedom of religion, freedom of the press, freedom of information, freedom of association, freedom of education, and the right to participate in the cultural life of the community. It is interesting to note that within the Commission there appears to have been a shift of emphasis from extra protection in relation to the cultural aspects of minority rights back to equality, nondiscrimination and generic universal rights in relation to cultural aspects. There was no discussion on the specific meaning of "culture' or a 'right to culture".

\subsection{The General Assembly (Third Committee)}

The Third Committee of the General Assembly negotiated the draft provision on minorities during its third session in September 1948. The main topics of discussion were the dilemma between special protection and integration, and the recognition of minorities as such. Several draft provisions included a right to culture. The USSR delegation, for example, submitted a text stating that, "...everyone has the right to his own ethnic or national culture, whether or not he is part of the majority concerning race, national origin or religion." These persons would also have the right to set up their own schools, develop education in their own language and use their language in the press. $^{8}$ The Yugoslavian representative emphasised the importance of recognising minorities as such, and formulated a draft article which stated that, "...every national minority, considered as an ethnic community, has the right to develop its ethnic culture and to freely use its language. The State should assure the protection of these rights."

\footnotetext{
Verdoodt, 1963, pp. 290-291; Morsink, 1999-A, pp: 272-273.

Verdoodt, 1963, pp. 293-294, 297.

Thomberry, 1991, p. 134; Verdoodt, 1963, pp. 294-295; Morsink, 1999-A, p. 274.

Thornberry, 1991, pp. 134-136; Verdoodt, 1963, p. 295; Morsink, 1999-A, p. 275.
} 
In the last instance, no compromise appeared possible between the supporters of assimilation of minorities and supporters of specific rights for minorities. Moreover, there was no agreement on the issue of collective rights and the recognition of minorities. Consequently, the General Assembly decided not to include a provision on rights of minorities in the final text of the Universal Declaration, given the difficulty of finding a uniform solution to this complex and delicate problem. ${ }^{10}$ The General Assembly requested ECOSOC to ask the Commission and the SubCommission to carry out further research on this issue in Resolution $217 \mathrm{c}$ (III), adopted by 46 votes to six, with two abstentions. "I

To conclude, the negotiations on the inclusion of minority rights in the Universal Declaration contain several references to culture that are linked to cultural identity. Indeed, the right to culture was part of several proposals that were rejected. In comparison with Article 27 UDHR on participation in culture, the term 'culture' was used in a much broader context during the negotiations on minorities, including language, religion, traditions, etc. Other interesting points were the discussion on whether minorities and their culture were in need of special protection in addition to that afforded by the general principles of equality and non-discrimination, and to what extent other rights could play a role in the protection of minority cultures. Finally, there was a debate on the issue of individual and collective rights. These points can also be found in the discussions on a right to cultural identity. The above shows that already during the drafting of the Universal Declaration the protection of minorities and their culture was part of the debate, although no agreement could be reached on the inclusion of these aspects in the Universal Declaration.

\section{Article 27 of the International Covenant on Civil and Polttical RIGHTS}

Following the failure to include minority protection in the Universall Declaration, the Sub-Commission continued its work on the protection of minorities. It decided not to submit a research report, as requested by the General Assembly, but to focus instead on drafting a provision to be included in the ICCPR, which became Article 27 ICCPR reading as follows:

"In those States, in which ethnic, religious or linguistic minorities exist, persons belonging to such minorities shall not be denied the right, in community with the other members of their group, to enjoy their own culture, to profess and practise their own religion, or to use their own language."

10 Morsink regrets this missed opportunity and pleas for the inclusion of an article on minority protection as an amendment to the Universal Declaration, see Morsink, 1999-B, pp. 1053-1060.

11 Thornberry, 1991, p. 149; United Nations, 1950, pp. 16, 108; Verdoodt, 1963, pp. 256, 298-299; Robinson, 1958, p. 29; Nowak, 1993, pp. 481, 483; Moskowitz, 1968, p. 168. 
This provision refers directly to the right to enjoy culture, albeit not as a universal right, but specifically for members of ethnic, religious or linguistic minorities. This provision illustrates that the concept of "culture" was considered in a broader context in relation to minority protection, than with regard to the universal right to take part in cultural life. Indeed, Article 27 ICCPR directly links culture with religion and language and with a collective dimension expressed in the term in community with the other members of their group". The analysis of the background and content of Article 27 concerns the question as to what extent Article 27 can play a role in the protection of the cultural identity of individuals and communities.

\subsection{The Drafting Process of Article 27 ICCPR}

During the drafting of a provision on minorities the Sub-Commission returned to equality as the starting point for minority protection, whilst recognising that de facto equality might imply special measures for certain communities. It argued that the essence of equality was to refuse to recognise irrelevant distinctions, rather than to erase all distinctions. ${ }^{12}$ The Sub-Commission described the term 'minorities' at its third session in 1950 as, "...only those non-dominant groups in a population which possess and wish to preserve stable ethnic, religious or linguistic traditions or characteristics markedly different from those of the rest of the population." These minorities were to be sufficiently large to be able to develop such characteristics and their members should be loyal to the State "of which they are nationals."13

A drafting committee of the Sub-Commission formulated a concrete proposal which stated that, "[e]thnic, religious and linguistic minorities shall not be denied the right to enjoy their own culture, to profess and practice their own religion, or to use their own language."14 The term "minorities' was subsequently replaced by 'persons belonging to minorities', since minorities were considered to lack legal personality. ${ }^{15}$ In order to indicate the collective character of the provision, the phrase, 'in community with the other members of their group' was included. The Sub-Commission adopted this draft in 1950 by nine votes to zero with one abstention and submitted it to the Commission for adoption. ${ }^{16}$

12 United Nations, 1950, p. 109; Moskowitz, 1968, pp. 168-169. The difference between formal equality and factual equality was already made by the Permanent Court of International Justice in the case concerning Minority Schools in Albania, Permanent Court of International Justice, Ser. $\mathrm{AB}, \mathrm{No} .64,1935$, p. 17. See also, Tomuschat, who argues that apart from non-discrimination or equality in law, Art. 27 also includes special protection or equality to protect minorities from compulsory assimilation; Tomuschat, 1983, pp. 966-968, 970 .

13 United Nations, 1950 , p. 110.

14 E/CN.4/Sub.2/112, see also, Nowak, 1993, p. 483.

15 On the issue of the legal personality of minorities, see, Meijknecht, 2001.

16 See, E/CN.4/358, 30 January 1950, \& 47, Resolution E; E/CN.4/641, 25 October 1951, Annex II; see also, Thornberry, 1991, p. 149; Nowak, 1993, p. 483. 
The Commission started negotiating the draft provision on minority rights in 1951. The main issues were minority protection through individual versus collective rights, State abstention versus positive State obligations, the definition and types of minorities to be protected, limitation of the protection to old, long-established minorities or extension to immigrants, and autonomy versus assimilation. Two drafts presented by the USSR and Yugoslavian delegations were rejected. The USSR draft ${ }^{17}$ proposed that States should guarantee their national minorities the right to use their own language and to set up their own schools, libraries, museums and other cultural and educational institutions. The Yugoslavian proposal ${ }^{18}$ included a specific prohibition of discrimination and the right of every member of a minority to make use of its national language, to be educated in one's own language, and to develop its own culture. ${ }^{19}$

Chile and Uruguay submitted amendments limiting the scope of the draft provision, because they were concerned that it could lead to restrictive policies on the part of States that had generally been willing to accept refugees and immigrants. It was feared that a provision on the protection of minority cultures would have a profound effect on national cultures, and it was consequently argued that immigrants and refugees be excluded from the scope of the provision. Chile proposed $^{20}$ to dlescribe minorities as groups of people that were stable, well-defined and long-established. Uruguay suggested ${ }^{21}$ the inclusion of a second paragraph stating that immigrant minorities were not allowed to form separate communities that might endanger national unity or security. ${ }^{22}$ In the last instance, the Uruguayan proposal was rejected, while the Chilean proposal was adopted in a modified form, removing "stable and well-defined" and replacing "have long been established' by "[i]n those States in which ethnic, religious or linguistic minorities exist..." The draft was adopted by five votes to one, with ten abstentions ${ }^{23}$, which is indicative of the ongoing difficulties and lack of agreement on the draft provision.

The Commission's draft was negotiated in the Third Committee of the General Assembly in 1961. The debate focused on the same matters as in the Commission, but no concrete amendments were submitted. Finally, the draft adopted by a vote of 80 to none, with one abstention (South Africa). ${ }^{24}$ The fact that no State voted against the provision indicates the strength of support for the provision on minority protection, which is interesting considering the lack of agreement within the Commission.

17 UN Doc. E/CN.4/L.222; see also, A/C.3/L.96 and A/C.3/SR.289.

18 UN Doe. E/CN.4/L.225; see also, A/C.3/L.92.

19. UN Doc. E/CN,4/528, 2 April 1951, pp. 10-11; see also, Thomberry, 1991, p. 150; Nowak, 1993, p. 484.

20 UN Doc. E/CN.4L.261.

21 UN Doc. E/CN.4/L.260.

22 UN Doc. E/CN.4/528, 2 April 1951, pp. 10-11; see also, Thornberry, 1991, pp. 150, 154-155; Nowak, 1993, p. 484 .

23 Thomberry, 1991, p. 150; Nowak, 1993, p. 484.

24 Thomberry, 1991, p. 151; Moskowitz, 1968, p. 157; Nowak, 1993, p. 485. 


\subsection{Interpretation of Article 27 ICCPR by Scholars and the Human Rights Committee}

While Chapter VI has highlighted how Article 15 ICESCR was neglected by States and scholars, and no General Comment was adopted on Article 15, much more interpretative work has been carried out on Article 27 ICCPR. Several scholars have interpreted the content and scope of Article 27, and examined the intentions of the drafters and subsequent developments. The supervisory body of the ICCPR, the Human Rights Committee (HRC), has done an important job in clarifying Article 27 through its comments on State reports, its individual complaint procedure, and in its General Comment on Article 27. The last two are discussed in detail, while the State reports are referred to more generally. Another important source of interpretation of Article 27 ICCPR is a report by a Rapporteur of the SubCommission, Francesco Capotorti, who dealt extensively with minority issues in his 'Study on the Rights of Persons belonging to Ethnic, Religious and Linguistic Minorities' of 1979 . These sources are dealt with thematically by subject, object and beneficiaries of Article 27 ICCPR. Several cases under Article 27 are dealt with in section 4 of this chapter.

\subsubsection{The Subject of Article 27 ICCPR: Members of Minorities}

The subjects of Article 27 are all those persons belonging to an ethnic, religious or linguistic minority. But precisely what is a minority in the sense of Article 27 ICCPR? Without going into detail on the definition debate, it should be noted that the meaning of the term is disputed, and that to date States have not agreed on a definition. $^{25}$ The failure to adopt a definition during the drafting process of Article 27 is ample proof of the disagreement among States on this matter. What the drafters had in mind was what Tomuschat refers to as, "stable units with a notable degree of historical continuity". The term 'minorities" only covered well-defined communities with a long-established presence on the territory of a State. ${ }^{26}$

The most widely used academic definition of minority is that of Special Rapporteur, Capotorti who defines minorities as:

"A group numerically inferior to the rest of the population of a State, in a nondominant position, whose members - being nationals of the State - possess ethnic, religious or linguistic characteristics from those of the rest of the population and show, if only implicitly, a sense of solidarity, directed towards preserving their culture, traditions, religion or language. ${ }^{327}$

25 On this matter, see, inter alia, Meijknecht, 2001, Chapters III and IV.

26 Tomuschat, 1983, p. 955.

27 Capotorti, 1979, p. $96(\$ 568)$. 
This definition contains two objective elements, the non-dominant position and the difference in ethnic, religious and linguistic characteristics, and one subjective element, namely the sense of solidarity including the wish to preserve these special characteristics.

In its General Comment 23 on Article 27, adopted in 1994, the HRC stated that Article 27 should not be confused with Article 1 on the right of peoples of selfdetermination. Instead of peoples, Article 27 applies to individuals belonging to minorities. The rights protected by Article 27 should be compatible with the sovereignty and territorial integrity of States, even though some of the rights in Article 27 , such as the right to enjoy culture, are closely related to that territory and its resources. ${ }^{28}$

Can aliens be considered minorities? The drafters intended that immigrants, including migrant workers, should not be considered minorities, as reflected in the emphasis on history and stability in the term 'exist'. In his definition, Capotorti concludes that only nationals are covered by the term 'minorities'. ${ }^{29}$ It would appear, however, that the meaning of the term 'minorities' in relation to Article 27 has changed over time. Some authors argue that aliens or immigrants are not automatically excluded from protection under Article 27, insofar as they can develop into stable units as required by Article 27. Although the underlying idea may have been that immigrants did not wish to remain a separate community within their new homeland and that they lacked a stable character, immigrant societies now often wish to preserve their identity and be acknowledged as separate entities. ${ }^{30}$ This view is confirmed by the HRC in its General Comment on Article 27 where it asserts that the subjects of Article 27 are persons belonging to a group who have a common culture, religion and/or language. The HRC uses the term 'group' instead of minority and also stipulated that aliens can be defined as 'minorities". 31 The decisive factor is no longer that minorities have to have a historical background, but that they constitute stable communities that have distinct characteristics which they wish to preserve.

Another question is whether indigenous peoples can be considered minorities. During the drafting of Article 27, some States explicitly stated that they did not consider indigenous peoples to be minorities. ${ }^{32}$ The general idea was that the culture of indigenous peoples was so backward and primitive that it did not need special protection and was doomed to disappear within modern society. Tomuschat considers this attitude as, "a naive feeling of cultural superiority", and argues that

28 Human Rights Committee, General Comment 23, Article 27, 1994, $\$ 2,3.1$ and 3.2 .

29 Capotorti, 1979, p. $12(\$ 57)$, p. $96(\$ 568)$.

30 Tomuschat, 1983 , pp. 958,962 ; Nowak, 1993, pp. 489-490.

31 Human Rights Committee, General Comment 23 on Article 27, fitteenth session, 1994, \$ 5.1: "The individuals designed to be protected need not be citizens of the State party."

32 These States were, for example, Chile and Australia. See Tonuschat, 1983, p. 962. 
indigenous peoples can constitute perfect examples of long-established ethnic, linguistic or religious minorities. ${ }^{33}$ Capotorti, on the other hand, makes no reference to indigenous peoples in his report. From analysing the practice of the HRC, several scholars agree that indigenous peoples may fall within the scope of Article 27. The HRC has declared several cases of communities that could be covered by the term indigenous peoples admissible under Article 27. ${ }^{34}$ They also assert that HRC practice in dealing with State reports reveals how it encourages States to take positive measures under Article 27 to protect the culture, language and religion of indigenous peoples, whereby this reference to indigenous peoples is in prineiple not disputed by States. ${ }^{35}$ In its General Comment on Article 27 the HRC indeed affirms that indigenous peoples, or the members of indigenous peoples, can fall within the scope of Article 27, especially with regard to their culture. ${ }^{36}$

The attitude of the HRC in this respect has been criticised by Marquardt who argues that, "...by reducing the issue of indigenous rights to one of minority protection, the HRC has in effect denied indigenous peoples any future opportunity to claim any right to self-government, autonomy or any related political rights under the ICCPR, since Article 27 of the ICCPR only protects individual rights relating to language, religion and culture." ${ }^{37}$ The question of whether indigenous peoples wish to be perceived as minorities or not, and the issue of the self-determination of indigenous peoples are dealt with in Chapter VIII. Here it is sufficjent to note that indigenous peoples have different feelings on this matter, some have invoked Article 27 to lodge complaints against their governments, whilst others specifically deny that they constitute minorities. ${ }^{38}$

\section{Individual or Collective Rights}

The concrete subject of Article 27 is not the minority as such, but every person belonging to an ethnic, religious and linguistic minority. This individual approach was chosen at the onset of the drafting process. States feared that by giving minorities per se specific rights and thereby legal personality, they would undermine national stability and tend to encourage separatist tendencies. States also wanted to ayoid a situation where minorities could lodge claims of rights violations with the HRC. The collective dimension was the reference to the common enjoyment with other members of the group. It is generally agreed that strictly

33 Tomuschat, 1983 , p. 962.

34 Among others, Kitok v. Sweden Comm. No. 170/1984 and 197/1985; Ominayak v. Canada, Comm. No. 167/1984; Lovelace v. Camada, Comm. No. 24/1977; Länsman v. Finland. Comm. No. 671/1995. These cases are discussed in more detail below.

35 Cholewinski, 1988, pp. 361-362; Rodley, 1995, pp. 61-62; Nowak, 1993, pp. 493-494.

36 Human Rights Committee, General Comment 23, Article 27, 1994, $\$ 5.1$ and 7; see also, Cholewinski, 1988, p. 361.

37 Marquardt, 1.995, p. 75.

38 Compare, for example, the cases cited in note 34, with the Sami in Norway, who have specifically denied that they fall under the term minorities, see Chapter XI. Both issues of the diffierence between indigenous peoples and minorities and self-determination are dealt with in Chapter VIII 
speaking Article 27 contains an individual right with a collective dimension. While this collective dimension is familiar in other human rights, such as the right to freedom of religion or freedom of association, Article 27 explicitly refers to the communal aspect of cullture, language and religion. Even though collective rights as such are not recognised in Article 27, this does not prevent a group of individuals from bringing a joint action to the $\mathrm{HRC}^{\prime}$ in cases where their rights are equally affected, whereby beneficial effects may extend to the community as a whole. ${ }^{39}$ As Tomuschat points out, the individual approach of Article 27 brings this provision under the individual complaint procedure, while collective rights such as Article 1 do not fall under this procedure. ${ }^{40}$ Thornberry argues that,

"[t]he rights in Article 27 are a hybrid between individual and collective rights, because of the community requirement: the right of a member of a minority is not exercised alone; enjoyment of culture, practice of relligion, and use of language presupposes at community of individuals endowed with similar rights.",41

\section{3,2.2 The Object: the Content of Article 27 ICCPR}

What is the object or content of Article 27, and what is the relationship between Article 27 and other international human rights provisions, such as Article 15 ICESCR and other cultural rights? To what extent does the interpretation of Article 27 include a reference to the protection of cultural identity? In his report, Capotorti argues that the right to enjoy culture as laid down in Article 27 involves other human rights, such as the freedom of expression, the right to education and the right to take part in cultural life. Compared to Article 15 ICESCR, Article 27 ICCPR establishes not only the right to participate in cultural life in general terms, but also the common enjoyment of a specific culture. According to Capotorti, the term 'culture' needs to be interpreted broadly, to include customs, morals, traditions, rituals, types of housing, eating habits, but also arts, music, cultural organisations, literature and education. ${ }^{42}$ Capotorti goes on to assert that the right to enjoy culture implies not only the recognition of the right to develop this culture, but also specific action to execute this right. This implies, for example, that measures should be taken in the field of arts and literature, such as the publication and translation of books in the minority language, exhibitions of art work, the preservation of legal traditions and cultural heritage and support for the diffusion of the culture of minoritie, through the press, radio and television. ${ }^{43}$ In short, Capotorti asserts that,

39 Rodley, 1995, p. 52; Nowak, 1993, pp. 495, 497, 499; Tomuschat, 1983, pp. 954, 966; Thornberry, 1991, pp. 187-188, 193, 197.

40 Tomuschat, 1983, p. 979; see also, Lubicon Lake Band v. Canada, Comm. No. 167/1984 below.

41 Thornberry, 1991, p. 173.

42 Capotorti, 1979, pp. 99-100 (8); see also, Nowak, 1993, p. 501.

43 Capotorti, 1979, p. $57(\$ 330)$, and p. $99(\$ 590-594)$. 
"...the objective to be attained is the preservation and natural development of the cultural identity of minorities: the State is therefore called upon to adopt all necessary means to that end." (Italics added by author)

In its General Comment on Article 27, the HRC endorses a broad concept of culture and adds that culture includes for example a particular way of life associated with the use of land resources, especially in relation to indigenous peoples. Traditional activities such as fishing or hunting are indeed protected under Article 27. ${ }^{45}$ There is further general agreement among scholars that Article 27 involves a broad interpretation of culture, and several of them specifically refer to cultural identity as an underlying value. Thornberry, for example, argues that the right to enjoy culture implies all aspects of that culture, including, "...the ability of minorities to preserve their cultural identity and their cultural inheritance..." Article 27 provides minorities with, "...the legal foundations for preserving their specific identity." 47

Some scholars link Article 27 to other cultural human rights, arguing that a broad interpretation of other human rights norms, such as non-discrimination (Article 26 ICCPR), freedom of association (Articles 21 and 22 ICCPR), the right to take part in cultural life (Article 15 ICESCR), and other substantive rights; could render Article 27 redundant. Furthermore, Article 18 ICCPR on freedom of religion may also protect religion and religious minorities, while language and linguistic minorities, together with the arts and other manifestations of culture, are protected by Article 19 ICCPR on the freedom of expression. It is argued that culture as a way of life, would be protected by human rights taken collectively. ${ }^{48}$ It is interesting to note that the broad range of human rights included in the ICCPR and the ICESCR could be important for the protection of cultural identity. Once again, this indicates the overlapping character of cultural rights important to protect cultural identity.

In short, in relation to Article 27 on the protection of minorities, a broad concept of culture is in place, which also reflects a way of life including language, religion, traditions and cultural heritage. This extensive scope is directly linked to cultural identity, not so much as a separate right, but as a general value which inspires such rights. In this respect, Article 27 should be seen in the context of other cultural rights, such as freedom of religion, freedom of expression and the right to participate in cultural life, which are relevant to the protection of cultural identity. The question is then to what extent these rights offer sufficient protection of cultural identity, which would make a separate right to cultural identity redundant. To answer this question, more clarity is needed of the obligations of States under Article 27.

44 Capotorti, 1979, p. $100(8599)$.

45 Human Rights Committee, General Comment 23 on Article 27, fifteenth session, 1994, 87.

46 Thomberry, 1991, pp. 187 (quotation), 188, 193, 197.

47 Tomuschat, 1983, p. 971.

48 Rodley, 1995, pp. 54-59 (quotation p. 59); Tomuschat, 1983, p. 952. 


\subsubsection{State Obligations}

Article 27 is formulated in negative terms, 'shall not be denied the right to', in order to avoid the possible stimulation of minority consciousness. ${ }^{49}$ But exactly what does this formulation mean for the State obligations under Article 27? Do States have only have negative obligations to respect under Article 27 or also positive obligations? It should be argued that States have both negative and positive obligations, in any case the obligation to respect and to protect, but the extent of these obligations remains unclear.

Several authors, such as Nowak and Tomuschat, argue that Article 27 firstly requires States to refrain from interfering in the enjoyment by minorities of their culture, language and religion. In other words, States have the obligation to respect. Article 27 also has a horizontal dimension which leads to an obligation to protect minorities, insofar as other forces in society may also threaten their existence and cultural survival. States should further protect minorities from such interference, for example, by multinational corporations. ${ }^{50}$

Nowak and Tomuschat do not support the view that Article 27 calls for positive action and obligations on the part of States. They argue instead that the negative wording of the provision was chosen deliberately, which makes it difficult to broaden the scope of Article 27 to encompass positive obligations. They assert that positive obligations would be unrealistic and impossible in many multi-ethnic or multi-linguistic States. Although Article 27 does not prevent States from tolerating certain minority issues, its scope should not be stretched in order to include positive obligations. It is argued, for example, that Article 27 implies, inter alia, that persons belonging to minorities have the right to use their native language in private and in public. However, Article 27 does not oblige States to accept the minority language as an official language before a court or administrative body. With regard to schools and cultural institutions, the children of minorities must have the opportunity to learn the culture and language of their minority, for example, by including the instruction in the mother tongue as part of the school syllabus. Article 27 does not, however, imply State funding of any of those institutions or schools, although it does not prohibit it. ${ }^{51}$ Positive action with regard to minorities can only be based on the general non-discrimination provision of Article 2(1). This implies that if other persons or communities are granted certain rights or funds related to their culture, then minorities are entitled to the same treatment. $^{52}$

49 A/2929, 1955, p. 63,183 and 188; see also, Nowak, 1993, p. 500.

50 Nowak, 1993, p. 503; Tomuschat, 1983, pp. 974-975.

51 Tomuschat, 1983, pp. 971-973; Rodley, 1995, pp. 54-57, 64.

52 Nowak, 1993, p. 504; Tomuschat, 1983, p. 970. 
Other authors argue, however, that Article 27 does, in fact, imply positive State obligations. Thomberry, for example, asserts that although tolerance and noninterference were the main intentions of the drafters of Article 27, its meaning has changed. If Article 27 is supposed to add anything to the other rights in the ICCPR, such as freedom of religion and freedom of expression, it must be given a forceful content, which implies more than passive behaviour on the part of the State. ${ }^{53}$ Capotorti agrees in his report that the right of members of a minority to enjoy their own culture would lose much of its meaning were no government assistance forthcoming. ${ }^{54}$ Rodley finally argues that, "... it is generally accepted that a positive right is implicit." ${ }^{55}$ These scholars have the HRC on their side. In its General Comment on Article 27 the HRC has made clear that States also have positive obligations under Article 27. Although the provision is written in negative terms, the HRC emphasises that positive measures may be necessary to protect the cultural, religious and social identity of minorities as well as their rights to enjoy and develop their culture and language and to practice their religion. These positive measures may include "...measures of protection...not only against the acts of the State party itself...but also against the acts of other persons within the State party: $: 56$ In relation to land rights and traditional activities, the HRC stated that "...the enjoyment of those rights may require positive legal measures of protection and measures to ensure the effective participation of members of minority communities in decisions which affect them.".57

The HRC has not always been so unanimous on the question of State obligations. Cholewinski points out that during the HRC's debate on the draft General Comment in 1985, there was no initial agreement on whether or not States had positive obligations under Article 27. In considering State reports, the HRC had already proved willing to interpret Article 27 as including positive obligations. Most State reports referred to positive State obligations, including financial efforts, to help minorities preserve their culture and language and distinct characteristics. The questions posed by the HRC with regard to State reports also suggested positive State responsibilities, for example with regard to minority languages, education and minority representation in decision-making process. In their answers States have not doubted the legitimacy of such questions, although they might not always have answered them. ${ }^{58}$ In short, while the negative wording and the drafting history of Article 27 tend to a negative interpretation excluding positive State obligations, a more dynamic interpretation including positive State obligations is currently more appropriate. Although the emphasis may lie on the obligation to respect and protect, States also have an obligation to fulfil under Article 27.

53 Thomberry, 1991, pp. 178-180; see also, Cholewinski, 1988, pp. 363-364.

54 Capotorti, 1979, p. $98(\$ 588)$.

55 Rodley, 1995, p. 50; Thornberry, 1991, pp. 200-201.

56 Human Rights Committee, General Comment 23 on Article 27 , fifteenth session, 1994, $\$ 6.1$.

57 Human Rights Committee, General Comment 23 on Article 27, fifteenth session, 1994, \&7.

58 Cholewinski, 1988, pp. 344, 346-359. 


\section{CASE LAW ON ARTICLE 27 ICCPR}

The HRC has ruled on a series of cases under Article 27 ICCPR and consequently developed and clarified the content and scope of this provision. With regard to the subject, it has ruled, for example, that members of indigenous peoples fall within the scope of Article 27 , whereas minorities within a province do not. ${ }^{59}$ It has also ruled that a person's legal status is not decisive when it comes to determining whether that person is a member of a minority, so that persons who have officially lost their "member of a minority" status could still fall within the scope of Article 27 if they have the ethinic background of a minority ${ }^{60}$ With regard to the object of the enjoyment of culture, the HRC has used a broad interpretation of 'culture', including for example economic activities such as fishing and hunting. Since these economic activities often concern land, the issue of land rights has gained importance under Article 27 ICCPR, even though it is not explicitly referred to in this provision. ${ }^{61}$ With regard to the addressee of Article 27, the HRC has developed a method to determine whether specific State interference with Article 27 constitutes a violation of that provision. In general, State measures which interfere with the enjoyment of culture must have a reasonable and objective justification and be compatible with the other provisions in the ICCPR. ${ }^{62}$ Subsequently, two other requirements were added, namely the obligation to consult the community involved, and to limit the impact of the measures taken. ${ }^{63}$ Below, several relevant cases are discussed to illustrate the diverse character of claims made with regard to culture under Article 27. ${ }^{64}$

\subsection{A Broad Concept of Culture}

One of the first cases in which the HRC had to rule on the enjoyment of culture under Article 27 was that of Lovelace $v$. Canada. ${ }^{65}$ Sandra Lovelace was a Maliseet Indian by ethnic origin, who had lost her legal status as a native Indian when she married a non-Indian, under Section 12(1)(b) of the Canadian Indian Act. The loss of her legal status as a member of a minority meant that she could no longer live on an Indian reserve and no longer had the right to use and benefit from the land assigned to native Indians. Under the Act, an Indian man who married a non-Indian

59 Indigenous peoples were inter alia involved in various Sami cases, such as Kinok vi Sweden (Comm. No. 197/1985) and Lamsman w. Finland (Comm. No. 511/1992 and 671/1995). The minority in a province issue was determined in the case of Ballantyne, Davidson, Mclntyre $v$. Canada (Comm. Nos. 359/1989 and 385/1989).

60 Lovelace v. Canada, Comm. No. $24 / 1977, \$ 14$.

61 See, for example, Länsman v. Finland, Comm. No. 511/1992 and 671/1995.

62 See, for example Lovelace v. Canada, Comn. No. 24/1977, \$16.

63 See, for exanple, Länsman v. Finland, Comm. No. 511/1992 and 671/1995.

64 The cases are grouped according to several themes, which means they are not necessarily in chronological order. For an overview of cases under Article 27 concerning the right to enjoy a distinct culture, see also, Scheinin, 2000, pp. 163-172.

65 Sandra Lovelace v. Canada, Comm. No. 24/1977, 30 July 1981. 
woman did not lose his rights. Lovelace wished to return to her reserve after her divorce, but was not allowed to do so since she had lost her rights in that respect. Lovelace argued that the Canadian Indian Act constituted a violation of Article 26 on non-discrimination and Article 27 on the enjoyment of culture. She claimed that, "[t] the major loss to a person ceasing to be an Indian is the loss of the cultural benefits of living in an Indian community... and the loss of identity."

This cultural element of the claim assumed particular importance when the HRC found Article 27 to be most directly applicable to this case. The HRC asserted that Article 27 does not guarantee the right to live on a reserve as such, but the fact that Lovelace could not live on the reserve with her family in an Indian community did hinder the enjoyment of her culture, which is guaranteed under Article 27. Putting the measures to the test of reasonable and objective justification, the HRC found the refusal to allow Lovelace to live on her reserve after her divorce unreasonable and not necessary to preserve the identity of the tribe. It concluded that by denying Sandra Lovelace the legal right to reside on the Tobique reserve, Canada had breached Article 27 of the ICCPR ${ }^{67}$ In Lovelace the HRC argued that residence on a reserve is important for the experience of culture and as such falls under the term 'enjoyment of culture' in Article 27.

\subsection{The Link between Culture and Traditional Economic Activities}

\subsubsection{Lubicon Lake Band versus Canada}

The HRC has dealt with several cases under Article 27 concerning the traditional use of land in relation to the enjoyment of culture. The relationship of land with the culture of a community was, for example, the central element in the case of the Lubicon Lake Band v. Canada. ${ }^{68}$ On behalf of the native Indian community, the Chief claimed a violation of the right to self-determination under Article 1 ICCPR. He argued that although the Canadian government had recognised the right of the Lubicon Lake Band to continue its traditional way of life through inter alia the Canadian Indian Act of 1970, the government had allowed the expropriation of land for the benefit of private corporate interests such as gas and oil exploration. The Band argued that such industrialisation destroying its environmental and economic base, constituted a violation of Article 1 ICCPR, and claimed that the Canadian authorities had not made a serious attempt to negotiate a settlement with the Band. ${ }^{69}$

In this case, the HRC applied its case law on Article I ICCPR on the collective right of self-determination. It decided that it could not deal with collective rights under Article 1, since the ICCPR's Optional Protocol (Article 1)

66 Sandra Lovelace v: Canada, Comm. No. 24/1977, 1,7, 13:1 and 13,2 .

67 Idem. \& 14-17 and 19. Following this case, Canada amended the Indian Act.

68 Bernard Ominayak, Chief of the Lubicon Lake Band v. Canada, Comm. No. 167/1984, 26 March 1990.

69 Lubicon Lake Band v. Canada, Comni. No. 167/1984, 29:1, 29.5 and 29.9. 
stipulates that only individuals who are victims of violations of rights under the ICCPR can submit claims. The HRC argued that an individual could not be a victim of a collective right to self-determination. Since communities as such do not have locus standi before the HRC, all cases under Article 1 are inadmissible. The HRC did, however, consider the claims as having been made by individuals but submitted collectively. Hence, they were admissible, although not under Article $1{ }^{70}$

The HRC concluded that many of the claims presented by the applicants raised issues under Article 27 and the enjoyment of culture. It concluded in a brief reasoning that historical inequities and recent developments threatened the way of life and the culture of the Lubicon Lake Band, and therefore constituted a violation of Article 27.71 Although land issues were cited in relation to Article 27, the HRC did not give an extensive legal reasoning for the applicability of Article 27, and no substantiation of its determination that Article 27 had been violated.

\section{Individual opinion}

In an individual opinion, one of the Committee members, Ando, expressed his uncertainty that the situation in question constituted a violation of Article $27 .^{72} \mathrm{He}$ argued that persons belonging to the Lubicon Lake Band had not been denied the right to practice their own religion or to speak their own language and he doubted whether the expropriation of land for commercial interests constituted a violation of the Band members" right to enjoy their own culture. According to Ando, the right to enjoy one's culture should not imply that the Band's traditional way of life should be preserved at all costs. Moreover, the refusal by a community to change its traditional way of life could hinder the economic development of the society as a whole. ${ }^{73}$ Ando not only doubted whether land issues would fall within the scope of enjoyment of culture in Article 27, but also gave priority to the economic development of society as a whole rather than to the more traditional ways of life of a specific community. However, Article 27 is designed to preserve and protect the culture of a minority against the developments of society as a whole. Land may be very important for the culture and way of life of communities and should logically be dealt with under Article 27. In the following cases the HRC confirmed that land issues and traditional economic activities do fall under Article 27, where this land is important for the culture of a given community.

70 Lubroon Lake Band v. Camada, Comm. No. 167/1984, 82.1 and 32.2

71 Lubicon Lake Band w. Canada, Comm. No. 167/1984, \$32.2 and 33.

72 Ando does not make clear whether he dissents or concurs with the findings of the HRC. He argues that he is, "uncertain if the situation...should be viewed as constituting a violation of... Article $27 .$. " He does, however, not oppose to the findings of the HRC. Marquardt concludes that Ando concurred, while his arguments seem to point at a dissenting opinion. See, Marquardt, 1994, pp. 72 73.

73 Lubicon Lake Band y. Canada, Comm. No. 167/1984, Appendix I. 


\subsubsection{Sami Cases versus Sweden and Finland}

The HRC has dealt with several cases of Sami applicants in Scandinavian countries. These cases concerned the use of land by the Sami to breed and herd reindeer in relation to government permission for companies to use the land for logging, mining or forestry. The Sami cases confirm that economic activities and the use of land fall under Article 27 where these activities constitute an essential element of the culture of a minority. Besides the criteria of reasonable and objective justification, the criteria of consultation and effective participation were applied. ${ }^{74}$ The HRC concluded, however, that in these cases the Sami were sufficiently consulted and involved during the decision-making process, even though they themselves found it unsatisfactory. In the Sami cases the measurement of impact became a decisive factor in determining whether or not a violation had occurred.

The first Sami case was that of Ivan Kitokv. Sweden. ${ }^{75}$ Kitok was a Swedish citizen of Sami ethnic origin who had been denied membership of the Sami community because he had not been practising reindeer husbandry for a period of over three years. According to the Swedish Reindeer Husbandry Act of 1971, Sami members with another profession for a period of three years or more lost their right to breed reindeer unless they were formally re-recognised by a Sami community as a member. The Act was passed in order to limit the number of reindeer breeders and to protect the environment and indigenous Sami culture. Kitok claimed that he had been denied his right to reindeer breeding and his right to enjoy his culture in community with others by way of formal exclusion. However, although Kitok had officially been denied membership of the Sami community, which normally implied he could no longer practice reindeer husbandry, he was, in fact, allowed to exercise a limited form of reindeer husbandry, because he owned reindeer and had the right to protect his interests in this respect.

The HRC confirmed in the Kitok case that the economic activity of reindeer husbandry is an essential component of the Sami culture and as such falls under Article 27. The HRC used the criteria of reasonable and objective justification, as used in the Lovelace case, but the decisive factor became the impact of the measures taken on the enjoyment of culture. In the Kitok case the HRC argued that Kitok had always retained links with the Sami community and had always lived on Sami land. It concluded that the impact of the rule on Kitok was limited, since Kitok was allowed, although not as a right, to herd reindeer. It found the rule objectively justified for the welfare of the minority as a whole and consequently concluded that no violation of Article 27 had occurred. ${ }^{77}$

74 Ilmari Länsman et al. y. Finland, Comm. No. 511/1992, 26 October $1994 \$ 9.5$; the General Comment on Article 27 uses the words, "[m]ay be taken", $\$ 7$.

75 Ivan Kitok w. Sweden, Comm. No. 197/1985, 27 July 1988.

76 Ivan Kitok v. Sweden, Comm. No. 197/1985, \$2.1, 2.2 and 4.2.

77 wam Kitok v. Sweden, Comm. No. $187 / 1985 \$ 4.3,9.2,9.7,9.8$. 
Two other important Sami cases were the Länsman cases against Finland. ${ }^{78}$ Both cases concemed reindeer breeders of Sami ethnic origin, who claimed a violation of their right to enjoy their culture as laid down in Article 27, because government authorities allowed respectively stone quarrying and logging and road construction on the land used for reindeer herding. In both Lânman cases, the HRC argued with regard to the impact of the measures on reindeer herding activities that reindeer breeding did not seem to be much affected by the quarrying and logging activities. In the first Lansman case, for example, the authorities had only authorised quarrying with a minimal effect on reindeer herding, which was reflected in the conditions laid down in the quarrying permit. The HRC concluded that the impact of the measures taken by the authorities on the enjoyment of culture was limited to such an extent that it did not constitute a violation of Article 27 ICCPR.

In the Lansman cases, the HRC did, however, express its concern about the permits issued by the authorities for private companies. In these and several other cases it took interim measures to prevent irreparable harm to the environment, which the claimants argued was vital for their culture. ${ }^{81}$ This indicates that the HRC initially was concerned that the measures could constitute a violation of the ICCPR and could cause irreparable harm. The HRC also warned Finland that future activities might constitute a breach of Article 27 if they had a significant negative impact on reindeer breeding and the enjoyment of the Sami culture. ${ }^{82}$

Soleinin, since 1997 himself a member of the HRC, has criticised the way the $\mathrm{HRC}$ used its impact measurement. He argues that the HRC decided that the projects took place on a relatively small part of the territory after a qwantitative comparison between the area subject to the disputed projects and the total area used by the Sami for reindeer herding. Scheinin argues that insufficient attention was paid to the argument of the minority claimants who emphasised the qualitative aspect of the specific importance of a certain area and its potential impact on their future livelihood. In the second Länsman case, the HRC again used a quantitative argument in stating that whilst separate activities may not constitute a violation of Article 27, such activities taken together may infringe Article $27 .{ }^{83}$ It is furthermore generally unclear when the measures taken are of such impact that they do

78 Ilmari Länsman ef al. v. Finland, Comm. No. 511/1992, 26 October 1994 and Jouni E. Länsman et al. w. Finland, Comm. No. 671/1995, 30 October 1996. There was another Sami case, O'Sara er al. v. Finland, Cornm. No, 43 1/1990, 23 March 1990 , but this case was declared inadmissible for nonexhaustion of local remedies. Since the case was not thoroughly considered by the HRC and the facts of the case are similar to the Lansman cases against Finland, the case of $O^{+}$Sara will not be dealt with separately.

79 Ibmar Lansman et al. v. Finland, Comm. No. $511 / 1992, \$ 2.1,2.3,3.1$; Joumi E Länsman er al v. Finkand, Comm. No. 671/1995, \$ 2.1-2.9.

80 Ilmari Länsman et al. v. Finland, Comm. No. $511 / 1992,8$ 9.1-9.8. Jowni E. Lämsman et al. v. Finland, Comm. No. 671/1995, \$10.1-10.6.

81 See for example O'Sara v. Finland and Jown Lansman w. Finland See also, Lubican Lake Band v. Canada.

82 Jouni E. Länsman er al. v. Finiand, Comm. No. 671/1995, \$ 10.7.

83 Scheinin, 2000, pp. 170,175 and 212. 
constitute a violation, in other words; where the boundary of permissibility lies. This is also visible in the case of Anni Aärelä and Jomi Näkkälajäròi v. Finland.

In the case of Anni Aärelä and Jouni Näkkäläjärvi v. Finland more attention was paid to the quality of the land. The case also concerned Sami reindeer herders who complained that their rights under Article 27 had been violated, because Finland had allowed logging and road construction. The Finnish national courts tried to establish whether the harmful impact of these activities was likely to impede the enjoyment of culture by the Sami. The applicants argued that the land concerned was the best winter grazing available, and consequently of strategic importance. The Finnish District Court agreed with the claimants and argued that this area was necessary for the Sami to enjoy their culture. The Court of Appeal however found that the proposed logging would partially contribute to the long-term sustainability of reindeer husbandry, and that the area in question was of secondary importance in the overall context of land.

The HRC argued that it did not have sufficient information from both parties in order to, "....draw independent conclusions on the factual importance of the area to husbandry and the long-term impacts on the sustainability of husbandry, and the consequences under Article 27..." could not conclude that the logging constituted a violation of Article $27{ }^{85}$ On the one hand, this case demonstrates that the HRC paid more attention to the quality of the land in question, whilst in the previous cases its decisions were mainly based on a purely quantitative assessment. On the other hand, it illustrates the difficulty of determining the importance of a certain piece of land. National courts did not agree in this case, which made it difficult to conclude on these matters at the international level. The HRC argued that it did not have sufficient information to take a decision, and that it could not therefore conclude that a violation had taken place: In future cases claimants should provide as much information as possible on the importanee of a piece of land in order to convince the HRC. In general, it remains unclear how large the impact of State measures must be to constitute a violation of Article 27.

\subsubsection{Apirana Mahuika versus New Zealand}

The impact of economic activity also played a decisive role in the case of Apirana Mahuika et al. $v$. New Zealand. ${ }^{86}$ The petitioners were New Zealand Maoris claiming that their rights had been violated by the New Zealand government under Article 27 ICCPR in a dispute over fishing rights. Following negotiations, a group

84 Anni Aäreld and Jouni Näkkalajärvi v. Finland, Comm. No. 779/1997, 24 October 2001, $\$ 7.6$.

85 The HRC did however decide that the case constituted a violation of Art. 14(1) in conjunction with Art. 2, because the applicants had to pay a large amount of money to the winning party, which had a deterrent effect on the ability of persons to seek a legal remedy $(\$ 7.2)$, and because the applicants did not have the opportunity to comment on a brief by the Forest authority $(87.4)$.

86 UN Dac. CCPR/C/70/D/547/1993, Apirana Mahuika et al. \%, New Zealand, Comm. No. 547/1993, 27 October 2000 , seventieth session. 
of Maori and the State signed a Memorandum of Understanding in August 1992 in which the Maori were allocated funds to purchase $50 \%$ of the major New Zealand fishing company, Sealords, which owned $26 \%$ of the available quota. The Maori would in return withdraw all pending litigation and support the repeal of several former rules on fishing rights for the Maori. However, the Maori negotiators had made clear that they did not represent all individual tribes and sub-tribes. In addition, the Memorandum was not sufficiently well communicated or explained to these tribes and sub-tribes. In accordance with the Memorandum and a Deed of Settlement, a law was adopted in Parliament in December 1992 called the Treaty of Waitangi (Fisheries Claims) Settlement Bill. ${ }^{87}$

The petitioners claimed that the Treaty of Waitangi confiscated their fishing resources, which interfered with their right to freely pursue their economic, social and cultural development, and that their right of self-determination under Article 1 ICCPR would only be effective if they would have access and control over such resources. Furthermore, they claimed that the government's actions threatened their way of life and culture in violation of Article 27. The State argued that it recognised that the right to engage in fishing constituted an integral part of Maori culture. It also accepted that it had positive obligations to guarantee the enjoyment of such cultural rights, but went on to argue that the settlement had achieved this, insofar as the Maori, who constituted $15 \%$ of the population, now had control of over $40 \%$ of New Zealand's fishing quota. ${ }^{88}$

The HRC repeated that it could not express its views on Article 1 on selfdetermination. However, it argued that "...the provisions of Article 1 may be relevant for the interpretation of other rights protected by the Covenant, in particular Article 27." fisheries constitutes part of the Maori culture. It based its final decision on the assessment of the impact on the traditional life forms of the community and on the question whether this community was given sufficient opportunity to participate in the decision-making process. The HRC concluded that New Zealand had engaged in a process of broad consultation with the Maori and had taken the necessary steps to ensure that the fisheries settlement was compatible with Article 27 ICCPR. Accordingly, no breach of Article 27 was found. ${ }^{90}$

It is further interesting to note that in the Apirana Makuika case, the HRC confirmed its dynamic approach to the issue of culture as developed in the Lansman cases. In the Länsman cases, the HRC had argued that Article 27 not only protects the traditional economic activities of a community. The fact that, for example, technological innovations are used in these economic activities, such as reindeer herding, does not imply that Article 27 is no longer applicable. In Apirana Mahuika

87 Apirana Mahuika et al v. New Zealand, Comm. No. 547/1993, \$1, 5.1-5.12.

88 Apirand Mahuika et al. v. New Zealand, Comm. No. 547/1993, \$6.1,6.2, 7.1 and 7.4.

89 Apirana Mahwika et al. v. New Zealond, Comm. No. 547/1993, \& 9.2.

90 Apirana Mahnika et al. v. New Zealand, Comm. No. 547/1993, \$9.3-9.8, 10. 
the HRC again asserted that Article 27 not only protects traditional means of livelihood of minorities; but also allows for adaptation of those means to the modern way of life and technology. These decisions indicate that the HRC enploys a dynamic concept of culture. Scheinin rightly argues that, "... the notion of culture in Article 27 is not frozen but ... may be invoked as support for an indigenous way of life that has a historical link to the traditional life style but has, nevertheless, undergone transformations...,"9!

\subsubsection{Diergaardt versus Namibia}

In order for land claims to fall under the enjoyment of culture, a close relationship must be demonstrated between the two. In J.G.A. Diergaardt (the late Captain of the Rehoboth Baster Community) et. al $v$. Namibia, ${ }^{92}$ this relationship was not sufficiently demonstrated. Diergaardt and others claimed that their rights under Article 27 had been violated by the Namibian government. In 1976, the Rehoboth people were granted self-government by the South African Parliament. According to the claimants, in 1989 , under extreme pressure, the community accepted a temporary transfer of their powers to the Administrator General of South West Africa. The claimants asserted that after the independence of Namibia in March 1990 the government of Namibia did not re-establish their independent status and expropriated all communal land. Since the community consisted mainly of cattle raising farmers, the claimants argued that such expropriation implied that the means of subsistence of the community as the basis of their cultural identity had effectively been destroyed. The government of Namibia did not respond to requests by the HRC for information. ${ }^{93}$.

With regard to the alleged violation of Article 27, the HRC argued that most of the events took place before the entry into force of the ICCPR for Namibia in February 1995. The question was whether or not a violation of Article 27 ICCPR had occurred, since cattle grazing was no longer an exclusive activity of the Rehoboth community. The HRC repeated that, in principle, economic activities including the use of land may fall within the scope of Article 27 if there is a direct link with the culture of the community involved. In this case, however, the HRC was not convinced that such a direct link existed and concluded that, "...although the link of the Rehoboth community to the lands in question dates back some 125 years, it is not the result of a relationship that would have given rise to a distinctive culture." In other words, the link between the use of the land including the way of raising cattle and the culture of the Rehoboth was not clearly established. The HCR therefore found no violation of Article 27 ICCPR. ${ }^{94}$

91 Scheinin, 2000, p. 169.

92 UN Doc. CCPR/C/69/D/760/1997, JG.A. Diergaardt (the late Captain of the Rehoboth Baster Community) et al, v. Namibia, Comm. No. 760/1997, 6 September 2000.

93 J.G.A. Diergaard et al v. Namibia, Comm. No. 760/1997, $81,2.3,2.5,3.1$ and 9.1.

94 J.G.A. Diergaardt et al. v. Namibia, Comm. No. 760/1997, \$10.6. 


\subsection{Language Rights: Culture and Freedom of Expression}

Article 27 establishes that members of minorities not only have the right to enjoy their culture, but also to speak their language and practice their religion. At the time of writing , no case concerning religion has been brought under Article 27, probably because such cases are brought under Article 18 on the freedom of religion. However, there was a case under Article 27 on language, in combination with Article 19 on the freedom of expression, namely the case of Ballantyne, Davidson and McIntyre v. Canada. ${ }^{95}$ Ballantyne, Davidson and McIntyre were respectively a painter, a designer and an undertaker, working and residing in the Province of Quebec. Their mother tongue, and that of many of their clients, was English. They claimed to be victims of a violation of Article 19 and 27 ICCPR because they were forbidden to use English for advertising purposes, for example commercial signs or the name of the firm. Canada argued that historical developments confirmed the need to protect the French language and culture in Quebec, and that Article 27 was intended to protect linguistic rights in the spheres of education, justice, public administration and cultural and religious institutions: Canada considered that the prohibition of commercial signs did not fall within the scope of Article 27. With regard to Article 19 on the freedom of expression, Canada asserted that this provision mainly concerned political, cultural and artistic expressions and did not extend to the area of commercial advertising. ${ }^{96}$

The HRC concluded that Article 27 was not applicable in this case, because it is only applicable to minorities in a State, and not to minorities in a province. ${ }^{97}$ The HRC did, however, consider the advertising rule to be a violation of Article 19 on the freedom of expression. The HRC disagreed with the idea that commercial advertising fell outside the scope of Article 19. Freedom of expression is not limited to political, cultural or artistic expression and could only be legally restricted in order to guarantee the rights of others. The right of the French-speaking people to use their own language was not jeopardised by the freedom of others to advertise in a language other than French, and public order was not endangered by commercial advertising in a language other than French. Consequently, the HRC concluded that Canada had violated Article 19 on the freedom of expression. ${ }^{98}$ This case indicates that linguistic issues, which are an important aspect of cultural identity, can also be placed under Article 19.

95 Ballantyne, Davidson. Mchtyre v. Canada, Comm. Nos. 359/1.989 and 385/1989, 31 March 1993.

96 Ballantbie Davidson, Mctnfyre v. Canada, Comm. Nos. $359 / 1989$ and $385 / 1989, \$ 1$.

97 Not all members agreed on this point. Mrs. Evati, co-signed by members Ando, Tulio, Cellu and Dimitrifevic, expressed difficulties with the interpretation of a minority merely on the basis of the number of members of the community in the whole State. Persons should not be excluded from the protection of Article 27 when their community is an ethnic, linguistic or cultural minority in an autonomous province of the State, but not a numericall minority in the State as a whole.

98 Ballantune, Davidson, Mcintyre v. Comada, Comm. Nos. 359/1989 and 385/1989, 11.2, 11.3 and 11.4 . 


\section{Individual Opinions}

Several members of the HRC submitted an individual opinion of which several specifically referred to Article 27. Ndiaye argued that even were Article 27 applicable, there would be no violation of this provision. He asserted that the rules on outdoor commercial advertising could be defended under Article 27 for the protection of the French language and culture. The rights in Article 27 were intended to guarantee the survival of the minority as an entity, in this case the French-speaking minority in Canada. The protection of this minority culture could, if necessary, imply the restriction of the freedom of expression on the basis of Article 19. Herndl agreed with the HRC that Article 27 was not at stake in this case. However, what was at stake here was not the fact that the claimants were not a minority in the meaning of Article 27, but that the rights invoked by them were in fact not minority rights in the meaning of Article 27 . Instead, these were rights related to the principle of freedom of expression. Wennergren also agreed that the petitioners did not have a valid claim under Article 27, because a prohibition to use any other language than French for commercial outdoor advertising did not infringe on any of the rights laid down in Article 27.

Language was also an issue in the case of Diergaardt versus Namibia, as described above. ${ }^{99}$ The claimants also complained about the prohibition on the use of their own language, in violation of Article 26 on non-discrimination and Article 27. The Namibian Constitution ruled that English is the sole official language. Parliament was empowered to adopt legislation that allows the use of other languages in administration, justice, education and public life. However, no such legislation had been passed, which, according to the claimants, constituted discrimination against non-English speakers. The claimants cited a circular which forbid civil servants to answer letters or telephone calls in Afrikaans. In the absence of an official response from the Namibian government, the HRC gave due weight to the allegation of the claimants and found a violation of Article 26 ICCPR. ${ }^{160}$

Several Committee members expressed an individual opinion on the issue of language in Diergaardt. Amor dissented on the finding of a violation of Article 26 , because the use of minority languages had not been limited apart from the official level. He also accepted the argument that giving the many tribal languages an official status would constitute an obstacle to nation-building. Committee members Ando, Bhagwati, Colville and Yalden also disagreed, because English was treated differently from all native languages, which were in turn all treated the same. Afrikaans was not discriminated against other languages except English. This constituted an objective and reasonable distinction permitted under Article 26. Committee member Lallah underlined the connection between language and Article 27 in arguing that this provision would be stretched too far if public authorities were obliged to guarantee the use of a non-official language in official affairs.

99 UN Doc. CCPR/C/69/D/760/1997, J.G.A. Diergaardt et al u. Namibia, Comm. No $760 / 1997$. 100 J.G.A. Diergaardt et al, v. Namibia, Comm. No. 760/1997, \& 3.4 and 10.10 


\subsection{The French Declaration Concerning Article 27 ICCPR and Minorities}

The HRC considered several other cases under Article 27. These cases, however, were declared inadmissible for failure to exhaust domestic remedies, or because there was obviously no violation of Article $27 .^{101}$ All cases with regard to Article 27 against France were declared inadmissible. ${ }^{102}$ France had submitted a declaration that since the French Constitution prohibits all distinctions between citizens on grounds of origin, race or religion, no minorities exist in France. Consequently, Article 27 would not be applicable with regard to France. In 1989, the HRC concluded that this declaration should be considered a binding reservation in accordance with the Vienna Convention on the Law of Treaties, Article 2(1). The HRC argued that the State clearly intended to exclude or modify the legal effect of this provision of the treaty. Consequently, the HRC did not consider itself competent to examine complaints directed against France concerning alleged violations of Article 27. ${ }^{103}$

Committee member Higgins dissented with this line of thought and emphasised that a distinction should be made between an interpretative declaration and a reservation. Higgins went on to argue that the HRC had on several occasions rejected the idea that the existence of minorities would be dependent on a form of discrimination. The existence of a minority is a factual matter and minorities can also exist within States that apply the principles of equality and non-discrimination. Higgins argued that the reasoning by France, that no minorities existed on its territory because French law prohibits such distinctions, is therefore false. The French declaration was incompatible with the HCR's interpretation of Article 27 and could not be interpreted as a reservation. ${ }^{104}$

I agree with Higgins" line of reasoning, because Article 27 is intended to protect minorities and their culture, inter alia, against interference by the State. The most obvious way for a State to interfere with minority rights is to simply deny the existence of minorities within its territory. This implies that there is no need for special measures or protection for such minorities as the latter will automatically be assimilated, which is precisely what Article 27 sets out to avoid. It is therefore vital that States do not make such reservations or interpretative declarations, or take other measures which give them the exclusive right to establish whether a

101 See, for exumple, Gerhard Malik y Czech Republic Comm. No. 669/1995 (21 October 1998); Ruediger Schlosser" v. Czech Republic Conm. No. 670/1995 (21 October 1998); " $X^{\text {nv }}$ v. Australia, Comm. No. 557/1993 (16 July 1996).

102 C.L.D. w. France, Comm. No. 228/1987 (18 Jully 1988); T.K. v. France Comm. No. 220/1987 (8 November 1989); M.K. v. France Comm. No. 222/1987 (8 November 1989; Dominique Guesdon v. France Comm. No. 219/1986 (25 July 1990); Herve Barzhig v. France Comm. No. 327/1988 (11 April 1991); Yves Cadoret and Herve Le Bihan v. France Comm. No. 221/1987 and 323/1988 (11 April 1991 ); G.B. v. France Comm. No. 348/1989 (1 November 1991); $S$ G. v. France Comm. No. 347/1988 (1 November 1991); R.L.M. v. France Comm. No. 363/1989 (6 April 1992).

103 T.K. w. France Comm. No. 220/1987, 8 November $1989, \$ 8.6$.

104 T.K. v France Comm. No. 220/1987, 8 November 1989, Appendix I. 
community constitutes a minority under Article 27. The HRC can be assumed to be more objective and authoritative when it comes to determining which communities fall within the scope of Article 27 than individual States. Scheinin in fact suggests that a general reservation on Article 27 would no longer be permissible according to the HRC's General Comment 24 on reservations adopted in 1994. This General Comment stipulates that provisions in the Covenant representing customary international law or peremptory norms may not be the subject of reservations, whereby one of the provisions specifically mentioned is Article $27 .{ }^{105}$

\subsection{Hopu and Bessert versus France}

The HRC created an interesting and creative way of circumventing Article 27 ICCPR in the case of Hopu and Bessert $v$. France. ${ }^{106}$ In this case the petitioners were indigenous Polynesians claiming ownership of a piece of land in Tahiti where the French-Polynesian authorities had started to build a hotel. The piece of land contained a traditional indigenous burial ground and a fishing lagoon. ${ }^{107}$ According to the logic of the HRC's case law, this case would fall under Article 27. It could, however, not be dealt with under this provision as a result of the French declaration described above. ${ }^{108}$ The HRC instead addressed the claim under Article 17 concerning privacy, family and home and Article 23 on the rights of the family. ${ }^{109} \mathrm{It}$ argued that the relationship of the claimants with their ancestors constituted an important element of their identity and played a defining role in their family life. Consequently, the claimants were not under any legal obligation to prove a direct kinship link with the remains in the burial grounds. ${ }^{10}$ The HRC concluded that the construction of a hotel on the traditional burial grounds of the Polynesians constituted an interference with the right to privacy and family life, which was neither reasonable nor justified. The petitioners had also claimed that the hotel construction interfered with the fishing activities of the indigenous community, but the HRC did not consider this matter any further. ${ }^{11}$

1.05 General Comment 24 on issues relating to reservations made upon ratification or accession to the Covenant or the Optional Protocols thereto, or in relation to declarations under Article 41 of the Covenant, 4 November 1994, 52nd session. See also, Scheinin, 2000, p. 218.

106 Francis Hopu and Tepoaitu Bessert v. France, Comm. No. 549/1993, 29 July 1997.

107 Hopu and Bessert v. France, Comm. No. 549/1993, 29 July 1997, 1 and 2.

108 Five members of the HRC - Elizabeth Evatt, Cecilia Medina, Fausto Pocar, Martin Scheinin and Maxwell Yalden - dissented and argued that the declaration was not of relevance to overseas territories under French sovereignty. See also, Scheinin, 2000, pp. 217-218.

109 Hopu and Bessert w. France, Comm. No. 549/1.993, 29 July 1997, 4.3 and 4.4.

110 Thomas Buergenthal, David Kretzmer, Nisuke Ando and Lord Colville dissented on this point, arguing that the term "family" does not include all members of one's ethnic community. Accordingly, in order to fall under Arts. 17 and 23 , the burial grounds should be connected to the direct family, which could not be established by the authors.

111 Hopu and Bessert v France, Conm. No. 549/1993, 29 July 1997, $\$ 10.3$ 


\section{Individual Opinions}

HRC members Buergenthal, Kretzmer, Ando and Colville were of the opinion that the issues of this case did not fall under the provisions on privacy and family life. They argued that the HRC emphasised the history and culture of the claimants, which referred to cultural values and not to family rights or privacy. Cultural values are protected under Article 27, which could not be applied in this case. While the dissenters expressed their concern with the construction of a hotel on a site obviously important for the cultural heritage of the Polynesian community, they disagreed on stretching the legal interpretation of family and privacy. ${ }^{12}$

Objectively speaking, the issues in this case fall under the category 'culture' and consequently, Article 27 would be the most appropriate provision in this case, whereas recourse to Articles 17 and 23 may appear to be far less tenable. Ideally, the HRC should dismiss the French declaration and declare Article 27 applicable in cases against France. However, that path seems to be elosed. In that light, a creative solution to complaints against France concerning cultural issues is important. In this case the burial ground could be dealt with under 'family life'. In other cases, other rights such as freedom of religion, expression or association might be suitable. Such a creative approach would imply that France could not avoid dealing with cases concerning cultural aspects of minority rights. Such an approach is allowed considering the cohesion of human rights, especially in relation to the protection of cultural identity.

\section{The Right to Enjoy Culture in Relation to a Right to Cultural IDENTITY}

In general, Article 27 ICCPR belongs to the narrow group of cultural rights that explicitly refer to culture. As such, it constitutes an important guide in the development of the concepts of culture and cultural identity. However, Article 27 has a special status, since it only applies to members of minorities and other specific communities rather than to everyone. The special reference to minorities fits, however, with the description of cultural identity, which is encouraged when it is in jeopardy, which is precisely the case with many minorities. Bearing in mind the restriction to minorities, the right to enjoy culture is an important starting point with regard to a possible right to cultural identity. In this respect, the meaning of the concept of culture, the individual and collective dimensions of the provision, the State obligations and its relationship with other cultural rights are of vital importance.

The Universal Declaration does not contain any provision on minorities. The debates on draft provisions concerning equality versus special protection, the broad concept of culture, and the issue of the recognition of minorities as collective

112 Hopu and Bessert v. France; individual opinion by Thomas Buergenthal, David Kretzmer, Nisuke Ando and Lord Colville. 
entities, however, form the background of Article 27 ICCPR on the right of members of minorities to enjoy their culture, language and religion. The above has shown that the content and scope of Article 27 have developed over time. It is worth noting that from the outset of the drafting process the concept of culture was understood in broad context. It appeared that compared to the drafting negotiations on, for example, Article 15 ICESCR, the concept of culture in relation to minorities included language, religion, cultural heritage and other potential characteristics of such communities. The drafting process did, however, reveal a cautious attitude towards minority rights, reflected in the negative formulation "shall not be denied the right to' which implied that States had only negative obligations under this provision. Over time, however, it has been recognised that States have all three forms of obligations to respect, protect and fulfil under Article 27. With regard to the subject of Article 27, the term 'minorities' was not defined during the drafting process, but States were quick to insist that members of minorities should be nationals of the State concerned and that indigenous peoples and immigrants did not meet this definition. Again, the provision has undergone change and currently members of indigenous peoples and other communities may fall under Article 27. In this respect it is interesting to note that although Article 27 was formulated in individual terms, its collective dimension was recognised in terms of "in community with others'. This collective dimension is also present in several cases, for example, because individuals present a collective claim on behalf of their community. These cases demonstrate that such collective actions can give an individual right a collective emanation, which is important in the protection of cultural identity.

The cases under Article 27 analysed above confirm the process of broadening its content and scope. All sorts of communities, represented by individuals, were accepted as claimants by the HRC. The HRC also uses a broad concept of culture, whereby culture is considered to reflect a way of life, including not only language and religion, but also economic activities. These activities have to be essential for the culture of the community, but do not have to remain rigidly traditional. Culture is not considered as something static; adaptation of traditional economic activities to modern techniques does not prevent such activities from falling under the term "culture'. The cases indicate that apart from cultural or linguistic rights, land rights and the right to live on an indigenous reserve may also fall under the enjoyment of culture in Article 27.

The HRC has developed a system of criteria to determine whether a State is violating Article 27 . In principle, not every interference with Article 27 constitutes a violation and States have a certain margin of discretion with regard to the application of Article 27. As laid down in several cases and confirmed by the General Comment on Article 27, restrictions must have a reasonable and objective justification and be compatible with the other provisions of the ICCPR. Two other important criteria were developed by the $\mathrm{HRC}$, namely the impact of the measures in question on the enjoyment of culture by the applicant, and the compulsory consultation of the community involved. Both are useful additions, but with regard 
to the impact assessment, attention should be paid to the quantitative as well as the qualitative aspects. It further remains unclear when the impact of measures is of such severity that they constitute a violation of Article 27. It should be noted that none of the cases were won by the applicants. In all cases, the State interference was not considered to be contrary to Article 27.

Several authors and the HRC linked the broad interpretation of Article 27 directly to the protection of cultural identity. The broad interpretation of Article 27 highlighted the tight relationship of Article 27 with other rights in the ICPPR and ICESCR concerning religion, expression and education. It was argued before that various cultural rights play a role in the protection of the cultural identity of individuals and communities. Whille Article 15 and other instruments may help protect the cultural identity of everyone, Article 27 in its broad sense could be important for the protection of the cultural identity of (individuals of) specific communities. Scheinin argues that in this respect Article 27,

“...does not address a category of separate 'minority rights' but rather affords members of minorities additional protection for their enjoyment of universal human rights - in particular those rights that are related to culture, language and religion." 113 .

Several ICCPR provisions provide protection for all the members of the population, for example Article 18 concerning freedom of religion in cases of religious rights, Article 19 on freedom of expression in relation to linguistic rights, and Articles 17 and 23 on family life in cases of specific dimensions of cultural identity. Article 27 provides additional protection for these rights in relation to members of minorities. ${ }^{114}$

In short, Article 27 may be important for the protection of the cultural identity of (members of) minorities. Indeed, the right to enjoy culture in community with others is quite similar to a right to culturall identity. The broad interpretation of 'enjoyment of culture', the inclusion of references to language and religion, which are important aspects of cultural identity, and its individual and collective dimension, make Article 27 extremely relevant with regard to the protection and development of the cultural identity of individuals and communities.

The breadth of the object and subject imply an equally broad content and scope of Article 27, making it difficult to make a general statement about the concrete obligations of States. The cases also illustrate the complexity of concrete actions with regard to the enjoyment of culture. The same problem was signalled with regard to a right to cultural identity, which embraces an entire range of issues from language, religion, cultural heritage to all forms of cultural expressions and behaviour. It seems to be difficult to translate a social concept, such as culture or cultural identity, in legal terms, because its content so broad and dynamic. In this respect, the supervisory role of the HRC has been very positive, and helps formulate 
the concrete actions and policies to be implemented by States. Its handling of reports and, in particular, its rullings on cases are important in this respect. This once again highlights the lack of an individual complaint procedure under the ICESCR which would allow the Committee on Economic, Social and Cultural Rights to play a comparable role with regard to Article 15 ICESCR.

\section{The Un Declaration on the Rights of Persons Belonging to NATIONAL OR ETHNiC, RELigIoUs AND Linguistic Minorities}

The formulation of Article 27 ICCPR and the development of minority rights have led to the adoption of the UN Declaration on the Rights of Persons Belonging to National or Ethnic, Religious and Linguistic Minorities (hereafter Declaration on Minorities ${ }^{115}$ ) in 1992. As mentioned in Chapter 1, a right to cultural identity has been included in several instruments of soft law. The Declaration on Minorities is one such instrument. Several provisions explicitly referring to culture or cultural identity are examined below to determine the meaning of such provisions, and their role in protecting the cultural identity of (members of) minorities. The issues to be analysed are the status of the Declaration, the individual and the collective dimension of its provisions, their content, and the corresponding State obligations.

\subsection{Background and Drafting Process of the Declaration on Minorities}

In his 'Study on the Rights of Persons Belonging to Ethnic, Religious and Linguistic Minorities', Special Rapporteur Capotorti recommended that the SubCommission instruct the Commission to draft a declaration on rights of members of minorities, "... within the framework of the principles set forth in Article 27 of the Covenant." 116 Accordingly, the Sub-Commission recommended in Resolution $5(\mathrm{XXX})$ that the Commission consider the preparation of such a declaration. In 1978, the Commission established an open-ended Working Group to start drafting the declaration. Yugoslavia submitted a first draft in 1978 after which the Chairman of the Commission's Working Group, Toševski, submitted a second draft two years later. Neither of the two drafts contain a reference to cultural identity. ${ }^{117}$

From the outset it was evident that States would not be willing to adopt a legally binding instrument on minorities. A draft International Convention on the Protection of National or Ethnic Groups or Minorities, prepared by the Minority Rights Group in 1979, was not adopted by States. ${ }^{1 / 8}$ The draft Convention

115. The term Declaration on Minorities is used, keeping in mind that it is officially "persons belonging to minorities'.

116 Capotorti, 1979, p. 102, $\$ 617$.

117 UN Doc. E/CN.4/L.1367/Rev.1,2 March 1978 and UN Doc. E/CN.4/Sub.2/L.734, 2 July 1980. See

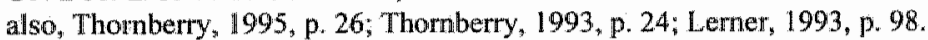

118 The draft Convention is reproduced in UN Doc. E/CN.4/NGO/231, Written Statement submitted by the Minority Rights Group, a non-governmental organisation in consultative status, 26 January 1979. 
contained collective rights for minorities as such. For example, Articles 1 and 2 stipulated that groups and minorities have the inalienable right to be recognised as national, ethnic and cultural entities, and they possess the, "...inalienable right to their own ethnic and cultural identity and to self-determination." It is worth noting that the right to cultural identity was included as a collective value of minorities which was to be protected by States. The draft also covered rights in relation to language, social, cultural and economic development, land usage, and the prohibition of forced assimilation, genocide and mass-expulsion. The right to selfdetermination was extensively present in the draft, varying from cultural and linguistic autonomy and participation rights, to secession where necessary. ${ }^{119}$ On the whole, the draft Convention was, what Lemer refers to as an, “...ambitious and controversial text." 120

In 1990, the Working Group of the Commission agreed on a first draft declaration including nine articles and a set of measures of implementation. ${ }^{121}$ The Commission adopted the final text in February 1992. ${ }^{122}$ The draft Declaration was approved by the Economic and Social Council ${ }^{123}$ and submitted to the Third Committee of the General Assembly. It was adopted by consensus in the General Assembly during its 47 th session in December $1992 .{ }^{124}$ The text adopted by the Working Group was not significantly changed by the Commission, the ECOSOC or the General Assembly. ${ }^{125}$ It is worth noting that a large proportion of the State representatives actively supported the drafting of the Declaration and its outcome. While some States, such as Turkey, expressed some dissatisfaction with the final version of the Declaration, mainly because of the absence of a clear definition of the term "minority', no State explicitly opposed the consensus in the General Assembly. This broad support contributes to the force of the Declaration. ${ }^{126}$

\subsection{Content of the Declaration on Minorities}

Article 27 thus constituted the starting point for the Declaration on Minorities. Paragraph 4 of the Preamble states that the Declaration is inspired by, rather than based on, Article 27 ICCPR, which implies that the Declaration is not limited to the content and interpretation of Article 27. The following focuses on several

119 See sections II and III of the draft.

120 Lemer, 1993, pp. 99-100.

121 UN Doc. E/CN.4/1990/41, 5 March 1990, Annex 1. On the process of adoption, see also, Thomberry, 1995, pp. 26-27; Thomberry, 1993, pp. 24-25.

122 Commission Resolution 1992/16, reproduced in UN Doc. E/CN.4/1992/84, January-March 1992, p. 54.

123 ECOSOC Resolution 1992/4, reproduced in UN Doc. E/CN.4/1992/84, January-March 1992, p. 2.

124 UN Doc. A/Res/47/135/Annex, Declaration on the Rights of Persons Belonging to National or Ethinic, Relligious and Linguistic Minorities, 18 December 1992.

125 Conmission Resolution 1992/16, reproduced in UN Doc. E/CN.4/1992/84, January-March 1992, p. 54. ECOSOC Resolution 1992/4, reproduced in UN Doc. E/CN.4/1992/84, January-March 1992, p. 2; UN Doc. A/Res/47/135/Annex, 18 December 1992. See also, Philips and Rosas, 1995, p. 194.

126 Thornberry, 1995, pp. 27-28; Thornberry, 1993, pp. 25-26. 
provisions of the Declaration that refer explicitly to culture or cultural identity. With regard to the interpretation of the Declaration, the travawo preparatoires and the work of scholars are important. The eases on Article 27 ICCPR have revealed the potential importance of a supervisory body in clarifying the content and scope of a provision. Although initially the Declaration did not establish a monitoring mechanism, in 1995 the Sub-Commission established a Working Group on Minorities to examine the application of the Declaration. The chairperson of the Working Group, Eide, submitted a report in which he commented on the background and content of the Declaration. Before examining specific provisions, some general remarks are made on the subject of the Declaration on Minorities.

\subsubsection{Subject of the Declaration on Minorities}

The Declaration guarantees rights to "persons belonging to minorities", which suggests that the Declaration does not contain collective rights. However, several provisions concerning State obligations refer alternatively to 'minorities' as such. In other words, the substantive rights apply to individuals, in line with Article 27 ICCPR. Minorities as such are only cited as beneficiaries of certain provisions, not as subjects. In the words of Eide, "[w] hile the rights are consistently set out as rights of individuals, the duties of States are in part formulated as duties towards minorities as groups." 127

Apart from the collective approach of several provisions concerning duties of States, the collective dimension of the Declaration is established in Article 3, which states that persons belonging to minorities can exercise their rights, 'individually as well as in community with others'. This provision is similar to Article 27 ICCPR, and emphasises the collective dimension of the provisions in the Declaration. Such an individual approach including a collective reference is a via media between individual rights and collective rights. It is worth noting that an earlier draft of the Declaration spoke of, 'individually or in community with others'. Thornberry rightly argues that, on the one hand, this left the choice to the individual, but that on the other hand, States might claim that, for example, the individual use of language would satisfy the Declaration. This would have led to a weakening of the provisions compared to Article 27 ICCPR. ${ }^{128}$

One of the issues which arose during the drafting of the Declaration was the definition of the term 'minority'. In 1984, the Commission asked the SubCommission to prepare a text on the definition of the term 'minority'. The SubCommission considered and transmitted a report by Special Rapporteur Deschênes

1.27 UN Doc. E/CN.4/Sub.2/AC.5/2001/2, Eide, 2 April 2001, p. 4, \$4. See also, Meijknecht; 2000, p. 137. It is worth noting that the first two drafts of the Declaration submitted by Yugoslavia and Tosevski did contain collective rights in the first article whereby minorities had the right to existence, respect for and promotion of their nationat ${ }_{s}$ cultural linguistic and other characteristics. See, UN Doc. E/CN.4/L.1367/Rev.1, 2 Mareh 1978 and UN Doc. E/CN.4/Sub.2/L.734, 2 July 1980 .

128 Thomberry, 1995, pp. 28-29; Thornberry, 1993, pp. 45-46. 
including such a definition. ${ }^{129}$ In the same way as the earlier definition of Special Rapporteur Capotorti, the Sub-Commission was again unable to reach an agreement. Thus, in 1986 a decision was made to postpone the question of the definition and to continue working on the draft. ${ }^{130}$ In the end, the Declaration was adopted without a definition of the term "minority". One of the arguments was that the Declaration could function perfectly well without a definition, because it was clear to which groups the term would apply in concrete cases. ${ }^{131}$ There is, however, uncertainty as to whether the Declaration would, for example, only apply to nationals, a discussion that has also been held in relation to Article 27. Many States, and the two main rapporteurs on this issue, Capotorti and Dechênes, insist on citizenship as a qualification for persons belonging to a minority. In his commentary to the Declaration, however, Eide argues that it has a broader scope than the traditional 'national minorities', and may also apply to non-nationals if they are part of a minority, which is in line with the current interpretation of Article 27 ICCPR. Eide goes on to argue against making a rigid distinction between 'old' and 'new' minorities or immigrants, and to avoid excluding the latter from the Declaration, although he admits that long-established minorities may have stronger rights and entitlements than those which have recently arrived in a host country:

\subsubsection{Provisions in the Declaration on Minorities concerning Cultural Identity}

\section{Article I}

Cultural identity is laid down in Article 1 as a general value to be protected by States, coupled with the existence of minorities,

"l. States shall protect the existence and the national or ethnic, cultural, religious and linguistic identity of minorities within their respective territories and shall encourage conditions for the promotion of that identity.

2. States shall adopt appropriate legislative and other measures to achieve those ends."

Although the first two drafts by Yugoslavia and Toševski did not contain a reference to 'identity', Toševski subsequently amended his draft for the Working Group meeting in 1986, including an explicit reference to the protection of cultural identity. His draft read as follows,

129 UN Doc. E/CN.4/Sub.2/1985/31 and Corr. 1, 14 May 1985, \$ 181. The definition of Dechênes is similar to that of Capotorti, and reads as follows: "A group of citizens of a State, constituting a numerical minority and in a non-dominant position in that State, endowed with ethnic, religious, or linguistic characteristics which differ from those of the majority of the population, having a sense of solidarity with one another, motivated, if only implicitly, by a collective will to survive and whose ain is to achieve equality with the majority in fact and in law."

130 UN Doc. E/CN.4/1986/43, \& 12 . For a compilation of proposals concerning the definition of "minority", see UN Doc. E/CN.4/1987/WG.5/WP.1.

131 UN Doc. ElCN.4/1991/53, \$9; Thornberry, 1995, pp. 30-31; Thomberry, 1993, pp. 28-33.

132 UN Doc. E/CN.4/Sub.2/AC.5/2001/2, Eide, 2 April 2001, pp. 3-4, \$ 9-11. 
"[Persons belonging to] [national or] ethnic, linguistic, and religious minorities... have the right to respect for, and the promotion of, their ethnic, cultural, linguistic and religious identity without any discrimination." ${ }^{133^{3}}$

The Working Group emphasised that the central elements in this provision were the preservation of identity and non-discrimination. It is worth noting that the use of the term 'identity" was particularly praised for, "...its modern correspondence to the wishes of minority groups." $" 134$ It is also interesting to see that at the time of writing the Working Group had not yet reached agreement on whether Article 1 should contain an individual right or a collective right. Earlier drafts contained collective rights for minorities with regard to the protection of their characteristics. However, no agreement was yet reached on this point. ${ }^{135}$

The Working Group made important changes to Article 1 during its session in February 1991. At this meeting several proposals were submitted on this provision, but without discussion on the content of the provision or the meaning of concepts used. ${ }^{136}$ The idea underlying the draft of the Working Group was to protect minorities against activities that may threaten their existence or their identity and would interfere with the development of their own characteristics. The delegations of Austria and the Ukraine submitted alternative proposals that emphasised the duties of States instead of the rights of minorities. The Austrian proposal stated that, "[t]he national, ethnic, cultural and linguistic identity of minorities must be protected and promoted:" The Ukrainian proposal read as follows: "National or ethnic, cultural, linguistic and religious identity of minorities shall be protected and conditions for the promotion of that identity shall be created." ${ }^{137}$ In the last instance, the Working Group adopted a draft text that was similar to the final text of the Declaration, however without the second paragraph. ${ }^{138}$ During the December meeting, Article 1 obtained its prominent place as the first provision and the second paragraph was added. ${ }^{139}$ The Commission, the ECOSOC and the General Assembly did not make changes in this provision.

The various proposals and the wording of the provision in the final text demonstrate the importance that States attached to the protection of the cultural (and ethnic, religious and linguistic) identity of minorities. It is interesting to note that the concept of identity was taken on board from the outset and was referred to

133 UN Doc. E/CN.41986/43, 10 March $1986, \$ 19$.

134 UN Doc. $\mathbb{E} / C N 41986 / 43,10$ March $1986, \$ 21$.

135 UN Doc. E/CN $41986 / 43,10$ March $1986, \$ 17$.

136 See UN Doc. E/CN.4/1991/52 and Add. 1 including an analytical compilation of comments on the draft text by States and NGOs. Article 1 used to be Article 2, when Article I contained a general provision on the beneficiaries of the provisions in the Declaration and the fact that they could enjoy these rights in community with others. In the December 1991 meeting the Working Group moved this provision to its present position. See, UN Doc. E/CN.4/1991/53, 5 March 1991, \& 70-82.

137 UN Doc. E/CN.4/1991/53, 5 March 1991, \$ 71-80, pp. 15-17.

138 UN Doc. E/CN.4/1991/53, 5 March 1991, $\$ 81-82$, p. 17 and Annex I, Article 2.

139 UN Doc. E/CN.4/1992/48, 16 December 1991, pp. 2-3; \& 7-15, p. 13, \$93-94, Annex 1, p. 17. 
as a fundamental characteristic of communities. The collective dimension was explicitly linked to the concept of cultural identity. The fact that cultural identity was also linked to existence is indicative of the importance attached to it. Cultural identity is recognised as a general underlying value that should be protected. Article 1 of the Declaration goes further than Article 27 in confirming that States not only have negative obligations to respect, but also positive obligations to protect and to promote the existence and identity of communities as such. This is reflected in the strong formulation using the word 'shall' instead of "should".

According to Eide, Article 1 concerns four requirements: protection of the existence of minorities, non-exclusion of minorities from the national society, nondiscrimination, and non-assimilation. The last aspect includes the promotion and protection of the group identity of minorities. According to Eide, the reference to 'identity" indicates a trend towards the protection of cultural diversity. ${ }^{140}$

Thornberry has made an interesting and relevant statement on the meaning of the concepts of existence and identity and their interrelation. $\mathrm{He}$ argues that 'existence' can have various meanings, including the right to be protected against genocide, and that it also has a close connection with other substantive rights; such as those concerning economic resources and cultural and spiritual protection, including protection against forced assimilation, ethnocide, and forced population transfers. He also rightly argues that although the terms "existence' and 'identity" may overlap, the term 'existence' essentially refers to a minimum level ' whilst 'identity' refers to a developmental process. Therefore the choice of the term 'to protect' in relation to existence and 'to protect and promote' with regard to identity in Article 1(1), is valid. ${ }^{141}$ The process or developmental aspect of identity together with its relationship with areas such as culture and economics is consistent with the use of the concept in this book.

The second paragraph of Article 1 makes generic reference to State obligations in the sense that States shall adopt legislative and other measures. This provision is unqualified, while the obligations elsewhere in the Declaration are conditional, adding references such as 'as far as possible', and 'where appropriate'. Article 1(2) requires legal and other measures. Earlier drafts used 'or' instead of 'and', since some delegations preferred the possibility for States to choose the means. However a majority agreed that this choice was assured by the inclusion of the term "appropriate". ${ }^{42}$ According to Eide, apart from legislation, other measures in the judicial, administrative, promotional and educational field, are necessary in order to ensure an effective implementation of Article 1. During the process of adoption of

140 UN Doc. E/CN.4/Sub.2/AC.5/2001/2, Eide, 2 April 2001, p. 6, \$ $24-27$.

141 Thornberry, 1995, pp: 40-41; Thornberry, 1993, pp. 39-40. Eide agrees that the protection and promotion of cultural identity is an ongoing process, since cultures are not static. UN Doc. E/CN.4/Sub.2/AC.5/2001/2, Eide, 2 April 2001, p. 7, 29.

142 Thomberry, 1995, p. 42; Thornberry, 1993, p. 41. 
such measures, the minority in question should be consulted on which measures they consider appropriate. ${ }^{14}$

The question then arises as to which concrete State actions follow from Article 1(1). It is generally agreed that States have all three obligations to respect, protect and fulfil under this provision. The obligation to respect implies that States respect the distinctive characteristics of minorities. The obligation to protect implies a non-assimilation policy by the State as well as protection of the minority against the potentially assimilatory activities of third parties. Finally, the obligation to fultil requires that States, to promote the identity of minorities, take special measures for the maintenance, reproduction and development of the minority culture. Such measures could, for example, be the removal of legal obstacles to cultural development, and the facilitation of cultural development including the creation of institutions and public funding. ${ }^{144}$ While these authors emphasise that States in principle have all three forms of obligations, it remains rather abstract and it is not specified which concrete measures States should take in order to protect and promote cultural identity, for example, in the field of language, religion and cultural heritage.

\section{Article 2}

Article 2(1) of the Declaration on Minorities contains a provision similar to Article 27 ICCPR concerning the right of members of minorities to enjoy their culture, to practice their religion, and to use their language. The difference with Article 27 is that the provision in the Declaration is formulated positively, in the form of 'have the right to", rather than 'shall not be denied'. According to Eide, the Declaration thereby confirms the common practice under Article 27 ICCPR that minority rights often require positive action by States. Article 2 adds that persons belonging to minorities can enjoy these rights in private and in public without interference or discrimination. This provision was hardly discussed during the drafting of the Declaration. ${ }^{145}$

It is worth noting that in switching to substantive rights, it is the individual members of minorities and not the minority as such that is referred to. Other rights included in Article 2 of the Declaration are participation rights, for example, the right to take part in cultural life, the right to establish institutions, and the right to establish and maintain peaceful contacts. All these rights are applicable to members of minorities; no collective rights are included.

143 UN Doc. E/CN.4/Sub.2/AC.5/2001/2, Eide, 2 April 2001, p. 7, \$30-31.

144 Thomberry, 1995, p. 41; Thornberry, 1993, p. 40; UN Doc. E/CN.4/Sub.2/AC 5/2001/2, Eide, 2 April 2001, p. $7,828-29$.

145 UN Doc. E/CN.4/Sub.2/AC.5/2001/2, Eide, 2 April 2001, p. 8, 33-34; see also, Thomberry, 1995, p. 42; Thomberry, 1993, p. 41 . 
Article 4(2)

Article 4 contains a non-discrimination clause in the first paragraph, while the second paragraph includes that

${ }^{48}$ States shall take measures to create favourable conditions to enable persons belonging to minorities to express their characteristics and to develop their culture, language, religion, traditions and customs, except where specific practices are in wiolation of national law and contrary to international standards."

The notion that minorities should be free to express their characteristics was already part of the first drafts submitted by Yugoslavia and Toševski. ${ }^{146}$ The last phrase was included to meet the familiar critique that minority traditions may incorporate practices that are incompatible with human rights. For that matter, Eide emphasises that this rule applies to the practices of both the minority and the majority. ${ }^{147}$ As stated earlier in this book, cultural practices that constitute serious violations of human rights should not be exonerated on the grounds of collective rights, minority rights, or any other invocation of cultural identity. On the other hand, Thornberry and Eide demonstrate that this provision prevents States from condemning cultures as a whole or from denying communities cultural developments that are compatible with international standards. While States have a certain margin of appreciation with regard to practices they wish to prohibit, they are not free to adopt any prohibitions they like to contain the cultural practices of minorities. Only specific cultural practices that violate national law and international standards do not deserve protection. ${ }^{148}$

Article $4(3)$ concerns the right to learn and receive schooling in the mother tongue, Article 4(4) deals with educational rights and the transfer of knowledge concerning the history, traditions, language and culture of minorities, and Article $4(5)$ ensures that persons belonging to minorities can participate in the economic progress and development of their State. All these provisions are cautiously formulated. They take the form of State recommendations, refer to persons belonging to minorities, and add extra criteria in the sense of "wherever possible" or 'were appropriate'. It is interesting to note that there is no special provision on rights related to religion.

\section{Self-determination}

The right of self-determination is not included in the Declaration on Minorities. In fact Article 8(4) of the Declaration emphasises that any activity deemed incompatible with the sovereign equality, territorial integrity and political independence of States may not be based on the Declaration. Self-determination

146 UN Doc. E/CN.4/L. 1367/Rev.I, 2 March 1978 and UN Doc. E/CN.4/Sub.2/L.734, 2 July 1980, Article 3 .

147 UN Doc. E/CN.4/Sub.2/AC.5/2001/2, Eide, 2 April 2001, p. 13, \$57.

1.48 Thornberry, 1995, p. 41; Thornberry, 1993, p. 48; UN Doc. E/CN.4/Sub.2/AC.5/2001/2, Eide, 2 April 2001, p. 13, \$ 58. 
seems to be less controversial in relation to minorities than in case of indigenous peoples. It would appear that, "... in contemporary international law, it is clear that minorities as such do not have the right to self-determination." 149 Minorities can, however, enjoy internal self-determination such as the right to determine their economic and cultural development, which are important for the protection of their cultural identity. In this respect, Eide argues that,

"[t]he duties of States to protect the identity of minorities and to ensure their effective participation might in some cases be best implemented by arrangements for autonomy in regard to religious, linguistic or broader cultural matters...But the Declaration does not make it a requirement for States to establish such autonomy."

\subsection{Supervision of the Declaration on Minorities}

The Declaration on Minorities is not a legally binding instrument, but the overall consensus and support that it enjoys are worth noting. It thas the form of a General Assembly Resolution adopted by consensus without any specific rejection. Thornberry argues that such resolutions, "...contribute to the development of international law when they declare rather than propose legal standards, and the declaration is supported by consensus or a vote without opposition."151

Declarations normally have no supervisory mechanism, because they do not contain legally enforceable rights. It is merely considered soft law, which establishes key principles and political goals, but not justiciable rights. A supervisory body could, however, be helpful in the interpretation and development of the Declaration. Initially the Declaration on Minorities did not contain a monitoring procedure. Since the adoption of the Declaration, the question of monitoring has remained on the agenda of the Commission and the Sub-Commission. In a working paper, Eide suggested that the Sub-Commission could monitor the Declaration by establishing a Working Group on Minorities. ${ }^{152}$ In 1994, the Sub-Commission proposed to establish such a Working Group, which would examine the application of the Declaration, make recommendations to UN bodies, and would promote the dialogue between and among minorities and governments. ${ }^{153}$

149 Thornberry, 1995, p. 54; Thornberry, 1993, p. 55.

150 UN Doc. E/CN.4/Sub.2/AC.5/2001/2, Eide, 2 April 2001, p. 5, 820.

151 Thornberry, 1995 , p. 28.

152 The Commission had in a resolution suggested to the Sub-Commission the preparation of a report on the feasibility and usefulness of a comprehensive programme for the prevention of discrimination and protection of minorities. UN Doc. E/CN.4/Sub.2/1995/2, Resolution 1994/4, Prevention of Discrimination and Protection of Minorities, adopted on 19 August 1994, pp. 31-33, $\$ 6$. The Working Paper became UN Doc. E/CN.4/Sub.2/1994/36, A. Eide, 6 July 1994, $\$ 39$. See, also, UN Doc. E/CN.4/Sub.2/1993/34/Add.4, A. Eide, 11 August 1993, Part c, 35-44. See also, Thomberry, 1995, p. 59.

153 UN Doc. E/CN.4/1995/2/E/CN.4/Sub.2/1994/56, SubmCommission resolution 1994/4, 19 August $1994,86-7$. 
The Commission followed this proposal and authorised the Sub-Commission to establish a Working Group on Minorities. ${ }^{154}$ The Working Group is a subsidiary organ of the Sub-Commission and is composed of five experts of the SubCommission. It holds annual sessions, which are open to government representatives, IGOs, NGOs with or without consultative status with ECOSOC and scholars. The main task of the Working Group is the promotion of the rights set out in the Declaration on Minorities. In particular, it focuses on the practical realisation of the Declaration and on possible solutions to minority problems. ${ }^{155}$

The Working Group has become an important forum for the discussion and co-ordination of UN activities in the area of minorities. Its recommendations included the setting up of a database on good practices adopted in protecting the rights of minorities and on national, regional and international recourse mechanisms. It has also proposed that the relevant treaty bodies and Special Rapporteurs should give due regard to minority issues in carrying out their mandates. The Working Group has carried out studies on, for example, multicultural and intercultural education and the protection of minorities, ${ }^{156}$ universal and regional mechanisms for minority protection, ${ }^{157}$ and minority rights and the prevention of ethnic conflict. ${ }^{158}$ With regard to the interpretation of provisions of the Declaration, the chairman of the Working Group, Eide, has prepared an extensive commentary to the Declaration, as referred to above. ${ }^{159}$

154 UN Doc. E/CN.4/1995/L.11/Add.2, Resolution 1995/24, adopted 3 March 1995, \& 9. The establishment of a Working Group on Minorities immediately raised questions concerning its relation with the UN Working Group on Indigenous Peoples and the Draft Declaration on Indigenous Peoples. Several meribers of the Sub-Commission expressed their concern that both working groups could deal with similar situations, since the distinction between minorities and indigenous peoples is not always clear. Until a final declaration on indigenous peoples is adopted, it is possible that indigenous peoples apply the Declaration on Minorities, although they consider themselves to be something else than minorities. No final solution was agreed on, but the SubCommission agreed that a pragmatic approach would be followed and that the chairpersons of both Working Groups could consult each other. See, Thomberry, 1995, p. 60. Both the Draft Declaration on Indigenous Peoples and the Working Group on Indigenous Peoples are dealt with in Chapter VIII.

155 Information on the Working Group and its composition can be obtained from the website of the UN High Commissionet for Human Rights http://www unhchroch.

156 UN Doc. E/CN.4/Sub.2/AC.5/1999/WP.5, Multicultural and Intercultural Education and Protection of Minorities, Working Paper by Mustapha Mehedi.

157 UN Doc. E/CN.4/Sul6.2/AC.5/1999/WP.6, Universal and Regional Mechanisms for Minority Protection, Working Paper by Vladimir Kartashkin.

158 UN Doc. E/CN.4/Sub 2/AC.5/2000/CRP.3, Minority Rights and the Prevention of Ethnic Conflicts, Paper by Dr. Ferdinand de Varennes http://www.unhchr.ch.

159 UN Doe. E/CN.4/Sub.2/AC.5/2001/2, Eide, 2 April 2001. 


\section{CONCLUDING REMARKS ON THE UN DECLARATION ON MINORITIES}

The adoption of the Declaration on Minorities not only provides a clarification of, and an addition to, Article 27 ICCPR, but also makes explicit reference to a right to cultural identity. The question is what this right adds to Article 27 ICCPR.

The protection of cultural (and religious, ethnic, and linguistic) identity is included in Article 1 as a duty of States to protect and promote the cultural identity of minorities without further specification on content or concrete State obligations. Cultural identity is considered an important general value to be protected and promoted by States. It is an 'umbrella' concept or principle under which members of minorities have specific rights, for example, to enjoy their culture, to use their language and practice their religion, as laid down in Article 2 of the Declaration. Article 4 further contains State obligations in relation to linguistic rights and educational rights. The provisions on language and education are more rigorously defined than the provision on cultural identity in adding that States should guarantee them as far as possible and where appropriate. It appears that the more specific the provisions, the more criteria are incorporated, while general values such as cultural identity lack such criteria.

The Declaration has a strong collective dimension reflected in several of its provisions. Article 3 refers to the possibility of collective enjoyment of the rights, similar to Article 27 ICCPR. However, while Article 27 is merely directed towards persons belonging to minorities, the Declaration also refers to minorities as such, especially with regard to the protection of their identity and existence, thereby recognising minorities as collectivities. However, these provisions referring to minorities as such are formulated as duties on the part of States, and not as rights for the communities involved. Thus, the latter are not the subjects of these provisions, but their beneficiaries.

With regard to State obligations, the Declaration is generally more positively formulated than Article 27 ICCPR. Article 27 is intended to give persons belonging to minorities the freedom to develop and preserve their culture, which initially implied mainly State obligations in the field of respect and protection. However, it is now generally accepted that Article 27 also includes positive obligations on the part of States. The Declaration, however, explicitly includes positive State obligations to protect and promote the cultural identity and characteristics of minorities, for example in Articles 1(2) and 4(2).

The provisions in the Declaration are formulated in a general way. Their content and concrete State obligations are not further specified in the text. Whilst difficult to formulate, this generates a certain ambiguity in what concrete measures States are obliged to take and what the beneficiaries can apply for. Omanga, for example, argues that the sole duty of States with regard to the Declaration is to do everything in their power to promote and protect minority rights, but that they do not have to be successful in doing so. States are free to choose the means to use and the results they wish to achieve. Omanga rightly argues that more clarity on the 
practical measures is desirable, including the obligation to achieve specific results. He suggests that such an obligation implies a supervisory mechanism to make the Declaration work effectively. ${ }^{160}$

It has already been argued in this study that a supervisory mechanism helps to clarify provisions and State obligations. The Declaration on Minorities is, however, not legally binding and initially did not contain a supervisory mechanism. Subsequently, limited supervision was established in the form of a Working Group that monitors the implementation of the Declaration. This system is merely political and does not provide legal means. States do not have reporting obligations and there is no complaint procedure. Although the Working Group has made an effort to shed light on the provisions of the Declaration, they remain norms of soft law that are not legally enforceable. Accordingly, in its current form, the Declaration does not add much to Article 27. ICCPR. It is somewhat stronger on several points, such as its collective dimension and the broad concept of cultural identity, but this line has also been established by the HRC and others with regard to Article 27. The fact that a right to cultural identity was included in the Declaration confirms it is considered a key value vis-a-vis the protection of minorities. However, it is mainly a general value or underlying principle of the various provisions. As such, this right to cultural identity does not add legal protection to Article 27 ICCPR. In the unlikely event of its becoming a legally enforceable right, it remains to be seen to what extent it would add protection to Article 27 ICCPR in combination with other rights. 


\section{ChAPTER VIII \\ CULTURAL IdENTITY AND INDigenous PEOPLES}

\section{INTRODUCTION}

Indigenous peoples are another group of subjects that have, like minorities, received increasing attention within the human rights discourse, and who now benefit from several human rights provisions designed to protect their cultural identity. Comparable to the previous chapter, these provisions are examined here with regard to their content, their individual and collective dimension, and the State obligations that they incur. A brief examination is also made of other provisions that indirectly refer to cultural identity, with special attention to a category of cultural rights especially important to indigenous peoples, namely land rights. Indigenous peoples have a special relationship with the territory on which they live, because it constitutes the territorial basis for their cultural identity. A representative of the World Council of Indigenous Peoples has once stated that, "[n]ext to shooting indigenous peoples, the surest way to kill us is to separate us from our part of the earth."."

The analysis in this chapter focuses on the International Labour Organisation (ILO) Convention 169 on Indigenous and Tribal Peoples, and the Draft Declaration on the Rights of Indigenous Peoples, both of which contain a series of provisions dealing with the protection of the cultural identity of indigenous peoples. ${ }^{2}$ The analysis of the provisions includes the drafting process, the text, and the supervisory mechanism. More general issues affecting indigenous peoples, for

1 UN Doc. E/CN.4/Sub.2/AC.4/1985/WP, 4, 29 July 1985, p. 5.

2 Another instrument in this field is the General Recommendation XXIII on the Rights of Indigenouss Peoples adopted by the Committee on the Elimination of Racial Discrimination (CERD), the supervisory body of the Convention on the Elimination of All Forms of Racial Discrimination (1965), in August 1997. Such recommendations have an important interpretative status, which can be compared to General Comments of the HRC or the CESCR. In this Recommendation CERD refers to cultural identity various times, for example by stating that the preservation of the culture and historical identity of indigenous peoples has been and still is jeopardised. CERD furthermore calls upon the States to recognise and respect indigenous cultures, history, language and way of life "as an enrichment of the State's cultural identity". States are requested to ensure that indigenouss peoples do not suffer from discrimination, "in particular that based on indigenous origin or identity". Finally the Recommendation lays down State obligations with regard to effective participation of indigenous peoples, the preservation and practice of culltural traditions and languages, and the use of land and resources. The Recommendation as well as the reports of CERD do not recognise a right to cultural identity as such and offer no new information on the concept of cultural identity. See, UN Doc. CERD/C/51/Misc.13/Rev/4, General Recommendation XXIII (5I) concerning Indigenous Peoples, adopted at the 1235 th meeting on 18 August 1997. See, also, Anaya, 1996-A, pp. 162-163 and Van Boven, 2000, pp. 271-287. 
example the question as to whether or not they are international legal subjects, the definition of indigenous peoples, and the development of indigenous peoples" rights are not dealt with in detail, but several general observations necessary for an understanding of the instruments in question are made in the following section.

\section{GENERAL OBSERVATIONS ON INDIGENOUS PEOPLES}

Until the 1980s, indigenous peoples had rarely been considered in terms of international law. Neither the Universal Declaration, the ICCPR, the ICESCR, nor the UN Convention on Racial Discrimination refer to indigenous peoples. During the first World Conference on Human Rights in Teheran in 1968, indigenous peoples were simply not part of the vocabulary used, whereas twenty-five years later, the World Conference in Vienna adopted several recommendations with regard to indigenous peoples. More recently, various instruments on the rights of indigenous peoples have been adopted, partly as a result of the pro-active attitude of indigenous peoples themselyes over the last twenty years. ${ }^{4}$

\subsection{The Definition Issue}

One of the theoretical problems to be faced when analysing the issue of the treatment of indigenous peoples, is precisely how to define the term indigenous peoples.5. The answer is, that there is no generally accepted definition, and that in the absence of one, the definition of Special Rapporteur Cobo together with that specified in ILO Convention 169 on Indigenous and Tribal Peoples are those generally used.

In his Study of the Problem of Discrimination against Indigenous Populations Jose Martinez-Cobo defines indigenous peoples as follows:

"Indigenous cormmunities, peoples and nations are those which, having a historical continuity with pre-invasion and pre-colonial societies that developed on their territories, consider themselves distinct from other sectors of the societies now prevailing in those territories, or parts of them. They form at present non-dominant sectors of society and are determined to preserve, develop and transmit to future generations their ancestral territories, and their ethnic identity, as the basis of their continued existence as peoples, in accordance with their own cultural patterns, social institutions and legal systems."

3 Thliere was the ILO Convention 107 of 1957 and several other documents, but since the eighties the protection of indigenous peoples and their culture has become a serious subject of discussion. See, on the question of intermational legal personality of indigenous peoples Meijknecht, 2001.

4 Burger and Hunt, 1994, p. 405; Lerner, 1992, pp. 213-215; Anaya and Williams, 2001, p. 34; Meijknecht; 2001, chapter IV.

5 See, on the discussion concerning the definition of indigenous peoples among others: Anaya, 1996A. Chapters 3 and 4 (pp. 75-128); Barsh; 1996, pp. 791-800; Lemer, 1992, pp. 215-219.

6 UN Doc. E/CN.4/Sub.2/1986/7/Add 4, José R. Martinez Cobo, p. $29, \$ 379$. 
Self-identification is a key aspect of the lives of indigenous peoples, which implies that an individual is indigenous on the basis of self-identification and acceptance by the community. Cobo argues that indigenous peoples themselves should have the right to decide who belongs to them without external interference. This inplies that they also have the right not to accept a person as a member although he or she may objectively be considered as belonging to the indigenous people, for example, on account of descent. Thus, a dilemma may arise between individual selfidentification and the decision made by the community to which he or she belongs.

Article 1(b) of ILO Convention 169 on Indigenous and Tribal Peoples states that the Convention applies to,

“...peoples in independent countries who are regarded as indigenous on account of their descent from the populations which inhabited the country, or a geographical region to which the country belongs, at the time of conquest or colonisation or the establishment of present State boundaries and who, irrespective of their legal status, retain some or all of their own social, economic, cultural and political institutions."

In Article 1(2) of Convention 169, self-identification is endorsed as a fundamental criterion for determining the communities to which the Convention applies. The difference between both definitions is that the ILO Convention includes 'descent' as a criterion, while Cobo's definition does not. Instead, Cobo's definition refers to the historical continuity between the pre-invasion and pre-colonial societies and the current indigenous people. This historical element is important to distinguish indigenous peoples from minorities insofar as indigenous peoples existed in the territories involved before other communities settled and became dominant. ${ }^{8}$

The discussion on the definition of indigenous peoples also focuses on the use of the terms 'peoples' or 'populations'. Indigenous peoples strongly support the use of "peoples" instead of "populations', since the latter does not reflect the social, cultural and political integrity of the communities involved, whereas the term "peoples' implies a positive recognition of a distinct identity and the social, political or cultural bond of the community involved. Furthermore, the recognition of indigenous peoples as 'peoples' would imply their right of self-determination under Article 1 ICCPR and ICESCR, which is precisely why States oppose the use of the term 'peoples'. Finally, indigenous peoples prefer the term 'peoples' as distinct from minorities, partly because it is generally agreed that the right of selfdetermination does not apply to minorities."

7 UN Doc. E/CN.4/Sub.2/1986/7/Add.4, José R. Martinez Cobo; p. 29, $\$ 381$ and 382. Several cases under Article 27, such as the Lubicon Lake Band and Kitok, suggest the exact opposite, namely that communities do not have the right to decide who belongs to them. In determining the membership of a minority or indigenous people, objective ethmic criteria may only be disregarded if the measure is shown to be reasonable and objectively justified, see, Chapter VII, section 4.2 .

8 Lerner, 1992, pp. 217-218.

9 Coulter, 1995, pp. 130-131; Anaya, 1996-A, p. 48; Brölmann and Zieck, 1995-A, pp. 194-195. 


\subsection{The Right of Self-Determination}

The right of self-determination is probably one of the most controversial and complicated concepts among the human rights instruments. Whilst an in-depth examination of the discussion on the right of self-determination falls outside the scope of this research, this right needs to be dealt with briefly, precisely because it is one of the main issues relating to indigenous peoples, and because the internal aspects of the right of self-determination are linked with the protection of cultural identity. $^{10}$

The right of self-determination was first included in the UN Charter (Articles 1(2) and 55), and later in Article 1 ICCPR and Article 1 ICESCR. There is, however, no consensus on the meaning and scope of the right of selfdetermination and on the subject of this right, particularly as regards the meaning of the term 'peoples'. Article 1 ICCPR and ICESCR reads as follows:

"1. All peoples have the right of self-determination. By virtue of that right they freely determine their political status and freely pursue their economic, social and cultural development.

2. All peoples may, for their own ends, freely dispose of their thatural wealth and resources without prejudice to any obligations arising out of international economic co-operation, based upon the principle of mutual benefit, and international law. In no case may a people be deprived of its own means of subsistence..."

The right of self-determination can be divided into external and internal selfdetermination. External self-determination means a people's capacity to free itself from colonial or racist rule. This can imply secession and the establishment of a new sovereign and independent State, the free association or integration with another independent State, or any other political status freely determined by the people involved. Internal self-determination implies the presence of a representative government, and a commitment by that government to respect human rights and freedoms with a special focus on the rights of peoples and communities. Internal self-determination includes the ability to participate in government and in the work of decision-making bodies, without discrimination on the basis of race, religion, language, etc. It may also refer to some form of self-government or autonomy in the economic, social or cultural field. In this respect, Article 1(2) ICCPR and ICESCR refers to the right of all peoples to freely dispose of their

10 See, on the right of self-determination among others the following books: P. Aikio and M. Scheinin (eds), Operationalising the Right of Indigenous Peoples to Self-Determination, Institute for Human Rights, Abo Akademi University, 2000; K. Henrard, Devising an adequate system of minority protection : individual human rights, minority rights and the right to self-determimation, Nijhoff Publishers, The Hague, 2000; H. Hannum, Autonomy, Sovereignty and Self-Determinarion, Uniwersity of Pennsylvania Press, Philadelphia, 1996; A Cassese, Self-determination of Peoples: A Legal Reappraisal, Cambridge University Press, Cambridge, 1995; C. Tomuschat (ed.), Modern Law of Self-determination, Dordrecht, Nijhorf, 1993. 
natural wealth and resources. In no case may peoples be deprived of their own means of subsistence. This implies that the subsistence of peoples, in political; economic and cultural terms, is an integral aspect of the right of self-determination. The internal aspects of the right of self-determination have a direct link with the protection of cultural identity, for example in the form of granting cultural or linguistic autonomy or with regard to land rights. ${ }^{\text {" }}$

With regard to external self-determination, the question arises to what extent the right of self-determination and/or secession is recognised outside of the context of decolonisation. Despite the references to 'all peoples' in the Covenants, in practice, the right of external self-determination has been limited to colonial situations or peoples under racist rule. No State has accepted an unconditional right of self-determination for all peoples, and the right to self-determination does not imply a right to secession, because the principles of national unity and territorial integrity generally prevail over claims of self-determination. In short, the international community recognises only a limited right of external selfdetermination, defined as a right to freedom from a colonial power ${ }^{12}$ The internal dimension of self-determination deserves, however, a somewhat broader approach. Anaya has formulated it as follows,

"[i]n my view, self-determination should not be equated with a right to independent statehood. Under a human rights approach, the concept of self-determination is capable of embracing much more nuanced interpretations and applications...Selfdetermination may be understood as a right of cultural groupings to the political institutions necessary to allow them to exist and develop according to their distinctive characteristics." "'s

However, external self-determination and fear of secession are often the reasons why States reject the right of self-determination as a whole. Consequently, much of the debate on the right of self-determination ends with a rejection of the right to secession without further discussion of the internal aspects of self-determination. Several authors have noted that indigenous peoples have not generally

11. The issue of internal and external self-determination is dealt with in all above-mentioned sources. See, also, Rosas, 1995, pp. 470-471; Advisory Committee on Human Rights and Foreign Policy, 1995, pp. 9-11; Advisory Committee on Human Rights and Foreign Policy, 1993, pp. 19-21.

12 See, note 10 supra. This approach is also present in the Declaration on Principles of International Law Concerning Friendly Relations and Comoperation among States adopted by the UN General Assembly in 1970 . While the Declaration endorses the principle of the self-determination of peoples, it is stated that nothing in the Declaration, "[s] hall be construed as authorising or encouraging any action which would dismember or impair, totally or in part, the territorial irtegrity or political unity of sovereign and independent States." The Declaration does not generally prohibit secession, but only allows it as a rare exception as when, for example, States fail to comply with the principles of the equal rights and self-determination of peoples. See UN Doc. A/RES/2625 (XXV), Declaration on the Principles of International Law Concerning Friendly Relations and Cooperation Among States, 24 October 1970, Annex, under the heading The principle of equal rights and self-determination of peoples.

13 Anaya, 1995, pp. 325-326. 
demonstrated aspirations for secession or independent statehood, preferring instead constitutional reforms and a degree of autonomy concerning cultural, economic, and political rights within existing States. Indigenous peoples mainly use the right to (internal) self-determination to demonstrate their desire to exist freely and to develop as distinct communities. They wish to live according to their own values and beliefs, and to be respected by their non-indigenous neighbours. This implies recognition of indigenous representatives and institutions, but does not necessarily imply the acquisition of the power for autonomy or secession. ${ }^{14}$

Internal self-determination, in the sense of cultural autonomy or land rights, may also play a role in the protection of cultural identity. However, most States tend to reject it as a whole and do not intend to protect cultural identity under the heading of self-determination. Moreover, the supervision of the right to selfdetermination is limited, since Article 1 ICCPR does not fall under the monitoring procedure of the HRC and the ICESCR does not have an individual complaint procedure. Supervision can only take place with regard to reports submitted by States, but as argued above, States prefer not to refer to self-determination.

\section{Ilo Convention 169 on Indigenous and Tribal Peoples}

The International Labour Conference of the ILO adopted in 1989 Convention 169 on Indigenous and Tribal Peoples in Independent Countries (hereafter Convention 169). Convention 169 was the revision of Convention 107 on Indigenous and Tribal Populations (hereafter Convention 107) adopted in $1957 . .^{15}$

\subsection{LLO Convention 107}

Why did a labour organisation such as the ILO concern itself with the issue of indigenous peoples, their self-determination, cultural rights and land rights, when such issues do not appear to fall within its mandate? ${ }^{16}$ The reason is that the ILO was set up after the First World War to promote social rights and that, as a result, it addressed, inter alia, the issue of 'native workers'. After the Second World War, the ILO broadened its focus from indigenous workers to indigenous peoples in general, since these communities often constituted an exploited labour force in the new economies. In 1953, the ILO carried out a study on indigenous peoples ${ }^{17}$ and began drafting Convention 107 on Indigenous and Tribal Populations, subsequently adopted in 1957. The underlying idea was to address the growing isolation of

14 UN Doc. E/CN.4/Sub.2/1993/26/Add.1, E-I. Daes, 19 Jully 1993, 58; Anaya, 1996-A, p. 48; Coulter, 1995, p. 131; Sanders, 1989, p. 429; E-I. Daes, 2000, pp. 79-80.

15 $1 \mathrm{LO}$ Convention 169 on Indigenous and Tribal Peoples in Independent Countries, adopted by the Intenational Labour Conference at its 76th session, 27 June 1989; ILO Convention 107 on Indigenous and Tribal Populations, 1957 .

16 Berman, 1988 , pp. 49 and 56.

17 ILO, Indigenous Peoples: Living and Working Conditions of Aboriginal Populations in Independent Countries, Geneva, 1953. 
indigenous communities in the wake of national development. Indigenous communities themselves did not participate in the drafting of Convention 107, which focused on the development of these 'less advanced' communities through integration and assimilation. State power was absolute, especially with regard to land rights, in the interest of national economic development. Cultural diversity was valued among States, but not within States. Convention 107 was thus designed for members of indigenous populations to ensure their equality with the rest of society. Land ownership and indigenous customary law were recognised to the extent that they were 'in transition' towards national integration and assimilation. ${ }^{18}$ Convention 107 has only been ratified by 27 States. ${ }^{19}$ ?

The paternalistic approach of assimilating indigenous peoples into the nonindigenous community, emphasised in Convention 107, was criticised by indigenous peoples, NGOs, and UN bodies alike. Within the UN, the on-going study started in 1972 by Special Rapporteur Cobo on the discrimination of indigenous people ${ }^{20}$ constituted an important source of inspiration. Indigenous peoples were no longer the mere objects of discussion, but instead became participants in the dialogue dealing with their rights in international bodies. In 1985, the ILO started the revision of Convention 107 with a meeting of a group of experts. This group concluded that Convention 107 no longer reflected current thinking, and stressed that indigenous peoples were under a pressure that threatened their cultural identity and even their existence, and that they needed a right to preserve their unique identity. The experts further argued that although selfdetermination might discourage ratification it should still be included in the revised Convention so as to meet the wishes of indigenous peoples. ${ }^{21}$ They should have as much control as possible over their own economic, social and cultural development, despite the lack of a consensus as to which indigenous peoples should have decision-making power. Accordingly, the term 'populations' was to be replaced by "peoples" in order to reflect the existence of a degree of social structure and unity. ${ }^{22}$

Once again, indigenous peoples themselves played hardly any part in the revision of Convention 107 . While they were increasingly involved in the work on indigenous peoples within the UN Sub-Commission, the ILO, with the participation of employer and employee organisations, seldom allowed NGOs to participate in its

18 Burger, 1998 , pp. 18-19; Barsh, 1987, pp. 756-757; Lerner, 1992, p. 222; Swepston, 1998, pp. 3839; Anaya, 1996-A, p. 44; Brölmann and Zieck, 1995-A, pp. 188-189, 200-203.

19 These States are: Angola, Argentina, Bangladesh, Belgium, Bolivia, Brazil, Colombia, Costa Rica, Cuba, Dominican Republic, Ecuador, Egypt, El Salvador, Ghana, Guinea-Bissau, Haiti, India, Iraq, Malawi, Mexico, Pakistan, Panama, Paraguay, Peru, Portugal, Syrian Arab Republic, Tunisia.

20 UN Doc. E/CN.4/Sub.2/1986/7, E/CN.4/Sub.2/1986/7/Add.1, E/CN.4/Sub.2/1986/7/Add.2, E/CN.4/Sub.2/1986/7/Add.3 and E/CN.4/Sub.2/1986/7/Add.4, J. Martinez-Cobo, Study of the Problem of Discrimination against Indigenous Populations, UN Sub-Commission on Prevention of Discrimination and Protection of Minorities.

21 The right of self-determination was, however, not included in the final text of Convention 169.

22 Barsh, Revision of ILO Convention 107, 1987, pp. 758-761; Berman, 1988, p. 48; Burger, 1998, p. 20; Debeljak, 2000, p. 267; Lerner, 1992, p. 222; Marquardt, 1995, pp. 55-56; Anaya, 1996-A, pp. $46-47$. 
standard-setting procedures. Consequently, indigenous peoples, the beneficiaries of the Corvention, had no formal role in the revision of Convention 107, and whilst a small number of indigenous organisations attended meetings and could make short statements, they had no involvement in the negotiations on draft provisions. ${ }^{23}$

\subsection{ILO Convention 169}

After the drafting committee had approved Convention 169 by consensus, the full conference adopted it in 1989 with an overwhelming majority of votes. None of the government representatives voted against its adoption, although a number abstained $^{24}$ Convention 169 came into force on 5 September 1991 , following the two ratifications required. To date, only fifteen States have ratified it. ${ }^{25}$

Convention 169 is composed of ten parts which deal respectively with general policy (I), land (II), recruitment and employment conditions (III), vocational training, handicrafts and rural industries (IV), social security and health (V), education and communication (VI), contacts and co-operation across borders (VII), administration (VIII), and general provisions (IX, X).

Convention 169 differs from Convention 107 in several respects. Firstly, Convention 169 uses the term 'peoples" instead of 'members of populations', thus incorporating a collective dimension. This collective dimension does not, however, take the form of substantive rights adjudged to indigenous peoples as such, but instead reflects State obligations towards those peoples. Thus, indigenous peoples are not the subjects of these provisions, but their beneficiaries, comparable to the UN Declaration on Minorities. Article 1(3) furthermore makes clear that, "[t]he use of the term 'peoples' in this Convention shall not be construed as having any implications as regards the rights which may attach to the term under international law." In other words, the use of the term "peoples' would have no implications regarding the right of self-determination as understood in international law. The right of self-determination was not included in Convention 169 because States were opposed to its incorporation in the final text. ${ }^{26}$

Another important difference between both Conventions is that Convention 107 presumed the eventual disappearance of indigenous peoples and their integration into the majority society. Convention 169 , on the other hand, does not

23 Berman, 1988 , pp. $49-52$.

24 The total vote was 328 in favour, 1 against, and 49 abstentions: Among the votes in favour were representatives of 92 States, while 20 State representatives abstained. The opposing vote was casted by the employer delegate from the Netherlands. See, International Labour Conference, Provisional Record 32,76 th session, 1989 , at $32 / 17-32 / 19$.

25 The first two States ratifying Convention 169 were Norway (19 June 1990) and Mexico (5 September 1990). The 15 current States Parties are: Argentina, Bolivia, Colombia, Costa Rica, Denmark, Ecuador, Fiji, Guatemala, Honduras, Mexico, Netherlands, Norway, Paraguay, Peru and Venezuela. (June 2002, see, www.ilo.org).

Anaya, 1996-A, p. 49; Berman, 1988, pp. 52-54. 
take this assimilationist approach but instead recognises that indigenous peoples should remain as distinct communities with a right to differ from the rest of the population, and to enjoy respect for their culture and characteristics. This respect for, and protection of, the cultural identity of indigenous peoples is laid down in Convention 169 when it refers to customs, traditions and values of indigenous peoples, and by providing that indigenous peoples should have a larger role with regard to decision making. ${ }^{27}$ Although Convention 169 does not include a separate right to cultural identity, Article 2(2) states that,

"[s] uch action [to protect the rights of indigenous peoples and to guarantee respect for their integrity] shall include measures for: (b) promoting the full realisation of the social, economic and cultural rights of these peoples with respect for their social and cultural identity, their customs and traditions and their institutions..."

Article 5 goes on to state that,

"[I]n applying the provisions of this Convention:

(a) the social, cultural, religious and spiritual values and practices of these peoples shall be recognised and protected..."

These provisions illustrate the recognition in Convention 169 of the value of cultural identity in relation to indigenous peoples. Article 2 focuses on respect for cultural identity, whilst Article 5 emphasises an active State policy to protect cultural values. What remains unclear, however, is the meaning of cultural identity and cultural values, and what concrete measures States should take in order to protect them. From the spirit of the Convention it would appear that indigenous peoples themselves need to be closely involved in the decision-making process on measures to protect their cultural identity and cultural values.

Land rights are established in Articles 13 to 19 of the Convention. Article 13 rules that,

"[g]overnments shall respect the special importance for the cultures and spiritual values of the peoples concerned of their relationship with the lands or territories...which they occupy or otherwise use, and in particular the collective aspects of this relationship."

The following provisions include several guarantees with regard to land, resources and removal. Ownership of the land, in Article 14, proved to be one of the controversial provisions of Convention $169 .{ }^{2.8}$ It reads as follows:

27 Burger, 1998, p. 23; Lemer, 1992, p. 226; Wolfrum, 1999, p. 373.

28 Berman, 1988 , p. 55 ; seweral States, among which Finland and Sweden, have refused to tratify Convention 169 because of the obscurity of Article 14. 
"The rights of ownership and possession of the peoples concerned over the lands which they traditionally occupy shall be recognised."

On the one hand, the provision affirms the prior rights of ownership and possession, insofar as the latter should be recognised rather than granted. On the other hand, Article 14 leaves the content and scope of the rights unclear. The supervisory body of the ILO, the Committee of Experts on the Application of Conventions and Recommendations, has stated that Article 14 does not necessarily imply full title over land as long as possession and use are secured. ${ }^{29}$ It has been argued that the Labour Conference never intended the Convention to require immediate recognition of a right to title over land, since that would imply that no State with a system of reserved land or restricted title could ever ratify the Convention. ${ }^{30}$

While Convention 169 was adopted with an overwhelming majority of votes, only fourteen States have ratified it. Many have refused to ratify it because of its collective dimension, the term 'peoples', and its provisions on land rights. Convention 169 is a legally binding instrument for the States that have ratified it. Within the ILO system, the adoption of an amended instrument (Convention 169), implies that the previous instrument (Convention 107) is closed to further ratification, and ratification of the new instrument automatically implies renunciation of the former. Accordingly, ILO Convention 107 remains in force for those States that have ratified 107 , but not $169 .^{31}$

\subsection{ILO Supervision}

The supervisory mechanism of the ILO is based on Article 22 of the ILO Constitution and consists of a State report procedure which obliged States to report on the Conventions they have ratified, and to submit such reports to the Committee of Experts on the Application of Conventions and Recommendations (CEACR) for examination. The CEACR presents its comments in the form of either direct requests, which are not published ${ }^{32}$ and concern less serious or preliminary points, for example, a request for further information or minor changes, and observations, which are published in the annual reports of the CEACR, and subsequently submitted to the International Labour Conference where they may be discussed. ${ }^{33}$

29 Burger, 1998 , p. 25.

30 Swepston, 1998, p. 43 .

31 These States are: Angola, Bangladesh, Belgium, Brazil, Cuba, Dominican Republic, Egypt, El Salvador, Ghana, Guinea-Bissau, Haiti, India, Iraq, Malawi, Pakistan, Panama, Portugal, Syrian Arab republic and Tumisia; see, www ilo.org.

32. Although they are not officially published in the CEACR reports, they can be found on the web site of the ILO: hitp///webfusion.lo.org/public/db/standards/normes/appl/index.cfm?lang=EN.

33 Burger, 1998, pp. 28-29; Brölmann and Zieck, 1995-A, p. 210; Anaya, 1996 A, p. 155; Sanders, 1989 , p. 420 . The observations of the Committee of Experts are available on the ILO website: www ilo, org. 
The first reports on Convention 169 were filed in $1993^{34}$ Several reports have since been filed under Convention 169, and several direct requests and observations in pursuance of Article 22 have been submitted by the CEACR. It is interesting to note that these direct requests and observations do not include any explicit reference to cultural identity, and that the term 'culture' is hardly ever used. Neither do they provide a general clarification of the provisions in the Convention. The observations and direct requests instead concern specific situations of indigenous peoples in certain States, especially with regard to land rights, whereby the CEACR makes much use of NGO reports. During its 2000 session, for example; the CEACR demanded more information on the autonomy of the indigenous people in Greenland, on the working conditions and transfer of land in relation to indigenous communities in Paraguay, and on human rights violations towards indigenous communities in Colombia. The CEACR mainly asks for more information, although it also 'reminds' States that they have positive obligations to ensure effective participation and consultation of the indigenous peoples involved. ${ }^{35}$

In addition to the reporting procedure, the ILO has two complaint procedures. Under Article 26 of the ILO Constitution, governments or State bodies may file a complaint against another State that has ratified the Convention involved, after which a Commission of Inquiry pays a visit to the State concerned to determine whether or not a violation has taken place. Under Article 24 of the ILO Constitution, workers or employers organisations may file a so-called representation concerning an alleged violation. In this case, a tripartite Governing Body Committee is formed which decides on the case, mostly based on an exchange of correspondence. The ILO has no individual complaint procedure. Consequently, indigenous peoples cannot file complaints themselves, since they do not have locus standi, and are de facto dependent on the willingness of States, labour organisations or employer organisations to take up their case. No complaints or representations by States have been filed under Convention 107, but several representations have been recorded under Convention $169 .^{36}$ The first representations under Convention 169 were filed in 1997 against Mexico and Peru, followed by representations against Bolivia and Mexico in 1998, against Colombia in 1999, and against Colombia, Denmark and Ectuador in 2000. The content of the

34 See, General Report of the Committee of Experts on the Application of Conventions and Recommendations, 1993, $\$ 48$. Unfortunately, no information is given on which States submitted these reports and on the comments of the Committee.

35. See, the direct requests and observations conceming Convention 169 in 1999 and 2000 to Denmark, Mexico, Paraguay, Colombia, Costa Rica and Peri. Direct requests and observations have also been submitted on Convertion 107 to Angola, Bangladesh, Haiti, India, Malawi, Egypt, El Salvador, Guinea-Bissau, Iraq, Pakistan and the Syrian Arabic Republic.. These can be found on: http//webfusion.ilo. org/public/db/standards/normes/appl/index cfin?lang=EN.

36 Burger, 1998, p. 30; Anaya, 1996-A, pp. 161-162; Brölmann and Zieck, 1995-A, p. 211. 
representations, and the reports adopted by the tripartite bodies, are not published in the anniual reports of the CEACR. ${ }^{37}$

The annual reports of the CEACR contain general information on ratifications and developments with regard to Conventions, and on co-operation with other international organisations, but do not provide further details on the observations made or the content of representations, with the exception of the 1999 report which contains a section on Convention 169. In this report the CEACR generally emphasises the importance of Convention 169 , which, " $\ldots$ is the most comprehensive instrument of international law for the protection in law and in practice of the right of indigenous and tribal peoples to preserve their own laws and customs within the national societies in which they live." The CEACR points out that the Convention establishes minimum rights to be respected and put into practice by the States that ratify it. With regard to the general principle underpinning Convention 169, the CEACR argued that, "....one of the fundamental precepts of this Convention is that a relationship of respect should be established between indigenous and tribal peoples and the States in which they live, a concept which should not be confused with autonomy or political and territorial independence from the Nation State. ${ }^{38}$. The focus is thus on respect for the characteristics of indigenous peoples, whilst emphasising that this does not imply self-government or secession.

\subsection{Concluding Remarks on ILO Convention 169}

In conclusion, cultural rights constitute an important part of ILO Convention 169, including an explicit reference to cultural identity as a value per se. The growing interest in the protection of the cultural identity of indigenous peoples is the result of the changing attitude towards indigenous peoples from that of mere assimilation, to the promotion and protection of their specific cultural identity. This concept is not described in more detail, but appears to serve as an umbrella for a series of cultural rights in matters of religion, language, education, cultural heritage and especially land. Nevertheless; the precise content of the provisions referring to the broad concepts of cultural identity and cultural values and measures to be taken by States remain vague. The overwhelming support during the adoption of Convention 169 may have been an indication that States acknowledge that indigenous peoples and their characteristics, including their cultural identity, are in need of preservation and promotion. The Convention is, however, hardly ratified by States, which shows their unwillingness to be legally bound such a Convention. This unwillingness is partly due to the sheer vagueness of the provisions and the corresponding State obligations as, for example, in relation to Article 14 on land rights, and to the

37 See, the General Reports of the Committee of Experts on the Application of Conventions and Recommendations, 1998, 1999, 2000 and 2001 on http.//wwwilo/org.

38 General Report of the Conmittee of Experts on the Application of Conventions and Reconmendations, 1999, \$ 98-102, quotation \$ 100 . 
collective dimension, and the debate on the self-determination of indigenous peoples. The number of ratifications is limited, which implies an equally low number of State reports and complaints. Accordingly, the supervisory mechanism cannot play a large role in the clarification of provisions. The impact of ILO Convention 169, as the only legally binding instrument making explicit reference to cultural identity, remains limited.

\section{UN DRAFT DEClaRATION ON THE RIGHTS OF INDIGENOUS PEOPLES}

\subsection{The History: the Working Group on Indigenous Populations}

Indigenous peoples themselves played an important role in the development of international legal standards concerning the protection of their rights. In the period between 1977 and 1981, indigenous organisations held a series of meetings and conferences to claim legal status under international law and to petition for special rights. Against the background of these developments the Sub-Commission recommended the creation of a Working Group on Indigenous Populations (hereafter Working Group), which was established by the ECOSOC in May $1982{ }^{39}$ Its mandate was to review the developments concerning the promotion and protection of the human rights of indigenous peoples and to formulate standards for the protection of their rights. The Working Group is composed of five independent experts of the Sub-Commission, and has proven, despite its low ranking in the UN system, to be an important 'think tank' for indigenous affairs and a platform for indigenous peoples to petition their case at UN level. It has grown from thirty participants, mainly State representatives, in 1982, to more than 1,000 delegates representing governments, indigenous peoples, IGOs and NGOs, in 2001. ${ }^{40}$

In 1985, the Working Group started to draft a Declaration on the Rights of Indigenous Peoples working closely with representatives of indigenous peoples and NGOs. The States, on the other hand, gradually withdrew from the drafting process, ${ }^{41}$ so that they had less influence on the final outcome of the Draft Declaration. This may explain why its content is relatively far-reaching and why, now that States have become part of the drafting process in the Commission, no final Declaration has been adopted.

The Working Group initially adopted seven draft principles, including a right to cultural identity. These principles were the right to the full and effective enjoyment of human rights as laid down in the international instruments; the right to equality

39 Sub-Committee Resolution 2 (XXXIV), 8 September 1981; ECOSOC Resolution 1982/34, 7 May 1982. See, also, Lerner, 1992 , p. 220.

40 Burger, 1998, pp. 3-5; Burger and Hunt, 1994, pp. 409-410; Sanders, 1989, pp. 407-409; see, for the reports of the meetings of the Working Group on Indigenous Populations and the list of participants http//www. unhichr.ch/indigenous/ind wgip.htm.

41. Barsh, 1996, pp. 782-83; Debeljak, 2000, p. 277. 
and non-discrimination, the collective right to exist; the right to manifest, teach, practice and observe religious traditions and ceremonies; the right to education; the right to promote intercultural information and education; and, "[t] he right to preserve their cultural identity and traditions, and to pursue their own cultural development, ${ }^{32}$ At this stage, the principles did not stretch to the more controversial claims of indigenous peoples, such as the right of self-determination and restitution or permanent control over land. ${ }^{43}$

The right to cultural identity and other cultural rights were also present in a draft text submitted to the Working Group by Ms. Erica Daes, chairperson of the Working Group, in 1988. Cultural rights in part If of the draft included, for example, the collective right of indigenous peoples to maintain and develop ethnic and cultural characteristics and identity, the right to preserve their cultural identity and traditions, and the right to pursue their own cultural development. The draft also included provisions on the right to exist, protection against ethnocide, freedom of religion, language rights, and educational rights. Rights related to land and resources were included in part III, while part IV contained social and economic rights and part $\mathrm{V}$ focused on participation rights. ${ }^{44}$

After eight years of debate, the Working Group agreed on a final version of the Draft Declaration at its 11 th session in 1993, and submitted this version to the Sub-Commission. ${ }^{45}$ The Sub-Commission did not amend the text and the Draft Declaration was accepted without a vote in August $1994{ }^{46}$ The Draft was then passed to the Commission for adoption. ${ }^{47}$ The Commission in turn established an open ended inter-sessional working group which met for the first time in 1995 in order to consider the Draft Declaration. ${ }^{48}$ At the time of writing the Commission had not yet adopted a final text to be submitted to ECOSOC and the General Assembly.

42 UN Doc. E/CN.4/Sub.2/1985/22, Anmex I1, Report of the Working Group on Indigenous Populations on its fourth session.

43 These issues were, however, later on included in the final Draft Declaration.

44 Draft Universal Declaration on Indigenous Rights submitted by Madame Ericaurene Daes to the United Nations Working Group on Indigenous Populations, August 1988, reproduced in Sanders, 1989, pp. $430-433$.

45 The drafting process of the Draft Declaration, including references to sessions of the Working Group, is described in Marquardt, 1995, pp. 49-50.

46 Draft Declaration on the Rights of Indigenous Peoples, UN Doc. E/CN.4/Sub.2/1994/2/Add.1 (1994).

47 Resolution 1994/45, 26 August 1994, E/CN.4/Sub.2/1994/56, p. 103.

48 Commission Resolution $1995 / 32$ in E/CN.4/RES/1995/32 (3 March 1995) and ECOSOC Resolution 1995/32 in E/RES/1995/32, Establishment of a working group of the Commission an Human Rights to elaborate a draft declaration in accordance with $\S 5$ of General Assembly resolution 49/214, 25 July 1995. Reports of the sessions of the Working Group can be found at http//www, unhchrch/indigenous/ind wgdd,htm. 


\subsection{Content of the Draft Declaration in Relation to Cultural Identity}

The Draft Declaration is a unique instrument for several reasons. Firstly, it has been drafted in close co-operation with the beneficiaries of the rights outlined in the text, namely indigenous peoples. Indigenous peoples are also entitled to participate in the negotiations in the Working Group of the Commission. Secondly, the draft is detailed and contains 45 provisions including an implementation mechanism. Thirdly, it contains not only individual rights, but also collective rights, recognising the legal personality of indigenous peoples as such. It goes further than ILO Convention 169 in its provisions on self-determination, rights to land and resources and rights of political autonomy.

The Draft Declaration has eight sections which deal respectively with general principles such as equal status and participation, as well as the right to maintain different characteristics and self-determination (I), provisions on the right to life and existence and the prohibition of ethnocide and cultural genocide (II), provisions relating to cultural traditions and customs as well as religion (III), rights related to language and education (IV), economic and social rights (V), rights to land and resources (VI), rights of indigenous peoples to autonomy and autonomous political institutions (VII), and finally the implementation of the Declaration and measures to be taken by States, UN organs, and specialised agencies (VIII), ${ }^{49}$

The Draft Declaration does not contain a definition of 'indigenous peoples' or 'peoples'. The Chairperson of the Working Group stated that the definition to be applied would be that formulated by Special Rapporteur Cobo. ${ }^{50}$ Not only States were hesitant to include a definition in the draft text. Indigenous peoples also opposed the inclusion of a definition, because any definition might eventually exclude some groups wrongly, thereby denying them the rights in the Declaration. Furthermore, some indigenous peoples argued that a definition would violate the right of self-determination and self-identification by which indigenous peoples are entitled to define themselves. ${ }^{51}$

The Draft Declaration covers a wide range of cultural rights, and reflects not only an increasing attention for the equality of indigenous cultures, but also an awareness of the possible need for affirmative action in order to remedy past undermining of their cultures. Thus, States should not merely refrain from applying assimilation policies with regard to indigenous peoples, but should take effective measures to safeguard manifestations of indigenous cultures, such as religion, language and education. ${ }^{52}$

49 The content of the Draft Declaration is discussed in detail by various authors, see, inter alia, Burger, 1998, pp. 2-36; Burger and Hunt, 1994, pp. 405-423; Barsh, 1996, pp. 782-813; Coulter, 1995, pp. 123-138; Debeljak, 2000, pp. 267-310.

$50 \mathrm{E} / \mathrm{CN}$ 4/Sub.2/1993/29, Report of the Working Group on Indigenous Populations on its eleventh session, p. 15. Cobo"s definition is reproduced in $\$ 2.1$. See, also, $\mathbb{E}-1$. Daes, 2000, pp. $70 \mathrm{~m} 7$.

51 Coulter, 1995 , p. 129, Debeljak, 2000, pp. 296-297.

52 Draft Declaration article 12 to 15 ; Anaya, 1996-A, pp. 102-103. 


\subsubsection{Cultural Genocide}

The Draft Declaration does not contain a right to cultural identity as such. Article 7 however concerns ethnocide and cultural genocide and prohibits threats to the culture and integrity of indigenous peoples, making it directly relevant to the protection of cultural identity. Burger and Hunt have argued that the protection of cultural identity is closely related to the collective right to existence of an indigenous people, which is different from the individual right to life. They formulate it as follows:

"The individual right [to life] may be respected at the same time as the collective right [to existence] is denied. This is because a people is not just a group of individuals but a collective entity with a shared culture, history and territory. If this shared experience is destroyed, individuals may continue to live, but the people ceases to exist." $"$ "

Article 7 of the Draft Declaration reads as follows:

"Indigenous peoples have the collective and individual right not to be subjected to ethnocide and cultural genocide, including prevention of and redress for:

(a) Any action which has the aim or effect of depriving them of their integrity as distinct peoples, or of their cultural values or ethnic identities;

(b) Any aetion which has the aim or effect of dispossessing them of their lands, territories or resources;

(c) Any form of population transfer which has the aim or effect of violating or undermining any of their rights;

(d) Any form of assimilation or integration by other cultures or ways of life imposed on them by legislative, administrative or other measures;

(e) Any form of propaganda directed against them."

Burger and Hunt point out that this provision, whilst innovative, is not entirely new. They argue that Article 7 of the Draft Declaration falls within the scope of Article 27 ICCPR on the protection of the cultures of minorities. Depriving an indigenous people of its cultural values or ethnic identity, comparable to ethnocide or cultural genocide in Article 7 of the Draft Declaration, would constitute a breach of Article 27 ICCPR. The importance lies in the fact that rights of indigenous peoples are now separately recognised, and not only as rights for minorities.

Burger and Hunt furthermore assert that Article 7 builds on the Genocide Convention, ${ }^{55}$ but adds innovative elements with regard to ethnocide and cultural genocide, two concepts that are not explicitly included in the Genocide Convention. A reference to cultural genocide can be found in Article II(e) of the Convention,

53 Burger and Hunt, 1994, p. 413.

54 Burger and Hunt, 1994, p. 416.

55 Convention on the Prevention and Punishment of the Crime of Genocide, 9 December 1948 , into force since 12 January 1961. 
"...any of the following acts committed with the intent to destroy, in whole or in part, a national, ethnical, racial or religious group, as such:...(e) Forcibly transferring children of the group to another group".

When the Genocide Convention was negotiated in the 1940s, there was much debate as to whether or not to include cultural genocide. The Draft Convention of the Secretariat included cultural genocide and defined it as,

"...destroying the specific characteristics of the group by (a) forced transfer of children to another human group; or (b) forced and systematic exile of individuals representing the culture of a group; or (c) prohibition of the use of the national language even in private intercourse; or (d) systematic destruction of books printed in the national language or of religious works or the prohibition of new publications; or (e) systematic destruction of historical or religious monuments or their diversion to alien uses, destruction or dispersal of documents and objects of historical, artistic or religious value and of objects used in religious worship."

The Ad Hoc Committee preparing the Draft Genocide Convention retained the issue of cultural genocide, but removed the secretariat's definition. ${ }^{57}$ ?

The Sixth Committee of the General Assembly was divided over the question of whether or not cultural genocide should be included in the final text. In general, the communist States and the Middle Eastern States supported the inclusion of a provision on cultural genocide, arguing that cultural genocide was often a preparatory stage for physical or biological genocide. In the General Assembly, the representative of the USSR submitted the following draft,

"[I]n this Convention genocide also means any deliberate act committed with the intent to destroy the language, religion or culture of a national group on grounds of national or racial origin, or religious beliefs such as:

- Prohibiting the use of the language of the group in daily intercourse or in schools or the printing and circulation of publications in the language of the group;

- Destroying or preventing the use of libraries, museums, schools, historical monuments, places of worship or other cultural institutions and objects of the group. ${ }^{58}$

The General Assembly rejected this proposal by 31 votes to 14 , with 10 abstentions. ${ }^{59}$ Amongst the opponents of such a provision were the States from Latin America (with the exception of Venezuela), the United States and most European countries. The main reasons were the vagueness of the concept of cultural

56 UN Doc, A/362, GAOR, second session, 6th Committee, Summary Records, 16 September-26 November 1947, Annex 3.

57 Burger and Hunt, 1994, p. 414 .

58 UN Doc. A/767, GAOR, third session, 1948. See, also, Morsink, 1999, pp. 1030-1031.

59 UN Doc. A/810, GAOR, third session, 1948, p. 848. See, also, Morsink, 1999, p. 1031. 
genocide and the argument that such an issue belonged under a general human rights instrument such as the Universal Declaration. ${ }^{60}$ Another argument against the inclusion of a provision on cultural genocide was that the Genocide Convention was to be applied by international and national tribunals and cultural genocide was not suited to such adjudication. ${ }^{6}$

In the last instance, the General Assembly decided not to include cultural genocide in the Convention, with the exception of the forcible transfer of children, as included in paragraph Ile. According to the drafters this part was meant to relate to culture because the forced removal of children from their parents might lead to the imposing of a distinct culture upon these children, which could lead to the disappearance of a community as a cultural unity. ${ }^{62}$

As shown above, the prohibition of cultural genocide was more explicitly included in the Draft Declaration. The prohibition of cultural genocide is also important in relation to the protection of cultural identity. Although the term cultural genocide remains vague, its impact is strong in the sense that not respecting or actively destroying the cultural identity of, in this case, indigenous peoples can be labelled cultural genocide. Cultural identity is thereby confirmed as an important value to be protected by States, in direct relation to the existence of a community.

\subsubsection{Other Provisions regarding Cultural Identity}

Another provision in the Draft Declaration which touches on the protection of cultural identity is Article 8, which states that,

"[i]ndigenous peoples have the collective and individual right to maintain and develop their distinct identities and characteristics, including the right to identify themselves as indigenous and to be recognised as such."

This provision emphasises the individual and collective dimension of the right of indigenous peoples to preserve their specific identity. Different aspects of this right are addressed in Articles 12 to 14 of the Draft Declaration, which deal with the right to practice and develop indigenous cultures. These provisions concern, inter alia, the protection and development of material and immaterial manifestations of culture, such as spiritual and religious traditions, languages and philosophies, burial and other sacred sites, and historical and cultural places and artefacts. ${ }^{63}$ Identity thus is understood as a general value which requires the protection of it specific aspects.

60 Morsink, 1999, pp. 1032-1043. Morsink tries to show that a firm relationship existed between the drafting of a prowision on cultural genocide in the Genocide Convention and the drafting of a minority provision in the Universal Declaration.

61 Burger and Hunt, 1994, p. 414.

62 Burger and Hunt, 1994, p. 414 ,

63 See, also, Coulter, 1995, pp. 133-134; Wolfrum, 1999, pp. 376-377. 
The Draft Declaration further contains several provisions dealing with cultural heritage. The protection of cultural heritage is essential to the economic and cultural survival of indigenous peoples. Indigenous peoples do not perceive cultural heritage in terms of property, but in terms of community and responsibility. Existing provisions on cultural heritage did not reflect this collective approach but focussed instead on individuals. The Draft Declaration intends to improve this situation by including collective provisions on the protection of cultural heritage, for example in Article 12 on the preservation of past, present and future manifestations of cultures. Furthermore, special attention is paid to the cultural and intellectual property of indigenous peoples, such as traditional health practices and medicines, knowledge of fauna and flora, oral traditions, literature, design and the performing arts in Article 24 and Article $29 .^{6.4}$ All of these constitute significant aspects of cultural identity.

Articles 25 and 26 of the Draft Declaration deal with yet another important issue regarding the protection of the cultural identity of indigenous peoples, that of rights to land and resources. The provisions state that indigenous peoples have the unrestricted right of ownership of the lands, waters and other resources traditionally owned or otherwise occupied or used by them. ${ }^{65}$

The issue of self-determination is dealt with in Articles 3 and 31 . Article 3 is similar to Article 1 ICCPR and ICESCR except for the change of 'all peoples' into 'indigenous peoples'. It lays down the right of external self-determination, by which indigenous peoples can freely determine their political status, and it contains aspects of internal self-determination in stating that indigenous peoples may freely pursue their economic, social and cultural development. Internal self-determination is furthermore laid down in Article 31 in which it is stated that,

"[i]ndigenous peoples, as a specific form of exercising their right of selfdetermination, have the right to autonomy or self-government in matters relating to their internal and local affairs, including culture, religion, education, information, media, health, housing, employment, social welfare, economic activities, land and resources management, environment..."

Self-determination has been and is one of the main issues of discussion in the various fora responsible for drafting the Declaration, and it is a significant factor delaying its final adoption. With some exceptions, States have continued to express uncertainty and refusal concerning self-determination. During the negotiations in the Commission, several States refused to accept a right of self-determination, whilst others wanted it to be more precisely defined. Most States emphasised that the right of self-determination could only be guaranteed if the sovereignty,

64 Burger and Hunt, 1994, pp. 417-419. Special Rapporteur Daes of the SubuCommission wrote at report on Intellectual Property of Indigenous Peoples: UN Doc. E/CN.4/Sub.2/1993/28, Study on the protection of the cultural and intellectual property of indigenous peoples, 28 July 1993. Articles 25-26 of the Draft Declaration on Rights of Indigenous Peoples. 
territorial integrity and political unity of the State were respected. The Draft Declaration therefore mainly focuses on internal self-determination through constitutional reform instead of external self-determination or secession. ${ }^{60}$

In an explanatory note on the Draft Declaration, Daes commented on the use of the term "peoples", and on the right of self-determination. She argued that indigenous peoples are, "...unquestionably "peoples" in every political, social, cultural and ethnological meaning of this term", since they have specific languages, values and traditions and a historical religious and spiritual relationship with the land on which they live. She concluded that indigenous peoples have correctly insisted on the right of self-determination, especially internal self-determination. Daes considered the right of internal self-determination as,

"...entitling a people to choose its political allegiance, to influence the political order in which it lives, and to preserve its cultural, ethnic, historical or territorial identity:"

She thereby confirmed the connection between internal self-determination and the protection of cultural identity. However, this leaves unsolved that many States reject self-determination as a whole, as well as the question of the practical impact of internal self-determination for the protection of cultural identity.

\subsection{The Status and Future of the Draft Declaration}

What will be the future of the Draft Declaration? Most States taking part in the negotiations in the Commission have endorsed the draft text as a valid basis for future drafting. However, States have also expressed criticism especially with regard to the collective nature of the text. Some States regarded the inclusion of collective rights as an undesirable evolution from existing human rights instruments, referring to the UN Declaration on Minorities, which has a more individual character. ${ }^{68}$ Other issues of debate were the right of self-determination, political participation, land rights and the implementation of the Declaration itself ${ }^{69}$

66 Daes, 2000, p. 71 and 78; Debeljak, 2000, pp. 285-292; Brolmann and Zieck, 1995-B, pp. 104-105.

67 E/CN.4/Sub/2/1993/26/Add.1. Explanatory note concerning the draft declaration on the rights of incligenous peoples, by Erica-Irene Daes, 19 July 1993, \$2, 7, 11, 17 and 19; see, also, Brólmann and Zieck, $1995-\mathrm{B}, \mathrm{pp} .106-107$.

68 As explained in the previous chapter, the Declaration on the Rights of Persons Belonging to National or Ethnic, Religious on Linguistic Minorities also contains a collective dimension, however without defining collective rights for minorities as such. The provisions referring to minorities as such include State obligations, whereby the minorities are the beneficiaries. See Chapter VII, section 6 .

69 Barsh, 1996, pp. 788-789, 795-803. Government representatives already expressed the same concerns in the Working Group, when it adopted the final version of the Dratt Declaration, see E/CN.4/Sub.2/1993/29, Report of the Working Group on Indigenous Populations on its eleventh session, 23 August 1993, pp. 16-21, $\$ 50,62,68$ and 70. See, also, Daes, 2000, p. 68; Debelfak, 2000, p. 297 , analysing the fourth inter-sessional Working Group on the Draft Declaration. 
The adoption of a final text for the Declaration appears an almost impossible objective. During the first sessions of the Commission's working group it was reported that, "...no substantial progress has been made." States objected to almost every provision, with the only undisputed provisions being Article 33 on the right of indigenous peoples to their own institutions, and Article 43 on gender equality. Although no State explicitly expressed hesitation or dissent on the concept of identity, which the States appear to have accepted as a general value to be respected, the formulation of the concrete obligations generated extensive debate. ${ }^{71}$

Upon adoption, the Draft Declaration will have the status of a Declaration and as such it will not impose legally binding obligations upon States, with the exception of the provisions which reflect international customary law or ius cogens. For example, Article 6 on genocide falls under ius cogens, whereas cultural genocide, or any other provision referring to cultural identity, do not. In general, the Declaration will be a statement of principles having moral and political foree, but without empowering indigenous peoples with a right to appeal. ${ }^{72}$

The Working Group on Indigenous Populations does, however, enjoy a supervisory role, albeit limited. Under the ECOSOC mandate the Working Group may receive written and oral reports from governments, IGOs, NGOs, and representatives of indigenous peoples. ${ }^{73}$ State reports generally focus on the progress made in the implementation of indigenous peoples" rights; whilst the reports from NGOs and indigenous peoples often emphasise the deficiencies in State policies. States are not formally required to report to the Working Group, but many do so periodically, especially those with large populations of indigenous peoples. States may fear that if they do not submit reports, the discussions in the Working Group will be dominated by reports focusing on their shortcomings. ${ }^{74}$

Apart from the reporting procedure, an informal 'complaint procedure' has developed in the deliberations of the Working Group insofar as the Group allows practically anybody to speak at its annual public sessions. Representatives of indigenous peoples or NGOs have repeatedly called attention to specific situations where a State is accused of neglecting or violating rights of indigenous peoples. The Working Group is not allowed to respond to, or to examine, such interventions officially, but there have been instances where the Working Group or one of the members provided an ad hoc response. The effect of these interventions mainly lies in the opportunity to voice such concerns at an international forum, and the potential embarrassment for the State involved. ${ }^{75}$

70 Daes, 2000, p. 73.

71 Barsh, 1996, p. 804 and Table 1 (pp. 808-813) which provides a scorecard of States' views on the Draft Declaration.

72 Burger and Hunt, 1994, p. 410; see, on the concept of iws cogens Brownlie, 1990, pp. 512-515; Malanczuk, 1997 , pp. $57-58$.

73 Writtem reports are published verbatim and circulated as UN documents. Oral reports are summarised in the annual reports of the Working Group.

74 Anaya, 1996-A, pp. 153-154.

75 Anaya, 1996-A, p. 159. 


\section{RECENT DEVELOPNENTS AND CONCLUDING REMARKS}

In July 2000, the ECOSOC has taken a remarkable step in the establishment of Permanent Forum on Indigenous Issues as a subsidiary and advisory organ of the $\mathrm{ECOSOC}$, with a mandate to discuss indigenous issues relating to economic and social development, culture, the environment, education, health and human rights. The Forum is the first permanent representative body within the UN where representatives of the States and non-State actors operate. The Forum will be comprised of sixteen independent experts, eight of whom are nominated by States while the other eight will be appointed by the President of the ECOSOC following formal consultations with States on the basis of consultations with indigenous organisations. The Forum is authorised to meet annually, and it has held its first session in May 2002. The relation between the Permanent Forum and the Working Group is unclear. The ECOSOC resolution states that the ECOSOC will review all existing mechanisms and procedures concerning indigenous peoples after the establishment of the Permanent Forum in order to avoid any overlap or duplication of competences. Until that date, the Working Group will remain in operation; what occurs subsequently, including its supervisory role, remains to be seen.

Another important development in the field of indigenous peoples is the appointment by the $\mathbb{E N}$ Commission Human Rights of a Special Rapporteur to deal with the situation of the human rights and fundamental freedoms of indigenous people (not indigenous peoples). Rodolfo Stavenhagen of Mexico has been appointed Special Rapporteur for a period of three years. His mandate includes the gathering and exchange of information from all relevant sources (including States, indigenous people and their organisations) concerning violations of human rights against indigenous people, the formulation of recommendations and proposals on appropriate measures and activities to prevent and remedy such violations. The Special Rapporteur can undertake a wide range of activities in order to fulfil the mandate, including fact-finding missions. The Special Rapporteur is supposed to work closely with the Working Group and the Permanent Forum. ${ }^{77}$

All these mechanisms indicate the increasing attention within the UN for indigenous peoples. States tend to take indigenous rights more seriously, even though the mechanisms established mainly have a political nature rather than a legal one. Once again, it should be emphasised that this is the result of much hard work on the part of indigenous peoples themselves and by several member of the SubCommittee, in particular, Erica Daes. Accordingly, now would be the time for States to adopt the Draft Declaration.

76 UN Doc. E/RES/2000/22, Economic and Social Council Resolution 2000/22, Establishment of a Permanent Forum on Indigenous Issues, 28 July 2000.

77 UN Doc. E/CN.4/RES/2001/57, Commission on Human Rights Resolution 2001/57 on Human Rights and Indigenous Issues, 24 April 2001. 
The content of the Draft Declaration confirms the developments initiated by the ILO with regard to indigenous peoples. Assimilation policies and formal equality are no longer the key issues here, and cultural identity is now considered one of the important values that deserves to be respected, preserved and promoted. The concept of cultural identity is used in the provisions in the Draft Declaration in various forms, for example, with regard to ethnocide and cultural genocide, but also as an umbrella under which specific aspects of indigenous cultural identity can be located. In short, cultural identity is included as a general value, but when it comes to rights and concrete obligations other more specific provisions are formulated, for example on language, religion, cultural heritage, land and education. The right to cultural identity seems to reflect more of a principle than a concrete right. This is also visible in the monitoring of Convention 169 by the CEACR, which examines specific situations in States, for example, with regard to land issues. It does not, however, bring these issues under the protection of cultural identity, but under the specific provisions on land or other cultural aspects.

There is, however, little willingness on the part of States to adopt the Draft Declaration, comparable to the lack of interest to ratify ILO Convention 169. States have difficulties in adopting provisions on indigenous peoples, mainly because of their collective dimension and the demand for self-determination. Cultural rights may also pose specific difficulties, for example, with regard to land and resources. It would therefore be doubtful that States would be willing to accept a legal right to cultural identity. Question is also what such a right to cultural identity can add to specific cultural rights concerning language, religion, cultural heritage, education and land, which can be used by different communities or individuals according to their needs and wishes. It appears that communities and cultural identities are extremely diverse, whereby an overlapping concept, such as that of cultural identity, may have more of a symbolic value that a legal value.

So far, this study has focused on the global level, approaching the concept of cultural identity internationally and analysing several legal and quasi-legal provisions in international human rights instruments. The next chapters focus on the regional perspective, by examining human rights instruments in Latin America and Europe. 


\section{CHAPTER IX \\ CULTURAL IDENTITY AND THE ORGANISATION OF AMERICAN STATES}

\section{INTRODUCTION}

This chapter focuses on the protection of cultural rights and the protection of the cultural identity of indigenous peoples at the regional level. An obvious region in this respect is the Americas, where over 40 million indigenous persons live. 'In this chapter, the protection of cultural identity within the Inter-American human rights system is analysed, where the Member States of the Organisation of American States (OAS) have adopted two important human rights instruments: the American Declaration on Human Rights and the American Convention on Human Rights. Both instruments do not include a right to cultural identity or any specific provision on indigenous peoples. They in fact hardly contain any rights which explicitly refer to culture. They do, however, include cultural rights in the sense of freedom of religion, expression, non-discrimination, education, etc. The role that these civil and political rights play in the protection of the cultural identity of indigenous peoples is illustrated by several cases that were decided by the Inter-American Commission on Human Rights and the Inter-American Court on Human Rights. In this chapter, first the general human rights system of the OAS, including the position of economic, social and cultural rights in this system, is briefly dealt with. Subsequently, several cases of the IACHR and the Inter-American Court, concerning the protection of indigenous peoples and their cultural identity, with particular focus on land rights, are analysed. Finally, attention is paid to the drafting of an OAS Declaration on Indigenous Peoples and the position of cultural rights and the concept of cultural identity in this instrument.

\section{Human Rights instruments and Procedures in the Americas}

The Charter of the OAS, adopted in 1948, contains the general principle that the Member States should protect and promote human rights, but it does not include specific human rights provisions. The Protocol of Buenos Aires, which amended the Charter in 1970, added various such provisions to the Charter. The first major human rights instrument in the Americas was, however, the American Declaration

1 Information of the Indian Law Resource Centre, http://www.indianlaw. org. 
of the Rights and Duties of Man, adopted in $1948 .^{2}$ When it was adopted, the American Declaration was meant to have no legally-binding force, but, comparable to the Universal Declaration of Human Rights, most of the principles included in the American Declaration have become binding as international customary law. ${ }^{3}$

Although the OAS Charter and the American Declaration already foresaw the establishment of an Inter-American Commission on Human Rights to supervise and promote respect for human rights, it was not established until 1959. In that year, the Ministers of Foreign Affairs of the OAS adopted a resolution establishing the Inter-American Commission on Human Rights (hereafter IACHR), composed of seven members serving in their personal capacity. ${ }^{4}$ In 1960 , the OAS Council adopted the Statute of the IACHR and elected its first members. Its mandate was originally limited to promoting awareness of human rights within the OAS and its Member States, to making recommendations to governments and to carrying out studies and reports. At its first session, in 1960, the IACHR made it clear that it was not allowed to consider individual complaints, although these petitions could serve as a source of information for the preparation of State reports. ${ }^{5}$ In 1965 , the mandate of the IACHR was expanded by a resolution of the Second Special InterAmerican Conference, which allowed it to work on an individual complaint system. ${ }^{6}$

In 1969, the American Convention on Human Rights was adopted, which defined two organs for its supervision: the existing Inter-American Commission on Human Rights (IACHR) and the Inter-American Court of Human Rights (Inter-American Court). The IACHR, in fact, combines two functions: that of an OAS Charter organ with jurisdiction over all OAS Member States, and that of a treaty body of the American Convention. The Inter-American Court set up by the American Convention is not mentioned in the OAS Charter, which limits the powers of the Court to those States that are parties to the Convention. The IACHR on the other hand, based on its powers under the OAS Charter, can investigate and carry out

2 American Declaration on the Rights and Duties of Man, OAS Res. XXIX, Final Act, 29, Ninth Internationall Conference of American States, Colombia, 1948.

3 The Inter-American Court submitted in 1989 an Advisory Opinion on the legal force of the Declaration. In argued that the Declaration was not intended to be and could not be seen as a treaty according to the Vienna Convention on the Law of Treaties. The Declaration could, however, serve as a tool for the interpretation of the American Convention and the Charter of the OAS. Advisory Opinion No. 10.1/A Court H.R. Series A No. 10 Appendix IV.109, 11 HRLR 118 , Interpretation of the Amertcan Declaration of the Rights and Duttes of Man within the Framework of Art 64 of the American Convention on Human Rights.

4. OAS Doc. OEA/Ser.CAI.5, Resolution VII, Fifth meeting of Consultation of Ministers of Foreign Aftairs, Santiago, Chile, 12-18 August 1959, Final Act., pp. 10-11.

5 OAS Doc. OEA/Ser.J/V/II.1, doc. 32, TACHR Report on the Work Accomplished During its First Session, 3-28 October 1960 , p. 10. See, also, Buergenthal and Shelton, 1995, pp. 48-50.

6 OAS Doc. OEA/Ser.C/.13, Resolution XXII, Second Special Inter-American Conference, Rio de Janeiro, Brizil, 17-30 November 1965, Final Act, 1965, pp. 32-43.

7 American Convention on Human Rights, 22 November 1969, OAS Treaty Series No. 36, 1144 UNTS 123 (entered into force on 18 July 1978), Chapter VII and VIII. 
studies even without a specific request or complaint. ${ }^{8}$ Individuals, groups and NGOs can file a complaint to the IACHR, even if they are not the vietims, and with or without the knowledge or consent of the victims. ${ }^{9}$ Furthermore, States Parties to the American Convention can file a complaint after they have recognised the jurisdiction of the IACHR. ${ }^{10}$ The conclusions and recommendations of the IACHR are, as such, not legally-binding and are initially not published. Only if the IACHR's recommendations are not implemented by the State involved and no other settlement has been reached, can the IACHR decide to publish its conclusions."

The Inter-American Court, set up in 1978 after the coming into force of the American Convention, has two functions. Firstly, it has contentious jurisdiction to judge disputes concerning alleged violations of the Convention by State Parties, if these States have accepted the optional jurisdiction of the Court. Only States and the IACHR can submit a complaint to the Inter-American Court, individuals do not have locus standi. ${ }^{12}$ Secondly, the Inter-American Court has advisory jurisdiction to interpret the American Convention. Not only can States Parties to the Convention ask for such an advisory opinion but also any OAS Member State or OAS organ can do so. Such a request may also concern the compatibility of national laws of the Member States with the American Convention. ${ }^{13}$ Furthermore, the Court is allowed not only to interpret the American Convention, but also any other instrument on the protection of human rights in the Americas, for example, the American Declaration. In an advisory opinion of July 1989 , requested by the government of Colombia, the Court argued that Article 64(1) of the American Convention authorises the Court to give an advisory opinion on the American Declaration

"...provided that, in doing so, the Court is acting within the scope and framework of its jurisdiction in relation to the Charter and Convention or other treaties concerning the protection of the human rights in the American States." 14

The relationship between the American Declaration and the American Convention is an interesting matter. 15 . Does the American Convention supersede the Declaration, which implies that, when ratifying the Convention, States no longer

8. See Buergenthal and Shelion, 1995, pp. 51.52 .

9 See the American Convention on Human Rights Article 44 and IACHR Regulations (April 1980 and amended in December 2000), Article 24.

10 See the American Convention on Human Rights Article 45 and IACHR Regulations (April 1980 and amended in December 2000), Article 48.

11 See the American Convention on Human Rights Article 50-5॥ and IACHR Regulations (April 1980 and amended in December 2000), article 44-46, 53. See, also, Anaya, 1996-A, p. 167.

12 See the American Convention on Human Rights, Articles 61-63.

13 See the American Convention on Human Rights, Article 64.

14 Inter-American Court of Human Rights, Advisory Opinion OC-10/89 of 14 July 1989, Series A No. 10, "Interpretation of the American Declaration of the Rights and Duties of Man within the Framework of Article 64 of the American Conwention". See, on the functioning of the InterAmerican Court, Buergenthal and Shelton, 1995, pp. 54-61.

15 For an extensive analysis of this issue, see, inter alia, Buergenthal and Shelton, 1995, pp. $71-91$. 
have obligations under the Declaration? Or does the Convention complement it, which implies that States have obligations based on both instruments? The texts of both instruments do not provide a solution. The IACHR at first tended to interpret the American Convention as superseding the Declaration, which meant that it only applied the Declaration to States that had not ratified the Convention. Consequently, the IACHR could only receive complaints on violations of the Declaration with regard to States that were not parties to the Convention. However, the IACHR has now adopted the view that it can, under certain circumstances, consider complaints based on the Declaration even in relation to States Parties to the Convention. It seems that both instruments are complementary and that the Declaration has thereby kept its normative force also for States that have ratified the Convention. ${ }^{16 .}$

\section{Cultural Rights in the American Instruments: the Protocol of SAN SALYADOR}

The American Declaration on Human Rights contains several cultural rights, such as the right to education (Article XII) and the right to taken part in cultural life (Article XIII). The American Convention on Human Rights, however, hardly pays attention to cultural rights. Several proposals were submitted including economic, social and cultural rights, similar to the ICESCR, but they were left out of the final text. It was argued within the IACHR that the Convention should only contain those rights that States were willing to protect, and that many States were unwilling to accept obligations in the field of economic, social and cultural rights. Furthermore, it was asserted that, within other international bodies such as the UN and the Council of Europe, States had also decided to draft separate documents on economic, social and cultural rights including a separate implementation procedure. The only reference in the American Convention to economic, social and cultural rights is Article 26 in which it is laid down that State Parties should adopt measures to achieve progressively "..the full realisation of the rights implicit in the economic, social, educational, scientific and cultural standards set forth in the Charter." This provision recognises the existence of economic social and cultural rights, but does not give them substance. According to several authors economic, social and cultural rights were at that time "...primarily conceived as objectives of national development rather than individual human rights." $\$ 7$

However, economic, social and cultural rights were not totally forgotten in the American human rights system. After the adoption of the American Convention, the attitude among the American States concerning economic, social and cultural rights changed. States and the IACHR realised that economic and social conditions were important factors in relation to human rights violations. It was, therefore, decided to draft a protocol on economic, social and cultural rights, in which these rights would not be referred to as goals or objectives of development, but instead

16 See Article 51 of the Commission's current regulations. See, also, Craven, 1998, pp. 301-304.

17 Craven, 1998, pp: 290, 297-298. See, also, Leblanc, 1992, pp. 130-132, 135-137. 
would be addressed as essential values. ${ }^{18}$ In 1988, the OAS General Assembly adopted the San Salvador Protocol on Economic, Social and Cultural Rights, which entered into force in November $1999 .{ }^{19}$ The Protocol contains provisions similar to the ICESCR, including the right to take part in the cultural life of the community (Article 14). No specific rights concerning indigenous peoples or minorities or the protection of their cultural identity or land rights were included.

The supervision of the Protocol takes place through a reporting procedure; However, it is not determined how frequently States should submit these reports. The IACHR may adopt observations concerning these reports in its annual reports to the General Assembly. The IACHR can also consider petitions on alleged violations, according to the same procedure as under the American Convention, but only concerning Article 8 , on trade union rights; and Article 13, on the right to education, of the Protocol: ${ }^{20}$

In short, the American Declaration hardly includes cultural rights and the American Convention does not include cultural rights at all. The Protocol of San Salvador contains various cultural rights, including the right to participate in the cultural life of the community, but these can hardly be enforced by individuals. As such they do not offer new insight into the protection of cultural identity or the right to cultural identity. However, within the American system an interesting way of protecting the cultural characteristics of specific communities has developed through the various rights that are included in the various instruments. In several cases concerning indigenous peoples in OAS Member States, civil and political rights, for example, the right to life, health, personal liberty and security, family life, equal protection, property and freedom of religion, movement and residence, have been 'used' to defend cultural interests. ${ }^{21}$ These cases before the IACHR and the Inter-American Court are analysed below. They provide an interesting view on how cultural rights in a broad sense can be tools for the protection of (aspects of) cultural identity.

\section{CASES BEFORE THE INTER-AMERICAN COMMISSION AND THE INTER- AMERICAN COURT ON HUMAN RIGHTS}

There are at least five cases before the IACHR and the Inter-American Court concerning the protection of cultural identity and they relate to indigenous

18 Leblanc, 1992, pp. 140-141, 148.

19 Only 12 States out of a total of 35 have ratified the Protocol of San Salvador: Brazil, Colombia, Costa Rica, Ectador, El Salvador, Guatemala, Mexico, Panama, Paraguay, Peru, Surinam and Untguay (June 2002).

20 Additional Protocol to the American Convertion on Human Rights in the area of Economic, Social and Cultural Rights "Protocol of San Salvador"; A-52, 1988, Article 19, $1-6$.

21 See Anaya and Williams, 2001, pp. 41 and 50. 
peoples. ${ }^{22}$ These cases concern indigenous communities in several American States which have been discriminated against through forced assimilation and land seizure, whereby their cultural identity and lifestyle, and sometimes even their existence were placed in jeopardy. Although many indigenous peoples have concluded treaties with their governments, they have been and are still in a vulnerable position. ${ }^{23}$ As argued earlier, a central element of the cultural identity of indigenous peoples is their land.

Originally, indigenous peoples were not of speciall concern to the OAS and no specific rights for indigenous peoples or the protection of their cultural identity were included in the American Declaration and the American Convention. Furthermore, the IACHR has no special authority or obligation to concern itself with indigenous peoples, although it has examined situations of indigenous peoples through individual complaints and through its State reports. ${ }^{24}$ A thorough study of State reports of the IACHR does, however, not offer much new insight into the concept of cultural identity or a right to cultural identity. Several authors have argued that, until the late 1970 s, the IACHR hardly paid ariy attention to cultural rights in its annual reports, because they were not considered as values, but instead as products of economic and social development. Cultural rights and indigenous issues were also rarely addressed by the IACHR in its early reports on the human rights situations in different States. Since the 1980 s, the IACHR deals with economic, social and cultural issues in its reports more frequently, mainly through general suggestions that States should acknowledge cultural diversity and take the necessary measures to enable indigenous peoples to survive and develop. Cultural identity, as such, is not being used by the IACHR as a value to be specifically protected. ${ }^{25}$

This is different with regard to various cases before the IACHR and the Inter-American Court. In the $1970 \mathrm{~s}$ and $1980 \mathrm{~s}$, there were cases concerning the Guahibo Indians in Colombia, the Aché Indians in Paraguay, the Yanomami Indians in Brazil and the Miskito Indians in Nicaragua. In the first three cases, the LACHR adopted rather short statements or resolutions, while in the Miskito case, the IACHR drew up a comprehensive report. ${ }^{26}$ More recently, the IACHR and the Inter-American Court have issued an important judgement in a case concerning the Awas Tingi community in Nicaragua. These cases analysed below serve as an

22 There are several other cases, but these were either solved by a friendly settlement, such as the Enxet-Lamenxay case v. Paraguay (Case 11.713, IACHR Annual Report 1999) or are still pending such as the Toledo Maya case v. Belize (Case 12.053, LACHR Report No. 78/00, 5 October 2000).

23 Grossman, 2001, pp 3-4; Hannum, 1998, pp. 323-324. The Sub-Commission on the Promotion and Protection of Human Rights has adopted a repont on treaties and agreements between States and indigenous peoples: UN Doc. E/CN.4/Sub.2/1995/27, 31 July 1995 , Study on the treaties, agreiments and other constructive arrangements between States and indigenous populations, second progress report by Special Rapporteur Miguel Alfonso Martinez.

24 Harinum; 1998, p. 325.

25 Craven, 1998, pp. 289, 311-313, 320; Leblanc, 1992, pp. 141-142; Hannum, 1998, p. 332.

26 Hannum, 1998 , p. 326. 
illustration of the possibilities offered within the Inter-American system to defend cultural identity even without legal provisions which directly refer to cultural identity. Without intending to provide an exhaustive overview of the indigenous case law within Inter-American system of human rights, these cases show that other human rights than a right to cultural identity or rights directly referring to culture can be helpful to protect cultural identity.

\subsection{The Guahibo Case v. Colombia ${ }^{27}$}

The first case concerning indigenous peoples was the request in 1970 by the Latin American Peasants Federation to the IACHR to consider the case of the Guahibo Indians in Colombia. The Guahibo case concerned clashes between the Guahibo Indians and colonists, supported by troops of the Colombian army, whereby the army was accused of harassing the Guahibo, taking away their land and arbitrarily arresting Indian leaders. The Colombian government maintained that these soldiers were merely restoring public order in the area, and denied all allegations of human rights violations. The IACHR considered the case for almost three years, exchanging formal notes with the Colombian government. Its main problem was to make the unwilling government of Colombia submit the necessary information. In 1973, the IACHR finally implicitly accepted the arguments of the Colombian government and was satisfied with the way the Colombian government and judiciary had investigated the situation. The IACHR suspended the case without making a formal statement on the facts or on the alleged human rights violations. ${ }^{28}$

\subsection{The Aché Case v. Paraguay ${ }^{29}$}

In 1974, the International League for the Rights of Man submitted a complaint to the IACHR on behalf of the Aché Indians. The complaint concerned allegations of human rights violations against the Aché Indians in Paraguay that followed from attacks by colonists to remove the Indians from their original land. The complaint included murder, torture, withholding medical care, inhumane conditions of work, the sale of children and acts aimed at the destruction of the indigenous culture leading up to the systematic extermination of the whole community. The situation of the Aché was serious; diseases killed so many of its members that the survival of the community was uncertain. The government of Paraguay never formally responded to the complaint submitted to the IACHR and refused to submit

27 OAS Doc. OEA/Ser.L/V/I1.30, doc. 45, rev.1, Case No. 1690 (Colombia), Report on the Work Accomplished by the Inter-American Commission on Human Rights during its Thirtieth Session, 1973. For an extensive discussion of the case, see Davis, 1988, pp. 17-26.

28 OAS Doc. OEA/Ser.L/V/II.30, doc. 45, rev.1, Case No. 1690 (Colombia), pp. $21-23$. See, also, Davis, 1988, p. 11; Anaya, 1996-A, pp. 167-168; Hannum, 1998, p. 326.

29 OAS Doc. OEA/Ser.L/V/II.43, doe. 21, Case No. 1802 (Paraguay), Annual Report of the Inter American Commission on Human Rights, 1977. For an extensive discussion of the case, see Davis, 1988, pp. 27-40. See, also, Hannum, 1998, p. 327. 
information. The IACHR found that many thuman rights violations had taken place, but hesitated as to whether these abuses were part of a government programme to destroy the Ache systematically. In 1975, the IACHR passed a provisional resolution in which it stated that the Paraguayan government had a policy of assimilating and integrating the Indian population, but did not deliberately try to exterminate its indigenous peoples physically. The IACHR decided to continue to follow the case. ${ }^{30}$

The IACHR took a final decision on the merits of the case in 1977, when it appeared impossible to reach an agreement with the government of Paraguay, which still refused to submit information. According to the IACHR's Regulations, if a party refuses to submit information, the IACHR may presume that the alleged events on which it has requested information have occurred, unless there is any other evidence to suggest that the allegations are false. ${ }^{3 .}$ Consequently, the IACHR confirmed the events in the Aché complaint and concluded that Paraguay had seriously wiolated several provisions in the American Declaration of Human Rights, such as the right to life, the right to family life and the right to health. It called upon the Paraguayan government to take strong measures to remedy these violations. ${ }^{32}$ The I.ACHR did not retain its earlier statement in which it had argued that the policy of the government of Paraguay was not aimed at the elimination of the Aché Indians, but was instead aimed at the assimilation and protection of the Aché. It shows the IACHR's uncertainty as to what extent the government was fully responsible for the human rights violations. ${ }^{33}$

In both the Guahibo case and the Ache case, the IACHR appeared to be very cautious in adjudging land rights to indigenous communities. Davis argues in her book on these cases that the IACHR's negligence of the issue of land was caused by a lack of expertise on indigenous peoples and their land rights. ${ }^{34}$ Anaya mentions another factor, namely, that the IACHR was bound by the norms in the American Declaration and the American Convention, which do not include a reference to indigenous peoples and land rights. ${ }^{35}$ In any case, no connection was made between land rights and the protection of cultural identity. However, in three subsequent cases, the IACHR appeared to be more willing to advance norms concerning indigenous peoples and their land as part of their cultural identity.

30 Davis, 1988, pp. 12, 32-34; Hannum, 1998, p. 327.

31 Article S1(1) of the Regulations of the IACHR. See, also, Davis, 1988, p. 12.

32 OAS Doc. OEASEr.L/V/I.43, doc. 21, Case No. 1802 (Paraguay), pp. 36-37.

33 Hannim, 1998, p. 327.

34 Davis, 1988, pp. 14-15.

35 Anaya, 1996-A, pp. 167-168. 


\subsection{The Yanomami Case v. Brazil ${ }^{36}$}

In 1980, a number of NGOs submitted a petition on behalf of the Brazilian Yanomami Indians, whose ancestral lands were being invaded by peasants, miners, gold prospectors and other outsiders. The problems began in 1973 with the construction of a new highway through the traditional territory of the Yanomami in order to exploit mineral resources. The uncontrolled contact with outsiders led to widespread diseases and deaths among the Yanomami, who used to be isolated forest-dwelling Indians. It also caused the uprooting and displacement of entire Yanomami villages. According to the complaint to the IACHR, the Brazilian government had, by permitting the construction of highways and mining activities, failed to protect the Yanomami. It was accused of having violated the right to life, the right to equality before the law, freedom of religion, the right to residence and movement, the right to property and the right to healthi. ${ }^{37}$

The government of Brazil actively participated in the case of the Yanomami. It launched various initiatives to protect their health and territory, such as the plan to demarcate a Yanomami Park, an idea that was supported by proIndian groups. The Brazilian government argued that sufficient legal provisions were developed to protect the rights of the Yanomami. As in earlier cases, the IACHR at first seemed to accept the government's assurance that the situation was being well taken care of. However, in the final resolution, passed in 1985, the IACHR concluded that several human rights had been violated. ${ }^{38}$ In this resolution, the IACHR recognised the important measures taken by the government of Brazil to protect the health and security of the Yanomami. It recommended the government to continue to take such measures, including the demarcation of the Yanomami Park. ${ }^{39}$ However, it also concluded that the exploitation of the natural resources in the Amazon area has caused thousands of Yanomami Indians to move from their ancestral lands. These invasions were being carried out without taking precautions for the safety and health of the Yanomami. Consequently, the civilian "attacks" on the Yanomami ancestral lands formed a threat not only to the physical well-being of the Yanomami Indians, but also to their culture and traditions. The Brazilian government had violated several rights in the American Declaration, such as the right to life, personal security, residence and health. ${ }^{40}$

36 OAS Doc. OEA/Ser.1/V/II.66, doc. 10, rev. 1, Case No. 7615 (Brazil), Inter-American Commission Res. No. 12/85, 5 March 1985, Awnual report of the Inter-American Commission on Hwman Rights, 1984-1985, 1 October 1985 . For an extensive discussion of the case, see Davis, 1988, pp. 41-62. See, also, Hannum, 1998, pp. 327-328; Buergenthal and Shelton; 1995, pp, 356-363.

Davis, 1988, pp. 13, 4-45; Hannum, 1998, p. 327; Anaya, 1996-A, p. 168.

38 Davis, 1988, pp. 46-51; Hannum, 1998, p. 328.

39 OAS Doc. OEA/Ser.l/W/II.66, doc. 10, rev. 1, Case No. 7615 (Brazil), 2-3, p. 33. Davis argues that it seems that the IACHR wished to encotrage the new civilian regime in Brazil, established in 1985 , to protect its indigenous peoples instead of just condemning its past record under the military regime 1988. See Davis, 1988, pp. 56-57.

40 OAS Doc. OEA/Ser.1/V/II.66, doc. 10, rev. 1, Case No. 7615 (Brazil), \& 1, p. 33. 
The IACHR invoked Article 27 ICCPR in this case, by arguing that

"...international law in its present state...recognises the right of ethnic groups to speciall protection on their use of their own language, for the practice of their own religion, and, in general, for all those characteristics necessary for the preservation of their cultural identity.

The IACHR hereby clearly aimed at the protection of the cultural identity of the Yanomami Indians, although such protection was not directly included in the American Declaration or the American Convention. The citation of Article 27 ICCPR is all the more interesting, since Brazil was not a party to the ICCPR at that time. The IACHR hereby indicated the character of the rule contained in Article 27 ICCPR as international customary law.

In the Yanomami case, the IACHR established a clear link between the protection of indigenous land rights and the protection of their cultural identity. It used "cultural identity" explicitly as a broad collective value including land rights, but also the right to life, health and residence. In this respect, the IACHR distinguished not only obligations of abstention towards the indigenous population, but also positive obligations. According to the IACHR, by permitting the exploitation of Amazonia, Brazil had allowed the displacement of the Yanomami from their ancestral land, had failed to establish a park for the protection of their heritage and had failed to protect them from diseases. Such special protection was needed to prevent discrimination '...that invalidates their members' potential as human beings through the destruction of their cultural identity..."44 In this case, the IACHR determined that, even without an explicit right to cultural identity, it is protected as a value by several other human rights provisions.

\subsection{The Miskito Case v. Nicaragua ${ }^{45}$}

The Miskito case concerned several Indian groups in Nicaragua. During the violent conflicts in Nicaragua in the 1980 s between the Sandinista government of Nicaragua and the 'contras', the Miskito, Sumo and Rama Indians of the Atlantic coast region were especially affected. During the violent conflict, Indian leaders were imprisoned, villages were forcibly relocated and many Indians were killed.

41 OAS Doc. OEA/Ser.1/Vil1.66, doc. 10, rev. 1, Case No. 7615 (Brazil), \& 7, p. 31.

42 Brazil ratified the International Coventant on Civil and Political Rights on 24 January 1992.

43 Anaya, 1996-A, p. 168; Hannum, 1998, p. 328; Anaya and Williams, 2001, pp. 52-53.

44 OAS Doc. OEA/Ser.l/V/II.66, doc. 10, rev. 1, Case No. 7615 (Brazil), 89, p. 31, and $\$ 10-11$, p. 32. See, also, Craven, 1998, p. 296.

45 OAS Doc, OEA/Ser.L/VMI.62, doc. 10 rev, 3 (1983), OAS Doc. OEA/SerL/V/Il.62, doc 26 (1984), Case No. 7964 (Nicaragua), Inter-American Commission on Human Rights, Report on the Siluation of Human Righrs of a Segment of the Nicaraguan Population of Miskito Origin and Resolution on the Friendly Settlement Procedure Regarding the Human Rights Situation of a Segment of the Nicaraguan Population of Miskito Origin. See, also, Hannum, 1998, pp. 328-330; Buergenthal and Shelton, 1995, pp. 347-355. 
The case was brought to the attention of the IACHR in 1981. While it originally concerned the forced displacement of the Indians, it grew more complex as new elements such as autonomy and self-determination were brought in. ${ }^{46}$

The government of Nicaragua actively participated in the procedure before the IACHR and invited the IACHR to carry out an on-site investigation into the complaints. The IACHR issued an extensive report on the situation of the Miskito between December 1981 and September 1983. Although the IACHR found that the government of Nicaragua had concretely violated several provisions in the American Convention, such as the right to life and liberty, the report mainly spelled out the facts and signalled problems that 'needed attention'. The IACHR argued that some of the forced relocations constituted permissible derogations from the human rights norms, because of the military situation in Nicaragua at the time. ${ }^{47}$

The IACHR took a rather reserved approach towards indigenous demands of the Miskito for political autonomy and land rights. With regard to land rights, the IACHR categorically denied that the Miskitos had any rights beyond those of the citizens of Nicaragua. It stated that it could not decide on legal validity of the indigenous land claims and that a just solution should be found that would balance the aspirations of the Indians with territorial unity. ${ }^{48}$

Concerning broader political claims of the Miskitos, the IACHR noted that the American Convention prohibits discrimination, but does not contain a specific provision on ethnic communities, such as the Miskitos. However, it again referred to Article 27 ICCPR, to which Nicaragua has been a party since 1980 , to argue that the obligations under this provision implied special legal protections for the Indians to function as a community and to preserve their cultural identity. These measures should extend to "...the aspects linked to productive organisation, which includes, among other things, the issue of ancestral and communal lands." ${ }^{, 49}$ Here, the IACHR recognises limited land rights for the Miskito as long as they remain within the unity of the State and are connected to the protection of their cultural identity. Other aspects in relation to the protection of cultural identity mentioned by the IACHR were freedom of thought, religion and expression, the right of assembly and association, the right to residence and rights to language. ${ }^{50}$ Again, the IACHR uses a broad concept of cultural identity, which should be protected by various cultural rights, even though these rights do not explicitly refer to cultural identity.

The IACHR also considered whether indigenous communities enjoy additional rights beyond Article 27, such as the right to self-determination or

46 Anaya, 1996-A, pp. 78-88, 169.

47 Anaya, 1996-A, p. 169; Hannum, 1998, p. 329

48 OAS Doc. OEA/Ser.L/V/I.62, doc. 10 rev. 3 (1983), OAS Doc. OEA/Ser.L/V/L.62, doc 26 (1984), Case No. 7964 (Nicaragua), pp. 126-127.

49 OAS Doc OEA/Ser.L/V/II.62, doc. 10 rev. 3 (1983), OAS Doc. OEA/Ser.L/V/L.62, doc 26 91984), Case No. 7964 (Nicaragua), p. 81. See, also, Buergenthal and Shelton, 1995, p. 355; Anaya and Williams, 2001 , pp. 52-53.

50 OAS Doc. OEA/Ser.L/V/II.62, doc. 10 rev. 3 (1983), OAS Doc. OEA/Ser.L/V/IL.62, doc 26 91984), Case No. 7964 (Nicaragua), pp. $81-82$. 
political autonomy. It concluded that, although international law recognises the right to self-determination of peoples to choose their political organisation and determine their economic, social and cultural development, "[t]his does not mean...that it recognises the right to self-determination of any ethnic group as

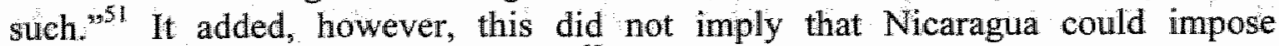
complete assimilation on the Indians. ${ }^{52}$ Thus, it appears that the IACHR is willing to accept some form of internal self-determination or cultural autonomy.

In conclusion; both the Miskito case and the Yanomami case show the increasing attention of the IACHR to indigenous issues, including land rights and cultural rights. Its views may seem modest, but this is because its main role is to convince governments to change their policies. This is confirmed by its acceptance of changes announced by governments, instead of merely condemning past violations. ${ }^{53}$ However, the IACHR has used several provisions in the American Convention, such as the right to life, health and residence, to protect (aspects of) cultural identity. Cultural identity was used as a broad general value because of which specific rights, for example to land, should be protected. The IACHR has furthermore shown creativity by invoking, for example, Article 27 ICCPR to urge States to take action to protect the cultural identity and well-being of indigenous peoples, including their rights to land. The IACHR clearly recognised the collective dimension of land rights and cultural identity. This approach to the protection of land rights as part of cultural identity, which included a clear collective dimension, was definitively secured by the Inter-American Court in the Awas Tingi case.

\subsection{The Awas Tỉngi Case v. Nicaragua ${ }^{54}$}

The Awas Tingi case is what can be called a 'landmark case' in the history of the IACHR and the Inter-American Court. It was the first case ever before the Court concerning indigenous peoples and land rights, and it turned out to be a victory for the indigenous community. The Court succeeded in reading a collective indigenous right to land into, inter alia, the rights to non-discrimination and to property in the American Convention.

51 OAS Doc. OEA/Ser.L/V/II.62, doc. 10 rev, 3 (1983), OAS Doc. OEA/Ser.L/V/II.62, doc 26 91984), Case No. 7964 (Nicaragua), pp. 78-79. See, also, Buergenthal and Shelton, 1995, p. 355.

52 OAS Doc. OEA/Ser.L/V/IL.62, doc, 10 rev. 3 (1983), OAS Doc. OEA/Ser.L/V/II.62, doc 26 91984), Case No. 7964 (Nicaragua), p. 81.

53 Hannum, 1998, p. 331.

54 The case of the Mayagna (Stmo) Indigenous Community of Awas Tingi versus the Republic of Nicaragial. The Commission's reports on the Awas Tingi case are confidential, but limited information can be found in a report by the Commission entitled "The Human Rights Situation of the Indigenous People in the Americas", OEA/Ser.L/V/II.108 doc. 62, 20 October 2000, also available on hth:/www.oas.org. The analysis given is mainly based on information of the Indian Law Resource Centre, representing the Awas Tingi in this case. See http:/www.indianlaw.org See, also, Anaya, 1996-B and Grossman, 2001. The Court took its decision on 31 August 2001 (No. 79), which is available at http:/www.corteidh.or.crindex-ingles.html. 
The community of the Awas Tingi is one of the Mayagna (Sumo) communities, which consists of approximately 150 families or 650 individuals. The Awas Tingi almost exclusively speak the Mayagna language, although some speak some Spanish as well. The Awas Tingi mainly live on agriculture, hunting and fishing. They hold their land collectively, while individual community members and families enjoy subsidiary rights of use and occupancy. From the beginning of the 1990 s, the Awas Tingi and the government of Nicaragua had been in a conflict over land rights. ${ }^{55}$

In 1995, the Nicaraguan government was planning to grant a Korean timber company logging concessions to a tropical forest occupied and used by the Awas Tingi community, without previously consulting them, let alone obtaining their consent. In October 1995, the Indian Law Resource Centre (Washington), representing the Awas Tingi, brought the case to the IACHR, alleging that the government of Nicaragua was failing to guarantee the community's use and enjoyment of ancestral lands. After an attempt to reach a friendly settlement had failed, the IACHR issued an interim measure in October 1997 requesting Nicaragua to suspend the logging permit to avoid irreparable harm being done to the Awas Tingi. In March 1998, the IACHR concluded that the Nicaraguan government had violated its legal obligations under the American Convention, because it had not demarcated land or guaranteed land rights for the Awas Tingi by granting the logging permission without the necessary involvement of the Awas Tingi. ${ }^{56}$

On 4 June 1998, after the Nicaraguan government had continued to fail to take measures in accordance with the IACHR's decision, the IACHR submitted the case to the Inter-American Court. Because the IACHR had brought the case, it acted as the representative of the Awas Tingi before the Inter-American Court. As such, it charged the Nicaraguan government with violating Article 1 (non-discrimination), Article 2 (domestic legal effects), Article 21 (right to property) and Article 25 (right to judicial protection) of the American Convention. The IACHR asked the Court to declare that the Nicaraguan government had failed to secure the collective right of the Awas Tingi to the ownership and enjoyment of their ancestral lands and natural resources. The Nicaraguan government argued in its defence that the Awas Tingi community had no ancestral claim to the land they occupied and that the community was not an indigenous people, because it consisted of different ethnic groups: 57

After the Court had declared the case admissible on 1 February 2000, it started hearings in November 2000. On 31 August 2001, the Court issued its remarkable final decision in favour of the Awas Tingi. The Court affirmed that indigenous peoples have the collective right to their traditional lands and resources, even if a State has not officially recognised the community and its ownership. The Court argued that the right to property of the Awas Tingi arose from their

55 See, on the background of the Awas Tingi Case, Anaya, 1996-B and Grossman, 2001

56 Anaya and Williams, pp. 37-38.

57 Anaya and Williarns, 2001, pp. 37-38; Grossman, 2001, pp. 2-3. 
traditional occupancy and use of these lands, and not from the State's recognition and registration. Indigenous custom, according to which the community has possession of land, should suffice to entitle these communities to obtain official recognition and registration of their rights of ownership. Nicaragua had violated these property rights in Article 21 of the Convention by not delimiting and demarcating the communal property of the Awas Tingi and by authorising third parties to exploit the land and resources in that same area. ${ }^{58}$. The Court, therefore, ordered Nicaragua to demarcate and recognise the ownership title over the land of the Awas Tingi in accordance with the community's values and customs. To ensure that Nicaragua implemented the necessary measures to satisfy the Court's decision, Nicaragua was ordered to submit a report on its actions to the Commission every six months, whereby the Court held additional jurisdiction to supervise Nicaragua's compliance with the Court's decision. 59

It is striking that the Inter-American Court used property rights, nondiscrimination and other provisions in the American Convention to defend collective land rights for indigenous peoples. ${ }^{60}$ The Court paid much attention to the collective dimension of ownership in relation to indigenous peoples:
"Among indigenous communities, there is a communal tradition, as demonstrated by their communal form of collective ownership of their lands, in the sense that ownership is not centred in the individual but instead in the group and in the community,?61

The Court further made an interesting connection between land rights and the existence and culture of an indigenous community.
"[T]he close relationship that the communities have with the land must be recognised and understood as a foundation for their cultures, spiritual life, cultural integrity and economic survival. For indigenous communities, the relationship with the land is not merely one of possession and production, but also a material and spiritual element that they should fully enjoy, as well as a means through which to preserve their cultural heritage and pass it on to future generations. ${ }^{162}$

The Court did not explicitly refer to cultural identity and did not use Article 27 ICCPR, as the IACHR had done in previous cases, but the general picture is the same, namely, that the State should protect land rights as an important aspect of the indigenous cultural identity. In this respect, I agree with Grossmann, member of the IACHR, who has argued that the Awas Tingi case concerned various other rights in the Convention, such as the right to life (Article 4), the right to honour and dignity

58 Awas Tingl v Nicaragua, Court Decision 31 August 2001, $\$ 151,153,155$.

59 Awas Tingi v Nicaragua, Court Decision 31 August 2001, \$164 and points of resolution.

60 Awas Tingi v Nicaragua, Court Decision 31 August 2001, \$ 144-146, 148.

61 Awas Tingiv Nicaragua, Court Decision 31 August 2001, 149.

62 Awas Tingl v Nicaragua, Court Decision 31 August 2001, $\$ 149$. 
(Article 11), freedom of religion (Article 12), freedom of association (Article 16), protection of the family (Article 17) and the right to movement and residence (Article 22). ${ }^{63}$ Even though none of these provisions explicitly refers to land rights, the Court may use them to protect land interests of the indigenous population. Since land is an important aspect of cultural identity, it can reasonably be argued that the protection of cultural identity as a value benefits from such developments.

The decision of the Inter-American Court in the Awas Tingi case is of importance to other cases, for example, the Toledo Maya case against Belize, which is pending before the IACHR. This case also concerns an indigenous community who claims that their rights have been violated by State permissions for logging and oil development. However, the case is somewhat different, in the sense that Belize is not a party to the American Convention. Instead, the alleged violations concern the American Declaration, inter alia Article 1 on the right to life, Article 3 on religious freedom, Article 6 on farnily life and Article 11 on the preservation of health and well-being. The case was brought to the IACHR on 7 August 1998 and was declared admissible on 5 October 2000 , after a long attempt to reach a friendly settlement had failed. ${ }^{64}$ It remains to be seen what the final decision of the IACHR will be, especially in the light of the recent case law of the Inter-American Court.

\section{The Draft american Declaration on the Rights of Indigenous PEOPLES}

Another interesting development concerning standard setting in the field of cultural identity within the Americas is the drafting of a declaration on the rights of indigenous peoples. In 1989, the IACHR recommended the OAS General Assembly to assign the IACHR the drafting of a legal instrument on indigenous rights. The IACHR proposed to draft a declaration or convention to be adopted by the General Assembly in 1992, on the occasion of the 500th anniversary of the arrival of Columbus on the American continent. ${ }^{65}$ The General Assembly adopted the IACHR's proposal in $1989^{66}$, although the proposed timetable proved to be too optimistic. The IACHR adopted a draft Declaration on the Rights of Indigenous Peoples in September 1995, which was sent to OAS governments and indigenous organisations. ${ }^{67}$ Based on their comments, the IACHR revised the draft in February 1997 and included, inter alia, a collective right to cultural identity. ${ }^{68}$

63. Grossman, 2001, p. 4.

64 LACHR Repart No. 78/00, case No. 12.053, Maya Indigenous Communities and their Members 1. Belize, 5 October 2000. See, also, Anaya and Williams, pp. 38+39.

65 See IACHR Annual Report 1988-89, pp. 244-252.

66 OAS General Assembly Resolution AG/Res. 1022 (XIX-0/89).

67 OAS Doc. OEA/Ser.L/N/I.90, doc. 9 rev. 1, Draft linter-American Declaration on the Rights of Indigenous Peoples, IACHR Annual Report 1995, pp: 207-218.

68. Proposed American Declaration on the Rights of Indigenous Peoples, approved by the IACHR at its 1333 rd session, 95 th regular session, 26 February 1997 . The text can be obtained from the web site of the OAS: www.oas.arg. See, also, Buergenthal and Shelton, 1995, Section 4, pp. 341-345. 
Several differences can be distinguished between the 1995 and the 1997 draft. The general tone of the $1997 \mathrm{draft}$ is different from that of the $1995 \mathrm{draft}$. The 1995 draft mainly speaks of 'States shall respect' and 'States shall recognise', thereby focusing on State obligations formulated rather firmly in terms of "shall'. In contrast, the 1997 draft contains explicit rights of indigenous peoples in the form of 'indigenous peoples have the right to'. Another difference is that the 1995 draft tries to define indigenous peoples in Article 1, while the 1997 text only states that the Deelaration applies to indigenous peoples without further defining them. With regard to cultural identity, a new provision was added in the 1997 text under the heading of forced assimilation:

"Indigenous peoples have the right freely to preserve, express and develop their cultural identity in all its aspects, free of any attempt at assimilation.

The right to cultural identity is explicitly recognised here in its collective form. Cultural identity is a general value that indigenous peoples should be able to preserve, express and develop as part of a policy of non-assimilation.

Identity can also be found in relation to cultural development and the right to cultural integrity. The 1997 draft states that:

"Indigenous peoples have the right to their cultural integrity, and their historical and archaeological heritage, which are important both for their survival as well as for the identity of their members.",

Here, the focus is on the individual identity of the members of indigenous peoples, which benefits from the protection of the cultural integrity and heritage of the whole community.

In addition, the 1997 draft contains provisions on language, education, religion, land and the environment. The rights to land are carefully formulated and hardly anything is said on the use of resources." With the exception of several protective provisions, the general collective approach of the 1997 draft apart is notable from several collective provisions. It is stated in Article II(2) that

"[i]ndigenous peoples have collective rights that are indispensable to the enjoyment of the individual human rights of their members. Accordingly, the States recognise inter alia the right of indigenous peoples to collective action, to their cultures, to profess and practice their spiritual beliefs, and to use their languages."

69 Proposed American Declaration on the Rights of Indigenous Peoples, Section 2, Article V.

70 Proposed American Declaration on the Rights of Indigenous Peoples, Section 3, Article VII.

71 Proposed American Declaration on the Rights of Indigenous Peoples, Section 3, Article XIII (Right to environmental protection) and Section 5, Article XVIII (Traditional forms of ownership and cultural survival. Rights to land; territory and resources). 
The Draft further firmly rejects assimilation and emphasises co-operation and consultation with the indigenous community. Finally, it should be noted that no reference to (the right to) self-determination is included in the 1997 draft. $^{72}$

The OAS General Assembly has been considering the Draft Declaration since 1998, but has still not adopted a final text. ${ }^{73}$ After consideration by governmental experts, the General Assembly decided, in 1999, to set up a Working Group to Prepare the Proposed American Declaration on the Rights of Indigenous Populations. ${ }^{74}$ This Working Group has met several times, but the process is slow and laborious. ${ }^{75}$ With regard to Article $V$, which includes the right to cultural identity, the text has, so far, remained intact, although non-assimilation has been broadened and placed in the second paragraph of Article V. No further discussion has taken place on the content and scope of the right to cultural identity. ${ }^{76}$

The American Draft Declaration on Indigenous Peoples contains several interesting elements in relation to cultural identity. The general idea behind this right is the prohibition of (forced) assimilation. Apart from the specific aspects of cultural identity in the draft, such as land rights and rights to religion and language, a general collective right to preserve one's own cultural identity apart from the culture of the rest of the population has been included. It is again not clear which concrete State obligations follow from this right. Cultural identity remains, above all, a general value.

The collective dimension of the draft is noteworthy. It is interesting that the draft contains a reference to the collective rights that indigenous peoples have to make the enjoyment of individual rights possible. Accordingly, collective rights are considered a prerequisite to individual rights. ${ }^{77}$ The other side of the coin is that the

72 During the negotiations in the Working Group of the General Assembly, most indigenous representatives insisted on the inclusion of a reference to self-determination, but no agreement could be reached. See OEA/Ser.K/XVI, GT/DADIN/doc. 23/01, 11 may 2001, Spectal meeting of the Working Group to Prepare the draft American Declaration on the Rights of Indigenous Peoples held from 2-6 April 2001, pp. 49, 52 .

73. See the following OAS General Assembly resolutions in which it requests the Pernanent Cotncil to continue to consider the Draft Declaration: OAS Doc. AG/RES. 1549 (XXVII1-0/98), June 1998; OAS Doc. AG/RES. 1610 (XXIX-O/99), June 1999; OAS Doc. AG/RES. 1708 (XXX-0/00), June 2000; OAS Doc. AG/RES. 1780 (XXX1-O/O!), June 2001. These resolutions are available on Www.oas,ong

74 See OAS Doc. AG/RES. 1610 (XXIX-O/99), June 1999.

75 In his Report of the session of April 2001, the Chair concluded that irregular participation in the Working Group was a shortcoming. "Sometimes the quorum for adopting decisions was not present. In other cases, certain delegations requested that discussions be reopened on points that had been agreed at prior meetings, which, in most cases, they had not attended". See OEA/Ser.K/XVI, GT/DADNN/doc. 23/01 (11 may 2001), Special meeting of the Working Group to Prepare the draft American Declaration on the Rights of Indigenous Peoples, held from 2.6 April 2001, p. 2.

76 Idem, pp. 22-26, 54 .

77 In this study, in particular in Chapter III and IV, it was argued that collective rights cannot prevail over individual rights and, if developed, can only serve in addition to individual rights. 
inclusion of collective rights, as well as the rights to land, constitute the reason why States are still hesitant to adopt the Declaration. This development is also visible in relation to the UN Draft Declaration on Indigenous Peoples, which contains similar provisions.

\section{CULTURAL IDENTITY IN THE INTER-AMERICAN HUMAN RIGHTS SYSTEM}

This chapter concerns the category of cultural rights in the human rights instruments in the Americas. The texts and the supervisory mechanism were analysed in the light of the clarification of the protection of cultural identity within this regional system. Emphasis was laid on several cases concerning the protection of rights of indigenous peoples that have been dealt with by the IACHR and the Inter-American Court on Human Rights.

It appeared that cultural rights are not a prominent part of the regional human rights system of the Americas. Rights explicitly referring to culture were scarcely included in the American Declaration and the American Convention. Although the Protocol of San Salvador includes cultural rights comparable to the ICESCR, its supervision is limited. The Americas, however, have specific problems with regard to indigenous peoples and the protection of their cultural identity, particularly reflected in the issue of land rights. However, land rights or other indigenous rights are nowhere to be found in the American human rights instruments. It is, therefore, interesting to note that the cultural identity of indigenous peoples and, more specifically, their rights related to land, appeared to be protected by other human rights, such as the right to life and health, nondiscrimination and property rights.

Although the situation in each of the cases analysed above was different, they all concerned the protection of indigenous rights, especially in relation to traditional land and cultural identity. The IACHR has only recently addressed the issue of indigenous peoples and the protection of their cultural identity, mainly because it is bound by the provisions included in the American Declaration and the American Convention, both of which scarcely contain cultural rights. However, the JACHR has shown creativity in this respect. The Yanomami case and the Miskito case confirm that the IACHR is willing to go beyond the norms laid down in the American Declaration and the American Convention by using Article 27 ICCPR with regard to the protection of the cultural identity of indigenous peoples. The complaint itself must, for admissibility purposes, focus on violations of the American Declaration and the American Convention, but the IACHR can, in considering the case, make use of other applicable international norms. ${ }^{78}$ The IACHR and the Inter-American Court have also used various provisions of the American Declaration and Convention which, at first sight, do not refer to culture at all, for example, the right to life and health, or which belong to the broad category of cultural rights, such as freedom of expression and religion, to protect the cultural

78 Anaya, 1996 A, p: 169. 
identity of indigenous peoples. The IACHR explicitly used the term "cultural identity" in a broad context as a general value because of which rights related to land, but also rights to language, religion and cultural heritage should be protected.

The case of the Awas Tingi forms the tentative culminating point with regard to land rights for indigenous peoples. The Inter-American Court affirmed that indigenous peoples have a collective right to ancestral land and the State has a responsibility to demarcate such land and to protect it from exploitation by third parties. Although the Court did not use the term cultural identity, it did establish a connection between the land and culture of the community involved. Without concrete cultural rights or land rights, and without a right to cultural identity, the cultural identity of indigenous peoples as a general value, in these cases reflected in land, is guaranteed by the existing human rights provisions.

Another notable point is the collective approach taken by the IACHR and the Inter-American Court. It has been argued that existing human rights lack this collective dimension, which would, therefore, make a collective right to cultural identity necessary. As shown above, within the Inter-American system, much attention is paid to the collective dimension of, for example, the rights related to land of indigenous peoples. The Court argued in the Awas Tingi case that indigenous peoples have the collective right to land, and paid much attention to the importance of the collective aspect of land. In my view, this shows the dynamic character of human rights. Even if human rights provisions have an individuall outlook, supervisory bodies may be prepared to approach them in a more collective way, as the IACHR and the Inter-American Court have done.

These cases of the IACHR and the Inter-American Court confirm the possibility of using existing human rights norms to protect and promote (aspects of) cultural identity. The I.ACHR even referred to relevant provisions such as Article 27 ICCPR, apart from the provisions in the Inter-American human rights instruments, even in a case where the State involved was not yet a Party to the ICCPR. However, the use of existing human rights provisions does not mean that no new developments with regard to standard-setting take place. When States agree there is need for extra human rights protection in a certain field, for example, in the case of land rights, the adoption of new rights has been tried. An example is the Draft American Declaration, which includes rights to language, religion, cultural heritage, land, etc. A collective right to cultural identity is also included in the Draft American Declaration. However, a closer look at this right reveals that it appears not so much to be a right which includes concrete State obligations, but a general value or underlying principle. It expresses the value of the existence of different cultural identities and emphasises the prohibition of assimilation, including positive State obligations to protect cultural characteristics. This can also be seen in the UN instruments on minorities and indigenous peoples. As such, it might add a new element or value to the existing human rights norms, albeit not as a legal right which includes concrete obligations. These concrete obligations stem from specific cultural rights, such as provisions concerning language, religion and land. 


\section{CHAPTER X \\ Cultural IDENTITY AND THE COUNCIL OF \\ EUROPE}

\section{INTRODUCTION}

This chapter focuses on the protection of cultural identity in the human rights instruments of another regional organisation, the Council of Europe, established in May 1949, and nowadays counting 44 Member States. The first major human rights instrument of the Council of Europe was the European Convention on Human Rights and Fundamental Freedoms, which contains civil and political rights. The European Social Charter complemented the European Convention in the economic and social field. Cultural rights were scarcely part of the human rights system in Europe at that time. In 1955, the Cultural Convention was signed, but this was an instrument concerning co-operation in the field of culture between Member States and did not contain cultural rights as such. Cultural rights and the protection of cultural identity were given impetus by the democratic changes in Central and Eastern Europe in the 1980s. As new Member States from these parts of Europe acceded, the Member States of the Council of Europe started to reflect on new human rights themes such as the protection of minorities, in which the protection of cultural identity played an important role.

In the light of all this, the Heads of State and Government of the Council of Europe initiated in 1993 two important developments in relation to the protection of cultural identity: the preparation of the Framework Convention for the Protection of National Minorities, which was finally adopted in 1995, and the preparation of an Additional Protocol to the ECHR in the Cultural Field, which was eventually suspended in January 1996. These instruments, analysed below, show the potentials and the problems of adopting cultural rights and a right to cultural identity.

Comparable to the OAS in the previous chapter, the supervisory mechanism within the Council of Europe is important with regard to the clarification and development of human rights provisions. It is thus interesting to examine how the European Commission and Court for Human Rights have dealt with matters such as culture, language and religion under the ECHR in relation to the protection of cultural identity. In the last part of this chapter, a selected number of cases is analysed under the rights to freedom of religion, expression, association and education in order to see to what extent these rights offer protection of the cultural identity of individuals and communities.

1 For an overview of Member States, see http://www.coe.int. 


\section{CULTURAL Rights IN THE EUROPEAN CONVENTION ON HUMAN RigitTS AND FundaMENTAL FREEDOMS AND THE EUROPEAN SOCLAL CHARTER}

The European Convention on Human Rights and Fundamental Freedoms (hereafter ECHR) was the first international legally-binding human rights instrument. It contains a list of civil and political rights and includes a supervisory mechanism. The ECHR was signed in Rome on 4 November 1950 and entered into force on 3 September 1953. It does not include a specific provision on the protection of culture or cultural identity. In fact, the term 'culture' is not mentioned anywhere in the text. The ECHR does, however, contain provisions on various aspects of cultural identity. These provisions are, inter alia, Article 8 on respect for private life and family life, home and correspondence, Article 9 on freedom of thought, conscience and religion, Article 10 on freedom of expression, Article 11 on freedom of assembly and association, and Article 2 of the First Protocol on the right to education. Article 14 contains a non-discrimination clause that can also play a role in the protection of cultural identity. Article 14 prohibits discrimination on the grounds of sex, race, colour, language, religion, political or other opinion, national or social origin, association with a national minority, property, birth or other status. ${ }^{2}$

These provisions of the ECHR and the First Protocol guarantee rights that are important in relation to the protection of cultural identity. They return in the negotiations on the Framework Convention on the Protection of National Minorities and the Draft Additional Protocol to the ECHR in the Cultural Field in relation to the question of what these new instruments could add to the ECHR. As such, they are of interest in the debate as to whether or not a separate right to cultural identity should be developed. It has been argued that such a right is not necessary, because existing rights, for example, in the ECHR, offer sufficient protection to the cultural identity of individuals and communities. In the previous chapter, it was concluded that civil and political rights could, in fact, play an important role in the protection of cultural identity. The selected case law analysed below shows that the provisions of the ECHR and the interpretation given by the European Court do, in fact, offer possibilities for the protection of cultural identity.

The European Social Charter (ESC), signed on 18 October 1961 and in force since 26 February 1965, contains social and economic rights, but no rights were included that explicitly refer to culture. The only connection with culture and cultural identity can be distinguished in the non-discrimination paragraph of the Preamble. In this paragraph, it is stated that social rights should be enjoyed without discrimination on grounds of race, colour, sex, religion, political opinion, national

2 Article 14 is only applicable in combination with another provision of the ECHR. The twelfth Protocol, adopted on 4 November 2000, will change this situation by adding to the ECHR a provision similar to Article 14, which makes a direct application of the non-discrimination principle possible. This Protocol needs 10 ratifications to enter into force. In Jume 2002, only Cyprus and Georgia had ratified the Protocol. 
extraction or social origin. In comparison with Article 14 of the ECHR, the ESC does not include discrimination on the ground of language, association with a national minority, property, birth or other status.

\section{The European Cultural Convention}

The first European instrument on cuiture was the European Cultural Convention signed on 19 December 1954 and in force since 5 May 1955. The Cultural Convention mainly focuses on the development of European unity as one of the aims of the Councill of Europe. ${ }^{3}$ It includes recommendations on co-operation in the field of developing and preserving a European culture, without describing what such a culture would entail. According to Article 2, for example, each Party will encourage the study of the languages, history and civilisation of the other Parties. Furthermore, the Parties will promote cultural activities and the movement and exchange of persons and objects of cultural value, as laid down in Articles 3 and 4 . All provisions in the Cultural Convention are formulated as State recommendations and not as substantive rights. Supervision is limited, and contains, according to Article 6 , that "proposals for the application of the provisions...and questions relating to the interpretation...shall be considered at meetings of the Committee of Cultural Experts of the Council of Europe." This Committee can submit recommendations to the Committee of Ministers. The European Court and Commission are not involved in this process. It is, however, worth mentioning that all Member States of the Council of Europe have ratified the Cultural Convention. Most of the current Member States signed the Cultural Convention (and other human rights instruments) before acceding to the Council of Europe. Although legally-binding, the Cultural Convention contains rather flexible obligations in the field of cuitural co-operation, which leave the States much room for interpretation and implementation. It is clear that the Cultural Convention, while recognising the general value of culture, does not aim at the protection of the cultural identity of individuals or communities, but instead relates to national cultures and a European culture. It does not contain cultural rights for individuals or conmunities and, as such, is not directly of importance to the protection of their cultural identity.

\section{The EURopean Charter for Regional or MinoRity LANguages}

The interest in the protection of cultural rights and cultural identity increased when States from Central and Eastern Europe acceded to the Council of Europe in the late 1980s and the early 1990s. These States knew minority problems that could have a destabilising effect on the whole of Europe. Accordingly, the Member States considered it necessary to establish arrangements concerning minorities whereby cultural rights and the protection of their cultural identity played an important role. The first European instrument adopted in this field was the European Charter for

3 See the preamble of the Statute of the Council of Europe. 
Regional or Minority Languages, adopted on 5 November 1992 and in force since 1 March 1998. The Charter again mainly emphasises the protection of the "European unity", but through linguistic rights, it indirectly relates to the protection of the cultural identity of individuals and communities.

Article 1 of the Charter contains a definition of 'regional or minority languages' as languages traditionally used by nationals who form a group which is numerically smaller than the rest of the population. Specifically not included are dialects of the official language and the languages of migrants. Regional and minority languages thus always concern nationals of the State involved. Furthermore, culture and languages are firmly related to one another in the Charter. In the preamble, it is, for example, stated that the protection of regional and minority languages will contribute to the "...maintenance and development of Europe's cultural wealth and traditions", and to the "...building of a Europe based on the principles of democracy and cultural diversity within the framework of national sovereignty and territorial integrity. ${ }^{.94}$

Article 7 on the objectives and principles of the Charter establishes another connection between language and culture. This provision concerns the recognition of cultural wealth, the promotion, facilitation, encouragement and safeguarding of regional and minority languages, and the development of cultural relations. Article 7 also includes the issues of equality, mutual understanding and respect, whereby Parties undertake to eliminate unjustified distinctions, restrictions and exclusion, and special measures to promote equality should not be considered discrimination. Parties have to take the needs and wishes of the communities involved into account, and respect their traditions and characteristics. Although cultural identity is not explicitly mentioned, these provisions generally establish a link with the protection of cultural identity, both individually as well as collectively. The Charter also contains all kinds of provisions concerning the use of regional and minority languages, for example, in education, in judicial procedures, in contacts with administrative authorities and public services, the media and economic, social and cultural life, including access to works produced in these languages, translations and the development of knowledge of regional and minority languages.

States Parties can, according to Article 3, specify the languages to which they apply the Charter. Not all provisions of the Charter have to be implemented by the States Parties. They can choose 'à la carte' which provisions they will implement, albeit with some minimum requirements established in Article 2. Each State Party must, inter alia, apply a minimum of 35 paragraphs chosen from the provisions in Part III of the Charter, which concerns measures to promote the use of regional and minority languages in public life.

The monitoring system of the Charter is laid down in Articles 15 and 16, and implies a State reporting procedure. These reports are examined by a committee

4 European Charter for Regional and Minority Languages, Strasbourg, 2 October 1992. Preamble recital 2 and 6 . 
of experts, whereby associations legally established in a State Party can draw the attention of the committee to a certain issue or submit a statement thereon. The Committee of Experts prepares a report for the Committee of Ministers, which can adopt recommendations on the different States. ${ }^{5}$

The Charter entered into force on 1 March 1998, after the necessary five States had ratified it. ${ }^{6}$ In June 2002,16 States had ratified the Charter and a further 12 had signed it but not ratified it. According to Article 20(1), non-member States of the Council of Europe can also accede to the Charter after its entry into force, but no non-member State has done so. The limited number of ratifications and the long period required to obtain the five ratifications necessary for the Charter to enter into force mark the difficulties that States have with the issues of minorities, language and culture. Although the obligations stemming from this Charter are limited and the States themselves can choose "à la carte" which provisions they will apply to which situations, they are still not eager to sign and ratify this Charter. As the only legally-binding instrument on languages, it is, however, an important step in the development of standards concerning minority protection and language rights and, as such, is important for the protection of eultural identity.

\section{The ViEnNa DeClaration}

The Heads of State and Government of the Council of Europe gave a new stimulus to the standard-setting concerning minorities by adopting the Vienna Declaration at their summit in October 1993. They decided to instruct the Committee of Ministers:

"- to draft with the minimum of delay a framework convention specifying the principles in which contracting States commit themselves to respect, in order to assure the protection of national minorities. This instrument would also be open for signature by non-member States;

to begin work on drafting a protocol which complements the European Convention on Human Rights in the cultural field by provisions which guarantee individual rights, in particular for persons belonging to national minorities."

On 4 November 1993, the Committee of Ministers set up the ad hoc Committee for the Protection of National Minorities (hereafter CAHMIN) composed of experts of the Member States. CAHMIN was instructed to draft these instruments and to finish its work on both documents on respectively 30 June 1994 and 31 December 1994. The work on the Framework Convention on the Protection of National Minorities

5 The Committee of Ministers, for example, adopted four recommendations in September 2001 on the Netherlands, Croatia, Finland and Hungary. See http:/www.cm.coe int.

6 These States were: Croatia, Finland, Hungary, the Netherlands and Norway.

7 Vienna Summit Declaration, 9 October 1993, Appendix II National Minorities, see hitp://www.cm,coe.int. 
was completed in October 1994. The completion date for the additional protocol to the ECHR was postponed to 31 December 1995 and was eventually suspended.

What was interesting in this mandate was that the Heads of State and Government decided to adopt a Framework Convention on National Minorities that would not so much include enforceable rights, but State obligations or principles of a programme-type nature. The second instrument to be drafted would be a protocol complementing the ECHR that would fall under the jurisdiction of the European Commission and Court of Human Rights. This protocol would merely contain individual rights, thus excluding the discussion on collective rights beforehand. Moreover, it should contain rights for all individuals in general, and for persons belonging to minorities in particular, which meant that the protocol would be of a more general nature than the Framework Convention, and would focus on the protection of culture, instead of minority protection. According to this mandate, the additional protocol would complement the ECHR and the ESC in the cultural field.

\section{The Framework Convention for the Protection of National MINORITIES}

The Framework Convention for the Protection of National Minorities (hereafter Framework Convention) was adopted on 1 February 1995 and entered into force on 1 February 1998, after 12 States had ratified it. ${ }^{8}$ In June 2002, 35 States had ratified the Framework Convention of which one non-member State and seven had signed it but not ratified it.? The Framework Convention is the first legally-binding international instrument on the protection of national minorities. It contains mainly so-called 'programme-type provisions' defining principles to be implemented by the State Parties. These principles are formulated in terms of State recommendations and define policy objectives that State Parties have to pursue. ${ }^{10}$ Only Article 3 contains a specific right for every person belonging to a national minority to choose whether or not to be treated as a member of a national minority. An explanatory report was added to the Framework Convention, clarifying its provisions and background. Although an explanatory report has no legal status, it is a useful instrument for the interpretation of the Framework Convention. According to the explanatory report, the programme type provisions are not directly applicable and leave the Member States a measure of discretion that allows them to take their

8 These twelve States were: Cyprus, Denmark, Estonia, Finlland, Germany, Hungary, Moldova, Romania, San Marino, Slovakia, Spain and Macedonia.

9 The non-member State is Yugoslavia. See hutp//www. Lumanights.coe. intMinorities/Eng/SiteMap, htm.

10 See the Preamble of the Framework Convention, which reads that "[b]eing determined to implement the principles set out in this Framework Convention..." See, also, Article 3(2) which says that "[p]ersons belonging to national minorities may exercise the rights and enjoy the freedoms flowing from the principles enshrined in the present Franework Convention..." 
particular circumstances into account." Although the definitive decision on direct applicability lies with the judiciary, the general idea behind the Framework Convention was to provide a framework for State policy instead of legally enforceable rights. However, the Framework Convention does create obligations for States, as is confirmed in the explanatory report, which says that the Framework Convention would transform political commitments, as far as possible, into legal obligations. ${ }^{12}$ Most European States did not want to adopt binding rules on the protection of minorities, because they feared that minority rights would encourage disintegration. They could promote ambitions for cultural autonomy followed by claims for administrative and political autonomy and finally secession. ${ }^{13}$

\subsection{The Development of the Framework Convention - Drafts and Proposals}

The drafting of the Framework Convention was mainly based on two proposals: a proposal for a European Convention for the Protection of Minorities by the Commission for Democracy through Law (hereafter the Venice Commission) submitted in $1991^{14}$ and Recommendation 1201 on an additional protocol on the rights of national minorities to the European Convention on Human Rights, ${ }^{15}$ submitted in 1993 by the Parliamentary Assembly. Both proposals started from the idea of adopting a legally-binding instrument and both included references to cultural identity.

The striking point in the Venice Commission's Proposal for a European Convention for the Protection of Minorities is the inclusion of collective rights. The protection of identity was also included as a collective right in Article 3, according to which minorities had the right "...to the respect, safeguarding and development of their ethnical, religious, or linguistic identity." It was also included as an individual right in Article 6, which read:

"...persons belonging to a minority shall have the right to preserve, express and develop freely their cultural identity in all its aspects, free of any attempts at assimilation against their will."

The draft of the Venice Commission also contained linguistic rights, such as the right to use the language of the minority freely, orally and in writing, and the right to learn this language, and the right to manifest religion and belief in worship, and

11 CoE Doc. Explanatory report on the Framework Convention for the Protection of National Minorities, N.CM-Bulletin 20-2 (1995), \&11, p. 201.

12 CoE Doc. Explanatory report on the Framework Convention, $1995, \S 10$, p. 201.

13 Klebes, 1995 , p. 92.

14 The Venice Commission is a consultative body of the Council of Europe on matters of constitutionall law composed of experts in the field of law and political science. Its proposal was reproduced in: Human Rights Low Journal, Vol. 12, 1991, No. 6-7, pp. 269-273. See also CoE Doc. CDL-MIN (93) 6, European Commission for Democracy through Law, Proposal for a Exropean Convention for the Protection of Minorities, 22 Fiebruary 1993.

15 Reproduced in: Hwman Rights Law Journal, Vol.14, No.3-4, 1993, pp. 144-146. 
teaching, etc. These provisions did not contain collective rights, but established that the rights may be enjoyed 'in community with others'.

The Additional Protocol on the Rights of National Minorities proposed by the Parliamentary Assembly contained a definition of national minority whereby cultural identity was referred to. Article 1 included that minorities should be motivated ". by a concen to preserve...their common identity, including their culture, their traditions, their religion or their language." Apart from factors such as citizenship and ties with the State, the emphasis was laid on the preservation of ethnic, cultural, religious, or linguistic characteristics. The Assembly furthermore proposed in Article 3 that

"[e]very person belonging to a national minority shall have the right to express, preserve and develop in complete freedom his/her religious, ethnic, linguistic and/or cultural identity, without being subjected to any attempt at assimilation against his/her will."

The Assembly had no intention of adopting collective rights, but emphasised in the Preamble that the rights in the draft could be exercised individually or jointly.

The Parliamentary Assembly further proposed the right to set up organisations, including political parties, linguistic rights such as the right to use and learn the mother tongue, the right to a name in the minority language, local names and signs in the minority language, etc., educational rights and trans-frontier contacts with persons with whom the minority shares ethnic, religious or linguistic features or a cultural identity. ${ }^{16}$

With these two drafts in mind, CAHMIN started the preparation of a Framework Convention for the Protection of National Minorities in April 1994 with its own preliminary draft. ${ }^{17}$ Important changes in relation to the earlier drafts were, firstly, that CAHMIN added a paragraph in the preamble concerning cultural identity, whereby cultural identity was recognised as a general value to be respected and protected by States. Secondly, the Framework Convention did not copy the collective aspirations of the earlier drafts and guarantees only individual rights. Most other draft articles have found their way into the Framework Convention.

\subsection{The Subject of the Framework Convention and the Definition of 'National Minority"}

Individuals belonging to national minorities are the subjects of the Framework Convention. No agreenent was reached on a definition of 'national minority', which was consequently not included in the Framework Convention. Several criteria have, however, been adopted to determine which persons belong to a

$16 \mathrm{~K}$ lebes, 1995, pp. 108-113.

17 CoE Doc. CAHMIN (94)12; Preliminary Draft Framework Convention for the Protection of National Minorities, April 1994. 
national minority. In the Framework Convention, the emphasis is put on the choice of the individual to belong to a minority as laid down in Article 3. The explanatory report adds to this subjective criterion the necessity of objective characteristics relevant to the person's identity. From the context, it can be argued that the most important characteristics of national minorities are the ethnic, cultural, linguistic and religious identities of the persons involved. ${ }^{18}$ Some authors argue that 'national minority' refers to a minority living on the national territory, but does not refer to an ethnic link with another nation, such as for example, Hungarians in Rumania. ${ }^{19}$ Others, however, assert that such communities may, in fact, fall under the Framework Convention. ${ }^{20}$ The latter approach is taken in practice. Several States ratifying the Framework Convention have issued a declaration to which minorities on their territory the Framework Convention applies, whereby they have confirmed that communities such as the Roma as well as minorities with an ethnic link to another State fall under the Framework Convention. ${ }^{21}$

The inclusion of collective rights had already been rejected by the Heads of State and Government in their mandate to CAHMIN. This is confirmed in the explanatory report according to which the Framework Convention does not imply the recognition of collective rights. The emphasis is laid on the protection of individuals, 'persons belonging to national minorities', who can enjoy their rights individually or in community with others.

\subsection{Cultural Identity in the Provisions of the Framework Convention}

The Framework Convention contains several explicit references to cultural identity. Apart from these, many other cultural rights that may be important for the protection of cultural identity were included. These provisions incorporate for example non-discrimination including the possibility of special positive measures for certain communities (Article 4), freedom of peaceful assembly, freedom of association, freedom of expression, and freedom of thought, conscience and religion (Articles 7, 8 and 9). Educational rights are laid down in Articles 12, 13 and 14, for example, the right to learn and teach knowledge of the minority culture and language, and to set up private educational institutions, without any financial obligations on the State involved. The emphasis in this section lies however on the provisions directly referring to cultural identity.

18. See the preamble, Article 5 and Article 6 of the Framework Convention. See, also, Rönquist, 1995, p. 41 ; Gilbert, 1996 , p. 169.

19 Klebes, 1995, p. 93.

20 Gilbert, 1996, pp. 169,176-177; Keller, 1998, pp. 44-45, 50 .

2. See, inter alia, the declarations of Germany, Macedonia and Slovenia.

22 See Article 3(2) of the Framework Convention; Explanatory Report, 13, p. 201 and CoE Doc. CAHMIN(94)5, January 1994, p. 3. See, also, Klebes, 1993, p. 143; Gilbert, 1996, pp. 169, 175. 


\subsection{Preamble}

In the Preamble of the Framework Convention, it is inter alia laid down that:

considering that a pluralistic and genuinely demoeratic society should not only respect the ethinic, cultural, linguistic and religious identity of each person belonging to a national minority, but also create appropriate conditions enabling them to express, preserve and develop this identity..."

This paragraph can be considered a starting point for the protection and development of cultural identity. Cultural identity is recognised as a value that not only requires respect, but also an active State that is instrumental in developing and preserving that identity.

\subsubsection{Article 5 on the preservation of identity.}

The protection of cultural identity is further laid down in Article 5:

"1. The Parties undertake to promote the conditions necessary for persons belonging to national minorities to maintain and develop their culture, and to preserve the essential elements of their identity, namely their religion, language, traditions and cultural heritage.

2. Without prejudice to measures taken in purstance of their general integration policy, the Parties shall refrain from policies or practices aimed at assimilation of persons belonging to national minorities against their will and shall protect these persons from any action aimed at such assimilation."

During the drafting of Article 5, CAHMIN agreed that the explanatory report should elaborate on the details of this provision, such as the fundamental elements of cultural identity. ${ }^{2.3}$ However, this has not been done. The explanatory report merely lays down that Article 5 is meant to "...ensure that persons belonging to national minorities can maintain and develop their culture and preserve their identity." It is further stated that the reference to traditions does not imply the acceptance of practices that are contrary to national and international standards and that voluntary assimilation is not prohibited. ${ }^{24}$

Article 5 is the most important provision in the Framework Convention concerning the protection of cultural identity. It does not include an explicit right to cultural identity or to the protection of cultural identity. Instead, it formulates a State obligation to "promote the conditions necessary" for the development of culture and the preservation of elements of identity. It is not the cultural identity as such of the individual members of minorities that is protected, but the essential elements of this identity, namely, religion, language, traditions and cultural heritage.

23 CoE Doo. CAHMMN (94)9, March 1994, p. 3.

24 CoE Doc. Explanatory Report on the Framework Convention, 1995, \$. 42-44, p. 205. 
It appears that cultural identity is used as a general value of which specific aspects should be preserved.

With regard to State obligations, it appears that Article 5 implies not only State abstention or respect for the values of culture, religion, language and cultural heritage, but also positive State obligations. ${ }^{25}$ This is confirmed by one of the final changes made to Article 5, which was the replacement of "... to create appropriare conditions allowing them to express, preserve and develop this identity", in "...to promote the conditions necessary enabling them to express..." concerns basically abstention in the sense that persons belonging to a minority should be permitted to express their identity. Instead, "to enable" requires a more active State policy which implies that the authorities should make it possible for the members of minorities to express their identity. This is also reflected in the use of the verb 'to promote'. However, the question remains as to which conditions are necessary for the development and protection of a culture and the preservation of elements of identity. The Framework Convention itself and the explanatory report do not clarify this matter. ${ }^{27}$

In the Framework Convention, as in the other instruments analysed earlier, the protection of cultural identity is part of a policy of non-assimilation. Accordingly, the second part of Article 5 prohibits forced assimilation. States should not only refrain from adopting a policy aimed at assimilation, they are also obliged to protect persons of national minorities against any other attempt to forced assimilation.

\subsubsection{Article 6 on Non-Discrimination Based on Cultural Identity}

Identity is also mentioned in Article 6 in relation to the obligation of States to encourage a spirit of tolerance and mutual respect, especially in the fields of education, culture and the media, among all persons "....irrespective of their ethnic, cultural, linguistic or religious identity." States also have to take measures to protect persons against discrimination or violence "... as a result of their ethnic, cultural, linguistic or religious identity."

According to the explanatory report, this provision was included to confirm that States should promote tolerance and intercultural dialogue to integrate persons belonging to national minorities into society whilst, at the same time, preserving their identity. ${ }^{28}$ Article 6 does not contain a right to cultural identity, but concerns a protection measure against discrimination and violence based on one's cultural identity. Cultural identity is again used as a general value which may not be discriminated against and whose value is part of a policy of tolerance and mutual respect.

25 See, also, Rönquist, 1995, p. 42.

26 CoE Doc. CAHMTN (94)28, September 1994, p. 28.

27 Keller, 1998, p. 51.

28 CoE Doc. Explanatory Report on the Framework Conwention, 1995,849, p. 205 . 


\subsubsection{Articles 10 and 11 on Linguistic Rights}

Articles 10 and 11 contain linguistic rights, such as the right to use a minority language, including in relations with the administrative authorities, and the right to use a name in the minority language. Most of these rights are limited by a number of criteria, for example, the fact that the national minority should inhabit the traditional area concerned or in substantial numbers. The request to use a minority language should, furthermore, correspond to a real need. With regard to the right to use a minority language in relation to public institutions, the delegates agreed that this provision should be flexible, and employed phrases such as "States shall endeavour, as far as possible..." It was decided within CAHMIN that it was not necessary to include a right of recognition of a minority language in the text as it was considered implicit in the linguistic freedoms in the Framework Convention. ${ }^{29}$

The link between linguistic rights and the protection of cultural identity has been emphasised. According to the explanatory report; these linguistic rights were in fact included, because the "...use of a minority language represents one of the principle means by which such persons can assert and preserve their identity." 30 CAHMIN also argued during its drafting that language could be "...a possible element of identity." was, in fact, rejected, with the argument that "... such a right would offer little to promote the identities of national minorities.",32

\subsubsection{Articles 17 and 20 on Trans-Frontier Contacts}

The concept of identity finally returns in Article 17 on trans-frontier contacts. According to Article 17, States may not interfere with the right of persons belonging to a national minority to establish and maintain contacts with persons across the border, "... in particular those with whom they share an ethnic, cultural, linguistic or religious identity, or a common cultural heritage." The explanatory report emphasises that international contacts can be important to the maintenance and development of the culture of members of national minorities and the preservation of their identity. ${ }^{33}$ Again, a provision concerning a certain right itself was included, in this case trans-frontier contacts, not only as such, but also as part of the protection and promotion of the general value of cultural identity.

29 ColE Doc. CAHMIN (94) 13, April 1994, p. 6.

30 CoE Doc. Explanatory Report on the Framework Convention, 1995, \$ 63, p. 207.

31 CoE Doc. CAHMIN (94) 13, April 1994, p. 6.

32 COE Doc. CAHMIN (94) 13, April 1994, p. 6.

33 CoE Doc. Explanatory Report on the Framework Convention, 1995, \$ 83, p. 210. 


\subsection{Implementation and Supervision of the Framework Convention}

The Framework Convention is an international treaty and, as such, legally-binding upon the Parties. However, the Framework Convention contains mainlly principles and objectives, instead of enforceable rights, whereby States Parties can choose the ways and means to put these principles into practice. In fact, the explanatory report determines that the provisions of the Framework Convention are not directly applicable. Although the final decision on direct effect should be taken by the national judiciary, it shows the cautious attitude of States with regard to minority rights. Furthermore, apart from the general measure of discretion stemming from the principle of a framework convention, many provisions contain restrictive clauses, such as 'as far as possible' or 'within the framework of their legal system', which weakens the text. ${ }^{34}$ However, the Framework Convention is important as the first legally-binding instrument on minorities. Large support by the Member States of the Council of Europe could increase its normative force.

In reality, the Framework Convention has received wide support. 34 States have ratified the Framework Convention, including one non-member State. ${ }^{35}$ Most States that have not ratified have specific legal problems with regard to minorities. ${ }^{36}$ This support gives the Framework Convention moral authority and thereby increases its value. It should, however, be recalled that every State can specify the territory and communities to which it applies the Framework Convention. This means that, while ratifying the Framework Convention, States can decide to leave out certain minorities from the working of the Framework Convention. The supervisory mechanism could be an important safeguard in encouraging States not to deny the working of the Framework Convention for certain communities.

The supervision of the Framework Convention caused large debates within CAHMIN. Several delegations argued that a framework convention does not require a specific monitoring mechanism, since it only defines goals and policy lines and not enforceable rights. Others were in favour of some form of supervision but did not agree on the form that it should take. ${ }^{37}$ CAHMIN eventually decided that a non-judicial, but political supervisory body would be the most compatible solution according to the nature of the Framework Convention and the principles to which the Parties would commit themselves. It was decided that the Committee of

34 Klebes, 1995, pp. 93-94; Keller, 1998, p. 32.

35 See Article 27 of the Framework Convention. The Non-member State is Yugoslavia.

36 France, for example, categorically denies that minorities live on its territory; this is based on its Constitution, which lays down that all persons are equal before the law. The French Consell Constitutionnel has, in fact, decided that the Charter on Regional and Minority Languages is contrary to the French Constitution, which leaves no hope for the French ratification of the Framework Convention (Décision No. 99-412 DC du 15 juin 1999: Charte européenne des langues régionales ou minoritaires). Turkey has a comparable argument that all minorities, including the Kurds, are Turks according to the Constitution. Belgium has specific problems with regard to the French and Flemish speaking parts of the country.

37 CoE Doc. CAHMIN (94) 5, January 1994, p. 4. 
Ministers would play the main role in the supervision, but no agreement could be reached on the issue of whether an independent body of experts would assist the Committee of Ministers in examining the State reports. In the end, this matter was deferred to the Committee of Ministers. ${ }^{38}$.

The Committee of Ministers laid down the monitoring mechanism in Articles 24 to 26 of the Framework Convention. No judicial, quasi-judicial or supranational enforcement mechanism was established, because the Ministers agreed with CAHMIN that the 'programme-type' provisions of the Framework Convention did not require such a mechanism. Accordingly, there is no complaint procedure and the legally-binding obligations merely arise between States on the basis of their being bound to comply with the treaty provisions. ${ }^{39}$ The Committee of Ministers is in charge of the monitoring of the implementation of the Convention. States have to report on a periodical basis, which is not further specified. The Committee is assisted by an Advisory Committee composed of experts in the field of minorities and human rights. ${ }^{40}$

The Committee of Ministers adopted the rules on the monitoring of the Framework Convention in Resolution (97)10 of September 1997. The Advisory Committee adopted its rules of procedure in October 1998. Within one year of the entry into force of the Framework Convention, States Parties have to submit a report on legislative and other measures they have taken to give effect to the principles of the Framework Convention. These State reports are made public and examined by the Advisory Committee, which can also use information from other sources than the State before preparing an opinion. Having received the opinion of the Advisory Committee, the Committee of Ministers can adopt conclusions and, where appropriate, recommendations with regard to the State Party concerned. The first State reports were submitted in February 1999 and in September 2000 the Advisory Committee adopted its first four opinions on Finland, Denmark, Hungary and Slovakia. ${ }^{41}$

The Advisory Committee has established country specific and thematic working groups and has visited all reporting States where it has spoken with government officials, but also with NGOs, local experts and representatives of minorities. ${ }^{42}$ The opinions of the Advisory Committee are extensive reports discussing the general situation in a State and the implementation of specific provisions of the Framework Convention. With regard to the protection of cultural identity, for example referred to in Article 5, the opinions of the Advisory

38 CoE Doc: CAHMIN (94) 16, June 1994, pp. 7-8; CoE Doc. CAHMIN (94) 28, September 1994, pp. 6-7.

39 Gilbert, 1996, p. 174:

40 Klebes, 1995 , p. 94.

41 All information on the State reports, as well as the opinions of the Advisory Committee and the recommendations of the Committee of Ministers can be found on http://www.humanrights coe.int/Minorities/Eng/SiteMap.htm.

$\$ 2$ See the first and second Activity Report of the Advisory Committee on hutp:/Www.humanrights.coe int/Minorities/Eng/SiteMap hutm 
Committee do not provide new insight, because this general concept is hardly referred to. The Advisory Committee does, however, give an extensive opinion on the implementation of aspects of cultural identity, such as language, religion, education and land. Although the latter is not specifically dealt with in the Framework Convention, it is dealt with by the Advisory Committee inter alia under Article $5 .{ }^{43}$ The first two sets of conclusions and recommendations of the Committee of Ministers on Finland and Denmark do not contain a reference to cultural identity. ${ }^{44}$

\subsection{Concluding Remarks on the Framework Convention}

It cannot be over-stressed that the Framework Convention is a remarkable step in the protection of the rights of minorities. In fact, "...the Framework Convention places minority rights firmly in the regime of international human rights law."45 However, taking a closer look at its provisions, its impact is rather limited. The programme-type provisions reflect principles, formulated in a flexible way, which were not meant to be directly applicable. The Framework Convention generally reflects the reserved attitude of States with regard to minority protection. Most important is that the States gave themselves a large influence on the working of the Framework Convention. They can decide to which minorities on their territory the Framework Convention applies and they have large influence on the supervision of the Framework Convention through the Committee of Ministers. ${ }^{46}$

With regard to the protection of cultural identity, the analysis of the Framework Convention confirms the lines set out earlier. The Framework Convention contains several references to cultural identity which confirm that cultural identity is considered an important general value. No explicit right to cultural identity is included, but several other provisions on language, trans-national contacts and others, are directly linked to the protection of cultural identity, Again, it should be noted that the provisions explicitly referring to cultural identity mainly reflect the general protection of this value as a principle, without clearly indicating which State obligations follow from it. It is mainly other cultural rights that provide for the content of this protection. This is confirmed by the supervision of the Framework Convention. In the various reports, everything and nothing is brought under the scope of Article 5, whereby cultural identity serves as an umbrella for concrete actions in the field of language, religion and land.

43 See, for example, the opinion of the Advisory Committee on Finland. The situation of Finland including the implementation of the Framework Convention is dealt with in detail in Chapter $\mathrm{XI}$.

44 See COE Doc. Resolution $\mathrm{CMN}(2001) 2$ on the implementation of the Framework Convention for the Protection of National Minorities by Denmark, and Resolution CMN(2001)3 on the implementation of the Framework Convention for the Protection of National Minorities by Finland, both adopted on 31 October 2001 at the 771 st meeting of the Ministers." Deputies.

45 Gillbert, 1996, p. 174; Keller, 1998, p. 31.

46 Keller, 1998, p. 31. 


\section{Proposal for an AdDTtonal Protocol to the ECHR in the Cultural FIELD}

After finishing the Framework Convention, CAHMDN started its work on an additional protocol which was to guarantee individual rights in the cultural field. At that time, Klebes argued: "..it will be much more difficult to reach agreement on the formulation of justiciable rights than on the contents of the Framework Convention where...many rights are worded in a rather flexible way and where no proper control mechanism is foreseen. ${ }^{34}$ At the time of speaking, he could not know how right this sentence would turn out to be.

\subsection{The Mandate of CAHMIN}

CAHMIN held six meetings on the drafting of the Additional Protocol between November 1994 and November $1995 .^{48}$ It had received the following instructions: firstly, the protocol should guarantee individual rights, not exclusively for persons belonging to national minorities, although the rights should have special relevance for them. Secondly, the rights should fall within the "cultural field', a notion not further described. Thirdly, the rights in the protocol should be fundamental rights and sufficiently precise to be justiciable before a court. ${ }^{49}$ Accordingly, CAHMIN set out four criteria of proposed rights to be included in the draft protocol:

1. The right should be additional to the rights guaranteed by the ECHR and its Protocols.

2. The right should be a fundamental right.

3. The right should correspond to a real need.

4. The right should be justiciable. ${ }^{50}$

The following contains an analysis of several provisions drafted by CAHMIN whereby the emphasis again lies on the provisions directly referring to culture or cultural identity, although attention is also briefly paid to several other provisions.

47 Klebes, 1995, p. 97.

48 CoE Doc. CAHMIN (95) 22 Add., November 1995, p. 3. CAHMIN had already started its discussions on the Additional Protocol during the meetings on the Framework Convention. However, due to lack of time, CAHMIN only actually started its work after the finishing of the draft Framework Convention.

49 CoE Doc. CAHMIN (95) 22 Add., November 1995, p. 4 and CoE Doc. CAHMIN (94) 33 , November 1994, p. 3.

50 CoE Doc. CAHMTN (94) 33, November 1994, p. 4. 


\subsection{Provisions in the Draft Protocol concerning Cultural Identity}

\subsubsection{The Right to Cultural Identity}

CAHMIN extensively discussed the right to cultural identity. Many proposals were submitted, which varied from the right to cultural identity and the right to respect for cultural identity, to the right to choose which cultural identity one wishes to belong to. ${ }^{51}$ CAHMIN recognised that the concept of cultural identity could only be considered in relation to groups of persons. "This however would not imply the acceptance of collective rights." It was argued that individual rights could also have a collective dimension without being a collective right. ${ }^{52}$ Supporters of a right to cultural identity considered this right a fundamental, universal right which would probably be justiciable. They emphasised the symbolic and political value of a right to cultural identity, which could, as such, be a genuine addition to the ECHR. Practice had shown that, in many parts of Europe, communities and individuals could not express or preserve their cultural identity, because of intolerance and discrimination. Their cultural identity therefore needed special protection by a right to cultural identity. ${ }^{53}$ However, many members of CAHMIN expressed their concern about the broadness of the concept of cultural identity and the implications this would have for the States involved. They argued that cultural identity, as such, was too vague, and that aspects of cultural identity were already covered by Articles 8 to 11 ECHR. It was further argued that the inclusion of a right to cultural identity could cause tension within the societies of the Member States. A right to cultural identity could not only encourage contentious practices, such as arranged marriages and the inferior position of women, but disproportionate attention to cultural identity could also advocate cultural activism that might lead to separatist tendencies in society. ${ }^{54}$

In the end a majority within CAHMIN rejected the inclusion of a right to (respect for) cultural identity or to replace the term cultural identity with notions such as cultural values, cultural traditions or cultural characteristics. All these concepts were considered to be too vague to be included in a protocol and to leave too much to be decided by judges. A justiciable right, which was one of the criteria set out by CAHMIN, should be more specific. Besides, the expressions of cultural

5) CoE Doc. CAHMIN (95) 1, Draft articles and alternative versions for possible inclusion in a protocol complementing the ECHR in the cultural field, p. 3; CoE Doc. CAHMIN (95) 22 Add., Activity report for the attention of the Committee of Ministers, January 1995, pp. 13-14. The proposal that "... any person shall have the right to choose his or her cultural identity", was rejected because it was argued that a right to choose a cultural identity would be meaningless without the protection of this identity." See CoE Doc. CAMMIN (95) 9, February/March 1995, pp. 6-7.

52 CoE Doc. CAHMIN (94) 35, December 1994 , p. 12.

53. CoE Doc. CAHMIN (94) 33, Nowember 1994, pp. 4-5; CoE Doc. CAlMMIN (94) 35, December 1994, p. 11; CoE Doc. CAHMIN (95) 16, May 1995, p. 6; CoE Doc. CAHMIN (95) 21, September 1995 , p. 5.

54 CoE Doc. CAMMIN (94) 35, December 1994, p. 11. 
identity were already protected by the provisions of the ECHR. Consequently, CAHMIN did not draft a final provision on cultural identity. ${ }^{55}$

The interest of this debate for this study is that all the arguments for and against a right to cultural identity passed the discussion in CAHMIN. Supporters of a right to cultural identity emphasised its symbolic function and the fact that practice had shown that the cultural identity of several communities and individuals was in jeopardy because of intolerance and discrimination, and thus was in need of special protection. Cultural identity was of such value that it was to be included in a specific protocol that was separate from the specific provisions in the ECHR. Opponents of a right to cultural identity considered it not to be justiciable, because the concept of cultural identity was too vague. Emphasis on cultural identity might further encourage tensions in society. Another argument put forward was that full respect for the provisions in the ECHR, including the promotion of tolerance and mutual understanding, would automatically lead to respect for cultural identity.

\subsubsection{The Right to Choose to Belong to a Group}

Closely related to a right to cultural identity was the right to choose to belong to a group. However, this right was also rejected in the end, because of lack of agreement. Several members of CAHMIN argued that this right presupposed the existence of different communities in society that should be treated differently and had their own rights, which was, in their opinion, against the spirit of the ECHR. Others argued that this right was already covered by Article 11 ECHR on the right to freedom of association. Supporters used the counter-argument that the concept of a cultural community was broader than an association. Two other proposals, concerning a right to be treated as a member of a cultural community and a right to identify with a cultural community, also did not receive enough support in CAHMIN. The majority of experts argued that meaning of "cultural community" was unclear and that these provisions were already covered by Article 11 ECHR ${ }^{56}$

\subsubsection{The Protection of Cultural and Scientific Heritage}

Another draft provision that did not make it into the final draft concerned the protection of cultural and scientific heritage, including the right to the access and the use of cultural property and the protection and conservation of it. It was argued that cultural heritage not only included monuments and public records but also immaterial aspects such as living memory. It was further asserted that the protection and preservation of cultural heritage involved more positive measures than merely

55. CoE Doc. CAHMIN (95) 9, February/March 1995, p. 5; CoE Doc. CAHMIN (95) 21, September 1995, p. 5 and 10; CoE Doc. CAHMIN (95) 22, November 1995, p. 4.

56 CoE Doc. CAHMIN (94) 35, December 1994, p. 5; CoE Doc. CAHMIN (95) 9, February/March $1.995, \mathrm{p}, 6$. 
the right to access. It was mainly because of the financial obligations that these rights and their positive measures might imply that made most delegates finally reject these proposals. Several delegations also argued that this right was included in the right to cultural identity, since respect for cultural identity would imply the protection and non-destruction of cultural heritage. They wished firstly to define a right to cultural identity, which was not successful, as described above. Because no agreement could be reached, the drafts were rejected. ${ }^{57}$

\subsubsection{The Right to Participate in Cultural Activities}

The proposals for a provision on the right to participate in cultural activities also did not receive sufficient support to be included in the additional draft protocol. It was criticised by the majority in CAHMIN, with the argument that such a provision was already covered by Articles 8,9 and 10 ECHR concerning familly life, religion and association. A minority in CAHMIN, however, felt that these provisions of the ECHR should be complemented in the protocol by specific provisions on cultural activities. The final decision on this point was initially postponed to after the completion of the work on a right to cultural identity. ${ }^{58}$ Considering the outcome of the discussions on a right to cultural identity, it is no surprise that the final decision on a right to participate in cultural activities turned out to be negative. ${ }^{59}$

\subsubsection{The Right to Set Up Cultural and Educational Institutions}

One of the proposals included in the final additional draft protocol was the right to set up cultural institutions. With regard to cultural institutions, it was again questioned as to whether such a right was already covered by Article 9 ECHR on freedom of religion for religious institutions, and Article 11 ECHR on freedom of association for other institutions. It was generally agreed that cultural institutions should be explicitly mentioned in the protocol. It was further discussed whether such a provision would give rise to positive obligations. It was finally agreed that it would not be appropriate to include possible claims for resources in the additional protocol. ${ }^{60}$

57 CoE Doc. CAHMIN (94) 35, December 1994, p. 6; CoE Doc. CAHMIN (95) 16, May 1995, pp. 35.

58 CoE Doc. CAHMIN (95) 9, February/March 1995, pp. 5-6.

59 CoE Doc. CAHMIN (95) 21, September 1995, p. 4.

60 CoE Doc. CAHMIN (94) 35, December 1994, pp. 7-8 and CoE Doc. CAHMIN (95) 9, February/March 1995, p. 10; CoE Doc. CAHMNN (95) 21, September 1995, p. 10. 


\subsection{Other Provisions in the Draft Protocol Relevant to the Protection of Cultural Identity}

\section{Linguistic Rights}

The initial proposal on linguistic rights concerned a right to use the language of one's choice. Later, CAHMIN decided to replace the right to use the language of one's choice with the freedom to use such a language. Again, several delegations in CAFMIN argued that such a right was already covered by Articles 8 and $10 \mathrm{ECHR}$, concerning the protection of private life and freedom of expression. Finally, however, CAHMIN agreed on the inclusion of the freedom to use the language of one"s choice. This right was meant to protect language as a means of expression, as an additional right to Article 10 ECHR. However, this freedom would not apply to relations between persons and public authorities, and also excluded the educational field. The right to the use of one's own language in relation to public signs and the right to be taught in one's own language were rejected because they were considered to be neither fundamental, universal, nor enforceable. It was also decided that the right to learn a language of one's choice would be included without any positive obligation for the State.

\section{The Right to a Name}

In CAHMIN many proposals in relation to the right to a name were submitted, such as the right to express one's name in one's own language, and the right to use, keep and change one's name. It was again argued that Article 8 ECHR, concerning respect for family life, already covered such rights. Others doubted the cultural nature of these rights. A name was considered a fundamental elements of the identity of every person, but not necessarily of the cultural identity. ${ }^{62}$ Despite these arguments against the right to a name, CAHMIN finally reached agreement on the inclusion of such a right. ${ }^{63}$

\section{Educational Rights}

No agreement could be reached within CAHMIN on any educational rights, which, accordingly, were not included in the draft additional protocol. It was inter alia argued that such rights were already covered by Articles 8 and 10 ECHR and Article 2 of the first Protocol. Furthermore, there was no agreement on what such rights implied in the sense of State obligations. Did they mean the right to freedom from State interference and the freedom to be taught one's language without any obligation for the State to take positive measures? Or was it a positive right

61 CoE Dac. CAHMIN (94) 33, November 1994, p. 7; CoE Doc. CAHMIN (95) 9, February/March 1995, pp. 8-9; CoE Doc. CAHMIN (95) 16. May 1995, pp. 9-12; CoE Doc. CAHMIN (95) 21, September 1995 , p. 7.

62 CoE Doc. CAHMIN (94) 33, November 1994, pp. $7-8$ and CoE Doc. CAHMIN (95) 9, February/March 1995, p. 7 .

63 CoE Doc. CAHMTN (95) 21, September 1995, p. 6. 
obligating the State to supply certain services? ${ }^{64}$ It also rejected both the right of access to information, because it was considered not to relate to the cultural field, and the right to intellectual property, because it was considered to be of such complexity that no justiciable right could be formulated. ${ }^{65}$

\subsection{Outcome of the Drafting Process}

In September 1995, CAHMIN had formulated four articles to be included in the Additional Draft Protocol to the ECHR in the Cultural Field: the right to a name, the freedom to use the language of one's choice, the right to learn the language of one's choice, and the right to establish cultural institutions. Cultural identity was referred to in the preamble:

"Considering the existence of differences in cultural identity and the importance, in a democratic society based on the principle of tolerance, of making provision for the further protection of the individual"s cultural identity..."

After examining the proposals by CAHMIN, the Committee of Ministers considered various ways of response. The first option would be for the Committee to adopt the proposals and open the Protocol for signature. The Committee could also instruct CAHMIN to complete the draft by incorporating additional rights. Finally, the Committee could suspend the work on the drafting of the protocol until a draft which was more substantial could be agreed upon. ${ }^{67}$ The last option was followed and in January 1996 the Committee of Ministers suspended sine die the work on the additional protocol. It found the outcome of the discussions in CAHMIN disappointing and argued that the four rights drafted by CAHMIN would not add much to the ECHR. It appears that the plans for an additional protocol have since been put on 'on ice'. It seems that it will take a lot of political heat to melt this ice in order to adopt an instrument on cultural rights.

The drafting process on the Additional Protocol shows how difficult it is to define rights to culture or cultural identity. It appears very difficult to transform such social concepts into legal standards. Secondly, it shows the hesitation of the Member States of the Council of Europe to adopt legally-binding provisions on culture and cultural identity. They are not only afraid that these will cause tensions and raise aspirations for autonomy, but, since the concepts are vague, the consequences and implications of legally-binding rights in the cultural field are hard to predict. Finally, an important argument was that such rights would not add much to the provisions in the ECHR.

64 CoE Doc. CAHMIN (94) 35, December 1994, p. 8.

65 CoE Doc. CAHMIN (94) 35, December 1994, pp. 9-10.

66 CoE Doc. CAHMIN (95) 22 Add., November 1995, pp. 8-9.

67 CoE Doc. CAHMIN (95) 22 Add., November 1995, p. 7. 


\section{Concluding Remarks on the Provisions in the Instruments of the COUNCIL OF EUROPE}

From the above, it can be concluded that the Council of Europe has paid increasing attention to the protection of cultural identity in the context of minority protection and in the broader context of the development of cultural rights. The discussions and efforts within the Council of Europe to define a right to cultural identity provide useful insight for the general development of such a right.

The ECHR and the ESC contain cultural rights relating to aspects of cultural identity such as freedom of religion or expression, but do not include any explicit reference to culture or cultural identity. The concept of culture was included in the European Cultural Convention, but this Convention was not meant to protect the culture or cultural identity of individuals or communities. The developments in Central and Eastern Europe caused increasing interest within the Council of Europe for cultural rights, especially in relation to the protection of minorities. Several instruments were adopted in this respect, such as the European Charter for Regional and Minority Languages and the Framework Convention for the Protection of National Minorities. This process should have been completed by an Additional Protocol to the ECHR on Rights in the Cultural Field, but the Member States did not succeed in drafting such a Protocol.

It was clear from the beginning that both the Framework Convention and the Additional Protocol were supposed to contain individual rights. The Member States acknowledged the collective dimension of cultural rights in general, and of a right to cultural identity in particular, but they firmly rejected collective rights. The mandate of CAHMIN set by the Heads of State and Government was also clear on this matter and no discussion on collective rights took place in CAHMIN. Individual rights were given a collective dimension by including that they could be enjoyed jointly or in community with others.

The Framework Convention includes specific references to cultural identity in both the Preamble and in Article 5. In addition, several aspects of cultural identity, such as religion, language and education, can be found in the different provisions. It appeared that cultural identity was considered an important value to be protected by States Parties to the Framework Convention. The legal impact of these provisions on the protection of cultural identity is, however, limited. In general, the provisions of the Framework Convention are of a programme-type nature and mainly lay down principles to be implemented by States Parties in their policies. These States Parties may determine to which minority communities on their territory the Framework Convention applies, because no definition was given of 'national minority'. The monitoring of the Framework Convention is mainly left in the hands of the Committee of Ministers assisted by an Advisory Committee. The provisions explicitly referring to cultural identity mainly reflect its protection as a general value or principle. While cultural identity deserves to be protected, rights concerning aspects of cultural identity provide for the content of this protection. 
More clarity could be expected from the drafting of an Additional Protocol to the ECHR on Rights in the Cultural Field. This additional protocoll would be part of the human rights system under the auspices of the European Commission and Court of Human Rights. It would lay down rights for all persons, not only those belonging to national minorities. Many proposals passed the drafting committee CAHMIN, among which the right to cultural identity. The main question in CAHMIN was whether the proposed provisions added anything to the ECHR and whether they were universal and justiciable. Most draft provisions did not pass this test and, in the end, CAHMIN could agree on no more than four provisions, mainly in the linguistic sphere. The Committee of Ministers suspended the work on the Additional Protocol.

The negotiations on a draft additional protocol confirm the difficulties in defining a right to cultural identity. A right to cultural identity and all other proposals that explicitly referred to 'culture' were rejected in CAHMIN, with the exception of the right to set up cultural institutions. While it was recognised that cultural identity was an important value that deserved to be protected, it appeared impossible to translate this value into a legal right. In fact, it almost seemed as if the Member States wanted to protect cultural identity with anything except a right to cultural identity. The main argument against such a right was that the concept of cultural identity was too vague and therefore not justiciable. Furthermore, it was argued that such a right could be interpreted as supporting questionable cultural activities and be misused by communities to obtain autonomy. Another important argument was that the right to cultural identity and other relevant rights did not add protection to the ECHR. However, as argued above, the provisions in the ECHR do not explicitly refer to cultural identity. This raises the question as to whether the protection of cultural identity could be 'read' in provisions on, for example, freedom of expression, religion and association, to be analysed in the next section.

\section{Selected Case law of the European Commission and European COURT OF HUMAN RIGHTS}

As set out above, the ECHR includes civil and political rights and does not contain a provision on culture or cultural identity or a provision on specific communities such as minorities. The ECHR does, however, enclose several provisions on aspects of cultural identity, such as language, religion, education and non-discrimination. ${ }^{68}$ This section analyses a selected number of cases before the European Commission and the European Court of Human Rights under Article 8 on respect for private life, family life and home, Article 9 on freedom of religion, Article 10 on freedom of expression, Article 11 on freedom of association and Article 2 of the First Protocol on the right to education. There are quite a number of cases under these provisions, but only those with a clear link to the protection of cultural identity are analysed below. Most cases have an individual character and concern specific situations of

68 The right to education is included in the First Protocol, article 2. 
persons who wish to defend their interest in the field of religion, education or language. These issues are directly linked to their individual cultural identity and play an indirect role in the protection of cultural identity of communities. The Court focuses mainly on the individual dimension of cultural identity although it sometimes refers to its collective dimension. The Court has generally confirmed the value of cultural diversity whereby it balances the interests of different communities within society and argues on the role of the State in this respect. Without being exhaustive, these cases offer an illustration of the possibilities that the provisions of the ECHR offer to protect cultural identity. These existing provisions, even without explicitly referring to cultural identity, provide protection of the cultural identity of individuals and communities. In other words, these provisions of the ECHR may protect implicitly what a right to cultural identity would protect explicitly.

\subsection{The Right to Education: the Belgian Linguistics Case ${ }^{69}$}

One of the first judgments of the European Court of Human Rights in relation to the protection of cultural identity was the Belgian Linguistics case concerning education in a certain language. Article 2 of the First Protocol not only contains the right to education, but also provides that the State shall respect the right of parents to ensure education for their children that is in conformity with their own religious and philosophical convictions. The meaning of 'religious and philosophical convictions' had been explained by the Court in several cases. ${ }^{70}$ The Belgian Linguistic case was one of these cases, which was also interesting for its reasoning on positive obligations of States with regard to education.

In the Belgian Linguistics case six groups of applicants, being Francophone residents in Flanders and the Brussels periphery, claimed that the Belgian linguistic system for education under the 1932 and 1963 Acts, was incompatible with Article 2 of the First Protocol. This Belgian linguistic legislation divided the national territory into regions and prescribed the language to be used in each region in school education. The applicants were French speaking parents of school children, who asserted that the Belgian government should provide for primary school education in French in the Flemish region they lived. This was refused by the Belgian government, because it considered it a unilingual Dutch region and because it argued that the individual freedoms of the ECHR implied only negative duties on the government. The European Commission argued that, in principle, the rights included in the ECHR not only had a negative character implying State abstention, but that instead every provision had to be examined in its own right. However, in

69. Roger wan de Berghe v. Belgium, Application No. 2924/66, European Court of Human Rights, Decision of 23 July 1968,11 YEHR, 1968, p. 412.

70 See Belgian Linguistic Case, Case relating to certain aspects of the laws on the use of languages in education in Belgium, Judgement of the European Court on Human Rights, 23 July 1968, Publications of the Court Series A, Vol. 6; Case of Kjeldsen, Busk Madsen and Pedersen, Judgement of 7 December 1976, Publications of the Court Series A, Vol. 23; Case of Campbell and Cosans, Judgement of 25 February 1982, Publications of the Court Series A, vol. 48. 
this case the majority of the Commission agreed that the right to education placed no positive obligation on States to make available any material provision for education. The drafters of the ECHR had intentionally used the negative formula to ensure that this provision could not be interpreted to impose positive obligations on States to enable everyone to receive the education that they desired. ${ }^{7 !}$

The Court agreed by eight votes to seven that Belgium had not violated Article 2 of the first Protocol as far as the applicants or their children were concerned. It agreed with the Commission that Article 2 of the First Protocol did not impose positive State action to establish or finance a particular type of education in a certain language. However, the Court held that this provision might impose positive obligations to ensure the equal enjoyment of the right to education. Accordingly, the Court held that there had been a violation of Article 2 of the First Protocol in conjunction with Article 14 ECHR on non-discrimination, only in so far as the Act of 1963 prevented certain children, only on the basis of the residence of their parents, from having access to the French language schools in the six "special status communes' on the Brussels periphery.

The Belgian Linguistics case shows the link between education and language and therefore with cultural identity. It is especially the issue of religious and philosophical convictions which brings the concept of cultural identity to the fore. In the Belgian Linguistics case the Court argued that 'philosophical convictions' did not mean education in a language preferred by the parents. In the case of Kjeldsen and in the case of Campbell and Cosans, the Court gave a broader interpretation of this concept, including the criteria that the religious and philosophical convictions of the parents should be compatible with the child's right to education and should fit in a democratic society. ${ }^{72}$ Several authors have argued that, considering this broad interpretation, linguistic preferences would, in fact, also fall under 'philosophical convictions'. I agree with this view that the wishes of parents to have their children educated in a certain language may reflect a vision of life, and language may embody a certain philosophy, or in other words; a cultural identity. ${ }^{73}$ However, the question remains as to what extent the State has positive obligations in this respect.

The Belgian Linguistics case also concerned language rights and nondiscrimination. It confirmed that the right to education implies inter alia the right of equal access to educational institutions and the right to be educated in the national language or in one of the national languages. However, according to the reasoning of the Court, the right to education does not require States to comply with parents"

71 Belgian Linguistic cases, Commission Report of 24 June 1965, B.3 (1967), pp. 305-306.

72 Campbel and Consans v. the United Kingdom, Application Nos. 7511/76 and 7743/76, European Court of Human Rights, decision of 25 February 1982, \$16. Kjeldsen, Busk, Madsen and Pedersen v. Denmark, Application Nos. 5095/71, 5920/72 and 5926/72, European Court of Hurnan Rights, decision of 7 December 1976.

73 See Coomans, 1992, pp. 167-169, who quotes an unpublished source of De Witte (1985). 
linguistic preferences in the educational field. The negative formulation of the first part of Article 2 emphasises the freedom of education rather than the right to education including the positive obligations of the State. The State does not have to finance education of any particular type, instead individuals merely have the right to use "...the means of instruction existing at a given time." While this case made it clear that the Court found that the State is not required to establish or subsidise education in a certain language, the reference to 'at a given time' suggests that the scope of Article 2 may vary between different States and may be subject to developments. As argued above, language might, in the meantime, fall under philosophical convictions. The question remains as to whether the State should positively support or finance education in a preferred language. In principle, States have the obligation to respect the wishes of minority communities if they wish to set up language education or education in a certain language by their own means, as long as the education itself complies with the general criteria of education. With regard to positive State obligations, the issue is more complex. It is understandable that a State cannot comply with all the individual preferences of parents. These matters should be dealt with on a case-to-case basis, taking the specific circumstances into account. However, in my view, it seems reasonable to apply the principle of non-discrimination to minority interests. This means that, first of all, minorities are entitled to access to the same facilities as the majority. However in order to receive factual equality, States may have to support certain minorities additionally. In these cases, certain criteria, such as numbers, have to be met. Finally, non-discrimination implies that, if one minority community receives funds for education, other comparable communities should be allowed the same. ${ }^{75}$

\subsection{The Right to Freedom of Thought, Conscience and Religion}

\section{9:2.1 Jehovah's Witnesses in Greece}

In its reasoning on various cases of Jehovah's Witnesses in Greece, the Court established an interesting theory under Article 9 ECHR on the value of religious pluralism, including religion as a factor of individual identity, the limited margin of appreciation of States in relation to religious affairs and non-discrimination in relation to religion.

74. Belgian Linguistic Case, Case relating to certain aspects of the laws on the use of languages in education in Belgium, Judgement of the European Court on Human Rights, 23 July 1968, \&31. See, allso, Keller, 1998 , p. 54.

75 See, also, Keller, 1998 , p. 54. 
Kokkinakis v. Greece ${ }^{76}$ and Manoussakis and others w. Greece?

The applicants these cases were Jehovah's Witnesses. Kokkinakis was convicted for proselytism because he had tried to convert a neighbour. Manoussakis was convicted for the establishment of a place of worship for religious meetings and ceremonies without the necessary permission from the authorities. Both applicants complained that the arrest and conviction constituted a violation of their freedom of religion under Article 9 ECHR. In the Kokkinakis case, the Court expressed that freedom of conscience and religion and the need to secure religious pluralism are inherent features of a democratic society. It further argued that freedom of religion is a fundamental element of a person's cultural identity. "It is, in its religious dimension, one of the most vital elements that go to make up the identity of believers and their conception of life..." ${ }^{78}$ According to the Court, freedom of religion included the right to try to convince someone else, because, otherwise, the freedom to change one's belief would remain empty. In the Court's view, the conviction of the applicant constituted interference with Article 9. It was indeed prescribed by law to pursue the legitimate aim of protecting the rights and freedoms of others, but the Court was not convinced that the measures taken were necessary in a democratic society. ${ }^{79}$ The Court argued that, although States have a certain margin of appreciation, the facts of this case did not show that the conviction of the applicant was justified by a pressing social need. The measures taken were disproportionate and, accordingly, constituted a violation of Article 9.80

In the Manoussakis case, the Court formulated an important theory on the margin of appreciation in religious affairs. The applicants maintained that the restrictions imposed on Jehovah's Witnesses by the Greek authorities effectively prevented them from exercising their right to freedom of religion. The Greek government argued that the sanctions imposed on the applicants had not been motivated by the manifestation of their religion, but by their disobedience to the law, because they had failed to comply with an administrative procedure. ${ }^{81}$ The Court argued that there was interference with Article 9. This interference pursued the legitimate aim of protecting public order. However, it found the measures

76 Kokkinakis v. Greece, Application No. 14307/88, European Court of Human Rights, decision of 25 May 1993.

77 Monoussakis and others v. Greece, Application No. 18748/91, European Court of Human Rights, decision of 26 September 1996, Report of Judgements and Decisions 1996-1V, no. 17.

78. Kokkinakis w. Greece, 25 May 1993, \$31.

79 The Commission had already expressed that it was not proportionate to limit a fellow eitizen's right to speak when he discussed religion with his neighbour.

80 Kokkinakis v. Greece, 25 May 1993, \$31-49. In a comparable case, Larissis v. Greece, the Court found no violation of Article 9, because it concerned high-ranking efficers of the Greek Arr Force who tried to convert members of their staff, whereby the Court found these persons should be protected from pressure from their superiors. See Larissis v. Greece, Application No. 23372/94, $26377 / 95$ and 26378/94, European Court of Human Rights, decision of 24 february 1998, Report of Judgments and Decisions 1998-1, No. 65.

81 Manoussakis and others v. Greece, 26 September $1996, \$ 36-42$. 
incompatible with Article 9 because they were disproportionate. ${ }^{82}$ The Court argued that "[t]he right to freedom of religion...excludes any discretion on the part of the State to determine whether religious beliefs or the means used to express such beliefs are legitimate. ${ }^{\$ 833}$ The Court thereby limited the margin of appreciation by States with regard to freedom of religion. The Court found the conviction a disproportionate sanction, because of its direct effect on the applicants' freedom of religion. Accordingly, the Court concluded that Greece had violated Article $9 .^{8.4}$

\section{Thlimmenos v. Greece 8.5}

This case is interesting for its theory on non-discrimination. The applicant was a Jehovah's Witness who refused to serve in the Greek military for religious reasons and was accordingly found guilty of insubordination. Six years later the applicant's appointment as an accountant was rejected because of his criminal record even though he had passed the relevant exams. He complained that his rights under Article 14 in combination with Article 9 had been violated. He argued that the offence for which he had been convicted had been prompted by his religious beliefs, which was not a felony related to the purposes of an appointment as an accountant. The Court argued that the case fell within Article 9 ECHR and that therefore Article 14 could also be applicable. It asserted that the non-discrimination provision of Article 14 was also violated when States, without any objective or reasonable justification, failed to treat differently persons whose situations were significantly different: The Court stated that the State had a legitimate aim to ban certain offenders from the profession of accountant, but that a conviction for refusing to serve in the military on religious grounds could not be seen as a felony which undermined the profession of accountant. Excluding the applicant was, therefore, unjustified, because such a second sanction for the conviction would be disproportionate. Consequently, the Court concluded that there was no reasonable justification for not treating the applicant differently than other persons convicted for a felony, which led to a violation of Article 14 taken together with Article 9.

82 The Commission had also argued that it was disproportionate to classify the operation of a place of worship without the prior consent of the authorities as a criminal offence.

83 Manoussakis and others v. Greece, 26 September 1996, \$47.

84 Manoussakis and others v. Grece, 26 September 1996, \$3. In similar cases, the Court reconfirmed its decision in the Manoussakis case: In the case of Pentidis and others $v$. Greece and Tisavachidis $v$. Greece, the Court noted that a friendly settlement had been reached between the Greek authorities and Jehovalh's Witnesses concerning the establishment of a place of worship, but. it nevertheless referred to its decision in the Manoussakis case and the Kokkinakis case. See Pentidis and others v. Greece, Application No. 23238/94, European Court of Human Rights, decision of 9 June 1997, Report of Judgments and Decisions 1997-HII, no. 39; Tswachidis $v$. Greece, Application No. 28802/95, European Court of Human Rights, decision of 21 January 1999.

85 Thlimmenos w. Greece, Application No. 34369/97, European Court of Human Rights, decision of 6 April 2000. 


\subsubsection{The Appointment of Muslim Leaders and Religious Pliralism}

Serifv Greece ${ }^{86}$ and Hasan and Chaoush v. Bulgaria ${ }^{87}$

Both cases concerned a dispute over the appointment of Muslim religious leaders whereby the Court developed case law on the role of the State in relation to different religious communities. In these cases, the authorities of Greece and Bulgaria respectively acknowledged or appointed Muslim leaders, who did not have the approval of the whole Muslim community, because part of the community followed another Muslim leader. These leaders and several followers were forcefully removed from their offices by the authorities and convicted of carrying out religious activities without being entitled to do so. They complained that their religious liberties and the rights of their believers to choose their leadership freely had been unlawfully interfered with, which constituted a violation of Article 9 ECHR.

In the Serif case, the Court argued that the measures taken by the Greek authorities constituted interference with Article 9. The measures had the legitimate aim of safeguarding public order so as to protect persons whose legal relationships could be affected by religious leaders. However, it was undisputed that the applicant had the support of a part of the Muslim community. The Court asserted that the applicant could not be punished for acting as a religious leader of a group that voluntarily followed him. Such punishment would be incompatible with the demands of religious pluralism in a democratic society. The Court explicitly confirmed the value of religious pluralism and argued that, in democratic societies, the State does not need to take measures to ensure that religious communities are brought under unified leadership. In fact, the State should not oppose possible tension between different communities by eliminating pluralism, but should ensure that religious communities tolerate each other. The Court concluded that, in this case, there was no pressing social need to interfere with the applicant's right to freedom of religion. The measures taken were not necessary in a democratic society and, consequently, constituted a violation of Article $9 .{ }^{88}$

The importance of religious pluralism was confirmed in the case of Hasan and Chaoush v. Bulgaria. In this case, the Court found that the Bulgarian authorities had failed to remain neutral and had interfered with the freedom of the believers to manifest their religion. The Court recalled its reasoning in the Manoussakis case by stating that States have only a very limited margin of discretion to determine whether religious beliefs or the expressions thereof are legitimate. Furthermore, it recalled the Serif case by arguing that, in democratic societies, the State does not need to take measures to ensure that religious

86 Serif v Greece, Application No. 38178/97, Exuropean Court of Human Rights, decision of 14 December 1999.

87 Hasan and Chaoush v. Bulgaria, Application No. 30985/96. European Court of Human Rights, decision of 26 October 2000 .

88 Serif v. Greece, 14 December 1999, see $\$ 39,45,50,52-45$. 
communities are brought under unified leadership. The Court argued that State action favouring one leader of a diwided community, with the purpose of forcing the community to come under a single leadership, constituted interference with Article 9, since there was no explanation why preference should be given to one or the other leader. In this case, the Court also found that the interference was not prescribed by law, because the relevant Bulgarian law did not provide for substantive criteria for registration of, and changes in, leadership, and there were no procedural safeguards. The interference was therefore arbitrary and based on legal provisions that did not meet with the standards of clarity and forseeability. The Court concluded that Bulgaria had violated Article $9 .{ }^{89}$

\subsubsection{Rinual Slaughtering: the Case of Cha'are Shalom ve Tsedek v. France}

The case of Cha'are Shalom ve Tsedek v. France concerned a dispute on ritual slaughtering in relation to Articles 9 and 14 ECHR. The applicant's association was refused a permit for a special form of ritual slaughtering according to strict religious rules to prepare special kosher meat ('glatt'), because the organisation of the applicant was not considered to be sufficiently representative as a Jewish organisation. Such a permit had been granted to another religious body (ACIP), which represented the majority of French Jews. However, ACIP did not slaughter according to the rules of the applicant's organisation, which involved a thorough inspection of the lungs of slaughtered oxen or sheep. ${ }^{91}$

The applicant argued that the refusal of the permit could not be justified as pursuing the legitimate aim of protecting public health, since the ritual slaughters of the applicant's organisation complied with hygiene procedures comparable to the ACIP slaughters. Furthermore, it was argued that the applicant's association was, in fact, a religious body, despite the fact that it represented a minority of orthodox Jews. While the government might have legitimate reasons to keep close relations with the most representative organisations, the applicant argued that the State also has a duty to respect the rights of minority organisations. The French government argued inter alia that glatt meat was, in fact, available, because several butchers sold such meat from slaughterhouses controlled by the ACIP, and the shops of the applicant"s association obtained such meat from Belgium. ${ }^{92}$

The Court argued that ritual slaughtering constituted a rite and, as such, was covered by Article 9 ECHR. According to the Court, the refusal of the permit for ritual slaughtering did not automatically constitute interference with Article 9 ECHR. In fact, Article 9 ECHR would only be interfered with if the illegality of the

89 Hasan and Chaoush v. Bulgaria, 26 October 2000, see $78-79,84-89$ and $90-91$.

90 Chaáre Shatom ve Tsedek v. France, Application No. 27417/95, European Court of Human Rights, decision of 27 June 2000 .

91 Chäre Shalom ve Tsedek v. France, 27 June $2000, \$ 27-34$. The Commission had declared by 14 votes to 3 that France had violated Article 9 taken together with Article 14. See Chaáre Shalom ve Tsedek $w$. France, 27 June $2000, \$ 3$.

92 Chaáre Shalon ve Tsedek w. France, 27 June 2000, $\$ 58-62,65$. 
ritual slaughtering had made it impossible for ultra-orthodox Jews to obtain meat from animals slaughtered in accordance with their religious prescriptions. In fact, Jews belonging to the applicant's association could obtain such meat in Belgium and from various butchers serving under the auspices of the ACIP. It concluded by twelve votes to five that the refusal of the permit did not constitute interference with Article $9 \mathrm{ECHR}^{93}$ The Court further concluded, by ten votes to seven, that there had not been a violation of Article 9 taken together with Article 14, because the difference in treatment between the applicant's organisation and the ACIP was limited in scope and pursued the legitimate aim of avoiding the proliferation of associations that carried out the exceptional activity of ritual slaughtering. ${ }^{94}$

\section{Joint Dissenting Opinion}

Judges Bratza (UK), Fischbach (Luxembourg), Thomassen (Netherlands), TsatsaNikolovska (former Yugoslav Republic of Macedonia), Pantiru (Moldova), Levits (Latvia) and Traja (Albania) jointly submitted a dissenting opinion. They disagreed with the conclusion of the Court that there was no interference with Article 9 and no discrimination under Article 14 in this case. They principally argued that the mere fact that the State had granted one religious body a permit for ritual slaughtering did not discharge it from carefully examining other requests for such a permit, even if it did concern the same religion. The dissenters referred to the Manoussakis case, in which the Court had stressed the limited margin of appreciation left to States with regard to the delicate relation between the State and religions. They furthermore cited the Serif case by arguing that the role of the State in such matters is not to remove tension by eliminating pluralism, but to take all necessary measures to ensure that different religious communities tolerate each other. The dissenters disagreed with the argument that there had been no interference with Article 9 because the applicants could obtain their 'glatt' meat elsewhere. By denying the applicant's organisation the status of religious body and rejecting the permit for ritual slaughtering, the State had unjustifiably restricted the right to freedom of religion.

With regard to Article 14, the judges noted in their dissenting opinion that the "limited effect" of the interference and the "limited scope" of the difference in treatment were invalid arguments to presume that there was no discrimination. The dissenters argued that the fact that the applicant's organisation was a minority in the Jewish community did not automatically imply that it could not be a religious body. In fact, the applicant's organisation was in an analogous situation to the ACIP and the right to non-discrimination implied that States should not treat persons or communities in analogous situations differently without an objective and reasonable justification. The government explained the difference in treatment by referring to the protection of public health and public order. However, there was nothing to suggest that ritual slaughtering in accordance with the applicant's rules did not meet

93 Chadre Shalom ve Tsedek v. France, 27 June 2000, $\$ 72-84$.

94 Chadre Shalom ve Tsedek $v$. France, 27 June $2000, \$ 86-88$. 
the hygiene standards and the dissenters did not see how the granting of a permit for the applicant's organisation would threaten or undermine public order. They asserted that the refusal of a permit "....amounted to a failure to secure religious pluralism or to ensure a reasonable relationship of proportionality between the means employed and the aim sought to be achieved."

The Court formulated some interesting principles in these cases under Article 9 with regard to the protection of cultural identity. First of all, the Court considers religion to be an important aspect of the identity of a person, and has stated that freedom of religion is one of the fundaments of a democratic society. The Court, therefore, argued that the State's margin of appreciation with regard to freedom of religion is limited. It emphasised that Article 9 implies State abstention and respect, since freedom of religion deprives States of the discretion to determine whether a religion or the expression thereof is legitimate. ${ }^{95}$ However, it remains unclear from these cases to what extent Article 9 implies positive State obligations. The Court also valued religious pluralism and stated that, in order to remove possible tension between groups of one religion, States should not eliminate pluralism by bringing these different groups under single leadership. Instead ${ }_{3}$ it should make sure that various religious groups tolerate each other. ${ }^{96}$ It seems that the Court values religious pluralism as a factor or consequence of freedom of religion, whereby it acknowledges a collective dimension. Such religious pluralism implies that different religious communities and sub-communities can exist next to each other and that the State should interfere with their free development as little as possible. Since religion is one of the main aspects of cultural identity, these considerations are important for the protection of the cultural identity of a community.

With regard to non-discrimination, the Court confirmed the principle that not only should equal cases be treated equally, but also that different cases should be treated differently. ${ }^{97}$ To this principle, the Court added that the impact of the difference in treatment also plays a role, whereby limited impact would not constitute discrimination. ${ }^{98}$ Some members disagreed and argued that there should be a reasonable justification for treating similar cases differently, notwithstanding the impact of the measures taken. With regard to the protection of cultural identity it could reasonably be argued that extra protection, in other words different treatment, of certain communities is possible, based on the fact that their situation is different.

\subsection{The Right to Freedom of Expression: Cases of Kurds against Turkey}

The cases selected under Article 10 on the right to freedom of expression concern convictions of authors and journalists by the Turkish authorities in relation to the

95 See, inter alia, the Manoussakis case.

96 See, inter alia, the Serif case.

97 See, inter alia, the Thlimmenos case.

98 See the case of Cha'are Shalom we Tsedek v. France. 
situation of the Kurdish minority in Turkey. These cases concern the existence and acceptance of a minority community through newspapers or political parties, which indirectly concerns the protection of the cultural identity of the minority. These cases do not explicitly refer to the protection of the cultural identity of the applicants, but, more generally, concern cultural diversity and the means of expression of a minority community. The Court, however, did not address the issue whether or not the Kurds form a minority within Turkey. Furthermore, it did not establish a clear link between the right to freedom of expression and the protection of cultural identity. This is understandable, because the Court was bound to the facts of the cases and the provisions of the ECHR, and did not want to be involved in such a sensitive issue as the minority status of the Kurds in Turkey. Accordingly, the Court was not prepared to label the situation of the Kurds in Turkey as discrimination in relation to Article 14.

\section{Arslan and others $v$. Turkey ${ }^{99}$}

This case concerned the author of a book which, according to the Turkish government, had led to the uprising of the Kurdish population and to hatred and violence. The applicant was sentenced to one year and eight months imprisonment. In this case, the Commission had asserted that, in his book, the applicant had alleged that the Turkish State was oppressing the population of Kurdish origin and trying to destroy its identity through genocide, evacuation and massacres. ${ }^{100}$

The Court argued that the measures taken by the Turkish authorities constituted interference with Article 10. The measures were prescribed by law and in pursuance of legitimate aims, namely, the protection of national security and territorial integrity and the prevention of disorder and crime. The Court acknowledged the sensitivity of the security situation in south-east Turkey and the government's responsibility to prevent violence. However, it found that the interference was not necessary in a democratic society, because there was no pressing social need and the measures taken were disproportionate. The Court argued that freedom of expression included the right to engage in open discussion on difficult problems, such as those in Turkey, with a view to analysing, for example, the underlying causes of the situation or to expressing opinions on possible solutions. According to the Court, it was obvious that the book was not a neutrall description of historical facts and that, through his book, the applicant had intended to criticise the actions of the Turkish authorities and to encourage the population concerned to oppose it. Notwithstanding this, the Court found that there was little scope under Article 10(2) for restrictions on political speech or debate on

99 Arstan v. Turkey, Application No. 23462/94, European Court of Human Rights, decision of 8 July 1999. This case was taken together with several other cases: Polat $v$. Twkey, Application No. 23500/94, European Court of Human Rights, decision of 8 July 1999; Erdogadn and Mace v. Turkey, Application No. 25067/94, 25068/94, European Court of Human Rights, decision of \& July 1999.

100 The full text of the Commission's opinion is annexed to the judgement of the European Court. See, also, Arslan v. Turkey, 8 July $1999, \$ 43$. 
questions of public interest. It asserted that the applicant was a private individual who made his views public by means of a literary work rather than through the mass media, which limited their potential impact on national security, public order and territorial integrity. The Court also noted that, although certain passages in the book painted an extremely negative picture of the population of Turkish origin, they did not constitute an incitement to violence, armed resistance or an uprising. Finally, the Court was struck by the severity of the penalty imposed on the applicant, which was also a factor to be taken into account when assessing whether the interference was proportionate. The Court concluded unanimously that the applicant's conviction was disproportionate to the aims pursued, and constituted a violation of Article $10 .^{101}$

\section{Özgür Gündem v. Turkey, ${ }^{102}$ Erdogu v. Turkey, ${ }^{103}$ Sener v. Turkey, ${ }^{104}$ and Ibrahim Aksoy v. Turkey. ${ }^{10 s}$}

The cases of Ozgür Gündem v. Turkey, Erdogu v. Turkey and Sener v. Turkey concerned editors of newspapers and reviews which published articles reflecting Turkish-Kurdish opinions, which were considered propaganda against the Turkish State. The case of Ibrahim Aksoy v. Turkey concerned a Turkish citizen and politician of Kurdish origin who was convicted for disseminating separatist propaganda in a speech, an article and a leaflet. In none of these cases did the Court find sufficient evidence that the applicants had intended to incite violence or an uprising or any other form of rejection of democratic principles. The Court concluded in all these cases that Turkey had violated Article 10 , because the interference with this provision was disproportionate to the legitimate aim of preventing disorder and crime. The Court attached much value to the freedom of the press and the right of the public to have access to different opinions and not just to those generally accepted. Although several articles were highly critical of the Turkish State, and could even be considered provocative in calling for a separate Kurdistan; the public had the right to be informed of different opinions and perspectives of the situation. Furthermore, in the last case, the Court emphasised the role of political parties and their programmes in a democratic society, even if these programmes call for a change of the organisation of the State, providing that they do not damage democracy itself. Here, however, the Court did not find a violation

101 Arstom v. Thrkey, 8 July $1999, \$ 44-50$.

102 Ozgur Gundem V. Tukey, Application No. 23144/93, European Court of Human Rights, decision of 16 March 2000.

103 Erdogu v. Turkey, Application No. 25723/94, European Court of Human Rights, decision of 15 June 2000.

104 Sener *. Threy, Application No. 26680/95, European Court of Human Rights, decision of 18 July 2000. In this case, the Court also found a violation of Article 6, which falls outside the scope of this survey.

105 Ibrahim Aksoy? v. Turkey, Application No. 28635/95, 30171/96, European Court of Human Rights; decision of 10 October 2000 . 
of Article 14, ${ }^{106}$ since the aim of preventing disorder was legitimate and the measures did not show a difference in treatment because of the applicant's national origin or association with a national minority.

\subsection{The Right to Freedom of Peaceful Assembly and the Freedom of Association}

\subsubsection{Political Parties in Turkey}

United Communist Party of Turkey (TBKP) v. Turkey ${ }^{107}$ and Freedom and Democracy Party (ÖZDEP) v. Turkey. ${ }^{108}$

The applicants in the cases of United Communist Party of Turkey (TBKP) v. Turkey and Freedom and Democracy Party (ÖZDEP) v. Turkey were representatives of political parties that were dissolved by the Turkish Constitutional Court, because the aims set out in their programmes were considered to undermine the territorial integrity and secular nature of the Turkish State. The TBKP, for example, referred in its constitution and programme to the Turkish nation as well as the Kurdish nation. The OZZDEP referred in its programme to a separate Kurdish people in Turkey and portrayed the Kurds as an oppressed people whose democratic rights were completely ignored. According to the Turkish Constitutional Court, there were no minorities in Turkey others than those acknowledged in the Treaty of Lausanne and the friendship treaty between Turkey and Bulgaria. All persons living on Turkish territory formed a union by their common culture, and the Turkish Constitution did not allow for distinctions to be made between minorities and majorities. Accordingly, persons of Kurdish ethnic origin enjoyed the same rights as other Turkish citizens. The Constitutional Court argued that the Constitution did not deny the existence of Kurdish identity and Kurds were not forbidden to express their Kurdish identity. For example, the Kurdish language could be used on all private premises, in workplaces, in the press and in works of art and literature.

According to the European Court, political parties fall under the fireedom of association as laid down in Article 11 because they are : a form of association essential to democracy. This implied that States have only a limited margin of appreciation in this respect. The Court argued that the fact that these political parties had been dissolved and their leaders banned from activities in any other political party constituted interference with Article 11. In fact, both parties had already been dissolved before they could even start their activities and the accusations were based on their constitutions and programmes. In both cases, the Court considered Article 11 in the light of Article 10 on freedom of expression,

106 Article 14 was not raised in the Erdogu case and the Sener case.

107 United Communist Party of Turkey w. Turkey, Application No. 19392/92, European Court of

Human Rights, decision of 28 October 1996, Report of Judgmints and Decisions 1998-1, No. 62.

108 Freedom and Democracy Party (OZZDEP) v. Turkey, Application No. 23885/94, European Court of

Human Rights, decision of 8 December 1999. 
which were both considered fundaments of a democratic society. It argued that there could be no justification for limiting the activities of a political party solely because it sought public debate on the situation of a part of the population and wished to take part in the political decision-making process. While the Court recognised the State's responsibility in the fight against terrorism, it could not find any call for the use of violence, uprising or any other form of rejection of democratic principles in either programmes. Although there was a reference to the right of self-determination of national and religious minorities in the programme of $O Z D E P$, the Court did not find this an encouragement for people to seek separation from Turkey. The Court expressed its awareness that behind words there might be violent actions, but, in the absence of any activity of both parties, the reasoning by the authorities that they were responsible for terrorist acts in Turkey was not justified. The Court concluded that the measures were disproportionate and that they, therefore, constituted a violation of Article 11 ECHR. ${ }^{109}$

\section{Welfare Party (Refah Partisi) v. Turkey ${ }^{\| 10}$}

The case of the Welfare Party (Refah Partisi) v. Turkey also concerned the prohibition of a political party in Turkey. Here the Court found no violation of Article 11. The Welfare Party, established in 1983, was dissolved in 1997 because the Turkish authorities found it incompatible with a democratic society. It considered the Welfare Party a centre of activities against the principle of secularism reflected in the party's objectives such as the institution of Sharia law and a theocratic regime. The party denied the allegations and emphasised that it had always respected secularism and did not seek the establishment of a totalitarian State:

The Court reaffirmed that States have a narrow margin of appreciation in the area of the dissolution of political parties, because pluralism of ideas and parties is an inherent element of democracy. The Court argued that the measures taken by the Turkish authorities were prescribed by law and pursued the legitimate aim of protecting national security and the rights and freedoms of others. It asserted that political parties are, in principle, protected under Article 11 even if they are striving for changes in legislation or in the legal or constitutional structure of the State. However, such parties had to comply with two criteria: the means used have to be democratic and lawful, and the proposed changes have to be compatible with fundamental democratic principles. Consequently, political leaders who incite others to use violence or support claims that are incompatible with the rules of

109 In a similar case of the Socialist Party and others $v$. Turkey, the Court reaffirmed its reasoning concerning the importance of political parties and the right to freedom of expression as essential elements of democracies and again found a violation of Article 11. See the Socialist Party and others v. Turkey, Application No. 21237/93, European Court of Human Rights, decision of 25 May 1998, Report on Judgments and Decisions 1998-III, No. 75.a.

110 Welfare Party (Refah Partisi) and others w. Turkey, Application Nos. 41340/98, 41342/98, $41343 / 98$ and $41344 / 98$, decision of 31 July 2001. 
democracy, for example, by suppressing the rights and freedoms of others, could not rely on the protection of the ECHR. ${ }^{\text {In }}$

In this case, the Court found that the measures were taken to meet a pressing social need and, as such, they were necessary in a democratic society, because severall leaders of the Welfare Party had openly declared their intention to establish a plurality of legal systems based on difference in religious belief. The Court found this incompatible with the ECHR because it would deny the State's role in guaranteeing individual rights and freedoms and in impartially organising the existence of different religions in a society. It would oblige individuals to follow the rules of the religion instead of the rules laid down by the democratic State. Besides, such difference in the treatment of individuals would infringe upon the non-discrimination rule of the ECHR. ${ }^{12}$ The applicants also intended to introduce Islamic law (the Sharia), a system of law that the Court described as clearly diverging from the Convention's values, especially in relation to its criminal law and procedure, its rules on the status of women, and its intervention in private and public life according to religious precepts. The Court argued that within the Sharia there was no room for principles such as pluralism in the political sphere or the evolution of public freedoms. ${ }^{13}$ Accordingly, the Court considered the actions and ideas of the Welfare Party to be incompatible with the norms of the ECHR, and coneluded that Turkey had justly taken steps to protect its democratic regime and had not violated Article $11 .{ }^{114}$

\section{Dissenting Opinion}

Judges Führmann (Austria), Loucaides (Cyprus) and Bratza (UK) wrote a dissenting opinion in which they argued that Turkey had, in fact, violated Article 11 , because the measures taken were a disproportionate restriction on the applicants' freedom of association. They compared the case with the earlier cases against Turkey conceming the dissolution of political parties as described above. They concluded that, while the earlier cases had concerned rather small parties that were dissolved in their infancy, the Welfare Party was a larger and more powerful party that had existed for nearly fourteen years before it had been dissolved. Furthermore, the dissolution was mainly based on public statements and actions by leaders of the party and not, as in the other cases, on the constitution and programme of the party. In fact, no evidence could be found in these documents that the party advocated the establishment of a theocratic State that would undermine the secular character of the State or would use violent or undemocratic means to replace the existing constitutional structure in Turkey. The dissenters emphasised that several individual actions had been the reason to dissolve a whole party, while Turkey had not taken action against these individuals themselves.

111 Welfare Party v. Turkey, 31 July $2001,842-44,46-47$

112 Welfare Party $y$. Turkey, 31 July $2001,870$.

113 Welfare Party v. Turkey, 31 July $2001, \$ 72$.

114 Welfare Party w. Turkey, 31 July 2001, \$81 and 84. 
Furthermore, they found that most actions by these individual did not pose a genuine threat to Turkish secularism, because they had been carried out many years before or by people who had not been leaders of the party. As such, they could not be sufficient justification for dissolution of the Party. The dissenters concluded that evidence was lacking to suggest that the party had taken steps to realise political aims that would have undermined the secular society or caused violence or religious hatred or any other threat to the Turkish legal and democratic order.

These cases reflect an interesting development in the Court's reasoning. Where in the cases concerning the Kurdish Parties the Court had found a violation, in the case of the Welfare Party, it concluded that no violation had occurred. While, in the Kurdish cases, the Court based itself on the programme of the party and argued that it could not anticipate what possible action lay ahead, in the case of the Welfare Party, it relied on concrete action by party members and left the party's programme aside It appears, however, that the case of the Welfare Party brought the Court to the boundary of Articles 10 and 11 in relation to the dissolution of political parties. In the cases of the Kurdish Parties it had already pointed out the fact that different opinions expressed through political parties were a valuable element of demacracy, as long as they did not reject democratic principles. The Court formulated the two criteria set out above to guarantee that freedom of expression and freedom of association were not misused to destroy the fundaments of the democratic State. It is striking that, in the case of the Welfare Party, the Court involved itself in a debate on religious fundamentalism and on the introduction of Sharia law, which it explicitly rejected as being contrary to the ECHR. The dissenting opinion pointed out that the programme of the party did not suggest a rejection of secularism or democratic values, and that most of the actions on which the Court based its judgement had been carried out a long time ago. However, the Court argued that this party could, in fact, be a threat to the Turkish democracy. The case shows the sensitive issues the Court has to deal with in relation to freedom of religion, expression and association. Here the Court might have invoked more severe rules, because it concerned not just a religious body, but one that was also politically active. As a political party, the Welfare Party was involved in the structure and organisation of the State. In my view the Court was correct that there were compelling reasons justifying the prohibition of the Welfare Party.

\subsubsection{Cultural Organisations}

The case of Sidiropoulos and others $v$. Greece ${ }^{115}$ concerned the refusall of Greek courts to register a Macedonian cultural organisation, 'Home of the Macedonian Civilisation', because it was suspected of undermining the territorial integrity of Greece. The Greek government argued that there were strong reasons behind this

115 Sidiropoulos and others v. Greece, Application No. 26695/95, Exropean Court of Human Rights, decision of 10 July 1998, Report on Judgments and Decisions 1998-IV, No. 79. 
decision, such as the maintenance of national security, the prevention of disorder, and the aim to uphold of Greek culture, its history and its symbols. The applicants argued that their freedom of association under Article 11 had been violated. The Court noted that only convincing and compelling reasons could justify restrictions of the freedom of association. ${ }^{116}$ It could not find evidence that the applicants had wished to undermine the territorial integrity or national security of Greece. The organisation's aim was to encourage consciousness of belonging to a minority and the preservation and development of the culture and traditions of that minority, which could not be seen as a threat to a democratic society. The applicant had not challenged the Greek identity of the Greek province of Macedonia, but had claimed that the Macedonian minority there was oppressed. The Court argued that "...the existence of minorities and different cultures in a country is a historical fact that a democratic society has to tolerate and even protect and support according to the principles of international law." 17 The Court referred to the Document of the Copenhagen Meeting of the Conference on the Human Dimension of the CSCE (Section IV, 29 June 1990), which Greece had signed, and argued that minorities are allowed to form associations to protect their cultural and spiritual heritage. The Court acknowledged, however, that it could be possible that such organisations, under the cover of legitimate aims, would engage in illegal activities. This, however, could only be proven by factual activities, which were absent in this case because the organisation had never been able to take any action. The Court concluded that the refusal to register the applicant's organisation was disproportionate to the aims pursued by Greece and had, therefore, constituted a violation of Article 11. 118

It is interesting to see that, in this case, the Court was willing to recognise the special position of the Macedonians as a minority in Greece, albeit in abstract terms, whereas, in the case of the Kurds, it was unwilling to go so far. In this case, the Court stated that the existence of minorities is a historical fact and that minorities are entitled to set up organisations to protect and develop their own culture. In short, cultural associations, which may form an important aspect of cultural identity, are protected under Article 11.

In another case concerning cultural organisations, the Court upheld its general line of reasoning. In the case of Stankov and the United Macedonian Organisation Ilinden v. Bulgaria, the Court decided that Bulgaria had violated Article 11 by prohibiting meetings of llinden. ${ }^{119}$ The purposes of llinden were, according to its

116 Sidiropoulos and others v. Greece, 10 July $1998, \$ 40$.

117 Sidiropoulos and others v. Greece, 10 July 1998, 41 and 44.

118 Sidiropowlos and others v. Greece, 10 July $1998, \$ 44,46$ and 47.

119. The organisation was also refused registration in 1990, but the Commission had declared inadmissible events between 1990 and 1993. Furthermore, several events relating to this case were still pending in different applications before the Court. Accordingly, this case only concerned the applicant's complaint that the authorities prohibited their meetings in 1994, 1995 and 1997. See 
programme, to unite Macedonians in Bulgaria on a regional and cultural basis and to achieve the recognition of the Macedonian minority in Bulgaria. The Court followed the Sidiropoulos case and assessed that minority consciousness cannot in itself justify interference with Article 11. The decisive factor is whether there has been a call for the use of violence of any other rejection of democratic principles. It concluded that there was no such real foreseeable risk, and, consequently, that Bulgaria had overstepped its margin of appreciation, because the measures that Bulgaria had taken were not necessary in a democratic society. ${ }^{120}$ Because of the limitation of the case decided by the Commission, the Court did not have to deal with the issue of whether or not the Macedonians were a minority, or with the purposes of the organisation itself. It could strictly restrain itself to the assessment of the prohibition of the meetings.

In a similar case of Gorzelik and others v. Poland, ${ }^{21}$ the Court argued that there had been no violation of Article 11. In this case, the Court had to consider the purposes of the organisation to assess whether they were truly of a cultural nature. The applicants were Polish citizens of Silesian origin who wanted to have their organisation, the 'Union of People of Silesian Nationality', registered. The aims of the Union were, according to its memorandum, inter alia, the awakening and strengthening of the national consciousness of Silesians, the restoration of Silesian culture and the protection of the ethnic rights of persons of Silesian nationality. However, the crucial problem in this case was paragraph 30 of the memorandum, in which it was stated that the Union was an organisation of the Silesian national minority. This paragraph together with the name of the organisation were the main reasons that registration was refused. The State argued that registration would imply recognition of the Silesians as a national minority, which implied special minority rights guaranteed by Polish law. These rights did not only lie in the cultural field, but the Polish Law on Parliamentary Elections laid down that electoral committees of registered organisations of national minorities have the right to be exempted from the 5 percent threshold of votes required to participate in the distribution of seats in Parliament. The Polish authorities did not consider the Silesians as a national minority but as an ethnic group of Poles. It found the name of the organisation to be misleading to the general public. Moreover, the authorities argued that it would have serious consequences for the Polish society, because if Silesians were granted the status of a national minority through the registration of this organisation, other ethnic groups of Polish citizens might wish the same. The State admitted that there was no other procedure in Poland for recognition as a national minority than the registration of associations. Apart from this, several

Stankov and the United Macedonian Organisation Ilinden v. Bulgaria, Application Nos. 29221/95 and 29225/95, European Court of Human Rights, 2 October 2001, $\$ 5 \%$.

120. Stankow and the United Macedonian Organisation IVinden v. Butgaria, 2 October $2001, \$ 111-112$.

121 Gorzelik and others v. Poland, Application No. 44158/98, European Court of Human Rights,

Decision of 20 December 2001. 
communities, such as Germans, Ukrainians, Lithuanians, Slovaks and Czechs, had been recognised in bilateral treaties on friendly co-operation. The authorities emphasised that had the organisation changed its name and removed paragraph 30 of its memorandum, it would have been registered without any difficulty. The applicants claimed that their memorandum did not suggest that they wanted to obtain recognition as a national minority or that they wished to benefit from privileges granted to national minorities. They argued there was no evidence that their intentions were different from those declared.

The Court argued that the refusal to register the association constituted interference with Article 11. This interference was prescribed by national law and pursued the legitimate aim of protecting the rights and freedoms of others. The Court refused to decide on the question of whether or not the Silesians are a national minority in Poland. However, it did notice that, if communities were not recognised through a bilateral treaty, they could only obtain indirect recognition through the registration of associations. Although the Court found this a lacuna in the Polish law, it did not find that this, as such, had consequences for the rights in Article 11. The Court further assessed that both the disputed paragraph of the memorandum and the name of the association gave the impression that, in the future, members of the association might, in addition to the other purposes, aspire to stand for election. The applicants could have dismissed the worries of the authorities by changing the name and removing the disputed paragraph. These measures would not have prevented the association from achieving its objectives. Accordingly, the Court found no violation of Article $11^{123}$

Although it concerned a cultural organisation with allegedly similar purposes as those dealt with in the Sidiropoulos case and the Stankov case, the Court found no violation. The possible consequences of registration and recognition as a national minority, including special legal guarantees, proved to be decisive. The applicants denied that they aimed at recognition as a national minority or that they aspired to these privileges. However, they refused to make changes in the name and the memorandum. As these changes would not have harmed its functioning in the protection and promotion of the Silesian culture, it rightly led to the suspicion that the organisation might have more in mind than just the awakening and strengthening of the national consciousness of Silesians. The Court refrained from discussing whether or not the Silesians were a national minority. This question was left to the State. In this respect, it is interesting to note that the Ilinden organisation in the Stankov case referred to the recognition as a 'national minority' in its statute and programme even more explicitly. However, in the Stankov case, the Court did not have to decide on this matter, because the scope of the case was limited to the prohibition of certain meetings. 


\subsection{The Right to Respect for Private Life and Family Life, Home and Correspondence}

While the above-mentioned cases show the potential of certain ECHR provisions for the protection of (aspects of) cultural identity, Article 8 ECHR on respect for private life and the home appears to be more directly linked to cultural identity with regard to the protection of land rights. As argued in previous chapters, land rights play an important role in the protection of the cultural identity of communities, especially of indigenous peoples. The European Court has issued several interesting judgments with regard to land, whereby, in some cases, it explicitly referred to the protection of the cultural identity of a community.

The case of $G$. and E. v. Norway ${ }^{124}$ concerned a conflict between indigenous and modern uses of land. The Norwegian authorities had planned the building of a water dam and a hydro-electric power station in a valley traditionally used by the Sami for reindeer herding, fishing and hunting. ${ }^{125}$ The Commission argued that, although the building of the dam interfered with the private life and traditional activities of the Sami, this interference was limited to the loss of a comparatively small piece of land. The Commission concluded that the interference was justified as being both in accordance with the law and necessary in a democratic society in the interest of the economic well-being of the country: ${ }^{126}$

Although it found no violation, the Commission's discussion shows the potential of Article 8 in relation to the protection of the cultural identity of communities. In its reasoning, the Commission recognised that the applicants belonged to a minority community that had, for centuries; been engaged in reindeer herding, fishing and hunting, which demanded a great amount of space. In fact, the applicants had argued that the loss of their land would mean loss of their identity. ${ }^{127}$ The Commission rejected the alleged violation of Article 14 on non-discrimination by arguing that the ECHR did not guarantee special rights for minorities and that the applicants were not treated in a discriminatory manner and were not forced to abandon their traditional lifestyle. However, the Commission argued that disrespect of the particular lifestyle of minorities might raise an issue under Article $8 .^{128}$ The Commission acknowledged the collective dimension in arguing that under Article 8 "...a minority group is, in principle, entitled to claim the right to respect for the particular lifestyle it may lead as being 'private life', 'family life' or 'home'.,"129 The Commission thereby connected Article 8 with the protection of a particular lifestyle or cultural identity.

$124 G$ and E. v. Norwoy, Application Nos. 9278/81 and 9415/81, European Commission on Human

Rights, decision of 3 October 1983 , Decisions and Reports, vol. 35 (1984), pp. $30-45$.

125 The so-called Alta Dam case; for more details, see Chapter 11 on the Sami, section 7.2.

$126 G$ and $E$. Norway, 3 October 1983 , p. $36, \$ 2$.

$127 \mathrm{G}$ and $E$. Norwa, 3 October 1983, pp. 34-35, \&4.

128 G. and E. v. Norway, 3 October 1983, p. $35, \$ 1$ and p. $38, \$ 7$.

$129 G$ and E n Norwo, 3 October 1983, p. 35, $\$ 2$. See, also, Scheinin, 2000, pp. 174-175. 


\subsubsection{Gypsy Cases: the Right to Respect for Home in Relation to Cultural Identity}

Under Article 8, the Court has dealt with several cases concerning gypsy families in the United Kingdom, which were not allowed to camp on a certain piece of land. In these cases, the Court made a remarkable link between the traditional way of life of the gypsies, which included living in caravans, and respect for their home and private life. The first case on this issue was the Buckley case, decided by the Court in 1996, on which the Commission had expressed a different view: The other more recent judgements concern five similar cases decided by the Court in January 2001: the cases of Chapman, Beard, Coster, Lee, and Jane Smith. These cases are dealt with in more detail, because they offer such interesting links with cultural identity.

\subsubsection{Buckley v. the United Kingdom ${ }^{130}$}

In Buckley $v$. the United Kingdom, the applicant was a British citizen of gypsy origin, who complained that her rights under Articles 8 and 14 ECHR had been violated. ${ }^{131}$ For most of her life she had travelled, but then she had decided to live on a permanent spot, because travelling with three young children was too hard and the children needed to attend school. The applicant indicated that she would pick up her travelling life in the future and pass on this tradition to her children. She presently lived in a caravan with her children on land owned by her. This piece of land was part of six neighbouring sites, all occupied by gypsies among which was one owned by her sister. Permanent planning permission had been given on one of the plots, her sister's plot enjoyed temporary permission, while the other sites, which included that of the applicant, had no planning permission and were subject to enforcement procedures. The applicant's planning permission had been refused for mainly two reasons: firstly, it was argued that adequate and sufficient provisions had been made for gypsy caravans elsewhere in the area. However, according to the applicant; the alternative accommodation was not suitable because criminal activities and fights had taken place there. The second argument was that the planned use of the land would detract from the rural and open quality of the landscape, and would destroy the character and appearance of the countryside. ${ }^{132}$ The Commission had concluded, by seven votes to five, that the UK had, in fact, violated Article 8. It argued that gypsies following a traditional lifestyle required special consideration in planning matters and that, in this case, a proper balance

130 Buckley v. The United Kingdom, Application No. 20348/92, European Court of Human Rights, decision of 25 September 1996, Reports of Judgments and Decisions 1996-1V, no. 16.

131 With regard to Article 1.4, the Court argued that it did not appear that the applicant had, at any time, been punished or treated unfavourably for trying to follow a traditional gypsy lifestyle. In fact, the rellevant national policies were aimed at enabling gypsies to provide for their own needs. Accordingly the applicant could not claim to be a victim of discrimination and the Court held, by eight votes to one, that there had been no violation of Article 14 taken together with Article 8. See Buckley $v$. The United Kingdom, 25 September 1996, 86-89.

132 Buckley $v$, the United Kingdom, 25 September 1996, \$ 7-27. 
between the interests of the community and those of the applicant had not been achieved. According to the Commission, the applicant had no alternative location, because the site close by was unsuitable, and private sites were rarely available and expensive. ${ }^{133}$

The Court unanimously rejected the Government's argument that Article 8 concerning respect for the applicant's home was only applicable to a legally established "home" and decided that Article 8 was applicable. The Court also referred to the fact that the case involved the traditional gypsy lifestyle of living in caravans and travelling, which might concern the applicant's 'private life' and 'family life'. However, in the end, the Court merely focused on the right to respect for home and found it unnecessary to decide whether the case also concerned private and family life. ${ }^{1.34}$

The Court argued that the measures constituted an interference with Article 8 (1) which was in accordance with national law. Furthermore, the measures taken pursued the legitimate aim of public safety, the preservation of the environment and public health. The Court also had to determine whether the interference was in accordance with Article $8(2)$ as being necessary in a democratic society, in other words, if there was a pressing social need and whether it was proportionate to the aim pursued. ${ }^{135}$ According to the Court, national authorities have a wide margin of appreciation in the case of town planning, since they are best situated to evaluate local needs and conditions. The generall interest should, however, be properly balanced against the applicant's right to respect for her home. The Court concluded that the applicant had enjoyed sufficient procedural safeguards within the regulatory framework to protect her interests. It concluded that the special needs of the applicant as a gypsy with a traditional lifestyle were sufficiently taken into account. ${ }^{136}$

The Court also argued that there was alternative accommodation available. This accommodation might not be as satisfactory as the home the applicant had now established against the legal requirements, but "... Article 8 does not necessarily go so far as to allow individuals" preferences as to their place of residence to override the general interest." 137 Finally, the Court alleged that the applicant had not been severely punished, since she had not been forcibly evicted and had had to pay only small fines. The Court concluded that the applicant's interests were properly taken into account. The means employed were not disproportionate and the State had not overstepped its margin of appreciation. Accordingly, the Court, different from the Commission, held, by six votes to three, that the UK had not violated Article $8 .^{138}$

133 Buckley v. the United Kingodom, 25 September 1996, \$ 71-73.

134 In later cases, the Court did include private life and family life in the assessment of the case. See the Chapman case dealt with below.

135 Buckley v. the United Kingdam, 25 September 1996, \$51-70.

136 Bucktey v, the United Kingdom, 25 September 1.996, \$74-80.

137 Buckley $v$, the United Kingdom, 25 September 1996, \$ 81-82.

138 Buckley $v$, the United Kingdom, 25 September 1996, \& 81-85. 


\section{Dissenting Opinions}

Three judges wrote a (partly) dissenting opinion in which they argued that they would find a violation of Article 8, based on the specific ethnic background of the applicant. ${ }^{139}$ Judge Repik (Slovakia) argued, however, that the case had never been considered in terms of the right of the applicant to respect for her home, or the importance of that right based on her financial and family situation. No account had been taken of the possible consequences for the applicant and her children if they were evicted from their land, which would include uncertainty as to where to live and the possibility of no education for her children. Repik found that the Court had been too hasty in invoking the State's margin of appreciation. Furthermore, he disagreed with the reasoning of the Court that there were alternative sites and that Article 8 could not take into account individual preferences as to the place of residence. The gypsy site close by was unsafe for her and her children. Official sites were not an option, since the applicant wished to travel during school holidays, a legitimate objective given the traditional way of life of gypsies, and she could not be sure of a vacant place on returning from her travels. Finally, the fact that at that time, she had only been punished by small fines and was not forcibly evicted from her land did not mean she would not face prosecution and more severe measures in the future.

Judge Lohmus (Estonia) also asserted that the UK had violated Article 8. He referred to a resolution of the Committee of Ministers that noted the need to safeguard the cultural heritage and identity of nomads. ${ }^{140}$ He asserted that, in this case, it had been argued that the applicant, as a gypsy, should receive the same treatment as other members of the community. However, in order to achieve factual equality of minorities, different treatment may be necessary to preserve their special life style and cultural heritage.

Judge Pettiti (France) argued that there had been a violation of Article 8 and Article 14. He alleged that the ECHR could provide a remedy for the former disrespect and non-recognition of the gypsy culture by imposing positive obligations on States to ensure that fundamental rights were guaranteed without discrimination. According to Pettiti, gypsies were discriminated against and suffered from disproportionate government measures. He gave the example that a British citizen who was not a gypsy who wished to live on his land in a caravan would not have had any difficulties, although it might be considered unorthodox. Special requirements relating to quality of landscape and environmental protection were only used against gypsies. Pettiti further disagreed that public safety, economic well-being and health protection had been legitimate aims in this case, and asserted that the alternative accommodation close by was not suitable. Pettiti concluded that the harassment and alleged safety measures taken against the applicant were disproportionate and were unnecessary in a democratic society.

139 See, also, Keller, 1998, p. 52.

140 Committee of Ministers Resolution (75)13 containing recommendations on the soctal situation of nomads in Europe, 245 th meeting, 22 May 1975. 


\subsubsection{Chapman v. the United Kingdom ${ }^{1 / 1}$}

Comparable to the Buckley case, the Chapman case concerned the refusal of a planning permission for a gypsy family to camp or build a bungalow on land owned by them. The applicant was a gypsy who, after several years of travelling wished to settle in a permanent place. She and her family had been on a waiting list, but had never been offered a permanent site. As a consequence, they had been moved constantly, which had had a severe impact on the health of the family members and on the education of the children. In the end, the family decided to buy a piece of land with the intention of living on it in their caravan. The authorities refused to give planning permission and the family returned to a nomadic life, which meant that the children could no longer attend school. ${ }^{142}$ The applicant claimed that the planning and enforcement measures taken against her violated her rights under inter alia Article 8 and Article 14. The Commission had expressed the opinion that there had been no violation of these rights. ${ }^{143}$

With regard to the alleged violation of Article 8, the Court recalled its decision in the Buckley case and emphasised that it was "... in the interest of legal certainty, forseeability and equality before the law, that it should not depart, without good reason, from precedents laid down in previous cases." "According to the Court, this case did not just concern respect for the applicant's "home'. In fact, the measures had a wider impact and affected her ability to maintain her identity as a gypsy and to lead her private and family life in accordance with her tradition. Accordingly, the Court maintained, as distinct from the Buckley case, that not only the applicant's right to respect for her home, but also for her private life and family life were at stake in this case. ${ }^{145}$ The Court hereby referred to the protection of the individual identity of the applicant, while, at the same time, recognising the collective dimension of this identity. The Court further argued that the measures taken by the authorities constituted an interference with Article 8(1). The Court found that they were in accordance with national law and pursued the legitimate aim of protecting the rights of others by preserving the environment. It now had to determine whether the interference was necessary in a democratic society. ${ }^{146}$

141 Chopman v the United Kingdon, Application No, 27238/95, European Court of Human Rights, decision of 18 January 2001 . The Chapman case was one of the five cases concerning applications the refusal of the government to provide gypsy families with planning permission. The circumstances in each case differed slightly, but the Court came to the same outcome in each case. The Chapman case was considered the 'leading case' and will, as a result, be dealt with in detail. The other four cases will be dealt with more briefly.

142 Chapman w the United Kingdom, 18 January $2001, \$ 10-18$.

143 The wotes were: 18 to 9 on Article eight and 18 to 9 on Article fourteen. See Chapmow w the United Kingdom, 18 January $2001, \$ 3-4$.

144 Chapman v. the United Kingdom, 18 January $2001, \$ 70$.

145 Chapman $v$, the United Kingdom, 18 January 2001, $\$ 71-74$.

146 Chapman $v$ the United Kingdom, 18 January 2001, \$ 75-82. 
The Court again referred to the Buckley case by stating that, in cases of site planning, the national authorities enjoy a wide margin of appreciation. The interesting part of the Chapman case is that, after citing the relevant national law of the UK, the Court inserted several relevant regional texts to examine whether certain developments in relation to the ECHR provisions had taken place, and whether there was European consensus on the protection of minorities. It quoted, inter alia, Articles 1, 4 and 5 of the Framework Convention, which concern the right of persons belonging to minorities to equality before the law and to protection of their religion, culture, language and identity. The Court noted that the UK had signed and ratified the Framework Convention and had, on that occasion, established that, for the UK, gypsies fell under the definition of a national minority. The Court also referred to Recommendation 1203 (1993) of the Parliamentary Assembly of the Council of Europe on Gypsies in Europe, which emphasised that gypsies, as one of the very few non-territorial minorities in Europe, need special protection, including rights in relation to their language and culture. The Court also noted the General Policy Recommendation No. 3 (1998) of the European Commission against Racism and Intolerance against Roma/Gypsies and a Resolution by the European Parliament of the EU on the situation of Gypsies in the Community (1994), both calling upon States to improve the situation of gypsies. Protection of minorities had, in fact, become one of the preconditions for accession to the EU. Finally, the Court quoted OSCE documents, where the situation of the Roma and Sinti had become a standard item on the agenda of the Section Human Dimension. On 7 April 2000, the High Commissioner for National Minorities had published a report on the situation of the Roma and Sinti in the OSCE area, in which it specifically criticised the situation of gypsies in the UK because of the insecurity in respect of housing. ${ }^{147}$

By citing international instruments on minorities, especially the Framework Convention, the Court observed that:

\begin{abstract}
"There may be said to be an emerging international consensus amongst the Contracting States of the Council of Europe that recognises the special needs of minorities and the obligation to protect their security, identity and lifestyle...not only for the purpose of safeguarding the interests of the minorities themselves, but to preserve a cultural diversity of value to the whole community."
\end{abstract}

Here, the Court again referred to the individual as well as the collective dimension of the protection of cultural identity. However, the Court continued by stating that there was no concrete consensus among States on which State action would be desirable in a given situation. The Court noted: 
"The Framework Convention, for example, sets out general principles and goals, but signatory States were unable to agree on means or implementation. This reinforces the Court"s view that the complexity and sensitivity of the issues involved in policies balancing the interests of the general population, in particular with regard to environmental protection and the interests of minority with possibly conflicting requirements, renders the Court's role a strictly supervisory one,"1/49

To determine whether the measures were proportionate to the aim pursued, the Court argued that it was relevant whether or not the home was established unlawfully and whether or not alternative accommodation was available. It noted that the applicant did not wish to lead a travelling life anymore and "...thus the present case is not concerned as such with traditional itinerant gypsy lifestyle." The Court further noted that there were strong environmental reasons for the refusal of the planning permission and that the applicant's circumstances had sufficiently been taken into account in the decision-making process. The Court observed that there may have been no alternative sites immediately available at the time either in the district or in the county as a whole. However, the applicant had not shown evidence of efforts to find another site and had not given information on her financial situation of on the qualities that a site should have to be suitable for her. The Court was, therefore, not convinced that there were no alternative sites available besides remaining on the land without a planning permit. ${ }^{151}$

The Court generally noted that the number of places acceptable to gypsies where they could lawfully place their caravans at an affordable price was inadequate. However, it did not find that "... "because statistically the number of gypsies is greater than the number of places available in authorised gypsy sites, the decision not to allow the applicant gypsy family to occupy land where they wished in order to install their caravan in itself, and without more, constituted a violation of Article 8." The Court found that Article 8 did not imply a right to be provided with a home. It did not accept the interpretation of Article 8 as involving such farreaching positive obligations of general social policy. ${ }^{153}$ It concluded that the measures taken were proportionate and held, by 10 votes to 7 , that Article 8 had not been violated. ${ }^{154}$

With regard to Article 14 on non-discrimination, the Court noted that the authorities could not treat a gypsy who illegally established a caravan site differently from a non-gypsy who did the same. The Court referred to Buckley by stating that the vulnerable position of gypsies as a minority required a special

149 Chapman $v$, the Unired Kingdom, 18 January 2001, \$94. This statement reflects the judictial constraint of the Court, whereby it acts with self-restraint to avoid overstepping its mandate. In such cases, the Court is not likely to be inclined to impose positive obligations on States.

150 Chopman w. the Uwited Kingdom, 1.8 January $2001, \$ 102-105$.

151 Chapman we Unted Kingdom, 18 January $2001,8110-113$.

152 Chapman v. the United Kingdom, 18 Jamuary $2001, \$ 98$.

153 Chopwam v. the Unted Kingdom, 18 January 2001, \$ 98-99.

154 Chopmon $v$ the United Kingdom, 18 January 2001, \$115-116. 
consideration of both their needs and their different lifestyle in regulatory planning. However, in this case, the Court found that gypsies were not treated worse than non-gypsies who wished to live in a caravan. In this case, the Court unanimously concluded that there had been no violation of Article 14, since the measures taken were objective and reasonably justified. ${ }^{155}$

\section{Joint Dissenting Opinion}

The seven judges who voted against the decision that Article 8 had not been violated submitted a joint dissenting opinion in which they posed several arguments to conclude that the UK had violated Article $8 .{ }^{156}$ Firstly, the dissenters argued that the Court had put too much emphasis on the Buckley case and on the fact that the Court should have compelling reasons to change its position. These judges wished to pay more attention to the changing conditions in States and to the emerging consensus in Europe concerning the standards to be achieved. Secondly, they asserted that, although the essential purpose of Article 8 was to protect the individual against arbitrary action by public authorities, it could imply positive obligations to make respect for private life, family life and home effective. According to the dissenters, there was an emerging consensus among the Member States of the Council of Europe that the protection of the rights of minorities, including gypsies, required not only State abstention and non-discrimination, but also positive action through legislation or specific programmes. They, therefore, disagreed with the position that this consensus was not sufficiently concrete. They also disagreed that the Court had merely a supervisory role because of the complexity of the competing interests. ${ }^{157}$.

The dissenters also emphasised that the impact of the measures on the applicant went beyond environmental concerns. There should have been compelling reasons for such measures, since the authorities had not shown that there was an alternative site available. The dissenters expressed their concern that, according to the statistics of the government itself, there was a significant shortfall of official sites available for gypsies. They considered that the burden placed on the applicant to show very special circumstances was extremely high, if not impossible. According to the dissenters, there was no pressing social need, in comparison to the situation of the applicant who had no indication that she had anywhere else to go to with her caravan and family. The judges finally disagreed with the idea that Article 8 did not constitute a right to be provided with a home. There was nothing in the Court's case law to imply that a right to be provided with a home would fall totally outside the scope of Article 8. Accordingly, they argued that the planning and enforcement measures had exceeded the margin of appreciation, were

155. Chapman w. the United Kingdom, 18 January 2001, 95-97, 117-130.

156 Joint dissenting opinion of Judges Pastor Ridruejo, Bonello, Tulkens, Strá Nickả, Lorenzen, Fischbach and Casadevall

157 Joint dissenting opinion of Judges Pastor Ridruejo, Bonello, Tulkens, Stra Nická, Lorenzen, Fischbach and Casadevall, $1-3$. 
disproportionate and could, therefore, not be regarded as necessary in a democratic society. ${ }^{158}$

With regard to non-discrimination, the dissenters did not agree with the view that in this case special protection under Article 8 would cause problems with Article 14. Such an approach ignored the previously acknowledged idea that the applicant's lifestyle as a gypsy would give a wider scope to Article 8 . The dissenters relied on the Thlimmenos case by arguing that discrimination may arise if States fail to treat different situations differently. The judges concluded that there had been a violation of Article 8 and that this article did impose "...a positive obligation on the authorities to ensure that gypsies have a practical and effective opportunity to enjoy their rights to home, private and family life, in accordance with their traditional lifestyle..."

\subsubsection{Beard v. the United Kingdom, Coster v. the United Kingdom, Lee v. the United Kingdom and Jane Smith v. the United Kingdom ${ }^{160}$}

The facts of these cases were similar to the Chapman case, and the Court came to the same conclusions, with the same ratio of votes. The Beard case concerned a gypsy family who wished to station a caravan on land owned by them, and were refused planning permission for reasons of visual amenity and highway safety. Because they faced serious punishment, they left the place and from that time had no fixed address for their caravans. The Coster family claimed that they had been forced to move to a regular house, because no official site was available for them. Later on, they bought a piece of land and moved on to it with their caravans. They were refused planning permission on the grounds that this would be a significant intrusion into an attractive rural area. After a series of injunction proceedings, they argued that they had no alternative but to accept council housing accommodation. Applicant Lee and his family had also bought a piece of land that was part of a special landscape area to station their caravans on. Planning permission was refused, because the site would be highly visible and this would be damaging to the landscape. Lee claimed that the official sites offered to him were not fit for human habitation, since they were located on rubbish sites or old sewage beds. Jane Smith and her family bought land for their caravans but were refused planning permission on the grounds that their occupation harmed a sensitive area of the countryside. She

158 Joint dissenting opinion of Judges Pastor Ridruejo, Bonello, Tulkens, Strá Nická, Lorenzen, Fischbach and Casadevall, $\$ 4-7$.

159 Joint dissenting opinion of Judges Pastor Ridruejo, Bonello, Tulkens, Strá Nická, Lorenzen, Fischbach and Casadevall, $\$ 8-10$.

160 Beard v. The Unired Kingdom, Application No. 24882/94, European Court of Human Rights, decision of 18 January 2001; Cosfer v. The United Kingdom. Application No. 24876/94, European Court of Human Rights, decision of 18 January 2001; Lee v. The United Kingdom, Application No. 25289/94, European Court of Human Rights, decision of 18 January 2001; Jane Smith $v$. The United Kingdom, Application No. 25154/94, European Court of Human Rights, decision of 18 January 2001 . 
complained that the accommodation offered to her had been in flats or in urban areas or it concerned land unsuitable for habitation because of pollution. The Court concluded in all four cases that there had not been a violation of Article 8 nor of Article 14, based on the same arguments as the Chapman case. The same judges submitted a dissenting opinion in which they emphasised that there was a significant shortfall of official lawful sites for gypsies in the whole of the UK, and that it should not be taken for granted that vacancies were availlable elsewhere. Accordingly, they argued that there had, in fact, been a violation of Article $8 .^{161}$

\subsubsection{Concluding Observations on the Gypsy Cases and Cultural Identity}

It appears from the cases concerning gypsy families, that Article 8 ECHR on the right to respect for private life, family life and home has, in principle, much to offer for the protection of cultural identity in relation to land. The Court has eye for the individual as well as the collective dimension of these matters. It is interesting to see that, while, in the Buckley case, the Court did not yet wish to link private life and family life to culture, the Court did take this step in the Chapman case. It explicitly referred to the identity of the gypsies and their traditional lifestyle and argued that they involved respect for private life and family life as guaranteed by Article 8 ECHR.

In comparing the Buckley case with the Chapman case, it is remarkable to note that, in Chapman, the Court hurried to state that it could only depart from its earlier case law in Buckley if there were compelling reasons to do so. While this may, in principle, be true for reasons of legal certainty, the dissenters in my opinion rightly softened this argument by emphasising that the Court should be aware of new developments within the Member States that might make a different view desirable. At least, this option should be left open, especially in cases concerning such a developing issue as minority protection.

The Court, however, was not totally insensitive to the developments that had occurred since Buckley, especially at the regional \evel. In fact, in the Chapman case, the Court referred to various European instruments on minorities and gypsies to determine whether there was an emerging consensus on the treatment of minorities. The reference to the Framework Convention is particularly interesting since the Framework Convention is the first international instrument on the protection of minorities which has a limited supervisory mechanism of its own. ${ }^{162}$ The fact that the Court directly referred to the Framework Convention in this case gives the Framework Convention extra value. It appears that the Framework Convention could serve as a normative framework for the development of minority rights under Article 8 and 14 ECHR. However, in searching for an emerging consensus on the treatment of minorities, the Court concluded that, while there was

161 See $\$ 3$ of the dissenting opinion of Judges Pastor Ridruejo, Bonello, Tulkens, Strá Nickă, Lorenzen, Fischbach and Casadevall attached to all four casses.

162 See Section 6.4 of this chapter. 
consensus on the special needs of minorities, there was no agreement on the concrete action to be taken by States in this respect. It thereby pointed to the weakness of the Framework Convention, which only provides a general framework without agreement on its implementation. While the above has shown that the provisions of the Framework Convention have a programme type character, I agree with the dissenting judges who emphasised that the adoption of such a document shows an emerging agreement on the treatment of minorities, including positive obligations.

Positive obligations under Article 8 were another point of debate. The Court rejected the idea that Article 8 would, apart from State abstention, imply the positive obligation of States to provide everyone with a home. Furthermore, the Court found that Article 8 could not be interpreted as including the right of everyone to choose where he or she wants to live and the obligation of States to provide the means to granting this choice. The dissenters adopted a different view and stated that Article 8 could indeed imply positive obligations in this case. They rightly argued that these cases did not so much concern the choice of place, but concerned the fact that no suitable alternatives were offered, which would have been a positive State obligation.

With regard to the special treatment of gypsies in relation to nondiscrimination under Article 14, the Court adopted a rather curious view, which was in my opinion rejected by the dissenting judges with good reason. On the one hand, the Court tried to show the developments with regard to the treatment of minorities and the special position that these communities may have in policy-making. On the other hand, however, the Court argued that, if gypsies in this case had been treated differently from other UK citizens, there would be a problem with Article 14. In my view, the Thlimmenos case has shown that non-discrimination not only implies that equal cases should be treated equally, but also that different situations should be dealt with differently. The situation of gypsies in, for example, planning policies is different from that of other UK citizens, in that gypsies may need special measures to protect their interests.

In conclusion, these cases show that Article 8 offers interesting possibilities for the protection of aspects of a particular lifestyle or cultural identity under the heading of private life, family life and home. The Court did not explicitly refer to cultural identity, but it is obvious that the issues involved concern the protection of the cultural identity of the individual and of the community. By referring to minorities, culture and identity, the Court recognised the collective dimension of the individual rights under Article 8, although it only dealt with individual cases. While the Court in these cases did not find a violation, it might do so in the future and expand the scope of Article 8 to include positive State obligations to protect certain rights related to land for minorities, in this case a piece of land to station a caravan. 


\subsection{Concluding Remarks on the Protection of Cultural Identity and the Selected Case-Law of the ECHR}

As stated above, the provisions of the ECHR do not directly refer to culture or cultural identity. However, they do guarantee rights that are very important for the development and protection of cultural identity. The provisions on, for example, freedom of religion, freedom of expression, freedom of association and the right to education can be used by individuals and by communities through a collective action not only to protect a certain interest in one of these fields, but also in connection with the general development and protection of their cultural identity. While, the applicants in these cases did not directly refer to cultural identity, the Court confirmed the link with cultural identity in several cases.

The earlier case law of the European Commission and Court on Human Rights shows that, in general, the cases were dealt with in an individual way and no reference was made to the more general and collective aspects, such as cultural identity or a cultural community. Important principles were established in various cases with regard to State obligations in relation to the freedom of religion, expression and education. In general, the value of religious pluralism was recognised. However, the Commission and the Court in these cases hardly referred to culture when speaking of religion or language, and did not place these issues in the more general context of culture. In the case of, for example, Cha'are Shalom ve Tsedek $v$. France on ritual slaughtering, no explicit reference was made to cultural identity. This is understandable, since the ECHR does not contain a provision explicitly referring to culture, and the Commission and the Court are bound by the facts of the case and the relevant provisions of the ECHR, which, in this case, was the freedom of religion.

However, in the more recent cases of Sidiropoulos v. Greece and Chapman $v$. the $U K$, the Court has made explicit references to the protection of minorities and their cultural identity. In Sidiropoulos, the Court argued that cultural organisations set up to preserve and develop the minority culture and traditions are protected under the right to freedom of association. In Chapman, the Court argued that, in principle, the traditional way of life of a gypsy minority is protected under Article 8 on the right to respect for private life, family life and home, although it did not wish to add positive State obligations to this protection. The Court recognised the collective dimension of such issues, despite the fact that the cases were dealt with on an individual basis. Minority issues were also indirectly dealt with in the cases of the Kurds against Turkey and in other minority related cases such as Stankov and Gorzelik. The Court did not explicitly recognise the Kurds or the other groups as minorities, but stated several times that it valued cultural diversity and pluralism. Such diversity should, at the very least, be respected by States, while the Court was more hesitant to add positive obligations.

In short, although cultural identity is not, as such, protected by the ECHR, and the Court did not establish an explicit relationship between religion, expression 
and education, and cultural identity, these cases show that several provisions of the ECHR offer potential tools to protect the general value of cultural identity. However, these cases refer to concrete situations and aspects of cultural identity and mainly offer protection of the aspects whereby cultural identity remains a general value without clear positive State obligations. The cases show that aspects of cultural identity are protected under the ECHR, and that the Court sometimes links these individual sifuations to the cultural identity of the persons or communities involved. The cases confirm the broad concept of cultural identity, whereby different ECHR provisions play a role. While the Court generally recognises negative State obligations with regard to the protection of the aspects of cultural identity, it remains reserved when it comes to positive State obligations. A separate right to culturall identity would probably not lead to more concrete positive State obligations and would, in general, not add much to these provisions, with the exception of the general recognition of cultural identity as a value. 


\section{CHAPTER XI \\ A Right TO CULTURAL IDENTITY AND THE SAMI IN NORWAY, SWEDEN AND FINLAND}

"Tell them we don't just wander""

\section{INTRODUCTION}

The previous chapters have generally focused on three issues: the elaboration of the concept of cultural identity, the possible translation of this social concept into a legal right, and the role of existing international human rights provisions. These have provided a picture on the concept of cultural identity, the importance of the protection of cultural identity for communities and individuals, and the possibilities offered by existing international human rights instruments. It was inter alia concluded that cultural identity is a value or common good to be preserved by human rights, since it is part of human dignity. The existing provisions on cultural identity mainly reflect the recognition of this general value without providing substantial rights. In fact, in searching for claims and State obligations under provisions concerning cultural identity, one arrives at the protection of aspects of cultural identity, such as language, religion, education and land. In this respect, other existing international human rights provisions also provide potential for the protection of these aspects and, as such, of cultural identity.

To give these conclusions a more human and practical outlook it is interesting to place them in the context of a concrete community. After all, it is the cultural identity of communities and their members that should benefit from a right to cultural identity. Firstly, it should be noted that no community can ever be representative of all communities and situations, and that, accordingly, a pragmatic choice is called for: Since this dissertation focuses on international human rights law, a community that has used international instruments to search for protection of its cultural identity was chosen, namely the Sami in northern Scandinavia. The Sami have brought several complaints both before the HRC and before the European Commission for Human Rights. They form an interesting illustration of an indigenous people with a different cultural identity than the majority in the States in which they live, which is, to a certain extent, protected by national and

॥ Quotation from a Sami herder, which shows the frustration of the Sami with the myths of their nomadic lifestyle, held by outsiders. See R. Paine, Herds of the Tundra, Washington: Smithsonian Institution Press, 1994, p. 11. 
international law. In other words, the Sami could be the subject of a right to cultural identity. The question is whether they need such a right to cultural identity, and what role international human rights provisions already play in the protection of their cultural identity.

First, a general description is given of the Sami as an indigenous people and of their cultural identity. Subsequently, the Lapp Codicil of 1751 is analysed, which is an important historical document in relation to Sami rights. Next, more recent national legal and political developments with regard to the Sami are dealt with. Finally, the role of international instruments relevant to the Sami is analysed, including the cases referred to above.

\section{The SAMI as AN INDigenous PeOPLE}

The Sami (also spelled Saami, Sámi or called Lapps) are an indigenous people in northern Scandinavia (Norway, Sweden and Finland) and northern Russia (the Kola peninsula). This chapter focuses on the situation of the Sami in Norway, Sweden and Finland. ${ }^{2}$ The exact numbers of the Sami are unclear, because no general survey has been carried out among them, and because the definition of who is a Sami differs among the States. Consequently, different numbers are mentioned. The average number is between 60,000 and 100,000 divided over the four countries: 40,000 in Norway, 20,000 in Sweden, 6,000 in Finland and 2,000 in Russia. ${ }^{3}$ The exact number of Sami depends on the definition used. The categories used in the Scandinavian countries are family heritage, language and individual perception of belonging to the Sami community. The issue of the Sami definition is discussed below.

2. The Sami in Russia could not be analysed because there was insufficient usable material. In general, it can be stated that the situation of the Sami in Russia is different from those of the Scandinavian countries, since the Sami in Russia do not have official status or an official institution, sucli as a Sami Parliament. The Sami in Russia traditionally herded their reindeer together with other ethnic groups. Under the Soviet regime, the means of production among the reindeer breeders were collectivised and the different groups were relocated into large towns. This forced relocation of indigenous peoples resulted in the destruction of indigenous social, culturat and conomic structures. From the beginning of the 1990s, after the collapse of the Soviet Union, private reindeer husbandry is again allowed. However, the Sami people in Russia do not have any rights to possess or use their traditional land, water or resources. The traditional Sami land is rented to private companies, Russian as well as foreign. Although the Russian Constitution of 1993 grants 10 indigenous peoples certain rights, they are neither politically nor legally implemented. See Henriksen, 1996, p. 10.

3 Lasko and Osherenko, 1999, p. 5. Other reports mention different numbers. Hellstén focuses on the Sami language and comes to the following numbers: Norway 25,000 Sami speakers, Finland 5700 with 3,000 Sami speakers, Sweden 17,000 with 10,000 Sami speakers and Russia 2000 with 1000 Sami speakers (Hellstén., 1998, p. 120). Henriksen speaks of 6,500 in Finland, between 40,000 and 60,000 in Norway, in Sweden between 15,000 and 20,000 and about 2,000 in Russia (Henriksen, 1996 , p. 5). Hyvärinen gives a number of 7,000 Sami in Finland (Hyvärinen, 1996, p. 14). Bear mentions the following numbers: 35,000 in Norway, 17,000 in Sweden, 5,000 in Finland and 2,000 in Russia (Baer, 1996-B, p. 17). Cranér speaks of 40,000 in Norway, 17,000 in Sweden, 4,000 in Finland and 4,000 in Russia (Cranér, 1994, p. 52). 
The main form of Sami social organisation used to be the siida' or Lapp village with its own geographical area and social system, where economic activities, such as hunting, fishing, berry picking and whaling were organised. The size of the "siida' was determined by the resources available in the area. Beyond this local level, the Sami use the term 'Sapmi' or 'Saapmi' to give expression to their collective identity. These terms have multiple translations such as Samiland, a Sami person, the Sami people and the Sami language. They encompass the geographical area as well as the Sami people, showing that the concept of land and people are intrinsically united. ${ }^{4}$ Traditionally, the regions where the Sami lived were called the Sami Homeland. Nowadays, only Finland still has a clear cut Sami Homeland, which is a region in the northern part of the country of about 35,000 square killometres. In Norway and Sweden, the Sami are more spread out over large parts of the country. Most no longer live in 'siidas', but in regular modern villages."

The Sami have a long history of being subject to violations of their cultural rights. Although they have not been subjected to (cultural) genocide, discrimination and the denial of cultural rights have taken place and continue to take place, for example, the prohibition of the Sami language, the lack of possibility to learn their language and their forced removal from their land. However, during the last fifteen years, the Sami in Norway, Sweden and Finland have been granted certain rights with regard to the protection of their cultural identity. It is interesting to note that these national Sami rights were either established long ago in the eighteenth century or recently during the last fifteen years. This has much to do with the historical fact that the territory of the Nordic countries has belonged to different States. The Sami people have been ruled by several national powers: Denmark, Finland, Norway, Sweden and Russia. For centuries, they have suffered various changes of political and legal regimes. Eventually, the Sami and their land were divided between Finland, Norway, Sweden and Russia. When new State power was established, the State wished to defend the unity of its country. Finland, for example, tried to defend its young nation after its independence from Russia in 1917. The Finnish population had to be united, and the development of a national identity was considered far more important than the protection of a minority. Generally speaking, the Nordic countries tried to assimilate the Sami for a long period, because they were regarded as 'uncivilised' or a people of a lower order, who should not stand in the way of civilisation, including modern forms of land use, such as mining, hydroelectric plants and logging. The focus on economic development and on the national language and national identity almost led to the end of the Sami language and culture. It was the Sami political movement from the 1980s onwards, using inter alia international law as a tool, which succeeded in putting Sami issues on the political agenda."

4 Oreskov, 1998, p. 67.

5 Seurujärvi-Kari and Pedersen, 1997 , pp. $4-9$.

6 Hellstén, 1998, p. 122; Oreskow, 1996, p. 2; Korsmo; 1.988, pp. $511-512$; Orton and Beach, 1998, p. 94; Henriksen, 1996, p. 5. 


\section{THE CULTURAL IDENTITY OF THE SAMI}

\subsection{Reindeer Herding and Land Ownership}

Traditionally, the Sami had a nomadic life style caused by their principal way of living, based on reindeer herding, fishing, hunting and gathering. Nowadays, this nomadic lifestyle has largely disappeared and only a minority of Sami still herd reindeer. These herders no longer cross such large territories and live in steady communities. However, the Sami still consider reindeer herding as one of the main features of the Sami cultural identity. Other economic activities, such as fishing, hunting, small-scale agriculture and berry gathering, are also considered important. Consequently, territory, including water; is a very important issue for the Sami.

The Sami generally do not own the land they occupy or use for their reindeer and other economic activities. The governments of Norway, Sweden and Finland generally consider the Sami territories as State property based on the principle of terra nullius. This principle of international law means that States could own all 'uncultivated' land that belonged to no other State. By annexing these lands many years ago, Norway, Sweden and Finland had taken possession of ownerless land. The Sami had no rights in this respect since, according to the States, their primitive, nomadic lifestyle gave them no legal control over the land they used. Although the principle of terra nullius is rather weak today, since there are hardly any parts of the world that can be considered terra mullius, it is still a leading principle with regard to indigenous land rights, including the Nordic countries. ${ }^{7}$ The States justify this principle by stating that, even if their past take-over of the land was unlawful, the ownership is lawful today, since the States have acted as its owners for such a long time. ${ }^{8}$ In 1981 , this point of view was confirmed by the Swedish Supreme Court in the Taxed Mountains case, which is discussed in more detail below. In its advisory opinion in the Western Sahara case, the International Court of Justice (ICJ) had given an interpretation of the principle of terra nullius concerning the colonisation of the Western Sahara by Spain. The ICJ argued, that according to State practice at that time, at the end of the nineteenth century, territories inhabited by tribes or peoples having a social and political organisation were not considered terra nullizs. Instead of occupying such areas, States had tried to conclude agreements with local rulers. ${ }^{9}$ Although the Sami may have no formal ownership of the land, they did have a social and political organisation, which would, according to the reasoning of the ICI, imply that their land was not terra nullius and that agreements with the Sami should have been concluded. ${ }^{10}$

7 See, on the principle of terra nulliks, Malanczuk, 1997, pp. 148-149.

8 Oreskov, 1996, pp. 4-6; Korsmo, 1988, pp. 513-514.

9 International Court of Justice, Western Sahara case, Advisory Opinion, 16 October $1975, \& 75-83$.

10. The principle of terra nulliws was also rejected by the High Court of Australia in the case of Mabo and Others $v$ the State of Qweensland (No. 2, 1992) 175 Commonwealth Law Reports 1.. The High Court argued that the continued use of the principle of terra mullius would perpetuate injustice and would persist in characterising indigenous peoples as too low in the social organisation to be 
One problem with regard to the ownership of land is that the Sami have never formally registered the land they used and occupied as their property. The Sami do not have such fixed, static notions of territory, since reindeer herding is dependent on seasonal migration, and a flexible and adaptive use of land. The use of land was not based on legal concepts of property or rights to use, but on knowledge, common heritage and control. This does not mean, however, that the Sami do not have any" notion of possession or belonging to the territory on which they herd. They do not simply follow their reindeer; they follow a pattern of seasonal migration and collective reindeer herding and have an intense relationship with their animals. The Sami consider man and nature as an integrated whole. This special territorial relationship is not reflected in the State policies towards the Sami, which are based on a notion of territoriality, where private ownership to land and resources is the key point."

\subsection{The Sami Language}

Another other important feature of the cultural identity of the Sami is their language. ${ }^{12}$ The Sami language is divided into several dialects, such as North Sami, South Sami, Skolt Sami and Inari Sami. The Sami language is very ecologically oriented and has, for example, hundreds of descriptions for reindeer, according to age, sex, colour and the form or absence of horns. The Sami language is, however, actively spoken by only 25 percent of the Sami, mainly because of assimilation policies that prevented the language from being taught at schools. Nowadays it forms a central aspect of the Sami policy of the Nordic countries. In Sweden, Sami children have the right to be taught in their own language and there are special Sami schools. In Norway, it is taught at schools and can also be the language of instruction. In Finland, the Sami language is also taught in schools, but there are no special Sami schools. The main problem in relation to the preservation of the Sami language is the lack of teachers. ${ }^{3}$ In recent years, further developments have taken place in Finland and Norway with regard to the preservation of the Sami language. In Finland, the Act of the Sami Language was passed in 1991 and entered into force in 1992. According to this law, any person who is recognised as a Sami can use that language for judicial and administrative proceedings before government authorities and certain municipalities. In Norway, the existing Sami legislation of 1987 was extended in 1991, with a new chapter containing similar provisions as the Finnish legislation. ${ }^{14}$

acknowledged as possessing rights and interests in land. Indigenous peoples have a connection to the land and should have the native title to it.

11 Dahl $_{*}$ 1996, pp. 16-17,22-23.

12 Other important features of the Sami cultural identity are handicrafts, traditional costume, chant and food culture.

13 Fitzmaurice, 1997, p. 215.

14 Fitzmaurice, 1997, p. 216. 
An important issue with regard to the Sami and their cultural identity is that only a small pereentage of the Sami are actively involved in the two important elements of their cultural identity, namely, reindeer herding and the Sami language. However, even though not many Sami herd reindeer or speak the Sami language, the Sami generally regard both issues as main features of their cultural identity to be preserved and developed. With regard to language, progress has been made to preserve the language in all three countries. The protection of reindeer herding is more problematic. Although it is officially recognised as part of the Sami culture, and reindeer herding is an exclusive Sami right in Norway and Sweden, all three States try to regulate and limit the herding territory and herd sizes. Another problem is that the special position of the reindeer herders has led to a split within the Sami community between reindeer herders with certain special rights and non-reindeer herders with no or few rights. Special Sami rights for the use of land for reindeer herding can also cause conflicts with non-Sami industries such as farming. ${ }^{15}$ In short, there are several potential conflicts or tensions involved in the protection of the cultural identity of the Sami through special rights. In this respect, the definition of who is a Sami is important.

\section{DEFINITION OF Who IS A SAMI}

The definition of who is a Sami is not only important to count their numbers, but also to determine who is entitled to special rights, for example, the right to herd reindeer. The fact that the Sami are often a minority, even in their Homeland, has created disputes concerning their definition and corresponding rights. Some residents of the Sami area want to become Sami to benefit from special legislation. The three Nordic countries have almost identical definitions of the Sami, laid down in the Acts on the Sami Parliaments, which determine who can vote and be elected in the Sami Parliament. An important subjective requirement is self-identification and an objective element is the Sami language. In Finland, according to the Act on the Sami Parliament, adopted in 1995, a Sami is a person who considers himself a Sami (subjective element) and who:

- himself, or at least one of his parents or grandparents, has learned Sami as his first language, or;

- is a descendant of a person who is registered in a land, taxation or population register as a mountain, forest or fishing Lapp, or;

- has at least one parent who could have been registered for election to the Sami Parliament (objective elements). ${ }^{16}$

Besides self-identification and language, this definition includes the descent of the person or his ancestry with the traditiona】 occupants of the lands as decisive elements. In the Norwegian definition, the person's parents or grandparents must

15 Orton and Beach, 1998, p. 92; Lasko, 1998, p. 70.

16 Myntti, 1998, pp. 288-293. 
have Sami as their home language, while, in Sweden, the term "language used at home' is applied. The Swedish and Norwegian definitions do not mention land or taxation registration criteria. In Finland, anyone who can give evidence of having a Sami among his ancestors can be defined as a Sami and can vote and be elected to the Sami Parliament. The former criteria were based on cultural background, whereas the new criteria are based on blood relationship. These descendants from the Sami, even if they neither speak Sami nor have any relationship with the current Sami or Sami Homeland, can enjoy Sami rights. Even if their parents could have been registered, the person can be a Sami. Originally, it was the Sami themselves who wished to broaden the definition, which used to be based merely on language. The wish to include descendants of the Sami into the definition was based on the idea that these descendants might be the rightful owners of the traditional Sami land. However, in a statement adopted in March 1996, the Finnish Sami Parliament rejected the wider definition and demanded the restoration of the definition based on language. ${ }^{17}$

The Finnish definition has caused much debate among the Sami, since it can lead to a large group of persons who have hardly any ties left with the Sami being elected to the Sami Parliament. On the other hand, it appeared that the single criterion of language was hard to maintain, since large numbers of Sami no longer speak Sami even though they have lived in the Sami Homeland for ages and have strong ties with the Sami culture. The determination of who is a Sami has become even more difficult because of mixed marriages, other professions than the traditional Sami livelihoods, and other residencies. ${ }^{18}$

\section{The History of SAMI RIGHTS: THE LAPP CODICIL}

As mentioned above, the Sami Homeland was an important arena for territorial rivalry among several kingdoms, such as Denmark-Norway, Sweden and Russia, all of whom sought control over the Sami as a check on foreign expansion by the other States. The Sami Homeland was first divided by land taxation regimes and later by border treaties between Sweden, Russia and Denmark-Norway. Consequently, border treaties have played a major role in the history of the Sami and their rights. These fixed and exclusive definitions of territory did not coincide with the Sami's 'siida' organisation and the collective Sami identity. Instead of forming a cohesive ethnic community, land taxation regimes and border treaties divided the Sami into Russian, Swedish or Danish subjects. ${ }^{19}$

One of these border treaties, the Lapp Codicil, turned out to be an important document concerning Sami territorial rights. The Lapp Codicil was an addendum to the border treaty between Denmark-Norway and Sweden (Finland)

17 Myntti, 1998, pp. 288-290, 292; The Finnisti Sami Parliament, 1997, p. 51; Oreskov, 1996, p. 3. Hyvärinen, 1996, p. 15; Baer, 1996-A, pp. 137-138.

18 Myntti $_{n} 1998$, pp. 292-293; Baer, 1996-A, pp. 137-138.

19 Seurujärvi-Kari, Pedersen and Hirvonen, 1997, pp. 10-14. 
signed in 1751 . The two States agreed upon a permanent border between them, which has since been the border between Norway and Sweden and Norway and Finland: When Denmark-Norway and Sweden (Finland) negotiated on the border treaty, they realised that the Sami often migrated from one country to the other following ecological principles. The Lapp Codicil aimed at the protection of the land use by the nomadic Sami. It recognised the right of the Sami to cross the border freely as part of their seasonal migration of reindeer herding, and included the use of land and water in another country. In the Codicil, it is stated that:

\begin{abstract}
"The Sami need the land of both States. Therefore, they shall, in accordance with tradition, be permitted, both in autumn and spring, to move their reindeer herds across the border into another State. And hereafter, ass before, they shall, like the State's own subjects, be allowed to use land and share it for themselves and their animals, except in the places stated below, and they shall be met with friendliness, protected and aided..., 20
\end{abstract}

The Lapp Codicil also laid down cultural rights and rights related to exclusive jurisdiction for the Sami in their own affairs, according to Sami customs. The Lapp Codicil recognised the Sami as a distinct people, showed respect for Sami interests and included a commitment to the survival of the Sami, their culture and traditions. $^{21}$

However, the continuing change of sovereignty made the execution of the Lapp Codicil uncertain. From 1751 to 1809 , the Lapp Codicil was not only applied to reindeer herders, but to all Sami. The Danish-Norwegian authorities also recognised seasonal migration across the border for, for example, salmon fishing purposes. In 1809, Finland was separated from Sweden, and became a Grand Duchy under the Russian Czar. Norway was administratively separated from Denmark in 1814 and forced into a union with Sweden under the Swedish king. Although it has been argued that, after 1809 Russia/Finland rejected its obligations under the Lapp Codicil, Russia did, in fact, confirm that it wished to respect all the existing rights of all Finish citizens at that time. The Lapp Codicill was indirectly reaffirmed in 1826 in a border convention between Russia and Sweden/Norway. In other words, the border arrangements made in 1751 were still in place and the Sami still had the right to cross the borders freely. ${ }^{22}$

It was in 1852 that Russia/Finland decided to close the border to transfrontier movements of reindeer herders. Sweden/Norway immediately followed this decision. It was one of the most dramatic events in Sami history, because the Sami had followed this ecological pattern for hundreds of years. The effects on the living conditions of the Sami were enormous. The Finnish authorities therefore started negotiations with the Swedish-Norwegian government to see

20 Sillanpäă, 1992 , p. 6 .

21 Alfredsson, 1999, p. 530; Pedersen, 1996, p. 76. UNESCO, World Culture Report 1998, p. 77; Pedersen, 1996, pp. 66-67, 75-76; Skensson, 1996, pp. 269-270.

22 Pedersen, 1996, pp. 78-80. 
whether it would be possible to restore the situation to what it had been before 1852. The border should be open again to enable the Sam to pick up their old pattern of migration and use resources on both sides of the border. An even more far-reaching solution was discussed among the Finnish authorities. If Sweden/Norway were not prepared to restore the provisions of the Lapp Codicil, Finland would be willing to give up the Sami territories of Utsjoki and Inari to Norway. Sweden/Norway did not want to restore the situation of the Lapp Codicil, because the closing of the border had given them much more control over the nomadic reindeer herders. However, they were not interested in gaining new territory, since they were too suspicious of the Russian intentions behind this offer. Consequently, no results came out of this Finnish initiative and no re-establishment of the traditional ways of migration and use of resources took place..$^{23}$

The current formal status of the Lapp Codicil is unclear. It thas never been formally abolished or suspended, and in Norway, it seems that it is still accepted as an intemational treaty, and could be applicable in Norwegian courts. ${ }^{24}$

\section{National Sami Policies and Legislation in Norway, Sweden and FINLAND}

The Sami are treated somewhat differently in the Nordic countries with regard to land rights, cuitural rights and the powers of the Sami Parliaments. This section gives an impression of policies and legislation in Norway, Sweden and Finland. In general, it can be stated that, after the Second World War, the three States changed their policies towards the Sami, recognising the legitimacy of their cultural rights to some extent, including the importance of reindeer herding as a material prerequisite of Sami culture. ${ }^{25} \mathrm{New}$ reindeer herding acts have been passed in all three countries. The general policy towards the Sami is, however, still generally based on national unity and territorial integrity. The reindeer acts start from the idea that State regulation is the best way of protecting the Sami culture. The restriction of land for reindeer herding and herd sizes, for example, may prevent overgrazing. However, such measures overlook the fact that the Sami have developed their own strategies for reindeer herding for hundreds of years, which have never led to overgrazing. The governments still regard reindeer breeding as a backward form of economic activity and tend to give more weight to modern forms of land use, such as agriculture, logging and mining, at the expense of traditional Sami activities. ${ }^{26}$

An important recent development has been the establishment of the Sami Parliaments. These Parliaments, whose members are chosen by the Sami themselves, have advisory status and can (and sometimes have to) be involved in policy-making with regard to the interests of the Sami. The establishment of the

23 Pedersen, 1996, pp. 81-83.

24 Pedersen, 1996, pp. 84-85.

25 UNESCO, World Culture Report 1998, p. 76.

26 Alfredsson, 1999, pp. 529, 533; Henriksen, 1996, p. 6. 
Sami Parliaments has considerably improved the possibilities for the Sami to develop their own language and culture on the basis of cultural autonomy and selfknowledge. ${ }^{27}$ Since February 2000 , the three Sami Parliaments of Norway, Sweden and Finlland together form the Sami Parliamentary Council, to improve Sami cooperation across the borders. The Sami consider it important to show that, although they live in various countries, they are one people and that their culture should be developed under similar political and economic conditions in each country. ${ }^{28}$

\subsection{Norway}

\subsubsection{Sami Rights and the Alta Dam Case}

Unlike Finland, Norway has no clear cut Sami Homeland. The only demarcation is provided by the Sami Language Act, which lays down the places in which Sami is an official language. This areal consists of the various towns in Finnmark and Troms, such as Karasjok, Kautokeino, Nesseby, Porsanger, Tana and Kafjord. However, this linguistic demarcation has no consequences for the Sami land rights in Norway. ${ }^{29}$

Although the Sami do not own the land they use, the right to own and breed reindeer is an exclusive Sami right in Norway. This right is guaranteed if the person considers himself a Sami and fulfils several objective criteria: The land is owned by the State or by private owners, and the Sami reindeer breeders have the exclusive right to use this land. Until 1996, the Sami reindeer owners had the burden of proof concerning their reindeer breeding rights on land owned by private owners. Since the adoption of the new Reindeer Husbandry Act in 1996, the landowners have the burden of proof of any claim of non-existing reindeer grazing rights. ${ }^{30}$ Norway has also introduced a far-reaching system to protect the Sami cultural heritage. Since 1994, the Sami Parliament in Norway has primary responsibility for the administration of Sami heritage. ${ }^{31}$

An important event in the history of the Sami in Norway was the building of the Alta dam in the late seventies and early eighties, when the Norwegian government decided to start a State managed hydropower development project in northern Norway. The Sami strongly objected to the building of the dam and the road construction, since it would destroy territory used for reindeer herding and other economic activities. In the political field, after the Parliament had rejected the preliminary protest of the Sami, the Sami organised two large demonstrations. One was an occupation on the territory itself to prevent the workers and bulldozers from entering the territory, which lasted almost one and a half years. The other protest

27 Hellstén, 1998, p. 134; Hywärinen, 1996, p. 16.

28 Lasko, 1998, p. 78.

29 Baer, 1996-A, pp. 133-134.

30 Henriksen, 1996, p. 9.

31 UNESCO, World Culture Report 1998, pp. 81-84. 
was a hunger strike, the first in Norwegian history, followed by a sit-in in front of the Parliamentary building in Oslo. The Norwegian government announced a preliminary stop in the construction plans, but, in February 1982, the work on the dam restarted. Through the legal system, the National Association of Reindeer Herding Sami took the case to the Norwegian Supreme Court. The Sami argued that the building of the dam would destroy parts of the Sami culture, whereby they, inter alia, referred to Article 27 ICCPR. The case turned out to be more than a mere expropriation case. Instead, it involved many human rights principles. The Sami finally lost this case in 1982 , but monetary compensation was granted to Sami individuals who would lose reindeer, and certain restrictions on the original plans were imposed to meet some of the Sami demands. ${ }^{32}$

Although the Sami lost the Alta Dam case, it played a major role in the reevaluation of Sami rights in Norway. Following the Sami protest against the building of the Alta Dam, the Norwegian government appointed a Sami Rights Commission to examine the Sami rights to land and water, which presented its first report in 1984. It examined whether the protection of culture as laid down in Article 27 ICCPR would, in the case of the Sami; apart from ideological expressions such as songs, literature and storytelling, also have implications for the material base for culture, for example, the protection of natural resources. The Commission maintained that the protection of natural resources could, indeed, fall under the term 'culture' in Article 27 and coneluded that the international protection of the Sami was, in fact, much stronger than the national protection. The Commission proposed to recognise the Sami culture and language in the Norwegian Constitution and to set up a Sami Parliament. Based on this report, the Norwegian Parliament adopted, in 1987 and 1988, amendments to the Constitution and the Sami Act thereby establishing the Sami Parliament. ${ }^{33}$

The Sami Rights Commission also appointed a group of six legal experts to analyse the legal aspects of the issue of Sami land rights and ownership. No Sami experts were part of this study group. In its recommendations submitted to the Commission in 1993, ${ }^{34}$ it concluded that the Norwegian State held the title to unregistered land areas in the Finnmark County. The majority of the group agreed that, although the historical take-over of the land might have been unlawful, the current situation was lawful, since a considerable length of time had passed. However, they agreed that the Sami had permanent right of usufruct of the land based on long-established use. Sami customary law with regard to ownership was

32 Somby, 1999, p. 58; Svensson, 1996, pp. 273-274; Korsmo, 1988, pp. 518 ; 519 . Two Sami took the Alta case to the European Commission on Human Rights, arguing that the building of the dam was a violation of Article 8 ECHR on the right to private life and family life. See the case of $G$. and $E$. 1. Norway, Application Nos. 9278/81 and 9415/81, European Commission on Human Rights, decision of 3 October 1983, Decisions and Reports, vol. 35 (1984), pp. 30-45. This case was dealt with in the prewious chapter, section 9.5 and also below in section 7.2 .

33 Fitzmaurice, 1997, p. 230; Baer, 1996-A, p. 133; Somby, 1999, p. 59.

34 Since the recommendations are in Norwegian, only secondary sources are used here (Norge Offentlige Utredninger (NOU 1993:34) - Retten till og forvaining av land og vann I Finmmark). 
not taken into account, because the members argued they had no expertise in this field. International law was also not taken into account.

The Norwegian Constitution now recognises the Sami in Norway as an indigenous people. In 1988, the Norwegian Parliament included a new Article 110A in the Constitution, in which it laid down that: "[i]t is incumbent upon the government authorities to take the necessary steps to enable the Sami population to safeguard and develop their language, culture and social life.",36 Furthermore, legislative reforms in $199 \|$ have granted the Sami in Norway official language rights. This means that the Sami language is recognised as an official administrative language in the Samiland on an equal basis with the Norwegian language. ${ }^{37}$

\subsubsection{The Norwegian Sami Parliament}

As in the other Nordic countries, the Sami in Norway have their own elected national Sami Parliament, the 'Saamidiggi', since 1989. The Sami Parliament replaced the former Norwegian Sami Council, which had been a consultative committee on Sami matters since 1964, and whose members were appointed by the government. The 39 representatives of the Sami Parliament are elected by direct ballot by the Sami who are registered in the Sami electoral register. The Sami Parliament can take initiatives on all matters it considers to be of concern to the Sami, and react to initiatives from governmental bodies. It can also bring matters to the attention of public authorities, private institutions or any other body. In some areas, public institutions are obliged to consult the Sami Parliament before taking decisions, especially in cases of funds to Sami cultural activities and education. ${ }^{38}$

\subsection{Sweden}

\subsubsection{Sami Rights and the Taxed Mountains Case}

In Sweden, as in Norway but unlike Finland, there is no clearly demarcated Sami Homeland. No special provisions on the Sami are incorporated in the Swedish Constitution. They fall under a general provision in the Constitution on minorities in which it is stated that the opportunities of ethnic, linguistic and religious minorities should be promoted in order to maintain and develop their cultural and social life. The Swedish Parliament concluded in 1977 that the Sami were an indigenous people and, as such, had a special status among minorities, which was officially recognised by the Swedish government in $2000 .{ }^{39}$

35. Henriksen, 1996, p. 8; Baer, 1996-A, p. 134; Somby, 1999, p. 62.

36 UNESCO, World Culture Report 1998, p. 77; Henriksen, 1996, p. 7; Baer, 1996-A, pp. 132-133.

37 Hellstén, 1998, p. 123; Henriksen, 1996, p. 7.

38 Hentiksen, 1996, p. 7; Baer, 1996-A. p. 133; Lasko, 1998, p. 73; Somby, 1999, pp. 59-60.

39 Baer, 1996-B, p. 17; UNESCO, World Culture Report 1998, p. 77; Baer, 1996-A, pp. 135-136; Swedish Report to the Council of Europe on the Framework Convention for the Protection of National Minarities, 1 June 2001. p. 4. 
As in the other Nordic countries, the Sami in Sweden do not own the land that they occupy and use. The legal basis as terra nullius was challenged in 1981 by an opinion of the Swedish Supreme Court. ${ }^{40}$. The so-called Taxed Mountains case concerned a legal dispute between Sami reindeer communities and the Swedish authorities in which the Sami claimed traditional ownership of the land in northern parts of Sweden, the Jämtland County. Although the Sami did not win their claim to the land ownership, the Swedish Supreme Court made an important point of principle. It declared that, at least in the 17 th century, it had been possible to acquire the title to land by using it for hunting, fishing and reindeer grazing. The Court thereby rejected Sweden's claim that nomads could not acquire the title to land. However, although the Supreme Court recognised this principle, it failed to give it legal effect in the current situation. It declared that the State was the present rightful owner of the area, and that the Sami had rights of use. Thus, although the Court rejected the Sami claim for ownership, it clearly stated that the Sami have fishing, hunting and reindeer breeding rights in the area. Furthermore, it stated that these usufructuary rights were based on immemorial usage and custom and should not be perceived as a privilege handed down by the State.

After the final judgment in the Taxed Mountains case, the government appointed a Commission to study Sami affairs and the status of the Sami in Sweden in 1982. The first report of this Sami Rights Commission was submitted in 1983, published in 1986 and finalised in $19900^{42}$ The conclusion of this report was that Swedish society generally recognised the Sami as a minority and an indigenous people. However, the Commission suggested legal revisions both to strengthen the position of reindeer herders against other industries and to give the Sami language increased status and financial support. It was also proposed to set up a Sami Parliament. The reports of the Sami Rights Commission did not, however, lead to positive measures strengthening Sami rights. On the contrary, the Swedish government took administrative measures that provided more restrictions and regulations, for example, by removing exclusive Sami hunting and fishing rights on parts of land that had been exclusively used by the Sami before. The Swedish government and parliament decided to open all traditional Sami hunting grounds for all Swedish citizens in 1992. Consequently, non-Sami could also hunt and fish unrestrictedly in traditional Sami areas. Only reindeer husbandry is recognised by Swedish legislation as an exclusive Sami right, comparable to that in Norway. ${ }^{43}$

While the 1992 Bill did not yet grant official status to the Sami language, the Swedish authorities changed their policy after ratifying the Charter on Regional and Minority Languages and the Framework Convention on National Minorities.

40 Supreme Court, decision handed down 29 January 1981.

41 Henriksen, 1996, pp. 6, 11; Svensson, 1996, pp. 271-273; Orton and Beach, 1998, pp. $97-98$.

42 Since the report is only in Swedish, only secondary sources are used here (Samernas Fokrättsliga Ställning, delbetänkande aw Samerättsutredningen (\$OU 1986:36)).

43. Henriksen, 1996, p. 12; Baer, 1996-B, pp. 17-18; Baer, 1996-A, pp. 135-137; Orton and Beach, 1998, pp. 101-103. 
Accordingly, since 1999, individuals have the right to use the Sami language in administrative authorities and courts. The authorities shall provide verbal answers in Sami and shall generally endeavour to deal with the individual in Sami. Furthermore, special measures were taken in education, whereby mother tongue education should be available to Sami children "...even if the number of pupils is less than five or if the language is not the language in daily use." However, the authorities are not obliged to arrange such teaching if no suitable teachers are available. To this end, there are special Sami schools where Sami children may fuiffil their first six years courses. Apart from the regular courses, special courses are given on Sami cultural heritage and the Sami language. ${ }^{44}$

\subsubsection{The Swedish Sami Parliament}

The Swedish Sami Parliament, or 'Sametinget', was set up in 1992 after the Swedish Parliament passed the Sami Act. The 31 members of the Sami Parliament are elected by the Sami with Swedish citizenship, which is required for participation in the elections. This is in contrast to Norway and Finland, where every adult Sami can take part in the elections regardless of citizenship as long as the person has been registered as a resident in the country for the last three years. The Sami Parliament is mainly an advisory body to the Swedish government. ${ }^{45}$

\subsection{Finland}

\subsubsection{Sami Rights}

The Sami in Finland mainly live in the northern part of the country known as the Sami Homeland, which is recognised in the Finnish Constitution and the Finnish Act on the Sami Parliament. The Sami Homeland is about 35,000 square kilometres and consists of the towns of Enontekiö, Inari and Utsjoki and the northern part of Sodankylla. Although this territory is called the Sami Homeland, the Sami actually form a minority, with the exception of Utsjoki. ${ }^{46}$

The Sami in Finland lost the exclusive right to reindeer herding after the adoption of the 1948 Reindeer Husbandry Act, according to which every Finnish citizen is granted the right to breed reindeer in a reindeer district. Unlike Norway and Sweden, Finland has not reserved the right to own and breed reindeer as an exclusive Sami right. Since, as a result of government support, reindeer breeding was a stable prosperous industry, the Sami have become a minority among herders. Every citizen also has fishing rights in the Sami Homeland, since the land and water are considered State property. With regard to land rights, the Finnish government

44 Swedish Report to the Council of Europe on the Framework Convention for the Protection of National Minorities, I June 2001, pp. 23, 28-30.

45 Henriksen, 1996, p. 11; Baer, 1996-A, p. 136; Baer, 1996-B, p. 18.

Baer, 1996-A. p. 131; Myntti, 1998, p. 287. 
recognised in 1976 that the Sami could have ancestral rights to the land and water that now belong to the State. The Finnish authorities acknowledged that the Sami have the right to use this land for their traditional subsistence, including reindeer breeding, hunting and fishing. The current Finnish legislation does not, however, acknowledge special Sami land rights, which means that the Finnish authorities can sell and lease the land and water in these areas, albeit under certain conditions. ${ }^{47}$

National legislation with regard to land does, however, contain several provisions which are important to the Sami. The Finnish Act on National Board of Forestry includes special provisions on the Sami. In Section 11, it is, for example, defined that the management, use and protection of natural resources in the Sami Homeland under the control of the National Board should be harmonised in order to safeguard and protect the Sami culture and traditional way of living. ${ }^{48}$ On 17 July 1995, a new section regulating the status of the Sami was incorporated in the Constitution Act. This new Section 3 guarantees the Sami, as an indigenous people, the right to maintain and develop their own language and culture. At the same time, a new Section 51a was added to the Constitution Act, according to which "...given their status as an indigenous people, and pursuant to the law, the Sami shall be accorded cultural autonomy in their homelands on matters relating to their language and culture." However, these provisions do not apply to rights to land or resources. ${ }^{49}$

With regard to language; the Sami have, since the adoption of the Sami Language Act in 1992, the right to use the Sami language before authorities, orally and in writing, and to receive a reply in the same language. The Sami Parliament has adopted three languages as official Sami languages in the Parliament: Inari Sami, Skolt Sami and Northern Sami. The State is funding various activities with regard to language whereby the Sami Parliament decides on the allocation of the budget. The Finnish Sami Language Act is not, however, as far-reaching as the corresponding Norwegian Sami Language Act, which recognised the Sami language as an official administrative language in the Samiland on an equal basis with Norwegian. ${ }^{50}$

\subsubsection{The Finnish Sami Parliament}

The Sami in Finland have had their representative body or Delegation for Sami Affairs since $1973 .^{51}$ In 1995, with the adoption of the Finnish Act on the Sami Parliament, the Sami Delegation was formally replaced by the new Sami Parliament or "Sami Ting". The Finnish Sami Parliament consists of 20 members, who are

47 Henriksen, 1996, pp. 6-7; Hyvärinen, 1996, p. 15.

48 Henriksen, 1996, p. 7; Baer, 1996-A, p. 131.

49 Finnish laws 17/7/1995/973 and 17/7/1995/974. See the Finnish Sami Parliament, 1997, pp. 50-51: Hellstén, 1998, p. 134; Hywärinen, 1996, p. 16; UNESCO, World Culture Report 1998, p. 77.

s0 The Finnish Sami Parliament, 1997, p. 50; Baer, 1996-A, p. 132.

51 Presidential Decree No. 824; Lasko, 1998, p. 71. 
elected by the Sami population from amongst themselves. According to the Finnish Act on the Sami Parliament, in force since 1 January 1996, all authorities, local, regional and national, shall negotiate with the Sami Parliament on all important measures that may directly influence either the status of the Sami as an indigenous people or the Sami Homeland. These issues concern, for example, community planning, the management and use of the territory, applications for mining licences or other patents, the teaching of the Sami language and other cultural matters. However, the Sami Parliament cannot veto government plans in this respect. The rule only obliges the authorities to negotiate with the Sami.

\section{INTERNATIONAL INSTRUMENTS}

\subsection{International Covenant on Civil and Political Rights}

All three Scandinavian countries have ratified the ICCPR. As described in Chapter VII, individual Sami have issued several complaints to the HRC under Article 27 with regard to the protection of their cultural identity. The Länsman cases, in particular, were important, in that they concerned government support for economic activities, such as stone quarrying and forestry, which interfered with the reindeer herding activities of the Sami. Although the Sami lost both cases, the HRC laid down several important principles, for example, that reindeer herding is an important element of the culture of the Sami and as such protected by article 27 . However, the measures taken in these cases had, in the opinion of the HRC, limited impact on the reindeer herding area of the Sami and thus did not constitute a violation of Article 27.53

Before bringing a case to the $H R C$, the local remedies have to be exhausted. In these national procedures, Article 27 ICCPR can also be influential. Scheinin has described several national cases in Norway and Finland in which Article 27 was invoked to protect the traditional means of livelihood of the Sami. In Finland, the ICCPR has been incorporated into Finnish law by an Act of Parliament and is, therefore, directly applicable before national courts. Scheinin argues that, although the Sami did not win most of their cases, national courts have applied Article 27 and have reasoned that Article 27 may imply positive obligations for States. The main reason why the Sami lost the cases was because the national courts laid emphasis on a quantitative assessment of the cases and not on the qualitative part. They mainly assessed the impact of the economic activities on the traditional use of the lands, whereby the size and not the value of the area where the mining or logging took place was decisive. Just as the HRC did in several cases, the national courts concluded that the negative consequences of logging or mining were of a degree that did not constitute a violation of Article $27 .^{54}$

52 Henriksen, 1996, p. 7; Baer, 1996-A, p. 131; Myntti, 1998, pp. 286-287; Lasko, 1998, p. 72.

53 See, for more details on these cases, Chapter VII, section 4.

54 Scheinin, 2000, pp. 212-214; see, also, Chapter VII, section 4. 
In Norway, international treaties are not incorporated into national law. However, Scheinin explains that national courts in Norway have referred to international law in interpreting nationall law, for example, Article 27 ICCPR. Scheinin argues that the reasoning of the Norwegian Supreme Court in the Alta dam case in February 1982, which was issued before the adoption of ILO Convention 169 (1989) and before the HRC developed international case law under Article 27, would nowadays be incorrect: In this case, the Supreme Court argued that Article 27 did not entail a minority having more than a right to equal treatment, in comparison with other communities, with regard to the enjoyment of their culture. The ICCPR did not; in the opinion of the Supreme Court, prevent States from taking measures that might affect the practical possibilities of a minority enjoying their culture. The Court also found no obligation on the part of the State to consult the Sami on these measures taken. In the meantime, the HRC has developed the interpretation of Article 27 through its case law, and such a ruling would no longer be sustainable. It failed to address the relationship between culture and economic activities, and failed to apply the justification test set out by the HRC on interference with culture, which includes an assessment of the impact of the measures and appropriate consultation with the community involved..$^{55}$

Sweden has a dualistic system, which means that international treaties have to be incorporated in national law. Thus, Article 27 forms a part of national law and is, therefore, directly applicable. Scheinin only mentions the Taxed Mountain case as a major national court case concerning the Sami. As described above, this case concerned the question of ownership of land traditionally used by the Sami for reindeer herding, hunting and fishing. The Supreme Court ruled against the Sami, and stated that the Sami did not own the land.

\subsection{The European Convention on Human Rights}

Norway, Sweden and Finland have ratified the ECHR and its protocols. Individual Sami have brought several cases under different provisions of the ECHR, and especially related to land rights, before the European Commission for Human Rights. Unlike the ICCPR, the ECHR has a provision on property rights for the 'peaceful enjoyment of possessions' it its First Protocol. Indigenous land claims can be based on this provision, perhaps in combination with non-discrimination. In the case of Könkämä and 38 other Sami Villages v. Sweden, the European Commission argued, in its inadmissibility decision, that exclusive hunting and fishing rights could be regarded as "possessions" under Article 1 of the First Protocol. ${ }^{57}$

Claims have also been brought under Article 6 ECHR on the right to a fair trial. In $S$. v. Sweden, the European Commission decided that the right of Sami

55. Scheinin, 2000, pp. 215-216.

56 Scheinin, 2000, p. 216.

57 European Commission of Human Rights, Könkamä and 38 Other Sami Villages $v$. Sweden, application no. 27033/95, decision 25 November 1996; see, also, Scheinin, 2000 ; p. 173. 
persons in Sweden to herd reindeer was indeed a civil right under Article 6 ECHR. In this case, it concluded that there had been a violation of that provision, since no recourse to a court was available against an administrative decision by which the applicant was denied a permit to maintain a herd of 400 reindeer. ${ }^{58}$ Claims concerning land rights have also been brought under Article 8 on the right to respect for private life and family life, as was extensively discussed in the previous chapter. One of the Sami cases in this respect, also discussed in the previous chapter, was $G$. and $E$. $v$. Norway concening the building the Alta Dam. The Commission declared the case inadmissible, but gave potential to Article 8 in relation to indigenous land rights. The Commission argued that "...under Article 8, a minority group is, in principle, entitled to claim the right to respect for the particular lifestyle it may lead as being private life, family life or home life." ${ }^{, 59}$ Similar to the HRC in its Article 27 cases, the Commission used the test of 'impact' to determine whether a violation had taken place. It found that the actual consequences of the flooding of a relative small part of land did not imply a violation of Article 8 . Furthermore, the Commission concluded that the economic well-being of the country, in other words, the majority of citizens, would be a sufficient justification for interfering with a minority culture. ${ }^{60}$

\subsection{The Framework Convention for the Protection of National Minorities}

Norway, Sweden and Finland have ratified the Charter on Regional and Minority Languages, which they all apply to the Sami language. They have also ratified the Framework Convention on National Minorities. ${ }^{61}$ In their reports on the Framework Convention, all three States refer to the Charter with regard to the protection of linguistic rights. In ratifying, Norway and Finland did not issue a declaration to specify the communities to which they apply the Framework Convention. In contrast, Sweden has issued such a declaration, in which it declares that, inter alia, the Sami are a national minority in Sweden.$^{62}$ As described in the previous chapter,

58 European Commission of Human Rights, $S . v$ Sweden, Application No. 16226/90, report of the Commission adopted 2 September 1992; see, also, Scheinin, 2000, p. 174.

59 European Commission of Human Rights, G. and E. v. Norway, Application Nos. 9278/81 and $9415 / 81$, decision of 3 October 1983 \& 2 , see, also, Scheinin, 2000 , pp. 174-175.

60 European Commission of Human Rights, $G$. and E v Norway, 3 October $1983 \& 36$; see, also, Scheinin, 2000, p. 175 . The potential of Article 8 ECHR for the protection of cultural identity was demonstrated in Chapter $X$.

61 Finland ratified the Framework Convention on 3 October 1997, Norway on 17 March 1999 and Sweden on 9 February 2000. Since the Framework Convention includes provisions on cultural identity, the focus in this section is on the Framework Convention.

62 See the website of the Framework Convention:

http:/www.humanrights.coe.int/Minorities/Eng/SiteMap.htm. Finland did not define its "national minorities" upon ratification. The reason was that "the existence of minorities does not depend on a declaration by a Gowernment but on the factual situation in a country". In practice, the Sami people, the Roma, the Jews, the Tartars, the Old Russians and the Swedish speaking Finns fall under the Framework Convention. See Council of Europe Doc. ACFC/SR (99) 3 , Report submitted by 
the monitoring of the Framework Convention is based on State reports to be examined by the Committee of Ministers assisted by an Advisory Committee. The reports of Finland, Norway and Sweden are analysed below in order to grasp the meaning and scope of the provisions on cultural identity, such as Article 5, in relation to the Sami.

Finland issued its first report in February 1999, in which it explained the legislation with regard to the protection of, inter alia, the Sami. With regard to Article 5 of the Framework Convention concerning the protection of (aspects of) cultural identity, the Finnish report mentions that Article 5 corresponds with Section 14 of the Constitution Act. Under Sub-section 3 of this Act, the Sami have the right to maintain and develop their own language and culture. The Act on the Use of the Sami Language before Authorities provides that Sami can be used both orally and in writing in the Sami Homeland, as well as before authorities and agencies. Furthermore, to ensure the preservation of the Sami language as a living language, a working group of the Ministry of Justice was set up to propose improvements to the language Act. ${ }^{64}$ The report also mentions that freedom of religion is generally protected under Section 9 of the Constitution Act. The Finnish report further discusses the difficulties with regard to the title to land, which had been an obstacle to the ratification of ILO Convention 169, and the lack of agreement on the definition of the Sami, including the re-linking of the Sami identity with knowledge of the Sami language. Finally, the report speaks of funds that are reserved for the promotion of cultural activities and publications "...for preserving their own cultures and identities." $" 65$

In a shadow report, the Finnish Branch of the Minority Rights Group (MRG-Finland) and the Finnish League for Human Rights noted, with regard to Article 5 and the protection of the Sami cultural identity, that the definition on the Sami was still not satisfactory linked to the Sami language. Both organisations express their concern at the possibility that, with this wide definition, many persons who have no knowledge of the Sami language or culture can have their names put on the Sami register. The organisations are also critical of the lack of action with regard to Sami land ownership. They argue that the government authorises increasing use and exploitation of traditional Sami lands to the Forestry Board and private enterprises, which forms a threat to the untouched nature necessary for

Finland pursuant to Article $25, \S 1$, of the Framework Convention for the Protection of National Minorities, 16 February 1999, p. 7.

63 The developments with regard to the monitoring of the Framework Convention can be followed through the Internet: http//www humanrights, coe int/Minorities/Eng/SiteMap htm.

64 Council of Europe Doc. ACFC/SR (99) 3, Report submitted by Finland pursuant to Article 25, 1 , of the Framework Convention for the Protection of National Minorities, 16 February 1999, pp. 2021.

65 Council of Europe Doc. ACFC/SR (99) 3, Report submitted by Finland pursuant to Article 25 , paragraph 1, of the Framework Convention for the Protection of National Minorities, 16 February 1999 , pp. 11-13. 
reindeer herding, without the consultation of the reindeer herders. Besides, the Finnish government has limited the number of reindeer in the Sami Homeland and has weakened the traditional Sami fishing rights. ${ }^{66}$

The Advisory Committee started the examination of the Finnish report in March 1999 and visited Finland in August 1999, where it spoke with government officials, Sami representatives, scholars and other persons and organisations involved. On 22 September 2000, the Advisory Committee adopted its opinion on Finland. It welcomed the measures taken to improve the protection of the Sami, but it expressed its concern at the unsolved question of land rights and the definition of the Sami, which caused tension in the Sami Homeland. These concerns were repeated in the review of Article 5, where the Committee explicitly connected land rights to the protection of the cultural identity of the Sami and acknowledged the central role of the Sami Parliament in this respect. It also expressed the hope that the fact that the Sami Parliament was now responsible for the allocation of the funds for the preservation of the Sami culture would not lead to a reduction of these funds by the State. The Advisory Committee proposed conclusions and recommendations to be adopted by the Committee of Ministers on the definition of the Sami, the dispute over land rights and the guarantee that the funds would remain the same. ${ }^{67}$

In October 2000, the Committee of Ministers adopted a resolution on the implementation of the Framework Convention by Finland. However, this resolution was not as extensive as that proposed by the Advisory Committee. The Committee of Ministers expressed its concern that the issues of land rights and the definition of the Sami were still unsolved and subsequently recommended Finland to take appropriate account of the comments of the Advisory Committee. ${ }^{68}$

Norway issued its first report under the Framework Convention in March 2001. However, this report does not discuss the Sami. While the Norwegian authorities argue that the Sami are a national minority under international law, the Norwegian Sami Parliament does not consider the Framework Convention applicable to the Sami, ".... since as an indigenous people the Sami have legal and political rights that exceed those covered by the provisions of the convention.". The Norwegian authorities respected this wish and did not pay attention to the Sami in their report. ${ }^{69}$

66. The Fimish Branch of Minority Rights Group International (MRG-Finland) and the Finnish League for Human Rights, Comments and additional information to the initial report of the government of Finland on its application of the Framework Convention on the protection of mational minorities, 17 August 1999, pp.6-8, 10-11.

67 Adwisory Conmittee on the Framework Convention on the Protection of National Minorities, Opinion on Finland adopted on 22 September 2000.

68 Committee of Ministers Resolution ResCMN(2001)3 on the implementation of the Framework Convention for the Protection of National Minorities by Finland, 31 October 2001.

69. Report submitted by Norkvay pursuant to article $25 \& 1$ of the Framework Convention for the Protection of National Minorities, 2 March 2001, p. $3 \& 1$. I. Norway has recognised in its report 
While this attitude of the Norwegian Sami Parliament may seem understandable, in that it wishes to emphasise the special status of the Sami as an indigenous people, for example with regard to land rights, it is not a very pragmatic one and perhaps even unwise. As previously explained, apart from ILO Convention 169, there are hardly any international legal provisions on indigenous peoples. However, it has generally been acknowledged that indigenous peoples and their rights to land fall under international provisions on minorities, such as Article 27 ICCPR and the Framework Convention. When searching for protection of their cultural identity and land, indigenous peoples can rely on these provisions. They may not provide for the symbolic recognition of indigenous peoples, but, apart from the right of selfdetermination, which is an issue too complex to be accepted by States anyway, they guarantee protection in the field of (aspects of) cultural identity. By placing oneself outside the scope of the Framework Convention, these guarantees cannot be invoked by the Sami in Norway.

Under Article 5 of the Framework Convention, the Norwegian report paid attention to religion, language and cultural heritage. The Norwegian authorities generally acknowledged that special measures might be necessary to meet the needs of national minorities. However, it was mentioned that these needs were met as far as possible within the framework of general arrangements. No detailed information was given on specific measures taken under Article 5, but general remarks were made on freedom of religion for all citizens, the official status of the Sami language, and the protection of the cultural heritage of national minorities as part of Norwegian cultural heritage. Furthermore, attention was paid to funds for libraries, museums and projects of national minorities in which the communities themselves are involved in the decision-making process as much as possible. ${ }^{70}$

Sweden issued its first report under the Framework Convention in June 2001. In this extensive document, it explained that the Swedish Riksdag had decided in December 1999 , before ratifying the Framework Convention, that five national minorities and languages should be recognised, among which the Sami. ${ }^{71}$ with regard to Article 5 of the Framework Convention, Sweden stated that the Sami language had been recognised and that the culture of the Sami was supported by special funds for the preservation, promotion and dissemination of Sami crafts, arts, music, and literature. These funds are allocated through the Sami Parliament. Furthermore, funds were available for non-profit Sami organisations, education and

five communities as national minorities: the Jews, Kven Roma/Gypsies, Romani/Travellers and Skogfinn.

70 Report submitted by Norway pursuant to Article 25, 8 \& of the Framework Convention for the Protection of National Minorities, 2 March 2001, pp. 23-26.

71 Swedish Report to the Council of Europe on the Framework Convention for the Protection of National Minorities, 1 June 2001, pp. 4, 7. 
research and various projects concerning the Samil culture. ${ }^{72}$ When this study was completed, the Norwegian and Swedish reports had not yet been discussed by the Advisory Committee.

These reports show that, under Article 5 of the Framework Convention, cultural identity is recognised as a general value, but that, in fact, its concrete protection comes down to the protection of specific aspects of cultural identity, such as language, religion and cultural heritage. The concept of cultural identity is not used in any of the reports. It appears that, when cultural identity, as a general value, is translated into policy or a legal provision, it concerns its concrete aspects. While the protection of these concrete aspects of cultural identity may benefit from a right to cultural identity, as is shown by the implementation of Article 5 of the Framework Convention, specific provisions on these aspects provide more clarity on the political and legal implications.

\subsection{ILO Convention 169 on Indigenous and Tribal Peoples}

Another important international instrument in relation to the Sami is ILO Convention 169 on Indigenous and Tribal Peoples. Norway has ratified the Convention, but Sweden and Finland have not. Article 14 of Convention 169 on land rights appears to be the main obstacle. In this article, it is inter alia stated that:

"The rights of ownership and possession of the peoples concerned over the lands which they traditionally occupy shall be recognised. In addition, measures shall be taken in appropriate cases to safeguard the right of the people concerned to use lands not exclusively occupied by them, but to which they have traditionally had access for their subsistence and traditional activities."

Norway was, in fact, the first State to ratify ILO Convention 169, in June 1990. However, the Norwegian government and the Norwegian Sami Parliament do not agree on the interpretation of Article 14(1). To fulfil the legal requirement in Article 14 on land ownership and possession, the Norwegian government finds it sufficient that the Sami enjoy a strongly protected usufruct, while the Sami Parliament maintains that, apart from that, ownership should also be implemented. ${ }^{73}$

The ILO Committee of Experts dealt with these contradictory positions in 1995, on the occasion of the examination of Norwegian reports by the government and Sami Parliament under Convention 169. The Committee of Experts argued that:

72 Swedish Report to the Council of Europe on the Framework Convention for the Protection of National Minorities, 1 June 2001 , pp. 11-12. Attention was also paid to measures in the fueld of religion, but these were not specitically relevant to the Sami.

73 Henriksen, 1996, pp. \&, 12. Norway has issued three reports under ILO Conwention 169 in 1992 , 1994 and 1998, in which it has dealt with the situation of the Sami. These reports are not available on the Intemet. Only the direct requests or observations of the Committee of Expents are available on wwwilo.org. 
"The Committee does not consider that the Convention requires land titles to be recognised in all cases in which indigenous and tribal peoples have rights to lands traditionally occupied by them, although the recognition of ownership rights by these peoples over the lands they occupy would always be consistent with the Convention."

In other words, the Committee left the question open for a final policy decision by the Norwegian government. It is interesting to note that, during the drafting of ILO Convention 169, Norway, supported by Canada, proposed an amendment to Article 14 , along the lines of its current interpretation to replace "rights to ownership and possession of lands" into 'rights to ownership, possession or use of lands'. However, this proposal was not accepted by the International Labour Conference. It was stated that "...to assimilate the term 'use' to ownership and possession would weaken the revised Convention in comparison to Convention No. 107, which recognises the right to ownership..." Finally, the issue of "use" was dealt with separately in the second sentence of Article 14(1). ${ }^{75}$ This matter remains unsolved. However, for the Sami it is important that they do not only have the right to use of the land, but also to ownership of the land, which gives them more certainty about the future use of the land. Considering the text of Article 14 and the drafting process, it was meant to include a recognition of the right to ownership.

Sweden has not ratified ILO Convention 169, because, according to the Swedish government, the ILO provisions on land rights are not compatible with Swedish law. In fact, the Swedish government holds the same opinion as the Norwegian government, and considers the right to usufruct as sufficient implementation of Article 14 of ILO Convention 169. Finland has not ratified ILO Convention 169 either, for mainly the same reasons as Sweden. ${ }^{76}$

\subsection{Protocol No. 3 to the Accession Treaty of Sweden and Finland to the EU}

A rather unknown instrument that could be relevant for the Sami is a Protocol to the Accession Treaty of Sweden and Finland to the European Union. Sweden and Finland acceded to the EU by signing the Accession Acts during the European Council meeting in Corfu in June 1994. In these Acts, special provisions were drafted on the Sami. In Protocol No. 3 of the Act of Accession, the parties recognise the national and international obligations and commitments of Sweden and Finland with regard to the Sami. It is stated that Sweden and Finland "... are committed to preserving and developing the means of livelihood, language, culture and way of life of the Sami people..." Furthermore, it is noted that the Sami culture depends on economic activities such as reindeer breeding in the traditional Sami areas. Consequently, the Parties agree that, notwithstanding the provisions of the EC

74. ILO Committee of Experts, Direct request to the Norwegian government, 1995.

75 Henriksen, 1996, pp. 12-13.

76 Baer, 1996-B, p. 18; Aamio, 1996, pp. 12-13. 
Treaty, exclusive rights may be granted to the Sami with regard to reindeer breeding in the traditional Sami areas. The Protocol may be extended to take account of further developments of exclusive Sami rights related to their traditional means of livelihood. ${ }^{77}$ Not only is this Protocol important for the recognition of the special position of the Sami, it also gives the Swedish and Finnish authorities the possibility of reserving the right to reindeer breeding as an exclusive Sami right. It is, therefore, not self-evident that Finland does not guarantee the Sami an exclusive right to reindeer herding. Part of the problem lies in the fact that this Protocol is not very well known by politicians and by Sami experts. ${ }^{78}$

\section{CONCLUDING REMARKS}

The Sami form an interesting example of a community whose cultural identity needs special protection. The cultural identity of the Sami has been structurally suppressed, because it was considered uncivilised and a threat to modernisation. Furthermore, the States put emphasis on the development of national unity, which implied assimilation of the different cultural communities. In short, the protection of cultural rights is very relevant to the Sami - the question is whether they would benefit from an international right to cultural identity.

The cultural identity of the Sami fits into the description of the concept of cultural identity as given in earlier chapters. The cultural identity of the Sami consists of aspects such as language and special economic activities and is jeopardised by the domination of the majority culture and State measures. The elements of changeability and progress are allso clearly visible in the case of the Sami cultural identity. For example, reindeer herding is nowadays done with modern equipment, such as snow scooters and mobile phones. This progress was actually used by the Finnish government in one of the Article 27 cases to deny that this form of reindeer herding should be considered 'culture'. However, the HRC argued in response that cultures can develop and that the use of modern techniques for reindeer herding does not imply that it can no longer be considered culture."

In general, it should be noted that the national policies of the three Scandinavian countries are no longer focused on assimilation, and that now Sami interests are taken into account. In all three States, Sami Parliaments have been set up to foster Sami interests and the States tend to co-operate with these Parliaments. Again, it should be concluded that the cultural identity of the Sami as such is indirectly protected through preservation of the various aspects of that cultural identity. The protection of Sami interests is, for example, reflected in the national

77 Protocol 3 on the Sami people (Article 49), Official Journal of the European Communities No. L $1 / 10,1-1-1995$.

78 Several experts mentioned unfaniliarity with the Protocol as a reason, among others Mr. Pekka Aikio, chairman of the Finnish Sami Parliament in an interview on 23 and 24 May 2000.

79 Länsman et al v. Funland, Comm. No. 511/1992, Human Rights Conmittee, Final Decisions, UN. Doc. CCPR/C/57/1, 24 October $1994,39.3$. 
policies with regard to the Sami language. The Sami language is taught at schools and, in some areas, can also be used in administrative procedures at the same level as the national language. With regard to reindeer herding, the situation is more difficult. Norway, Sweden and Finland are not actively trying to destroy reindeer herding, but sometimes give preference to other economic activities, such as mining and logging, which take place at the expense of the territories used for reindeer herding. The States further try to limit herd volumes and the size of reindeer territory to allow other economic activities to take place. The main problem in this respect, which can be seen both at national and international level, is the measuring of the impact of such measures on reindeer herding. The measuring often has a quantitative character, meaning that the impact is related to the size of the land that is taken away from the Sami. However, some territories are more important and useful than others. Consequently, both a quantitative and a qualitative control are appropriate to determine whether the measures are compatible with national and international standards.

As stated earlier, the Sami as a community are especially interesting because they have used international instruments and supervisery bodies to claim protection of their cultural rights. Several Sami have brought cases before the HRC under Article 27 ICCPR and have had complaints before the European Commission for Human Rights on several provisions of the ECHR. Although the Sami lost their cases, several important principles have come out of them. The HRC has determined that indigenous peoples can fall under the term "minorities" in Article 27 and that the term 'culture' should be interpreted broadlly, including material resources, thereby implying that land rights fall under Article 27. With regard to the European cases, the European Commission has opened the door for the protection of minority culture under Article 8 on the protection of private and family life. The collective dimension of the claims was also recognised despite the fact that they were brought under individual rights provisions. The importance of these cases therefore lies in the fact that they show the potential of existing human rights provisions for the protection of cultural identity. Again, however, these cases also show that the main issue was not the protection of the cultural identity as such, but of elements of cultural identity whereby the supervisory bodies referred to cultural identity as a general value.

It appears that the Sami are rather successful in preserving their cultural identity in co-operation with the States. One of the reasons is that the Scandinavian countries are economically as well as socially developed countries in which the Sami have also benefited from economic growth. The Sami are not per se poor or uneducated people and the general human rights record of these countries is good. The (physical) existence of the Sami is not threatened. Furthermore, the Sami consider themselves a 'diplomatic people', who have through a pragmatic approach 
towards their governments kept an open dialogue with them. Finally, the Sami are well-organised in Sami Parliaments and active national groups. ${ }^{80}$

International instruments play an important role in the protection of the cultural identity of the Sami. These international instruments have been used by the Sami directly, but they have also influenced national legislation and policies. The special measures that have been taken focus on concrete aspects of the cultural identity, for example, reindeer herding or language, whereby cultural identity plays an indirect role as an underlying principle. Whether this protection would be improved by the development of a separate international right to cultural identity is doubtful. While it may have a symbolic function, such a right would not lead to a concrete improvement in the situation of the Sami. With regard to protection, it needs to come in concrete aspects of their cultural identity, such as the ownership and use of land, for example, for reindeer herding. The Sami have already found their way to international level to claim protection of such aspects, for example under article 27 ICCPR, whereby the protection of their cultural identity played a role in the background. Developing and strengthening these existing international provisions so that the Sami may win future cases is a better way of protecting their cultural identity. A separate general right to cultural identity would be too general and therefore a vague norm. The States, but also the Sami themselves, need more clarity on the obligations and (financial) consequences of such a provision.

80 These conclusions are drawn from discussions with members of the Sami Parliament and members of Sami youth organisations in Mlay 2000. See, also, Korsmo, 1988, p. 517. 


\section{CHAPTER XII \\ TOWARDS A RIGHT TO CULTURAL IDENTITY?}

\section{INTRODUCTION}

Over the last 20 years, the question of whether a right to cultural identity should be developed has been the subject of considerable debate. Although the incorporation of cultural identity as a concept in human rights instruments is not entirely new, and the protection of cultural identity has been included in several, mainly soft law, instruments, no separate right to cultural identity has been adopted. Supporters of the adoption of such a separate right argue that the existing human rights system, with its individual character and underdevelopment of cultural rights, does not meet the claims of individuals and communities for the recognition and protection of their cultural identity. However, the development of a separate right to cultural identity also encounters critics who argue that the concept of cultural identity is too vague to be transformed into a right, and that such a right might cause tension within society and could lead to the approval of intolerable cultural practices. Hence, more clarity is needed on the nature, scope and content of a right to cultural identity. The aim of this research was to examine to what extent a right to cultural identity should be further developed as a separate right within the framework of international human rights law, and what the nature, scope and content of this right could be. To address the subject matter, two lines of research have been followed. The first chapters include a theoretical analysis of the background, nature, scope and content of a right to cultural identity. The subsequent chapters contain a study of existing human rights provisions in international instruments that explicitly or implicitly refer to the protection of cultural identity or aspects of cultural identity. In this concluding chapter, the findings of the research are presented and several concluding observations are put forward on the basis of several questions.

\section{What IS THE VALUE OF CULTURAL IDENTITY?}

The starting point for the research on a right to cultural identity was the clarification of the complex concept of cultural identity (Chapter II). Cultural identity can be seen as the 'personification' of culture. For the purpose of this book, cultural identity was described as a broad concept that involves various culturall aspects such as religion, language, education, cultural heritage and land, which are central to people's everyday lives. Furthermore, it is a dynamic concept that can change and 
develop over time, and it has both an individual and a collective dimension. Cultural identity is an important value for communities and individuals, since it concerns their belonging, their 'roots", and way of thinking, feeling and acting. Most people consider their cultural identity as essential to their life, and value the choice they have made to belong to a certain cultural community because these communities give them valluable life options. As such, cultural identity should be considered as an important element of human dignity. Human dignity is the intrinsic worth of every human being and, as such, the core or basic value of human rights. Respect for human dignity means that individuals are not treated as mere instruments of the will of others, but that the choices of individuals are valued. These choices also include cultural choices. In fact, the suppression or limitation of the development and expression of cultural identity can make people feel alienated, which seriously affects their human dignity. Practice shows that, when the cultural identity of a person or community is jeopardised, suppressed or ignored, the human dignity of that person or community is seriously affected, which can lead to violent conflicts. When cultural identity is threatened or in crisis, in other words, when its cultural aspects are denied development and expression, people become even more aware of the value of their cultural identity. Accordingly, international developments such as liberalisation movements during colonisation and decolonisation as well as the process of globalisation, where cultural identities were, and, indeed, still are, suppressed or surpassed by others, have contributed to the increase in the awareness of the cultural identity of individuals and communities. This awareness has; in turn, led to the claim for the protection of cultural identity as a right.

\section{In What Forms CoUld CULTURAL IDENTITy BE RECOGNISEd?}

Behind the debate on the protection of cultural identity as a right lies a more general discussion on the various ways of accommodating cultural differences in society (Chapter II and III). Policies of tolerance and multi-culturalism have been developed to build a society in which different cultural communities can exist side by side, whereby these communities are both able and allowed to keep a distinct cultural identity against policies of assimilation. Within these policies, different forms of recognising cultural identities can be found. Taylor, for example, suggests the positive recognition of cultural differences by acknowledging specific rights, for example, a right to cultural identity. At the other end of the spectrum, Margalit proposes a negative recognition of cultural differences by emphasising equality and eliminating humiliating treatment. Existing human rights in the field of nondiscrimination and freedom of religion, expression and association play a role in this respect. Margalit suggests that the value of cultural identity for communities and their members should be indirectly endorsed by recognising different cultural communities and identities as a confirmation of the value of difference, without developing a separate right to cultural identity. 
Several times in this book, the different levels of recognition have been addressed. When cultural identity is recognised as a value, several levels of legall recognition are open. A right to cultural identity can be recognised in the form of soft law, which implies a political norm, but has no legally binding force. A step further would be a right to cultural identity as a legal norm in the form of hard law, which has a legally binding character and may be justiciable. Such a right could be an individual right or a collective right. Kymlicka has developed a theory to protect cultural differences by defending collective cultural rights from a liberal perspective. He divides collective rights into self-government rights, polyethnic rights and special representation rights. He argues that some minority communities can rationally claim these collective rights in the light of the value of cultural diversity so as to obtain factual equality with the majority. A collective right to cultural identity falls within the category of polyethnic rights by which communities can develop and preserve their cultural characteristics. However, in my view, these collective rights remain problematical, for example, in relation to the definition of the community and its cultural identity, the 'locking up' of individuals in a collective cultural identity, the relationship between the individual and the community, and the possible confliet between individual and collective rights.

\section{How has Cultural Identity Been Included in Existing human RIGHTS INSTRUMENTS?}

The concept of cultural identity has been included in various international legal instruments, most of which concern minorities or indigenous peoples. In these instruments, which mainly reflect soft law; cultural identity is generally used as a general value or principle, not as a right. This is confirmed by the fact that cultural identity can mainly be found in the Preamble or in one of the first provisions of these instruments.

With regard to minorities, two international instruments that include a reference to the protection of cultural identity have been adopted: the UN Declaration on Rights of Persons belonging to National or Ethnic, Religious and Linguistic Minorities (Chapter VII) and the Framework Convention on the Protection of National Minorities of the Council of Europe (Chapter X). While the UN Declaration is not legally binding, the Framework Convention is, although it contains programme-type provisions that may not be directly applicable and mainly reflect the policy ends to be implemented by State Parties:

The concrete meaning of the provisions that refer to cultural identity is, however, not clear. Cultural identity seems to be used as a general value that underlies specific rights for members of minorities, for example, the right to enjoy their culture, to use their language and practice their religion, as well as their educational rights. These aspects of cultural identity are also included in separate provisions. Because of the general character of the provisions on cultural identity, their content and concrete State obligations are unclear. With regard to the 
collective dimension of cultural identity, the Declaration has a stronger collective outlook than the Framework Convention. The Declaration contains several provisions which refer to minorities as such, which are, however, formulated in terms of duties of States, and not as substantive rights for these communities. The provisions in the Framework Convention are formulated in an individual way, whereby the collective dimension is established by adding that these rights can be enjoyed in community with others.

With regard to indigenous peoples, ILO Convention 169 on Indigenous and Tribal Peoples is, in fact, the only legally binding instrument that includes an explicit reference to cultural identity, although not as a substantive right (Chapter VIII). The UN Draft Declaration on Indigenous Peoples, as well as the draft American Declaration on Indigenous Peoples by the OAS Member States also includes a right to cultural identity (Chapter VIII and IX). In these instruments, cultural identity is again recogmised as a general value that deserves to be respected, protected and promoted, in particular, by various cultural human rights which relate to specific aspects of cultural identity such as language, religion, cultural heritage and land. The new element of a right to cultural identity lies in the field of the recognition of cultural diversity, but does not directly imply a legally binding right that includes concrete State obligations. Such obligations stem from specific cultural rights, for example, concerning language, religion and land.

All instruments pay specific attention to the collective dimension of the rights of indigenous peoples. The collective provisions are mainly formulated as State obligations, and not as substantive rights upon communities, with the exception of the OAS Draft Declaration, which contains a true collective right for indigenous peoples as such. The problems that remain are the definition of the communities, the legal character of indigenous peoples, and the issue of selfdetermination. These form the main reasons why States hesitate to adopt binding provisions. They rarely ratify a binding instrument, such as ILO Convention 169, and, even on a potentially non-binding instrument, such as a Draft Declaration, there appears to be hardly any agreement, which makes its future uncertain.

UNESCO has always been active in the field of cultural rights and a right to cultural identity, which is reflected in several UNESCO instruments that contain a reference to cultural identity (Chapter V), such as the Recommendation on the Participation by the People at Large in Cultural Life and their Contribution to it, and the Declaration on Race and Racial Prejudice. The provisions on cultural identity are not defined in terms of legally enforceable rights, but as general statements on the background of differences between people. The protection of cultural identity as a general value also played an important role in various other UNESCO documents, for example, the Mexico Declaration of the second World Conference on Cultural Policies and the report entitled "Our Creative Diversity" by the Commission on Culture and Development. However, the promotion of cultural rights and a right to cultural identity were heavily criticised by the Member States and UNESCO was forced to follow a less ambitious road. This finally led to the adoption of the 
Declaration on Cultural Diversity in 2001. This Declaration, again, mainly confirms the value of cultural diversity without explicitly defining cultural rights. Many States are, in fact, opposed to the action plan of the Declaration because it includes obligations for States to develop policies.

These developments show that States attach increasing importance to the concept of cultural identity. This concept is used more as a general value than as a right, and, as such, can be seen as a sort of 'underlying principle' of other cultural human rights in the field of language, religion and education. States are not willing to adopt legally binding provisions on cultural identity because of the vagueness and the collective dimension of this concept.

\section{What Role do Other human Rights Provisions Play in the Protection of Cultural IDENTITy?}

From a legal point of view, a right to cultural identity falls naturally within the category of cultural human rights (Chapter IV). Cultural rights are a complex category of human rights, overlapping other categories and including both an individual and a collective dimension. In general, these rights have been neglected by States and scholars. This is due to the vagueness of the concept of culture, the fear that States have that cultural rights may encourage tension within society, and the obscurity of the State obligations which would flow from these rights. These rights are, however, important for the well-being and dignity of human beings and deserve the same attention as other categories of human rights. The importance of cultural identity for human dignity should not be underestimated. Cultural rights are not something "extra" or rights whereby States have mainly a negative role to play. Because of negligence, cultural rights in fact have some catching up to do with regard to their development and clarification. This has been confirmed by the UN Commission, which adopted a resolution in April 2002; which it stressed the importance of the promotion of cultural rights for everyone and respect for different cultural identities. It furthermore emphasised that cultural rights are an integral part of human rights and that States have the main responsibility for the promotion and protection of the full enjoyment of cultural rights by everyone.

In this book, a distinction has been made between cultural rights in a narrow sense, which consist of provisions that explicitly include the term "culture", and cultural rights in a broad sense, which, besides the aforementioned provisions, also contain all other human rights provisions that concern aspects of culture, such as language, education and religion. A right to cultural identity fits both into the narrow group, since it explicitly refers to culture, and into the broad group, according to its broad description, and the fact that it is perceived as a process. Due to its comprehensive scope, a right to cultural identity could actually be considered to be one of the central cultural rights, including an individual and a collective

1 See Commission on Human Rights Resolution 2002/26. Promotion of the enjoyment of the cultural rights of everyone ond respect for different cultural identivies, 22 April 2002, Preamble and 5 . 
dimension. The main question is what role existing human rights alleady play in relation to the protection of cultural identity. In this book, several cultural rights which belonged to the narrow group were extensively discussed, while other provisions which belonged to the broad group were elaborated upon on the basis of the case law of various supervisory bodies. It appeared that several of these rights offer important possibilities for the protection of cultural identity.

The first provision that comes to mind is the right to participate in cultural life, which is a legally binding provision laid down in Article 15 of the International Covenant on Economic, Social and Cultural Rights (Chapter VI). The content and State obligations of the right to participate in cultural life have been developed. While it was initially meant to make material culture available and accessible to the masses, and no reference was made to the protection of the cultural identity of individuals or communities, it now has a much broader scope and content. Although not yet officially confirmed in a General Comment, it is generally agreed that Article 15 ICESCR no longer merely refers to national culture; States are also considered to have a responsibility for the preservation of the cultural identities of other communities, whereby the collective dimension of Article 15 is also acknowledged. Furthermore, a broad approach towards the concepts of culture and participation seem to be appropriate. Although the Committee on Economic, Social and Cultural Rights still seems to stress negative State obligations, such as the obligation to respect, in my view, Article 15 implies negative as well as positive obligations, and includes the obligation to respect, protect and fulfil. These obligations include, inter alia, respect for the freedom to provide and collect cultural information, protection of culture from disrespect by others, and active support, also financial, of the accessibility of culture, including the necessary cultural infrastructure. As such, the right to participate in cultural life could be important for the protection of the cultural identity of individuals and communities.

Another important provision in relation to the protection of cultural identity is Article 27 of the International Covenant on Civil and Political Rights, which concerns the right to enjoy culture, language and religion for members of minorities (Chapter VID). Although formulated in individual terms, its collective dimension is recognised by adding that the rights can be enjoyed 'in community with others'. In comparison with the drafting of Article 15 ICESCR, the concept of culture in relation to minorities was broader from the beginning of the drafting, and included language, religion, cultural heritage and other characteristics of these communities. The subject and State obligations of Article 27 have developed into a broader perspective than was foreseen by its drafters. The subject of Article 27 now also includes members of indigenous peoples and other communities, who do not have to be nationals of the State. Furthermore, although formulated in the negative terms of 'shall not be denied the right to', it is generally agreed upon that States have all three types of obligations to respect, protect and fulfil under Article 27. 
The relevant cases confirm the broadening of the content and scope of Article 27. The Human Rights Committee accepts all kinds of communities, represented by individuals, as claimants, and it uses a broad and dynamic concept of culture, including aspects such as language and religion; but also economic activities. These activities have to be essential for the culture of the community, but do not have to remain as traditional as they were. For example, adaptation of traditional economic activities to modern techniques does not prevent such activities from falling under the term "culture'. These cases show that, apart from cultural or linguistic rights, land rights also fall under the classification of 'enjoyment of culture' in Article 27. The interpretation by the Human Rights Committee shows the significance of this provision for the protection of the cultural identity of individuals and communities. The protection of cultural identity as an overarching value is referred to as the background of Article 27 in several cases.

Besides the provisions that directly refer to culture, other provisions relating to aspects of cultural identity also turned out to be important for the protection of cultural identity. The European Convention on Human Rights, for example, does not include a provision on cultural identity, but various cases before both the European Commission and the European Court on Human Rights show that several ECHR provisions offer possibilities in relation to the protection of cultural identity (Chapter X). In several cases, the protection of cultural identity is 'read into' ECHR provisions on, for example, freedom of expression, religion and association. In the Cases of Sidiropoulos v. Greece and Chapman v. the UK in particular, the European Court makes an explicit reference to the protection of minorities and their cultural identity. In Sidiropoulos, the Court argued that cultural organisations set up to preserve and develop the minority culture and traditions are protected under the right to freedom of association. In Chapman, the Court argued that, in principle, the traditional way of life of a gypsy minority is protected under Article 8 on the right to respect for private life, family life and home. Hence, although cultural identity is not, as such, protected by the ECHR, and the Court has not yet established an explicit relationship between religion, expression and education, and cultural identity, various provisions of the ECHR offer potential tools for the protection of cultural identity. While the Court generally recognises negative State obligations with regard to the protection of aspects of cultural identity, it does, however, continue to have reservations with regard to positive State obligations.

Within the human rights system of the Organisation of American States a similar outcome was found (Chapter IX). Cultural rights are not a prominent part of this human rights system: rights explicitly referring to culture were hardly included in either the American Declaration or the American Convention. The Protocol of San Salvador includes cultural rights comparable to the ICESCR, but its supervision is limited. However, the Americas have specific problems with regard to indigenous peoples and the protection of their cultural identity, which is, in particular, reflected in land rights. Land rights or other indigenous rights, too, are nowhere to be found 
in the American human rights instruments. It is, therefore, interesting to note that the protection of the cultural identity of indigenous peoples and, more specifically, their rights to land, appear to fall under other human rights, such as the right to life and health, the right to non-discrimination, and property rights. The Yanomami Case and the Miskito Case show that the Inter-American Commission on Human Rights (IACHR) is willing to go beyond the norms laid down in the American Declaration and the American Convention by using Article 27 ICCPR with regard to the protection of the cultural identity of indigenous peoples. The IACHR and the Inter-American Court also use various provisions of the American Declaration and Convention to protect the cultural identity of indigenous peoples, for example, the right to life and health, and freedom of expression and religion. The IACHR explicitly uses the term "cultural identity" in a broad context as a general value which not only implies land rights, but also rights to language, religion and cultural heritage. The case of the Awas Tingi forms the culminating point with regard to land rights for indigenous peoples. In this case, which was the first case on indigenous land rights ever brought before the Inter-American Court, the Court affirmed that indigenous peoples have the collective right to ancestral land and that the State has a responsibility to demarcate such land and to proteet it from exploitation by third parties. Although the Court did not use the term 'cultural identity', it established a connection between the land and culture of the community involved. Without concrete cultural rights or land rights, and without a right to cultural identity, the cultural identity of indigenous peoples, in these cases reflected in land, is protected by existing human rights provisions.

\section{What ARE THE SUBJECT, OBJECT AND State Obligations of A Right TO CULTURAL IDENTITY?}

The above has clearly established that cultural identity is an important value and an element of human dignity that deserves to be protected. The central question is, however, to what extent a separate right to culturall identity should be developed. To answer this question, more clarification was searched for with regard to the object, subject and addressee of this right.

\section{Subject}

The subject of a right to cultural identity could be the individual or the community. Many have promoted the adoption of a collective right to cultural identity, because the collective character of cultural identity could only be protected by a collective right. It is clear that cultural communities are important for the well-being of individuals and that individuals create and develop their cultural identity through participation in different communities. The demand for a collective right to cultural identity might, therefore, be justifiable from a social perspective, but, in legal terms, it remains problematic. In general, it was argued in this book that collective rights should only be developed if they add protection to individual human rights, 
whereby, in principle, individual rights and freedoms precede over collective rights. Otherwise, there would be a risk that collective rights diminish the protection and promotion of individual human rights.

However, a collective right to cultural identity poses many difficulties. First, it is nearly impossible to draft a definition of the subject of collective rights, for example a people or a community as such, acceptable to communities and States. Secondly, the object of a collective right to cultural identity, in the sense of the cultural identity of a community as such, is difficult to describe, and depends partly on the level of community. The cultural identity of a State, for example, is more complex and broad than the cultural identity of a specific religious community. The more comprehensive the community, the more complex the content of a right to cultural identity becomes. An important question in this respect is: who decides what the cultural identity of the community is? This brings us to the final and most important issue that raises serious concerns; the position of the individual in relation to the community. In principle, the collective cultural identity of a community should be developed and established by the collective will of the (majority of its) members, and should not be imposed from above by a small élite. Individual members should be able to take part in the decision-making process concerning the content and development of the cultural identity of the community to be protected. Furthermore, a collective right to cultural identity, which protects the cultural identity of the community, should not imply that individuals belonging to that community have less opportunity to develop their own cultural identity. They should not be 'locked up' in a collective cultural identity that they do not consider to be theirs. A single right to exit is not a sufficient guarantee in this respect, because it is not always an option in practice.

It was concluded in this study that a right to cultural identity should not be developed as a collective right. There is no doubt that cultural identity has a strong collective dimension that should be recognised in a right to cultural identity. However, the aforementioned issues regarding the content, collective subject, and position of the individual cannot be solved. In particular, the arguments of "locking up' individuals in a collective cultural identity, the suppression of individual freedoms by the collective protection of cultural identity, and the representation of individuals in the decision-making on what the cultural identity of the community is, are convincing. In relation to cultural communities, there are numerous examples of the oppression of individuals by the community's 'cultural' rules, in particular, the subordinate and vulnerable position of women. In my view, a collective right to cultural identity would merely add a symbolic gesture to individual rights by recognising the importance of cultural communities for the human dignity of individuals. However, such recognition could also be achieved by an individual right if it included a firm collective dimension. By adding that such a right could be enjoyed in community with others, or by individuals as members of a community, the collective dimension, which is essential in relation to the collective nature of cultural identity, would be established without developing a collective right. 


\section{Object and State Obligations}

The object of a right to cultural identity is cultural identity itself. As shown above, cultural identity is a complex concept, including various aspects, such as language, religion, education and land. Cultural identity is also a dynamic concept which can change and develop. The broad nature and scope of a right to cultural identity make it difficult to determine specific State obligations and a core content. It remains unclear what one is entitled to when invoking a right to cultural identity.

In general, the State obligations relating to a right to cultural identity are of a broad nature and include positive as well as negative obligations, including obligations to respect, protect and fulfil. As to their content, it has been argued that these State obligations do not relate to the protection of cultural identity as such, but instead concern the protection of particular aspects of cultural identity. As such, a general right to cultural identity may imply obligations in the fields that cover the various aspects of cultural identity, such as language, religion and land, which could include all three types of obligations to respect, protect and fulfil. With regard to indigenous land rights, for example, States are obliged to respect the traditional use of the land, or lands, of an indigenous community. They should also protect this use of land against interference by third parties. An obligation to fulfil, recognised by the Inter-American Court of Human Rights in the Awas Tingi Case, is that the State should demarcate the land(s) of indigenous peoples. The European Court of Human Rights is less convinced of positive State obligations in the field of cultural identity, but has, for example, in the Sidiropowlos Case, argued that the State should respect, protect and support minority cultural organisations. Under Article 27 ICCPR, the Human Rights Committee has determined that States are, inter alia obliged to consult the community involved, and to limit the impact of the measures taken.

In short, a broad range of State obligations in relation to the various aspects of cultural identity could fall under a right to cultural identity. The promotion and protection of these aspects of cultural identity would, however, benefit more from further developing these aspects as separate rights, than from a general right to cultural identity. For example, in the fields of linguistic rights and land rights, more clarification and better implementation appear to be necessary. Apart from developing and clarifying such cultural rights, the cultural dimension of other human rights should be developed. Instead of developing new rights, such as a right to cultural identity, the protection of cultural identity could be 'read' into the existing cultural human rights, whereby cultural identity would serve as an underlying principle ${ }^{2}$ not only for the further development of cultural rights, such as linguistic rights, religious rights and land rights, but also for other human rights, such as the right to family life, housing and health.

2. The general term 'underlying principle" or 'principte' has often been used in this study. These terms may refer to a policy objective, as, for example, in the Framework Convention on the Protection of National Minorities (Preamble and Article 3(2), or to the underlying idea or starting point for the elarification and implementation of cultural rights. The question as to whether the right to cultural identity could be considered a principle of human rights law is adoressed below. 


\section{Should a SEParate Human Right to CUltural IDENTITy be DEVELOPED?}

Whether or not a separate right to cultural identity should be developed, depends, to a certain extent, on what kind of right is to be developed. In fact, the central question focused on whether or not a right to cultural identity should be developed as a separate human right within the framework of the International Bill of Human Rights, which implies a right in a legally-binding instrument which is, possibly, of a justiciable nature: But, as explained above, other levels of recognition, for example, in the form of soft law, are also possible. The above leads primarily to the conclusion that no separate right to cultural identity should be developed in the form of hard law or soft law. Although it is true that cultural rights have generally been neglected and that the protection of cultural identity as an important value and element of human dignity would fit into the human rights sphere; translating cultural identity into a separate right is neither desirable nor necessary. It is not desirable because translating the vague and general concept of cultural identity into a right would risk abuse or suppression of individual rights and freedoms withiri a cultural context. It is not necessary because existing cultural rights in the broad sense already offer possibilities for the protection of cultural identity. Hence, a separate right to cultural identity cannot satisfy the criteria for the proliferation of human rights, namely, that new rights should only be developed if they truly add something to the existing human rights, if there is sufficient consensus among States, and if they are sufficiently clear to bring about rights and obligations. ${ }^{3}$

The concept of cultural identity is too broad and vague to be translated into a separate human right. The comprehensive nature of cultural identity cannot be reduced to a concrete right. Both the object and the State obligations of such a right would be equally broad and, therefore, vague, which would prevent such a right from being justiciable. A right, especially if it were to have a justiciable character, should be sufficiently clear to be used before a judicial body, and the State obligations to the right should be concrete. Both are problematical in relation to a right to cultural identity, because cultural identity is a broad and dynamic concept. In principle, various other human rights relate to vague and dynamic concepts, for example, freedom of religion or the right to privacy or family life, but cultural. identity concerns so many different fields and aspects that it is difficult to determine what one is actually entitled to when invoking this right. This is confirmed by the analysis of the existing provisions that explicitly refer to cultural identity. A closer look at them reveals that they do not so much contain justiciable rights, but more generally express the importance of cultural identity as a general value that deserves protection through rights relating to specific aspects of cultural identity. Again, several other human rights can also be described as broad, but, basically, they remain in one field, for example, religion. In contrast, cultural identity covers many

3 These criteria are taken from Alston, 1984, pp. 614-615. See, also, Chapter I of this sturdy. 
different fields, such as language, religion, education, land, and cultural heritage, which all have their own object, subject and State obligations. ${ }^{4}$

However, the broadness of the concept alone would be insufficient reason to reject a right to cultural identity. It is the risk of the abuse of this vague and broad right, for example the suppression of individual rights and freedoms, that is decisive. Because the concept and thereby the right would be vague and general, it could be misused to excuse intolerable practices. This is, for example, the difference between cultural identity and non-discrimination. Both concepts are broad and cover many different fields. However, the right or principle of nondiscrimination does not risk being abused in the way that a right to cultural identity does. A separate right to cultural identity might be abused to excuse questionable cultural practices within cultural communities. In this book, it has been argued that, in general, the rights of communities should not prevail over the rights of the individual members. Kymlicka, for example, asserts that, although cultural communities may have collective rights against the majority in the form of "external protection'; they should respect the rights of their members and may not impose what he ealls 'internal restrictions'. Several authors, however, argue that communities may limit the rights of their members as long as the right to exit is guaranteed. In my view, the right to exit does not provide sufficient protection of individual interests against potential suppression by the cultural community, because, in practice, it is not always an option. These matters should, in principle, be dealt with on a case-to-case basis, depending on the community and situation involved. However, it has also been argued in this book that, although cultural communities may have a certain freedom to organise their internal structure, they should always guarantee the physical and mental well-being of their members and respect their rights to participate in society in general, for example, through education or elections, in order to be able to develop themselves. Furthermore, members should be able to participate in the community, to be able to take part in the decision-making process of the community in order to change things. If certain groups for example women, are excluded from the decision-making process of cultural communities such as religious communities, they still have to depend on men to change rules if they wish to do so.

The vagueness of the concept of cultural identity is one of the main reasons that States are hesitant to adopt a separate right to cultural identity or other legally binding provisions in relation to cultural identity. They generally appear to be unwilling to be legally bound by cultural rights, and have reservations about positive obligations in relation to cultural rights. The failure to adopt the Additional Protocol to the ECHR in the Cultural Field is a good example in this respect. The attempt to draft such an Additional Protocol shows how difficult it is to draft a legal

4 The concept of cultural identity could, in fact, be even broader, to include the arts, literature, museums, sports, etc., which were excluded from this research but fall within the concept of cultural identity. 
instrument on cultural rights including a right to cultural identity. Hardly any draft provision could pass the test of adding something to the ECHR and being universal and justiciable. The right to cultural identity was rejected mainly since it was considered not to be justiciable, because of the vagueness of the concept, and because a right to cultural identity would not add protection to the ECHR. Furthermore, it was asserted that emphasis on cultural identity might encourage tensions such as xenophobia, nationalism and tribalism, and that such a right could be interpreted as supporting questionable cultural activities. Another example where States hesitated to be bound by cultural rights is the UNESCO Declaration on Cultural Diversity. Although States have confirmed the value of cultural diversity in this Declaration and have laid down interesting principles, most States explicitly objected to its plan of action, according to which concrete policies had to be adopted.

The UNESCO Declaration is a form of soft law, which could, in principle, be an alternative for developing a separate right in the form of hard law. Soft law or a declaration would establish its value, but concrete measures that States should take generally remain rather open-ended, because the rights are not legally enforceable. As soft law, a separate individual right to cultural identity would not, in my opinion, add extra protection of cultural aspects or cultural identity to the existing human rights provisions if they were further clarified and implemented.

Another reason to reject a separate right to cultural identity is that existing human rights provisions at the international and regional level already offer possibilities in relation to the protection of (aspects of) cultural identity; for example, through freedom of expression, freedom of religion, freedom of association, and the right to education. Land rights could be claimed under various provisions, such as the right to life, health, family life and home. By protecting and promoting these provisions, they would indirectly protect and promote cultural identity as a general value. In several cases, supervisory bodies have established that certain State obligations in relation to specific cultural aspects serve the more general value of cultural identity as part of human dignity. In other words, developing a separate right to cultural identity is not necessary. A right to cultural identity must avoid meeting the same fate as the right to development, which was laid down in a LNN Declaration, and adopted by the UN General Assembly by a small majority and without general consensus. ${ }^{5}$ Although the right to development was confirmed at the Human Rights World Conference in Vienna, its practical impact is still limited. The dispute on the content and scope of the right to development is ongoing and many reject it as not workable as a human right. Such a rejection obscures the fact that, similar to a right to cultural identity, a legitimate claim lies behind the right to development."

5 Declaration on the Right to Development, UN General Assembly Resolution 41/128, annex, 41 UN GAOR Supp. (no. 53) at 186, UN Doc. A/41/53 (1986)

6 Vienna Declaration and Programme of Action, 1993, 10 and 11. See, on the right to development, for example, Steiner and Alston, 2000, pp. 1315-1333. 
However, the possibilities offered by existing human rights provisions for the protection of cultural identity should be further developed through the clarification and implementation of these provisions in the light of the protection of cultural identity. The general concept of cultural identity could thereby play its own role as an underlying principle for this process of implementation and clarification.

\section{The Emergence of Cultural Identity as a Principle of Human RIGHTS LAW}

Cultural identity should not be developed as a separate individual human right. Instead, as an important element of the dignity of human beings, it could be used as an emerging principle of human rights law for the interpretation, development and implementation of human rights, especially cultural rights. Principles of international law are those principles that can be found in almost any legal system in the world and which are necessary for a proper application of the law (Chapter IV). These principles include, for example, good faith, the prohibition of the threat or use of force, peaceful dispute settlement, non-interference in internal affairs, the duty to co-operate, reciprocity, the equality of States and the legal vallidity of agreements. In relation to human rights, under the core value of human dignity, principles of law include, for example, equality, non-discrimination, and selfdetermination of colonial peoples. ${ }^{8}$ Cultural identity has been argued to be an important element of human dignity, which is based on the right to be different as an elaboration of the principle of non-discrimination. As such, cultural identity can be used as an emerging principle of human rights law.

Cultural identity is, however, not yet a principle of law, which is why I chose the term 'emerging'. It has been increasingly used in international instruments, but, compared to other principles, such as non-discrimination and selfdetermination, it is less developed and clarified and not always specifically recognised as a principle. It is therefore 'emerging', but I consider this development important, and would plea for the development of cultural identity into a principle.

In fact, this principle should be formulated as freedom of cultural identity. As explained in the general introduction, the right to cultural identity is a rather odd formulation, because cultural identity, as such, cannot be given to individuals. Protection or development of cultural identity could be an alternative, but freedom of cultural identity is a better way of formulating the matter, because it reflects a more dynamic approach and implies the right to change cultural identity. In this respect, it resembles the right to freedom of religion, which is also a general

7 See, irter alla, Kooijmans, 2000, p. 14 and Brownlie, 1990, p. 19, and UN Doc. A/Res. 2625 (XXV) or A/8028, Declaration on Principles of International Law concerning Friendly Relations and Co-operation among States in accordance with the Charter of the United Nations, adopted by the General Assembly on 24 October 1970.

8 De Wart, 1991, pp. 228-229. In its interesting to note that, in this article, de Waart argues that the rigltt to development is a new principle of modern international law. See, also, Kooijmans, 2000, p. 14 and the Preamble and Article $\$ of the Charter of the United Nations. 
concept with an individual and a collective dimension. To avoid confusion with a right, I have chosen the formulation of freedom of cultural identity, without any reference to a right. The formulation of freedom of cultural identity does not, however, imply an emphasis on negative State obligations. It implies, in principle, negative as well as positive obligations. It includes respect for cultural identity, the protection of cultural identity, as well as the promotion of cultural identity.

Freedom of cultural identity as an emerging principle has a different character than as a separate right. Dworkin has made a firm distinction between principles and rules of law. His characterisation of principles of law shows several similarities to the way that $I$ suggest that freedom of cultural identity be considered. Dworkin argues that principles of law have a more general character than rules of law, which should have a more concrete content. Furthermore, principles are of a normative nature and have no direct effect, but indirectly influence the implementation and interpretation of rules of law. Finally, they have a less coercive character. More than one principle may be applicable to a certain case, and supervisory bodies should evaluate which principle has the most importance in that specific case and should be given precedence.

Freedom of cultural identity as a principle has the same characteristics. It has been demonstrated in this book that cultural identity is increasingly used in international human rights instruments, mainly 'soft law" declarations. In these instruments, it can often be found in the Preamble or in one of the first provisions, showing its general character as an underlying principle for the provisions in the instrument. Furthermore, the general character of freedom of cultural identity exceeds the various categories of human rights and, as such, gives expression to the indivisibility of human rights. Freedom of cultural identity as an emerging principle of human rights law could form one of the basic or underlying ideas for the interpretation and implementation of human rights, especially cultural rights. It may be applicable next to other principles such as non-discrimination, whereby supervisory bodies decide which one takes precedence over the other in a specific case.

9 Dworkin has elaborated this difference in his Taking Rights Seriously, Harvard University Press, 1977. This volume was a reaction to positivism represented, inter alia, by Hart in The Concept of Low, Clarendon Law Series, 1961. His firm distinction between principles and rules of law has been criticised by others, for example, by N. MacCormick in Legal Reasoning and Legal Theory, Kluwer, 1982, and R. Alexy in Rechtspegeln und Rechsprinzipien, Archiv fur Rechts und Sozialphilosophie, 1979. Several reactions to Dworkin are incorporated in M. Cohen (ed.), Ronald Dworkin and Contemporary Jurisprudence, Duckworth London, 1984. Findeed, it could be argued that the firm distinction between prineiples and rules of law should be softened, since principles are important as instruments in interpreting rules of law. Especially in a human rights context, the difference between principles and rules of law is not that strong, since several principles have also been codified as rules, for example, non-discrimination, and because both often hawe a general character.

10 Dworkin, 1977, pp. 24-28. See, also, Bruggink, 1990, pp. 132, 136. 
Freedom of cultural identity as a principle could help to 'colour' existing human rights provisions. Human rights provisions should be considered from a more cultural perspective, whereby the cultural dimension of all human rights is developed, using a broad concept of cultural identity and its collective dimension. The emergence of cultural identity as a principle is beneficial to both the narrow and the broad group of cultural rights, which are most directly applicable to the protection of cultural identity. It is, however, also relevant for other human rights outside the category of cultural rights. In fact, the UN Commission on Human Rights recognised in a resolution on cultural rights of April 2002 that "...the promotion of the cultural rights of everyone, of respect for distinct cultural identities of peoples... advances the implementation and enjoyment of all human rights by all." It further recognised that States have the primary responsibility for the enhancement of respect for different cultural identities."

The Committee on Economic, Social and Cultural Rights has already started to include a cultural paragraph into several General Comments on provisions of the ICESCR. It has, for example, determined that the right to adequate housing implies that the construction of houses, the building materials and the supporting policies "...must appropriately enable the expression of cultural identity and diversity of housing." "With regard to the right to health, the Committee has, inter alia, determined that "...all health facilities, goods and services must be...culturally appropriate, i.e. respectful of the culture of individuals, minorities, peoples and communities, and sensitive to gender and life-cycle requirements..."13 The clarification of other rights, such as the right to freedom of expression, religion or association, could also be given a cultural dimension, whereby freedom of cultural identity serves as one of the principles for the interpretation and clarification of these rights. Supervisory bodies and States could, for example, determine both the core content and State obligations of specific cultural rights provisions, in which they could also pay attention to the role of these provisions in the protection of cultural identity. They should also involve the collective dimension of cultural identity in this process. Supervisory bodies could, for example, pay attention to communities in dealing with State reports and could refer to the community behind the individual claimant in certain cases. The clarification and implementation of existing human rights provisions, especially cultural rights, against the background of the right to freedom of cultural identity, diminishes the need to develop a separate right to cultural identity and will probably be more successful than the

11 See Commission on Human Rights Resolution 2002/26, Promotion of the enjoyment of the cultural rights of everyone and respect for different cultural identities, 22 April 2002, $\$ 5$ and 11 .

12 Committee on Economic, Social and Cultural Rights, General Comment No. 4 on the Right to Adequate Housing (Article 11(1)), 31. December 1991, \$8g.

13 Committee on Economic, Social and Cultural Rights, General Comment No. 14 on the Right to the Highest Attainable Standard of Health (Article 12), $1 \|$ August 2000, $\$ 12 \mathrm{c}$. In General Comment No. 12 on the Right to Adequate Food (12 May 1999) and General Comment No. 13 on the Right to Education (\& December 1999), several references be found that the guarantees provided should be culturally appropriate or acceptable. 
development of such a right. As such, it will be more beneficial for the Yanomami Indians in Brazil, the Indians of the Awas Tingi community in Nicaragua, the Aborigines in Australia, the Kurds in Turkey, the Sami in Finland, the Rona in many parts of Europe, but also new immigrant communities and all other individuals and communities who are fighting for the protection of their cultural identity.

Article 15 ICESCR on the right to take part in cultural life is an important cultural right that could accordingly be clarified by the Committee on Economic, Social and Cultural Rights in a General Comment. In such a General Comment, the Committee should endorse the broad concept of culture, including not only its practical results, but also non-material aspects, such as language, religion, education, and land. The Committee should also establish the collective dimension of Article 15, for example, by referring to the importance of cultural communities for individuals. The Committee should further determine that participation in culture is more than having access to it, and that it includes active participation in the decision-making process and the ability to contribute actively to culture. With regard to State obligations the Committee could stress the negative obligations, such as the obligation to respect the free development and expression of culture, but it should also define positive obligations to protect and to fulfil. States should, for example, protect cultural participation from disrespect by others, and should take various positive measures with regard to the collection and dissemination of cultural information and the accessibility of culture. In order to keep it as open as possible, the Committee should not list these measures exhaustively, but it could identify various issues, such as exemptions from laws that penalise cultural practices, for example, special hunting and usufruct laws, or specific measures, such as motorcycle helmet laws for Sikhs, the funding of ethnic associations or multilingual ballots or special voting measures, or the protection of symbolic claims, such as religious holidays. ${ }^{14}$ Finally, the Committee should, in its General Comment, deal with sensitive issues, such as cultural activities that violate human rights. The Committee could, for example, explicitly determine that the implementation of Article 15 may not restrict the individual rights and freedoms of the International Bill of Human Rights.

The 'colouring' of human rights provisions by the emerging principle of freedom of cultural identity could also take place in case law. Freedom of cultural identity could be a guiding principle in the application of vague norms. As such, it could play an important role in specific cases, where claimants apply existing human rights provisions, but where a broader, more cultural perspective of the case would be appropriate. Existing examples are the Chapman Case and the Awas Tingi Case, which show that land rights or housing rights could be placed in a broader context, whereby freedom of cultural identity serves as a guiding principle. These cases

14 See, for example, Levy, 1997, p. 25. 
were not only considered from the mere perspective of land or home, but from the broader perspective of freedom of cultural identity. The same can be said for the Sidiropoulos Case, which strictly concerned freedom of association, but where a broader context including freedom of cultural identity was adopted, because the organisation involved concemed the cultural identity of a minority group. Another example could be a case concerning the protection of a certain language in education, in the form of language courses in a minority language. Supervisory bodies could deall with such a case not only from the strict perspective of the right to education or linguistic rights, but could also consider the broader context by applying freedom of cultural identity. They could, depending on the circumstances, argue that the State should support language courses in the minority language, because of the importance of this language in relation to the freedom of cultural identity of the applicant and thereby the community involved.

An advantage of developing freedom of cultural identity as a principle, instead of a legal right, is that it does not have to be laid down or described in a specific document, not even a soft law declaration; supervisory bodies can use it anyway. Freedom of cultural identity as a principle could thereby reflect its broad and dynamic character, not limited by a certain description. The proposed use of freedom of cultural identity does not so much concern the legal form, but mainly concerns the substantive side of using this normative concept for the interpretation or clarification of legal norms.

It would be a big step further to establish this principle explicitly as an element of human dignity, for example, in a General Comment. This would not so much imply the codification of cultural identity as a separate right or the recognition of a new rule, but the confirmation of a principle to be used to clarify and implement provisions in the Covenants. As argued above, the general character of freedom of cultural identity makes it more suitable for a principle to be used in the interpretation and development of human rights, than for a separate human right by itself. Such codification should emphasise this character, and could include, for example, which human rights play a role in this respect.

Such a General Comment could be adopted by the Human Rights Committee and the Committee on Economic, Social and Culturall Rights together, since freedom of cultural identity involves various human rights provisions from both Covenants. It should be noted that such a step, which requires consensus among the Committees, will not be taken soon. So far, the Committees have never adopted joint General Comments and, to date, General Comments have always concerned specific provisions of the Covenants and not, as suggested here, a certain principle. Freedom of cultural identity would, however, pre-eminently require the co-operation of both supervisory bodies, which would also improve the coherence of both Covenants. The outcome of the discussion on a General Comment on Article 15 ICESCR on the right to participate in cultural life will be an important guideline in this respect. 
The proposed protection of freedom of cultural identity as a principle of human rights law connects with the policies of tolerance and multi-culturalism, recognising the value of cultural differences and of cultural diversity. Not recognising a separate right to cuitural identity, but developing this concept as a principle for the interpretation and implementation of cultural rights, relates to the 'negative recognition' of cultural differences as suggested by Margalit (Chapter II). Instead of positively recognising cultural identity in the form of a right, he suggests that cultural identities be recognised negatively by confirming the value of difference, and eliminating disrespect and discrimination. Human rights provisions, such as non-discrimination and freedom of religion, expression and association, play a role in this respect. In this book, a similar suggestion has been put forward, not to develop a right to cultural identity as a separate right, but, instead, to have it serve as an emerging principle for the interpretation and implementation of existing human rights.

However, an important comment should be made here. Even as a principle, cultural identity could be misused, in an indirect way, by States or communities to impose a cultural identity upon individuals or to restrict individual freedoms under the denominator of cultural identity. Policies of tolerance and multi-culturalism should not be applied uncritically. They should not imply the uncritical acceptance of cultural practices that limit the rights and freedoms of others. In fact, the policy of multi-culturalism has been criticised by various scientists and politicians. ${ }^{15}$ While a critical attitude towards cultural communities is necessary to protect individuals against their community, this critical attitude should not lead to a rejection of cultural rights or cultural identity as a whole. Cultural human rights as well as freedom of cultural identity as a principle are essential to protect an important part of the dignity of human beings. Many communities and individuals need such protection and need extra attention for their cultural identity. However, freedom of cultural identity as a principle should not be used to excuse or tolerate cultural practices that violate human rights. While supervisory bodies should be aware of this principle and should, where appropriate, apply it, they should take into account that the protection and promotion of cultural identity as an emerging principle should not restrict the implementation of human rights and should not be in conflict with the core value of human rights, namely, human dignity. Tolerance and multiculturalism should be the basis not only to end policies of forced assimilation and discrimination of individuals and communities, but also to respect the right to be different based on the human rights principle of equality. The right to be different, as described in the Preamble of the UNESCO Declaration on Race and Racial Prejudice, implies the right not to be exciuded, humiliated, exploited or forcibly assimilated. It is in relation to these issues that freedom of cultural identity should be respected, protected and promoted.

15 After the terrorist attacks in September 2001, the idea of multi-culturalism and respect for different cultural identities has been under heavy pressure. During the Dutch election campaign in April 2002, it was suggested that 'the multi-cultural society be abolished'. See, also, Entzinger, 2002. 


\section{SAMENVATting}

De laatste 20 jaar is steeds meer discussie ontstaan over de vraag of binnen het internationale mensenrechten systeem een recht op culturele identiteit moet worden ontwikkeld. De voornaamste reden hiervoor is dat het bestaande mensenrechten systeem, met haar individuele karakter en matige ontwikkeling van culturele rechten, niet tegemoet komt aan de roep van individuen en gemeenschappen om hun culturele identiteit te erkennen en beschermen. Tegenstanders van het ontwikkelen van een dergelijk recht stellen echter dat het concept van culturele identiteit te vaag is om in een recht te worden omgezet. Bovendien kan dit recht spanningen in de maatschappij oproepen en kan het leiden tot een goedkeuring van onacceptabele culturele praktijken. Kortom, meer helderheid is nodig inzake de achtergrond, reikwijdte en inhoud van een recht op culturele identiteit. Centrale vraag in dit onderzoek was dan ook in hoeverre een recht op culturele identiteit verder zou moeten worden ontwikkeld als een afzonderlijk recht binnen het kader van de internationale mensenrechten en wat de achtergrond, reikwijdte en inhoud van dit recht zouden kunnen zijn.

\section{Het concept culturele identiteit en de erkenning van culturele verschillen}

Voorafgand aan de analyse van een recht op culturele identiteit; moet er meer duidelijkheid zijn over het concept 'culturele identiteit' (hoofdstuk II). Culturele identiteit kan worden beschouwd als de personificatie van cultuur. Het is een breed concept dat verschillende culturele aspecten in zich draagt, zoals religie, taal, onderwijs, cultureel erfgoed en land. Het is voorts een dynamisch concept, dat zich kan ontwikkelen en veranderen en het heeft een individuele en collectieve dimensie. Culturele identiteit is nauw verbonden met de menselijke waardigheid, aangezien het te maken heeft met de 'roots' en de manier van denken, voelen en doen. Het moet dan ook beschermd worden, omdat de onderdrukking of beperking ervan mensen een gevoel van vervreemding kan geven. Culturele identiteit wordt in feite steeds belangrijker gevonden als het bedreigd wordt, met andere woorden, wanneer culturele aspecten en uitingen niet kunnen of mogen worden ontwikkeld. Daarom hebben internationale ontwikkelingen zoals kolonisatie en globalisering, waar culturele identiteiten worden onderdrukt of overvleugeld, een belangrijke invloed op de bewustwording van culturele identiteit, inclusief de roep om bescherming middels een recht.

Nauw verwant aan het debat inzake de bescherming van culturele identiteit is de discussie over hoe om te gaan met culturele verschillen in een maatschappij. Beleid gebaseerd op tolerantie en multiculturalisme werd ontwikkeld om verschillende culturele identiteiten naast elkaar te kunnen laten bestaan. Sommigen 
stellen dat culturele verschillen positief moeten worden erkend door speciale rechten, zoals een recht op culturele identiteit. Anderen pleiten voor het erkennen van culturele verschillen in negatieve zin, door de nadruk te leggen op gelijkheid en het wegnemen van disrespect en wernederend gedrag, middels het bevorderen van mensenrechten, zoals non-discriminatie, vrijheid van religie en meningsuiting. Kymlicka ontwikkelde in dit verband een liberale theorie inzake de bescherming van culturele verschillen middels collectieve rechten (hoofdstuk III). Hij verdeelt collectieve rechten in rechten op zelfbestuur, poli-etnische rechten en speciale vertegenwoordigingsrechten. Hij stelt dat sommige minderheden terecht deze collectieve rechten claimen om feitelijke gelijkheid met de meerderheid te verkrijgen en als teken van de waarde van culturele verschillen. Een collectief recht op culturele identiteit valt binnen de categorie van de poli-etnische rechten waarmee gemeenschappen hun culturele eigenheden kunnen ontwikkelen en bewaren. Critici van Kymlicka stellen echter dat deze rechten vanuit praktisch oogpunt problematisch zijn. Hierbij spelen argumenten zoals de definitie van de gemeenschap en haar culturele identiteit, het opsluiten van individuen in een collectieve culturele identiteit en mogelijke conflicten tussen individuele en collectieve rechten een rol.

Een ander punt van discussie is hoe om te gaan met onaanvaardbare culturele praktijken binnen gemeenschappen. Volgens Kymlicka moeten gemeenschappen de rechten van hun leden respecteren en mogen zij hen geen beperkingen opleggen. Ik ben met hem eens dat de rechten van gemeenschappen niet mogen prevaleren boven de rechten van individuen. Het simpele recht om uit de gemeenschap te stappen geeft in dit verband onvoldoende garantie tegen de mogelijke onderdrukking door gemeenschappen, aangezien het in de praktijk niet altijd een reële optie is. Hoewel het moeilijk is in het algemeen te oordelen over culturele praktijken en deze zaken in principe per casus moeten worden bekeken, kan in het algemeen worden gesteld dat hoewel gemeenschappen een bepaalde mate van vrijheid hebben om zich intern te organiseren, zij altijd het fysieke en mentale welzijn van hun leden moeten bevorderen en respect moeten hebben voor de rechten van de leden om deel te nemen in de gemeenschap en in de maatschappij.

\section{Culturele rechten en collectieve rechten}

Vanuit juridisch perspectief valt een recht op culturele identiteit binnen de categorie van de culturele mensenrechten (hoofdstuk IV). Culturele rechten zijn een complexe categorie die de andere categorieën mensenrechten overlapt en een individuele en collectieve dimensie heeft. In het algemeen zijn culturele rechten lange tijd genegeerd door staten en wetenschappers, waardoor zij minder ontwikkeld zijn. Dit heeft te maken met de vaagheid van het concept cultuur, de angst dat culturele rechten leiden tot spanning in de maatschappij en de onduidelijkheid van de verplichtingen van staten. 
Een recht op culturele identiteit kan vanwege het brede en overkoepelende karakter gezien worden als een centraal cultureel recht. Het brede karakter van dit recht maakt het echter wel moeilijk om een kern en specifieke verplichtingen van staten vast te stellen van dit recht. In het algemeen roept een recht op culturele identiteit zowel positieve als negatieve verplichtingen op voor staten. Deze verplichtingen liggen niet zozeer op het terrein van de bescherming van culturele identiteit als zodanig, maar meer de bescherming van diverse aspecten van culturele identiteit, zoals taal, religie en land. Wellicht bieden specifieke rechten op deze deelterreinen meer duidelijkheid en zekerheid dan een algemeen recht op culturele identiteit.

Eén van de redenen voor het ontwikkelen van een recht op culturele identiteit was de bescherming en bevordering van de collectieve dimensie van culturele identiteit middels een collectief recht. Het is duidelijk dat culturele gemeenschappen belangrijk zijn voor individuen en dat zij hun culturele identiteit ontwikkelen door deelname aan verschillende gemeenschappen. Het ontwikkelen van een collectief recht mag daarom gerechtvaardigd zijn vanuit een sociaal perspectief, maar vanuit juridisch perspectief is het meer problematisch. In dit boek wordt betoogd dat collectieve rechten alleen moeten worden ontwikkeld als zij iets toevoegen aan individuele rechten en dat individuele rechten in principe prevaleren boven collectieve rechten, om te voorkomen dat collectieve rechten de bescherming van individuele rechten ondermijnen. Een collectief recht op culturele identiteit roept veel problemen op. Het is allereerst moeilijk het collectieve subject, zoals volk of gemeenschap, te omschrijven. Ook het object, de culturele identiteit van de groep, is moeilijk te definiëren en de vraag blijft wie bepaalt wat deze culturele identiteit is. Ten slotte roept de positie van het individu binnen de gemeenschap serieuze zorgen op. Individuele leden van de gemeenschap moeten deel uit kunnen maken van het besluitvormingsproces over de inhoud en ontwikkeling van de culturele identiteit van de gemeenschap en de collectieve culturele identiteit mag niet in de weg staan van de ontwikkeling van individuele culturele identiteit. Individuen mogen niet worden opgesloten in een collectieve identiteit waar zij zich niet (langer) thuisvoelen.

In dit boek wordt dan ook geconcludeerd dat een recht op culturele identiteit niet moet worden ontwikkeld als een collectief recht. Met name de argumenten van het mogelijk opsluiten van individuen in een collectieve culturele identiteit, de mogelijke onderdrukking van individuele vrijheden en de vertegenwoordiging van individuen in de besluitvorming inzake de collectieve culturele identiteit van de gemeenschap, zijn doorslaggevend: Met betrekking tot culturele gemeenschappen bestaan talrijke voorbeelden van de onderdrukking van individuen door de culturele regels van de gemeenschap, met name de ondergeschikte en kwetsbare positie van vrouwen. Om de collectieve dimensie van culturele identiteit te weerspiegelen zou in plaats van een collectief recht een individueel recht kunnen worden ontwikkeld met een collectieve dimensie, door toe te voegen dat het recht kan worden genoten samen met anderen of door individuen als leden van een gemeenschap. 


\section{Culturele identiteit en UNESCO}

Eén van de voornaamste internationale organisaties die zich met culturele rechten bezighoudt is UNESCO, de cultuur en onderwijs organisatie van de VN (hoofdstuk V). De activiteiten van UNESCO liggen niet zozeer op het terrein van het ontwikkelen van juridische normen, maar meer op het terrein van het ontwikkelen van waarden die in beleid moeten worden omgezet. De bescherming van culturele identiteit is in diverse UINESCO instrumenten opgenomen als een algemene waarde die beschermo moet worden, niet zozeer middels juridisch afdwingbare rechten, maar staten moeten hiertoe cultureel beleid ontwikkelen. De ontwikkelingen binnen UNESCO tonen aan dat staten toenemend belang hechten aan het brede concept van culturele identiteit. Het laatste UNESCO instrument inzake cultuur was de Verklaring inzake Culturele Diversiteit. Deze verklaring bevestigt andermaal de waarde van eulturele diversiteit zonder expliciet culturele rechten te formuleren. Staten hebben zelfs bezwaar tegen het actieplan bij de Verklaring aangezien dit plan verplichtingen aan staten oplegt op het terrein van cultureel beleid.

\section{Culturele identiteit en het recht op participatie in het culturele leven.}

Eén van de bestaande mensenrechten die direct refereren aan cultuur en als zodanig een rol zou kunnen spelen bij de bescherming van culturele identiteit, is het recht op participatie in het culturele leven (hoofdstuk VI). Dit recht is vastgelegd in artikel 27 van de Universele Verklaring van de Rechten van de Mens en artikel 15 van het Internationale Verdrag inzake Economische, Sociale en Culturele Rechten (IVESCR). Toen dit recht werd aangenomen was het bedoeld om het enge cultuurconcept in de vorm van kunst en literatuur, bereikbaar en toegankelijk te maken voor de grote massa, in plaats van voor slechts een kleine elite. Inmiddels heeft dit recht een bredere betekenis gekregen. Het Comité inzake Economische, Sociale en Culturele Rechten verbreedde de reikwijdte van artikel 15 in de richtlijnen voor de rapportage procedure, waarin het artikel 15 koppelde aan culturele identiteit en het recht om cultuur te uiten. Artikel 15 ging niet langer alleen over nationale cultuur, maar omvatte ook de culturele identiteit van andere gemeenschappen, waarmee ook de collectieve dimensie van artikel 15 werd erkend.

Het Comité heeft daarna tijdens een algemene discussie over artikel 15 deze ontwikkeling bevestigd. Met betrekking tot verplichtingen van staten benadrukten de Comitéleden echter de negatieve verplichtingen en besteedden zij nauwelijks aandacht aan positieve verplichtingen. Diverse auteurs wijzen echter terecht op het feit dat artikel 15 zowel negatieve als positieve verplichtingen met zich meebrengt. Geconcludeerd moet worden dat artikel 27 van de Universele Verklaring en artikel 15 IVESCR van belang zijn voor de bescherming van culturele identiteit als zij ruim worden geïnterpreteerd inclusief het brede cultuurbegrip, de individuele en de collectieve dimensie en zowel positieve als negatieve verplichtingen voor staten. 


\section{Culturele identiteit en minderheden en inheemse volken}

Binnen de ontwikkeling van rechten voor minderheden en inheemse volken, neent de bescherming van culturele identiteit een belangrijke plaats in (hoofdstuk VII en VIII). Eén van de belangrijkste bepalingen met betrekking tot minderheden en hun cultuur is artikel 27 van het Internationaal Verdrag inzake Burgerrechten en Politieke Rechten (IVBPR). De bepaling behelst het recht van personen behorend tot een minderheid om hun eigen cultuur en religie te beleven en hun taal te spreken samen met andere leden van hun groep. Ook artikel 27 heeft zich in de loop der jaren ontwikkeld. Niet alleen leden van minderheden, maar ook van inheemse volken kunnen inmiddels aanspraak maken op deze bepaling. Voorts is erkend dat de staat niet alleen negatieve, maar ook positieve verplichtingen heeft onder artikel 27 , ondanks de negatieve formulering in de vorm dat het recht niet zal worden ontkend.

Diverse zaken voor het Mensenrechtencomité, het toezichthoudend organ van het IVBPR, bevestigen deze ontwikkeling. Het Comité accepteert individuen van allerlei gemeenschappen als klagers en gebruikt een breed cultuurbegrip, waar miet alleen taal en religie, maar ook economische activiteiten onder kunnen vallen, mits deze essentieel zijn voor de cultuur van die gemeenschap. Dil bevestigt tevens dat rechten in relatie tot land, hoewel niet expliciet genoemd in artikel 27 , wel onder deze bepaling kunnen vallen. Hierbij wordt in verschillende zaken verwezen naar culturele identiteit als overkoepelende waarde.

In een ander instrument inzake minderheden, de VN Verklaring inzake de Rechten van Personen behorend tot een Nationale of Etnische; Religieuze en Linguïstische Minderheid, wordt expliciet verwezen naar de bescherming van culturele identiteit. Culturele identiteit wordt echter vooral als een algemene waarde gebruikt onderliggend aan verschillende specifieke rechten voor minderheden, zoals het recht hun cultuur te beleven, hun taal te spreken en hun religie te belijden.

Ook binnen de ontwikkeling van mensenrechten voor inheemse volken heeft de bescherming van culturele identiteit een belangrijke plaats ingenomen (hoofdstuk VIII). Conventie 169 van de Internationale Arbeidsorganisatie (ILO) inzake Inheemse Volken is in feite het enige juridisch bindende instrument dat een expliciete verwijzing naar culturele identiteit bevat. In deze Conventie, evenals in de VN Ontwerp Verklaring over Inheemse Volken, wordt tevens specifieke aandacht besteed aan de collectieve dimensie van de rechten van inheemse volken. In deze instrumenten wordt culturele identiteit wederom als een algemene waarde erkend die gerespecteerd, beschermd en bevorderd moet worden, middels culturele mensenrechten inzake aspecten van culturele identiteit, zoals taal, religie, cultureel erfgoed en land. Problemen met de definitie van inheemse volken, de collectieve rechten en het gebrek aan duidelijkheid over zelfbeschikking zijn de voornaamste redenen dat staten aarzelen instrumenten aan te nemen. Slechts weinig staten ratificeren een bindend instrument zoals ILO Conventie 169 en zelfs over een nietbindend instrument zoals de Ontwerp Verklaring bestaat geen overeenstemming. 


\section{Culturele identiteit en de Organisatie van Amerikaanse Staten (OAS)}

Naast internationale mensenrechteninstrumenten werden ook enkele regionale instrumenten onderzocht in Europa en Amerika. Beide regio's hebben een uitgebreid mensenrechten systeem, waarbinnen echter geen recht op culturele identiteit als zodanig is vastgelegd. De bescherming van culturele identiteit is echter "ingelezen' in andere mensenrechten bepalingen.

Culturele rechten zijn geen voornaam onderdeel van de mensenrechten instrumenten van de OAS (hoofdstuk DX). Ook landrechten kunnen niet in deze instrumenten worden teruggevonden. En dat terwijl deze regio specifieke problemen kent met betrekking tot inheemse volken en de bescherming van hun culturele identiteit en land. Het is daarom interessant te zien dat beiden onder andere rechten vallen, zoals het recht op leven en gezondheid, non-discriminatie en eigendom. Voorbeelden zijn de Yanomami zaak en de Miskito zaak, waar de InterAmerikaanse Commissie voor de Rechten van de Mens bereid was verder te kijken dan de normen in de Amerikaanse Verklaring en het Amerikaanse Verdrag voor de Rechten van de Mens en gebruik makte van artikel 27 IVBPR voor de bescherming van de culturele identiteit van inheemse volken. De Inter-Amerikaanse Commissie verwees expliciet naar culturele identiteit als een waarde die niet alleen landrechten impliceert, maar ook rechten op taal, religie en cultureel erfgoed. De Awas Tingi zaak vormde het voorlopige hoogtepunt inzake landrechten voor inheemse volken. In deze zaak, de eerste over inheemse volken voor het InterAmerikaanse Hof voor de Rechten van de Mens, besliste het Hof dat inheemse volken een collectief recht op land hebben en dat de staat een verplichting heeft dit land af te bakenen en te beschermen tegen inmenging door derden. Hoewel het Hof niet de term "culturele identiteit" gebruikte, legde het een duidelijke link tussen land en de culturele identiteit van de gemeenschap. De culturele identiteit van inheemse volken als algemene waarde, in deze zaken weerspiegelt in land, wordt hier dus beschermd door bestaande mensenrechten bepalingen. Deze zaken bevestigen de mogelijkheid die bestaande mensenrechten bieden om culturele identiteit te beschermen en te bevorderen.

\section{Culturele identiteit en de Raad van Europa}

Vergelijkbare ontwikkelingen hebben plaatsgehad binnen het mensenrechtensysteem van de Raad van Europa. De twee voornaamste instrumenten, het Europees Verdrag voor de Rechten van de Mens (EVRM) en het Europees Sociaal Handvest bevatten geen expliciete verwijzing naar cultuur of culturele identiteit, maar wel diverse rechten die te maken hebben met aspecten van culturele identiteit, zoals vrijheid van religie of meningsuiting. De ontwikkelingen in Centraal en OostEuropa hebben het belang van culturele rechten binnen de Raad van Europa doen toenemen, met name met betrekking tot minderheden. De lidstaten hebben dan ook 
enkele instrumenten aangenomen, zoals het Kaderverdrag voor de Bescherming van Nationale Minderheden. Dit Kaderverdrag bevat verwijzingen naar culturele identiteit, waarmee staten bevestigen het een belangrijke waarde te vinden. Daarnaast worden aspecten van culturele identiteit middels diverse bepalingen beschermd, zoals religie, taal en onderwijs. In het algemeen hebben de bepalingen van het Kaderverdrag een programma-achtig karakter, wat wil zeggen dat zij voornamelijk beleidsdoelen formuleren die partijstaten moeten implementeren.

De ontwikkeling van culturele rechten zou voltooid moeten worden door een Additioneel Protocol bij het EVRM inzake Rechten op Cultureel Terrein, maar de lidstaten zijn er niet in geslaagd een dergelijk protocol aan te nemen. Veel voorstellen werden besproken, waaronder het recht op culturele identiteit. De voornaamste criteria waren dat de bepalingen iets moesten toevoegen aan het EVRM en dat zij universeel en afdwingbaar moesten zijn. De meeste voorstellen konden deze test echter niet doorstaan. Het recht op culturele identiteit werd verworpen omdat het niet afdwingbaar zou zijn, vanwege de vaagheid van het concept culturele identiteit en omdat een dergelijk recht geen bescherming zou toevoegen aan het EVRM. Daarnaast werd gesteld dat teveel nadruk op culturele identiteit allerlei spanningen in de samenleving zou opwekken en dat een dergelijk recht zou kunnen worden geïnterpreteerd als ondersteuning van bedenkelijke culturele activiteiten. Uiteindelijk heeft het Comité van Ministers de werkzaamheden aan het Protocol opgeschort.

Hoewel het EVRM geen bepaling bevat over culturele identiteit, bewijzen diverse zaken voor de Europese Commissie en het Europese Hof voor de Rechten van de Mens dat bepalingen uit het EVRM mogelijkheden bieden voor de bescherming van culturele identiteit. In diverse zaken werd deze bescherming 'ingelezen' in bepalingen over bijvoorbeeld vrijheid van meningsuiting, religie en vereniging. In de zaken van Sidiropoulos en Chapman refereert het Hof expliciet aan de bescherming van minderheden en hun culturele identiteit. In Siridopoulos bepaalde het Hof dat culturele organisaties die zijn opgezet om de cultur wan een minderheid te beschermen en ontwikkelen beschermd worden door vrijheid van vereniging en vergadering. In Chapman stelde het Hof dat de traditionele manier van leven van een zigeuner minderheid in principe beschermd is onder het recht op respect voor privé-leven en familieleven.

\section{De culturele identiteit van de Sami}

Voor een meer praktische benadering van het onderwerp werd een gemeenschap geanalyseerd voor wie de bescherming van hun culturele identiteit belangrijk is, namelijk de Sami in Noorwegen, Zweden en Finland. De Sami zijn een inheems volk wier culturele identiteit met name gekarakteriseerd wordt door het hoeden van rendieren en de Sami taal. De culturele identiteit van de Sami werd aanvankelijk onderdrukt, omdat het werd beschouwd als ongeciviliseerd en een bedreiging voor modernisatie, maar ook omdat de betrokken staten de nadruk legden op de 
ontwikkeling van de nationale eenheid middeîs de assimilatie van verschillende culturele gemeenschappen. In alle drie de landen wordt inmiddels meer rekening gehouden met de belangen van de Sami en is het nationale beleid niet langer gericht op assimilatie. De culturele identiteit van de Sami wordt met name bescherma middels het beschermen van diverse aspecten van deze culturele identiteit, bijvoorbeeld de Sami taal. Met rendier hoeden ligt de situatie moeilijker. Hoewel de overheden van Noorwegen, Zweden en Finland niet actief proberen het rendier hoeden te vernietigen, geven zij dikwijls voorkeur aan andere economische activiteiten, zoals mijnbouw en bosbouw, dat plaatsvindt in gebieden waar de Sami hun rendieren hoeden.

De Sami hebben actief gebruik gemaakt van internationale instrumenten om bescherming van hun culturele rechten af te dwingen, bijvoorbeeld bij het Mensenrechten Comité onder artikel 27 van het IVBPR en bij de Europese Commissie voor de Rechten van de Mens onder bepalingen uit het EVRM. Hoewel de zaken werden verloren door de Sami, werden een aantal belangrijke regels ontwikkeld. Het Mensenrechten Comité bevestigde dat inheemse volken ook onder de term 'minderheden' vallen uit artikel 27 en voorts werden kwesties met betrekking tot land ook onder het begrip 'cultuur" uit artikel 27 gevat. In het geval van het EVRM stelde de Commissie dat een bepaalde levensstijl van een minderheid onder het recht op privé leven en familieleven kan vallen. Hoewel de bescherming van culturele identiteit van de Sami wellicht symbolisch zou profiteren van een apart recht op culturele identiteit, zijn het meer de afzonderlijke aspecten van culturele identiteit die beschermd moeten worden, bijvoorbeeld taal en het bezit en gebruik van land. Hiertoe moeten bestaande culturele rechten beter worden geïmplementeerd, waarbij culturele identiteit, indirect, wordt beschermd.

\section{Conclusie: geen recht op culturele identiteit, maar een beginsel}

Uit bovenstaande volgt de conclusie dat geen apart recht op culturele identiteit moet worden ontwikkeld. Hoewel het duidelijk is dat culturele mensenrechten verwaarloosd en onderontwikkeld zijn en dat de bescherming van culturele identiteit als een belangrijke waarde en element van menselijke waardigheid zou passen in de sfeer van de mensenrechten, is het vertalen van culturele identiteit in een recht wenselijk noch noodzakelijk. Het is niet wenselijk omdat het vertalen van een vaag en algemeen concept zoals culturele identiteit in een recht mogelijk leidt tot misbruik van dit recht of beperkingen van individuele rechten en vrijheden in een culturele context. Het is niet noodzakelijk, omdat bestaande mensenrechten reeds mogelijkheden bieden om culturele identiteit te beschermen. Kort gezegd kan een recht op culturele identiteit niet voldoen aan de criteria voor proliferatie van mensenrechten, namelijk dat nieuwe rechten alleen moeten worden ontwikkeld als zij daadwerkelijk iets toevoegen aan bestaande mensenrechten, als er voldoende consensus onder staten is en als zij voldoende duidelijk zijn om rechten en plichten met zich mee te brengen. 
Het veelomvattende karakter van culturele identiteit kan niet worden teruggebracht tot een concreet specifiek recht. Het object en de verplichtingen van staten zouden dermate breed en vaag zijn dat een dergelijk recht moelijk afdwingbaar is. In beginsel bevatten diverse andere mensenrechten vage en dynamische concepten, zoals vrijheid van godsdienst of het recht op privacy en familie leven. Culturele identiteit omvat echter zo veel verschillende terreinen en aspecten, zoals taal, godsdienst, onderwijs, land en cultureel erfgoed, dat het moeilijk te bepalen is waar men precies recht op heeft als men zich beroept op het recht op culturele identiteit en wat precies de verplichtingen voor staten zijn op deze terreinen. Dit werd bevestigd in de analyse van de bestaande bepalingen die expliciet verwijzen naar culturele identiteit. Deze bepalingen bevatten niet zozeer afdwingbare rechten, maar uiten meer het belang van culturele identiteit als algemene waarde die beschermd moet worden middels rechten inzake de specifieke aspecten van culturele identiteit.

In principe zou de breedheid van het concept alleen niet voldoende reden zijn om een recht op culturele identiteit te verwerpen. Het is echter het risico van misbruik van dit brede en vage recht dat de doorslag geeft, in de zin van de mogelijke beperking van andere rechten en vrijheden. Het algemene recht op culturele identiteit kan worden misbruikt als excuus voor onacceptabele praktijken binnen culturele gemeenschappen. Hier schuilt bijvoorbeeld het verschil met een ander breed en algemeen recht, namelijk het recht op non-discriminatie. Beide concepten zijn breed en omvatten verschillende terreinen. Het recht op nondiscriminatie kan echter niet op een zodanige manier worden misbruikt als het recht op culturele identiteit. Met betrekking tot dit mogelijke misbruik, wordt in dit boek gesteld dat in het algemeen de rechten van gemeenschappen miet boven de rechten van individuen gaan. Hoewel gemeenschappen een zekere vrijheid hebben om hun interne organisatie te regelen, moeten zij altijd het fysieke en mentale welzijn van hun leden garanderen. Daarnaast moeten gemeenschappen de rechten van hun leden respecteren om deel te nemen aan de maatschappij in het algemeen, bijvoorbeeld middels kiesrecht en onderwijs, maar ook aan de gemeenschap en de beslissingen die daar worden genomen om wellicht bepaalde zaken te kunnen veranderen. Als bepaalde groepen, bijvoorbeeld vrouwen, structureel worden uitgesloten van het beslissingsproces van een culturele gemeenschap blijven zij afhankelijk van mannen om bepaalde regels te veranderen.

De vaagheid van het concept culturele identiteit is één van de voornaamste redenen dat ook staten huiverig blijken om een apart recht op culturele identiteit te ontwikkelen of andere bindende bepalingen inzake culturele identiteit aan te nemen. Voorts zijn zij terughoudend ten aanzien van positieve verplichtingen voor culturele rechten. De mislukking van het Additioneel Protocol bij het EVRM inzake culturele rechten is hiervan een goed voorbeeld. Het laat zien hoe moeilijk het is een dergelijk instrument vast te stellen. De criteria waren dat de bepalingen iets moesten toevoegen aan het EVRM en universeel en afdwingbaar moesten zijn. Vrijwel geen enkele ontwerptekst kon deze test doorstaan. Een ander voorbeeld van de aarzeling van staten om gebonden te zijn aan culturele rechten is de UNESCO Verklaring 
inzake Culturele Diversiteit. Hoewel staten de waarde van culturele diversiteit hebben bevestigd in deze Verklaring en enkele belangrijke principes hebben vastgelegd, hebben veel staten grote bezwaren tegen het actieplan dat concrete beleidsplannen voorschrijft.

De andere reden om een apart recht op culturele identiteit te verwerpen is dat bestaande mensenrechten bepalingen op internationaal en regionaal niveau reeds mogelijkheden bieden ten aanzien van de bescherming van (aspecten van) culturele identiteit, bijvoorbeeld vrijheid van meningsuiting, vrijheid van godsdienst, vrijheid van vereniging en het recht op onderwijs. Landrechten kunnen onder diverse bepalingen vallen, zoals het recht op leven, gezondheid en familieleven. Door het bevorderen van deze bepalingen, zullen zij ook indirect bescherming bieden aan culturele identiteit als een algemene waarde. In diverse zaken hebben toezichthoudende organen gesteld dat bepaalde verplichtingen van staten ten aanzien van culturele aspecten ten dienste staan van de meer algemene waarcle van culturele identiteit als onderdeel van menselijke waardigheid. Met andere woorden, het ontwikkelen van een apart recht op culturele identiteit is niet nodig. De mogelijkheden die bestaande mensenrechten bileden voor de bescherming van culturele identiteit moeten echter verder worden ontwikkeld door de uitleg en implementatie van deze bepalingen in het licht van de bescherming van culturele identiteit. Het algemene concept van culturele identiteit kan daarbij een eigen rol spelen als beginsel.

\section{De opkomst van culturele identiteit als beginsel van mensenrechten}

Culturele identiteit moet niet worden ontwikkeld als een apart mensenrecht. In plaats daarvan moet het als belangrijk element van menselijke waardigheid worden gebruikt als opkomend beginsel van mensenrechten ten behoeve van de interpretatie, ontwikkeling en implementatie van mensenrechten, met name culturele rechten. De basiswaarde van mensenrechten is menselijke waardigheid. Beginselen van mensenrechten die daaruit voortvloeien zijn bijvoorbeeld gelijkheid, non-discriminatie en zelfbeschikking van koloniale volken. Culturele identiteit is een belangrijk element van menselijke waardigheid, dat voortkomt uit het recht om anders te zijn, als een uitwerking van het beginsel van non-discriminatie. Als zodanig kan culturele identiteit worden gebruikt als een opkomend beginsel van mensenrechten. Ik gebruik de term 'opkomend', omdat het op dit moment nog niet voldoende is uitgewerkt als beginsel. Het wordt weliswaar steeds meer in internationale instrumenten gebruikt, maar in verhouding tot de andere beginselen zoals gelijkheid en non-discriminatie, is het veel minder ontwikkeld en niet altijd erkend als beginsel. $\mathrm{lk}$ zou echter willen pleiten voor de verdere ontwikkeling van culturele identiteit als beginsel.

Culturele identiteit niet als recht, maar als beginsel, zou moeten worden geherformuleerd als vrijheid van culturele identiteit. Zoals uitgelegd in hoofdstuk I 
is het recht op culturele identiteit een nogal vreende formulering. Culturele identiteit kan niet als zodanig worden gegeven aan individuen, culturele identiteit is iets dat je nou eenmaal hebt. Bescherming of ontwikkeling van culturele identiteit zou een alternatief kunnen zijn, maar de beste formulering is vrijheid van culturele identiteit, aangezien dit het dynamische karakter weerspiegelt en het recht om culturele identiteit te veranderen impliceert. Om verwarring met een recht te voorkomen, laat ik de referentie naar "recht" helemaal weg. Vrijheid van culturele identiteit wil echter niet zeggen dat de nadruk moet worden gelegd op negatieve verplichtingen voor staten. In principe kan vrijheid van culturele identiteit zowel positieve als negatieve verplichtingen met zich meebrengen.

Vrijheid van culturele identiteit als opkomend beginsel heeft een ander karakter dan een apart recht. Beginselen hebben een meer algemeen en normatief karakter dan rechten, die een meer concrete inhoud zouden moeten hebben. Voorts hebben beginselen geen directe werking, maar beïnvloeden zij indirect de implementatie en interpretatie van rechten. Tenslotte hebben beginselen een minder dwingend karakter. Meer dan één beginsel kan in een bepaalde zaak van toepassing zijn, waarbij de rechter of toezichthouder bepaalt welk beginsel voorrang geniet. Vrijheid van culturele identiteit heeft deze kenmerken van een beginsel. Het wordt steeds meer gebruikt in internationale instrumenten, waar het meestal in de Preambule of én van de eerste bepalingen is opgenomen. Dit laat het algemene karakter zien als achtergrond voor de overige bepalingen in het instrument. Vrijheid van culturele identiteit als opkomend beginsel van mensenrechten zou een leidraad kunnen vormen voor de interpretatie en implementatie van mensenrechten, met name culturele rechten. Het kan van toepassing zijn naast andere beginselen, zoals non-discriminatie, waarbij een toezichthouder kan bepalen welk beginsel voorgaat in een specifieke zaak.

Een voordeel van het ontwikkelen van vrijheid van culturele identiteit als beginsel in plaats van als recht is dat het niet hoeft te worden vastgelegd in een bepaald instrument. Ook zonder instrument kumen toezichthouders er gebruik van maken. Vrijheid van culturele identiteit als beginsel weerspiegelt beter het brede en dynamische karakter, niet beperkt door een bepaalde beschrijving.

Vrijheid van culturele identiteit kan als beginsel bestaande mensenrechten als het ware 'inkleuren', waarbij de culturele dimensie van diverse mensenrechten wordt ontwikkeld, inclusief een collectieve dimensie. Vrijheid van culturele identiteit als beginsel is met name van belang voor culturele rechten, maar ook voor mensenrechten die minder direct in verband staan met culturele identiteit. Het Comité inzake Economische, Sociale en Culturele Rechten heeft in dit verband een aantal General Comments (Algemene Aanbevelingen) aangenomen, waarin het de culturele kant van bepaalde mensenrechten erkent. Het heeft bijvoorbeeld gesteld dat het recht op huisvesting impliceert dat de bouwmaterialen en het bouwbeleid rekening moeten houden met de culturele identiteit en diversiteit van huisvesting. 
Met betrekking tot het recht op gezondheid heeft het Comité bepaald dat faciliteiten voor gezondheidszorg zogenaamd cultureel 'geschikt" moeten zijn, met respect voor de cultuur van individuen en volken.

De uitwerking van andere rechten, zoals het recht op vrijheid van meningsuiting, religie of vereniging, zou ook een dergelijke culturele dimensie kunnen krijgen, warbij vrijheid van culturele identiteit als een beginsel kan fungeren voor de interpretatie van deze rechten. De interpretatie en implementatie van bestaande mensenrechten bepalingen tegen de achtergrond van vrijheid van culturele identiteit, vermindert de noodzaak om een apart recht op culturele identiteit te ontwikkelen en zal meer succesvol zijn dan het ontwikkelen van een dergelijk recht.

Het 'inkleuren' van mensenrechtenbepalingen door het beginsel van vrijheid van culturele identiteit kan ook middels jurisprudentie, waarbij vrijheid van culturele identiteit een leidraad kan zijn bij het toepassen van vage normen. Het kan een belangrijke rol spelen in specifieke zaken waar individuen zich beroepen op bestaande mensenrechten, maar waarbij een breder, meer cultureel perspectief gewenst is. Bestaande voorbeelden zijn de Chapman zaak en de Awas Tingi zaak, die laten zien dat landrechten of rechten met betrekking tot huisvesting in een bredere context kunnen worden gezien, waarbij vrijheid van culturele identiteit als leidend beginsel dient. Hetzelfde kan worden gezegd van de Siridopoulos zaak. Deze zaak betrof strikt het recht op vrijheid van vereniging en vergadering, maar een bredere context werd gehanteerd inclusief de vrijheid van culturele identiteit, aangezien de betrokken organisatie direct te maken had met de culturele identiteit van een minderheid. Men kan bijvoorbeeld ook denken aan een zaak over de bescherming van een taal in het onderwijs, in de vorm van taallessen in een minderheidstaal. Toezichthouders zouden een dergelijke zaak kunnen bekijken niet alleen vanuit het strikte perspectief van het recht op onderwijs of taalrechten, maar zouden ook naar de bredere context kunnen kijken door het toepassen van vrijheid van culturele identiteit. Het zou bijvoorbeeld kunnen stellen, afhankelijk van de omstandigheden, dat staten taallessen in de minderheidstaal moeten ondersteunen vanwege het belang van deze taal in relatie tot de vrijheid van culturele identiteit van de klager en de gemeenschap daaromheen.

De voorgestelde bescherming van culturele identiteit als een beginsel van mensenrechten sluit aan bij het beleid van tolerantie en multiculturalisme, aangezien het de waarde erkent van culturele verschillen en culturele diversiteit. Het niet ontwikkelen van een recht, maar erkennen van een beginsel voor de interpretatie en implementatie van mensenrechten, past in het kader van de 'negatieve erkenning' van culturele verschillen. In plaats van het positief erkennen van culturele identiteit in de vorm van een recht, worden culturele identiteiten negatief erkend, door het wegnemen van disrespect en discriminatie. Mensenrechten zoals non-discriminatie en vrijheid van religie, meningsuiting en vereniging spelen hierbij een rol. Een belangrijk punt moet hier echter worden 
gemaakt: zelfs als beginsel zou vrijheid van culturele identiteit, hoewel niet rechtstreeks toepasbaar, door staten of gemeenschappen kunnen worden misbruikt om een bepaalde culturele identiteit op te dringen aan individuen, of individuele vrijheden te beperken onder de noemer van vrijheid van culturele identiteit. Beleid van tolerantie en multiculturalisme moet niet inhouden het onkritisch accepteren van culturele praktijken die de rechten en vrijheden van individuen beperken. Multiculturalisme wordt door velen daarom afgewezen. Vrijheid van culturele identiteit mag echter nooit als excuus dienen voor culturele praktijken die in strijd zijn met mensenrechten. Een kritische houding ten opzichte van culturele gemeenschappen is dus noodzakelijk om individuen te beschemen tegen hun gemeenschappen. Dit moet echter niet leiden tot het verwerpen van culturele rechten of vrijheid van culturelle identiteit als geheel. Beiden zijn essentieel om een belangrijk deel van de menselijke waardigheid te beschermen. Veel individuen en gemeenschappen hebben deze bescherming nodig en verdienen extra aandacht voor hun culturele identiteit.

Toezichthoudende organen moeten dit beginsel, waar geschikt, toepassen, maar zij moeten tegelijkertijd zorgdragen dat dit beginsel de implementatie van mensenrechten niet beperkt. Tolerantie en multiculturalisme moeten de basis vormen om een eind te maken aan gedwongen assimilatie en discriminatie van individuen en gemeenschappen. $\mathrm{Zij}$ moeten leiden tot respect voor het recht om anders te zijn gebaseerd op het beginsel van gelijkheid en non-discriminatie. Het recht om anders te zijn wordt in de preambule van de UNESCO Verklaring inzake Ras omschreven als het recht niet te worden uitgesloten, vernederd, uitgebuit of gedwongen geassimileerd. Het is in het kader van deze zaken dat vrijheid van culturele identiteit zou moeten worden gerespecteerd, beschermd en bevorderd. 


\section{BIBLIOGRAPHY}

Aarnio, EJ., "The Future of Indigenous Peoples", in: I. Seurujärvi-Kari and U-M. Kulonen(eds.), Essays on Indigenous Identity and Rights, Helsinki University Press, 1996, pp. 10-14.

Addis, A., "On Human Diversity and the Limits of Toleration", in: W. Kymlicka and I. Shapiro (eds.), Ethnicity and Group Rights, New York University Press, New York/London, 1997, pp. 112-153.

Advisory Committee on Human Rights and Foreign Policy (Dutch Ministry of Foreign Affairs), Indigenous Peoples, Advisory Report No. 16, 1993.

Advisory Committee on Human Rights and Foreign Policy (Dutch Ministry of Foreign Afrairs), Collective Rights, Advisory Report No. 19, 1995.

Aikio, P., and M. Scheinin (edis.), Operationalising the Right of Indigenous Peoples to SelfDetermination, Institute for Human Rights, Abo Akademie University, 2000.

Alfredsson, G., "The Rights of Indigenous Peoples with a Focus on the National Performance and Foreign Policies of the Nordic Countries", Zeitschrift, fur ausländischex öffentliches Recht und Völkerrecht (Heidelberg Joumal of International Lawi), Vol. 59(2), 1999, pp.529-542.

Alston, Ph., "A third generation of solidarity rights: progressive developments or obfuscation of international human rights", Netherlands International Law Review, 29, 1982, pp. 307-322.

Alston, $\mathrm{Ph}$., "Conjuring up new human rights: a proposal for quality control", in: The American Journal of International Law, 78, 1984, pp. 607-621.

Alston, Ph., "Out if the Abyss: The Challenges Confronting the New UN Committee on Economic, Social and Cultural Rights", Human Rights Quarterly, Vol. 9, 1987,pp. 332381.

Alston, Ph. and G. Quinn, "The Nature and Scope of States Parties' Obligations under the International Covenant on Economic, Social and Cultural Rights", Humaw Rights Quarterly, Vol. 9, 1987, pp. 156-229.

Anaya, S.J., "The Capacity of International Law to Advance Ethnic or Nationality Rights Claims", in: W. Kymlicka (ed.), The Rights of Minority Cultures, Oxford University Press, Oxford, 1995, pp. 321-330.

Anaya, S.J., Indigenous Peoples in International Law, Oxford University Press, Oxford, 1996-A.

Anaya, S.J. and S. Crider, "Indigenous Peoples, The Environment, and Commercial Forestry in Developing Countries: the Case of Awas Tingi, Nicaragua", Human Rights Quarterly, 18, 1996-B, pp. 345-367.

Anaya, S.J., "On Justifying Special Ethnic Group Rights: Comments on Pogge", in: W. Kymlicka and I. Shapiro (eds.), Ethnicity and Group Rights, New York University Press, New York/London, 1997, pp. 222-231. 
Anaya, S.J. and R.A. Williams Jr., "The Protection of Indigenous' Peoples Rights over Lands and Natural Resources Under the Inter-American Human Rights System", Harvard Human Rights Journal, Vol. 14, Spring 2001, pp. 33-86.

Appiah, K.A., "Identity, Authenticity, Survival: Multicultural Societies and Sociall Reproduction", in: A. Gutman (ed.), Multiculturalism - Examining the Politics of Recognition, Princeton University Press, Princeton, 1994, pp. 149-164.

Appiah, K.A., "The Multiculturalist Misunderstanding", The New York Review of Books 44, 15,1997, pp. 30-36.

Arambulo, M.K., Strengthening the Supervision of the International Covenant on Economic, Social and Cultural Rights - Theoretical and Procedural Aspects, School of Human Rights Research Series No. 3, Hart/Intersentia, Antwerp/Groningen/Oxford, 1.999.

Baehr, P.R. and K. vander Wal, "Human Rights as Individual and as Collective Rights", in: Berting. J. et al. (eds.), Human Rights in a Pluralist World, Meckler Westport/London, 1990, pp. 33-37.

Baehr, P.R., The Role of Human Rights in Foreign Policy, second edition, MacMillan Press, London, 1996-A.

Baehr, P.R., "The Universality of Human Rights", in: P.R. Baehr et al. (eds.), Human Rights:Chinese and Dutch Perspectives, Martimus Nijhoff, Dordrecht/Bostons/London, 1996-B, pp. 25-41.

Baer, L-A., Self-government in Sápmi-Samiland, in: F. Horn (ed.), Minorities and their right of political participation, Lapland's University Press, Rovaniemi, 1996-A, pp. 129138.

Baer, L-A., "Sweden, Indigenous People's Land Rights", Indigenous Affairs, No. 2, 1996B, pp. 17-19.

Barsh, R.L., "Revision of ILO Convention No. 107", The American Journal of International Law, Vol. 81, 1987 , pp. 756-762.

Barsh, R.L., "Indigenous Peoples and the UN Commission on Human Rights: A Case of the Immovable Object and the Irresistible Force", Human Rights Quarterly, 18(1996), pp. $782-813$.

Benda-Beckman, K. von and M. Verkuyten (eds.), Nationalism, Ethnicity and Cultwal Vientity in Europe, European Research Centre on Migration and Ethnic Relations, Utrecht Uniwersity, Utrecht, 1995.

Benda-Beckman, $K$. von and M. Verkuyten, "Introduction: Cultural Identity and Development in Europe", in: Benda-Beckman, K. von and M. Verkuyten (eds.), Notionalism, Ethnicity and Cultural Identity in Europe, European Research Centre on Migration and Ethnic Relations, Utrecht University, Utrecht, 1995-A, pp. 1-29.

Berkel, K. van, Renaissance der Cultuwwetenschap [Renaissance of Cultural Science], Nijhoff, Leiden 1986.

Berman, H.R., "The International Labour Organisation and Indigenous Peoples: Revision of ILO Convention No. 107 at the 75th Session of the International Labour Conference $^{*}$, Review of the International Commission of Jurists, No. 41/1988, pp. 4857.

Berting, I, et al. (eds.), Human Rights in a Pluralist World, Meckler Westport/London, 1990. 
Boas, F., Race, Language, Culture, The Free Press, New York, 1966 (or. ed. 1940).

Boutros-Ghali, B., "The Right to Culture and the Universal declaration of Human Rights", in: UNESCO, Cultural Rights as Human Rights, Paris, 1970, pp. 73-75.

Boven, Th. C. van, "Human Rights and the Rights of Peoples", European Journal of International Low, Vol. 6, No. 3, 1995, pp. 461-476.

Boven, Th. C. van, C. Flinterman and I. Westendorp (eds.), "The Maastricht Guidelines on Violations of Economic, Social and Cultural Rights", SIM Special No. 20, SIM, Utrecht, 1998.

Boven, Th. C. van, "The Petition System under the International Convention on the Elimination of All Forms of Racial Discrimination - A Sobering Balance Sheet", in: J.A. Frowein and R. Wolfrum (eds.), Max Planck Yearbook of United Nations Law, Kluwer Law International, 2000, pp. 271-287.

Brems, E., Human Rights: Universality and Diversity, International studies in human rights, vol. 66, The Hague Nijhoff, 2001.

Brölmann, C., R. Lefeber and M. Zieck (eds.), Peoples and Minorities in Intenational Law, Martinus Nijhoff Publishers, Dordrecht, 1995.

Brölmann, C.M. and M.Y.A. Zieck, "Indigenous Peoples", in: C. Brölmann, R. Lefeber and M. Zieck (eds.), Peoples and Minorities in International Law, Martinus Nijhoff Publishers, Dordrecht, 1995-A, pp. 187-220.

Brölmann, C.M., and M. Y.A. Zieck, "Some Remarks on the Draft Declaration on the Rights of Indigenous Peoples", Leiden Journal of International Law, Vol. 8, No. 1, 1995-B, pp. 103-113.

Brownlie, I., The Rights of Peoples in Modern International Law, in: J. Crawford (ed.), The Rights of Peoples, Clarendon Press Oxford, 1988, pp. 1-16.

Brownlie, I., Principles of Public International Law, Clarendon Press Oxford, fourth edition, 1990.

Bruggink, J.J.H., Op zoek naar het Recht [In search of the Law], second edition, WoltersNoordhoff, Groningen, 1990, pp. 131-147.

Buergenthal, T. and D. Shelton, Protecting Human Rights in the Americas - Cases and Materials, Engel, Strasbourg, fourth revised edition, 1995.

Burger, J. and P. Hunt, "Towards the International Protection of Indigenous Peoples" Rights", Netherlands Quarterly of Human Rights, No. 4, 1994, pp. 405-423.

Burger, J. and L. Swepston, "Indigenous peoples and the United Nations", in: C. Price Cohen (ed.), Human Rights of Indigenous Peoples, Transnational Publishers, New York, 1998, pp. 2-36.

Burgers, J.H., "The Right to Cultural Identity", in: J. Berting et al. (eds.), Human Rights in a Pluralist World, Meckler Westport/London, 1990, pp. 251-254.

Capotorti, F., Study on the Rights of Persors belonging to ethric, religious and linguisticminorities, E/CN.4/Sub.2/384/Rev.1, 1979.

Cassese, A., Self-determination of Peoples: A Legal Reappraisal, Cambridge University Press, Cambridge, 1995.

Cassin, R., La Déclaration Universelle et la mise en auvre des droits de l'homme, Recueil des cours de l'Académie de Droit International, Vol. 79, II, 1951. 
Chapman, A.R., "A "Violations Approach' for Monitoring the International Covenant on Economic, Social and Cultural Rights", Human Rights Quarterly, Vol. 18, 1996, pp. 2366.

Cholewinski, R., "State duty towards ethnic minorities: positive or negative?", Human Rights Quarterly, Vol. 10, No. 3, 1988, pp. 344-371.

Cliteur, $\mathrm{P}$, De filosofie van mensenrechten [The philosophy of human rights], Ars Aequi Libri, Nijmegen, 1997, pp. 79-90.

Coomans, A.P.M., De Internationale Bescherming van het Recht op Onderwijs [The International Protection of the Right to Education], Stichting NJCM Boekerij 20, Leiden/Maastricht, 1992.

Coomans, F., "Economic, Social and Cultural Rights", SIM Special No. 16, Utrecht, 1995, pp. $3-52$.

Coomans, $\mathrm{F}_{*}$ " "UNESCO and Human Rights", in: R. Hanski and M. Suksi (eds.), $A n$ Introduction to the International Protection of Human Rights - A Texrbook, Institute for Human Rights, Abo Akademi University, second edition, Turku/Åbo, 1999, pp. 219230.

Cor Konate, S. "Le Comité des Droits Economiques, Sociaux et Culturels: Une Conception Lacunaire et Mercantile de la Culture", in: Meyer-Bisch, P. (ed.), Les Droits Culturels, une catégorie sous-développée de droits de l'homme, Actes du VIHe Colloque interdisciplinaire sur les droits de l'homme, Editions Universitaires Fribourg Suisse, 1993, pp. 105-106.

Coulter, R.T., "The Draft UN Declaration on the Rights of Indigenous Peoples: What is it? What does it mean?", Netherlands Quarterly on Human Rights 2(1995), pp. 123-138.

Council of Europe, "Explanatory report on the Framework Convention for the Protection of National Minorities" NJCM-Bulletin 20-2 (1995), pp. 199-213.

Cranér, T., "Sami legal rights cleansing in Scandinavia", Indigenous Affairs, No. 3, July/August/September 1994, pp. 52-55.

Cranston, M., What are Human Rights?, Bodley Head, London, 1973.

Craven, M., "The Protection of Economic, Social and Cultural Rights under the InterAmerican System of Human Rights", in: D.J. Harris and S. Livingstone (eds.), The Inter-American System of Human Rights, Clarendon Press Oxford, 1998, pp. 289-322.

"Cultural Rights: An Underdeveloped Category of Human Rights, Conclusions of the Eighth Interdisciplinary Colloquium on Human Rights, organised by the University of Fribourg, 28-30 November 1991", The Review of the International Commission of Jurists, No. 49/1992, pp. 51-53.

Daes, E-I., "The Spirit and Letter of the Right to Self-Determination of Indigenous Peoples:Reflections on the Making of the United Nations Draft Declaration", in: P. Aikio and M. Scheinin (eds.), Operationalizing the Right of Indigenous Peoples to SelfDetermination, Institute for Human Rights, Åbo Akademie University, 2000,pp. 67-84.

Dahl, J., "Arctic Peoples, their lands and territories" in: I. Seurujärvi-Kari and U-M. Kulonen (eds.), Essays on Indigenous Identity and Rights, Helsinki University Press, 1996, pp. 15-31.

Davis, S.H., Land Rights and Indigenous Peoples - The Role of the Inter-American Commission on Human Rights, Cambridge, 1988. 
Debeljak, I., "Indigenous Rights: Recent Dewelopments in International Law", Intemational Jounal of Legal Information, Vol. 28 No.2, 2000, pp. 266-310.

Dinstein, $Y_{,}$"Collective Human Rights of Peoples and Minorities", Thterwational and Comparative Law Quarterly, Vol. 25, Jan. 1976, pp. 102-120.

Donders, Y., K. Henrard, A. Meijknecht and S. Tempelman (eds.), Law and Cwtural Diversity, SIM Special 25, Utrecht, 1999.

Donders, Y., "The Development of the Right to Cultural Identity in International Muman Rights Law", in: Y. Donders, K. Henrard, A. Meijknecht and S. Tempelman (eds.), Low and Cultural Diversity, SIM Special 25, Utrecht 1999, pp. 65-94.

Donnelly, J., Universal Human Rights in Theory and Practice, Comell University Press, London, 1989.

Donnelly, J., "Human Rights, Individual Rights and Collective Rights" in: Berting, J. et al. (eds.), Human Rights in a Pluralist World, Meckler Westport/London, 1990, pp. 39-62.

Donnelly, J., The Universal Declaration Model of Human Rights. A Liberal Defense, Human Rights Working Papers, No. 12, posted 12 February 2001 on http://www.du.edu/humanrights/workingpapers/index.html

Dyke, V. van, "The Cultural Rights of Peoples", Universal Human Rights, Vol. 2, No. 2, April-June 1980, pp. 1-21.

Dworkin, R., Taking rights seriously, Harvard University Press, Cambridge, 1977.

Eide, A., C. Krause and A. Rosas (eds.), Economic, Social and Cultural Rights - A Textbook, Second Revised Edition, Martinus Nijhoff Publishers, Dordrecht, 2001.

Eide, A., "Economic and Social and Cultural Rights as Human Rights", in: A. Eide, C. Krause and A. Rosas (eds.), Economic, Social and Cultural Rights - A Textbook, Second Revised Edition, Martinus Nijhoff Publishers, Dordrecht, 2001-A, pp 9-28.

Eide, A., "Cultural Rights as Individual Human Rights", in: A. Eide, C. Krause and A. Rosas (eds.), Economic, Social and Cultural Rights - A Textbook, Second Revised Edition, Martinus Nijhoff Publishers, Dordrecht, 2001-B, pp. 289-302.

Entzinger, H., Voorbij de multiculturele samenleving [Beyond the multicultural society], Van Gorcum, Assen, 2002.

Finmish Sami Parliament, "Land Rights, Linguistic Rights and Cultural Autonomy for the Finmish Sami People", Indigenous Affairs, No. 3-4, July-December 1997, pp. 48-51.

Fitzmaurice, M., "The Sami people: current issues facing an indigenous people in the Nordic region", in: Finnish Yearbook of International Low, Vol. V1II, 1997, Martinus Nijhof Publishers, The Hague, pp. 200-243.

Flinterman, C. "Three generations of human rights", in: Berting, J. et al. (eds.), Human Rights in a Plwralist World, Meckler Westport/London, 1990, pp. 75-81.

Gallenkamp, M. "Collective Rights: Much Ado About Nothing? A Review Essay", in: Netherlands Quarterly of Human Rights, 3/1991, pp. 291-307.

Galenkamp, M., "Collective Rights", SIM Spectal No. 16, Utrecht, 1995, pp. 53-102.

Galenkamp, M., "Speciale Rechten voor Minderheden? Een commentaar op Kymlicka"s Multicultural Citizenship" [Special Rights for Minorities? A comment on Kynilcka"s Multicultural Citizenship], Recht en Kritiek, 22 (1996) 2, pp. 202-224. 
Galenkamp, $\mathrm{M}_{, *}$ Individualism versus Collectivism - The concept of collective rights, Gouda Quint, 1998.

Gilbert, G., "The Council of Europe and Minority Rights", Human Rights Quarterly, 18 (1996), pp. 160-189.

Glazer, N., "Individual Rights against Group Rights", in: W. Kymlicka, (ed.), The Rights of Minonty Cultwres, Oxford University Press, Oxford, 1995, pp. 123-138.

Goudsblom, J, Nihilisme en Culuw [Nihilism and Culture], Meulenhoff, Amsterdam 1987.

Green, L., "Internal Minorities and their Rights", in: W. Kymlicka, (ed.), The Rights of Minority Cultures, Oxford University Press, Oxford, 1995, pp. $256-272$.

Groeneveld, $\mathrm{K}$. (ed.), Proliferatie van mensenrechten [Proliferation of human rights], Prof. mr. B.M. Teldersstichting, The Hague, 1996.

Grossman, $C$. "Awas Tingi v. Nicaragua: A Landmark Case for the Inter-American System", Human Rights Brief, Vol. 8, No. 3, Spring 2001, pp. 2-4 and 8.

Gutman, A. (ed.), Multiculturalism - Examining the Politics of Recognition, Princeton University Press, Princeton, 1994.

Gutman, A.y "Introduction", in: A. Gutman (ed.), Multiculturalism-Examining the Politics of Recognition, Princeton University Press, Princeton, 1994, pp. 3-24.

Habermas, J., "Struggles for Recognition on the Democratic Constitutional State, in: A. Gutman (ed.), Multiculturalism - Examining the Politics of Recognition, Princeton University Press, Princeton, 1994, pp. 107-148.

Hall, S., "Cultural Identity and Diaspora", in: J. Rutherford, J. (ed.), Identity - Community, Culture, Difference, Lawrence and Wishart, London, 1990, pp. 221-237.

Hannum, H., Autonomy, Sovereignty and Self-Determination, University of Pennsylvania Press, Philadelphia, 1996.

Hannum, H., "The Protection of Indigenous Rights in the Inter-American System", in: D.I. Harris and S. Livingstone (eds.), The Inter-American System of Human Rights, Clarendon Press Oxford, 1998, pp. 323-344.

Hanski, R. and M. Suksi (eds.), An Introduction to the International Protection of Human Rights - A Textbook, Institute for Human Rights, Ábo Akademi University, second edition, Turku/Abo, 1999.

Hartney "., "Some Confusions Concerning Collective Rights", in: W. Kymlicka, (ed.), The Rights of Minority Cultures, Oxford University Press, Oxford, 1995, pp. 202-227.

Hellstén, M., "The Sami Identity: a souvenir or something living?", Language and Education, Vol. 12, No. 2, 1998, pp. 119-136.

Henrard, K., Dewising an adequate system of minority protection : individual human rights, minority rights and the right to selfdetermination, Nijhoff Publishers, The Hague, 2000.

Henriksen, J.B., "'The legal status of Saamiland rights in Finland, Russia, Norway and Sweden", Indigenous Afform, No. 2, 1996, pp. 4-13.

Hoof, G.J.H. van, "The Legal Nature of Economic, Social and Cultural Rights: a Rebuttal of Some Traditional Views", in: Ph. Alston and K. Tomaševski (eds.), The Right to Food, Martinus Nijholf Publishers/SIM, Utrecht, 1984, pp. 97-111. 
Horn, F., (ed.), Economic, Social and Cultural Rights of the Sami - Intemational and national aspects, Juridica Lapponica No. 19, Lapland's University Press, Rovaniemi, 1998.

Humphrey, J.P., Human Rights and the United Nations: a great adventure, Transnational Publishers, New York, 1984.

Hyvärinen, H.J., "Finland, threats to the cultural autonomy of the Saamir", Indigenous Affairs, no. 2, 1996, pp. 14-16.

International Labour Organisation, Indigenous Peoples: Living and Working Conditions of Aboriginal Populations in Independent Countries, Geneva, 1953.

Johnson, G. and J. Symonides (eds.), The Universal Declaration of Human Rights - A History of its creation and implementation 1948-1998, UNESCO Publishing, Paris, 1998.

Johnston, D.M., "Native Rights as Collective Rights: A Question of Group Preservation", in: W. Kymlicka, (ed.), The Rights of Minority Cultures, Oxford University Press, Oxford, 1995, pp. 179-201.

Kanger, H., Human Rights in the UN Declaration, Upsala-Stockholm, 1984.

Kartashkin, V., "Cultural Rights", in: $\mathrm{K}$. Vasak and Ph. Alston (eds.), The International Dimensions of Human Rights, UNESCO Paris, 1982, pp. 127-130.

O'Keefe, R., "The "Right to Take Part in Cultural Life" under Article 15 of the ICESCR", International and Comparative Law Quarterly, Vol. 47, No. 3/4, October 1998, pp. 904-923.

Keller, P., "Re-thinking Ethnic and Cultural Rights in Europe", Oxford Journal of Legal Studies, Vol. 18, Spring 1998, pp. 29-59.

Klebes, H., "Parliamentary Assembly of the Council of Europe, Draft Protocol on Minority Rights to the ECHR - Introduction", Human Rights Liw Journal, Vol. 14, No. 3-4, 1993, pp. 140-148.

Klebes, H., "The Council of Europe's Framework Convention for the Protection of National Minorities", Human Rights Law Journal Vol. 16, No.1-3, 1995, pp. 92-115.

Kooijmans, P.H., "Human Rights - Universal Panacea? Some reflections on the so-called human rights of the third generation", in: Netherlands International Law Review, Vol.37, no. 3, 1990, pp. 315-329.

Korsmo, F.L., "Nordic security and the Saami minority: territorial rights in Northern Fennoscandia", Human Rights Quarterly, Vol. 10 no. 4, 1988, pp. 509-524.

Kukathas, Ch., "Are There Any Cultural Rights?", in: W. Kymlicka, (ed.), The Rights of Minority Cultures, Oxford University Press, Oxford, 1995, pp. 228-255.

Kukathas, Ch. "Cultural Toleration", in: W. Kymlicka and I. Shapiro (eds.), Ethmicity and Group Rights, New York University Press, New York/London, 1997, pp. 69-104.

Kymlicka, W. (ed.), The Rights of Minority Cultures, Oxford University Press, Oxford, 1995-A.

Kymlicka, W., Multi-Cultural Citizenship - A Liberal Theory of Minority Rights, Clarendon Press Oxford, Oxford, 1995-B. 
Kymlicka, W. and I. Shapiro (eds.), Ethnicity and Group Rights, New York University Press, New York/London, 1997.

Lasko, L-N., "Sami political organisation in Sweden", in: F. Horn (ed.), Economic, Social and Cultural Rights of the Sami - International and notional aspects, Juridica Lapponica No. 19, Lapland's University Press, Rovaniemi, 1998, pp. 66-79.

Lasko, L-N. and G. Osherenko, The Sani People and the Northern Sea Route: Juridical, Social and Cultural Concerns, INSROP Working paper no. 154, 1999 (ISBN 82-7613340-1).

Leander, B., Preliminary List of Cultural Rights, UNESCO, Culture and Development Coordination Office, Paris, 1996.

Leblanc, L., "The Economic, Social and Cultural Rights Protocol to the American Convention and its Background", Netherlands Quarterly of Human Rights 2 (1992), pp. 130-154.

Lemaire, $T$., Over de waarden van kulturen - een inleiding in de kulturfilosofie [The value of cultures - an introduction in cultural philosophy], AMBO Baarn 1976.

Lerner, N., Group Rights and Discrimination in International Law, Martinus Nijhoff Publishers, Dordrecht/Boston/London, 1991.

Lerner, N., "The 1989 ILO Convention on Indigenous Populations: New Standards?" in: Y. Dinstein and M. Tabory (eds.), The Protection of Minorities and Human Rights, Kluwer Dordrecht, 1992, pp. 213-232.

Lemer, $\mathrm{N}$., "The evolution of Minority Rights in International Law", in: C.Brölmann, $\mathrm{R}$. Lefeber and M. Zieck (eds), Peoples and Minorities in International Law, Martinus Nijhoff Publishers, Dordrecht, 1993, pp. 77-101.

Leuprecht, P., "Le Sous-Développement des Droits Culturels, vu depuis le Conseil de l'Europe", in: Meyer-Bisch, P. (ed.), Les Droits Culturels, une catégorie sousdéveloppée de droits de l'homme. Actes du VIIIe Colloque interdisciplinaire sur les droits de l'homme, Editions Universitaires Fribourg Suisse, 1993, pp. 73-97.

Levy, J.T., "Classifying Cultural Rights", in: W. Kymlicka and I. Shapiro (eds.), Ethnicity and Group Rights, New York University Press, New York/London, 1997, pp. 22-66.

Lijphart, A., "Self-Determination versus Pre-Determination of Ethnic Minorities in PowerSharing Systems", in: W. Kymlicka, (ed.), The Rights of Minority Cultures, Oxford University Press, Oxford, 1995, pp. 275-287.

"Limburg Principles on the Implementation of the International Covenant on Economic, Social and Cultural Rights", Human Rights Quarterly, vol. 9, 1987, pp. 122-135; also published as UN Doc. E/CN.4/1987/17.

"The Maastricht Guidelines on Economic, Social and Cultural Rights", in: Th.C. van Boven, C. Flinterman and I. Westendorp (eds.), SIM Special No. 20, SIM, Utrecht, 1998, pp. 1-12.

Malanczuk, P., Akehurst's Modern Introduction to International Law, seventh revised edition, Routledge, London/New York, 1997.

Margalit, A. and M. Halbertal, "Liberalism and the Right to Culture", Social Research, Vol. 61, No. 3, Fall 1994, pp. 491-510.

Margalit, A. and J. Raz, "National Self-Determination", in: W. Kymlicka, (ed.), The Rights of Minority Cultures, Oxford University Press, Oxford, 1995, pp. 79-92. 
Margalit, A., The Decent Society, Harvard University Press, London, 1996.

Marie, J-B., "Les Droits Culturels: Interface entre les Droits de l'Individu et les droits des Communautés", in: Meyer-Bisch, P. (ed.), Les Drouts Cultwels, wne categorie sousdéveloppée de droits de l'homme, Actes du VIITe Colloque interdisciplinaire sur les droits de l'homme, Editions Universitaires Fribourg Suisse, 1993, pp. 197-213.

Marks, S.P., "UNESCO and Human Rights: The Implementation of Rights relating to Education, Science, Culture and Communication", Texas International Law Journal, Vol. 13(35), 1977, pp. 35-67.

Marks, S.P. "Emerging Human Rights: A New Generation for the 1980s?" Ratgers Law Review (33), 1981, pp. 435-452.

Marks, S.P., "Education, Science, Culture and Information", in: O. Schachter and C.C. Joyner (eds.), United Nations Legal Order, Vol. 2, Cambridge University Press, 1995, pp. $577-630$.

Marquardt, S., "International Law and Indigenous Peoples", International Jownal on Group Rights, Vol. 3, No. 1, 1995, pp. 47-76.

Maskaminan Makagiansar, "Looking back at the World Conference on Culturall Policies", Cultures: dialogue between peoples of the world, Vol. IX, no. 1, 1983, pp. 15-21.

Meijknecht, A., Towards International Personality: The Position of Minorities and Indigenous Peoples in International Law, School of Human Rights Research Series No. 10, Hart/Intersentia, Antwerp/Groningen/Oxford, 2001.

Mercer, K. "Welcome to the Jungle: Identity and Diversity" in Postmodern Politics", in: J. Rutherford, J. (ed.), Identity - Community, Culture, Difference, Lawrence and Wishart, London, 1990, pp. 43-71.

Meyer-Bisch, P. (ed.), Les Droits Culturels, une catégorie sous-développée de droits de l'homme, Actes du VIIT Colloque interdisciplinaire sur les droits de l"homme, Editions Universitaires Fribourg Suisse, 1993.

Meyer-Bisch, P., "Les Droits Culturels Forment-ils une Catégorie Spécifique de Droits de l'Homme? Quelques difficultés logiques", in: P. Meyer-Bisch (ed), Les Droits Culturels, une catégorie sous-développée de droits de l homme, Actes du Vhle Colloque interdisciplinaire sur les droits de thomme, Editions Universitaires Fribourg Suisse, 1993-A, pp. 17-43.

Meyer-Bisch, P. "L'Idée de Démocratie Culturelle - Note d'introduction a l'interprétation politique des droits culturels", in: Meyer-Bisch, P. (ed.), Les Droits Culturels ine catégorie sous-développée de droits de lhomme, Acres du Whie Colloque interdisciplinaire sur les droits de l'homme, Editions Universitaires Fribourg Suisse, 1993-B, pp. 279-290.

Morley, D., and K. Robins, Spaces of Identity - Glabal Media, Electronic Landscapes and Cultural Boundaries, Routledge, London, 1995.

Morsink, J., The Universal Declaration of Human Rights - Origins, Drafing and Intent, University of Pennsylvania Press, Philadelphia, 1999-A.

Morsink, J., "Cultural Genocide, the Universal Declaration, and Minority Rights", Human Rights Quarterly, Vol. 21, 1999-B, pp. 1013-1028.

Moskowitz, M., The Politics and Dynamics of Human Rights, Oceana Publications Dobs Ferry, New York, 1968. 
Myntti, K, "The beneficiaries of autonomy arrangements - with special reference to indigenous peoples in general and the Sami in Finland in particular", in: M. Suksi (ed.), Autonomy, applications and implications, Kluwer Law International, The Hague, 1998, pp. $277-294$.

Nedjati, Z.M., Human rights under the European Convention, Amsterdam, Elsevier NorthHolland, New York, 1978.

Nickel, J.W., "Group Agency and Group Rights", in: W. Kymlicka and I. Shapiro (eds.), Ethnicity and Group Rights, New York University Press, New York/London, 1997, pp. 235-256.

Niec, H. Cultural Rights: At the end of the World Decade for Cultural Development, Conference paper for the Intergovernmental Conference on Cultural Policies for Development, Stockholm, Sweden, 30 March-2 April 1998, UNESCO Doc. CLT98/Conf. 210/Ref.2, Paris, December 1997.

Niec, H., (ed.), Cultural Rights and Wrongs, A Collection of Essays in Commemoration of the 50th Anniversary of the Universal Declaration of Human Rights, UNESCO Publishing, 1998.

Niec, H., "Casting the Foundation for the Implementation of Cultural Rights", in: H. Niec (ed.), Cultural Rights and Wrongs, A Collection of Essays in Commemoration of the 50th Anniversary of the Universal Declaration of Human Rights, UNESCO Publishing, Paris, 1998-A, pp. 176-190.

Nowak, M, UN Covenant on Civil and Political Rights - CCPR Commentary, Engel, KehlStrasbourg-Arlington, 1993.

Omanga, B.I., "The Draft Declaration of the United Nations on the Rights of Persons Belonging to National, Ethnic, Religious and Linguistic Minorities", ICJ Review, No. 46/1991, pp. 33-41.

Oreskov, C., "Editorial" Indigenous Affairs, No. 2, 1996, pp. 2-3.

Orton, F. and H. Beach, A New Era for the Saami People of Sweden, in: C. Price Cohen (ed.), The Human Rights of Indigenous Peoples, Transnational Publishers, New York, 1998, pp. 91-107.

Orwin, C. and T. Pangle, "The Philosophical Foundation of Human Rights", in: M.F. Plattner (ed.), Human Rights in Our Time - Essays in Memory of Victor Baras, Westview Press, Boulder/London, 1984, pp. 1-22.

Parekh, B., Rethinking Multiculturalism - Cultural Diversity and Political Theory, Macmillan Press, Basingstoke, 2000.

Pedersen, S., "Saami Rights: A Historical and Contemporary Outlook", in: I. SeurujärviKari and U-M. Kulonen (eds.), Essays on Indigenous Identity and Rights, Helsinki University Press, 1996, pp. 66-86.

Philips, A. and A. Rosas (eds.), The UN Minority Rights Declaration, Turku/Abo/London, 1993.

Pogge, Th.W., "Group Rights and Ethnicity", in: W. Kymlicka and I. Shapiro (eds.), Ethnicity and Group Rights, New York University Press, New York/London, 1997, pp. 187-221. 
Price Cohen, C. (ed.), The Human Rights of Indigenous Peoples, Transnational Publishers, New York, 1998.

Procee, H., Over de grenzen van culturen - voorbij universalisme en relativisme [Crossing the borders of cultures - beyond universalism and relativism], Boom, Amsterdam 1991.

Prott, L.V., "Cultural Rights as Peoples' Rights in International Law", in: J. Crawford (ed.), The Rights of Peoples, Clarendon Press Oxford, 1988, pp. 93-106.

Prott, L.V., "Understanding One Another on Cultural Rights", in: H. Niec (ed.), Cultural Rights and Wrongs, A Collection of Essays in Commemoration of the 50 th Anniversary of the Universal Declaration of Human Rights, UNESCO Publishing, Paris, 1998, pp. 161-175.

Raz, J., "Multiculturalism: a liberal perspective", in: N.J.H. Huls en H.D. Stout (eds.), Recht in een multiculturele samenleving [Law in a multicultural society], Tjeenk Willink, Zwolle, 1993.

Robertson, A., Human rights in Europe: being an account of the European comvention for theprotection of human rights, Manchester University press, Manchester, 1963.

Robinson, N., The Universal Declaration of Human Rights-Its Origin, Significance, Application and Interpretation, New York, 1958.

Rockefeller, S.C. "Comment on Taylor's Politics of Recognition", in: A. Gutman (ed.), Multiculturalism - Examining the Politics of Recognition, Princeton University Press, Princeton, 1994, pp. 87-98.

Rodley, N.S., "Conceptual Problems in the Protection of Minorities: International Legal Developments", Human Rights Quarterly, Vol. 17, No. 1, 1995, pp. 48-71.

Rönquist, A., "The Council of Europe Framework Convention for the Protection of National Minorities", Helsinki Monitor Vol. 6, No. 1, 1995, pp. 38-44.

Rosas, A." "The Right of Self-Determination", in: A. Eide, C. Krause and A Rosas (eds.), Economic, Social and Cultural Rights - A Textbook, Martinus Nijhoff Publishers, Dordrecht, 1995, pp. 79-86.

Rutherford, J. (ed.), Identity - Community, Culture, Difference, Lawrence and Wishart, London, 1990.

Rutherford, J., "A Place Called Home: Identity and the Cultural Politics of Difference", in: J. Rutherford, J. (ed.), Identity - Community, Culture, Difference, Lawrence and Wishart, London, 1990-A, pp. 9-27.

Sanders, D., "The UN Working Group on Indigenous Populations", Human Rights Quarterly, Vol. 11, 1989, pp. 406-433.

Schachter, O., "Human Dignity as a Normative Concept", American Iloumal of International Law, vol. 77, 1983, pp. 848-854.

Scheinin, M., "Land Rights and the Right to Culture", in: I. Seurujärvi-Kari and UM.Kulonen (eds.), Essays on Indigenous Identity and Rights, Helsinki University Press, 1996 , pp. $87-100$.

Scheinin, M., "The right to enjoy" a distinct culture: indigenous and competing uses of land", in: Th. S. Orlin, A. Rosas and M. Scheinin (eds.), The Jurisprudence of Human Rights Law: A Comparative Interpretive Approach, Institute for Human Rights, Turku/Åbo, 2000, pp. 159-222. 
Seurujärvi-Kari, I. and U-M. Kulonen (eds.), Essays on Indigenous Identity and Rights, Helsinki University Press, 1996.

Seurujärvi-Kari, I. and S. Pedersen, Les Sámi; Le peuple indigène de Grand Nord, Bureau Européen pour les Langues Moins Répandues, Brussels, 1997.

Sillanpää, L., Impact of International Low on Indigenous. Rights in Northern Europe, Ottawa, Indian and Northern Affairs Canada, 1992.

Somby, A., "The Alta Case: a story about how another hydroelectric dam project was forced through in Norway", Indigenous Affairs, no. 3-4, June/December 1999, pp. 5663.

Stavenhagen, R., "The Right to Cultural Identity", in: Berting, J. et al. (eds.), Human Rights in a Pluralist World, Meckler Westport/London, 1990, pp. 255-258.

Stavenhagen, R., "Cultural Rights: a Social Science Perspective", in: H. Niec (ed.), Cultural Rights and Wrongs, A Collection of Essays in Commemoration of the 50th Anniversary of the Universal Declaration of Human Rights, UNESCO Publishing, Paris, 1998, pp. 1-20.

Stavenlagen, R., "Cultural Rights: a Social Science Perspective", in: A. Eide, C. Krause and A. Rosas (eds.), Economic, Social and Cultural Rights - A Textbook, Second Revised Edition, Martinus Nijhoff Publishers, Dordrecht, 2001, pp. 85-110.

Steiner, $\mathrm{H}$. . and $\mathrm{Ph}$. Alston, International human rights in context: law, politics, morals texts and materials, second edition, Oxford University Press Oxford, 2000.

Stocking, G.W., Race, Culture and Evolution, University of Chicago Press, Chicago 1968.

Suksi. M., (ed.), Autonomy, applications and implications, Kluwer Law International, The Hague, 1998.

Symonides, J., "The History of the Paradox of Cultural Rights and the State of the Discussion within UNESCO", in: Meyer-Bisch, P. (ed.), Les Droits Culturels, une catégorie sous-développée de droits de l'homme, Actes du VIIIe Colloque interdisciplinaire sur les droits de lhomme, Editions Universitaires Fribourg Suisse, 1993, pp. 47-72.

Symonides, J. (ed.), Human Rights: Concept and Standards, UNESCO Publishing, Paris, 2000.

Symonides, J., "Cultural Rights", in: J. Symonides, (ed.), Human Rights: Concept and Standards, UNESCO Publishing, Paris, 2000-A, pp. 175-227.

Svensson, T., "The attainment of limited self-determination among the Sami in recent years", in: R.Kuppe and R. Potz (eds.), Low and Philosophy, Vol. 8, Kluwer Law International, The Hague, 1996, pp. 267-278.

Swepston, L., "Economic, Social and Cultural Rights under the 1989 ILO Convention", in: F. Horn (ed.), Economic, Social and Cultural Rights of the Sami - International and national aspects, Lapland University Press, Rovaniemi, 1998, pp. 38-46.

Szabó, 1., Cultural Rights, A.W. Sijthoff. Leiden, 1974.

Taylor, Ch. "The Politics of Recognition", in: A. Gutman (ed.), Multiculturalism Examining the Politics of Recognition, Princeton University Press, Princeton, 1994 , pp. $25-74$.

Thomberry, P., International Law and the Rights of Minorities, Clarendon Press, Oxford, 1991. 
Thomberry, P., "The UN Declaration on the Rights of Persons Belonging to National or Ethnic, Religious and Linguistic Minorities: Background, Analysis and Observations", in: A. Philips and A. Rosas (eds.), The UN Minority Rights Declaration, Turku/ABbo, 1993, pp. 11-72.

Thornberry, P. "The UN Declaration on the Rights of Persons Belonging to National or Ethnic, Religious and Linguistic Minorities: Background, Analysis, Observations and an Update", in: A. Philips and A. Rosas (eds.), Universal Minority Rights, Turku/Abo and London, 1995, pp. 13-77.

Toebes, B.C.A., The Right to Health as a Human Right in International Law, School of Human Rights Research Series No. 1, Hart/Intersentia, Antwerp/Groningen/Oxford, 1999.

Tolley, H. Jr., The UN Commission on Human Rights, Colorado, Westview Press, 1987.

Tomuschat, C., "Protection of Minorities under article 27 of the International Covenant on Civil and Political Rights", in: Volkerrecht als Rechtsordnung. Internationale Gerichtsbarheit Menschenrechte: Festschrift fuir Hermann Mosler, Berlin/Heidelberg/New York, Springer Verlag, 1983, pp. 949-980.

Tomuschat, C., (ed.), Modern Law of Self-determination, Dordrecht, Nijhoff, 1993.

Tylor, E.B., "The Science of Culture", in: E.B. Tylor, Primitive Culture: researches into the development of mythology, philosophy, religion, language, art and custom, John Murray, London, 1920 (original edition 1858), pp. 1-25.

United Nations, These Rights and Freedoms, UN Publications New York, 1950.

United Nations Educational, Scientific and Cultural Organisation (UNESCO), Cultural Rights as Human Rights, Paris, 1970.

United Nations Educational, Scientific and Cultural Organisation (UNESCO), Culture and Development Co-ordination Office, Working Group on Cultural Rights, 30 September 1996.

United Nations Educational, Scientific and Cultural Organisation (UNESCO), The Power of Culture, Conference Report (Amsterdam, 8-9 November 1996), Den Haag 1997.

United Nations Educational, Scientific and Cultural Organisation (UNESCO), World Culture Report: Culture, Creativity and Markets, Paris, 1998.

Vasak, K. "Pour une troisième génération des droits de l'homme", in: C. Swinarskí (ed.), Essays on International Humanitarian Law and Red Cross Principles in Honour of Jean Pictet, The Hague, Martinus Nijhoff, 1984, pp. 837-850.

Verdoodt, A., Naissance et Signification de la Déclaration Universelle des Droits de l'Homme, Louvain-Paris, 1963.

Vierdag, E., "The Nature of the Rights Granted by the International Covenant on Economic, Social and Cultural Rights", Netherlands Yearbook of International Law, vol. 9, 1978, pp. 69-105.

Vlemminx, F., Grondrechten en Moderne Beeldende Kunst [Basic Rights and Modern Plastic Art], W.E.J. Tjeenk Willink, Zwolle, 1992.

Vlemminx, F., Het Profiel van de Sociale Grondrechten [The Profile of Social Rights], W.E.J. Tjeenk Willink, Zwolle, 1994. 
Vlemminx, F., Een Nieuw Profiel van de Grondrechten - Een Analyse van de Prestatieplichten ingevolge Klassieke en Sociale Grondrechten [A New Profile of Basic Rights - An Analysis of the Obligations of Conduct of Classic and Social Rights], W.E.J. Tjeenk Willink, Zwolle, 1998.

Waart, PJIM., de, "Recht op Ontwikkeling als Nieuw Beginsel van Modern Volkenrecht" [Right to Development as New Principle of Modern International Law], in: M. Dolman, E. Florijn, R. Glas, M. Hesselink en H. Krmingk (eds.), Rechtsbeginselen [Principles off Law], Ars Aequi No. 40, Nijmegen, 1991, pp. 228-236.

Waldron, J., "Minority Cultures and the Cosmopolitan Alternative", in: W. Kymlicka, (ed.), The Rights of Minority Cultures, Oxford University Press, Oxford, 1995, pp. 93-119.

Walzer, M., "Comment on Taylor's Politics of Recognition", in: A. Gutman (ed.), Multiculturalism - Examining the Politics of Recognition, Princeton University Press, Princeton, 1994, pp. 99-103.

Walzer, M., "Pluralism: A Political Perspective", in: W. Kymlicka, (ed.), The Rights of Minority Cultures, Oxford University Press, Oxford, 1995, pp. 139-154.

Walzer, M. "Response to Kukathas", in: W. Kymlicka and I. Shapiro (eds.), Ethnicity and Group Rights, New York University Press, New York/London, 1997, pp. 105-111.

Watney, S., "Practices of Freedom: "Citizenship" and the Politics of Identity in the Age of AIDS", in: J. Rutherford, J. (ed.), Identity - Community, Culture, Difference, Lawrence and Wishart, London, 1990, pp. 157-187.

Weeks, J., "The Value of Difference", in: J. Rutherford, J. (ed.), Identity - Community, Culture, Difference, Lawrence and Wishart, London, 1990, pp. 88-100.

Wilhelm, M., "L'Entendue des Droits a l'Identité a la Lumière des Droits Autochtones", in: Meyer-Bisch, P. (ed.), Les Droits Culturels, une catégorie sous-développée de droits de l'homme, Actes du VIITe Colloque interdisciplinaire sur les droits de l'homme, Editions Universitaires Fribourg Suisse, 1993, pp. 212-244.

Witte, B. de, "Trade in Culture: International Legal Regimes and EU Constitutional Values", in: Burca, G. de and J. Scott (eds.), The EU and the WTO: Legal and Constitutional Aspects, Hart Publishers, Oxford, 2001, pp. 237-255.

Wolfrum, R., "The Protection of Indigenous Peoples in International Law", Zeitschriff für ausländisches offentliches Recht und Völkerrecht, Heidelberg Journal of International Law, Vol. 59 No. 2, 1999, pp. 369-382.

World Commission on Culture and Development, Our Creative Diversity, UNESCO, Paris, 1996. 


\section{SELECTED DOCUMENTS OF THE UNITED NATIONS, UNESCO, THE ORGaNISATION OF AMERICAN STATES AND THE COUNCIL OF EUROPE}

\section{UNITED NATIONS DOCUMENTs (in chronological order, by theme)}

International Covenants on Civil and Political Rights and Economic, Social and Cultural Rights (1966)

UN Doc. A/C3/SR.150, Summary Record of the third session of the General Assembly, 1948.

UN Doc. E/CN.4/358, Report of the Third Session of the Sub-Commission on the Prevention of Discrimination and the Protection of Minorities to the Commission on Human Rights, 30 January 1950.

UN Doc. E/CN.4/364, Report by the Secretary General on the activities of United Nations organs and specialised agencies in matters within the scope of articles 22-27 of the Universal Declaration of Human Rights, May 1950.

UN Doc. A/C.3/SR 289, Draft first international covenant on human rights and measures of implementation, fifth session, 19 September - 15 December 1950.

UN Doc. A/C.3/SR 299, Draft first international covenant on human rights and measures of implementation, fifth session, 19 September -15 December 1950 .

UN Doc. E/CN.4/L.222 (UN Doc. A/C.3/L.96) in: A/C.3/SR.289, General Assembly, fifth session, Summary Record, 19 September-15 December 1950.

UN Doc. E/CN.4/L.225 (UN Doc. A/C.3/L.92) in: A/C.3/SR.289, General Assembly, fifth session, Summary Record, 19 September - 15 December 1950.

UN Doc. E/CN.4/513, Commission on Human Rights Seventh Session, Agenda Item 3, Memorandum by the Secretary General, 2 March 1951.

UN Doc. E/CN.4/529, Commission on Human Rights Seventh Session, Agenda 1tem 3, Memorandum by the Secretary General, 29 March 1951.

UN Doc. E/CN.4/528, Commission on Human Rights, Seventh Session, ltem 3, Memorandum by the Secretary General, 2 April 1951.

UN Doc. E/CN.4/ 541, Commission on Human Rights Seventh Session, Agenda Item 3, Draft articles on educational and cultural rights submitted by the Director-General of the United Nations Educational, Scientific and Cultural Organisation, 18 April 1951.

UN Doc. E/CN.4/541 Rev.1, Commission on Human Rights Seventh Session, Agenda Item 3, Suggestions submitted by the Director-General of the United Nations Educational, Scientific and Cultural Organisation, 27 April 1951.

UN Doc. E/CN.4/613 and E/CN.4/613 Rev.1., Commission on Human Rights, Seventh Session. Chile: Proposal on the Right to Education and Cultural Rights based on Suggestions of UNESCO, 5 and 7 May 1951. 
UN Doc. E/CN.4/AC.14/SR.1, Commission on Human Rights Seventh Session, Working Group on Economic, Social and Cultural Rights, Summary Record of the first meeting, 17 May 1951.

UN Doc. E/1992 (E/CN.4/640), Report of the Seventh Session of the Commission on Human Rights, 24 May 1951 .

UN Doc. E/CN.4/641, Report of the Fourth Session of the Sub-Commission on the Prevention of Discrimination and the Protection of Minorities to the Commission on Human Rights, 25 October 1951.

UN Doc. A/C.3/SR.371, Draft international covenant on human rights and measures of implementation, December 1951.

UN Doc: E/CN.4/655/Add.4, Commission on Human Rights, eighth session, Observations submitted by Specialized Agencies on the Proposed Covenant on Economic, Social and Cultural Rights in pursuance of Resolution 543 (VI) of the General Assembly, 17 April 1952.

UN Doc. E/CN.4/L.52, Commission on Human Rights, Eighth Session, Union of Soviet Socialist Republics: Draft amendment to article 30,25 April 1952.

UN Doc. E/CN.4/L.75, Commission on Human Rights, Eighth Session, France: Draft amendment to article 30,29 Apri1 1952.

UN Doc. E/CN.4/L.81, Commission on Human Rights, Eighth Session, United States of America: Draft amendment to article 30, 2 May 1952.

UN Doc. E/CN.4/L.105 and E/CN.4/L.105 Rev.1, Commission on Human Rights, Eighth Session, Lebanon: amendment to the amendment submitted by the United States of Anerica (E/CN.4/L.81), 13 May 1952.

UN Doc. E/CN.4/L.81/Rev. 1, Commission on Human Rights, Eighth Session, United States of America: Draft amendment to article 30, 14 May 1952.

UN Doc. E/CN.4/666/Add.5, Commission on Human Rights, Eighth Session, Article --- of the Draft Covenant on Economic, Social and Cultural Rights: text adopted by the Commission at its 294th meeting, on 14 May 1952.

UN Doc. E/2256, Report of the Eighth Session of the Human Rights Commission, AprilJune 1952.

UN Doc. E/CN.4/SR.293, Commission on Human Rights, Eighth Session, Summary Record of the Two Hundred and Ninety Third meeting, 27 May 1952.

UN Doc. E/CN.4/SR.294, Commission on Human Rights, Eighth Session, Summary Record of the Two Hundred and Ninety Fourth meeting, 27 May 1952.

UN Doc. A/C.3/SR.565, Draft international covenant on human rights and measures of implementation, October 1954.

UN Doc. A/C.3/SR.566, Draft international covenant on human rights and measures of implementation; October 1954.

UN Doc. E/2573, Annex I, Draft International Covenants on Human Rights, 1954.

UN Doc. A/2929, Annotations on the text of the draft International Covenants on Human Rights, New York, 1 July 1955.

UN Doc. A/C.3/L.633, Czechoslovakia: amendment to article 16 of the draft Covenant on Economic, Social and Cultural Rights (E/2573, Annex IA). To be found in: A/OR/12 Annexes; General Assembly, Twelfth session, Third Committee, 795-799th meeting, October-November 1957. 
UN Doc. A/C.3/L.634, Saudi-Arabia: amendment to document A/C.3/L.633. To be found in: A/OR/12 Annexes, General Assembly, Twelfth session, Third Committee, 795799th meeting, October-November 1957.

UN Doc. A/C.3/L.635, Greece: amendment to article 16 of the draft Covenant on Economic, Social and Cultural Rights (E/2573, Annex IA). To be found in: A/OR/12 Annexes, General Assembly, Twelfth session, Third Committee, 795-799th meeting, October-November 1957.

UN Doc. A/C.3/L.636 and Add.1, Costa Rica and Uruguay: amendment to article 16 of the draft Covenant on Economic, Social and Cultural Rights (E/2573, Annex IA). To be found in: A/OR/12 Annexes, General Assembly, Twelfth session, Third Committee, 795-799th meeting, October-November 1957.

UN Doc. Annexes, agenda item 33, General Assembly, official records twelfth session, New York, October - November 1957.

UN Doc. A/C.3/SR. 796, Summary record of the General Assembly, Third Committee, twelfth session, 796th meeting, 31 October 1957.

UN Doc. A/C.3/SR. 797, Summary record of the General Assembly, Third Committee, twelfth session, 797th meeting, 31 October 1957.

UN Doc. A/C.3/SR. 799, Summary record of the General Assembly, Third Committee, twelfth session, 799th meeting, 4 November 1957.

UN Doc. E/3616/Rev: 1, Report of the Commission on Human Rights, 18th Session ECOSOC, 19 March-14 April 1962, New York.

UN Doc. E/CN.4/Sub.2/384/Rev.1, F. Capotorti, Study on the Rights of Persons belonging to ethnic, religious and linguistic minorities, 1979.

UN Doc. E/CN:4/Sub.2/1987/23, The Right to Adequate Food as a Human Right, Report prepared by Mr. A. Eide, 1987.

UN Doc. E/CN.4/Sub.2/1989/19, Realisation of Economic, Social and Cultural Rights, Preliminary Report prepared by Mr. Danilo Türk; Special Rapporteur, 28 June 1989.

UN Doc. E/1991/23, Annex 4, Committee on Economic, Social and Cultural Rights, Report of the Fifth Session, revised guidelines, 1990.

UN Doc. E/CN.4/Sub.2/1990/19, Realisation of Economic, Social and Cultural Rights, Progress Report prepared by Mr. Danillo Türk, Special Rapporteur, 6 July 1990.

UN Doc. E/CN.4/Sub.2/1991/17, The Realisation of Economic, Social and Cultural Rights, Second Progress Report prepared by Mr. Danilo Türk, Special Rapporteur, 18 July 1991.

UN Doc. E/CN.4/Sub.2/1992/16, The Realisation of Economic, Social and Cultural Rights, Final Report submitted by Mr. Danilo Türk, Special Rapporteur, 3 Jully 1992.

UN Doc. E/C.12/1992/WP.4, Implementation of Cultural Rights, Analytical study of article 15 of the International Covenant on Economic, Social and Cultural Rights, by Mr. S.R. Konaté, 25 November 1992.

UN Doc. E/C.12/1992/SR.17, General discussion on the right to take part in cultural life as recognised in article 15 of the Covenant, 11 December 1992.

UN Doc. E/CN.4/Res/2002/26, Commission on Human Rights, Resolution on the Promotion of the Enjoyment of the Cultural Rights of Everyone and Respect for Different Cultural Identities, 22 April 2002. 


\section{Minorities}

UN Doc. E/CN.4/L.1367/Rev.1, Rights of Persons belonging to National, Ethnic, Religious and Linguistic Minorities, Draft Declaration proposed by Yugoslavia, 2 March 1978.

UN Doc. E/CN.4NGO/231, Rights of Persons belonging to National, Ethnic, Religious and Linguistic Communities, Written Statement submitted by the Minority Rights Group, a non-governmental organisation in consultative status, 26 January 1979.

UN Doc. E/CN.4/Sub.2/L.734, Rights of Persons bellonging to National, Ethmic, Religious and Linguistic Minorities, Draft Declaration prepared by Mr. Toševski, 2 July 1980.

UN Doc. E/CN.4/Sub.2/1985/31 and Corr. 1, J. Deschênes, United Nations SubCommission on the Prevention of Discrimination and Protection of Minorities, Proposal concerning a Definition of the Term "Minority", 14 May 1985.

UN Doc. E/CN.4/1986/43, Report of the Open-Ended Working Group set up by the Commission on Human Rights to Consider the Drafting of a Declaration Rights of Persons belonging to National, Ethnic, Religious and Linguistic Minorities, 10 March 1986.

UN Doc. E/CN.4/1987/WG.5/WP.1, A compilation of proposals concerning the definition of "minority" published by the Secretariat, 1987.

UN Doc. E/CN.4/1990/41 + Annex 1, Report of the Working Group on the Rights of Persons Belonging to National, Ethnic, Religious and Linguistic Minorities, 5 March 1990.

UN Doc. E/CN.4/1991/52 + Add.1, Analytical Compilation of the comments received in pursuance of paragraph 3 of the Commission on Human Rights Resolution 1990/45 on the rights of persons belonging to national, ethnic, religious and linguistic minorities, 30 January 1991.

UN Doc. E/CN.4/1991/53, Report of the Working Group on the Rights of Persons Belonging to National, Ethnic, Religious and Linguistic Minorities, 47th session, 5 March 1991.

UN Doc. E/CN.4/1992/48, Report of the Working Group on the Rights of Persons Belonging to National, Ethnic, Religious and Linguistic Minorities, 48 th session, 16 December 1991 .

UN Doc. E/CN.4/1992/84, Resolution 1992/16, Commission on Human Rights, Report of the Forty-Eighth Session, ECOSOC Official Records, 1992, Supplement 2, 27 January 6 March 1992.

UN Doc. A/Res/47/135/Annex, Declaration on the Rights of Persons Belonging to National or Ethnic, Religious and Linguistic Minorities, 18 December 1992.

UN Doc. E/CN.4/Sub.2/1993/34/Add.4, A. Eide, Possible ways and means of facilitating the peaceful and constructive solution of problems involving minorities, 11 August 1993.

UN Doc. E/CN.4/Sub.2/1994/36, A. Eide, Working paper containing suggestions for a comprehensive programme for the prevention of discrimination and protection of minorities, 6 July 1994.

UN Doc. E/CN.4/1994/50, Resolution 1994/22, Rights of Persons belonging to National or Ethnic, Religious and Linguistic Minorities, adopted 1 March 1994, Commission on Human Rights, Report on the Fiftieth Session, ECOSOC Official Records, 1994, Supplement No. 4. 
UN Doc: E/CN.4/1995/2/E/CN.4/Sub.2/1994/56, Sub-Commission resolution 1994/4, adopted on 19 August 1994.

UN Doc. E/CN.4/Sub.2/1995/2, Resolution 1994/4, Prevention of Discrimination and Protection of Minorities, adopted on 19 August 1994.

UN Doc. E/CN.4/1995/L.11/Add.2, Resolution 1995/24, Rights of Persons belonging to National or Ethnic, Religious and Linguistic Minorities, adopted 3 March 1995.

UN Doc. E/CN.4/Sub.2/AC.5/2001/2, Final text of the Commentary to the Declaration on Rights of Persons belonging to National or Ethnic, Religious and Linguistic Minorities, by Asbjørn Eide, 2 April 2001.

\section{Indigenous Peoples}

UN Doc. E/CN.4/Sub.2/AC.4/1985/WP.4, Rights of Indigenous Peoples to the Earth, paper submitted to the UN Working Group on Indigenous Populations, 29 July 1985.

UN Doc. E/CN.4/Sub.2/1985/22, Annex 11, Report of the Working Group on Indigenous Populations on its fourth session, 27 August 1985.

UN Doc. E/CN.4/Sub.2/1986/7, E/CN.4/Sub.2/1986/7/Add.1, E/CN.4/Sub.2/1986/7/Add.2, E/CN.4/Sub.2/1986/7/Add.3 and E/CN.4/Sub.2/1986/7/Add.4, J.Martinez-Cobo, Study of the Problem of Discrimination against Indigenous Populations, UN Sub-Commission on Prevention of Discrimination and Protection of Minorities, 1986.

UN Doc. E/CN.4/Sub.2/1988/25, A Working paper by Ms. Erica-Irene Daes containing a set of draft preambular paragraphs and principles for insertion into a universal declaration on indigenous rights, 21 June 1988.

UN Doc. E/CN.4/Sub.2/1993/26/Add.1, Explanatory note concerning the draft declaration on the rights of indigenous peoples, by Erica-Irene Daes, 19 July 1993.

UN Doc. E/CN.4/Sub.2/1993/28, E.I. Daes, Study on the protection of the cultural and intellectual property of indigenous peoples, 28 July 1993.

UN Doc. E/CN.4/Sub.2/1993/29, Report of the Working Group on Indigenous Populations on its eleventh session, 23 August 1993.

UN Doc. E/CN.4/Sub.2/1994/2/Add.1, Draft Declaration on the Rights of Indigenous Peoples, 20 April 1994.

UN Doc. E/CN.4/Sub.2/1994/56, Report of the Sub-Commission on Prevention of Discrimination and Protection of Minorities on its 46th Session, Resolution 1994/45adopted at 26 August 1994, 28 October 1994.

UN Doc. E/CN.4/RES/1995/32 Commission Resolution 1995/32, Establishment of a working group of the Commission on Human Rights to elaborate a draft declaration,3 March 1995.

UN Doc. E/RES/1995/32, ECOSOC Resolution 1995/32, Establishment of a working group of the Commission on Human Rights to elaborate a draft declaration in accordance with paragraph 5 of General Assembly resolution 49/214, 25 July 1995.

UN Doc. E/CN.4/Sub.2/1995/27, Study on the treaties, agreements and other constructive arrangements between States and indigenous populations, second progress report by Special Rapporteur Miguel Alfonso Martinez, 31 July 1995.

UN Doc. CERD/C/51/Misc.13/Rev.4, General Recommendation XXIII (51) concerning Indigenous Peoples, adopted at the 1235th meeting on 18 August 1997. Also 
reproduced as General Assembly, Official Records, fifty second session, Supplement no. $18(\mathrm{~A} / 52 / 18)$, annex $\mathrm{V}$.

UN Doc. A/RES/53/144, Declaration on the Right and Responsibility of Individuals, Groups and Organs of Society to Promote and Protect Universally Recognised Human Rïghts and Fundamental Freedom Rights and Responsibility of Individuals, Groups and Organs of Society to Promote and Protect Universally Recognised Human Rights and Fundamental Freedoms, General Assembly resolution 53/144, 85th plenary meeting 9 December 1998, 8 March 1999 .

\section{UNESCO DOCUMENTS (in chronological order)}

UNESCO, "A Statement by Experts on Race Problems", International Social Science Bulletin, Vol. II, pp. 391-394, July 1950.

UNESCO Doc. UNESCO/CUA/42, Programme of UNESCO for 1952 - Resolution 4.52 Study of the "Right to Participate in Cultural Life" - Basic Document, 6th session, Paris, 2 May 1952.

UNESCO Doc. 7C/PRG/10, Report on the proceedings of the Committee of Experts formed to study the Right to Participate freely in the Cultural Life of the Community, Paris, 3 November 1952.

UNESCO Doc. $7 \mathrm{C} / \mathrm{PRG} / 10$, Add., Report on the proceedings of the Committee of Experts formed to study the Right to Participate freely in the Cultural Life of the Community, Comments of the Executive Board, Paris, 12 November 1952.

UNESCO Statement on the Nature of Race and Race Differences, Paris, June 1951; Proposals on the Biological Aspects of Race, Moscow, 18 August 1964.

UNESCO Doc. SHC/MD/21, Meeting of experts on the concepts of race, identity and dignity, Paris, 17 November 1972.

UNESCO Doc. $94 \mathrm{EX} / 18$, Possible international instrument on action to ensure that the people at large have free, democratic access to culture and participate actively in the cultural life of society, Paris, 5 June 1974.

UNESCO Doe. $18 \mathrm{C} / 36$, Generall Conference, eighteenth session, Preliminary study on the legal and technical aspects of a draft declaration on race and racial prejudice, Paris, 19 September 1974.

UNESCO Doc. 94 EX/Decisions, Executive Board, Decision 4.4.3.3, Paris, 24 June 1974.

UNESCO Doc. $18 \mathrm{C} / 31$, General Conference, eighteenth session, Desirability of Adopting an International Instrument on Action to Ensure that the People at Large have Free, Democratic Access to Culture and Participation Actively in the Cultural Life of Society, Paris, 20 September 1974.

UNESCO Doc. $18 \mathrm{C} /$ Resolutions 3.462, Paris, October, November 1974.

UNESCO Doc. SHC/MD/28, Action to ensure that the people at large have free, democratic access to culture and participate actively in the cultural life of society, Preliminary report drawn up in accordance with article 10.1 of UNESCO's Rules of Procedure concerning Recommendations to Member States and International Conventions covered by the terns of article IV (4) of the Constitution, Paris, 22 August 1975. 
UNESCO, Committee of Governmental Experts to Prepare a Draft Declaration on Race and Racial Prejudice, Background Paper 1: Statement on Race and Racial Prejudice, Paris, September 1967, publication 15 September 1975.

UNESCO, Committee of Governmental Experts to Prepare a Draft Declaration on Race and Racial Prejudice, Background paper 2: Results of an expert consultation on possible changes in the 1967 Statement on Race and Racial Prejudice, Paris, Jully 1973, publication 16 September 1975.

UNESCO Doc. SHC/MD/31, Annex I and II, Action to ensure that the people at large have free, democratic access to culture and participate actively in the cultural life of socien, Final Report, Paris, 11 March 1976.

UNESCO Doc. SHC/MD/33, Committee of Governmental Experts to Prepare a Draft Declaration on Race and Racial Prejudice, Prelimmary draft of a Declaration on Race and Racial Prejudice, Paris, 14 June 1976.

UNESCO Doc. $19 \mathrm{C} / 27$ Annex II, General Conference, nineteenth session, Report of the Special Committee of Governmental Experts, Paris, 6 August 1976.

UNESCO Doc. $19 \mathrm{C} / 27$, General Conference, nineteenth session, Draft Recommendation on action to ensure that the people at large have free, democratic access to culture and participate actively in the cultural life of society, Paris, 6 August 1976.

UNESCO Doc, SS-77/CONF.201/1, Working paper of the meeting of government representatives to prepare a draft declaration on race and racial prejudice, Paris, 18 August 1977.

UNESCO Doc, SS-78/CONF.201/8, Working paper of the meeting of government representatives to prepare a draft declaration on race and racial prejudice, Paris, 20 March 1978.

UNESCO Doc. 104/EX/3.3, Decisions adopted by the Executive Board at its 104th session, Paris, Decision 3.3, Study of the procedures which should be followed in the examination of cases and questions which might be submitted to UNESCO concerning the exercise of human rights in the spheres of its competence in order to make its action more effective, 24 April - 9 June 1978.

UNESCO Doc. 20 C/18, General Conference, twentieth session, Draft Declaration on Race and Racial Prejudice, Paris, 25 September 1978.

UNESCO Doc. 20 C/26, General Conference, twentieth session, Initial Special Reports submitted by Member States on the action taken by them upon the Recommendation on Participation by the People at Large in Cultural Life and Their Contribution to It, adopted by the General Conference during its nineteenth session, Paris, 23 October 1978 and Add. 1, 2 and 3, Paris, 28 October 1978.

UNESCO Doc. 21C/78, General Conference, twenty-first session, Comprehesisive report by the Director-General on the world sination in fields covered by the Declaration on Race and Racial Prejudice and recommendations made with a view to promoting implementation of that decision, Paris, 11 October 1980.

UNESCO Doc. CC/CSP/CP/4, The Nairobi Recommendation on Participation by the People at Large in Cultural Life and Their Contribution to It (1976), The situation ten years later, by Pierre Moulinier, Paris, 1986.

UNESCO Doc. $24 \mathrm{C} / 14$, General Conference, twenty-fourth session, Application of the Resolution Concerning the Implementation of the Dectaration on Race and Racial Prejudice, 22 September 1987. 
UNESCO Doc, $26 \mathrm{C} / 104$, General Conference, twenty-sixth session, Application of the Resolution Concening the Implementation of the Declaration on Race and Racial Prejudice, 4 October 1991.

UNESCO Doc. $28 \mathrm{C} / 23$, General Conference, twenty-eighth session, Application of the Resolution Concening the Implementation of the Declaration on Race and Racial Prejudice, 3 October 1995 .

\section{UNESCO Conferences on Cultural Policies}

UNESCO Doc. SHC/MD/13, General Report, Intergovernmental Conference on Institutional, Administrative and Financial Aspects of Cultural Policies, Venice, 24 August - 2 September 1970.

UNESCO Doc. $16 \mathrm{C} / 84$, Report of the Director-General on the Intergovermmental Conference on Institutional, Administrative and Financial Aspects of Cultural Policies, 16 October 1970.

UNESCO Doc. SHC/EUROCULT/4, Intergovernmental Conference on Cultural Policies in Europe, Item 7 of the agenda: Larger Access to and Participation in Culture, Paris, 30 March 1972.

UNESCO Doc. SHC/MD/20, General Report, Intergovernmental Conference on Culnural Policies in Europe, Helsinki, 19-28 June 1972.

UNESCO Doc. $17 \mathrm{C} / 70$, Report of the Director-General on the Intergovernmental Conference on Cultural Policies in Europe, Paris, 15 September 1972.

UNESCO Doc. SHC/MD/23, General Report, Intergovernmental Conference on Cultural Policies in Asia, Yogyakarta, 10-19 December 1973.

UNESCO Doc. $18 \mathrm{C} / 88$, Report of the Director-Genenal on the Intergovernmental Conference on Cultural Policies in Asia, Paris, 23 August 1974.

UNESCO Doc. SHC/MD/25, General Report, Intergovernmental Conference on Cultural Policies in Africa, Accra, 27 October- 6 November 1975.

UNESCO Doc. $19 \mathrm{C} / 107$, Report of the Director-General on the Intergovernmental Conference on Cultural Policies in Africa, Paris, 30 September 1976.

UNESCO Doc. SHC/MD/39, General Report, Intergovemmental Conference on Cultural Policies in Latin America and the Caribbean, Bogota, 10-12 January 1978.

UNESCO Doc. $20 \mathrm{C} / 87$, Report of the Director-General on the proceedings of the Imergovernmental Conference on Cultural Policies in Latin America and the Caribbean, Bogota, 10-12 January 1978.

ALECSO, Final Report of the Third Conference of Ministers Responsible for Cultural Affoirs in the Arab Countries, Baghdad, 2-5 November 1981.

UNESCO Doc: CLT/MD/1, General Report, World Conference on Cultural Policies, Mexico City, 26 Jully to 6 August 1982.

UNESCO Doc. CLT/MD/1 Part IV, Mexico City Declaration on Cultural Policies, World Conference on Cultural Policies, Mexico City, 26 July to 6 August 1982.

UNESCO Doc. CLT-98/Conf. 210/3, Intergovernmental Conference on Culmiral Policies for Development - Background Document, 6 February 1998.

UNESCO Doc. CLT-98/Conf. 210/4Rev2, Action Plan on Cultural Policies for Development, adopted in Stockholm on Thursday 2 April 1998 by the Intergovernmental Conference on Cultural Policies for Development, 8 April 1998. 
The Power of Culture - Background Document, (consulted on 19 May 1998):

http:/www unesco-sweden.org/conference/background.htim.

\section{UNESCO Declaration on Cultural Diversity}

UNESCO Doc. 160 EX/Decision 3.1.1, Part II - Cultural diversity in the context of glabalisation, 2001 .

UNESCO Doc. $161 \mathrm{EX} / 12$, Report by the Director-General on the Progress of the UNESCO Draft Declaration on Cultural Diversiby, Paris, 12 April 2001.

UNESCO Doc. 161 Ex/INF. 19, Report of the Director-General on the Progress of the UNESCO Draft Declaration on Cultural Diversity, Paris, 4 June 2001.

UNESCO Doc. 162 EX/15, Draft UNESCO Declaration on Cultural Diversity, Paris, 20 August 2001.

UNESCO Doc. $31 \mathrm{C} / 44$, Draft UNESCO Declaration on Cultural Diversity, 20 August 2001.

\section{DOCUMENTS OF THE ORGANISATION OF AMERICAN STATES (in chronological order)}

OAS Doc. OEA/Ser.C/II.5, Resolution VII, Fifth meeting of Consultation of Ministers of Foreign Affairs, Santiago, Chile, 12-18 August 1959, Final Act., 1950.

OAS Doc. OEA/Ser.1/V/I1.1, doc. 32 (1961), Inter American Commission on Human Rights, Report on the Work Accomplished During its First Session, 3-28 October 1960.

OAS Doc. OEA/Ser.C/I.13 (1965), Resolution XXII, Second Special Inter-American Conference, Rio de Janeiro, Brazil, 17-30 November 1965, Final Act.

OAS Doc. OEA/Ser.L/V/II.30, doc. 45, rev.1, Case No. 1690, Colombia, Report on the Work Accomplished by the Inter-American Commission on Human Rights During its Thirtieth Session, 1973.

OAS Doc. OEA/Ser.L/V/II 43, doc. 21, Case No. 1802, Paraguay, Annual Report of the Inter-American Commission on Human Rights, 1977.

OAS Doc. OEA/Ser.1/V/I.66, doc. 10, rev. 1, Case No. 7615, Brazil, Inter-American Commission Res. No. 12/85, 5 March 1985, Annual report of the Inter-American Commission on Human Rights, 1984-1985, 1 October 1985.

OAS Doc. OEA/Ser.L/V/11.62, doc. 10 rev. 3 (1983) and OAS Doc. OEA/Ser.L/V/11.62, Doc 26 (1984), Case No. 7964 Nicaragua, Inter-American Commission on Human Rights, Report on the Situation of Human Rights of a Segment of the Nicaraguan Population of Miskito Origin and Resolution on the Friendly Settlement Procedure Regarding the Human Rights Situation of a Segment of the Nicaraguan Population of Miskito Origin, 1984.

OAS Doc. Inter-American Court of Human Rights, Advisory Opinion OC-10/89, Series A No. 10, Interpretation of the Americon Declaration of the Rights and Duties of Man within the Framework of Article 64 of the American Convention, 14 July 1989.

OAS Doc. OEA/Ser.L/V/II.90, doc. 9 rev. 1, Draft Inter-American Declaration on the Rights of Indigenous Peoples, IACHR Annual Report 1995, pp. 207-218.

OAS General Assembly Resolutions AG/RES. 1549 (XXVII-O/98), Draft American Declaration on the Rights of Indigenous Populations, June 1998. 
OAS General Assembly Resolution AG/RES. 1610 (XXIX-O/99), Proposed American Declaration on the Rights of Indigenous Populations, June 1999.

OAS General Assembly Resolution AG/RES. 1708 (XXX-O/00), Proposed American Declaration on the Rights of Indigenous Populations, June 2000.

OAS Doc, OEA/Ser.K/XVI, GT/DADIN/doc. 23/01 (11 may 2001), Special meeting of the Working Group to Prepare the draft American Declaration on the Rights of Indigenous Peoples, 2-6 April 2001.

OAS General Assembly Resolution AG/RES. 1780 (XXXI-O/01), American Declaration on the Rights of Indigenous Peoples, June 2001.

OAS case of the Mayagna (Sumo) Indigenous Community of Awas Tingi versus the Republic of Nicaragua, Petition No. 11.577, Inter-American Court Decision No. 79 of 31 August 2001.

\section{DOCUMENTS OF THE COUNCIL OF EUROPE (in chronological order)}

CoE Doc. Committee of Ministers, Resolution (75)13 containing recommendations on the social situation of nomads in Europe, 245th meeting, 22 May 1975.

CoE Doc. Parliamentary Assembly Recommendation 1134 on the Rights of Minorities, 14 th session, 1990 .

CoE Doc. Parliamentary Assembly Recommendation 1177 on the Rights of Minorities, 21 st session, 1992.

CoE Doc. Parliamentary Assembly Recommendation 1201 on an Additional Protocol on the Rights of National Minorities to the European Convention on Human Rights, 22th session, 1993

CoE Doc: CLD-MIN (93) 6, European Commission for Democracy through Law, Proposal for a European Convention for the Protection of Minorities, Strasbourg, 22 February 1993.

CoE Doc. CDDH (93) 22, Steering Committee for Human Rights, Extraordinary meeting Protection of National Minorities, Strasbourg, 8 September 1993.

CoE Dot. CAHMIN (94) 4, Preliminary Draft Protocol to the European Convention for the Protection of Human Rights and Fundamental Freedoms on the recognition of cultural rights, prepared by the Working Party following up the 8th Fribourg Colloquy, Strasbourg, 21 December 1993.

CoE Doc. CDCC Misc (94) 2, Think Tank Meeting on Cultural Rights, Strasbourg, 13 and 14 January 1994.

CoE Doc. CAHMIN (94) 5, Ad Hoc Committee for the Protection of National Minorities, Meeting Report, 1st meeting, Strasbourg, 25-28 January 1994.

CoE Doc. CAHMIN (94) 9, Ad Hoc Committee for the Protection of National Minorities, Meeting Report, 2nd meeting, Strasbourg, 14-18 March 1994.

CoE Doc. CAHMTN (94) 12, Ad Hoc Committee for the Protection of National Minorities, Preliminary Draft Framework Convention for the Protection of National Minorities, Strasbourg, April 1994.

CoE Doc. CAHMIN (94) 13, Ad Hoc Committee for the Protection of National Minorities, Meeting Report, 3rd meeting, Strasbourg, 11-15 April 1994.

CoE Doc. CAHMIN (94) 14 rev., Proposals concerning the preliminary draft Framework Convention for the Protection of National Minorities, Strasbourg, June 1994. 
CoE Doc. CAHMIN (94) 16, Ad Hoc Committee for the Protection of National Minorities, Meeting Report, 4th meeting, Strasbourg, 6-10 June 1994.

CoE Doc. CAHMIN (94) 19, Ad Hoc Committee for the Protection of National Minorities, Meeting Report, 5th meeting, Strasbourg, 27 June - 1 July 1994.

CoE Doc. CAHMIN (94) 22, Ad Hoc Committee for the Protection of National Minotities, Austrian proposal for an additional Protocol in the Cultural Field to the European Convention on Human Rights with Explanatory Memorandum, Strasbourg, 16 September 1994.

CoE Doc. CAHMIN (94) 28, Ad Hoc Committee for the Protection of National Minorities, Meeting Report, 6th meeting, Strasbourg, 12-16 September 1994.

CoE Doc. CDCC Misc (94) 3 rev 1, Directorate of Education, Culture and Sport, Draft List of Cultural Rights, Strasbourg, 10 October 1994.

CoE Doc. CAHMTN (94) 33, Ad Hoc Committee for the Protection of National Minorities, Meeting Report, 8th meeting, Strasbourg, 7-10 November 1994.

CoE Doc. CAHMIN (94) 35, Ad Hoc Committee for the Protection of National Minorities, Meeting Report, 9 th meeting, Strasbourg, 5-9 December 1994.

CoE Doc. Explanatory report on the Framework Convention for the Protection of Nationall Minorities, in: NJCM-Bulletin, Vol. 20, No.2, 1995, pp. 199-213.

CoE Doc. Parliamentary Assembly Recommendation 1255 on the protection of the Rights of National Minorities, January 1995.

CoE Doc. CDCC (95) 11 rev., Council for Cultural Co-operation, Reflections on Cultural Rights - Synthesis Report, 31 meeting, 63 session, Strasbourg, 24-26 January 1995.

CoE Doc. CAHMIN (95) 1, Ad Hoc Committee for the Protection of National Minorities, Draft articles and alternative versions for possible inclusion in a protocol complementing the ECHR in the cultural field by provisions guaranteeing individual rights, in particular for persons belonging to national minorities prepared by a working party of the CAHMTN and other proposals by nembers of the CAFIMTN, Strasbourg, 1 February 1995.

CoE Doc. CAHMIN (95) 9, Ad Hoc Committee for the Protection of National Minorities, Meeting Report, 10th meeting, Strasbourg, 27 February - 3 March 1995.

CoE Doc. CAHMIN (95) 16, Ad Hoc Committee for the Protection of National Minorities, Meeting Report, 11 th meeting, Strasbourg, $15-19$ May 1995.

CoE Doc. CAHMIN (95) 21 , Ad Hoc Committee for the Protection of National Minorities, Meeting Report, 12 th meeting, Strasbourg, 11-15 September 1995.

CoE Doc. CAHMIN (95) 22, Ad Hoc Committee for the Protection of National Minorities, Meeting Report, 13th meeting, Strasbourg, 6-10 November 1995.

CoE Doc. CAHMIN (95) 22 Add., Ad Hoc Committee for the Protection of National Minorities, Activity Report for the attention of the Committee of Ministers, Strasbourg, 24 January 1996.

CoE Doc. ACFC/SR (99) 3, Report submitted by Finland pursuant to article 25, paragraph 1, of the Framework Convention for the Protection of National Minorities, 16 February 1999. 


\section{TABLE OF CASES}

\section{Human Rights COMmtTee (ICCPR)}

Aärelä v. Finland: UN Doc. CCPR/C/73/D/799/1997, Mrs. Anni Aärelä and Mr. Jouni Näkkäläjärvi v. Finland, Communication No. 779/1997, 24 October 2001, seventy-third session. [see p. 181]

Ballantyre v. Canada: UN Doc. CCPR/C/47/D/359/1989 and 385/1989Rev.1, Ballantyne, Davidson, McIntyre v. Canada, Communication No. 359/1989 and 387/1989, 31 March 1993, forty-seventh session. [see p. 184]

Diergaardt v. Namibia: UN Doc. CCPR/C/69/D/760/1996, J.G.A. Diergaardr (late Captain of the Rehoboth Baster Community) et al. v. Namibia, Communication No. 760/1997, 25 July 2000 , sixty-ninth session. [see pp. 183, 185]

Hopu and Bessert v. France: UN Doc. CCPR/C/60/D/549/1993, Francis Hopu and Tepoaitu Bessert v. France, Communication No. 549/1993, 29 July 1997, sixtieth session. [see pp. 187-188]

Kitok v. Sweden: UN Doc. CCPR/C/33/D/197/1985, Ivan Kitok v. Sweden, Communication No. 197/1985, 27 July 1988, thirty-third session. [see p. 179]

Länsman v. Finland: UN Doc. CCPR/C/52/D/51 1/1992, Ilmari Länsman et al. v. Finland, Communication No. 511/1992, 26 October 1994, fifty-second session. [see p. 180]

Länsman v.Finland: UN Doc. CCPR/C/58/D/671/1995, Jouni E. Länsman et al. v. Finland, Communication No. 671/1995, 30 October 1996, fifty-eight session. [see p. 180]

Lovelace v. Canada: UN Doc. CCPR/C/OP/1 at 83 (1984), Sandra Lovelace v. Canada, Communication No. 24/1977, 30 July 1981, thirteenth session. [see pp. 176-177]

Lubicon Lake Band v. Canada: UN Doc. CCPR/C/38/D/167/1984, Chief Bernard Ominayak and the Lubicon Lake Band v. Canada, Communication No. 167/1984, 26 March 1990, thirty-eight session. [see pp. 177-178]

Mahuika v. New Zealand: UN Doc. CCPR/C/70/D/547/1993, Apirana Mahwika et al. v. New Zealand, Communication No. 547/1993, 27 October 2000, seventieth session. [see pp. 181-183]

O. Sara v. Finland: UN Doc. CCPR/C/50/D/431/1990, O. Sara et al. v. Finland, Communication No. 431/1990, 23 march 1994, fiftieth session. [see p. 180]

\section{INTER-AMERICAN COMmisSION AND COURT ON HUMAN RIGHTS (OAS)}

Aché v. Paraguay, OAS Doc. OEA/Ser.L/V/II.43, doc. 21, Case No. 1802, Paraguay, Annual Report of the Inter-American Commission on Human Rights, 1977.

[see p. 233-234]

Awas Tingi v. Nicaragua, OAS case of the Mayagna (Sumo) Indigenous Community of Awas Tingi versus the Republic of Nicaragua, Petition No. 11.577, Inter-American Court Decision No. 79 of 31 August 2001. [pp. 238-241] 
Guahibo v Colombia, OAS Doc. OEA/Ser.L/V/II.30, doc. 45, rev.1, Case No. 1690 , Colombia, Report on the Work Accomplished by the Inter-American Commission on Human Rights During its Thirtieth Session, 1973. [p. 233]

Miskito v. Nicaragua, OAS Doc. OEA/Ser.L/N/I.62, doc. 10 rev. 3 (1983) and OAS Doc. OEA/Ser.L/V/I.62, Doc 26 (1984), Case No. 7964 Nicaragua, Inter-American Commission on Human Rights, Report on the Situation of Human Rights of a Segment of the Nicaraguan Population of Miskito Origin and Resolution on the Friendly Settlement Procedure Regarding the Human Rights Situation of a Segment of the Nicaraguan Population of Miskito Origin, 1984. [pp. 236-238]

Yanomami v. Brazil, OAS Doc. OEA/Ser.1/V/II.66, doc. 10, rev. 1, Case No. 7615, Brazil, Inter-American Commission Res. No. 12/85, 5 March 1985, Annual report of the InterAmerican Commission on Human Rights, 1984-1985, 1 October 1985. [see p. 235-236]

\section{EUROPEAN COMMISSION AND COURT OF HUMAN RIGHTS (ECHR)}

Arslan v. Turkey, Application No. 23462/94, European Court of Human Rights, decision of 8 July 1999. [see pp. 279-280]

Beard v. The United Kingdom, Application No. 24882/94, European Court of Human Rights, decision of 18 January 2001. [see pp. 296-297]

Buckley v. The United Kingdom, Application No. 20348/92, European Court of Human Rights, decision of 25 September 1996, Reports of Judgements and Decisions 1996-IV, no. 16. [see pp. 289-291]

Campbel and Consans v. the United Kingdom, Application Nos. 7511/76 and 7743/76, European Court of Human Rights, decision of 25 February 1982. [see p. 270-271]

Chadre Shalom ve Tsedek v. France, Application No. 27417/95, European Court of Human Rights, decision of 27 June 2000. [see pp. 276-278]

Chapman v. the United Kingdom, Application No, 27238/95, European Court of Human Rights, decision of 18 January 2001. [see pp. 292-296]

Coster v. The United Kingdom, Application No. 24876/94, European Court of Human Rights, decision of 18 January 2001. [see pp. 296-297]

Erdogdu and Ince v. Turkey, Application No. 25067/94, 25068/94, European Court of Human Rights, decision of 8 July 1999. [see pp. 280-281]

Freedom and Democracy Party (ÖZDEP) v. Turkey, Application No. 23885/94, European Court of Human Rights, decision of 8 December 1999. [see pp. 281-282]

G. and E. v. Norway, Application Nos. 9278/81 and 9415/81, European Commission on Human Rights, decision of 3 October 1983, Decisions and Reports, vol. 35 (1984), pp. 30-45. [see p. 288, 317-318]

Gorzelik and others v. Poland, Application No. 44158/98, European Court of Human Rights, Decision of 20 December 2001. [see pp. 286-287]

Hasan and Chooush v. Bulgaria, Application No. 30985/96, European Court of Human Rights, decision of 26 October 2000. [see pp. 275-276]

Ibrahim Aksoy v. Turkey, Application No. 28635/95, 30171/96, European Court of Human

Rights, decision of 10 October 2000. [see pp. 280-281]

Jane Smith v. The United Kingdom, Application No. 25154/94, European Court of Human Rights, decision of 18 January 2001. [see pp. 296-297] 
Kjeldsen, Busk, Madsen and Pedersen v, Denmark, Application Nos. 5095/71, 5920/72 and 5926/72, European Court of Human Rights, decision of 7 December 1976. [see p. 270]

Kokkinakis v. Greece, Application No. 14307/88, European Court of Human Rights, decision of 25 May 1993, A 260-A. [see pp. 273-274]

Könkämä and 38 other Sami villages v. Sweden, Application No. 27033/95, European Commission on Human Rights, decision of 25 November 1996, Decisions and Reports, vol. 87A (1997), pp. 78-89. [see p. 317]

Larissis v. Greece, Application No. 23372/94, 26377/95 and 26378/94, European Court of Human Rights, decision of 24 February 1998, Report of Judgements and Decisions 1998-I, No. 65. [see p. 273]

Lee v. The United Kingdom, Application No. 25289/94, European Court of Human Rights, decision of 18 January 2001. [see pp. 296-297]

Manoussakis and others v. Greece, Application No. 18748/91, European Court of Human Rights, decision of 26 September 1996, Report of Judgements and Decisions 1996-IV, no. 17. [see pp. 273-274]

Özgür Gündem v. Turkey, Application No. 23144/93, European Court of Human Rights, decision of 16 March 2000. [see pp. 280-281]

Pentidis and others v. Greece, Application No. 23238/94, European Court of Human Rights, decision of 9 June 1997, Report of Judgements and Decisions 1997-[IT, no. 39. [see p. 274]

Polat v. Turkey, Application No. 23500/94, European Court of Human Rights, decision of 8 July 1999. [see p. 279]

Roger van de Berghe v. Belgium (Belgian Linguistic Case), Application No. 2924/66, European Court of Human Rights, Decision of 23 July 1968, 11 YEHR, 1968. [see pp. 270-272]

S. v. Sweden, European Commission of Human Rights, Application No. 16226/90, report of the Commission adopted 2 September 1992. [see pp. 317-318]

Sener v. Turkey, Application No. 26680/95, European Court of Human Rights, decision of 18 July 2000. [see pp. 280-281]

Serif v. Greece, Application No. 38178/97, European Court of Human Rights, decision of 14 December 1999. [see pp. 275-276]

Sidiropoulos and others v. Greece, Application No. 26695/95, European Court of Human Rights, decision of 10 July 1998, Report on Judgements and Decisions 1998-IV, No. 79. [see p. 284]

Socialist Party and others v. Turkey, Application No. 21237/93, European Court of Human Rights, decision of 25 May 1998, Report on Judgements and Decisions 1998-III, No. 75a. [see pp. 281-282]

Stankov and the United Macedonian Organisation Mlinden v. Bulgaria, Application Nos. $29221 / 95$ and 29225/95, European Court of Human Rights, 2 October 2001.

[see pp. 285-286]

Thlimmenos v. Greece, Application No. 34369/97, European Court of Human Rights, decision of 6 April 2000. [see p. 274]

Tsavachidis v Greece, Application No. 28802/95, European Court of Human Rights, decision of 21 January 1999. [see p. 274] 
United Communist Party of Turkey v. Turkey, Application No. 19392/92, European Court of Human Rights, decision of 28 October 1996, Report of Judgements and Decisions 1998-I, No. 62. [see pp. 281-282]

Welfare Party (Refah Partisi) and others v. Turkey, Application Nos. 41340/98, 41342/98, $41343 / 98$ and $41344 / 98$, European Court of Human Rights, Decision of 31 July 2001. [see pp. 282-284] 


\section{LIST OF INTERNATIONAL TREATIES AND DECLARATIONS}

Additional Protocol to the American Convention on Human Rights in the Area of Economic,Social and Cultural Rights (Protocol of San Salvador), adopted 17 November 1988.

African (Banjul) Charter on Human Rights and Peoples' Rights, adopted 26 August 1981,entry into force: 21 October 1986.

American Convention on Human Rights, OAS Treaty Series No. 36, 1144 UNTS 123, adopted 22 November 1969, entry into force: 18 July 1978.

American Declaration on the Rights and Duties of Man, OAS Res. XXIX, Final Act, 29 , Ninth International Conference of American States, Colombia, 1948.

Charter of the United Nations, San Francisco, adopted 26 June 1945, entry into force: 24 October 1945.

Convention on the Prevention and Punishment of the Crime of Genocide, adopted 9 December 1948, entry into force: 12 January 1961.

Declaration on Principles of International Law concerning Friendly Relations and Cooperation among States in accordance with the Charter of the United Nations, General Assembly Resolution 2625 (XXV), adopted 24 October 1970.

Declaration on the Right to Development, General Assembly Resolution 41/128, annex UN Doc. A $41 / 53,1986$.

Declaration on the Rights of Persons belonging to National or Ethnic, Religious and Linguistic Minorities, UN Doc. A/Res/47/135/Annex, 18 December 1992.

Draft American Declaration on the Rights of Indigenous Peoples, approved by the InterAmerican Commission on Human Rights at its 133rd session on 26 February 1997. OEA/SerL/II.95.doc.7, rev. 1997.

Draft Declaration on the Rights of Indigenous Peoples, UN Doc. E/CN.4/Sub.2/1994/2/Add.1, 1994.

European Charter for Regional and Minority Languages, Strasbourg, adopted 2 October 1992, entry into force: 1 March 1998.

European Convention for the Protection of Human Rights and Fundamental Freedoms, Strasbourg, adopted 4 November 1950, entry into force: 3 September 1953.

European Social Charter, Strasbourg, adopted 18 October 1961, entry into force: 26 February 1965.

Explanatory report on the Framework Convention for the Protection of National Minorities, in: N/CM-Bulletin, Vol. 20, No. 2, 1995, pp. 199-213.

Framework Convention for the Protection of National Minorities, Strasbourg, adopted 1 February 1995, entry into force: 1 February 1998.

ILO Convention 107 on Indigenous and Tribal Populations, adopted by the General Conference of the ILO at its 40th session, 26 June 1957, entry into force: 2 June 1959. 
ILO Convention 169 on Indigenous and Tribal Peoples in Independent Countries, adopted by the International Labour Conference at its 76th session, 27 June 1989, entry into force: 5 September 1991.

International Covenant on Civil and Political Rights, General Assembly Resollution 2200A (XXI), UN Doc. A/6316 (1966), adopted 16 December 1966, entry into force: 23 March 1976.

International Covenant on Economic, Social and Cultural Rights, General Assembly Resolution 2200A (XXI), UN Doc. A/6316 (1966), adopted 16 December 1966, entry into force: 3 January 1976.

Optional Protocol to the International Covenant on Civil and Political Rights, General Assembly Resolution 2200A (XXI), UN. Doc. A/6316 (1966), adopted 16 December 1966, entry into force: 27 February 1970.

UNESCO Deciaration of the Principles of International Cultural Co-operation, adopted by the General Conference at its fourteenth session, Paris, 4 November 1966.

UNESCO Declaration on Race and Racial Prejudice, adopted by the General Conference at its 20th session, Paris, 27 November 1978 (UN Doc. E/CN.4/Sub.2/1982/2/Add.1, annex V).

UNESCO Recommendation on Participation by the People at Large in Cultural Life and Their Contribution to $I t$, adopted by the General Conference at its nineteenth session, 30 November 1976.

Universal Declaration on Human Rights, General Assembly Resolution 217A (III), UN Doc. A/810 (1848), adopted 10 December 1948.

Vienna Convention on the Law of Treaties, adopted 23 May 1969, entry into force: 27 January 1980. 
Aborigines $1,118,208,343$

Accession treaty 323

Aché Indians 232-234

Additional Protocol to the American

Convention on Human Rights in the

Advisory Committee (Council of

Europe) $260,261,268,304,319$, 320,322

addressee $10-12,20,81,95,96$, $120,121,143,154,176,334$

Advisory Committee on Human Rights and Foreign Affairs 94- 96, 98, 104,207

affirmative action $50,54,217$

Alta Dam 288, 310, 311, 317, 318

American Convention on Human

Rights 227-232, 234, 236-241, $244,333,334$

American Declaration on the Rights and Duties of Man 227-236,333, 334

Apartheid 7

Apirana Mahuika 181, 182

Area of Economic, Social and Cultural

Rights (Protocol of San Salvador)

$230,231,244,333$

assimilation $3,8,41,42,46,55,61$, $120,121,166,168,192,196,197$, $209,211,214,217,218,224,232$, $234,238,242,243,245,253,254$, $256,257,305,324,328,345$

Australia 1, 20, 188, 170, 186, 304, 343

Austria 195, 283

Autonomy 54, 59, 101, 122, 153, 157, $168,213,221,267,269$

Awas Tingi $1,232,238-241,245$, $334,336,343$ beneficiary/beneficiaries $10,81,169$, $193,195,201,210,217,222$

Bill of Human Rights 2, 8, 21, 139 , $140,337,343$

Brazil 1, 141, 209, 212

Bulgaria $155,275,276,281,285,286$

Canada $20,117,136,176,177,184$, 185,323

Chapman 289, 292-299, 333, 343

Charter of the United Nations 80,81 , 340

Chile $118,140,141,147,168,170$ citizenship $37,43,194,254,314$ civil and political rights $2,4,66,70$, $71,82,87,94,102,139,163,166$, $227,231,247,248,269,332$

collective action $95,189,242,299$

collective rights $2,4,6,7,16,19-21$, 42 , chapter III, chapter IV, 329 , 334,335

collectivity/collectivities $3,34,96,97$, 155,201

Colombia $209,210,213,229,232$, 233

colonisation $13,24,36,46,117,127$, $138,205,304,328$

Commission on Human Rights (UN) $1,2,28,67,79,81,91,132,139$, $146,164,165,216,224,331,342$

Committee of Ministers (Council of Europe) $249,251,260,261,267-$ 269,292

Committee on Economic, Social and Cultural Rights $82,84,91,146$, $150,151,154,191,332,342,343$, 344

Committee on the Elimination of all

Forms of Racial Discrimination 
common heritage $4,77,94,111,113$, $120,128,1.30,305$ complaint procedure $66,111,169$, $172,191,202,208,213,223,260$

Convention on the Prevention and Punishment of the Crime of Genocide $69,218-220$

Copenhagen Document 285

core content $10,84-85,90-93,154$, $155,161,336,342$

Council of Europe $4,9,13,21,29,31$, $80,132,230,247,249,251,253$, $259,267,268,293,295,312,314$, $318,319,321,322,329$

cultural $119,124,158,192,199,207$, $208,238,253,310,315$

cultural community $34,35,41,51-53$, $57,62-64,76,77,83,100,129$, $153,264,299,328,338$

cultural diversity $31,53,54,77,108$, $129,134,135,136,137,138,196$, $209,232,250,270,279,293,299$, $329-331,339,345$

cultural rellativism $14,27,28$ customs $12,13,18,26,29,30,32,45$, $70,73,111,123,137,154,172$, $198,211,214,217,308,313$

day of general discussion 151,154 , 156,157

Declaration on Principles of International Law concerning Friendly Relations and Cooperation among States in accordance with the Charter of the United Nations $81,207,340$

Declaration on the Right to Development 339

Declaration on the Rights of Persons belonging to National or Ethnic, Religious and Linguistic Minorities $9,21,191-202$

decolonisation $24,28,36,46,122$. 207,328

deficiency thesis 56

Development, right to 339
Diergaardt 183,185

different, right to be $4,6,10,15,36$, $119,121,129,340,345$

dignity, human $1,3,4,6,8,9,13-17$, $28,31,46,57,62,73,77,79-81$, $96-98,100,103,104,152,301$, $328,332,334,335,337,339,340$, 344,345

discrimination $1,3,44,50,55,85$, $123,168,186,195,197,206,209$, $236,237,248-250,263,264,277$ $279,291,296,298,303,345$

diversity $1.4,15,24,28,31,37,38$, $40,42,53,54,57,58,77,111,119$, $120,129,134,135-137,196,209$, $232,250,270,279,293,299,329-$ $331,339,342,345$

domination $13,41,50,115,117,126$, $128,129,138,324$

Draft American Declaration on the

Rights of Indigenous Peoples 241, 243

Draft Declaration on Cultural Rights (Fribourg Group) 76,791

Draft Declaration on the Rights of Indigenous People (UN) 203, 215 , 216,222

Economic and Social Council 79,88 Economic, Social and Cultural Rights $2,4,18,19,66,67,82-84,86,87$, $88,90,94,140,144,227,230$ education $10,13,14,17,19,20,30$, $40,46,50,54,69,70,73,103,109$, $112,114,117,118,120,123-127$, $130,133,136,142,147,153,154$, $160,175,184,185,190,214,224$, $225,242,250,257,261,268,269$, $270,327,339,344$ education, right to $3,14,55,63,71$, $72,74-76,82,87,91,94,146,153$, $165,172,198,201,216,217,227$, $230,231,248,255,265,266,269$, $270-272,299,329,331,333,336$, $338,343,344$

equality $4,14,15,24,28,36,37,40$, 
$41,42,44,46,50,53,54,57-59$, $63,80,81,94,111,113,115,117$, $124,126,129,164,165,166,186$, $188,198,209,215,217,223,225$, $235,328,329,340,345$

ethnicity 33,36

ethnic group/comm. $45,50,57,58$, $60,63,64,75,99,102,120,122$, $124,150,160,165,236,237,238$, $239,286,307$

ethnic identity $13,36,37,50,57,70$, $114,135,165,170,176,179,201$, $204,216,218,222,253-258,291$ ethnic minority $125,135,150,153$, $160,164,166-168,170,171,191$ -

193,312

European Charter on Regional and

Minority Languages 249-251, 268, 313,318

European Commission for Human

Rights $247,252,269,270,293$, 299,333

European Convention for the

Protection of Human Rights and

Fundamental Freedoms 22, 247, $248,251,253,317,333,269-298$

European Court of Human Rights

$248,249,269-298$

European Social Charter $22,247,248$ exit, right to $61-64,335,338$

Explanatory report on the Framework

Convention for the Protection of

National Minorities $252,253,255$ 259

external protection $58,59,99,338$

family life, right to $7,187,188,190$, $231,234241,248,265,266,269$, $288-298,318,325,333,336,337$, 339

FGM (female genital mutilation) 63 female circumcision 8,61 forced marriage 8 Framework Convention for the Protection of National Minorities
$22,247,248,251-261,268,293-$ $294,297-298,313,318-322,329$, 330

France $3,117,136,148,186-188,276$ Fribourg Group $4,76-80-, 103,135$ fulfil, obligation to $11,88-90,92,159$, $175,197,336$

General Assembly (OAS) 231, 241, 243

General Assembly (UN) 2,81, 122 , $130,131,140-146,148-150,164$, $165,166,168,192,195,199,216$. $219,220,339,340$

General Comment $151,161,342,344$ On Article 27 ICCPR 169 -

$171,173,175,189$

On Article 2 ICESCR $84,85,90$, 91,

On Article 15 ICESCR 161,332 , 343

genocidle $69,93,164,192,196,220$, 223,279

cultural $217-220,223,225,303$

Genocide Convention $69,218-220$

globalisation $13,24,36-39,46,133$, 134,328

Greece $272-275,284,285,299,333$

group rights 4,49

group-specific rights 50

group-differentiated rights $49,53,57$ 59

Guahibo Indians 232-234

Guidelines ICESCR 146, 150-152, 157,160

Gypsy cases $289-298,333$

home, right to a $74,187,248,269$, $288-299,333,339,344$

Hopu and Bessert 187-188

housing, right to $82,293,336,342$, 343

human dignity $1,3,4,6,8,9,13-17$, $28,31,46,57,62,73,77,79-81$, $96-98,100,103,104,152,301$, $328,332,334,335,337,339,340$, 
344,345

Human Rights Committee 22, 169 .

$171,173,175,176-191$

Hungary $20,251,252,260$

immigrants $57,58,60,118,125,127$, $168,170,189,194,343$

immigration $37-39,57,58,60,64$, $127,305,308,309$

ILO Convention 107 on Indigenous and Tribal Populations 208-210, 212,213

ILO Convention 169 on Indigenous and Tribal Peoples in Independent Countries 9,2$\rfloor, 133,203-205$, $208,215,217,225,317,319,321$ 323,330

Indian Law Resource Centre 227 , 238,239

indigenous culture $217,220,233$ indigenous people(s) Chapter VII, IX indigenous population $204,209,215$, $223,236,241,243$

integration $13,22,27,38,59,102$, $118,125,127,165,206,209,210$, 218,256

Inter-American Commission of Human

Rights $22,227,228,231,233$, $235,236,334$

Inter-American Court of Human Rights $22,227-229,231,232,23-241,244$, $245,334-336$

interdependence of human rights 2 , 82,87

internall restriction $58,59,61,62,64$, $99,102,338$

International Convention on the

Elimination of All Forms of Racial

Discrimination $122,203,204$

Interiational Court of Justice 80,304 International Covenant on Civil and

Political Rights $2,98,163,166$, $236,316,332$

International Coventent on Economic, Social and Cultural Rights 2, 11, $18,83,144,145,332$ international customary law 18,79 , $80,187,223,228,236$

International Labour Organisation 21 , $67,203,208-215,322,323,330$ International Law Commission 82 , 131,132 intolerable practices $20,42,49,61$, $63,64,327,338$

ius cogens 79,223

Jehovas witness $40,272,273,274$ jurisdiction $58,89,228,229,240$, 252,308

justiciability/justiciable $7,16,18,66$, $67,79,80,84,85,87,90,199,262-$ $264,267,269,329,337,339$

land rights $13,43,93,103,175,176$, $189,203,207-209,211-214,222$, $227,231,234,236-241,243-245$, $288,304,309-311,314,315,317$, $318,320,321,323,325,333,334$, $336,339,343$

language rights $1,17,184,216,251$, 271,312

Lapp Codicil 302, 307-309

liberal theory $20,49,50,61,63$

life, right to $69,74,217,218,231$, $234-238,240,241,244,334,339$

Limburg Principles on Economic, Social and Cultural Rights 11,18 , $29,83-85$

limitation clause $85,86,90,142,159$ linguistic minorities $114,135,166$ -

$168,169,171,173,191,192,329$

linguistic rights $17,20,43,70,82,91$, $93,103,184,189,190,201,250$, $253,254,258,266,318,333,336$, 344

Lubicon Lake Band 177,178

Maastricht Guidelines on Violations of

Economic, Social and Cultural

Rights $12,18,19,68,82,84-89$

Maliseet Indian 176

margin of appreciation $272-274,277$, 
$278,281,282,286,290,291,293$, 295

margin of discretion $87,189,198,275$ Mexico 6, 123, 129, 130, 134, 135,

$138,210,213,224$

migrant workers 170

minority culture $40,53,63,116,118$, $166,168,185,197,255,299,318$, 325,333

minority group $38,40,55,58,102$, $195,288,318,344$

minority language $118,172,174,175$, $185,249,250,254,258,269,313$, 318,344

Minority Rights Group 191

Miskito Indians 232, 236, 237, 238, 244,334

monitoring $20,22,74,110,144,150$, $155,193,199,208,225,250,259$, $260,268,319$

mother tongue $136,174,184,198$, 254,314

multi-culturalism $24,36,37,39,41$ $43,46,47,143,328,345$

Muslim leaders 275

Namibia 183,185

nationality $5,33,37,45,46,286$

nomad 291, 292, 304, 308, 309, 313 non-discrimination $4,15,24,36,40$. $42,47,63,80,81,83,85,94,99$, $125,152,158,164-166,173,174$, $177,185,186,195,196,198,216$, $227,238-240,244,248,255,257$, $269,271,272,274,277,278,283$, $288,294-296,298,317,328,334$, $338,340,341,345$

non-recognition $35,43,291$

numerical criterion $100,101,169$,

$184,194,250$

OAS General Assembly $231,241,243$ Organisation of American States 21, 22,227 , chapter IX, 333

object $6,7,10,12,17,20,95,96,97$, $1.03,107,115,117,120,121,126$,
$139,142,154,161,169,170,172$, $190,334-338$

obligation of conduct 81,82

obligation of result 81,82

obligation to fulfil $11,65,88-90,92$, $159,161,175,197,332,336,343$, obligation to protect $11,65,88,89$, $92,143,155,158,159,161,174$, $175,197,332,343$

obligation to respect $11,17,65,82$, $88,89,92,143,155,158,161,174$, $175,197,272,332,343$

Optional Protocol to the International Covenant on Civil and Political Rights $66,177,187$

Organisation for Security and $\mathrm{Co}-$ operation in Europe 21

Organisation of African Unity 21 Our Creative Diversity 108, 130-134, 138

Paraguay 232-234

participation $5,13,33,70,72,75,76$, $79,112,114-119,125,127,129$, $135,137,140,141,143,144,199$, $203,213,217,222,332,334,343$ participation rights $63,64,88,96$, $192,216,297$

peoples $6,7,11,25,37,70-72,93,96$, $109,114,115,119,126-130,147$. $170,205-207,340,342$

Permanent Court of International Justice 167

Permanent Forum for Indigenous Peoples 224

pluralism $6,36,40,41,82,115,129$, $131,134,143,282,283,299$

religious $272,273,275,277$, 278

Poland 286,287

policy principle $18,76,80,103,112$, $117,121,130,336,339-341$

political $58,171,206,214,217,237$, 238,253

political institutions $205,207,217$ political parties $52,254,279,280-284$ 
poly-ethnic rights $58-60,63,329$ positive action $174,197,295$

positive obligations $71,78,79,82,88$, $90,103,151,154,155,158,161$, $174,175,182,196,201,213,236$, $265,266,270-272,291,294-296$, $298,299,316,332,388,341,343$ principle(s) of law $2,4,15,41,42,49$, $50,57,76,79,80,8185,93,94$, $103,104,124,125,329,331,336$, $338,340-345$

programme-type provisions 252,260 , $261,268,329$

proliferation 16,337

protect, obligation to $11,65,88,89$, $92,143,155,158,159,161,174$, $175,197,332,343$

Protocol of San Salvador 230, 231, 244,333

quasi-judicial bodies $18,225,260$ Quebec 184

racial discrimination $121,122,204$ recognition $1,4,5,15,16,17,19,24$, 34-36, 41-47, 49, 54, 55, 57, 59, 62, $76,78-80,90-92,96,102,103,105$, $113,115,118,126,127,129,165$, $166,188,240,286,327-330,335$, 337,345

refugee $37,38,57,58,168$ reindeer $304-306,308-311,313-318$, $320,323-326$

religion $3,5,6,7,9,10,13,14,19$, $20,23,26,29,30,32-34,39,43$, $46,47,54,55,69-75$

religious community 11,335 religious institutions $158,184,265$ reporting procedure $66,110,143,146$,

$150,154,160,202,213,223,231$, 250,260

representation $7,8,32,105,335$ representation (ILO) 213,214 representation rights $58,60,63,83$, 96,329

representative $56,96,102,206,224$,
276,301

respect, obligation to $11,17,65,82$, $88,89,92,143,155,158,161,174$, $175,197,272,332,343$

right of self-determination $3,93,95$, $177,182,198,205,206,207,210$, $216,217,221,222,282,321$

right to a name $254,266,267$ right to be different $4,6,10,15,36$,

$119,121,129,340,345$

right to education $3,14,55,63,71$, $72,74-76,82,87,91,94,146,153$, $165,172,198,201,216,217,227$, $230,231,248,255,265,266,269$, $270-272,299,329,331,333,336$, $338,343,344$

right to exit $61-64,335,338$

right to family life, home and

correspondence $7,74,187,188$, $190,231,234,241,248,265,266$, $269,288-299,318,325,333,336$, $37,339,344$

right to freedom of expression 3,50 , $51,73,74,76,79,82,129,153$, $172,173,175,184,185,190,244$, $248,255,266,269,278,279,281$, $284,299,333,334,339,342$ right to freedom of thought, conscience and religion $3,6,7,14,47,55,71$ $74,76,87,96,102,165,1.72,173$, $175,184,188,190,216,227,231$, $235,241,247,265,268,269,273-$ $275,277,278,284,299,319,321$, $328,337,339,340,345$

right to freedom peaceful assembly and association $3,55,61,64,73,74$, $94-96,165,172,173,241,255$, $264,265,269,281,283-285,299$, $333,339,344$

right to life $69,74,217,218,231$, $234-238,240,241,244,334,339$ ritual slaughtering $276,277,299$ Roma 1, 255, 293, 343

Rumania 255

Russia $302,303,307,308$ 
Sami chapter II, 1, 22, 343, 288

Sami Parliament $306,307,309,310$

Norway 312

Sweden 314

Finland $307,315,316$

San Salvador, Protocol of 230,231 , 244,333

secession $122,192,206-208,214$, 222,253

self-determination

Internal $206,208,221,222$

External $206,207,221,222$

self-govermment $58-60,63,171,183$, $206,214,221,329$

self-identification $45,205,217,306$

sense of solidarity $40,169,170,194$

South Africa $5,7,168,183$

sovereignty $116,127,170,187,206$, $221,250,308$

Special Rapporteur $67,68,169,191$, $193,194,200,204,209,217,224$

State abstention $11,71,82,89,92$, $158,168,257,270,278,295,298$

Sub-Commission on Prevention of Discrimination and Protection of

Minorities $88,139,140,163-167$, $169,191,193,194,199,200,209$, $215,216,232$

The Sub-Commission on the Promotion and Protection of Human Rights 232

subsistence $88,89,183,206$, $207,315,322$

Taxed Mountains case $304,312,313$, 317

territory $43,127,169,170,180,186$, $203,218,235,242,255,259,261$, $268,270,281,303-307,309,310$, $314,316,325$

Tobique reserve 177

tradition(s) $15,26,27,29,30,35,36$, $38,40,45,46,61,73,77,78,102$, $129,135,137,142,153,154,160$, $166,167,169,172,173,198,211$, $216,217,220,221,222,235,240$,
$250,254,256,263,285,288,289$, $292,299,308,333$

traditional economic activities 173 , $175,177,178,182,183,189,288$, 333

traditional knowledge 136,221

traditional lifestyle/way of life 1,177 , $178,182,183,288,289,290,291$, $294,296,297,299,315,333$

traditional practices/valies 28,101 travaux préparatoires $86,139,140$, 193

Article 15 ICESCR 146-150

Article 27 ICCPR 167,168

Article 27 UDHR 141,142

Treaty of Lausanne 281

tribal peoples $9,203,204,205,208$, $214,322,323,330$

tripartite typology of State obligations $11,65,81,87-90,104,143$

Turkey $1,3,136,192,259,278-283$, 299,343

typology of State obligations 11 , $65,81,87-90,104,143$

United Kingdom $108,116,117,136$, $140,271,289,290,292-296$

United Nations $2,80,81,107,114$

UN Charter $80,81,340$

UN Commission on Human Rights 1 , $2,28,67,79,81,91,132,139,146$, $164,165,216,224,331,342$

UN General Assembly 2, 81, 122, 130 , $131,140, \sqrt{4} 42,144-146,148-150$, $164-166,168,192,195,199,216$, $219,220,339,340$

UNESCO Declaration on Cultural Diversity 134-137

UNESCO Declaration of the Principles of International Cultural Cooperation 111,112

UNESCO Declaration on Race and Racial Prejudice 119.123

UNESCO Recommendation on Participation by the People at Large in Cultural Life and Their 
Contribution to It $112-119$

UN Human Rights Committee 22 , $169-171,173,175,176-191$

UN Permanent Forum for Indigenous

Peoples 224

UN Working Group on Indigenous

Populations $215,216,222,223$

UN Working Group on Minorities $193,199,200$

Universal Declaration of Human Rights

$2,21,28,69,74,113,121,139$,

$140,141,142,143,144,145,147$,

$149,163,166,188,204,220,228$

Vienna Convention on the Law of

Treatics $139,143,186$

Vienna Declaration 251-252,339

vulnerable groups 16,159

Working Group on Indigenous

Populations $215,216,222,223$

Working Group on Minorities 193, 199,200

Yanomami Indians $1,232,235,236$, $238,244,334,343$ 


\section{CURRICULUM Vitae}

Yvonne Donders (1972) studied General Arts at Utrecht University. In 1996 she obtained here degree in the specialisation of international relations. In 1997 she started working as a research associate at the Law Faculty of Maastricht University. Besides her $\mathrm{PhD}$ research, she has taught international and European law, human rights and public authorities, and has given various lectures on cultural human rights. She has been involved in various other activities, inter alia, as Vice-Chairperson of the Dutch United Nations Association (NVVN), as member of the editorial board of the UNA quarterly UN Forum (in Dutch), as member of the Working Group on the International Protection of Human Rights of the Dutch Section of the International Commission of Jurists (NJCM), and as Chairperson of the PhD Commission of the Law Faculty of Maastricht University. 


\section{SCHOOL OF HuMAN RightS RESEARCH SERIES}

The School of Human Rights Research is a joint effort by human rights researchers in the Netherlands. Its central research theme is the nature and meaning of international standards in the field of human rights, their application and promotion in the national legal order, their interplay with national standards, and the international supervision of such application. The School of Human Rights Research Series only includes English titles that contribute to a better understanding of the different aspects of human rights.

Editorial Board of the Series: Prof. dr C. Flinterman (Utrecht University), Prof. dr W.J.M. valn Genugten (Tilburg University), Prof. dr A.P. van Goudoever" (Utrecht University), Prof dr M.T. Kamminga (Maastricht University), Prof. dr P.A.M. Mevis (Erasmus University Rottendam) and dr H. Werdmölder (Utrecht University)

Published titles within the Series:

1. Brigit C.A. Toebes, The Right to Health as a Human Right in International Law ISBN 90-5095-057-4

2. Ineke Boerefijn, The Reporting Procedure under the Covenant on Civil and Political Rights, Practice and Procedures of the Human Rights Committee ISBN 90-5095-074-4

3. Kitty Arambulo, Strengthening the Supenision of the International Covenant on Economic, Social and Cultural Rights, Theoreticat and Procediral Aspects ISBN $90-5095-058-2$

4. Marlies Glasius, Foreign Policy on Human Rights. Its Influence on Indonesia under Soeharto

ISBN 90-5095-089-2

5. Comelis D. de Jong, The Freedom of Thought, Conscience and Religion or belief in the United Nations (1946-1992)

ISBN $90-5095-137-6$

6. Heleen Bosma, Freedom of Expression in England and under the ECHR: in Search of a Common Ground. A Foundation for the Application of the Humaw Rights Act I998 in English Law ISBN 90-5095-136-8

7. Mielle Bulterman, Human Rights in the External Relations of the European Union ISBN 90-5095-164-3 
8. Esther M. van den Berg, The Influence of Domestic NGOs on Dutch Human Rights Policy. Case Studies on South Africa. Namibia, Indonesia and East Timor ISBN 90-5095-159-7

9. Ian Seiderman, Hierarchy in International Law: the Human Rights Dimension ISBN 90-5-95-165-1.

10. Anna Meijknecht, Towards Intemational Personality: the Position of Minorities and Indigenous Peoples in International Low

ISBN 90-5095-166-X

11. Mohamed Eltayeb, A Human Rights Approach to Combating Religious Persecution, Cases from Pakistan, Saudi Arabia and Sudan

ISBN 90-5095-170-8

12. Machteld Boot, Genocide, Crimes Against Hwmanity, War Crimes: Nullum Crimen Sine Lege and the Subject Matter Jurisdiction of the International Criminal Court ISBN 90-5095-216-X

13. Corinne Packer, Using Human Rights to Change Tradition. Traditional Practices Harmful to Women s' Reproductive Health in sub-Saharan Africa ISBN 90-5095-226-7

14. Theo van Banning, The Human Right to Property ISBN 90-5095-203-8

15. Yvonne M. Donders, Towards a Right o Cultural Identity? ISBN 90-5095-238-0 